CENTRO UNIVERSITÁRIO FEI

ERYKA EUGENIA FERNANDES AUGUSTO

O IMPACTO DA COLABORAÇÃO E COOPERAÇÃO NA IMPLEMETAÇÃO DOS MODELOS DE LOGÍSTICA REVERSA DE REEE: Os casos brasileiro e europeus.

EL IMPACTO DE LA COLABORACIÓN Y COOPERACIÓN EN LA IMPLEMENTACIÓN DE LOS MODELOS DE LI DE RAEE: Los casos brasileño y europeos.

São Paulo 


\title{
O IMPACTO DA COLABORAÇÃO E COOPERAÇÃO NA IMPLEMETAÇÃO DOS \\ MODELOS DE LOGÍSTICA REVERSA DE REEE: Os casos brasileiro e europeus.
}

\author{
EL IMPACTO DE LA COLABORACIÓN Y COOPERACIÓN EN LA \\ IMPLEMENTACIÓN DE LOS MODELOS DE LI DE RAEE: Los casos brasileño y
}

europeos.

Tese apresentada em Regime de cotutela ao Centro Universitário FEI, como parte dos requisitos necessários para obter o título de Doutora em Administração de Empresas e á Universidad de Alicante, Instituto Universitario del Agua y de las Ciencias Ambientales, Doctorado en Agua y Desarrollo Sostenible para a obtenção do título de Doutora pela Universidad de Alicante. Orientado pelo Prof. Dr. Jacques Demajorovic, Prof. Dr. Antonio Aledo Tur y Prof. Dr. Joaquín Melgarejo Moreno.

Tesis presentado en Régimen de cotutela al Centro Universitário da FEI, como parte de los requisitos necesarios para obtener el título de Doctor en Administración de Empresas y la Universidad de Alicante, Instituto Universitario del Agua y de las Ciencias Ambientales, Doctorado en Agua y Desarrollo Sostenible para la obtención del título de Doctora por la Universidad de Alicante. Orientado por el Prof. Dr. Jacques Demajorovic, Prof. Dr. Antonio Aledo Tur y Prof. Dr. Joaquín Melgarejo Moreno.

São Paulo 
Fernandes Augusto, Eryka Eugênia.

O impacto da colaboração e cooperação na implementação dos modelos de logística reversa de REEE: os casos brasileiro e europeus / Eryka Eugênia Femandes Augusto. São Paulo, 2018.

$344 \mathrm{f}$ : il.

Tese - Centro Universitário FEI

Orientador: Prof. Dr. Jacques Demajorovic.

Coorientador: Prof. Dr. Antonio José Aledo Tur.

1. Colaboração. 2. Cooperação. 3. Logística Reversa (LR). 4. REEE. 5. Parcerias. I Demajorovic, Jacques, orient. II Título.

Elaborada pelo sistema de geração automática de ficha catalográfica da FEI com os dados fornecidos pelo(a) autor(a). 
Dedico essa tese aos amores da minha vida, meu marido, Luis Fernando, meus pais, Gilberto e Edméa, meus filhos de coração, Vinícius e Enzo e minhas irmãs. Obrigada por serem a motivação para meu desenvolvimento e aperfeiçoamento. 


\section{AGRADECIMENTOS}

Agradeço ao meu orientador e meus diretores de tese Prof. Doutor Jacques Demajorovic, Prof. Doutor Joaquin Melgarejo Moreno e Prof. Doutor Antonio Aledo Tur por terem me aceito como sua orientanda, por sua paciência, generosidade e alegria, que foram tão importantes na realização e orientação deste trabalho.

Ao meu amado marido, Luis Fernando, por ter me ajudado a realizar mais esse sonho e segurado a minha mão nos momentos mais difíceis. Sou muito grata por sua participação nesse processo. Sem ele a vida não seria tão especial e feliz. Aos meus filhos de coração, Enzo e Vinicius, pelo carinho e paciência, pois não foram poucos finais de semanas que tiveram que ficar em casa, enquanto eu escrevia essa tese. Aos meus pais amados, que resignados aceitaram a distância da nossa convivência para que eu alcançasse mais esse objetivo na minha jornada. Vocês são a minha razão de viver.

Ao Centro Universitário FEI, a todos os distintos professores do Programa de PósGraduação em Administração e aos colaboradores do campus Liberdade, pela generosidade e profissionalismo em todos os momentos. Em especial ao meu coordenador Prof. Dr. William pelo apoio, às Sra. Carmen Carlos e Ana Paula, da secretária da pós-graduação e à D. Rosa por toda generosidade, sorrisos e carinho. A Patrícia Braghin, por sua orientação e ajuda na formatação desse trabalho.

A minha amiga Ana Lúcia Santiago que plantou a sementinha da dupla titulação no meu coração e me ajudou a regá-la.

E por último, mas não menos importante, aos amigos anjos que me socorreram nos muitos momentos de desespero, doando o seu tempo para me socorrer, me acalmar ou simplesmente para me mostrar algo bonito no país em que eu estivesse. Não tenho palavras para agradecer por esse presente precioso à Lyvia, Rosmá, Gilmara, Edgardo, Anna Bracher, Cristina Murachco e Sara Molina. 


\section{RESUMO}

O crescimento acelerado do mercado de Equipamentos Eletro Eletrônicos (EEE), a obsolescência programada e o aumento do descarte dos Resíduos de Equipamentos Eletro Eletrônicos (REEE) geram impactos socioambientais em todo o mundo. A gestão desses resíduos motivou vários países a fazer uma reflexão sobre os pré-requisitos para o gerenciamento de REEE de forma ambientalmente saudável, por meio da Logística Reversa (LR) de REEE. A Europa surge no cenário mundial como exemplo de implementação de LR de REEE devido aos modelos de alto desempenho, que revelam uma lista de fatores comuns: parcerias, engajamento dos consumidores e compartilhamento de informação, leis claras, com papéis bem definidos, esforços coordenados dos atores da LR para alcançar o mesmo objetivo. Esses elementos de comportamento cooperativo e colaborativo entre os atores envolvidos na LR de REEE podem explicar em parte o êxito de alguns países europeus. Essa pesquisa buscou entender como a colaboração e a cooperação estão influenciando a implementação do modelo de LR de REEE no cenário europeu e brasileiro. Para isso, optou por uma abordagem qualitativa, exploratória e descritiva. A coleta de dados foi feita por meio de estudos de caso múltiplos, entrevistas em profundidade semiestruturadas, aplicadas aos principais atores da LR de REEE no Brasil, Espanha, Portugal e Suíça. A análise dos dados usou a técnica de análise de conteúdo. Os resultados mostram que, aplicando a matriz dos atributos de determinantes de colaboração e cooperação elaborada a partir do referencial teórico nos quatro países estudados, os que apresentaram o maior número de conformidades com o modelo proposto foram também os que registraram maior eficiência em seus sistemas de LR. Além disso, pode-se inferir que atributos motivacionais como predisposição e histórico de parcerias aumentam positivamente o impacto da colaboração ou cooperação na LR de REEE. Percebeu-se também que a obrigatoriedade de fazer algo por força de lei não estimula os atores a ultrapassarem as metas exigidas, ainda que seja uma motivação importante, principalmente se for externa, como no caso da Diretiva europeia de REEE. Nesse cenário, sem nenhuma não conformidade e com predisposição para trabalho em conjunto para solução de desafios socioambientais, a Suíça é o país com o melhor resultado na coleta de REEE. Em segundo ficou Portugal com uma não conformidade na dimensão Estrutura e a necessidade de atender a Diretiva como principal fator motivacional. Espanha vem em seguida ao modelo português, com igual necessidade de atender à legislação externa, mas com uma não conformidade em motivação, pois não se sentia obrigada a cumprir as metas até 2019. Já o Brasil registrou o maior número de não conformidades com a matriz proposta. Destaca-se, no caso brasileiro, a falta de motivação para colaborar de todos 
os atores da cadeia reversa, o que explica os poucos avanços registrados após oito anos de aprovação da PNRS. A matriz proposta auxilia ainda na identificação de elementos da estrutura operacional que favoreçam processos de colaboração e cooperação no modelo brasileiro de LR de forma a contribuir com impactos positivos.

Palavras-chaves: Colaboração. Cooperação. Logística Reversa (LR). REEE. Parcerias. 


\begin{abstract}
The accelerated growth in the market of Electrical and Electronic Equipment (EEE), the planned obsolescence and the rise in the disposal of Waste of Electrical and Electronic Equipments (WEEE) cause socio-environmental impacts worldwide. Management of those wastes encouraged several countries to consider the prerequisites for the management of WEEE in an environmentally healthy way, through WEEE Reverse Logistics (RL). Europe appears on the world stage as an example of RL implementation of WEEE due to high performance models, which reveal a list of common factors: partnerships, consumer engagement and information sharing, accurate laws, well-defined roles, coordinated efforts of RL players to achieve the same goal. Those elements of cooperative and collaborative behaviors, among the players engaged in the RL of WEEE, may partially explain the success of some European countries. This study sought to realize how collaboration and cooperation are influencing the implementation of the RL model of WEEE in the European and Brazilian scenarios. In so doing, a qualitative, exploratory and descriptive approach was adopted. Data collection was done through multiple case studies, semi-structured in-depth interviews, applied to the main players of RL of WEEE in Brazil, Spain, Portugal and Switzerland. The technique of content analysis was used for data analysis. The results show that, by applying the matrix of attributes of collaboration and cooperation determinants, elaborated from the theoretical framework in the four countries studied, the ones that presented the greatest rate of conformities with the proposed model were also the ones that registered the highest efficiency in their systems of RL. In addition, it may be inferred that motivational attributes such as predisposition and history of partnerships positively increase the impact of collaboration or cooperation in the RL of WEEE. It has also been realized that the obligation to do something by law does not encourage players to exceed the required targets, even if it is an important motivation, especially if it is an external one, as in the case of the European Directive of WEEE. In this scenario, with no non-conformity and predisposition to work together to overcome socio-environmental challenges, Switzerland holds the best result in collecting WEEE. Portugal comes second, with a non-conformity in the Structure dimension and the need to comply with the Directive as the main motivational factor. Spain comes after the Portuguese model, with the same need to comply with foreign legislations, but with a nonconformity in motivation, as they did not feel bound to meet the targets until 2019. Brazil, on the other hand, registered the highest rate of non-conformities with the proposed matrix. In the Brazilian case, the lack of motivation to collaborate with all the players of the reverse chain excels, which explains the little progress made after eight years of approval of the PNRS. The
\end{abstract}


proposed matrix also helps identify elements of the operational structure that favor processes of collaboration and cooperation in the Brazilian RL model in order to contribute with positive impacts.

Keywords: Collaboration. Cooperation. Reverse Logistic (RL). WEEE. Partnerships. 


\section{RESUMEN}

El acelerado crecimiento del mercado de Aparatos Eléctricos y Electrónicos (AEE), la obsolescencia programada y el aumento del descarte de los Residuos de Aparatos Eléctricos y Electrónicos (RAEE) están generando impactos socioambientales en todo el mundo. La gestión de dichos residuos ha motivado a varios países a reflexionar sobre los prerrequisitos para la gestión de RAEE de forma ambientalmente saludable, a través de la Logística Inversa (LI) de RAEE. Europa surge en el escenario mundial como ejemplo en la implementación de la LI de RAEE debido a los modelos de alto desempeño, que revelan varios factores en común. Trabajo conjunto, compromiso de los consumidores, intercambio de información, leyes claras, con roles bien definidos, esfuerzos coordinados de los actores de la LI para alcanzar los mismos objetivos. Tales elementos de comportamiento cooperativos y colaborativos entre los actores da LI de RAEE pueden explicar en parte el éxito de algunos europeos. Esta investigación buscó entender cómo la colaboración y la cooperación están influenciando la implementación del modelo de LI de RAEE en el escenario europeo y en el brasileño. Para ello, esta investigación tuvo un enfoque cualitativo, exploratorio y descriptivo. La recolección de datos fue hecha por medio de estudios de caso múltiples, entrevistas em profundidades semiestructuradas, aplicadas a los principales drivers de la LI de RAEE en Brasil, España, Portugal y Suiza. El análisis de los datos usó la técnica de análisis de contenido. Los resultados muestran que, aplicando la matriz de los atributos determinantes de colaboración y cooperación, em los cuatro países estudiados, aquellos que presentaron el mayor número de conformidades con el modelo propuesto fueron también los que registraron mayor eficiencia en sus sistemas de LI. Además, se puede inferir que atributos motivacionales como predisposición e histórico en trabajos conjuntos aumentan positivamente el impacto de la colaboración o cooperación en la LI de RAEE. También se notó que la obligatoriedad de hacer algo, solo por fuerza de ley, no estimula a los actores a superar las metas exigidas, aunque sea una motivación importante, principalmente si ésta es externa, como es el caso de la Directiva europea de RAEE. En ese escenario, sin ninguna no conformidad y con predisposición para el trabajo conjunto para solucionar desafíos socioambientales, Suiza es el país con el mejor resultado en la recogida de RAEE. En segundo lugar está Portugal con 1 no conformidad en la dimensión Estructura y la necesidad de atender a la Directiva como principal factor motivacional. España sigue al modelo portugués, con igual necesidad de atender a la legislación externa, pero con 1 no conformidad en motivación, ya que no se sentía obligada a cumplir con las metas hasta el 2019. Por otro lado, Brasil registró el 
mayor número de no conformidades con la matriz propuesta. Se destaca, en el caso brasileño, la falta de motivación en colaborar, de parte de todos los actores de la cadena inversa, lo que explica los pocos avances registrados tras 8 años de aprobación de la PNRS. La matriz propuesta ayuda también a identificar elementos de la estructura operacional que favorezcan procesos de colaboración y cooperación en el modelo brasileño de LI, de modo de contribuir con impactos positivos.

Palabras-clave: Colaboración. Cooperación. Logística Inversa (LI). RAEE. Trabajo conjunto. 


\section{LISTA DE FIGURAS}

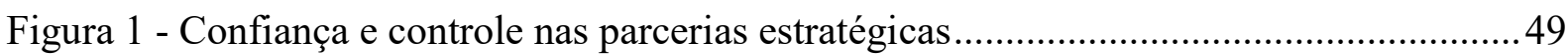

Figura 2 - Visões de colaboração e cooperação ......................................................................52

Figura 3 - Fatores determinantes para a escolha por cooperar ou colaborar ...........................62

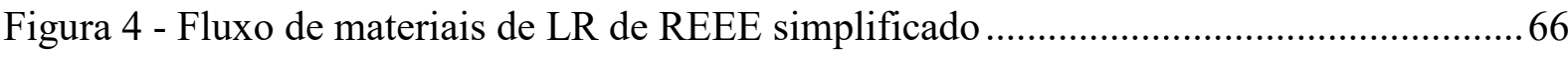

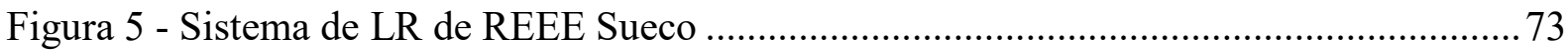

Figura 6 - Comparação dos atributos de colaboração e cooperação com as características do

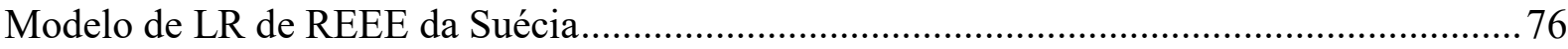

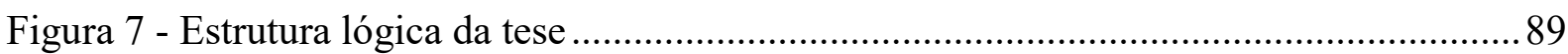

Figura 8 - Categorias de análise com base no referencial teórico .........................................99

Figura 9 - Sistema de Financiamento Suíço para a reciclagem dos REEE ........................... 115

Figura 10 - O volume de REEE processados na Suíça pela SWICO e SENS de 2003 até 2016

Figura 11 - Taxa de Reciclagem por objetivos mínimos de valorização, reutilização e reciclagem em Portugal

Figura 12 - Valorização Global dos REEE e resumo da gestão dos REEE 2015 em Portugal

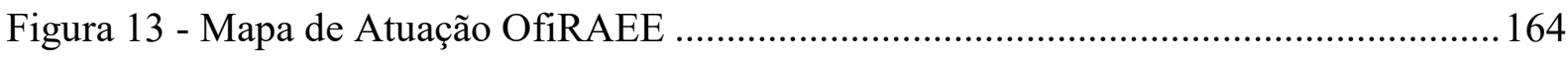

Figura 14 - Volume de REEE coletados na Espanha de 2006 a 2015 ................................... 168

Figura 15 - Total de REEE coletados em 2015 por países na UE, comparado com a média percentual de $45 \%$ e $65 \%$.

Figura 16 - Estrutura de implementação do PP 196

Figura 17 - Resultado da coleta de REEE, por forma de coleta [Esquerda: Unidades, Direita: Peso]

Figura 18 - Resultado da coleta de REEE, por mês [Esquerda: Unidades, Direita: Peso] .....203

Figura 19 - Resultado da coleta de REEE, por loja [Esquerda: Unidades, Direita: Peso] .....205 Figura 20 - Resultado da coleta de REEE, por categorias [Esquerda: Unidades, Direita: Peso] 


\section{LISTA DE QUADROS}

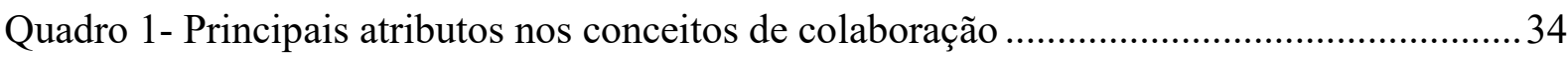

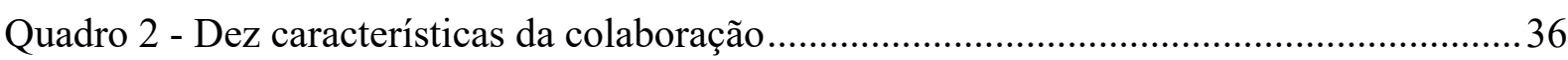

Quadro 3 - Principais atributos nos conceitos de cooperação …............................................. 42

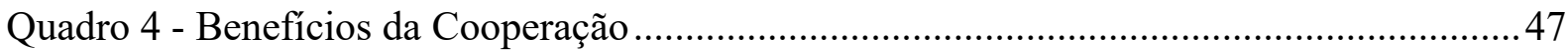

Quadro 5 - Colaboração e Cooperação na Pesquisa Acadêmica ................................................53

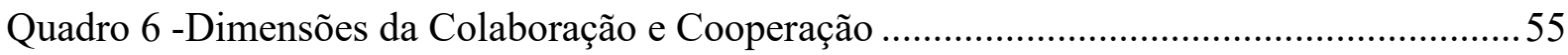

Quadro 7 - Matriz dos atributos de colaboração e cooperação detalhada. …...........................57

Quadro 8 - Metas de coleta de REEE das Diretivas EU 2002/96 e 2012/19 ...........................69

Quadro 9 - Característica do sistema de LR da Suécia ........................................................ 71

Quadro 10 - Seis pontos pendentes para o Acordo Setorial de LR de REEE .......................... 84

Quadro 11- Resultado da pesquisa sobre colaboração e cooperação nas bases de dados ........92

Quadro 12 - Relação dos atores entrevistados.....................................................................95

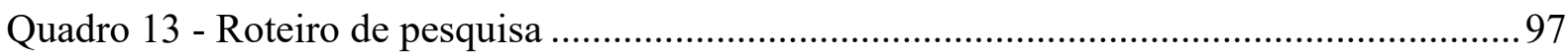

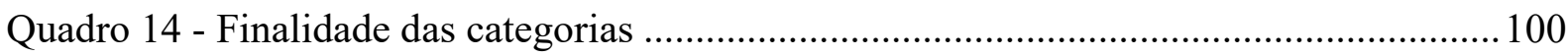

Quadro 15 Objetivos de coleta de REEE definidos pelo RD 110/2015 ................................ 167

Quadro 16 - Resumo dos Atributos da dimensão Motivação no Brasil e países europeus ....222

Quadro 17 - Escopo da colaboração e cooperação na LR de REEE nos países europeus e no

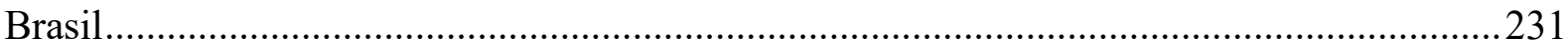

Quadro 18 - Síntese das não conformidades na colaboração ..............................................249

Quadro 19 - Matriz do impacto da colaboração em Portugal, Suíça e Brasil.........................251

Quadro 20- Síntese das não conformidades na cooperação .................................................257

Quadro 21- Matriz do impacto da cooperação na Espanha, Portugal, Suíça e Brasil. ...........258

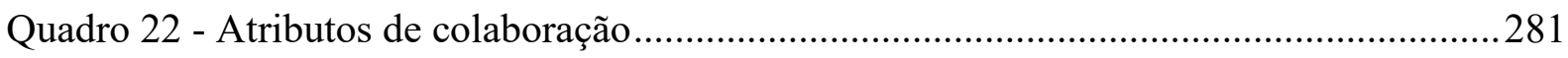

Quadro 23 - Atributos de cooperação ...............................................................................28

Quadro 24 - Análise dos atributos de colaboração e cooperação ...........................................290

Quadro 25 - Esquema de palavras para busca de colaboração, cooperação e LR de REEE ..298

Quadro 26 - Palavras-chaves para colaboração, cooperação e áreas a fins de LR de REEE .300

Quadro 27 - Conjunto de palavras-chaves com operadores booleanos .................................302

Quadro 28 - Matriz detalhada do impacto da cooperação na Espanha, Portugal, Suíça e Brasil

Quadro 29 - Matriz detalhada do impacto da colaboração em Portugal, Suíça e Brasil .........308 


\section{SUMÁRIO}

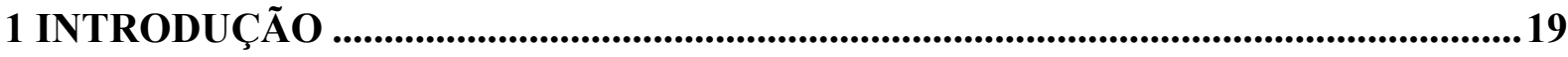

2 COLABORAÇÃO E COOPERAÇÃO: CONCEITOS E ELEMENTOS ......................29

2.1 EVOLUÇÃO DO ESTUDO SOBRE COLABORAÇÃO E COOPERAÇÃO ...................29

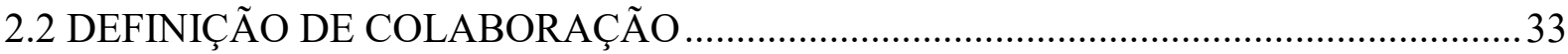

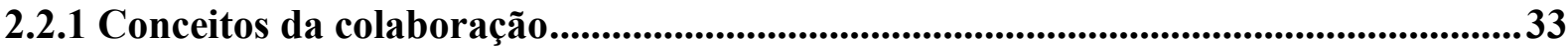

2.2.2 Características e elementos/atributos da colaboração ................................................35

2.2.3 Benefícios da colaboração ................................................................................................39

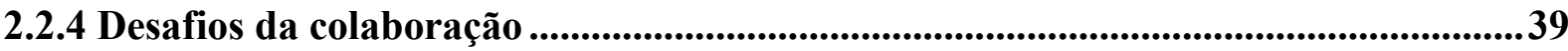

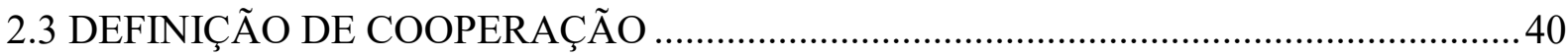

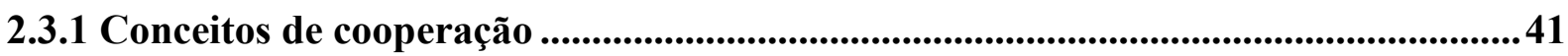

2.3.2 Características e Elementos/atributos da cooperação...............................................43

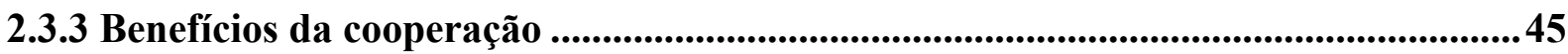

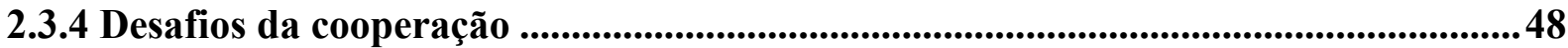

2.4 AS DIFERENÇAS E SEMELHANÇAS ENTRE COLABORAÇÃO E COOPERAÇÃO

2.4.1 Fatores que definem a decisão de colaborar ou cooperar ........................................61

3 MODELOS DE LR DE REEE E O IMPACTO DA COLABORAÇÃO E/OU COOPERAÇÃO NA IMPLEMENTAÇÃO E PERFORMANCE. ..................................65

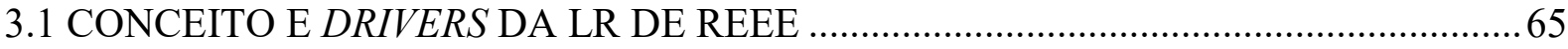

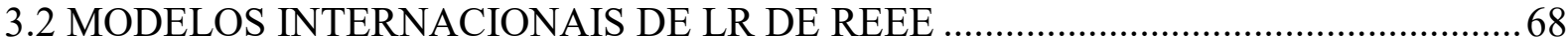

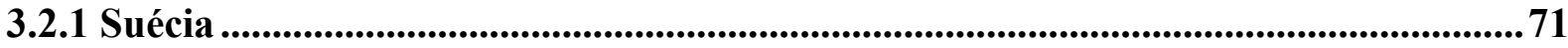

3.2.2 Visão geral sobre os modelos de LR de REEE da Noruega, Finlândia e Itália ....... 76

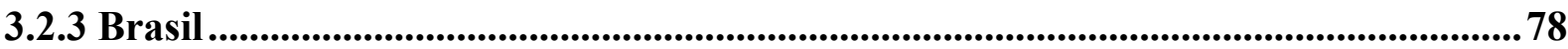

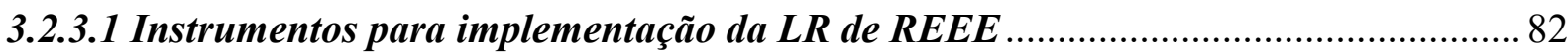

3.2.3.2 $\mathrm{O}$ modelo de LR de REEE proposto e o projeto piloto................................................. 85

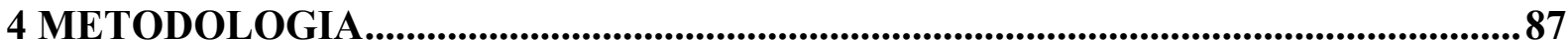

4.1 NATUREZA DA PESQUISA, FINS E MEIOS DE INVESTIGAÇÃO ............................87 
4.2 O PROCESSO DE SELEÇÃO DA LITERATURA …................................................... 90

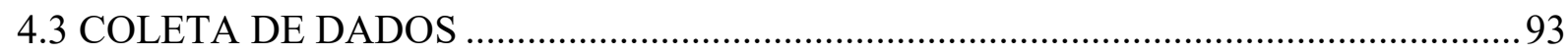

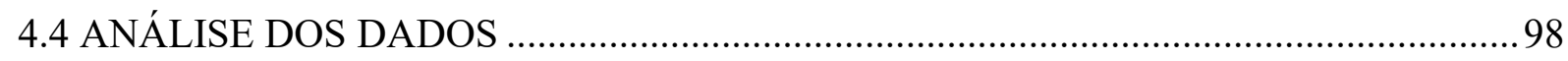

5 APRESENTAÇÃO DOS RESULTADOS E DISCUSSÃO ........................................... 101

5.1 ESTUDO DE CASO DA LR DE REEE NA SUÍÇA ................................................... 101

5.1.1 Os atributos da dimensão "Motivação" na LR de REEE na Suíça ........................101

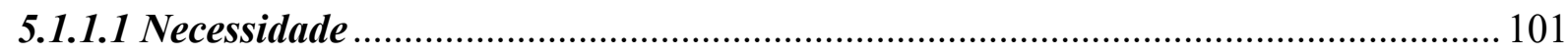

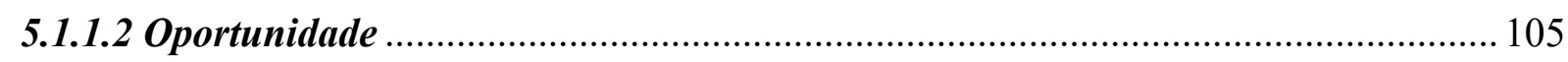

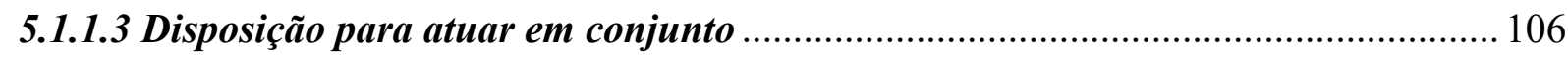

5.1.2 Os atributos da Dimensão Escopo na LR de REEE na Suíça.................................106

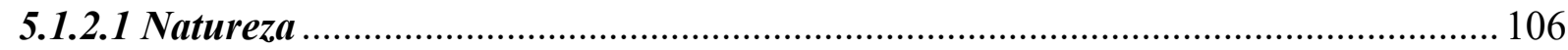

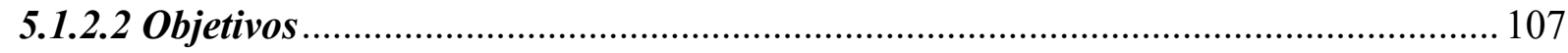

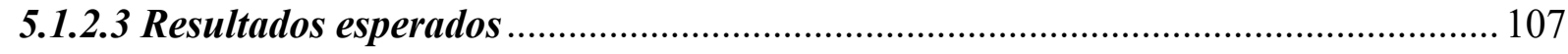

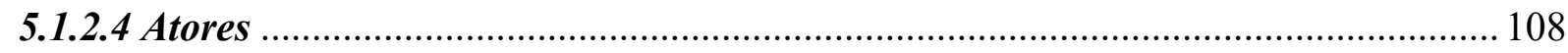

5.1.3 Os atributos da Dimensão "Estrutura” na LR de REEE na Suíça...........................110

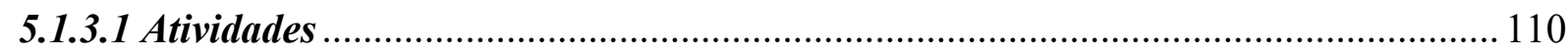

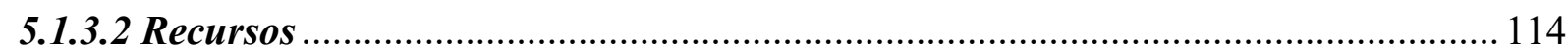

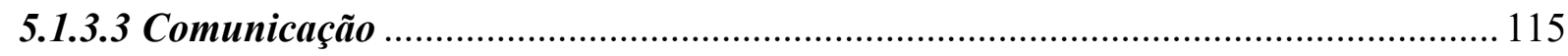

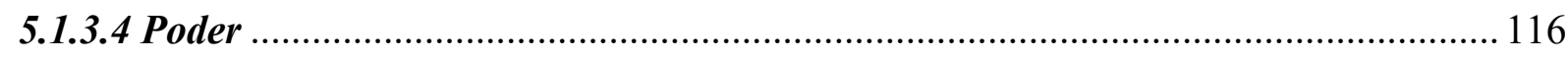

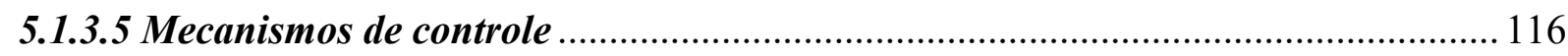

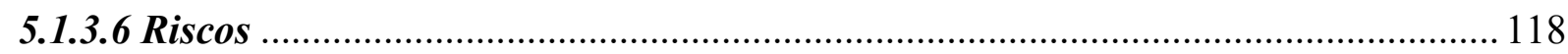

5.1.4 Os atributos da Dimensão "Impactos" na LR de REEE na Suíça..........................118

5.2 ESTUDO DE CASO DA LR DE REEE EM PORTUGAL …...................................... 123

5.2.1 Os atributos da Dimensão "Motivação" na LR de REEE em Portugal ...................123

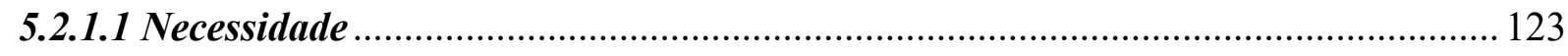

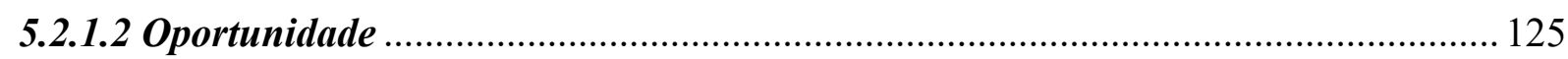

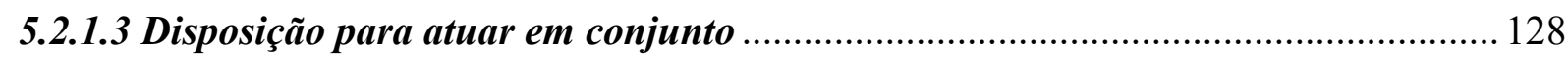


5.2.2 Os atributos da Dimensão "Escopo" na LR de REEE em Portugal

5.2.2.1 Natureza

5.2.2.2 Objetivos

5.2.2.3 Resultados esperados

5.2.2.4 Atores

5.2.3 Os atributos da Dimensão "Estrutura" na LR de REEE em Portugal

5.2.3.1 Atividades

5.2.3.2 Recursos

5.2.3.3 Comunicação

5.2.3.4 Poder

5.2.3.5 Mecanismos de controle

5.2.3.6 Riscos

5.2.4 Os elementos da Categoria "Impactos" na LR de REEE em Portugal 143

5.3 ESTUDO DE CASO DA LR DE REEE NA ESPANHA

5.3.1 Os atributos da Dimensão "Motivação" na LR de REEE na Espanha 151

5.3.1.1 Necessidade

5.3.1.2 Oportunidade

5.3.1.3 Disposição para atuar em conjunto

5.3.2 Os atributos da Dimensão "Escopo" na LR de REEE na Espanha 155

5.3.2.1 Natureza. 155

5.3.2.2 Objetivos. 155

5.3.2.3 Resultados esperados 155

5.3.2.4 Atores 156

5.3.3 Os atributos da Dimensão "Estrutura" na LR de REEE na Espanha 156

5.3.3.1 Atividades 157

5.3.3.2 Recursos 162

5.3.3.3 Comunicação 163 
5.3.4 Os elementos da Categoria "Impactos" na LR de REEE na Espanha

5.4 ESTUDO DE CASO DA LR DE REEE NO BRASIL, DA ELABORAÇÃO DO ACORDO SETORIAL À IMPLEMENTAÇÃO DO PROJETO PILOTO DE COOPERAÇÃO DESCARTEON

5.4.1 Acordo Setorial da LR de REEE no Brasil ................................................................... 171

5.4.1.1 Os atributos da Dimensão "Motivação" no AS de LR de REEE do Brasil. 171

5.4.1.1.1 Necessidade 172

5.4.1.1.2 Oportunidade

5.4.1.1.3 Disposição para atuar em conjunto

5.4.1.2 Os atributos da Dimensão “Escopo” no Acordo Setorial da LR de REEE no

Brasil

5.4.1.2.1 Natureza

5.4.1.2.2 Objetivos

5.4.1.2.3 Resultados esperados

5.4.1.2.4 Atores

5.4.1.3 Os atributos da Dimensão "Estrutura" no Acordo Setorial da LR de REEE no Brasil

5.4.1.3.1 Atividades

5.4.1.3.2 Recursos

5.4.1.3.3 Comunicação

5.4.1.3.4 Poder

5.4.1.3.5 Mecanismos de controle

5.4.1.3.6 Riscos

5.4.1.4 Os elementos da Categoria "Impactos" no Acordo Setorial da LR de REEE no Brasil 
5.4.2.1 Os atributos da Dimensão "Motivação" no PP

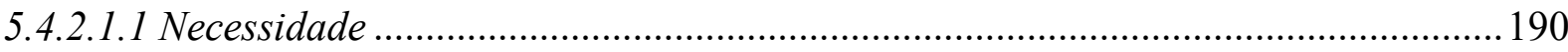

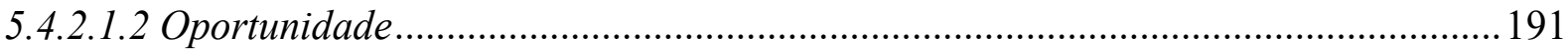

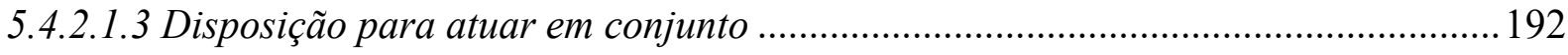

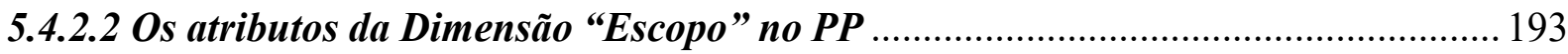

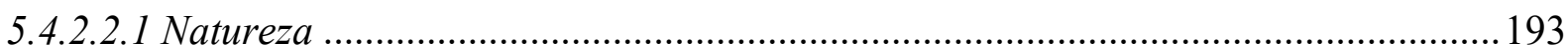

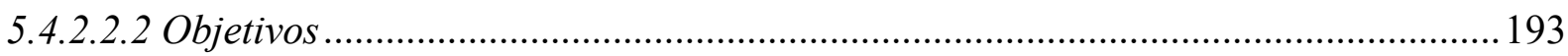

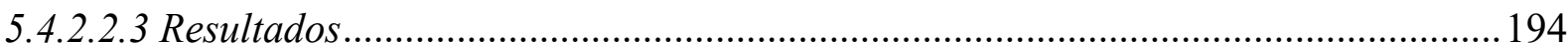

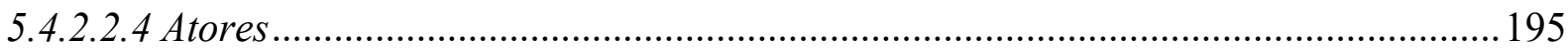

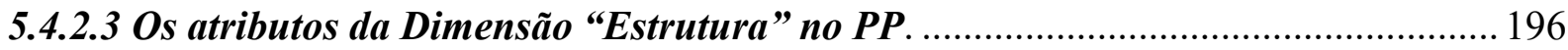

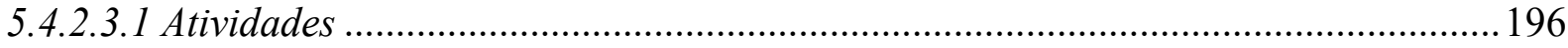

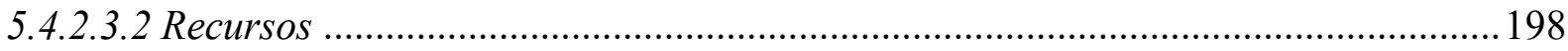

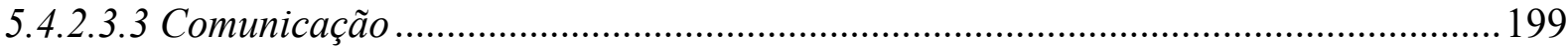

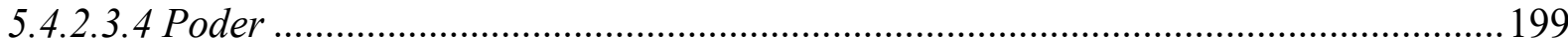

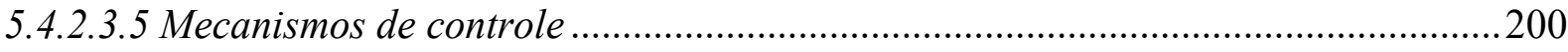

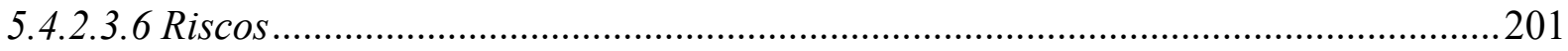

5.4.2.4 Os elementos da categoria “Impactos” no Projeto Descarte ON ........................... 201

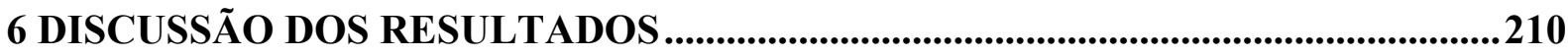

6.1 A MOTIVAÇÃO PARA BUSCA DE PARCERIAS NA IMPLEMENTAÇÃO DA LR DE REEE NA ESPANHA, PORTUGAL, SUÍÇA E BRASIL .................................................210

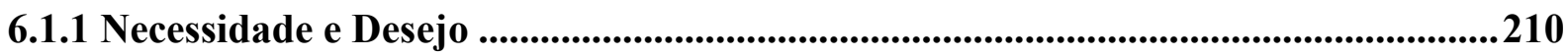

6.1.2 Oportunidade ....................................................................................................................................2214

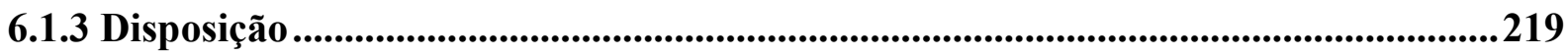

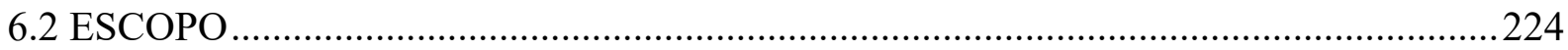

6.2.1 Natureza .................................................................................................................................224

6.2.2 Objetivos..........................................................................................................................224 


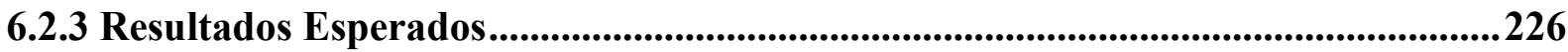

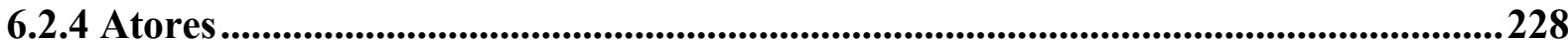

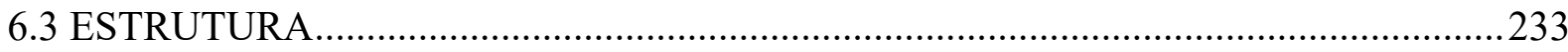

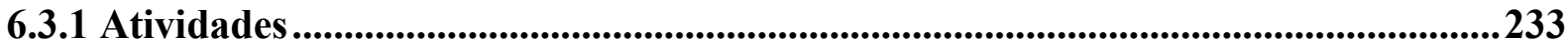

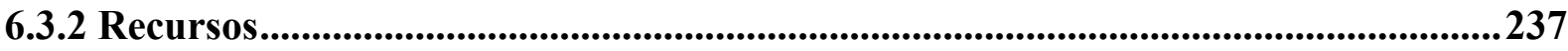

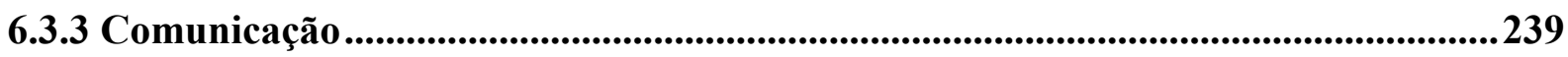

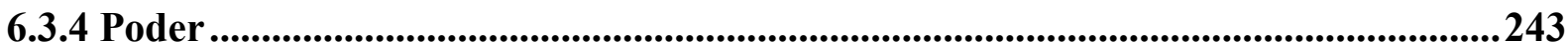

6.3.5 Mecanismos de Controle ......................................................................................244

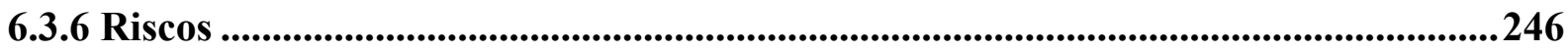

6.4 IMPACTOS DA COLABORAÇÃO E DA COOPERAÇÃO .........................................246

6.4.1 Impactos, benefícios e desafios da colaboração ...................................................247

6.4.2 Impactos, benefícios e desafios da cooperação...................................................253

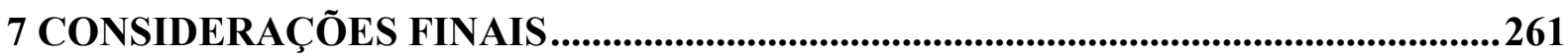

REFERÊNCIAS

APÊNDICE A - Atributos de colaboração ..............................................................280

APÊNDICE B - Atributos de cooperação ..............................................................284

APÊNDICE C - Análise dos atributos de colaboração e cooperação ..............................289

APÊNDICE D - Esquema de palavras para busca de colaboração, cooperação E LR de

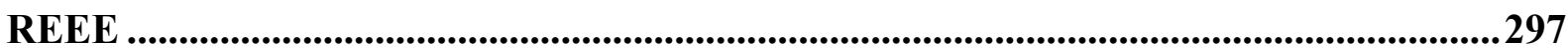

APÊNDICE E - Palavras-chaves para colaboração, cooperação, e áreas a fins de LR de

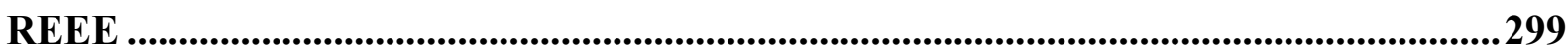

APÊNDICE F - Conjunto de Palavras-chaves com operadores booleanos......................301

APÊNDICE G - Matriz detalhada do impacto da cooperação na Espanha, Portugal, Suíça

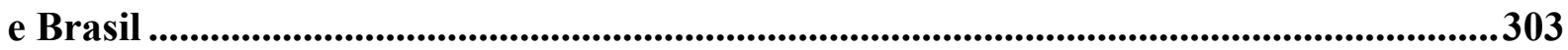

APÊNDICE H - Matriz detalhada do impacto da colaboração em Portugal, Suíça e Brasil 307

APÊNDICE I - Resumen expandido en español. 310 


\section{INTRODUÇÃO}

O acelerado crescimento do mercado de Equipamentos Elétricos Eletrônicos (EEE), a obsolescência programada e aumento exponencial do descarte dos seus resíduos ao final de vida têm gerado impactos socioambientais em todo o mundo. No caso específico dos celulares, a obsolescência programada e perceptiva como estratégia de marketing das empresas para incentivar o consumo dos seus produtos é responsável por cerca de $90 \%$ das aquisições desses aparelhos. Cerca de $66 \%$ dos consumidores brasileiros trocam seus aparelhos celulares por estarem desatualizados tecnologicamente, por acreditar que eles estão velhos ou para comprar um modelo mais atual, todos fatores relacionados à obsolescência perceptiva; $24 \%$ o fazem por motivo de quebra, que pode estar relacionado à obsolescência programada; e apenas $10 \%$ por outros motivos, como roubo ou perda. Na maioria dos casos, isso ocorre em um período inferior a 2 anos de uso. Todo esse processo contribui para o volume crescente de resíduos gerados que necessitam ser destinados de forma correta, seja para sua reutilização e reciclagem, seja para sua disposição ambientalmente segura (KOGA et al., 2014).

Em 2010, foram produzidos 33,8 milhões de toneladas de Resíduos de Equipamentos Elétricos Eletrônicos (REEE) no mundo. Em 2014, esse número passou para 41,8 milhões de toneladas de REEE, contabilizando um aumento de $24 \%$, ao passo que a população cresceu $14 \%$ nesse mesmo período, apresentando, portanto, um crescimento desproporcional (BALDÉ et al., 2015). Os autores alertam a respeito do fato que, do total de REEE gerados em 2014, apenas 6,5 milhões foram coletados por sistemas de coleta oficiais, capazes de monitorar seu volume e fluxo e garantir o processo ambientalmente correto. Entre os fatores que prejudicam a apuração dos dados sobre o destino do restante de REEE gerados, encontram-se os sistemas de LR (Logística Reversa) de REEE em países em desenvolvimento, mal estruturados ou sem controle de dados sobre as etapas do processo, o transbordo ilegal desses resíduos com o objetivo de externalizar os custos da reciclagem de forma ambientalmente correta e os sistemas informais de LR de REEE (BALDÉ et al., 2015).

Nesse contexto, as situações de riscos potenciais inerentes aos REEE se elevam. Contribuem para este cenário o fato dos EEE possuírem, em sua composição, substâncias tóxicas, ou raras, com valor econômico. Esses fatores aumentam o risco de escassez de alguns elementos essenciais para o funcionamento dos EEE, como ouro e prata, assim como potencializam os riscos à saúde e ao meio ambiente, por conterem elementos nocivos, como chumbo, retardantes de chama que liberam dioxinas, além de cádmio (SCHLUEP et al., 2009; 
MANOMAIVIBOOL; VASSANADUMRONGDEE, 2011; WANG et al., 2012. AUGUSTO, 2014).

Este fenômeno mundial, no entanto, ganhou especial relevância nos países em desenvolvimento nas últimas décadas (SCHLUEP et al., 2009; WANG et al., 2012). O aumento do PIB nos países pobres, associado à redução do ciclo de vida do produto, estimula o debate sobre LR de REEE. O desenvolvimento econômico muda os hábitos da população, tanto em termos do uso doméstico de EEE, que se torna mais intenso, quanto em termos de tempo de vida desses dispositivos, já que existe uma tendência de trocar o que está quebrado ou desatualizado, em vez de conservá-lo. Além disso, em países desenvolvidos, os EEE duram a metade do tempo do que em países em desenvolvimento (TORRETTA et al., 2013).

Dessa forma, nos últimos anos, a LR de REEE ganhou reconhecimento acadêmico e profissional. Além dos riscos à saúde e meio ambiente e do rápido crescimento dos REEE, drivers como a evolução da legislação ambiental, o aumento da pressão dos consumidores para que as empresas assumam políticas de responsabilidade social e ambiental e a colaboração entre os atores da cadeia reversa figuram entre os fatores que potencializam o resultado da LR (LAU; WANG, 2009; JANSE; SCHUUR; BRITO, 2009). Este contexto tem gerado modelos diferentes de LR em países desenvolvidos e em desenvolvimento.

A Europa surge no cenário mundial como exemplo na implementação da LR de REEE devido aos números alcançados ao longo dos anos desde a aprovação da Diretiva WEEE de 2002, que estabelece normas e metas para o descarte correto de REEE em todos os países membros da União Europeia. Para esta pesquisa, é importante salientar que diversos países começaram suas atividades reversas no setor de EEE antes da legislação europeia, antecipandose até mesmo à entrada em vigor de leis nacionais, como é o caso da Suécia e da Noruega (AUGUSTO, 2014; YLÄ-MELLA et al., 2014).

A Diretiva Europeia determina, desde 2002, metas de coleta e reciclagem, assim como o modelo baseado na Responsabilidade Estendida do Produtor (REP) com o objetivo de implementar um sistema de tratamento de REEE. Trata-se, portanto, de um ator com um papel claramente definido na cadeia reversa de REEE. Entretanto, a definição do conjunto de atores que participarão do sistema de coleta dos REEE é definida nas legislações nacionais, bem como a forma de organização do sistema de LR e seu financiamento (ROTTER; CHANCEREL; SCHILL, 2011).

O resultado do engajamento dos países membros em prol da implementação da Diretiva de REEE pode ser observada nos relatórios do Eurostat, escritório de estatísticas da União Europeia que tem o objetivo de fornecer dados para balizar as ações de desenvolvimento dos 
países pertencentes ao bloco (EUROSTAT, 2016). Os países membros mostram avanços significativos na implementação ou aperfeiçoamento dos sistemas de LR de REEE, com o aumento exponencial da coleta dos REEE (EUROSTAT, 2015; YLÄ-MELLA et al., 2014). Suécia, Noruega, Dinamarca, Bélgica e Finlândia ocupam os 5 primeiros lugares respectivamente no ranking dos países que seguem a Diretiva de REEE da União Europeia, no quesito quantidade de REEE em quilogramas coletados por habitantes ao ano (EUROSTAT, 2015). Um bom exemplo é a Suécia, que teve um aumento de $260 \%$ sobre a quantidade inicial de REEE coletados, sendo que o número per capita passou para 17,313 kg de REEE/hab/ano, ultrapassando em mais de 3 vezes as metas estabelecidas pela Diretiva WEEE, de $4 \mathrm{~kg}$ de REEE/hab/ano (EUROSTAT, 2015).

O sistema de LR de REEE na Europa está evoluindo para eficiência em reciclagem, não ficando restrito apenas à quantidade de REEE coletados, mas também ao desenvolvimento de melhores práticas, tanto nos processos produtivos, quanto nos processos de reciclagem, para aumentar sua reciclabilidade, superando as metas de coletas impostas pela Diretiva de REEE (YLÄ-MELLA et al., 2014; EUROSTAT, 2012). Os excepcionais resultados apresentados entre os países líderes da Europa devem ser seguidos por todos os países membros, em busca da eficiência dos seus sistemas de LR de REEE, pois a diretiva reformulada, 2012/19/UE, que entrou em vigor em 13 de agosto de 2012, introduz objetivos de coleta graduais, mais elevados, exigindo que os países membros coletem $45 \%$ do peso médio dos EEE colocados no mercado nos 3 últimos anos, a partir de 2016 até 2018, passando para 65\% desse total a partir de 2019 (EUROSTAT, 2012).

Um Sistema de LR de REEE eficaz exige ações coordenadas de todas as etapas e atores envolvidos, regido por leis claras (TORRETTA et al., 2013; AUGUSTO, 2014). Ele inicia na coleta, exigindo capilaridade e mobilidade dos postos de descarte, assim como a atitude consciente de descarte por parte do consumidor, coordenado com transporte, préprocessamento, reciclagem e destinação ambientalmente correta (JANG, 2010; MIGLIANO, 2012; TORRETTA et al., 2013; WANG et al., 2012; DEMAJOROVIC; MIGLIANO, 2013; AUGUSTO, 2014; DEMAJOROVIC; AUGUSTO; SOUZA, 2016). Os altos índices de coleta dos países membros da União Europeia estão relacionados aos esforços dos governos na criação de leis nacionais com o objetivo de atender à Diretiva WEEE, como no caso da Finlândia, que criou uma legislação e uma infraestrutura funcional e eficiente de LR de REEE em um curto espaço de tempo que se encontra em vigor desde 2004, de acordo com Ylä-Mella et al. (2014). Além disso, vários países que já possuíam leis nacionais sobre REEE em vigor e LR de REEE implementada adaptaram sua legislação nacional e fizeram as alterações necessárias no sistema 
para alinhar seus resultados às metas da diretiva, como é o caso da Suécia e da Noruega (YLÄMELLA et al., 2014). Os esforços governamentais não se limitam a legislar em favor do objetivo comum de atender à diretiva; os governos participam ativamente do sistema de coleta por intermédio dos municípios, que criam postos de consolidação de REEE, pontos de coletas fixos próximos às áreas residenciais e coleta seletiva móvel para atender à demanda dos EEE ao final de vida, de forma a garantir a capilaridade e alcançar todas as oportunidades de descarte correto, a exemplo da Itália, que buscou a colaboração do consumidor, diversificando as formas de coleta. Suécia, Noruega e Finlândia, por sua vez, criaram postos de descarte de resíduos especiais próximos às residências, além de coleta seletiva móvel, pois são países com baixa densidade demográfica e grande espaçamento da população (YLÄ-MELLA et al., 2014). Outro exemplo de esforço do governo para tornar a coleta eficiente, atendendo às metas da Diretiva de REEE da EU, foi o caso da Romênia, que sentiu a necessidade de propor políticas de incentivos financeiros e educação ambiental para criar a cultura de descarte correto na população (TORRETTA et al., 2013).

Outra característica desses modelos de sucesso é a forma de organização do sistema de LR de REEE que, normalmente, é regido pela Organização de Responsabilidade do Produtor (ORP), criada pelos fabricantes com o objetivo de garantir a eficiência do sistema (SINHAKHETRIWAL; KRAEUCHIB; SCHWANINGER, 2005; HISCHIER; WÄGER; GAUGLHOFER, 2005; KHETRIWAL; KRAEUCHI; WIDMER, 2009; YLÄ-MELLA et al., 2014). Esse tipo de sistema conta muitas vezes com a parceria do governo local, que se responsabiliza por uma parte da operação, pelos custos e colabora com a fiscalização da coleta (KHETRIWAL; KRAEUCHI; WIDMER, 2009). O sistema de financiamento da LR pode ser garantido por Tarifas Antecipadas de Reciclagem (TAR), pagas pelo consumidor no momento da compra e destacadas na nota fiscal (KHETRIWAL; KRAEUCHI; WIDMER, 2009) ou pela indústria de EEE (SINHA-KHETRIWAL; KRAEUCHIB; SCHWANINGER，2005; HISCHIER; WÄGER; GAUGLHOFER, 2005). Países como Suécia, Noruega e Finlândia, entre outros, têm seus sistemas executados por esse tipo de instituição, ORP, que garante a performance da LR acima da média.

Os resultados dos países da União Europeia mostram um rol de países com modelos de alta performance implementados nos quais se pode perceber fatores comuns na implementação e manutenção de LR de REEE: leis claras, com papéis bem definidos (MIGLIANO, 2012; AUGUSTO, 2014), esforços coordenados dos atores da cadeia reversa para alcançar os mesmos objetivos, entre setor de EEE, varejistas e governo, assim como com ORP (SINHAKHETRIWAL; KRAEUCHIB; SCHWANINGER, 2005; HISCHIER; WÄGER; 
GAUGLHOFER, 2005; KHETRIWAL; KRAEUCHI; WIDMER, 2009; TORRETTA et al., 2013; YLÄ-MELLA et al., 2014) que permitem uma maior capilaridade dos postos de coletas (SINHA-KHETRIWAL; KRAEUCHIB; SCHWANINGER, 2005). Segundo Lau e Wang (2009), a parceria dos governos é fundamental para diminuir a resistência dos setores empresariais em iniciar programas de LR, devido ao elevado custo envolvido nesta atividade. Outros fatores importantes são o nível de conscientização do cidadão (AUGUSTO, 2014; YLÄMELLA et al., 2014) e a existência de estratégias de comunicação e educação sobre o descarte correto dos REEE (DEMAJOROVIC et al., 2012; YLÄ-MELLA et al., 2014).

Nesse sentido, observa-se que diferentes autores utilizam palavras distintas para um dos elementos centrais do sucesso dos modelos de LR: parcerias, esforços coordenados, engajamento dos consumidores e compartilhamento de informação reforçam a ideia de que os atores da cadeia reversa precisam estar dispostos a colaborar na construção e operação de fluxos reversos (SINHA-KHETRIWALA; KRAEUCHIB; SCHWANINGER, 2005; HISCHIER; WÄGER; GAUGLHOFER， 2005; KHETRIWAL; KRAEUCHI; WIDMER， 2009; TORRETTA et al., 2013; WANG et al., 2012; AUGUSTO, 2014; YLÄ-MELLA et al., 2014). Ainda assim, poucas pesquisas sobre a temática se dedicaram a entender de forma aprofundada o papel da colaboração ou cooperação de LR de REEE. Esta pesquisa assume como pressuposto que nos programas de LR de REEE, por se tratar de sistemas complexos envolvendo múltiplos atores, é fundamental estabelecer relações sólidas e complementares (VIEIRA, 2006) na busca de objetivos comuns, nas quais cada ator sabe qual é seu papel, qual o resultado desejado e quais as metas com as quais ele se compromete (GATTAZ, 2010).

Nesse sentido, a efetividade de sistemas complexos depende da disponibilidade de diferentes atores colaborarem ou cooperarem para um objetivo comum. No entanto, estes conceitos não são sinônimos segundo Polenske (2004). No caso da colaboração, os atores trabalham juntos, como, por exemplo, no desenvolvimento de uma tecnologia nova, de forma vertical e interna, por um determinado tempo. Nesse caso, os atores envolvidos obtêm vantagem pelo uso mútuo de recursos, tanto físicos, quanto humanos (POLENSKE, 2004). Já no caso da cooperação, eles trabalham de forma individualizada, horizontal e externa, compartilhando informação, como no caso dos clusters, que se beneficiam do ambiente cooperativo que propicia a inovação, o aperfeiçoamento de técnicas e processos, gerando redução de custo (POLENSKE, 2004). Segundo Polenske (2004), colaboração e cooperação são formas semelhantes de comportamento coletivo, pois podem igualmente ocorrer em empresas do setor público, do setor privado, em organizações locais, sindicatos, entre membros da força de trabalho ou outros 
agentes, ocorrendo dentro da entidade ou região ou além das fronteiras regionais, nacionais e internacionais.

Ainda de acordo com Polenske (2004), o gestor público capaz de entender a distinção entre cooperação, colaboração e competitividade poderá projetar políticas industriais e regionais relevantes para ajudar as empresas a competir no mercado global e superar os limites de atuação impostos pela concorrência. Dessa forma, essas políticas permitirão que as empresas criem regras de reciprocidade para a troca de informações de forma mais fácil, com o objetivo de criar, melhorar e modificar processos de produção através de compartilhamento de informação, adotar novas tecnologias ou desenvolver novas relações entre os atores de uma determinada cadeia. Entretanto, poucos trabalhos se dedicam a fazer essa diferenciação com pesquisas em profundidade para teorizar sobre os conceitos de forma distinta e produzir modelos que definam os fatores que as compõem. No que se refere à LR de REEE não foi encontrada pesquisas sobre o tema. Por outro lado, não é uma questão exclusiva da cadeia reversa, pois as mesmas questões se apresentam na cadeia de suprimento direta (OLIVEIRA et al., 2016).

Esses elementos do comportamento dos atores envolvidos em processos de colaboração e cooperação podem explicar em parte o sucesso dos países europeus. No entanto, enquanto potencializam os resultados das iniciativas nesses países, verifica-se que a ausência de colaboração ou cooperação pode explicar também menores níveis de efetividade dos modelos implementados. A Itália, antes de adaptar a legislação nacional à Diretiva, não tinha um objetivo comum a todos os atores, pois coletava apenas resíduos que interessavam ao reciclador, com objetivo financeiro. Inicialmente, faltavam clareza da legislação, padronização do sistema de LR de REEE e coleta desses resíduos separada dos outros. Na primeira fase da operação, mesmo após resolver problemas iniciais, os resultados foram limitados. A partir desse cenário, buscouse a cooperação dos cidadãos. Foram criados cursos sobre LR de REEE em escolas, com o objetivo de entender o que precisa ser feito para a população atuar de forma coordenada para diminuir o desperdício e fazer o descarte correto (TORRETTA et al., 2013).

No caso da Romênia, foi necessário aumentar o grau de conscientização da população. Com efeito, esta política somada ao tempo de vida útil dos EEE, que é aproximadamente o dobro da média europeia, além da diminuição da população, devido à baixa taxa de natalidade, eram fatores críticos para que a Romênia conseguisse alcançar a meta de 4kg/por habitante de REEE coletados. Para tanto, o governo romeno criou um projeto piloto com campanhas de descarte de REEE, concentradas em datas específicas, em nível nacional, para aumentar conscientização e o incentivo ao descarte de REEE junto à população. Esses eventos 
aumentaram consideravelmente os índices de coleta de REEE. Para o governo romeno, não bastaria apenas dar as informações aos cidadãos sobre a LR de REEE, precisaria mesclar esforços com campanhas e incentivos para que a população fizesse o descarte dos REEE. Em paralelo, o governo obrigou os consórcios de gestão de resíduos a melhorarem a comunicação, de forma a desempenhar integralmente o seu papel na cadeia, para garantir o alcance das metas (TORRETTA et al., 2013).

Mesmo os países líderes em coleta de REEE, como Suécia, Noruega e Finlândia, tiveram problemas com a crise econômica mundial e a consequente diminuição de consumo e descarte de EEE. Entretanto, acredita-se que, para ampliar a eficiência da LR, realizar plenamente o potencial de reciclagem de REEE e estabelecer sistemas de recuperação de REEE eficaz, ainda é necessário mais informação e comunicação para o engajamento do consumidor

Ao se discutir estas questões em países em desenvolvimento, os desafios são ainda maiores, pois seus modelos ainda estão em estágios preliminares e a realidade sociocultural e econômica é muito diferente. Essas questões são mais evidentes devido ao aumento do PIB, que altera o comportamento do cidadão, aumentando o consumismo e as trocas mais frequentes dos EEE por modelos mais novos, de acordo com Torretta et al. (2013). Iniciativas em economias emergentes, como Índia, China, Coreia do Sul e Brasil mostram que os modelos precisam ser adaptados à realidade local (SCHLUEP et al., 2009; MANOMAIVIBOOL; VASSANADUMRONDEE, 2011; WANG et al., 2012; AUGUSTO, 2014). O modelo emergente de LR nesses países deve lidar com a falta de legislação adequada e de incentivos econômicos, com a baixa sensibilização do consumidor, com produtos sem marca e catadores informais de rua, responsáveis pelo aumento da coleta, e com um processamento de REEE pouco preocupado com a saúde, segurança e proteção do meio ambiente (SCHLUEP et al., 2009; MANOMAIVIBOOL; VASSANADUMRONGDEE, 2011; WANG et al., 2012; AUGUSTO, 2014).

No caso do Brasil, existe um paradoxo, pois apesar dos problemas peculiares aos países em desenvolvimento enfrentados no país, existe uma legislação inovadora e muito avançada, que trata dos Resíduos Sólidos (RS): a Política Nacional de Resíduos Sólidos, de 2010. No setor de EEE, a PNRS obriga produtores, importadores e empresas de varejo a desenvolver e implementar um sistema de LR independente do sistema de gestão de resíduos público (BRASIL, 2010a). A PNRS também é a primeira legislação em nível mundial a reconhecer a importância das organizações de catadores na cadeia de reciclagem e a exigir a integração desses trabalhadores no sistema LR de forma colaborativa (DEMAJOROVIC; MIGLIANO, 2013; AUGUSTO, 2014). A LR pode ser implementada através de decreto, termo de 
compromisso ou Acordo Setorial (AS). Entretanto, existe um consenso de que a melhor forma seria por meio de Acordo Setorial, já que o governo não se sente capaz de desenhar o sistema com todas as variáveis e complexidade peculiar aos REEE (AUGUSTO, 2014).

Todavia, os atores que deveriam apresentar a proposta de acordo setorial têm postergado de todas as formas a sua elaboração e efetivação, devido aos conflitos de interesse, gerando uma incrível morosidade. São mais de 27 anos desde a primeira Proposta de Lei do Senado (PLS) apresentada ao senado até o momento (AUGUSTO, 2014), mas essa morosidade parece ter sempre o mesmo motivo: transferir a responsabilidade e o custo, ao máximo, para os outros atores da cadeia, ficando com a menor parte para si. Dessa forma, por um lado, o governo não resolve as diversas questões que se encontram em sua alçada como conflitos entre leis, incentivos e financiamento para o sistema de LR, bitributação da cadeia reversa, classificação do REEE e declara que só as resolverá após a assinatura de um acordo setorial - mas não baixa um decreto. Do outro lado, fabricantes, distribuidores e varejistas, tentam limitar a sua ação no sistema de LR, alegando que a Lei não especifica o papel exato de cada ator na responsabilidade compartilhada pelo ciclo de vida do produto. O setor privado entra em consenso quando atribui a lentidão do processo ao governo, que não atende às reinvindicações sobre os requisitos básicos legais e estruturais para implementação da LR. O governo, por sua vez, acusa os atores de tentar postergar ao máximo a definição do Acordo Setorial e sua implementação (AUGUSTO, 2014).

Nesse contexto, é possível inferir que faltam elementos que favoreçam a colaboração e cooperação nesses países, em especial no Brasil, sobre a responsabilidade compartilhada na LR. Ela exige ações coordenadas, colaboração e cooperação entre todos os membros da cadeia reversa e o governo, que deveriam ter como objetivo comum um sistema de LR de REEE eficiente, com definição de papéis e resultados esperados, definidos de forma clara para cada ator, inclusive consumidor e governo, transparência nos processos, comprometimento pelo todo e compartilhamento de informações, treinamentos, e recursos para efetiva implementação do modelo brasileiro, que ajudasse a estabelecer um ambiente de confiança e que possibilitasse essa troca (GATTAZ, 2010; MIGLIANO, 2012; AUGUSTO, 2014). Entretanto, o cenário é oposto ao que se espera para ter condições mínimas de cooperação, com um ambiente no qual as partes atuam e recebem os benefícios de forma equilibrada (GATTAZ, 2010).

Apesar dos conflitos existentes entre os atores da cadeia reversa de EEE do Brasil estarem relacionados aos elementos essenciais à colaboração e cooperação (DEMAJOROVIC; MIGLIANO, 2013; JANG, 2010; DEMAJOROVIC; AUGUSTO; SOUZA, 2016), como objetivos comuns, definição clara do papel de cada ator, responsabilização pelos resultados desejados e compromissos assumidos (GATTAZ, 2010), verifica-se que existem poucas 
pesquisas que mencionam o papel desses dois conceitos na cadeia reversa de EEE (JANG, 2010; WANG et al., 2012; AUGUSTO, 2014; DEMAJOROVIC; AUGUSTO; SOUZA, 2016). Existe, assim, uma lacuna na literatura sobre a cooperação e colaboração na cadeia reversa de REEE, o que justifica a importância do estudo proposto.

Desta forma, o projeto de tese parte da definição dos fatores que envolvem a implantação e manutenção dos sistemas de Logística Reversa (LR) de REEE no mundo e no Brasil, definidos a partir da dissertação da autora e da atualização da literatura. Entre esses fatores destacam-se: legislação, tecnologia, engajamento de membros da cadeia, conscientização de consumidores, entre outros. Embora a literatura mostre de que forma alguns destes fatores podem ser mais relevantes em diferentes cenários para explicar a efetividade dos diferentes modelos, considera-se que a colaboração ou cooperação potencializam cada uma dessas variáveis. Nesse contexto, a pergunta de pesquisa é: Como a colaboração e cooperação estão influenciando a implementação do modelo de LR de REEE no cenário europeu e brasileiro? Todos estes fatores serão avaliados para entender como sua presença ou ausência impacta na predisposição dos atores envolvidos na LR de REEE para colaborar e cooperar na formulação de política públicas ou na sua implantação e execução. Para atender a esse fim, o objetivo geral da presente tese é discutir o impacto da colaboração e cooperação na implementação do modelo de LR de REEE no Brasil.

Para responder à pergunta de pesquisa e alcançar o objetivo central, os objetivos específicos serão:

a) Discutir os principais atributos dos conceitos da colaboração e da cooperação.

b) Identificar os elementos da colaboração e da cooperação nos modelos internacionais de LR de REEE.

c) Aplicar os fatores determinantes da colaboração e cooperação da LR de REEE nos modelos espanhol, português, suíço e brasileiro.

d) Comparar os modelos a partir dos resultados de forma a entender o impacto da colaboração e cooperação no modelo brasileiro.

Assim, o trabalho segue a seguinte estrutura, além desta introdução. O segundo capítulo discute os conceitos de colaboração e cooperação destacando seus principais atributos. $\mathrm{O}$ terceiro capítulo levanta as principais características dos modelos de LR de REEE relacionandoas com os elementos que compõem a colaboração e cooperação. No quarto capítulo serão apresentados os procedimentos metodológicos, destacando a natureza da pesquisa, as técnicas de coleta de dados e a estratégia de análise. O quinto capítulo reúne os resultados encontrados 
no trabalho de campo e, no sexto capítulo, tais resultados são discutidos à luz da literatura. Por fim, chega-se às considerações finais.

Dessa forma, a pesquisa visa contribuir para a implantação de modelos de LR de REEE no Brasil, fomentar as políticas públicas e colaborar com a implantação de LR de REEE em empresas privadas. 


\section{COLABORAÇÃO E COOPERAÇÃO: CONCEITOS E ELEMENTOS}

No atual cenário globalizado, as instituições precisam encontrar formas de gestão e operação que lhes garantam resultados positivos e sustentáveis (WINCKLER; MOLINARI, 2011). A colaboração e a cooperação são reconhecidas como elementos essenciais para a efetividade de sistemas complexos com múltiplos atores, tanto no ambiente de políticas públicas (ANSELL; GASH, 2008), como na implementação de estratégias empresariais (WINCKLER; MOLINARI, 2011). Poucos estudos, no entanto, abordaram esta temática no âmbito da LR, especialmente quando se discute REEE. Este capítulo apresenta a evolução dos estudos sobre colaboração e cooperação, a conceituação dos termos e seus principais elementos na implementação de políticas públicas e organizacionais em diferentes setores.

\subsection{EVOLUÇÃO DO ESTUDO SOBRE COLABORAÇÃO E COOPERAÇÃO}

Os estudos sobre cooperação surgem no início do século XIX para investigar como as associações entre empresas podem gerar vantagem competitiva, seja na forma de consumo coletivo para ganhar escala, seja no financiamento de atividade conjuntas (DRURY, 1937), devido ao crescimento das associações e institutos cooperativos, com o objetivo de se ajudar mutuamente em operações de compra, crédito, canais de distribuição (GAULT, 1937; PALMER, 1937), troca de informação sobre mercado, desenvolvimento tecnológico, entre outros (GAULT, 1937). Essas pesquisas, desenvolvidas no campo teórico e prático, eram lideradas pelas escolas de pensamento econômico e social (DRURY, 1937). Visto que a cooperação é uma forma democrática e voluntária de associação e não é discriminatória, os grupos usavam seus princípios e introduziam suas características nos projetos. A falta de clareza sobre sua essência, sua natureza e as circunstâncias de sua existência, porém, gerava desentendimento, fazendo com que o termo fosse banalizado ou considerado como um idealismo impraticável (DRURY, 1937). Foi na década de 1930 que a ideia ganha relevância nos EUA, saindo da posição de um objeto de estudo das diversas escolas de pensamento, para ascender ao papel principal com o surgimento da Escola de Economia Cooperativa (DRURY, 1937).

Na década de 1940, procurava-se entender as relações entre grupos e a melhor forma de operacionalizar a cooperação internacional (LANDECKER, 1940). O assunto ganhou importância especial após a $2^{\mathrm{a}}$ Guerra, devido à necessidade de recuperação econômica mundial, pois a restauração dos países envolvidos no conflito requeria a participação 
cooperativa de todos em um programa comum, que visava expandir o comércio, concentrando esforços na redução de tarifas e outras barreiras comerciais, facilitar o investimento internacional na produção e manter os acordos de trocas regulamentados (BERNSTEIN, 1945), evoluindo ao final da década para a cooperação na cadeia de suprimentos, entre fabricantes e distribuidores (HART, 1948).

Nos anos 1950, as pesquisas seguem na direção da cooperação entre consumidores, organizados em associações sem fins lucrativos, que buscavam maximizar os resultados do seu consumo. Nesse período, buscava-se entender os fatores necessários à existência das organizações de compras cooperativas e como elas funcionavam (KEBKER, 1951). É no final dessa década que se iniciam os estudos sobre colaboração na área de pesquisa científica, com o estudo sobre o aumento dos artigos realizados com coautoria (BALANCIERI, 2004).

Ao chegar à década de 1960, os estudos sobre colaboração nas redes de pesquisa se intensificam, com o objetivo de compreender quais são as formas colaborativas e identificar os chamados "colégios invisíveis", nome atribuído ao agrupamento informal de instituições ou pesquisadores, para realização de pesquisas, troca de informações e publicação. Também foi analisado como se davam as relações nas publicações em coautorias, e o quanto os pesquisadores estavam próximos uns dos outros, remetendo à teoria do mundo pequeno, que defende que cada pessoa está no máximo a 6 pessoas de distância da outra (BALANCIERI et $a l ., 2005)$. Ainda no início dessa década, dá-se a discussão sobre a colaboração entre empresas do mesmo setor, para estudar modelos que possam ser generalizados, fatores que levam a seu sucesso, métodos de produção individuais ou em grupo, seus resultados e o impacto da colaboração na comercialização dos produtos, crescimento e poder de abrangência global das empresas (ODLE, 1964). Na segunda metade da década de 1960, surgem as primeiras pesquisas sobre o impacto da TI, na perspectiva de cooperação homem-máquina, para melhoria da tomada de decisão e planejamento empresariais (CARROLL, 1966).

A partir de década de 1970, com o aumento da concorrência em uma economia em processo de globalização, o foco dos estudos passa a ser como aumentar a competitividade nas organizações (BALANCIERI et al., 2005). Nesse sentido, Baumgart (1974) aborda de que forma a cooperação entre empresas do mesmo setor e o governo podem criar programas de interesse dos consumidores, como os canais de relacionamento pré e pós-venda na indústria de eletrodomésticos, o que possibilita resolver questões de interesses comuns do setor, com respaldo jurídico. Os resultados positivos dessas parcerias despertam o interesse pelos fatores determinantes para a efetivação da cooperação interorganizacional (SCHERMERHORN, 1975) e pelos elementos motivadores da colaboração entre as comunidades acadêmicas 
(BALANCIERI, 2004), assim como pelos elementos que geram conflitos nas relações de colaboração (THOMAS; JAMIESON; MOORE, 1978).

A cooperação como estratégia começa a ser discutida a partir de 1980, com o objetivo de entender os fatores ambientais e de concorrência para sua implantação (HARRIGAN, 1988). No campo das pesquisas científicas, são levadas à tona as questões sobre os impactos da colaboração na visibilidade dos indivíduos e no reconhecimento dos coautores. Nesse período, as pesquisas buscam definir parâmetros para a escolha dos pares, assim são as métricas para aferir os resultados da colaboração científica (BALANCIERI, 2004). De acordo com Hord (1981), as palavras colaboração e cooperação são usadas alternadamente na literatura para descrever esforços organizacionais de trabalho conjunto. Entretanto, os termos representam formas de operações distintas, com entradas e resultados esperados diferenciados, o que exige clareza entre os pares sobre os objetivos e expectativas. O entendimento das diferenças permite que os atores envolvidos escolham o melhor modelo para trabalhar juntos (HORD, 1981). Nesse cenário, as necessidades individuais e organizacionais, a infraestrutura disponível e desejável, o tipo de concorrência e a distribuição equitativa dos resultados começam a ganhar força sobre a tomada de decisão, em relação ao uso estratégico da cooperação ou da colaboração, ficando claro que sua escolha deve considerar todos os elementos envolvidos para sua modelagem (HARRIGAN, 1988; BALANCIERI, 2004).

Nos anos 1990, o papel estratégico da colaboração e da cooperação para assegurar vantagem competitiva já está consolidado. Nesse cenário, o interesse é entender como manter a vantagem competitiva obtida. Nessa perspectiva, surgem os estudos sobre a atuação de sistemas de informação que facilitam e apoiam a colaboração entre grupos de trabalhos nas empresas. Esses sistemas otimizam tempo e local de trabalhos, ajudam a coordenar os grupos, possibilitando uma melhor gestão da informação e do fluxo de trabalho (KOLBUS, 1992). Os estudos apontam para a importância da colaboração e da cooperação em cenários de recessão, pois tornam possíveis redução de custo e geração de novas oportunidades em mercados altamente tecnológicos e turbulentos, como o de EEE (LEE-MORTIMER, 1993), em processos como pesquisa, inovação, desenvolvimento tecnológico e de novos produtos, fabricação, logística e gestão da cadeia de suprimentos (KOLBUS, 1992; LEE-MORTIMER, 1993). Outro setor estudado nessa década, que tem relação como o objeto de pesquisa desta tese, é a resolução de problemas sociais por meio da colaboração entre setores público e privado, em torno de temas como formação profissional, renovação urbana, custo da saúde e habitação (HOOD; LOGSDON; THOMPSON, 1993). Nesse cenário, diversas pesquisas são desenvolvidas com vistas à modelagem da colaboração (HOOD; LOGSDON; THOMPSON, 1993; BRNA, 1998) 
e da cooperação (MORROW, 1994; LANDRY; TRUDEL; DIORIO, 1998), ampliando o uso e os resultados dessas estratégias em diversos setores. O aumento do uso desses elementos chamou a atenção dos pesquisadores para o outro lado da moeda. Assim, as pesquisas após meados de 1990 abordam fatores críticos, tais como o abuso de poder nas relações de colaboração, em especial na cadeia de suprimentos, com potencial de transformar as relações ganha-ganha, em outras mais benéficas para o ator mais forte da parceria (LANDRY; TRUDEL; DIORIO, 1998). Os pesquisadores queriam entender quais eram os papéis de cooperação, colaboração, competição e confiança nas estratégias empresariais e a possibilidade de sua coexistência no mesmo cenário (DAS; TENG, 1998; LANDRY; TRUDEL; DIORIO, 1998).

A partir do início do século 21, o Brasil começa a dar maior relevância para o tema da cooperação e as vantagens que ela pode assegurar para seus participantes. Nesse âmbito, os estudos sobre cooperação no país estão centrados, predominantemente, em quatro aspectos: estratégia, dependência de recursos, redes sociais e institucional. As instituições que mais tiveram destaque quantitativamente na publicação de artigos sobre esse tema, no período de 2000 a 2006, foram a Universidade Federal do Rio Grande do Sul (UFRGS), a Universidade do Vale do Rio dos Sinos (UNISINOS), a Universidade Federal da Bahia (UFBA), a Universidade Federal de Santa Maria (UFSM), a Universidade Federal do Rio de Janeiro (UFRJ) e a Universidade de São Paulo (USP), de acordo com Balestrin, Verschoore e Reyes Junior (2010).

Além do aumento de interesse pelo tema, refletido na quantidade de publicações dedicadas a ele, e do aprofundamento dos fatores que facilitam ou dificultam a adoção de colaboração e cooperação nos mais diversos setores da economia na primeira década do século XXI, alguns autores chamam a atenção para a importância da diferenciação clara entre os termos e seus reflexos na construção de parcerias públicas e privadas (POLENSKE, 2004; WINCKLER; MOLINARI, 2011). Mais recentemente, esta temática aprofunda os estudos também no campo das políticas públicas, como forma de aumentar a eficiência das iniciativas governamentais e a validação das suas ações com apoio da sociedade e setores afins (ANSELL; GASH, 2008). Nesse sentido, Verschoore e Balestrin (2008) abordam o impacto de leis que viabilizem a cooperação, estimulando e fortalecendo as redes de cooperação entre pequenas empresas no Sul do Brasil. Esse é a proposta da PNRS, que determina que diversos setores devam implementar a LR de forma conjunta. Nesse caso, infere-se que os processos de colaboração ou cooperação entre os atores podem promover resultados mais efetivos da LR de REEE. Entretanto, até o momento não parece haver consenso entre os autores sobre se há 
diferença entre os termos e o que os caracteriza e os difere de fato. Considerando o presente cenário de pesquisa que ora trata os dois conceitos como sinônimos, ora como distintos, e por vezes inverte o significado dos termos (POLENSKE, 2004; KEMCZINSKI et al., 2008), discute-se a seguir, de forma mais aprofundada, os dois conceitos, destacando-se suas principais características, resultados e desafios.

\subsection{DEFINIÇÃO DE COLABORAÇÃO}

Nesta seção serão apresentadas definições teóricas, características, benefícios e desafios da colaboração, sem restringir a área de estudo, com o objetivo de capturar como a palavra tem sido conceituada e tratada pela literatura. Serão citados apenas autores que deixam claro a distinção entre os termos colaboração e cooperação, tentando diferenciá-los, ou quando os distinguem antes de optar por qual será o conceito tratado.

\subsubsection{Conceitos da colaboração}

Segundo Winckler e Molinari (2011, p. 10), “colaboração é a ação que gera benefício para um parceiro, num sentido horizontal ou vertical, e na qual o ganho não precisa ser conjunto, visto que é um apoio, sem esperar retribuição", pois trata-se do prazer de ajudar que move os envolvidos. É o que se verifica nas situações de apoio organizacional que empresas oferecem umas às outras. $\mathrm{O}$ resultado pode ser positivo para ambas num sentido de imagem e reputação, mas ele não é obrigatório e é implícito, ainda segundo os autores.

Para Polenske (2004), a colaboração se dá de forma vertical hierarquizada, não simétrica em relação às capacidades, competências, riscos, benefícios e resultados esperados pelos atores envolvidos na relação. Além disso, ela não exerce forte influência sobre a competitividade dos atores envolvidos, sendo exercida, na maior parte das vezes, como apoio ao parceiro. Winckler e Molinari (2011) corroboram esta relação de apoio entre atores, muitas vezes de forma hierarquizada na colaboração. Os atores ainda observam uma diferença sutil na finalidade da ação, que não prevê benefícios para ambos, nem se enquadra como recíproca, pois trata-se de apoio de um dos atores ao outro, gerando benefício para um dos parceiros. Já para Kemczinski et al. (2008, p. 4), colaboração "não é uma relação hierárquica, onde as coisas são impostas, mas uma relação entre pessoas que saibam ouvir, compartilhar ideias e trabalhar conjuntamente, permitindo que haja uma constante interação entre os membros do grupo" em prol de um 
objetivo comum. Nesse sentido, para esses autores, o termo vai além da soma das contribuições individuais no desenvolvimento de um projeto.

Segundo Brna (1998), a colaboração é um conjunto de relações possíveis entre os participantes e a atuação dos atores envolvidos nas parcerias depende de sua contextualização. Para ele, é necessário entender qual é a forma de execução da atividade, se é sincronizada ou dividida em tarefas, se é um estado ou um processo, se é o meio para atingir algum objetivo ou é seu fim e, por último, se os participantes têm ciência de estar participando da colaboração, de maneira formal, contratual ou não. Para Hargrove (1998), por sua vez, colaboração é o ato ou processo de fazer algo junto com outro, por necessidade ou desejo de criar ou realizar algo novo, de tal forma que o resultado seja melhor e factível, visto que sozinho a tarefa seria mais complexa ou até inviável de ser executada. Apesar dos autores concordarem em alguns elementos, não existe uma congruência na sua definição, principalmente no que tange a sentido, hierarquia e poder, conforme apresentado no Quadro 1, que apresenta os principais atributos nos conceitos de colaboração discutidos até aqui.

Quadro 1- Principais atributos nos conceitos de colaboração

\begin{tabular}{|c|c|c|c|c|c|}
\hline Atributos & $\begin{array}{l}\text { Winckler e } \\
\text { Molinari } \\
(2011) \\
\end{array}$ & Polenske (2004) & $\begin{array}{l}\text { Kemczinski et } \\
\text { al. (2008) }\end{array}$ & Brna (1998) & $\begin{array}{c}\text { Hargrove } \\
(1998)\end{array}$ \\
\hline Objetivo & $\begin{array}{l}\text { Comum na } \\
\text { elaboração de } \\
\text { algo }\end{array}$ & $\begin{array}{l}\text { Comum ao } \\
\text { grupo }\end{array}$ & $\begin{array}{l}\text { Comum ao } \\
\text { grupo }\end{array}$ & $\begin{array}{l}\text { Comum ao } \\
\text { grupo }\end{array}$ & $\begin{array}{l}\text { Comum ao } \\
\text { grupo }\end{array}$ \\
\hline Resultados & $\begin{array}{l}\text { Tangíveis: não } \\
\text { precisa ser } \\
\text { mútuo. } \\
\text { Intangíveis: } \\
\text { filantrópico, } \\
\text { imagem } \\
\text { compensa a } \\
\text { falta do } \\
\text { tangível. }\end{array}$ & $\begin{array}{l}\text { Tangíveis: não } \\
\text { precisa ser } \\
\text { mútuo. } \\
\text { Intangíveis: } \\
\text { compensa a falta } \\
\text { do tangível. }\end{array}$ & Mútuos & $\begin{array}{l}\text { Baseados em } \\
\text { expectativas }\end{array}$ & $\begin{array}{l}\text { É melhor do } \\
\text { que quando faz } \\
\text { sozinho. Mútuo }\end{array}$ \\
\hline Atividade & & Conjunta, direta & Conjunta, direta & $\begin{array}{l}\text { Conjunta, } \\
\text { sincronizada }\end{array}$ & $\begin{array}{l}\text { Interna, } \\
\text { conjunta }\end{array}$ \\
\hline Atuação & $\begin{array}{l}\text { Apoio, } \\
\text { contribuição }\end{array}$ & Apoio & & & \\
\hline Competências & Assimétricas & $\begin{array}{l}\text { Assimétricas, } \\
\text { complementares }\end{array}$ & $\begin{array}{l}\text { Assimétricas, } \\
\text { complementares }\end{array}$ & & Assimétricas \\
\hline Comunicação & & $\begin{array}{l}\text { Informação } \\
\text { limitada ao que } \\
\text { se quer oferecer }\end{array}$ & $\begin{array}{l}\text { Troca intensa e } \\
\text { aberta a todos }\end{array}$ & & \\
\hline Poder & $\begin{array}{l}\text { Horizontal ou } \\
\text { vertical }\end{array}$ & Vertical & $\begin{array}{l}\text { Decidem em } \\
\text { conjunto, } \\
\text { horizontal. }\end{array}$ & & \\
\hline Controle & & & & Não é formal & \\
\hline Riscos & & Assimétricos & & Oportunismo & \\
\hline Competividade & $\begin{array}{l}\text { Quase não } \\
\text { afeta }\end{array}$ & Quase não afeta & & & \\
\hline
\end{tabular}


Para o presente estudo, contudo, é importante a adoção de um conceito base, definido a partir da revisão da literatura, baseado nos construtos de LR de REEE e na PNRS. Dessa forma, assumiremos o seguinte conceito: colaboração é o ato de trabalhar junto (BRNA, 1998; HARGROVE, 1998; POLENSKE, 2004; WINCKLER; MOLINARI, 2011), em prol de um objetivo comum de grupo para elaboração ou realização de algo, como a produção de um artigo ou a formulação de uma lei (BRNA, 1998; HARGROVE, 1998; POLENSKE, 2004; KEMCZINSKI et al., 2008; WINCKLER; MOLINARI, 2011). Os atores não possuem papéis muito bem definidos, têm competências assimétricas e complementares (BRNA, 1998; HARGROVE, 1998; POLENSKE, 2004; KEMCZINSKI et al., 2008; WINCKLER; MOLINARI, 2011), atuam de forma vertical ou horizontal (WINCKLER; MOLINARI, 2011), sem definição clara de poder (KEMCZINSKI et al., 2008; WINCKLER; MOLINARI, 2011), podendo ser mútuo, ou exercido pela parte mais forte da relação (POLENSKE, 2004). Os resultados são assimétricos no que se refere à similaridade, pois nem sempre são tangíveis para ambos, podendo cada ator receber um tipo de ganho (BRNA, 1998; HARGROVE, 1998; POLENSKE, 2004; KEMCZINSKI et al., 2008; WINCKLER; MOLINARI, 2011), já que se trata de uma relação essencialmente de apoio ou contribuição (POLENSKE, 2004; WINCKLER; MOLINARI, 2011).

\subsubsection{Características e elementos/atributos da colaboração}

Para estabelecer relações de colaboração é importante conhecer os fatores que a motivam, bem como os elementos de manutenção e motivação, para que se possa estimulá-los, garantindo a participação dos atores nas tarefas definidas (BRNA, 1998). Por isso, é importante entender quais são os objetivos, valores, crenças e conhecimentos de cada membro ao iniciar o processo de colaboração (KIRSCHNER; DICKINSON; BLOSSER, 1996).

Para Hord (1981), colaboração é um processo que se inicia pelo interesse mútuo de dois ou mais indivíduos ou organizações, estabelecendo a troca de tarefas, produtos ou serviços, definidos no momento do planejamento, elaborado de forma conjunta, assim como são definidas metas, resultados, produtos ou serviços esperados e benefícios.

Segundo Polenske (2004), as relações de colaboração caracterizam-se por incluir a participação direta de dois ou mais atores na concepção, produção ou comercialização de um produto. As relações entre os atores são frequentemente mecanismos internos, geralmente verticais, às vezes entre as divisões na mesma empresa ou ao longo de cadeias de fornecimento. Podem incluir joint ventures. 
Hord (1981) levantou as 10 principais características das relações de colaboração, apresentadas no Quadro 2. Para ela, além de identificar necessidades e oportunidades para iniciar o trabalho em parceria, é importante estar atento as outras características. Segundo a autora, os resultados da ação precisam valer a pena, devido a todo o investimento na relação, que requer tempo e energia. Além disso, membros da equipe e líderes precisam ter características colaborativas e proativas. Paciência e empatia também são comportamentos exigidos. Os recursos físicos, financeiros (que podem ser requeridos a terceiros) e humanos, assim como os resultados do projeto devem ser compartilhados. Nesse contexto, Hord (1981) explica que a comunicação deve ser contínua, intensa e em todos os níveis. Os riscos e ações são assumidos por todos os atores e o comprometimento torna-se o principal elemento para a colaboração.

Quadro 2 - Dez características da colaboração

\begin{tabular}{|c|c|}
\hline Característica & Descrição \\
\hline $\begin{array}{l}\text { 1. Necessidades e } \\
\text { interesses }\end{array}$ & Precisa haver um senso de ganho para cada um e um interesse suficientemente elevado. \\
\hline 2. Tempo & $\begin{array}{l}\text { Requer mais tempo, pois precisa de muitos esforços conjuntos. As atividades são } \\
\text { realizadas de forma mútua e compartilhada ao invés de permitidas. }\end{array}$ \\
\hline 3. Energia & $\begin{array}{l}\text { Requer mais esforço. Para tanto, pessoas com iniciativa e espírito colaborativo são } \\
\text { necessárias para iniciar e manter a colaboração mútua. }\end{array}$ \\
\hline 4. Comunicação & É intensa e contínua, com reuniões entre todos os níveis das organizações envolvidas. \\
\hline 5. Recursos & $\begin{array}{l}\text { Organizações compartilham fundos, equipe e outros recursos. Os resultados devem valer } \\
\text { o investimento de cada participante. }\end{array}$ \\
\hline $\begin{array}{l}6 . \text { Fatores } \\
\text { organizacionais }\end{array}$ & $\begin{array}{l}\text { Pessoas colaborativas em uma organização promovem atividades similares entre elas, } \\
\text { dentro da estrutura organizacional. }\end{array}$ \\
\hline 7. Controle & $\begin{array}{l}\text { Deve ser dividido, pois é importante que os atores estejam dispostos a assumir riscos em } \\
\text { um ambiente flexível e sejam encorajados a ter tolerância à plasticidade. }\end{array}$ \\
\hline 8. Percepções & $\begin{array}{l}\text { É vital conseguir ver o mundo do ponto de vista do outro, ter empatia, afetando } \\
\text { positivamente todos os outros fatores. }\end{array}$ \\
\hline 9. Liderança & $\begin{array}{l}\text { Precisa ser forte, dando exemplos positivos e entusiásticos de colaboração para engajar } \\
\text { todos os níveis organizacionais. }\end{array}$ \\
\hline $\begin{array}{l}\text { 10. Características } \\
\text { pessoais }\end{array}$ & É requerido paciência, persistência e disposição para compartilhar. \\
\hline
\end{tabular}

Fonte: Hord, 1981, p. 11-13

Para Hargrove (1998), a colaboração pode ter a forma de rede de pesquisa, equipe multidisciplinar ou coalizão. Ainda segundo o autor, para a efetivação da colaboração e potencialização dos resultados é necessário haver objetivos e problemas comuns, além de diferentes perspectivas e pontos de vistas entre os atores envolvidos, fator imprescindível para o desenvolvimento e o aprendizado, o estabelecimento de metas compartilhadas e o surgimento de novos valores. De acordo com Vivaldini, Souza e Pires (2007), por sua vez, uma cultura organizacional focada na transparência, no ganha-ganha, na equidade e na lealdade é 
fundamental para a construção da confiança, o comprometimento e o comportamento colaborativo.

Balancieri (2004) define como elementos chaves para a colaboração: metas comuns, esforço coordenado, compartilhamento da responsabilidade e crédito pelos resultados ou produtos do projeto com os quais os colaboradores estão envolvidos. Já Ansell e Gash (2008), ao discutirem sobre a construção da colaboração na governança pública, defendem o diálogo presencial, o fortalecimento da relação de segurança e o desenvolvimento do comprometimento e compreensão mútua como elementos de sucesso para o início da colaboração. Ainda segundo os autores, tempo, confiança e interdependência atuam como elementos de moderação para a efetiva implementação e são tidos como contingências centrais para sua gestão, pois o processo de entendimento mútuo e construção de confiança, exigem tempo. A confiança é igualmente necessária para que se possa trabalhar junto de forma interdepende, com ganhos mútuos, estabelecimento de negociações leais e sinergia nos processos, de acordo com Ansell e Gash (2008). E, por último, o entendimento da interdependência e sua efetivação são cruciais na colaboração. A interdependência permite que os atores trabalhem junto, mesmo quando existem conflitos gerados pela baixa confiança, pois promove o desejo de participar e o comprometimento com o projeto. Nesse aspecto, Kirschner, Dickinson e Blosser (1996) conjecturam sobre a necessidade dos atores não terem papéis muito delimitados, facilitando o entrosamento e a troca de informação entre eles.

De acordo com Balancieri (2004), entre os fatores que facilitam a adoção da colaboração estão: a proximidade geográfica; a necessidade de compartilhar equipamentos tecnológicos caros e complexos; a equidade da capacidade produtiva de cada ator, que aumenta a produtividade à medida que aumenta a colaboração; a interdisciplinaridade dos temas e a percepção da exigência de integração de especialistas de diversas áreas para maior entendimento e desenvolvimento das questões estudadas; e o reconhecimento dos projetos, baseados na quantidade de atores envolvidos na parceria, de forma a atingir direta e proporcionalmente a confiança atribuída ao grupo, ao passo que pesquisadores solitários tendem a ter menos credibilidade em suas pesquisas. Além disso, determinadas características pessoais dos colaboradores e da liderança são cruciais para o sucesso da empreitada colaborativa. Pessoas que tenham empatia, paciência, persistência e predisposição para colaborar são essenciais na formação das equipes. Dos líderes, é requerido entusiasmo ao colaborar, para inspirar a todos a agir da mesma forma, nos mais diversos níveis organizacionais (HORD, 1981). Mas, de acordo com Balancieri (2004), os principais fatores para impulsionar a colaboração são as redes sociais capilarizadas nas quais os atores estão inseridos, e a utilização 
da Tecnologia da Informação e Comunicação (TIC), que amplia a comunicação, diminuindo distância e tempo, disponibiliza e dissemina o conhecimento rompendo as barreiras geográficas, por meio de plataformas dos governos e sistemas de gestão do conhecimento.

A revisão da literatura sobre as características da colaboração gerou um quadro síntese sobre seus atributos, apresentado no Apêndice A, que ajudou a realçar elementos mais fortemente debatidos entre os autores. Esse quadro estará incorporado mais adiante ao quadro Matriz dos atributos de colaboração e cooperação, Quadro 7.

Dessa forma, no que tange às relações entre os atores, o poder pode ser exercido tanto de forma unilateral, quanto mútua. Mas, quando se descreve como se dá a atuação nas atividades, trabalhar junto e apoiar/contribuir um com o outro são condições sine qua non na colaboração, assim como ter competências assimétricas, que permitam a troca de conhecimento, sinergia e resultados melhores do que se não houvesse a colaboração são consenso entre quase todos os autores. A comunicação intensa e constante é outra característica forte das relações colaborativas.

No que se refere aos atributos que definem o uso dos recursos, o uso intenso da troca de informação e a necessidade de mais tempo para estabelecimento de uma relação produtiva de colaboração se destacam. Compartilhamento é a palavra chave no que tange aos recursos de $\mathrm{RH}$, financeiros e infraestrutura.

O senso comum diz que os objetivos são os do grupo e os resultados são mútuos, mas assimétricos; no entanto, resultados tangíveis não são garantidos para ambas as partes e os intangíveis podem ser percebidos como recompensas.

Nesse cenário, pode-se apresentar alguns exemplos de colaboração, que pode se dar na forma de: rede de pesquisa; equipe multidisciplinar ou coalizão (HARGROVE, 1998); joint ventures entre duas ou mais empresas privadas ou empresas público-privadas; por oferta por parte da empresa contratante para uma empresa fornecedora de acessórios, por exemplo, para desenvolvimento de um produto ou serviço; ou com a criação de conselhos para ajudar essas empresas a cumprir as normas da indústria de qualidade de controle (POLENSKE, 2004).

De acordo com Kemczinski et al. (2008), a colaboração é caracterizada pela intensa operação mental relacionada à sinergia do grupo com troca de ideias e reflexões constantes tentando resolver um problema. Essa sinergia, garantida por relações flexíveis e intensas, e o compartilhamento dos recursos possibilitam uma série de ganhos. 


\subsubsection{Benefícios da colaboração}

Nesse cenário, pode-se afirmar que a colaboração traz uma série de benefícios, tais como: facilitação do processo de criação de novos produtos e serviços, gerando solução para questões complexas (HARGROVE. 1998); redução dos altos custos com formulação de políticas incoerentes ou contraditórias ao interesse de todos, com a ampliação da participação democrática na gestão pública (ANSELL; GASH, 2008), facilitando até mesmo a aprovação de legislação inovadora (HARGROVE, 1998), devido ao foco na resolução de problemas de forma consensual (ANSELL; GASH, 2008); troca de experiências produtivas entre integrantes do mesmo setor, concorrentes ou setores públicos e privados (ANSELL; GASH, 2008), com o aumento das perspectivas entre os atores envolvidos (HARGROVE, 1998), aprendizagem coletiva acelerada (ANSELL; GASH, 2008), e fazendo proveito de todos os seus conhecimentos e habilidades distintas (HARGROVE, 1998).

\subsubsection{Desafios da colaboração}

Apesar dos benefícios listados anteriormente, é importante relatar que a colaboração apresenta desafios relevantes na sua implementação. Diferenças de poder (BRNA, 1998; ANSELL; GASH, 2008), capacidade organizacional (ANSELL; GASH, 2008), comprometimento, confiança, falta de políticas de incentivo à colaboração (HORD, 1981; BRNA, 1998; POLENSKE, 2004; ANSELL; GASH, 2008), falta de liderança entusiástica com a colaboração (HORD, 1981), falta de experiências em programas colaborativos (ANSELL; GASH, 2008) e desconhecimento do conceito de colaboração e dos elementos que a compõem (HORD, 1981) estão entre os fatores críticos de sucesso.

Quando existe diferença de poder entre as organizações envolvidas na colaboração, os stakeholders mais fortes podem manipular o processo (BRNA, 1998; ANSELL; GASH; 2008), enviesando-o segundo seus interesses (ANSELL; GASH, 2008) ou gerando conflitos devido a um comportamento controlador, pois isso levará à quebra do senso colaborativo dos atores que se sentirem controlados (BRNA, 1998). O poder desigual pode ser exercido pela manipulação do que se supõe ser o correto a fazer. De fato, por exemplo, no processo de colaboração, contratos formais são substituídos por obrigações implícitas para definição de papéis. Entretanto, por vezes, não existem contratos formais, nem contratos implícitos, dando margem ao surgimento da colaboração oportunista, baseada em um conjunto de obrigações implícitas e de comportamentos esperados (BRNA, 1998). A diferença de poder pode ser resultado da falta 
de capacidade organizacional para participar de forma equitativa do processo colaborativo, devido a seu tamanho, estrutura financeira e física ou cultura organizacional (ANSELL; GASH, 2008).

Nesse cenário, em que o comprometimento com a colaboração é essencial, parcerias entre governo, setor privado e sociedade para elaboração e implementação de políticas públicas enfrentam a falta de compromisso real com a colaboração por parte dos órgãos públicos (ANSELL; GASH, 2008). As diferenças de poder e comprometimento resultam em outro desafio para a colaboração, a falta de confiança, que se torna uma barreira para a negociação leal e para a efetivação ou a manutenção de processos colaborativos (ANSELL; GASH, 2008).

Além do comprometimento e capacidade organizacional, Ansell e Gash (2008), apontam como fatores críticos para o sucesso da colaboração: uma liderança apta para guiar o processo; a quantidade necessária de ações corretivas para a construção de confiança; o estabelecimento de políticas de incentivos para a colaboração, em especial quando um ou mais atores importantes têm capacidade de atuar sozinhos; e o histórico de colaboração dos atores e entre eles.

De acordo com Hord (1981), é crucial que os atores envolvidos entendam bem as necessidades, atributos, metas, resultados esperados e recompensas de uma relação de colaboração. Se acreditarem estar realizando um processo colaborativo quando, na realidade, as características da relação desenvolvida pertencerem a uma relação de cooperação, o fracasso seria quase inevitável. Entender quais fatores levam ao início de cada tipo de relação é o primeiro passo para a escolha adequada do modelo. A autora ressalta que, no caso da colaboração, os pares precisam de clareza nas expectativas, objetivos e metas. Da mesma forma, os processos de cooperação têm suas especificidades. Dessa forma, serão abordadas, na sequência do presente trabalho, as definições, características, benefícios e desafios da cooperação, para que, em seguida, seja feita uma relação e análise das diferenças, o que permitirá, por sua vez, elencar quais são os elementos que definem a escolha de uma ou outra.

\subsection{DEFINIÇÃO DE COOPERAÇÃO}

Nesta seção, serão apresentados definições teóricas, características, benefícios e desafios da cooperação. Para atender o objetivo central deste trecho, serão usados os mesmos critérios da seção que define colaboração, não restringindo a área de estudo, mas citando apenas os autores que deixam de forma clara a distinção entre os termos, tentando diferenciá-los, ou quando os distinguem, antes de optar qual será o conceito tratado. Esse posicionamento limita 
a quantidade de artigos que podem ser usados, mas privilegia a qualidade do que é falado sobre cooperação.

\subsubsection{Conceitos de cooperação}

Os conceitos sobre cooperação estão alicerçados na divisão de tarefas, objetivos individuais e estruturação de mecanismos de controle. De acordo com Kemczinski et al. (2008, p. 4), “cooperação implica em trabalhar em um projeto, onde é feita a divisão de trabalhos do projeto e cada integrante do grupo realiza uma parte da tarefa individualmente e no final são unidas as partes e concluído o projeto", enfatizando a divisão de tarefas e a definição clara dos papéis dos atores. Hord (1981) também trabalha na perspectiva de processos organizacionais para distinguir cooperação e colaboração. Para Hord (1981, p. 6), na cooperação “as atividades são mutuamente aceitáveis, mas não necessariamente para o benefício mútuo", a organização que lidera e opera o processo fica com o resultado da ação, seja um serviço, pesquisa ou produto, enquanto outra parte, que permitiu, facilitou ou deu acesso a informações, pode usufruir desse resultado com o uso, sentimento de altruísmo ou contribuição social.

Para Polenske (2004), a cooperação é o comportamento que se dá entre parceiros, também em sentido horizontal, externalizado e não excludente, pois há compartilhamento do conhecimento entre todos em processos de Pesquisa e Desenvolvimento (P\&D). Nessa forma de relacionamento, os atores não trabalham juntos, na produção ou venda de um produto por exemplo, mas podem criar uma organização, como uma cooperativa, para compartilhar custos da produção, obtendo ganho de escala em todo o processo de forma global e redução de custo. Pode igualmente ocorrer que um dos atores consiga autorização da outra parte para pesquisar ou complementar uma tarefa. Nesse caso, os recursos pertencem a quem está controlando a pesquisa e a troca de informação é realizada em intervalos ocasionais. A liderança é unilateral e o controle continua em cada organização. Ao final, segundo Polenske (2004), com o produto, pesquisa ou serviços desenvolvidos e concluídos, o ator que comandou o processo fica com o resultado e a outra parte pode se beneficiar do resultado, fazendo uso conforme o que foi acertado previamente de forma clara.

Winckler e Molinari (2011) também definem cooperação como um comportamento, que se dá de forma horizontal, entre os parceiros, com motivações distintas ou semelhantes, baseado na relação de reciprocidade, em que cada ator disponibiliza o que tem de melhor e age de forma complementar. Nesse cenário, o resultado é mútuo, mas não simétrico. Os interesses individuais são atendidos, de tal forma que gere benefícios para ambos, pois os resultados esperados são 
definidos de forma clara e explícita. Ainda de acordo com as autoras, a cooperação tem como abordagem teórica principal, para explicar sua origem, a Teoria dos Jogos, em especial o dilema do prisioneiro, que deve privilegiar o comportamento cooperativo para obtenção do melhor resultado para ambos, com divisão igualitária do resultado. Dessa forma, com foco em resultados de médio e longo prazo para o sucesso e sobrevivência no negócio, os atores de um determinado setor econômico, público e/ou privado, devem optar por soluções que contemplem o coletivo, ao invés de pensar em si primeiramente. O Quadro 3 apresenta os principais atributos nos conceitos de cooperação discutidos até aqui.

Quadro 3 - Principais atributos nos conceitos de cooperação

\begin{tabular}{|c|c|c|c|c|}
\hline Atributos & Hord (1981) & Polenske (2004) & $\begin{array}{c}\text { Kemczinski et al. } \\
(\mathbf{2 0 0 8 )}\end{array}$ & $\begin{array}{c}\text { Winckler, Molinari } \\
\text { (2011) }\end{array}$ \\
\hline Objetivo & Individuais & Individuais & & Individuais \\
\hline Resultados & $\begin{array}{l}\text { Tangíveis: para } \\
\text { quem opera } \\
\text { obrigatoriamente. } \\
\text { Intangíveis: como } \\
\text { compensação }\end{array}$ & $\begin{array}{l}\text { Tangíveis: ambos. } \\
\text { Cada um recebe o } \\
\text { que foi combinado }\end{array}$ & Iguais & $\begin{array}{l}\text { Tangíveis: ambos. } \\
\text { Cada um recebe o } \\
\text { que foi combinado }\end{array}$ \\
\hline Tipo de ator & & Pode ser concorrente & & \\
\hline Atividade & Externa, separada & $\begin{array}{l}\text { Externa, separada, } \\
\text { divisão clara de } \\
\text { papéis ou criam uma } \\
\text { organização }\end{array}$ & $\begin{array}{l}\text { Externa, separada, } \\
\text { divisão clara de } \\
\text { papéis }\end{array}$ & \\
\hline Atuação & Reciprocidade & Reciprocidade & Reciprocidade & Reciprocidade \\
\hline Competências & Complementares & Complementares & Complementares & Complementares \\
\hline $\begin{array}{l}\text { RH e } \\
\text { Estrutura }\end{array}$ & & É de quem opera & & \\
\hline Comunicação & & $\begin{array}{l}\text { Relatada } \\
\text { esporadicamente }\end{array}$ & & \\
\hline Comunicação & & $\begin{array}{l}\text { Relatada } \\
\text { esporadicamente }\end{array}$ & & \\
\hline Poder & & $\begin{array}{l}\text { Fica na organização, } \\
\text { proponente lidera }\end{array}$ & $\begin{array}{l}\text { Horizontal, no seu } \\
\text { processo }\end{array}$ & $\begin{array}{l}\text { Horizontal, no seu } \\
\text { processo }\end{array}$ \\
\hline Controle & & & & Formal, pré-definido \\
\hline Competividade & & $\begin{array}{l}\text { Gera vantagem } \\
\text { competitiva }\end{array}$ & & $\begin{array}{l}\text { Gera vantagem } \\
\text { competitiva }\end{array}$ \\
\hline
\end{tabular}

Fonte: Autora, 2016

O conceito de cooperação na literatura é mais estruturado, sem muitos elementos conflituosos entre os autores. Entretanto, como dito na seção de colaboração, é importante que a pesquisa assuma um conceito base extraído da literatura, baseado nos construtos de LR de REEE e na PNRS. Assim, para a tese, cooperação é o ato de trabalhar em um processo de forma individualizada, com papéis bem definidos e divisão de tarefas claras (HORD, 1981; POLENSKE, 2004; KEMCZINSKI et al., 2008). O poder na cooperação mantém-se centrado 
em cada organização (POLENSKE, 2004; KEMCZINSKI et al., 2008; WINCKLER; MOLINARI, 2011), podendo uma das organizações, normalmente a proponente do processo, exercer uma certa liderança na gestão, contanto que atenda às exigências estabelecidas pela outra parte, garantindo a soberania das organizações (POLENSKE, 2004). As empresas não partilham pessoas, nem cedem equipamentos para uso mútuo. Tudo é provisionado para que cada um execute a sua parte. Outra alternativa é a criação de outra empresa para operar a atividade na qual ambas estão cooperando, como um processo de produção (POLENSKE, 2004). Nesse tipo de relação, a motivação é atender ao interesse individual de cada parte, de tal forma que o processo gere benefícios para ambas as partes. Nesse caso, as expectativas, resultados esperados e atribuições de cada parte foram acertados previamente (HORD, 1981; POLENSKE, 2004; WINCKLER; MOLINARI, 2011). A troca de informação é ocasional e esporádica, mas garante o compartilhamento do conhecimento adquirido no processo, como legado (POLENSKE, 2004). Dessa forma, a cooperação gera vantagem competitiva para todos os envolvidos e pode ser operacionalizada por atores do mesmo setor ou outros complementares, eventualmente competidores no mesmo mercado (POLENSKE, 2004; WINCKLER; MOLINARI, 2011). Pode-se inferir, então, que a cooperação é uma forma de viabilizar e operacionalizar os objetivos estratégicos de cada empresa por meio de parceria, alianças estratégicas, sem comprometer a identidade e cotidiano de cada ator (HORD, 1981; POLENSKE, 2004; WINCKLER; MOLINARI, 2011).

\subsubsection{Características e Elementos/atributos da cooperação}

Nesse contexto a cooperação pode ser definida por diversos elementos. Uma das características da cooperação é sua estruturação e planejamento, que iniciam quando uma empresa identifica uma deficiência em seus recursos ou processos. No momento em que assume que a parceria lhe trará uma vantagem ou permitirá executar uma tarefa, que sozinha não seria possível (HORD, 1981), ela inicia o processo de identificação de parceiros potenciais (SILVA, 2007), com competências assimétricas (HORD, 1981; HORD, 1986; POLENSKE, 2004; KEMCZINSKI et al., 2008; WINCKLER; MOLINARI, 2011) e complementares (POLENSKE, 2004; KEMCZINSKI et al., 2008; WINCKLER; MOLINARI, 2011), escolheos (SILVA, 2007) e consegue seu consentimento para cooperar ou ter acesso a processos ou conhecimentos de forma cooperativa (HORD, 1981), sem objetivar compartilhar recursos financeiros, físicos ou humanos (HORD, 1981; POLENSKE, 2004). Então é feita a definição do projeto, a divisão do trabalho a ser executado (HORD, 1981; HORD, 1986; POLENSKE, 
2004; KEMCZINSKI et al., 2008) e o levantamento das condições materiais e intangíveis de cada um (HORD, 1981). Considera-se que os objetivos dos atores envolvidos nesse processo não precisam serem os mesmos (HORD, 1981; HORD, 1986; POLENSKE, 2004; KEMCZINSKI et al., 2008; WINCKLER; MOLINARI, 2011), pois não há obrigatoriedade do objetivo de um atender ao objetivo de outro (HORD, 1981). Após a conclusão da tarefa, os resultados são relatados à outra parte (HORD, 1981; POLENSKE, 2004). Os resultados esperados são definidos previamente (POLENSKE, 2004; KEMCZINSKI et al., 2008; WINCKLER; MOLINARI, 2011), de tal forma que atenda às necessidades coletivas (KEMCZINSKI et al., 2008; WINCKLER; MOLINARI, 2011). Portanto, cada ator tem a clareza dos benefícios tangíveis e intangíveis que a cooperação oferecerá (POLENSKE, 2004; KEMCZINSKI et al., 2008; WINCKLER; MOLINARI, 2011).

Nesse cenário, com metas individuais, o processo cooperativo não exclui a competitividade entre os atores, podendo, por exemplo, um grupo de fabricantes de um determinado setor se reunir para implementar um serviço, sem afetar a competitividade entre eles (HORD, 1981). De acordo com Silva (2007), as empresas cooperam para poder competir com outras fora da parceria. Hord (1981) compara esse processo a uma partida de futebol, na qual os times precisam cooperar para que ocorra o evento, sem que ambos deixem de competir durante a partida.

Nessa forma de relacionamento, os atores não trabalham juntos em uma atividade (HORD, 1981; HORD, 1986; POLENSKE, 2004; KEMCZINSKI et al., 2008; WINCKLER; MOLINARI, 2011), mas de forma complementar e encadeada, com cada ator terminando a tarefa do outro (POLENSKE, 2004; KEMCZINSKI et al., 2008), onde cada um oferece o melhor que tem (WINCKLER; MOLINARI, 2011), ou podendo ainda criar uma organização, como uma cooperativa, para compartilhar custos da produção, obtendo ganho de escala em todo o processo de forma global e redução de custo (POLENSKE, 2004). Assim, cada parceiro é coresponsável pelo produto e pelo sucesso da operação (SILVA, 2007), as relações são externas (POLENSKE, 2004; KEMCZINSKI et al., 2008), horizontais (POLENSKE, 2004; KEMCZINSKI et al., 2008; WINCKLER; MOLINARI, 2011) e não excludentes (POLENSKE, 2004), pois todos têm acesso aos resultados da cooperação (POLENSKE, 2004). O controle se mantém centrado nas organizações (HORD, 1981; POLENSKE, 2004) e a liderança costuma ser unilateral, exercida pela empresa que lidera o processo (HORD, 1981; POLENSKE, 2004).

A clareza nos processos, a mensuração e o alinhamentos das expectativas, (POLENSKE, 2004; KEMCZINSKI et al., 2008; WINCKLER; MOLINARI, 2011), a existência de mecanismos de controle (HORD, 1981; WINCKLER; MOLINARI, 2011) com a 
formalização dos papéis e resultados (HORD, 1981; POLENSKE, 2004; KEMCZINSKI et al., 2008; WINCKLER; MOLINARI, 2011) aumentam a confiança entre os atores (HORD, 1981; POLENSKE, 2004; KEMCZINSKI et al., 2008), diminuindo a exigência de esforços e tempo empreendidos na efetivação e manutenção na cooperação. Além disso, a distância das relações externalizada e a autonomia sobre a parte que cabe a cada ator, sem a necessidade de permissão para toda e qualquer ação, não obrigam os diversos atores a conviver diretamente e diminuem o risco de transferência de informação sem intenção (HORD, 1981; POLENSKE, 2004; KEMCZINSKI et al., 2008).

Nesse sentido, a cooperação pode ocorrer entre empresas que guardam sua independência na coordenação de uma atividade determinada, como a criação de novos mercados, o suporte de custos e riscos em pesquisa e desenvolvimento, os consórcios de compra, as associações profissionais, (BALESTRIN; VARGAS, 2004) ou a criação de organizações especializadas para dividir o custo da operação (POLENSKE, 2004)

A revisão da literatura sobre as características da cooperação possibilitou a elaboração do quadro que compila seus atributos, apresentado no apêndice B, e permitiu a reflexão sobre os elementos com maior destaque nas pesquisas. No caso da cooperação, as características mais marcantes são a divisão clara de tarefas e papéis e a declaração dos objetivos individuais e os resultados possíveis para cada ator, definidos formalmente por contratos, e permitem sua efetivação mais rápida, com um menor investimento de tempo e recursos, gerando ganhos competitivos para as partes.

\subsubsection{Benefícios da cooperação}

Segundo Silva (2007), a cooperação é uma das únicas formas de atingir objetivos comuns no mundo globalizado e de gerar oportunidades para os países em desenvolvimento, respeitando a individualidade das empresas. Com efeito, esse tipo de relação evita anomalias de mercado, como os monopólios. Nesse cenário, a confiança é construída de forma sólida, já que no processo de definição de objetivos individuais e comuns a serem atendidos pela interação entre os atores, eles compartilham visões e maneiras de engajar o trabalho intelectual conjunto, por meio do diálogo. As relações pessoais são aprofundadas, ampliando para o nível de grupo, criando coesão, fortalecimento da rede, diminuição de comportamentos oportunistas e aumento da confiança entre os membros (KIRSCHNER; DICKINSON; BLOSSER, 1996).

As parcerias levam às economias de escala externas, afetando a posição global, com redução de custo em todas as escalas de produção, transação, escopo e especialização 
(POLENSKE, 2004; BALESTRIN; VARGAS, 2004; VERSCHOORE; BALESTRIN, 2008), em especial para as pequenas e médias empresas (POLENSKE, 2004), podendo utilizar as redes de cooperação como recurso estratégico de competitividade (BALESTRIN; VARGAS, 2004.). Nesse contexto, as vantagens econômicas são obtidas também com a comercialização dos produtos em feiras e entre as empresas, com o aumento do poder de barganha nos preços junto aos clientes, bem como com o acesso a novos representantes e à garantia do fornecimento de crédito, inclusive junto ao governo, através de lobbying (BALESTRIN; VARGAS, 2004.). Para Verschoore e Balestrin (2008), o custo do risco de determinadas ações também é dividido ao longo da cadeia. Todos esses fatores geram vantagens competitivas para as empresas. Verschoore e Balestrin (2008) dividem os ganhos competitivos da cooperação em cinco dimensões, especificadas pelas variáveis de cada uma delas, para que se possa mensurar os benefícios auferidos nas relações cooperativas. São elas: escala e poder de mercado, acesso a soluções, inovação e aprendizado, redução de custos e riscos, e relações sociais.

Verschoore e Balestrin (2008) defendem que esses 5 fatores são potencializados por dois elementos comuns à todas as redes de cooperação: tempo e quantidade de atores associados à rede. A escala e poder da rede de cooperação está diretamente relacionada à quantidade de atores envolvidos e ao tempo de existências. Segundo os autores, as redes com pouco tempo de existência estão focadas na redução dos custos e em oferecer soluções para seus membros. Assim como as relações sociais, o processo de aprendizagem e inovação é aprimorado conforme as redes de cooperação alcançam o amadurecimento.

O interesse pelo ganho competitivo da cooperação para as empresas se reflete na criação de políticas para a promoção de redes. Um caso de sucesso no Brasil é o Programa Redes de Cooperação (PRC) do Governo do Estado do Rio Grande do Sul, que fomenta desde 2000 a geração de um amplo e variado conjunto de redes de cooperação, afirmam Verschoore e Balestrin (2008).

A produção de conhecimento e a ifusão são ampliadas exponencialmente (POLENSKE, 2004; SILVA, 2007), ofertando provisão de soluções (VERSCHOORE; BALESTRIN, 2008), mais inovação, desenvolvimento tecnológico e aprendizagem (BALESTRIN; VARGAS, 2004; SILVA, 2007; VERSCHOORE; BALESTRIN, 2008). De acordo com Balestrin e Vargas (2004), a partilha de informações possibilita a implementação de melhorias incrementais, em especial no processo de produção, com redução de até $40 \%$ do custo em alguns casos, sem a necessidade de investimento financeiro, apenas com o uso de assessoria contratada pela rede de cooperação. Esses fatos evidenciam a ausência direta de disputa em termos de apropriação do conhecimento e de tecnologias entre os parceiros, já que os acordos e convênios são formais e 
trazem cláusulas de propriedade intelectual e industrial (SILVA, 2007). Nesse modelo, a forte interação entre as empresas impacta o aprendizado e desenvolvimento organizacional, permitindo o acesso a cursos e treinamentos com custos reduzidos devido ao seu compartilhamento (KIRSCHNER; DICKINSON; BLOSSER, 1996; POLENSKE, 2004; VERSCHOORE; BALESTRIN, 2008) ou porque são financiados pelas associações de crédito que suportam atividades na rede de cooperação (BALESTRIN; VARGAS, 2004; POLENSKE, 2004). Dessa forma, a cooperação permite o crescimento sustentável para os pares (BALESTRIN; VARGAS, 2004; SILVA, 2007). O Quadro 4 apresenta os benefícios da cooperação.

Quadro 4 - Benefícios da Cooperação

\begin{tabular}{|c|c|c|}
\hline Benefícios & Descrição & Autores \\
\hline $\begin{array}{l}\text { Aprendizagem } \\
\text { coletiva }\end{array}$ & $\begin{array}{l}\text { Compartilhamento de cursos, treinamentos e informações } \\
\text { sobre processos. Competências complementares. }\end{array}$ & $\begin{array}{l}\text { Balestrin e Vargas (2004); } \\
\text { Polenske (2004); Silva (2007) }\end{array}$ \\
\hline $\begin{array}{l}\text { Acesso às } \\
\text { soluções }\end{array}$ & $\begin{array}{l}\text { Os serviços, os produtos e a infraestrutura disponibilizados } \\
\text { pela rede para o desenvolvimento de conhecimentos sobre } \\
\text { resoluções de problemas. }\end{array}$ & Verschoore e Balestrin (2008) \\
\hline $\begin{array}{l}\text { Facilitação da } \\
\text { Inovação }\end{array}$ & $\begin{array}{l}\text { Troca de informação, conhecimentos complementares e } \\
\text { consultorias compartilhadas. }\end{array}$ & $\begin{array}{l}\text { Balestrin e Vargas (2004); } \\
\text { Polenske (2004); Silva (2007) }\end{array}$ \\
\hline $\begin{array}{l}\text { Economia em } \\
\text { escala }\end{array}$ & $\begin{array}{l}\text { Melhoria dos processos de produção, logística, gestão do } \\
\text { conhecimento, marketing em rede, capacidade de atender } \\
\text { demandas urgentes e maiores por meio de ações coletivas }\end{array}$ & $\begin{array}{l}\text { Kirschner, Dickinson e Blosser } \\
\text { (1996); Balestrin e Vargas } \\
\text { (2004); Polenske (2004); Silva } \\
(2007)\end{array}$ \\
\hline $\begin{array}{l}\text { Economia de } \\
\text { escopo e } \\
\text { especialização }\end{array}$ & $\begin{array}{l}\text { Aumento do portfólio, cada empresa produz tipos } \\
\text { específicos de produtos, nas dimensões de suas } \\
\text { especializações. Quanto maior o número de empresas, } \\
\text { melhor. }\end{array}$ & $\begin{array}{l}\text { Balestrin e Vargas (2004); } \\
\text { Polenske (2004); Silva (2007) }\end{array}$ \\
\hline $\begin{array}{l}\text { Redução dos } \\
\text { Riscos }\end{array}$ & $\begin{array}{l}\text { Divide os custos e os riscos de determinadas ações e } \\
\text { investimentos comuns aos participantes. }\end{array}$ & Verschoore e Balestrin (2008) \\
\hline $\begin{array}{l}\text { Poder de } \\
\text { barganha }\end{array}$ & $\begin{array}{l}\text { Na compra, venda e aquisição de insumos e recursos } \\
\text { financeiros. Obtenção de incentivos junto ao governo. }\end{array}$ & $\begin{array}{l}\text { Balestrin e Vargas (2004); } \\
\text { Polenske (2004); Silva (2007) }\end{array}$ \\
\hline $\begin{array}{l}\text { Ampliação de } \\
\text { mercado }\end{array}$ & $\begin{array}{l}\text { Capacidade de atender mercado global. Acesso a novos } \\
\text { clientes, representantes e mercados. }\end{array}$ & $\begin{array}{l}\text { Balestrin e Vargas (2004); } \\
\text { Polenske (2004); Silva (2007) }\end{array}$ \\
\hline $\begin{array}{l}\text { Redução do } \\
\text { custo de } \\
\text { transação }\end{array}$ & $\begin{array}{l}\text { Troca de máquinas, insumos e mercadorias. } \\
\text { Compartilhamento de serviços e processos devido ao } \\
\text { aumento de confiança }\end{array}$ & $\begin{array}{l}\text { Balestrin e Vargas (2004); } \\
\text { Polenske (2004); Silva (2007) }\end{array}$ \\
\hline $\begin{array}{l}\text { Relações } \\
\text { sociais }\end{array}$ & $\begin{array}{l}\text { Estreitamento dos laços dentro do grupo inibe o } \\
\text { comportamento oportunista, cria vínculos e novos negócios } \\
\text { entre os membros. }\end{array}$ & Verschoore e Balestrin (2008) \\
\hline Ganhos mútuos & Evita anomalias de mercado. Todos ganham. & $\begin{array}{l}\text { Balestrin e Vargas (2004); } \\
\text { Kirschner, Dickinson e Blosser } \\
(1996) .\end{array}$ \\
\hline
\end{tabular}


Conclusão

\begin{tabular}{|c|l|l|}
\hline $\begin{array}{c}\text { Respeito à } \\
\text { individualidade } \\
\text { da empresa }\end{array}$ & $\begin{array}{l}\text { As empresas entram com o que melhor sabem fazer, suas } \\
\text { especialidades e atendem os objetivos individuais e do } \\
\text { grupo. }\end{array}$ & $\begin{array}{l}\text { Balestrin e Vargas (2004); } \\
\text { Kirschner, Dickinson e Blosser } \\
(1996) .\end{array}$ \\
\hline $\begin{array}{c}\text { Confiança } \\
\text { facilitada }\end{array}$ & $\begin{array}{l}\text { Definição de objetivos individuais e comuns a serem } \\
\text { atendidos pela interação entre os atores, por meio do } \\
\text { diálogo e acordo formal, diminuição de comportamentos } \\
\text { oportunistas. }\end{array}$ & $\begin{array}{l}\text { Kirschner, Dickinson e Blosser } \\
\text { (1996); Balestrin e Vargas } \\
(2004)\end{array}$ \\
\hline
\end{tabular}

Fonte: Autora, 2016

Nota: Elaborado com base em Balestrin e Vargas, 2004

Entre os benefícios mais almejados figuram os que garantem a possibilidade de ampliar a força de ação de uma empresa pela união com outras empresas. Em contrapartida, aquele que é menos lembrado pelos empresários na pesquisa de Verschoore e Balestrin (2008) é a redução de custo. Nesse contexto, Verschoore e Balestrin (2008) enfatizam que a cooperação traz resultados para todos.

\subsubsection{Desafios da cooperação}

Conhecer os riscos e benefícios da cooperação é o primeiro desafio a ser enfrentado para se estabelecer essa relação entre as empresas (DAS; TENG, 1998; SILVA, 2007). Entre os desafios da cooperação, a seleção de fornecedores pode ser considerada seminal para sua implementação, pois ela é a base para sua operacionalização (LIU; ZHANG, 2011). Para tanto, é importante que a organização tenha claro o que precisa dos outros pares, o que cada um tem para oferecer e como as relações podem ser encadeadas, permitindo que a escolha do parceiro seja mais assertiva (SILVA, 2007), tornando-se fator chave para melhorar o poder competitivo das organizações envolvidas no processo (LIU; ZHANG, 2011). Ainda segundo Silva (2007), é muito complexo chegar a um acordo e sustentá-lo até o final do projeto, pois, nesse processo, todos os atores tentam maximizar os seus interesses, exigindo habilidade das partes para negociar até alcançar um acordo.

Em um cenário onde cada um precisa saber o que espera do outro e quais são os recursos tangíveis e intangíveis que cada um tem para oferecer para que se atinja objetivos estratégicos, como ocorre em toda negociação, é preciso poder confiar no seu parceiro, mesmo que as relações de cooperação não sejam tão estreitas como as de colaboração. Afinal, o que se espera para o sucesso da empreitada é que cada um dê o melhor que tem. Dessa forma, Das e Teng (1998) destacam a importância da construção da confiança na cooperação.

Das e Teng (1998), além disso, descrevem dois tipos de confiança, confidence, como os motivos para acreditar na parceria cooperativa, e trust, como o fato de acreditar no outro, ter 
expectativas positivas por si só. O nível de confiança (trust) atua como moderador nos mecanismos de controle, que geram confidence, justificando sua existência e facilitando sua implementação. Os autores defendem, portanto, a necessidade da coexistência de confidence e trust em paralelo, não de forma independente ou antagônicas, e sim interdependentes. Assim, para construir a confiança (confidence) é importante saber quais riscos serão assumidos, garantir a preservação da equidade, comunicação clara e precisa, e fazer as adaptações interfirmas necessárias. Quanto melhor esses fatores forem estabelecidos, maior será o nível de confiança. A quantidade de mecanismos de controle que será exigida na parceria é afetada de forma inversamente proporcional ao nível de confiança (trust). Os mecanismos que estabelecem o nível de controle de controles são três: (1) definição de metas; (2) especificações estruturais; e (3) mistura das culturas organizacionais. São os níveis de confiança e os de controle que determinam a confiança (confidence) na cooperação dos parceiros. Estas relações são apresentadas na Figura 1, com o objetivo de ajudar a compreender as várias alternativas para o desenvolvimento de confiança na parceria cooperativa.

Figura 1 - Confiança e controle nas parcerias estratégicas

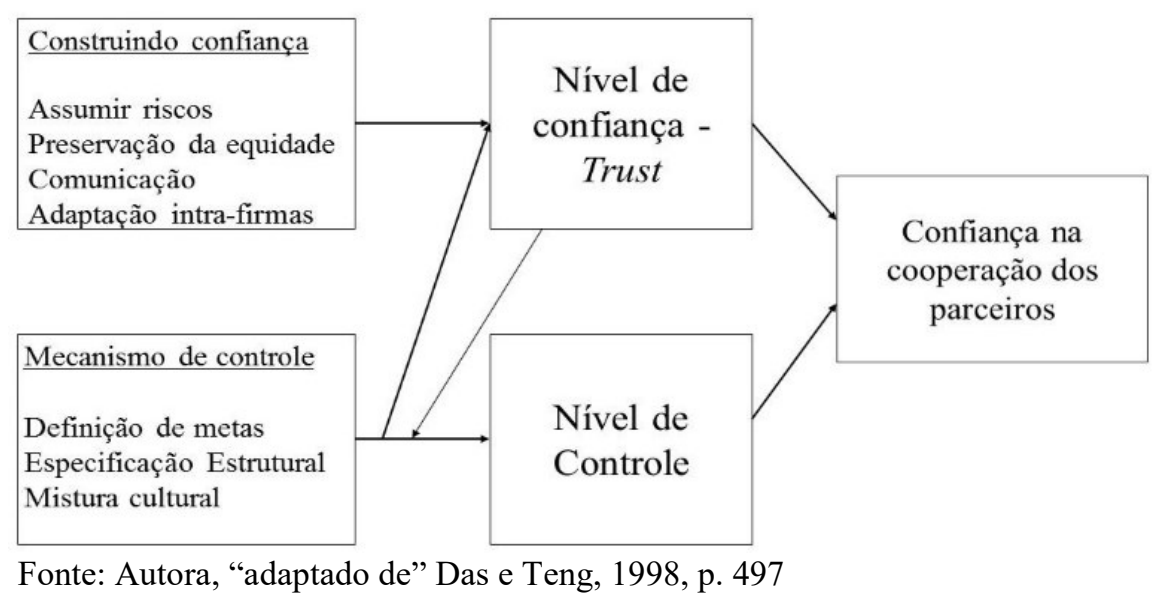

Dessa forma, fica claro que a confiança pode e deve ser construída, mas os mecanismos de controle também precisam ser implementados à medida que for necessário, pois essa construção requer recursos de uma forma ou de outra, que podem gerar altos custos.

Para Silva (2007), no entanto, entre os 5 principais desafios cooperativos estão, primeiro, a possível perda de liberdade de ação, já que os papéis são delimitados. Com efeito, pode-se criar dependência entre os pares, pois sua relação está baseada no comportamento interdependente, em que cada um faz uma parte de forma encadeada, ou participa de uma associação que executa parte do produto ou serviço que uma organização não teria como fazer 
se estivesse sozinha. Nesse sentido, o segundo desafio que corrobora o risco da dependência e perda de liberdade é apresentado por Landry, Trudel e Diorio (1998) na cadeia de suprimentos, quando as relações de cooperação existem há muito tempo. Nesse cenário, corre-se o risco da cooperação se transformar em abuso, pois o equilíbrio do poder pode ser alterado, conforme alertam os autores. Eles afirmam que, devido à intimidade do relacionamento estreitado ao longo do tempo, pode-se transferir mais do que informações, ou as necessidades do comprador podem interferir na missão do fornecedor, que se adequa a todas as necessidades do seu cliente, e potencializa assim a relação de dependência, não diversificando seus compradores ou seus produtos, e a organização pode se ver obrigada a trabalhar com margens muitas vezes insustentáveis. O terceiro desafio abordado por Silva (2007) é o aumento da complexidade da gestão, com mais atores e processos para controlar. A transferência de conhecimento sem intenção pela comunicação muito pessoal, é o quarto desafio, também abordado por Silva (2007), como elemento pernicioso nesse tipo de relação, já que, para potencializar os resultados da cooperação, os atores tentam assimilar conhecimentos dos seus parceiros anteriores à parceria. Posto isso, Silva (2007) alerta finalmente, e este é o quinto desafio, sobre o perigo de se promover o fortalecimento involuntário de futuros competidores.

No caso de operações interorganizacionais internacionais, é importante criar políticas que garantam que, ao cooperar, os países não percam seus direitos autorais, marcas e patentes, com a criação de novos produtos em parcerias, perdendo o direito de receber os dividendos desses projetos. Isto é especialmente verdadeiro porque ainda existe o risco político da cooperação falhar (SILVA, 2007).

A falta de estrutura legislativa que suporte o processo de cooperação pode dificultar a sua efetivação não somente na cooperação internacional, mas entre empresas no mesmo país, já que leis que objetivam criar um cenário forte para o crescimento dessas parcerias poderiam disponibilizar mecanismos de incentivos fiscais e financeiros para o seu desenvolvimento, assim como criar mecanismos de fiscalização, como entidades especializadas para acompanhar os processos de efetivação. Da mesma forma, essa legislação poderia estabelecer mecanismos mínimos de controle, como contratos, ou até mesmo suporte que ajuda as empresas a escolherem os melhores parceiros e definirem os termos da cooperação. Uma lei criada no Rio Grande do Sul com foco em cooperação, por exemplo, permitiu a criação de mais de 120 redes de cooperação entre PME, ajudando-as a ganhar competitividade (VERSCHOORE; BALESTRIN, 2008). 


\subsection{AS DIFERENÇAS E SEMELHANÇAS ENTRE COLABORAÇÃO E COOPERAÇÃO}

Poucos estudos abordam a diferenciação entre os conceitos de colaboração e cooperação (HORD, 1981; HORD, 1986; KIRSCHNER; DICKINSON; BLOSSER; 1996; BRNA, 1998; POLENSKE, 2004; SILVA, 2007; KEMCZINSKI et al., 2008; VERSCHOORE; BALESTRIN, 2008; BALESTRIN; VERSCHOORE; REYES JUNIOR, 2010; WINCKLER; MOLINARI, 2011; OLIVEIRA et al., 2016). A maioria os tratam como sinônimos, alternando aleatoriamente o seu uso ao longo do texto, sem se preocupar com o significado ou semântica, ou simplesmente usam a colaboração de forma genérica (KOLBUS, 1992; LEE-MORTIMER, 1993; HARGROVE, 1998; VIEIRA, 2006; VIVALDINI; SOUZA; PIRES, 2007; ANSELL; GASH, 2008; GIGANTE; RIGOLIN; MARCELO, 2012). Alguns autores associam esse fenômeno às semelhanças entre os elementos que compõem cada conceito (HORD, 1981; POLENSKE, 2004; ANSELL; GASH, 2008) ou à falta de consenso na literatura sobre o que compõe cada termo, e o que os diferenciam (KEMCZINSKI et al., 2008; WINCKLER; MOLINARI, 2011). Esse fato se deve em parte à evolução da compreensão histórica dos conceitos e sua aplicação nas mais diversas áreas. De acordo com Polenske (2004), existem 4 semelhanças básicas entre os conceitos, o que pode levar a maioria dos autores a tratá-los de forma igual. São elas:

a) Ambos podem ocorrer entre os atores (privados ou empresas públicas, setor público, organizações locais, membros da força de trabalho ou outros agentes) dentro da entidade ou região ou além das fronteiras regionais, nacionais e internacionais;

b) A interação pode ocorrer entre as empresas do setor privado, entre uma empresa privada e do setor público ou entre os outros tipos de agentes, tais como associações comerciais e sindicatos;

c) Podem ou não serem adotados para aumentar a competitividade de uma empresa;

d) Podem durar um longo ou curto período de tempo, dependendo de fatores econômicos, sociais e políticos, entre outros.

Brna (1998) argumenta que o termo colaboração é usado de forma amplamente genérica, ou intencionalmente ambígua, para definir relações colaborativas, gerando discordância acadêmica sobre sua definição. Já para Kemczinski et al. (2008), a literatura não apresenta consenso sobre os termos, sendo ora tratados como sinônimos, ora como excludentes, ou seja, cada sistema tem apenas características dele mesmo, ou sistemas que possuam um grau mais elevado de colaboração, com alguns elementos da cooperação, ou vice-versa, sendo o mais importante então, identificar as características preponderantes de cada um. Após os autores 
mapearem as abordagens teóricas que tratam dos dois termos e compilar em 4 tipos de definição dos conceitos de cooperação e colaboração, eles desenvolveram uma quinta tipologia, baseada na teoria dos conjuntos, que faz a intersecção entre colaboração e cooperação, que denominaram de "visão ampla". A Figura 2 apresenta como a visão ampla atende aos 4 tipos de conceituação dos termos.

Figura 2 - Visões de colaboração e cooperação

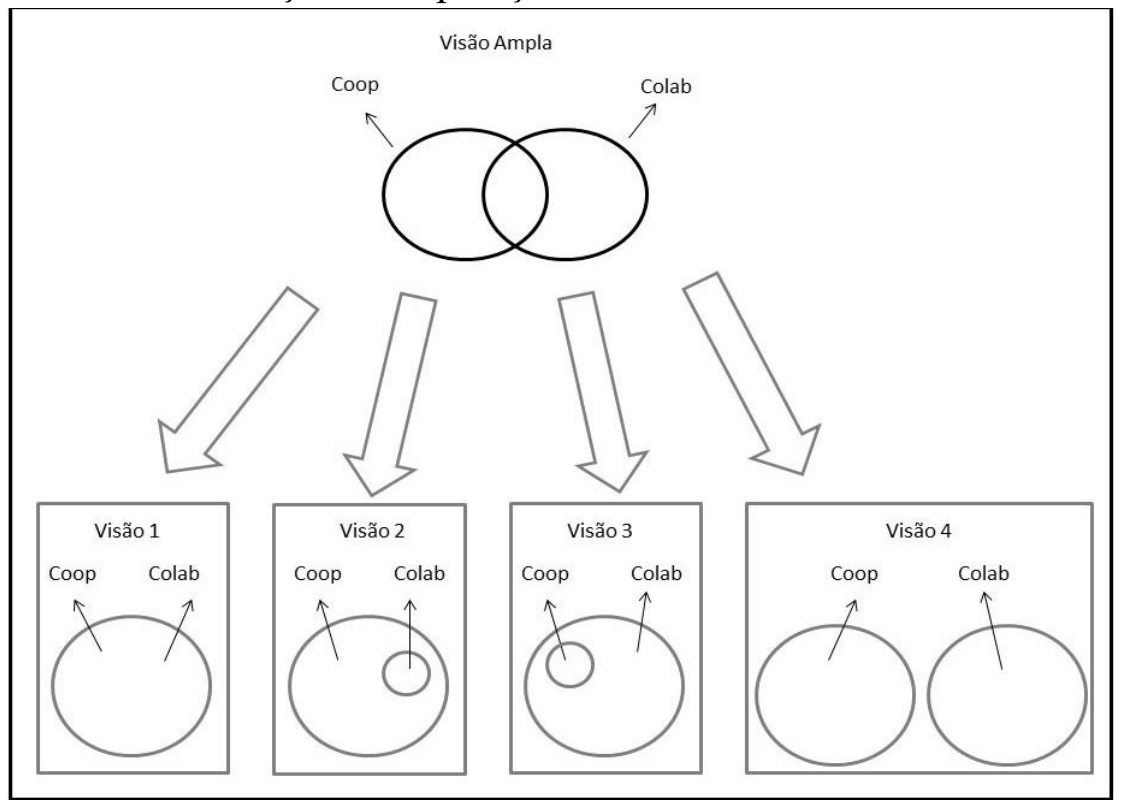

Fonte: Kemczinski et al., 2008, p. 6

Para sustentar a visão ampla e sua aplicabilidade em Ambientes de E-Learning (AEL), Kemczinski et al. (2008) estabeleceram as variáveis que definem colaboração e cooperação que, quando aplicadas às práticas de parcerias, tornam possível identificar a qual visão uma prática determinada pertence, dependendo do modo como as variáveis se apresentam e qual a sua importância no modelo estudado. As variáveis que definem colaboração e cooperação foram agrupadas em seis características: divisão de tarefas, objetivo, dinâmica da tarefa, hierarquia, competência e comunicação, e permitem a visualização da diferença entre os conceitos em AEL.

De acordo com Hord (1981), a colaboração não é possível sem a cooperação, mas o inverso não é verdadeiro, o que corrobora a Visão 2, proposta por Kemczinski et al. (2008). A colaboração exige muito mais esforço, mas geralmente, seu produto gera maior rendimento (HORD, 1981). A cooperação é possível com o menor esforço, pois é mais estruturada, com objetivos organizacionais definidos, podendo ser diferentes (KIRSCHNER; DICKINSON; BLOSSER, 1996; HORD, 1981), expectativas claras para as partes (HORD, 1981), com papéis 
bem definidos, assim como qual a contribuição de conhecimento cada um oferecerá (KIRSCHNER; DICKINSON; BLOSSER, 1996). Os atores entram com suas agendas e as conciliam com a do projeto, responsabilizando-se por sua parte, aferindo benefícios para ambos os lados (KIRSCHNER; DICKINSON; BLOSSER, 1996).

Para explicar a diferença, Hord (1981) usa a metáfora do namoro e casamento, de modo que empreender de forma cooperativa equivale ao estágio de namoro e a colaboração ao de casamento. Ressalva-se o fato de alguns casamentos nunca chegarem ao status de colaboração de fato, pois criam expectativas pouco claras ou não correspondidas, o que pode levar ao seu insucesso. Para evitar o fracasso, é necessária clareza sobre os fatores que iniciam cada um dos processos, assim como os resultados e recompensas esperadas. Nesse cenário, Hord (1981) analisou o processo de colaboração na área de pesquisa acadêmica, concluindo que o sucesso dessa relação dependia da clareza da distinção entre colaboração e cooperação, e construiu um modelo para cada processo, elencando seus elementos, conforme apresentado no Quadro 5.

\begin{tabular}{|c|c|}
\hline Modelo A Cooperação & Modelo B Colaboração \\
\hline \multicolumn{2}{|c|}{ Passos iniciais do processo } \\
\hline $\begin{array}{l}\text { A organização }(\mathrm{X}) \text { aborda a outra }(\mathrm{Y}) \text { e recebe } \\
\text { permissão para completar uma tarefa (pesquisa, análise } \\
\text { etc.). }\end{array}$ & $\begin{array}{l}\text { As organizações acordam sobre uma troca de tarefas, } \\
\text { cada uma oferecendo à outra um produto ou serviço. }\end{array}$ \\
\hline $\begin{array}{l}\text { X completa sua tarefa com a ajuda, tolerância e } \\
\text { cooperação de Y, mas sem a contribuição dos recursos } \\
\text { de Y. }\end{array}$ & $\begin{array}{l}\text { As organizações unem forças (pessoas se juntam) para } \\
\text { planejar e executar o desenho do projeto compartilhado. } \\
\text { Um sistema de "equipe unida" se desenvolve. }\end{array}$ \\
\hline $\begin{array}{l}\text { X relata a Y seus resultados, achados e o que quer que } \\
\text { tenham projetado como resultado de sua tarefa - X } \\
\text { desenvolve um "produto" sozinho, mas como um } \\
\text { resultado da cooperaça de Y. }\end{array}$ & $\begin{array}{l}\text { As organizações acordam resultados, desfechos, produtos, } \\
\text { serviços etc. projetados. Objetivos compartilhados são } \\
\text { alcançados e um plano de ação é delineado. }\end{array}$ \\
\hline \multicolumn{2}{|c|}{ Comunicação } \\
\hline $\begin{array}{l}\mathrm{X} \text { transmite informação a Y em intervalos ocasionais. X } \\
\text { determina a natureza da comunicação, apesar de } \\
\text { também responder a exigências de Y. }\end{array}$ & $\begin{array}{l}\text { Papéis de comunicação são estabelecidos e canais } \\
\text { definidos são criados para interações através da } \\
\text { organização relativa ao projeto. Muitos “níveis” de } \\
\text { comunicação são estabelecidos, já que informação clara é } \\
\text { a base do sucesso do esforço. }\end{array}$ \\
\hline \multicolumn{2}{|c|}{ Recursos e propriedade } \\
\hline $\begin{array}{l}\text { X fornece recursos e conhecimento, Y fornece acesso, } \\
\text { ambiente e situação. }\end{array}$ & $\begin{array}{l}\text { As organizações envolvidas contribuem com pessoas, } \\
\text { tempo, recursos e capacidades. Isso geralmente é definido } \\
\text { no processo de planejamento. }\end{array}$ \\
\hline \multirow[t]{2}{*}{$\begin{array}{l}\mathrm{X} \text { fornece financiamento, pode até pagar Y pelas suas } \\
\text { contribuições. }\end{array}$} & $\begin{array}{l}\text { Financiamento mútuo é obtido, talvez de uma fonte } \\
\text { externa, dependendo da natureza das instituições (privada, } \\
\text { pública, não-lucrativa, internacional etc.). }\end{array}$ \\
\hline & $\begin{array}{c}\text { Modo de processo "nós" se desenvolve - propriedade do } \\
\text { sistema. }\end{array}$ \\
\hline \multirow{3}{*}{$\begin{array}{c}\text { X identifica uma área problemática e Y permite a } \\
\text { pesquisa ou análise da mesma. OU é verificado que uma } \\
\text { área de interesse de X vai lucrar com alguma associação } \\
\text { com Y, e permissão de Y é obtida para continuar tal } \\
\text { associação. }\end{array}$} & $\begin{array}{c}\text { As organizações envolvidas gastam muito tempo e } \\
\text { energia. }\end{array}$ \\
\hline & Os grupos assumem ações e riscos. \\
\hline & $\begin{array}{c}\text { Muitas reuniões, pequenas e grandes, são organizadas } \\
\text { com frequência. }\end{array}$ \\
\hline
\end{tabular}


Conclusão

\begin{tabular}{|c|c|}
\hline \multicolumn{2}{|c|}{ Requerimentos/características } \\
\hline & Compromisso é uma necessidade, muitas trocas são \\
\hline & arranjadas. \\
\hline & $\begin{array}{c}\text { Um time compartilhado, talvez até troca ou empréstimo } \\
\text { de equipe, passa a ocorrer. }\end{array}$ \\
\hline & $\begin{array}{c}\text { Conhecimentos de tipos diferentes são compartilhados } \\
\text { por cada grupo (o que é uma das principais motivações } \\
\text { para colaboração, afinal). }\end{array}$ \\
\hline \multicolumn{2}{|c|}{ Liderança e controle } \\
\hline 1. Liderança unilateral é característica. & 1. Liderança dispersa é característica. \\
\hline 2. Controle Central continua em cada organização. & $\begin{array}{l}\text { 2. A responsabilidade é delegada. Os indivíduos devem } \\
\text { estar dispostos a usar julgamento independente sobre } \\
\text { assumir a responsabilidade. }\end{array}$ \\
\hline & $\begin{array}{l}\text { 3. Compartilhado, controle mútuo é o ideal. Objetivos } \\
\text { compartilhados fornecem a congruência com o esforço. }\end{array}$ \\
\hline \multicolumn{2}{|r|}{ Recompensas } \\
\hline $\begin{array}{c}\text { 1. X recebe o produto. Y pode usá-lo. Y pode } \\
\text { simplesmente beneficiar de um sentimento de altruísmo } \\
\text { ou contribuição social. }\end{array}$ & $\begin{array}{l}\text { 1. As organizações envolvidas são capazes de } \\
\text { compartilhar em um (ou muitos) produto ou serviço o que } \\
\text { não teria sido possível como agentes separados. }\end{array}$ \\
\hline & $\begin{array}{l}\text { 2. O produto/serviço compartilhado pode ser uma } \\
\text { libertação de uma responsabilidade que nenhum deles } \\
\text { poderia ter realizado sozinho. }\end{array}$ \\
\hline & $\begin{array}{l}\text { 3. No caso das organizações de serviço público, o público } \\
\text { pode obter maior benefício do esforço conjunto do que } \\
\text { cada organização separada poderia ter oferecido. }\end{array}$ \\
\hline & $\begin{array}{l}\text { 4. O produto do esforço conjunto pode levar a uma } \\
\text { relação permanente, abrindo o caminho para uma maior } \\
\text { partilha e benefícios mútuos. }\end{array}$ \\
\hline & $\begin{array}{l}\text { 5. Cada organização pode experimentar uma expansão de } \\
\text { possibilidades sem ter de ser "espalhado". }\end{array}$ \\
\hline & $\begin{array}{l}\text { 6. Embora mais tempo / energia / recursos podem ter sido } \\
\text { gasto, muitas vezes ao mesmo tempo, energia e recursos } \\
\text { são, em última análise, conservados pelo esforço } \\
\text { compartilhado. Duplicação de serviços é por vezes } \\
\text { eliminada, melhorando a qualidade geral do serviço. }\end{array}$ \\
\hline
\end{tabular}

Fonte: Hord, 1981, p. 15

Segundo Hord (1981), esses modelos representam uma base sólida inicial para fazer a distinção entre os processos. Com eles, ficam evidentes as diferenças de expectativas de cada processo, quando bem definidos. Além disso, fica claro quais são os conflitos que surgem quando não se tem a definição clara de qual modelo de processo deverá ser adotado.

Dessa forma, entende-se que o uso de cooperação e colaboração como sinônimos é um erro (POLENSKE, 2004; WINCKLER; MOLINARI, 2011) que pode dificultar a elaboração de políticas públicas e criar um clima de desconfiança entre os atores, já que o comportamento, integração e resultados esperados são diferentes para cada um dos conceitos, assim como as especificidades dos acordos, normas e tipos de incentivos (POLENSKE, 2004).

Winckler e Molinari (2011, ) estabelecem essa diferença salientando que, no caso da colaboração, os resultados são mais focados em cada ator, tendo um comportamento de apoio na parceria, que pode acontecer tanto de forma horizontal, como vertical, mas com ganhos individuais, ao passo que, no caso da cooperação, o comportamento entre os atores é de reciprocidade, ocorre de forma horizontal e objetiva ganhos mútuos. Polenske (2004), por sua 
vez, estabelece as diferenças entre colaboração e cooperação a partir dos papéis assumidos pelos atores envolvidos nas parcerias, de forma que, na primeira, os atores trabalham juntos para desenvolver um determinado produto ou serviço, e, na outra, trabalham separadamente, de forma encadeada. Outro aspecto importante é a forma como se dá a colaboração para Polenske (2004), pois ele considera que ela acontece apenas de forma vertical e com a criação de mecanismos para o trabalho conjunto interno, como por exemplo em uma Joint Venture, por tempo limitado e com transferência de conhecimento. Na cooperação, essas questões se apresentam de outra forma, pois as relações ocorrem de forma horizontal e externa, como na criação de uma organização para operar uma parte do processo de forma contínua, com resultados comuns de redução de custo para todos os envolvidos. Brna (1998), no entanto, acredita que, quando se tenta estabelecer a diferença entre colaboração e cooperação de acordo com a forma de realizar a tarefa, incorre-se no erro de que colaboração pode ser um processo ou estado. Assim, por exemplo, quando as tarefas são divididas e cada ator é responsável pela parte que the foi confiada, agindo cooperativamente, está se definindo que o processo foi cooperativo, mas mantém-se um estado colaborativo na execução da atividade.

A partir dos atributos que caracterizam as palavras cooperação e colaboração, dos elementos comuns e dos que diferem, serão apresentados quadros-síntese dos dois processos. O quadro a seguir consistem em uma síntese que reúne todas essas informações, para que se possa ter uma visão global das variáveis, assim como quais atores fazem com que sejam diferentes, quais são iguais e quais são excludentes, apresentados no apêndice C. No Quadro 6, identifica-se 3 dimensões e seus respectivos atributos, construídos a partir da revisão da literatura, que influenciam a escolha do processo de colaboração ou cooperação.

Quadro 6 -Dimensões da Colaboração e Cooperação

\begin{tabular}{|c|c|c|}
\hline Dimensões & Atributos & Definição \\
\hline Motivação & $\begin{array}{c}\text { Necessidade ou } \\
\text { desejo de fazer } \\
\text { algo }\end{array}$ & O ator precisa fazer algo muito complexo ou além de suas competências ou recursos \\
(HORD, 1981; POLENSKE, 2004).
\end{tabular}

Continua... 
Conclusão

\begin{tabular}{|c|c|c|}
\hline \multirow[t]{4}{*}{ Escopo } & Natureza & $\begin{array}{l}\text { Define o que será executado, podendo ser uma ação mental de planejamento, inovação, } \\
\text { desenvolvimento ou uma decisão estratégica de operacionalização externa de um } \\
\text { processo, mecanização, serviço, etapa, com a criação ou não de uma organização para sua } \\
\text { execução junto com outros atores. }\end{array}$ \\
\hline & Objetivo & Define a quem atendem os objetivos. Os objetivos podem ser do grupo ou de cada ator. \\
\hline & Resultados & $\begin{array}{l}\text { Definem quem e como recebe os resultados. Todos recebem algo, mas não } \\
\text { obrigatoriamente os resultados são tangíveis para todos, com resultados intangíveis } \\
\text { motivando a participação do outro, ou; geram resultados tangíveis para ambos }\end{array}$ \\
\hline & Atores & $\begin{array}{l}\text { Definem que tipo de atores podem participar. Todos os setores podem se relacionar em } \\
\text { ambos os conceitos, mas os atores podem ser concorrentes ou esse fator pode gerar riscos } \\
\text { muito altos para a relação devido às características estruturantes. }\end{array}$ \\
\hline \multirow[t]{6}{*}{ Estrutura } & Atividades & $\begin{array}{l}\text { Definem como executam as atividades: trabalham juntos, na mesma atividade; } \\
\text { simultaneamente, em forma de apoio, contribuição; separados, com cada um fazendo uma } \\
\text { etapa de forma complementar e recíproca; ou com a criação de uma nova organização para } \\
\text { execução do processo. }\end{array}$ \\
\hline & Recursos & $\begin{array}{l}\text { Os recursos humanos, físicos e financeiros são compartilhados, com uso mútuo, e as } \\
\text { informações compartilhadas; ou fazem uso do seu próprio recurso, criando fundos para } \\
\text { estruturação das ações e reportam informações e resultados. }\end{array}$ \\
\hline & Comunicação & $\begin{array}{l}\text { É intensa, aberta, presencial, tenta limitar-se ao que quer cada ator, com TIC síncrona; ou } \\
\text { limitada ao processo, por relatórios periódicos e TIC assíncrona. }\end{array}$ \\
\hline & Poder & Mútuo, ou centralizado nas organizações. \\
\hline & Controle & $\begin{array}{l}\text { Poucos mecanismos de controle, com contratos informais; ou mecanismos de controle } \\
\text { estruturados e contratos formais. }\end{array}$ \\
\hline & Risco & Pode ser mútuo pela proximidade das relações, ou divido por quem opera a etapa. \\
\hline
\end{tabular}

Fonte: Autora, 2016.

Considerando estas dimensões e atributos, detalha-se no Quadro 7 como cada atributo se aplica nos processos da decisão entre colaborar ou cooperar. Os atributos da dimensão Motivação Inicial não constam na matriz, já que fazem parte do processo de percepção da necessidade, oportunidade e disposição para atuar em conjunto com outros atores, que antecede o dilema da escolha do tipo de parceria, baseada nas características necessárias para seu estabelecimento (HORD, 1981; POLENSKE, 2004; KEMCZINSKI et al., 2008) 
Quadro 7 - Matriz dos atributos de colaboração e cooperação detalhada.

\begin{tabular}{|c|c|c|c|}
\hline \multicolumn{4}{|c|}{ ATRIBUTOS DO ESCOPO: Natureza } \\
\hline Colaboração & Referência & Cooperação & Referência \\
\hline $\begin{array}{l}\text { Natureza: Criação, desenvolvimento ou elaboração de algo } \\
\text { (ação mental). Ex. Lei, Artigo Científico, JoinVenture. }\end{array}$ & $\begin{array}{c}\text { Brna (1998); } \\
\text { Kemczinski et al. }(2008)\end{array}$ & $\begin{array}{c}\text { Natureza: Operacionalização de processo, serviço ou } \\
\text { aprimoramento de algo. Ex. cadeia de suprimento, criação } \\
\text { de organização especializada para dividir o custo da } \\
\text { operação. }\end{array}$ & $\begin{array}{l}\text { Brna (1998); Silva (2007); } \\
\text { Kemczinski et al. (2008); } \\
\text { Winckler e Molinari (2011) }\end{array}$ \\
\hline \multicolumn{4}{|c|}{ ATRIBUTOS DO ESCOPO: Objetivo } \\
\hline $\begin{array}{l}\text { Definição dos objetivos comum: Claros para ambos, senso } \\
\text { comum do que será feito. }\end{array}$ & $\begin{array}{l}\text { Brna (1998); Ansell e Gash } \\
\text { (2008); Polenske (2004) }\end{array}$ & $\begin{array}{c}\text { Definição dos objetivos comum: Claros, são pré- } \\
\text { estipulados }\end{array}$ & $\begin{array}{l}\text { Hord (1981); Polenske (2004); } \\
\text { Kemczinski et al. (2008) }\end{array}$ \\
\hline $\begin{array}{c}\text { Objetivo individuais: Objetivo comum ao grupo é mais } \\
\text { importante do que os individuais, não se sobrepõe ao comum. } \\
\text { Nem sempre é declarado. }\end{array}$ & \begin{tabular}{|c|} 
Hord (1981); Brna (1998); \\
Polenske (2004); Kemczinski et \\
al. (2008)
\end{tabular} & $\begin{array}{c}\text { Objetivo individuais: } \\
\text { Não precisam ser iguais. São importantes e garantidos } \\
\text { pelo objetivo comum. }\end{array}$ & $\begin{array}{l}\text { Hord (1981); Polenske (2004); } \\
\text { Kemczinski et al. (2008) }\end{array}$ \\
\hline \multicolumn{4}{|c|}{ ATRIBUTOS DO ESCOPO: Resultados } \\
\hline $\begin{array}{l}\text { Resultados do Projeto: Mútuos. Ambos recebem algo na } \\
\text { parceria, tangível ou intangível. }\end{array}$ & $\begin{array}{c}\text { Balancieri (2004); Ansell e Gash } \\
\text { (2008); Winckler e Molinari } \\
\text { (2011) }\end{array}$ & Mútuo & $\begin{array}{l}\text { Polenske (2004); Kemczinski et } \\
\text { al. (2008); Winckler e Molinari } \\
\text { (2011) }\end{array}$ \\
\hline $\begin{array}{l}\text { Equidade dos Resultados: Assimétricos, podem ser } \\
\text { diferentes para cada um. Nem todos precisam receber } \\
\text { resultados tangíveis. }\end{array}$ & $\begin{array}{l}\text { Polenske (2004); Winckler e } \\
\text { Molinari (2011) }\end{array}$ & Assimétricos & $\begin{array}{l}\text { Hord (1981); Polenske (2004); } \\
\text { Winckler e Molinari (2011) }\end{array}$ \\
\hline $\begin{array}{l}\text { Propriedade dos Resultados: Compartilham resultados do } \\
\text { projeto entre os atores que estão envolvidos. }\end{array}$ & Balancieri (2004) & $\begin{array}{c}\text { Propriedade dos Resultados: Resultados são relatados } \\
\text { por quem opera, divididos conforme acertado e podem } \\
\text { dar acesso a quem cooperou }\end{array}$ & Hord (1981); Polenske (2004) \\
\hline $\begin{array}{l}\text { Resultados Esperados: Baseados em expectativas, sem } \\
\text { contrato formal. }\end{array}$ & Brna (1998) & $\begin{array}{l}\text { Resultados Esperados: Pré-definidos de forma clara e } \\
\text { formal. }\end{array}$ & $\begin{array}{l}\text { Kemczinski et al. (2008); } \\
\text { Winckler e Molinari (2011) }\end{array}$ \\
\hline $\begin{array}{l}\text { Resultados Tangíveis (lucro, redução de custo, otimização de } \\
\text { processos, capacidade operacional, novo produto/serviço): } \\
\text { Não precisam ser mútuos. Resultados Intangíveis: Podem } \\
\text { compensar a ausência do tangível (imagem, influência, } \\
\text { sentimento de altruísmo). }\end{array}$ & $\begin{array}{l}\text { Polenske (2004); Winckler e } \\
\text { Molinari (2011) }\end{array}$ & $\begin{array}{l}\text { Resultados Tangíveis (lucro, redução de custo, } \\
\text { otimização de processos, capacidade operacional, novo } \\
\text { produto/serviço): Ambos recebem resultados tangíveis, } \\
\text { mas cada um fica com a parte que lhe cabe. Resultados } \\
\text { Intangíveis: Podem ser esperados (imagem, influência, } \\
\text { sentimento de altruísmo) }\end{array}$ & $\begin{array}{l}\text { Hord (1981); Polenske (2004); } \\
\text { Winckler e Molinari (2011) }\end{array}$ \\
\hline
\end{tabular}

Continua... 
Continuação

\begin{tabular}{|c|c|c|c|}
\hline \multicolumn{4}{|c|}{ ATRIBUTOS DO ESCOPO: Atores } \\
\hline Setores: Pode ser entre qualquer setor. & Polenske (2004) & Setores: Pode ser entre qualquer setor. & Polenske (2004) \\
\hline Atores: Não devem ser concorrentes. & Winckler e Molinari (2011) & Atores: Podem ser concorrentes. & $\begin{array}{l}\text { Hord (1981); Winckler e } \\
\text { Molinari (2011) }\end{array}$ \\
\hline \multicolumn{4}{|c|}{ TRIBUTOS DA ESTRUTURA: Atividade } \\
\hline Colaboração & Referência & Cooperação & Referência \\
\hline $\begin{array}{l}\text { Relação na atividade: Trabalham junto na execução da } \\
\text { tarefa, internamente. }\end{array}$ & \begin{tabular}{|c|} 
Hord (1981); Balancieri (2004); \\
Polenske (2004); Kemczinski et \\
al. (2008); Winckler e Molinari \\
(2011); Ansell e Gash (2008)
\end{tabular} & $\begin{array}{l}\text { Relação na atividade: Trabalham separados, cada um } \\
\text { executa uma parte separada, externamente. }\end{array}$ & \begin{tabular}{|c|} 
Hord (1981); Polenske (2004); \\
Kemczinski et al. (2008); \\
Winckler e Molinari (2011)
\end{tabular} \\
\hline $\begin{array}{l}\text { Dependência na atividade: Interdependentes, mantém a } \\
\text { dependência com o grupo em todas as decisões e ações. }\end{array}$ & $\begin{array}{c}\text { Hord (1981); Ansell e Gash } \\
\text { (2008); Kemczinski et al. (2008) }\end{array}$ & $\begin{array}{c}\text { Dependência na atividade: Independente na atividade } \\
\text { executada, respeitando o plano. Após divisão de tarefas } \\
\text { mantém autonomia sobre o processo. }\end{array}$ & Kemczinski et al. (2008) \\
\hline $\begin{array}{l}\text { Papel: Não é tão delimitado, para aumentar a sinergia, estão } \\
\text { sempre negociando. }\end{array}$ & $\begin{array}{c}\text { Brna (1998); Hord (1981); } \\
\text { Kemczinski et al. (2008); Ansell } \\
\text { e Gash (2008) }\end{array}$ & $\begin{array}{l}\text { Papel: Atividade com divisão clara de papéis, pré- } \\
\text { determinada por líder no planejamento. }\end{array}$ & $\begin{array}{l}\text { Hord (1981); Polenske (2004); } \\
\quad \text { Kemczinski et al. (2008) }\end{array}$ \\
\hline Tipo de atuação: Compartilhada, de apoio, contribuição & $\begin{array}{l}\text { Hord (1981); Balancieri (2004); } \\
\text { Winckler e Molinari (2011); } \\
\text { Kemczinski et al. (2008) }\end{array}$ & $\begin{array}{c}\text { Tipo de atuação: Complementar, cada um completa a } \\
\text { tarefa do outro e oferece o que tem de melhor, } \\
\text { reciprocidade. }\end{array}$ & $\begin{array}{c}\text { Polenske (2004); Kemczinski et } \\
\text { al. (2008); Winckler e Molinari } \\
\text { (2011) }\end{array}$ \\
\hline $\begin{array}{l}\text { Sentido da atividade: Vertical, com níveis diferentes }{ }^{1} \text {, ou } \\
\text { horizontal, no mesmo nível }{ }^{2} \text {. }\end{array}$ & $\begin{array}{c}\text { Polenske (2004) }{ }^{1} ; \\
\text { Winckler e Molinari }(2011)^{2}\end{array}$ & $\begin{array}{c}\text { Sentido da atividade: Horizontal, podem criar uma } \\
\text { organização, como uma cooperativa, para operacionalizar } \\
\text { um processo. }\end{array}$ & $\begin{array}{l}\text { Polenske (2004); Kemczinski et } \\
\text { al. (2008); Winckler e Molinari } \\
\text { (2011) }\end{array}$ \\
\hline Competitividade: Competitividade quase não é afetada & Wincler e Molinari (2011). & Competitividade: Gera vantagem competitiva & \begin{tabular}{|c|}
$\begin{array}{c}\text { Polenske (2004); Silva (2007); } \\
\text { Winckler e Molinari (2011) }\end{array}$ \\
\end{tabular} \\
\hline \multicolumn{4}{|c|}{ ATRIBUTOS DA ESTRUTURA: Recursos } \\
\hline $\begin{array}{c}\text { Competências ([CH]|A): Assimétricas. Conhecimento e } \\
\text { habilidades são diferentes. }\end{array}$ & \begin{tabular}{|c|} 
Balancieri (2004); Ansell e Gash \\
(2008); Hord (1981); Polenske \\
(2004). Kemczinski et al. (2008)
\end{tabular} & $\begin{array}{c}\text { Competências ([CH]|A): Assimétricas. Conhecimento e } \\
\text { habilidades são diferentes. }\end{array}$ & \begin{tabular}{|c|} 
Hord (1981); Polenske (2004); \\
Kemczinski et al. (2008); \\
Winckler e Molinari (2011)
\end{tabular} \\
\hline $\begin{array}{c}\text { Competências }(\mathbf{C H}[\underline{\mathbf{A}}]) \text { : Colaborativa, de } \\
\text { compartilhamento, espírito de equipe, exige } \\
\text { comprometimento, paciência, empatia e saber ouvir. }\end{array}$ & $\begin{array}{l}\text { Hord (1981); Kemczinski et al. } \\
\text { (2008); Ansell e Gash (2008) }\end{array}$ & 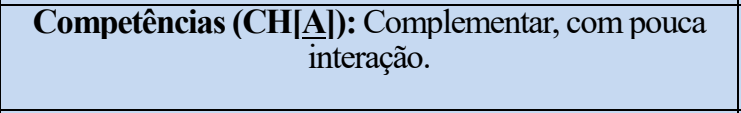 & $\begin{array}{l}\text { Polenske (2004); Kemczinski et } \\
\text { al. (2008); Winckler e Molinari } \\
\text { (2011) }\end{array}$ \\
\hline $\begin{array}{c}\text { Competências (CH[A]): maior proximidade gera atitudes } \\
\text { oportunistas. }\end{array}$ & Brna (1998) & $\mathrm{X}$ & $\mathrm{X}$ \\
\hline RH: Compartilhados. & Hord (1981); & RH: Cada um opera com o seu. & Hord (1981); Polenske (2004) \\
\hline
\end{tabular}




\begin{tabular}{|c|c|c|c|}
\hline $\begin{array}{c}\text { Infraestrutura: Compartilham infraestrutura e } \\
\text { equipamentos. }\end{array}$ & Hord (1981) & $\begin{array}{c}\text { Infraestrutura: Cada opera com a sua ou cria uma } \\
\text { estrutura nova. }\end{array}$ & Hord (1981); Polenske (2004) \\
\hline $\begin{array}{l}\text { Financeiro: Compartilham recursos financeiros, obtém } \\
\text { financiamento mútuo. }\end{array}$ & Hord (1981) & $\begin{array}{l}\text { Financeiro: Não compartilham recursos financeiros, } \\
\text { criam fundos para sustentar a operação. }\end{array}$ & $\begin{array}{l}\text { Silva (2007); Kemczinski et al. } \\
\text { (2008); Hord (1981); Polenske } \\
\text { (2004) }\end{array}$ \\
\hline $\begin{array}{l}\text { Tempo necessário para efetivar: Muito tempo. O } \\
\text { estabelecimento da parceria exige energia devido à forte } \\
\text { interação. }\end{array}$ & $\begin{array}{l}\text { Hord (1981); Ansell e Gash } \\
\text { (2008) }\end{array}$ & $\begin{array}{l}\text { Tempo necessário para efetivar: Menos tempo. Tudo é } \\
\text { pré-definido e a confiança construída por controle }\end{array}$ & $\begin{array}{l}\text { Hord (1981); Polenske (2004); } \\
\text { Kemczinski et al. (2008) }\end{array}$ \\
\hline \begin{tabular}{|c|} 
Limitação do Recurso Informação: Limitadas ao que se \\
quer oferecer, recebe quem está diretamente ligado ao projeto.
\end{tabular} & Polenske (2004) & $\begin{array}{c}\text { Limitação do Recurso Informação: Limitadas ao } \\
\text { processo, mas todos os atores recebem os resultados da } \\
\text { cooperação. }\end{array}$ & $\begin{array}{l}\text { Hord (1981); Polenske (2004); } \\
\text { Kemczinski et al. (2008) }\end{array}$ \\
\hline Capilaridade da rede: Quanto mais, melhor. & Balancieri (2004) & Capilaridade da rede: Quanto mais, melhor. & Kemczinski et al. (2008) \\
\hline \multicolumn{4}{|c|}{ ATRIBUTOS DA ESTRUTURA: Comunicação } \\
\hline Forma de Comunicação: Direta e pessoalmente. Constante. & Kemczinski et al. (2008) & $\begin{array}{l}\text { Forma de Comunicação: Indireta por meio de canais } \\
\text { Intermitente. }\end{array}$ & Kemczinski et al. (2008) \\
\hline $\begin{array}{l}\text { Intensidade das Comunicações: Intensa, muitas reuniões } \\
\text { presenciais e em todos os níveis. }\end{array}$ & $\begin{array}{l}\text { Hord (1981); Kemczinski et al. } \\
\text { (2008) }\end{array}$ & $\begin{array}{l}\text { Intensidade das Comunicações: Menos intensas, com } \\
\text { menos reuniões presenciais. }\end{array}$ & Hord (1981); Polenske (2004); \\
\hline $\begin{array}{c}\text { Canais de Comunicação: Diálogo presencial, } \\
\text { essencialmente. }\end{array}$ & Ansell e Gash (2008) & Canais de Comunicação: Relatórios/TIC. & Kemczinski et al. (2008) \\
\hline $\begin{array}{l}\text { TIC na Comunicação: Síncrona, com videoconferência, } \\
\text { chat, ICQ, teleconferência, uso de sistemas online. }\end{array}$ & Kemczinski et al. (2008) & $\begin{array}{l}\text { TIC na Comunicação: Assíncrona, por e-mail, lista de } \\
\text { discussão, fórum, FAQ (Perguntas Frequentes), uso de } \\
\text { sistemas off-line. }\end{array}$ & Kemczinski et al. (2008) \\
\hline \multicolumn{4}{|c|}{ ATRIBUTOS DA ESTRUTURA: Poder } \\
\hline Poder: Mútuo, decidem em conjunto. & Kemczinski et al. (2008) & $\begin{array}{l}\text { Poder: Controle se mantém centrado em cada } \\
\text { organização. }\end{array}$ & Hord (1981); Polenske (2004) \\
\hline $\begin{array}{c}\text { Hierarquia do Poder: Hierarquizado, por ser vertical ou por } \\
\text { força de um dos atores. }\end{array}$ & Winckler e Molinari (2011) & $\begin{array}{l}\text { Hierarquia do Poder: Pode ser hierarquizado, devido à } \\
\text { maior força de um dos atores. }\end{array}$ & Winckler e Molinari (2011) \\
\hline Liderança: Mútua, lideres comandam juntos as equipes. & $\begin{array}{l}\text { Polenske (2004); Kemczinski et } \\
\text { al. (2008); Winckler e Molinari } \\
\text { (2011) }\end{array}$ & $\begin{array}{c}\text { Liderança: Unilateral, por parte da empresa que lidera o } \\
\text { processo. }\end{array}$ & Hord (1981); Polenske (2004) \\
\hline Responsabilidade: Mútua. & $\begin{array}{l}\text { Hord (1981); Balancieri (2004); } \\
\text { Ansell e Gash (2008) }\end{array}$ & $\begin{array}{l}\text { Responsabilidade: Corresponsáveis pelo produto e } \\
\text { sucesso. }\end{array}$ & Hord (1981) \\
\hline
\end{tabular}




\begin{tabular}{|c|c|c|c|}
\hline \multirow{2}{*}{\multicolumn{4}{|c|}{ ATRIBUTOS DA ESTRUTURA: Controle }} \\
\hline & & & \\
\hline Mecanismos de controle: Internos, junto ao processo. & Polenske (2004) & $\begin{array}{c}\text { Mecanismos de controle: Externos, que possibilitem ser } \\
\text { acessado de outras partes, como TIC. }\end{array}$ & $\begin{array}{c}\text { Polenske (2004); Kemczinski et } \\
\text { al. (2008) }\end{array}$ \\
\hline $\begin{array}{l}\text { Estrutura de Controle: Frágil, baseada na confiança por si } \\
\text { só nas relações, mas a sua falta pode gerar desconfiança. }\end{array}$ & Brna (1998); Hord (1981) & $\begin{array}{l}\text { Estrutura de Controle: Forte, bem estruturada, definiçãa } \\
\text { prévia de papéis, objetivos e resultados, e mecanismos de } \\
\text { apuração e comunicação. }\end{array}$ & $\begin{array}{l}\text { Hord (1981); Polenske (2004); } \\
\text { Kemczinski et al. (2008); Das e } \\
\text { Teng (1998) }\end{array}$ \\
\hline \begin{tabular}{|c|} 
Confiança: Existe por si só, importante fortalecer as relações, \\
sem muitos mecanismos de controle.
\end{tabular} & $\begin{array}{l}\text { Das e Teng (1998); Ansell e } \\
\text { Gash (2008) }\end{array}$ & $\begin{array}{l}\text { Confiança: Precisa de mecanismos de controle para } \\
\text { existir. }\end{array}$ & Ansell e Gash (2008 \\
\hline Contratos: Sem contratos,. & Brna (1998) & Contrato: Formalizado previamente. & $\begin{array}{l}\text { Hord (1981); Silva (2007); } \\
\text { Kemczinski et al. (2008) }\end{array}$ \\
\hline \multicolumn{4}{|c|}{ ATRIBUTOS DA ESTRUTURA: Riscos } \\
\hline Risco: Mútuo. Todos são afetados, pois participam juntos. & Hord (1981); Hord (1986) & $\begin{array}{l}\text { Risco: Dividido, cada um é responsável por sua parte, e } \\
\text { dividem ao longo processo os riscos. }\end{array}$ & $\begin{array}{c}\text { Polenske (2004); Kemczinski et } \\
\text { al. (2008) }\end{array}$ \\
\hline $\begin{array}{l}\text { Assimétricos: Apesar de mútuos, não são iguais, pois um dos } \\
\text { atores pode ser mais afetado. }\end{array}$ & Polenske (2004) & $\begin{array}{l}\text { Unilateral: Atinge apenas a uma parte do processo } \\
\text { devido à divisão clara de papéis. }\end{array}$ & Hord (1981) \\
\hline
\end{tabular}

Fonte: Autora, 2018

ATRIBUTOS DA ESTRUTURA: Controle acessado de outras partes, como TIC. $\quad$ al. (2008)

Estrutura de Controle: Forte bem estruturada definição Hord (1981); Polenske (2004);$$
\text { Teng (1998) }
$$
muitos mecanismos de controle.

Hord (1981); Silva (2007);

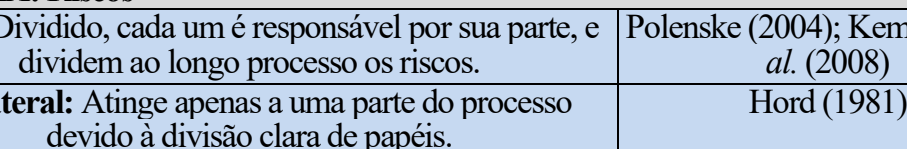

Fonte. Autora, 2018 
A matriz apresentada no Quadro 7 amplia o entendimento dos fatores que caracterizam cada um dos conceitos, possibilitando uma reflexão sobre os fatores determinantes para a decisão de colaborar ou cooperar. Dessa forma, a seguir se discute os fatores que incorporam o processo de decisão entre um conceito e outro, em ordem de prioridades, baseados nas dimensões que compõem essas relações.

\subsubsection{Fatores que definem a decisão de colaborar ou cooperar}

A definição por colaboração ou cooperação é baseada na necessidade ou desejo de fazer algo com outra organização, por necessidade de atender demandas de mercado ou para contribuir com algum projeto, de tal forma que se obtenha alguma vantagem, com base nos objetivos organizacionais para efetivação das alianças (POLENSKE, 2004; SILVA, 2007; WINCKLER; MOLINARI, 2011). Como ambas podem aumentar competitividade de uma empresa (POLENSKE, 2004), entender qual é a motivação para sua efetivação é primordial. Sendo assim, esses elementos antecedem a decisão de colaborar e cooperar, definidos como a dimensão Motivação Inicial

Nesse cenário, é válido ressaltar que o estabelecimento de relações de colaboração e cooperação levam tempo e dinheiro, por isso é importante avaliar, se o custo para auferir os benefícios é maior do que estes, ou se o ganho do outro é maior do que o custo da parceria. Além disso, estas relações envolvem fatores de aprendizagem e desenvolvimento organizacional, correndo-se o risco de transferência de conhecimento involuntária entre organizações ou mesmo entre países (POLENSKE, 2004). A confiança é outro fator crítico, exigindo que as organizações sejam capazes de sentir empatia uma pela outra, para aumentar o potencial de sucesso ao trabalharem juntas de alguma forma (HORD, 1981). A clareza dos objetivos, resultados esperados, definição de quem são os parceiros e porque é interessante trabalhar junto constroem a dimensão Escopo, que pode ajudar a decidir pelo modelo mais adequado aos interesses dos parceiros, e ajudar a estabelecer os fatores que constituem a dimensão Estrutura dos modelos de colaboração ou cooperação, como apresentado na Figura 3. 
Figura 3 - Fatores determinantes para a escolha por cooperar ou colaborar

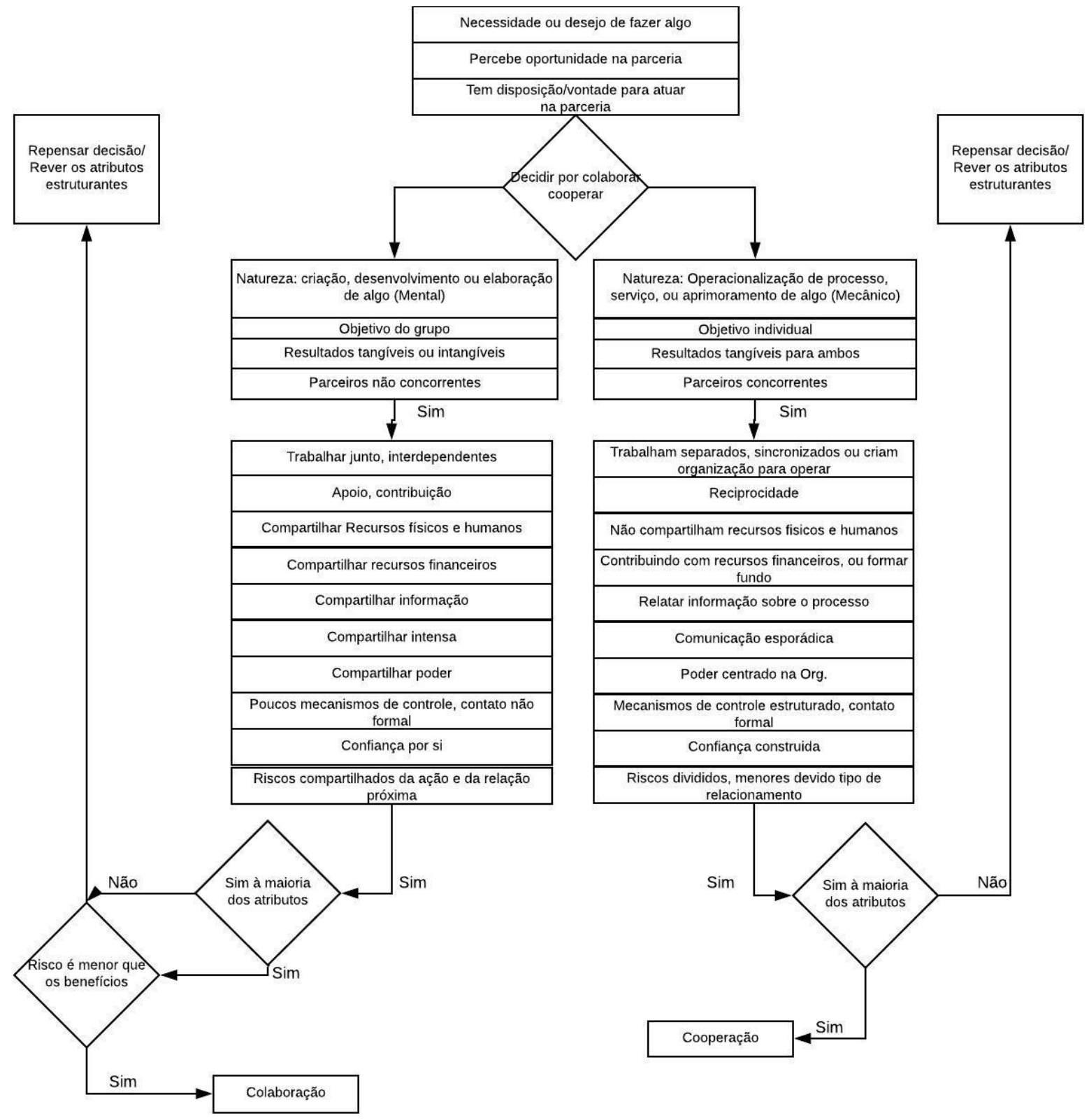

Fonte: Autora, 2016

As organizações que optam por colaboração precisam atuar no desenvolvimento, planejamento ou criação de algo que, de forma geral, atende essencialmente os objetivos do grupo, e traz resultados para todos os parceiros, sem a necessidade de serem tangíveis. A elaboração de uma lei, de um artigo acadêmico ou de uma pesquisa científica são exemplos que contemplam os 3 fatores iniciais que determinam a colaboração, pois nem todos receberão resultados tangíveis, mas todos se beneficiarão de alguma forma. Em questões de pesquisa ou desenvolvimento de leis, o uso de colaboração é mais apropriado, pois exigir limitação de 
papéis, pode inibir o processo de criação, deixando os atores desmotivados a participar plenamente.

Entretanto, a proximidade das relações é condição sine qua non da colaboração, exigindo que os atores envolvidos tenham menos temores com o relacionamento, estando mais abertos para assumirem riscos, compartilharem o controle e alimentarem a plasticidade das relações e processos, tornando o ambiente mais flexível e favorável ao sucesso (HORD, 1981). Segundo Rosas e Camarinha-Matos (2009) é importante que as empresas demonstrem a capacidade de aderir às regras de governança estabelecidas, seguir protocolos e estratégias acordadas, comprometer-se com os processos de negócios, prover o espírito de equipe entre os participantes, compartilhar recursos e trocar conhecimento. Por ser uma atividade na qual o controle não é rigoroso e as informações fluem de forma mais aberta, muitas vezes estendendose além do escopo do projeto, não é recomendável que ocorra entre atores concorrentes, a não ser que o risco de fortalecer o oponente seja menor do que o benefício recebido.

Já no caso da cooperação, as organizações vão buscar por esse tipo de processo quando há escassez de recursos, uma forte demanda está forçando essa situação, ou o desempenho está em risco (HORD, 1981), fazendo com que busquem alianças estratégicas para sobreviverem no mercado globalizado (SILVA, 2007), posto que o interesse é operacionalizar um processo, etapa ou serviço, pois a cooperação permite acesso ao mercado ou aproveitamento da capacidade ociosa de produção, sem comprometer a soberania de cada empresa (WINCKLER; MOLINARI, 2011). Nesse cenário, a definição de papéis e resultados esperados precisa ser estruturada por meio de contratos e mecanismos de controle, pois os atores não estão dispostos a atuar de forma muito próxima, correr riscos de transferências de conhecimento de forma involuntária e compartilhar recursos, mas sim somar, oferecendo o que têm de melhor para viabilizar o projeto. O foco é obter resultados tangíveis para as organizações, sendo possível atuarem como concorrentes (WINCKLER; MOLINARI, 2011).

De acordo com Silva (2007), a escolha pela cooperação é facilitada quando o governo cria políticas para favorecer um ambiente de negócios para cooperação, com estabilidade macroeconômica, arcabouço legal ágil e credibilidade, bem como infraestrutura revitalizada e diminuição dos juros para incentivar parcerias entre empresas. No caso de processos operacionais, com pessoas do mesmo setor ou de setores complementares, seja para fabricar um produto, operacionalizar um serviço ou trabalhar em cadeia, a cooperação mostra-se também mais adequada, pois cada parceiro tem seu papel, a troca de informação é menos intensa, e todos recebem os ganhos desejados. Além disso, os mecanismos de controle diminuem a insegurança e desconfiança entre os pares. 
A ausência de literatura que trate diretamente de colaboração ou cooperação em sistemas de logística reversa de REEE, exigiu que fosse desenvolvido um modelo global dos dois conceitos. Contudo, para atender o objetivo de diferenciar os conceitos, fez-se a opção por usar apenas autores que fizessem a distinção entre ambos para compilação dos atributos que os compunham. Esse procedimento excluiu autores que abordavam um dos termos ou ambos sem distinção, em assuntos considerados construtos essenciais da implementação da LR de REEE, como cadeia reversa e de suprimento, elaboração ou implementação de políticas públicas.

Dessa forma, a revisão de literatura e a consolidação dos atributos que compõem os conceitos de cooperação e colaboração efetuadas ao longo deste capítulo permitiram a elaboração de um modelo conceitual de processo de decisão entre os conceitos que visa facilitar a escolha por uma das formas de formulação de parcerias entre organizações, conforme apresentado na Figura 3. Este modelo será empregado como instrumento analítico dos processos de implementação da LR de REEE nos quatro países estudados, sendo detalhados a seguir os procedimentos metodológicos da pesquisa realizada. 


\section{MODELOS DE LR DE REEE E O IMPACTO DA COLABORAÇÃO E/OU COOPERAÇÃO NA IMPLEMENTAÇÃO E PERFORMANCE.}

Esse capítulo objetiva resgatar da pesquisa de dissertação da autora quais são os elementos que compõem a LR de REEE e os fatores que a motivam, assim como os que criam barreiras para sua efetivação. $\mathrm{Na}$ sequência, serão identificados e discutidos os principais fatores relacionados à colaboração e à cooperação que influenciam a implantação e funcionamento dos modelos internacionais de LR de REEE em países desenvolvidos e em países em desenvolvimento. Além disso, serão revistas as principais ações desenvolvidas até o momento para a implementação da LR de REEE no Brasil, considerando a Lei 12.305/2010 e o decreto que a regulamenta, para analisar os atributos contemplados nelas, e para avaliar se, a elaboração da lei bem como o tipo de sistema de LR solicitado por ela e descrito no decreto e no edital de chamamento estão de acordo com os atributos referentes a cada um dos processos, conforme definido no capítulo anterior.

\subsection{CONCEITO E DRIVERS DA LR DE REEE}

A LR é o processo de planejamento, implementação e controle do custo efetivo, do fluxo eficiente de matérias-primas, em processo de inventário, produtos acabados e informações relacionadas, desde o ponto de consumo até o ponto de origem, com o objetivo de recapturar valor ou descarte ambientalmente adequado, podendo ser incluídas em nele as atividades de remanufatura e recondicionamento (ROGERS; TIBBEN-LEMBKE, 1999). Para Brasil (2010a, p. 2), no entanto, LR é um instrumento de desenvolvimento econômico e social que envolve "um conjunto de ações, procedimentos e meios destinados a viabilizar a coleta e a restituição dos resíduos sólidos ao setor empresarial, para reaproveitamento, em seu ciclo ou em outros ciclos produtivos, ou outra destinação final ambientalmente adequada". Ambas as definições são caracterizadas por um conjunto de tarefas encadeadas, com o fluxo oposto ao das cadeias de suprimento, sendo o consumidor final o agente que inicia o processo e tendo como elo final desse sistema a disposição dos rejeitos de forma ambientalmente correta no meio ambiente ou o abastecimento da cadeia produtiva que recebe o produto resultante da LR (AUGUSTO, 2014).

A LR de REEE se inicia com o descarte do EEE, ao final do ciclo de vida, em postos de coleta específicos para este fim, com envio dos resíduos às centrais de consolidação, para que seja feita sua triagem por tipos, desmontagem e separação dos equipamentos em partes tóxicas, rejeitos que não são passíveis de reciclagem, mas não estão contaminados, materiais recicláveis 
e partes valiosas. As partes triadas são transportadas para aterros especiais para substâncias tóxicas, aterros, recicladoras e mineradoras de metais preciosos, respectivamente. Dessa forma, os materiais recicláveis retornam à cadeia produtiva (JANSE; SCHUUR; BRITO, 2009; JANG, 2010; LAU; WANG, 2009; MIGLIANO, 2012; AUGUSTO, 2014), conforme apresentado na Figura 4.

Figura 4 - Fluxo de materiais de LR de REEE simplificado

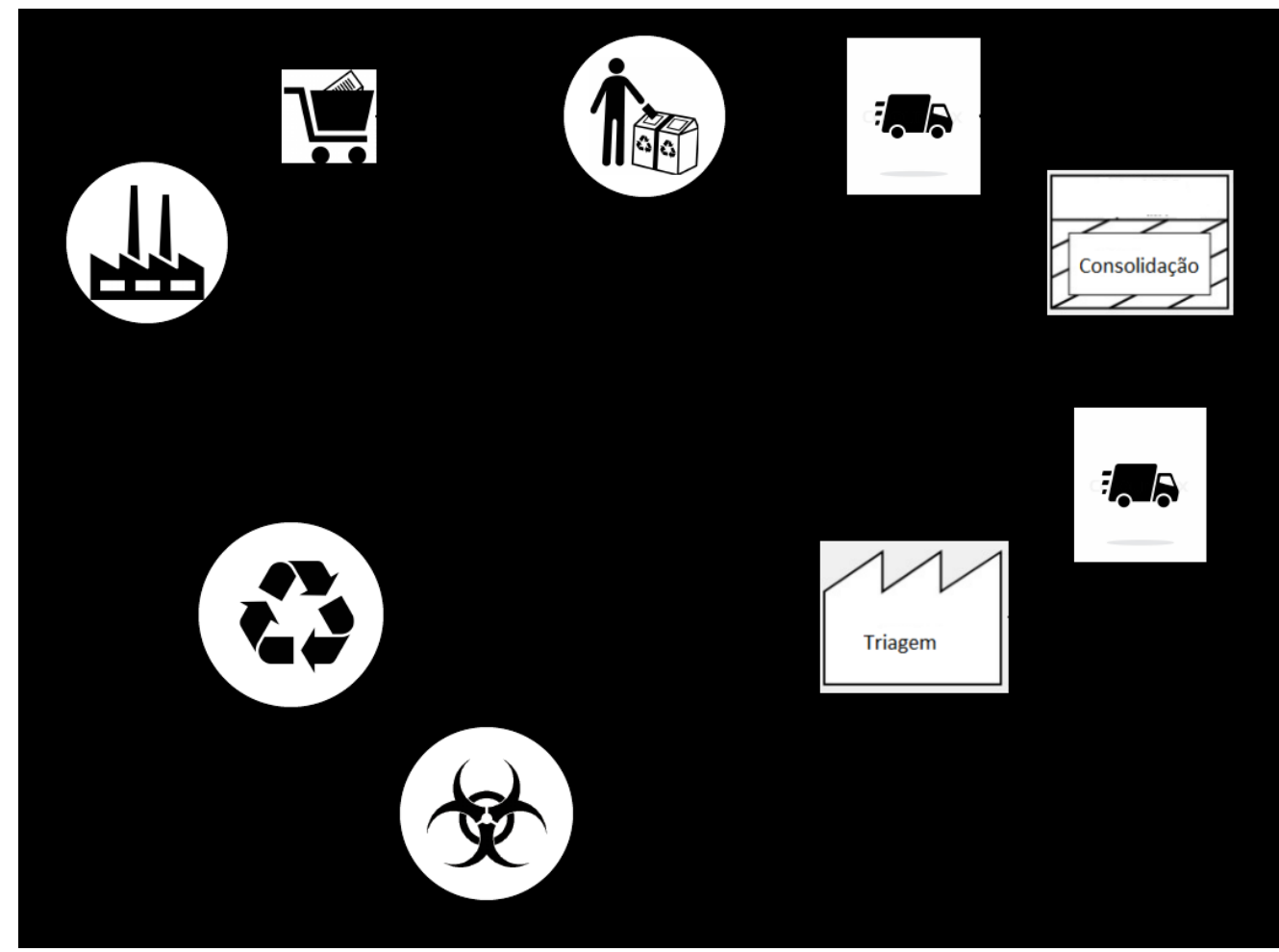

Fonte: Autora, 2018

Nesse cenário, a LR diminui os impactos ambientais causados pelos resíduos eletrônicos e aumenta os ganhos de eficiência e sustentabilidade das operações nas organizações (LEITE; LAVEZ; SOUZA, 2009). De fato, vários fatores contribuíram para o maior interesse pelos programas de LR por parte dos gestores e acadêmicos a partir da década de 1990, tais como a evolução da legislação ambiental (JAYARAMAN; LUO, 2007), a pressão dos consumidores e competidores e os benefícios para a imagem corporativa (JANSE; SCHUUR; BRITO, 2009; LAU; WANG, 2009).

Destaca-se ainda que o desenvolvimento de novos materiais que facilitam a reutilização e reciclagem de componentes de produtos contribui também para a inserção de LR em práticas de gestão (MIGLIANO, 2012). Segundo Araujo et al. (2012), o uso de Ecodesign para o desenvolvimento de novos produtos potencializa os resultados da LR na recuperação de 
materiais, facilitando e diminuindo o custo no desmonte dos REEE, além de reduzir o impacto ambiental devido às escolhas apropriadas de materiais menos tóxicos. O Ecodesign aumenta a taxa de reciclabilidade do produto, pois todo processo de criação é desenvolvido visando o fluxo reverso, principalmente quando projetado para retornar ao fabricante original do equipamento. Esses fatores potencializam os resultados econômicos do sistema reverso de ciclo fechado e aumentam a sua importância.

Segundo Torretta et al. (2013), o desenvolvimento econômico muda os hábitos da população, tanto em termos do uso doméstico de EEE, quanto em termos de tempo de vida destes dispositivos. Com efeito, com uma renda maior, as famílias tendem a fazer uso mais intensivo e diversificado dos EEE, assim como os trocam com maior frequência, tornando a coleta seletiva de REEE cada vez mais relevante. Além disso, o consumo é ampliado pelas políticas de obsolescência programada e perceptiva empregadas pelas empresas em suas estratégias.

Nesse contexto, as principais vantagens da LR para as organizações são: a obtenção de vantagem competitiva, redução de custo e impacto ambiental, perpetuação de recursos naturais e melhoria da imagem corporativa (AUGUSTO, 2014; DEMAJOROVIC; AUGUSTO; SOUZA, 2016).

Apesar da presença de fatores indutores, a literatura indica também barreiras para a implementação de LR. Os altos custos para implementação e manutenção de LR de REEE, relacionados à infraestrutura necessária para coletar resíduos ao fim do ciclo de vida e para reciclar ou reutilizar este material, faz com que a indústria de EEE adie os investimentos nesse sistema (JAYARAMAN; LUO, 2007). A complexidade das relações entre os diversos atores da cadeia reversa com interesses conflitantes configura-se como outra barreira para sua efetivação (ROGERS; TIBBEN-LEMBKE, 1999; LAU; WANG, 2009; MIGLIANO, 2012; AUGUSTO, 2014; DEMAJOROVIC; AUGUSTO; SOUZA, 2016). Esse fator é potencializado quando não há definição clara de papéis (MIGLIANO, 2012; AUGUSTO, 2014; DEMAJOROVIC; AUGUSTO; SOUZA, 2016), essenciais em parcerias cooperativas (SILVA, 2007; KEMCZINSKI et al., 2008, DEMAJOROVIC; AUGUSTO; SOUZA, 2016), impossibilitando a delimitação da atuação, a responsabilidade sobre a etapa e custos, a divisão de riscos e a clareza dos resultados esperados por cada ator. Todos esses elementos contribuem para construir mecanismos de controle e a confiança entre os membros envolvidos (DAS; TENG, 1998; VERSCHOORE; BALESTRIN, 2008; BALESTRIN; VERSCHOORE; REYES JUNIOR, 2010). Além disso, deficiências na legislação tornam este trabalho na cadeia ainda mais desafiador, por não oferecerem mecanismos que favoreçam e incentivem as relações de 
cooperação na cadeia reversa, tais como instrumentos de incentivo financeiros, tributários e fiscais (VERSCHOORE; BALESTRIN, 2008; SCHLUEP et al., 2009; BALESTRIN; VERSCHOORE; REYES JUNIOR, 2010; AUGUSTO, 2014; DEMAJOROVIC; AUGUSTO; SOUZA, 2016).

Outro desafio importante para os países em desenvolvimento é o papel do setor informal de catadores e recicladores que já operam com esse tipo de resíduo, sem nenhuma segurança e infraestrutura, o que traz ameaças à saúde dos seres vivos e ao meio ambiente. Em alguns casos, como na China, estes grupos dominam os meios para captar resíduos e sua exclusão levou ao fracasso da estruturação da LR em um projeto implementado em parceria com a ONU (WANG et al., 2012). Nesse sentido, entender quais são os atributos que contribuem para relações de cooperação são primordiais, tendo em vista que LR é um processo essencialmente cooperativo. Assim, a capacitação de atores que possam ou precisem atuar na cadeia, faz parte das responsabilidades dos atores envolvidos em ações de cooperação, não sendo apenas uma atitude de altruísmo.

A conscientização do consumidor e falta de clareza do seu papel como ator nesse sistema constitui outra barreira para o sucesso da LR. Na Coreia do Sul, por exemplo, o consumidor se recusava a participar caso não houvesse um incentivo financeiro em troca do descarte do aparelho celular de forma ambientalmente correta (AUGUSTO, 2014; JANG, 2010). Koga et al (2014) reforçam este argumento com uma pesquisa no Brasil que mostra que apenas $6 \%$ dos consumidores reciclam seu celular, 5\% o jogam no lixo e quase 50\% preferem deixá-lo guardado na gaveta. Entretanto, quando as operadoras de celulares premiaram o descarte correto desses aparelhos na troca por um novo modelo, a coleta aumentou 400\% em relação a outros períodos sem incentivo (AUGUSTO, 2014).

Neste cenário, vários modelos de gestão de LR foram criados nos países desenvolvidos e, mais recentemente, nos países em desenvolvimento. Mapear os elementos presentes que caracterizam cada um deles pode ajudar a entender quais são os fatores determinantes que motivam a colaboração e cooperação e como esses conceitos impactam a performance da LR de REEE.

\subsection{MODELOS INTERNACIONAIS DE LR DE REEE}

A Europa surge no cenário mundial como exemplo na implementação da LR de REEE devido aos números alcançados ao longo dos anos, desde a aprovação da Diretiva WEEE de 2002 (2002/96/EC), que estabelece normas e metas para o descarte correto de REEE em todos 
os países da UE. No entanto, diversos países começaram suas atividades reversas no setor de EEE antes da legislação da União Europeia (UE), antecipando-se até mesmo à entrada em vigor de leis nacionais, como é o caso da Suécia. Dessa forma, vários países membros da UE superaram as metas de coleta e reciclagem de $4 \mathrm{~kg} /$ ano por habitante logo que a diretiva entrou em vigor (YLÄ-MELLA et al, 2014), ajudados ainda pelo fato de que novos tipos de EEE, que antes não eram contabilizados ou não estavam inclusos no escopo dos sistemas de LR dos países europeus, foram incluídos. Esse resultado mostra que, apesar da legislação ser um forte indutor para a implementação de LR de REEE (LAU; WANG, 2009), existem outros elementos que a propiciam.

Outro fator que justifica o destaque dos países da Europa quanto aos resultados na implementação da LR de REEE é o avanço da legislação, que foi aprimorada com a aprovação da Diretiva 2012/19/EU, que revê a Diretiva 2002/96/EU, com metas muito mais audaciosas. Em 2016, os fabricantes de EEE terão que recolher 45\% da média total do peso de EEE colocados no mercado nos 3 anos anteriores. Esse número chegará a 65\% a partir de 2019, conforme apresentado no Quadro 8 (EUR-LEX, 2012).

Quadro 8 - Metas de coleta de REEE das Diretivas EU 2002/96 e 2012/19

\begin{tabular}{|c|l|}
\hline \multicolumn{2}{|c|}{ Diretiva 2002/96/EU } \\
\hline $\begin{array}{c}\text { Prazo } 31 \text { de } \\
\text { dezembro de } \\
2015\end{array}$ & $\begin{array}{l}\text { Pelo menos 4 kg de REEE/habitante provenientes de residências; ou o mesmo peso da } \\
\text { média da quantidade de REEE coletados no Estado-Membro nos 3 anos anteriores; } \\
\text { (qualquer um dos dois números que for mais elevado continua a ser aplicável). }\end{array}$ \\
\hline \multicolumn{2}{|c|}{ Diretiva 2012/19/EU } \\
\hline $\begin{array}{c}\text { De 2016 a } \\
2018\end{array}$ & $\begin{array}{l}\text { 45\% de EEE colocados no mercado, calculado com base em: } \\
\text { - peso total dos REEE coletados; e } \\
\text { - peso médio dos EEE colocados no mercado nos três anos anteriores. }\end{array}$ \\
\hline A partir de & $\begin{array}{l}\text { 65\% de EEE colocados no mercado, calculados com base em: } \\
\text { - peso total dos REEE recolhidos; e } \\
\text { - peso médio dos EEE colocados no mercado nos três anos anteriores. } \\
\text { ou } \\
85 \% \text { dos REEE gerados no território desse Estado-Membro (Estados-Membros serão } \\
\text { capazes de escolher qual das duas maneiras equivalentes para medir a meta desejam } \\
\text { comunicar.) }\end{array}$ \\
\hline
\end{tabular}

Fonte: Autora, “adaptado de” Eur-Lex, 2012, p. 8-9

A diretiva reformulada (2012/19/EU) entrou em vigor em 13 de agosto de 2012 e seus objetivos de coleta deverão ser atendidos de forma gradual até 2019. Entretanto, alguns Estados-Membros poderão prorrogar as novas metas, caso justifiquem baixo consumo de EEE ou falta de infraestrutura necessária (EUR-LEX, 2012; EUROSTAT, 2012).

A evolução do sistema de LR de REEE pode ser observada nos relatórios do Eurostat, escritório de estatísticas da UE que tem o objetivo de fornecer dados estatísticos para balizar as 
ações de desenvolvimento dos países pertencentes ao bloco (EUROSTAT, 2016). Os resultados mostram conquistas significativas dos países membros, com o aumento exponencial da coleta dos REEE entre 2005 e 2013. Suécia, Noruega, Dinamarca, Bélgica e Finlândia ocupam os 5 primeiros lugares, respectivamente, no ranking dos países da UE, no quesito quantidade de EEE, em quilogramas, coletados por habitantes ao ano, conforme apresentado na Tabela 1.

Tabela 1 - Coleta de REEE nos países da União Europeia

\begin{tabular}{|c|c|c|c|c|c|c|c|c|c|}
\hline TIME & 2005 & 2006 & 2007 & 2008 & 2009 & 2010 & 2011 & 2012 & 2013 \\
\hline Suécia & 4.79 & 12.702 & $15.027(\mathrm{~s})$ & 15.116 & $\begin{array}{r}15.39 \\
3\end{array}$ & 15.877 & 17.653 & 16.58 & 17.313 \\
\hline Noruega & $:$ & 7.87 & 14.918 & 13.112 & $\begin{array}{r}15.36 \\
4\end{array}$ & 15.798 & 16.576 & 15.064 & 14.192 \\
\hline Dinamarca & $:$ & 10.816 & 17.737 & 13.854 & $\begin{array}{r}14.97 \\
6\end{array}$ & 14.803 & 15 & 13.436 & 12.617 \\
\hline Bélgica & $6.503(\mathrm{~s})$ & $7.219(\mathrm{~s})$ & 7.637 & 8.118 & 9.147 & 9.341 & 9.991 & 10.06 & 10.336 \\
\hline Finlândia & 2.644 & 7.065 & 8.755 & 9.787 & 9.534 & 9.109 & 9.23 & 9.246 & 9.783 \\
\hline Luxemburgo & $:$ & 8.083 & 8.44 & 8.517 & 9.511 & 9.364 & 9.556 & 9.379 & 9.47 \\
\hline Áustria & 2.304 & 7.423 & 7.424 & 8.797 & 8.964 & 8.722 & 8.91 & 9.088 & 8.964 \\
\hline Liechtenstein & $:$ & $:$ & $:$ & : & $:$ & $:$ & 4.353 & 3.812 & 7.85 \\
\hline Alemanha & $:$ & $8.616(\mathrm{~s})$ & 6.29 & 7.822 & 9.435 & 8.836 & 7.914 & 7.723 & 7.649 \\
\hline Reino Unido & $:$ & $:$ & 3.008 & 6.816 & 7.353 & 7.379 & 7.886 & 7.673 & 7.403 \\
\hline Irlanda & $:$ & $:$ & 8.548 & 8.831 & 8.368 & 8.06 & 7.556 & 7.531 & 7.229 \\
\hline França & $:$ & 0.085 & 2.492 & 4.418 & 5.758 & 6.433 & 6.877 & 6.918 & 6.924 \\
\hline Países Baixos & 5.424 & 5.68 & 5.84 & 6.117 & 6.191 & 7.284 & 7.445 & 6.974 & 6.549 \\
\hline Lituânia & 0.807 & 2.752 & 3.496 & 3.54 & 2.159 & 2.85 & 3.779 & 4.477 & 5.204 \\
\hline Islândia & $:$ & $:$ & $:$ & : & 2.553 & 4.286 & : & : & 4.97 \\
\hline Hungria & $1.532(\mathrm{~s})$ & $2.365(\mathrm{~s})$ & 3.541 & 4.468 & 4.643 & 3.865 & 3.469 & 4.283 & 4.845 \\
\hline $\begin{array}{l}\text { República } \\
\text { Checa }\end{array}$ & $:$ & $:$ & 3.111 & 4.296 & 5.424 & 4.976 & 5.223 & 4.945 & 4.78 \\
\hline Portugal & $:$ & $0.4(\mathrm{~s})$ & 2.346 & 3.901 & 4.227 & 4.412 & 5.531 & 4.061 & 4.737 \\
\hline Bulgária & $:$ & $:$ & $2.805(\mathrm{~s})$ & $5.233(\mathrm{~s})$ & 4.446 & 6.045 & 5.277 & 5.158 & 4.668 \\
\hline Espanha & $:$ & $3.583(\mathrm{~s})$ & $5.966(\mathrm{~s})$ & $6.228(\mathrm{~s})$ & 2.697 & 3.189 & 3.087 & 3.127 & 4.328 \\
\hline Polônia & $:$ & 0.137 & 0.27 & 0.957 & 2.658 & 2.801 & 3.564 & 4.346 & 4.303 \\
\hline Eslováquia & 0.658 & 1.546 & 2.666 & 3.546 & 4.069 & 3.962 & 4.248 & 3.986 & 3.924 \\
\hline Eslovênia & $:$ & $:$ & 1.735 & 2.7 & 3.824 & 4.03 & 4.375 & 4.298 & 3.884 \\
\hline Itália & $:$ & $:$ & 1.989 & 2.661 & 3.67 & 4.279 & 4.199 & 3.69 & 3.473 \\
\hline Grécia & 0.009 & 0.871 & 2.601 & 3.999 & 5.658 & 4.006 & 3.589 & 3.25 & 3.36 \\
\hline Estônia & $:$ & 4.307 & 4.616 & 4.408 & 3.53 & 4.186 & 4.93 & 4.064 & 3.041 \\
\hline Malta & 0.106 & 0.088 & 0.017 & 0.04 & 1.409 & 3.363 & 3.183 & 2.854 & 2.858 \\
\hline Chipre & $:$ & $:$ & 3.142 & 2.876 & 2.818 & 3.109 & 3.132 & 2.819 & $2.595(\mathrm{e})$ \\
\hline Letônia & $:$ & $:$ & 2.794 & 2.795 & 1.949 & 1.988 & 1.888 & 1.885 & 2.366 \\
\hline Croácia & $:$ & $:$ & $:$ & $:$ & $:$ & $:$ & 2.265 & 2.269 & 2.122 \\
\hline Romênia & $:$ & $0.041(\mathrm{~s})$ & 0.163 & 0.876 & 1.663 & 1.148 & 0.955 & 1.036 & \\
\hline
\end{tabular}

Fonte: EUROSTAT, 2015, p.1

De 2005 a 2013, a coleta de REEE aumentou significativamente nesses países, chegando a $260 \%$ sobre a quantidade inicial. No caso da Finlândia, a coleta foi de 9,78 kg de REEE/hab/ano, seguida pela Suécia, com 253\% de aumento e 17,313 kg de REEE/hab/ano, ultrapassando aproximadamente em 3 vezes as metas estabelecidas pela Diretiva WEEE. Esses 
resultados mostram países com modelos de alta performance implementados, com fatores comuns na implementação e manutenção de LR de REEE. Apesar dos resultados positivos, a tabela mostra que outros países ainda não conseguiram alcançar as metas da Diretiva WEEE. O estudo sistemático desses países pode revelar elementos comuns que viabilizam a LR de REEE, bem como os fatores que funcionam como barreira para seu desenvolvimento. Considerando esses fatores, será possível relacioná-los com os atributos que compõem a colaboração e cooperação. Nessa perspectiva, pode-se entender qual é seu impacto nos processos que circundam a sua implementação e manutenção, assim como quais elementos não foram atendidos, entendendo sua influência nos resultados.

\subsubsection{Suécia}

A Suécia, considerada um modelo de sucesso em LR de REEE, começou a preparar sua legislação para gestão desses resíduos no final da década de 1990 (YLÄ-MELLA et al., 2014). Em 2001, fabricantes de EEE, representados pela ORP El-Kretsen, e as autoridades dos 290 municípios suecos estabeleceram o acordo do sistema de cooperação, baseado na responsabilidade do produtor. Nesse modelo, os municípios são responsáveis pelo sistema de coleta dos REEE e os fabricantes por todo o resto da LR de REEE, assegurando que serão transportados, tratados, reciclados e descartados de forma ambientalmente correta (SEPA, 2009; EL-KRESTSEN, 2016). A lei sueca foi revisada duas vezes, em 2005 e 2014, para atender à legislação da EU sobre REEE, Diretiva 2002/96/CE e 2012/19/UE, respectivamente (YLÄMELLA et al., 2014), conforme apresentado no Quadro 9.

Quadro 9 - Característica do sistema de LR da Suécia

\begin{tabular}{|l|l|}
\hline Legislação & 2001 - Entra em vigor a Lei de responsabilidade do produtor; \\
& 2005 - Revisão da Lei para atender à Diretiva 2002/96/CE. \\
& 2014 - Nova alteração da Lei para atender à Diretiva 2012/19/EU \\
\hline Financiamento & Taxa de reciclagem incluída nos preços dos EEE \\
\hline Coleta de REEE & 2002 - Lançamento da coleta separada \\
\hline ORP & 2 sistemas coletivos de coleta e de financiamento: \\
& (I) 2001 - El-Kretsen (pontos de coleta municipais e cobrança B2B) \\
& (II) 2008 - EÅF (coleta na loja) \\
\hline Quantidades coletadas de REEE & $2010-17,2 \mathrm{Kg} /$ per capita/ ano \\
\hline
\end{tabular}

Fonte: Autora, 2016, Adaptado de Ylä-Mella et al., 2014, p.12

Em 2008, a Swedish Association of Recycling Electronic Products (EÅF - Associação Sueca de Produtos Eletrônicos de Reciclagem - tradução nossa) foi lançada como uma ORP. A EÅF usa as lojas de seus membros como ponto de coleta. Nas cidades onde não há postos de 
coletas, contudo, ela é operacionalizada pela El-Krestsen, por meio de um acordo de compensação financeira, permitindo que seus membros paguem as mesmas taxas para reciclagem dos REEE que os membros da El-Krestsen (SEPA, 2009).

O sistema de coleta da Suécia começa com a entrega do equipamento eletrônico usado pelo consumidor, gratuitamente, aos pontos de coleta municipais que, na maioria dos casos, também funcionam como centros de reciclagem (ELRETUR, [2010?]). Nas últimas décadas surgiram diversas formas para realização do descarte do REEE e dos resíduos perigosos nos municípios. Além dos pontos fixos de coletas, o consumidor pode descartar seu REEE em caminhões que fazem a coleta seletiva desse tipo de resíduo em dias e itinerários fixos, solicitar ao município que faça a coleta a domicílio ou em postos localizados em supermercados, para dispositivos menores (BERNSTAD; LA COUR JANSEN; ASPEGREN, 2011; EL-KRETSEN, 2016). Atualmente, o sistema de coleta sueco conta com 10.000 caixas para descarte de baterias, 600 centros de reciclagem, 30 sites de reciclagem e mais de 1.500 .000 pontos de coleta em todo o país (EL-KRETSEN, 2016).

Após o recebimento dos REEE pelo município, eles são transportados para as instalações de reciclagem escolhidas pela El-Kretsen, que se responsabiliza pelo custo da LR a partir dessa etapa. Nas plantas de pré-tratamento, os produtos são descarregados e registrados, separados por tipo e desmontados. Nessa etapa são removidas as partes perigosas, que requerem um tratamento especial, definido conforme a Diretiva.

Depois da desmontagem e da separação mecânica, as frações dos dispositivos são encaminhadas às devidas recicladoras. As partes com potencial de reciclagem ou geração de energia são entregues às recicladoras, que podem pagar ou receber por elas, dependendo da expectativa de ganho ou custo envolvida no processo de reciclagem. Já as partes que contém substâncias tóxicas são entregues para os recicladores especializados em descontaminação e destinação ambientalmente correta, e os rejeitos, livres de sustâncias nocivas ao meio ambiente e à saúde, vão para aterros (YLÄ-MELLA et al., 2014). As principais etapas do sistema de LR de REEE na Suécia são apresentadas na Figura 5. 
Figura 5 - Sistema de LR de REEE Sueco

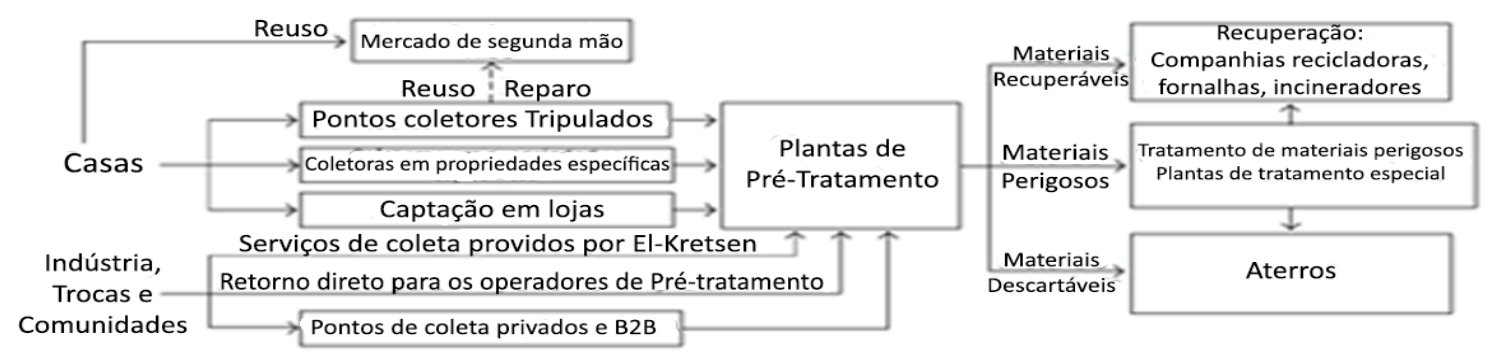

Fonte: Ylä-Mella et al., 2014, p. 10

Além dos REEE, EEE em funcionamento podem ser descartados em recipientes especiais, mas a El-Kretsen não está envolvida com o mercado de segunda mão. Sendo assim, as empresas responsáveis pelos pontos de coleta podem cuidar da reutilização desses equipamentos (YLÄ-MELLA et al., 2014).

A contratação das empresas de transporte e plantas de tratamento é feita por meio de concursos, pela El-Kretsen. As organizações que concorrem a uma vaga precisam atender a todos os requisitos ambientais e de qualidade, com base em cinco categorias diferentes: bens elétricos e eletrôni.cos variados, grandes produtos de linha branca, frigoríficos, freezers e iluminação. No caso do transporte, a quantidade de empresas é restrita a duas ou três com objetivo de otimizar as rotas e reduzir custos (YLÄ-MELLA et al., 2014). Todas as empresas concursadas obedecem a padrões de processos estabelecidos pelo sistema, regulamentados por Lei, e ao código de conduta anexado a todo contrato da El-Kretsen, segundo dados divulgados pela Elretur (ELRETUR, [2010?]).

Em 2007, a EPA - Environment Protection Agency (Agência de Proteção Ambiental tradução nossa) sueca elaborou diretrizes gerais sobre garantias financeiras que teriam que ser ofertadas pelos fabricantes e importadores de EEE para evitar problemas com custo dos REEE em caso de falências ou saída do mercado da organização, de modo a precaverem-se de problemas como free riders. Os membros do EÅF usam um seguro para assegurar a garantia financeira cujo valor é calculado com base nas vendas dos produtos e em seu custo de reciclagem. O prêmio de seguro vai para um fundo que financia os custos de reciclagem. Caso o produtor tenha algum problema, a companhia de seguros continuará a pagar os custos de reciclagem do produtor. A El-Kretsen criou um rol de medidas para assegurar sua operação, dentre as quais estão um capital operacional assegurando a sua exploração por um ano, uma conta bancária bloqueada, constituída por um fundo de reserva a ser apurado em favor da EPA sueca e um contrato de seguro coletivo para os produtores, de forma a assegurar o custeio em 
casos de falência ou saída do mercado, ou uma solução coletiva entre alguns membros (SEPA, 2009).

Nesse cenário, fabricantes e importadores que vendam quaisquer produtos incluídos na Diretiva REEE devem inscrever-se na EPA sueca para comunicar as quantidades vendidas, recolhidas e tratadas a cada ano civil, e comunicar a forma como é assegurada a garantia financeira. A agência sueca lida com o procedimento de registro relativo à Diretiva REEE que utiliza o registo EE. Esta é uma ferramenta de relatório eletrônico disponível no site (SEPA, 2009). Membros da EL-Kretsen também têm um formulário online no site da ORP para cadastrar a quantidade e volume em Kg dos produtos vendidos no ano (EL-KRETSEN, 2017).

Em 2007, foi criado um sistema de informação online para gestão da informação e maior otimização dos recursos da LR de REEE. Dessa forma, toda a logística ficou informatizada, permitindo que as transportadoras tenham acesso aos relatórios de estoque de todos os pontos de coleta para planejar e relatar suas remessas por meio de computadores portáteis. Com os dados das remessas cadastrados nos sistemas, os recicladores também podem checar quando serão feitas as entregas (YLÄ-MELLA et al., 2014).

O modelo sueco de LR de REEE está baseado em uma solução coletiva gerida por uma ORP, com operações centralizadas e otimizadas, gerando economia de escala por toda a cadeia, capilaridade na rede de coleta e eficiência ao processo. Entretanto, as empresas conveniadas são na maioria de grande porte, deixando uma parcela muito pequena para empresas sócias (YLÄ-MELLA et al., 2014).

O exemplo da Suécia aponta para a importância das parcerias com os governos locais e os varejistas, bem como entre os sistemas de reciclagem de REEE geridos por grupos distintos de fabricantes. O país tornou-se líder mundial na coleta de REEE em 2001 (SEPA, 2009) e se mantém como líder no fluxo de materiais de LR de REEE de acordo com Ylä-Mella et al. (2014). Dois fatores são considerados essenciais para esses resultados: capilaridade dos postos de coleta (SEPA, 2009; BERNSTAD; LA COUR JANSEN; ASPEGREN, 2011) e alta conscientização do consumidor sueco (YLÄ-MELLA et al., 2014).

$\mathrm{O}$ acordo firmado entre fabricantes de EEE, representados pela El-Kretsen, e autoridades locais, já no início das operações deu a base da eficiência da Suécia na coleta de REEE (SEPA, 2009). Além disso, com a entrada da EÅF, a capilaridade foi ampliada, facilitando o descarte dos REEE de forma separada dos resíduos domiciliares (SEPA, 2009). Segundo Bernstad, La Cour Jansen e Aspegren (2011), o aumento da acessibilidade e a proximidade dos postos de coleta específicos para REEE diminuíram em $76 \%$ a quantidade de REEE descartados junto com os resíduos secos, aumentando a eficiência do sistema. 
O segundo fator essencial para o sucesso da LR de REEE na Suécia é a alta conscientização dos consumidores suecos, devido ao seu comportamento engajado em causas ambientalmente e a sua disposição para fazer o descarte correto dos seus resíduos, de acordo com Ylä-Mella et al. (2014). Cidadãos suecos retornaram à reciclagem mais de $17 \mathrm{~kg}$ per capita por ano de REEE em 2013 (YLÄ-MELLA et al., 2014). A evolução da LR de REEE é percebida pela evolução da coleta de REEE, que era de 4 kg per capita em 2002 (SEPA, 2009). Em 2010, o modelo sueco já tinha atingido os objetivos estipulados para 2019 pela Diretiva 2012/19/EU, de 65\% dos EEE colocados no mercado nos três anos anteriores (YLÄ-MELLA et al., 2014).

Sendo a El-Kretsen, a ORP dominante do modelo sueco, a parceria com autoridades municipais e a EAF resultam em mais benefícios para a LR de REEE. Ao controlar toda a cadeia de recuperação de REEE, a El-Kretsen é capaz de oferecer soluções práticas e rentáveis, com a otimização do transporte dos pontos de coleta para centrais de tratamento, afirmam Ylä-Mella et al. (2014).

SEPA (2009) destaca a importância da participação das partes interessadas tanto no processo de elaboração da lei sueca, como na sua reformulação para atender às Diretivas europeias, pois muitos dos processos da LR foram decididos pelos produtores. Além disso, governo e indústria de EEE já estavam preparados para atender à legislação, pois já vinham criando alternativas para responder às pressões dos consumidores suecos, altamente conscientizados ambientalmente.

Ao analisar os atributos de colaboração e cooperação no modelo sueco de LR de REEE, percebe-se que ele é fortemente caracterizado pelo segundo conceito, conforme observado na Figura 6. 
Figura 6 - Comparação dos atributos de colaboração e cooperação com as características do Modelo de LR de REEE da Suécia

\begin{tabular}{|c|c|c|c|c|c|}
\hline $\begin{array}{l}\text { Necessidade ou desejo } \\
\text { de fazer algo }\end{array}$ & $\rightarrow$ & $\begin{array}{l}\text { Diminuir impacto e atender } \\
\text { consumidor }\end{array}$ & SEPA (2009) & $\leftarrow$ & $\begin{array}{l}\text { Necessidade ou desejo de } \\
\text { fazer algo }\end{array}$ \\
\hline $\begin{array}{c}\text { Percebe oportunidade } \\
\text { na parceria }\end{array}$ & $\rightarrow$ & Redução de custo, melhor gestão & Ylä-Mella et al (2014) & $\leftarrow$ & $\begin{array}{l}\text { Percebe oportunidade na } \\
\text { parceria }\end{array}$ \\
\hline $\begin{array}{l}\text { Tem disposição/ } \\
\text { vontade para atuar } \\
\text { na parceria }\end{array}$ & $\rightarrow$ & Sim, iniciativa voluntária & SEPA (2009) & $\leftarrow$ & $\begin{array}{l}\text { Tem disposição/ vontade } \\
\text { para atuar na parceria }\end{array}$ \\
\hline $\begin{array}{l}\text { Criação, } \\
\text { desenvolvĩento ou } \\
\text { elaboração de algo }\end{array}$ & $\mathrm{x}$ & Operacionalização da LR de REEE & Ylä-Mella et al (2014 & $\leftarrow$ & $\begin{array}{l}\text { Operacionalização de } \\
\text { processo, serviço, ou } \\
\text { aprimoramento de algo }\end{array}$ \\
\hline Objetivo do grupo & $\mathrm{x}$ & $\begin{array}{c}\text { Cada membro tem um objetivo, desde } \\
\text { as autoridades municipais, aos } \\
\text { operadores }\end{array}$ & $\begin{array}{l}\text { Ylä-Mella et al (2014), SEPA } \\
\qquad(2009)\end{array}$ & $\leftarrow$ & Objetivo Individual \\
\hline $\begin{array}{l}\text { Resultados tangiveis } \\
\text { ou intangiveis }\end{array}$ & $\mathrm{x}$ & $\begin{array}{l}\text { Eficiências para ORP e seus Gestores, } \\
\text { ganhos econômicos e de escala para } \\
\text { operadores, ORP e municipios. }\end{array}$ & $\begin{array}{l}\text { Ylä-Mella et al (2014), SEPA } \\
(2009)\end{array}$ & $\leftarrow$ & $\begin{array}{l}\text { Resultados tangiveis para } \\
\text { ambos }\end{array}$ \\
\hline $\begin{array}{l}\text { Parceiros não } \\
\text { Concorrentes }\end{array}$ & $\mathrm{x}$ & $\begin{array}{l}\text { Tem parceiros concorrentes do Setor } \\
\text { de EEE }\end{array}$ & $\begin{array}{l}\text { Bernstad, Jansen e Aspegren, } \\
(2011)\end{array}$ & $\leftarrow$ & Parceiros Concorrentes \\
\hline $\begin{array}{l}\text { Traballar junto, } \\
\text { interdependentes }\end{array}$ & $\mathrm{x}$ & $\begin{array}{l}\text { Trabalhar separados, sincronizados por } \\
\text { meio de ORPs e municipios }\end{array}$ & $\begin{array}{l}\text { Bernstad Jansen e Aspegren } \\
\text { (2011); Ylä-Mella et al (2014) }\end{array}$ & $\leftarrow$ & $\begin{array}{l}\text { Trabalhar separados, } \\
\text { sincronizados ou criar } \\
\text { organização para operar }\end{array}$ \\
\hline Apoio, Contribuição & $\mathrm{x}$ & Capilaridades, Escala & $\begin{array}{l}\text { Bernstad, Jansen e Aspegren, } \\
(2011)\end{array}$ & $\leftarrow$ & Reciprocidade \\
\hline $\begin{array}{l}\text { Compartilhar } \\
\text { recursos fisicos e } \\
\text { humanos }\end{array}$ & $\mathrm{x}$ & $\begin{array}{l}\text { Municipio faz a coleta, } O R P \text { contrata } \\
\text { empresas para operar a LR de REEE }\end{array}$ & $\begin{array}{l}\text { SEPA (2009): Bernstad Jansen e } \\
\text { Aspegren, (2011): Ylä-Mella et al } \\
\text { (2014) }\end{array}$ & $\leftarrow$ & $\begin{array}{l}\text { Não compartilham recursos } \\
\text { fís. e humanos }\end{array}$ \\
\hline $\begin{array}{l}\text { Compartilhar } \\
\text { recursos financeiros }\end{array}$ & $\mathrm{x}$ & $\begin{array}{l}\text { Formam fundo, e seguro garantia de } \\
\text { reciclagem }\end{array}$ & SEPA (2009) & $\leftarrow$ & $\begin{array}{l}\text { Contribuir com recursos } \\
\text { financeiros, ou formar } \\
\text { fundo }\end{array}$ \\
\hline $\begin{array}{c}\text { Compartilhar } \\
\text { informação }\end{array}$ & $\mathrm{x}$ & $\begin{array}{c}\text { Relatar informação sobre o processo, } \\
\text { Sistema online para informar produçã̃o } \\
\text { e operação }\end{array}$ & $\begin{array}{l}\text { Ylä-Mella et al (2014), SEPA } \\
(2009)\end{array}$ & $\leftarrow$ & $\begin{array}{c}\text { Relatar informação sobre o } \\
\text { processo }\end{array}$ \\
\hline Comunicação intensa & $\mathrm{x}$ & Relatórios informatizados & SEPA (2009); El-Kretsen (2016?) & $\leftarrow$ & Comunicação esporádica \\
\hline Compartilhar poder & $\mathrm{x}$ & $\begin{array}{c}\text { Poder fica em cada ORP, Empresas e } \\
\text { municipio }\end{array}$ & $\begin{array}{l}\text { SEPA (2009): Bernstad, Jansen e } \\
\text { Aspegren, (2011); Ylä-Mella et al } \\
\text { (2014) }\end{array}$ & $\leftarrow$ & Poder centrado na Org. \\
\hline $\begin{array}{l}\text { Poucos mecanismos de } \\
\text { controle, s/contrato } \\
\text { formal }\end{array}$ & $\mathrm{x}$ & $\begin{array}{l}\text { Contrato formal e mecanismo de } \\
\text { adesão e garantias }\end{array}$ & Ylä-Mella et al (2014), & $\leftarrow$ & $\begin{array}{l}\text { Mecanismos de controle } \\
\text { estruturado, contrato } \\
\text { formal }\end{array}$ \\
\hline
\end{tabular}

Fonte: Autora, 2016

Levando em conta que a operacionalização da LR é um processo tipicamente cooperativo devido às suas características e necessidades, pode-se inferir que o modelo de LR de REEE sueco usufrui do resultado da escolha adequada de parceria cooperativa, corroborando Polenske (2004) sobre a importância da diferenciação entre os termos e a escolha do tipo de parceria adequado para o sucesso do trabalho conjunto.

\subsubsection{Visão geral sobre os modelos de LR de REEE da Noruega, Finlândia e Itália}

É interessante notar que modelos baseados em soluções coletivas têm melhores resultados do que aqueles centrados em soluções isoladas (KHETRIWAL; KRAEUCHI; WIDMER, 2009). Além da Suécia, pode-se citar Noruega e Finlândia como exemplos de alta performance na gestão dos REEE na Europa (YLÄ-MELLA et al., 2014). Os autores destacam a similaridade dos modelos de LR de REEE de Suécia, Finlândia e Noruega, pois operam com modelos coletivos por meio das ORP e com uma ampla rede de coleta de REEE, formada por 
varejista e pontos e sistemas de coletas de REEE municipais. Além disso, os três países contam com um sistema de financiamento de reciclagem pago por uma taxa para este fim incluída no valor dos EEE no momento da compra. O consumidor, além de pagar a taxa, também desempenha um papel fundamental no resultado da coleta de REEE ao fazer o descarte correto devido a sua alta conscientização sobre da importância da destinação correta dos seus EEE ao final de vida. Diante desse cenário, esses três países podem servir de modelo para as outras nações que precisam implementar sua legislação nacional de REEE (YLÄ-MELLA et al., 2014).

A Itália é outro exemplo interessante do resultado positivo de ações coletivas, que envolveram todos os atores, do fabricante e governo ao consumidor, de forma coordenada e cooperativa. Apesar dos resultados atuais serem positivos, o país enfrentou sérios problemas no início, quando transformou as Diretivas RoHS (Restriction of the use of certain Hazardous Substances - Restrição de Certas Substâncias Perigosas, tradução nossa) e WEEE em lei nacional, em 2005, para implementar o sistema de LR de REEE italiano.

De fato, até 2008, os cidadãos não estavam envolvidos com a importância do descarte correto dos REEE, não havia uma rede de coleta seletiva integrada, nem fundos financeiros para manter a coleta organizada, e cada organização fazia uma parte de forma desconectada. Além disso, as leis não eram claras em relação aos papéis e definições de padrões de reciclagem. Diante disso, a maior parte do país não cumpria a legislação.

Esse cenário começou a se alterar com a mudança nas leis e a organização de sistemas de coleta de REEE nos Ecopontos municipais. A nova legislação estabeleceu papéis mais claros e classificou os REEE como históricos (aqueles produzidos antes de 2006) e atuais. Uma subclassificação dos REEE atuais definiu-os como residenciais (seu descarte deveria ser feito pelo consumidor gratuitamente nos postos de coleta) e profissionais (o produtor deveria fazer a retirada no local). Essas medidas iniciais, no entanto, alcançaram resultados mínimos.

Com o objetivo de envolver os cidadãos e garantir sua participação de forma cooperativa no descarte dos REEE, foi iniciada uma forte campanha de educação ambiental sobre os REEE e o consumo consciente. O programa fornecia informações de como, onde e porque fazer o descarte dos EEE ao fim de vida. No caso dos EEE residenciais, os fabricantes poderiam cobrar uma taxa ecológica embutida no valor de venda para custear a reciclagem, com exceção de equipamentos da linha branca de grande porte, ao qual a cobrança da taxa era feita de forma destacada na NF. Já no caso dos EEE profissionais, a reciclagem deve ser garantida pelos fabricantes. O sistema de reciclagem é operado por consórcios, aos quais os fabricantes aderem, pagando uma tarifa anual com base nos produtos vendidos. Os consórcios proporcionam à 
organização todas as atividades necessárias para a correta gestão e eliminação dos REEE, garantindo as normas de segurança fundamentais no processo de tratamento e eliminação e a obtenção de um elevado nível de recuperação de materiais. O resultado foi o aumento significativo da coleta de REEE, graças ao esforço coordenado de governo, empresas e consórcios de reciclagem (TORRETTA et al., 2013).

Os resultados de Suécia, Noruega, Finlândia e Itália evidenciam a importância da cooperação de todos os atores no sistema de LR de REEE, deixando claro que cada um tem seu papel. Além disso, demonstram como soluções coletivas podem oferecer uma série de benefícios para o desenvolvimento e manutenção de modelos de LR de REEE, que são complexos, caros e muitas vezes possuem atores com interesses conflitantes.

São necessárias, contudo, condições iniciais básicas para que exista colaboração ou cooperação: necessidade, oportunidade e benefícios, assim como a vontade de atuar em relações conjuntas (HORD, 1981; POLENSKE, 2004). Na LR de REEE, leis ou a pressão da sociedade e dos mercados são fatores determinantes para sua implementação. As oportunidades de trabalhar conjuntamente são muitas, conforme visto nos exemplos dos países até aqui abordados, mas é necessário ter também disposição para participar dessas parcerias (JANG, 2010).

\subsubsection{Brasil}

No caso do Brasil, a LR de REEE ainda não se efetivou, embora o Brasil tenha aprovado a Política Nacional de Resíduos Sólidos (PNRS) em agosto de 2010, que normatiza a gestão dos RS e define a obrigatoriedade de seis setores, entre eles, o setor de EEE, implementarem seus sistemas de LR, por meio da responsabilidade compartilhada entre os atores que formam sua cadeia direta. Portanto, fabricantes, importadores, distribuidores e comércio varejista de produtos EEE devem garantir o retorno dos seus produtos, após o uso pelo consumidor, dandolhes a destinação ambientalmente correta (BRASIL, 2010a).

A lei é considerada um marco regulatório na gestão de Resíduos Sólidos (YOSHIDA, 2012), com características e conceitos de Política Pública (AUGUSTO, 2014). Sua aprovação foi uma conquista importante para a sociedade, após tramitar por mais de 21 anos pelo Congresso Nacional (GUARNIERI, 2011). Na verdade, interesses conflitantes chegaram a retirar o setor de EEE da Lei, devido à pressão empresarial sobre o grupo parlamentar que a redigia. As organizações da sociedade civil, que acompanhavam o processo em tramitação, pressionaram os parlamentares envolvidos na redação da Lei fazendo com que o setor voltasse 
a integrar o artigo 33, que estabelece quais os setores que precisam implementar a LR (AUGUSTO, 2014).

Os interesses em conflitos ampliaram a discussão sobre a lei, e permitiram a inclusão de conceitos inovadores tais como responsabilidade compartilhada, acordo setorial, logística reversa, produtor-recebedor e inclusão social (GUARNIERI, 2011; REVEILLEAU, 2011; YOSHIDA, 2012). Por suas características inéditas, ela cria resistências, por vezes pelo fato de ainda ser novidade, mas sempre de alguma forma relacionadas aos custos (AUGUSTO, 2014). De acordo com Mendes et al. (2016), além dos novos custos, a LR de REEE traz novas responsabilidades para as empresas, impactando na forma de gestão, obrigando-as a repensar seus produtos e seu modelo de negócio, pois será necessário rever temas como responsabilidade corporativa, ecodesign, impacto ambiental e gestão de resíduos.

Percebe-se que, ao contrário de países onde a LR de REEE foi implementada de forma eficaz, como o caso da Suécia, no Brasil, o setor empresarial não participou de forma proativa para a regulamentação da LR. Nesse cenário, fica evidente que o governo brasileiro não conseguiu valer-se do conceito de governança colaborativa para validar a PNRS no período de elaboração, conforme apresentado por Ansell e Gash (2008). Nesse caso, para que a colaboração fosse possível, todos atores precisariam ter poder nas decisões, bem como a percepção de ganhos mútuos, participação no processos e objetivos comuns (ANSELL; GASH, 2008). Entretanto, esses atributos de colaboração não foram encontrados no processo de tramitação da lei (MIGLIANO, 2012; DEMAJOROVIC; AUGUSTO; SOUZA, 2016).

Em paralelo com o processo de elaboração e aprovação da PNRS, o arcabouço legislativo federal para a sustentabilidade foi criado a partir da década de 1980, de acordo com Migliano (2012). Além disso, de acordo com Xavier et al. (2013), estados como Minas Gerais, Paraná e São Paulo criaram leis sobre a gestão dos RS antes da aprovação da PNRS. Entretanto, essas leis precisaram ser revistas para se atualizar à lei federal. Para Yoshida (2012), o fato de muitos estados e municípios já possuírem legislação sobre seus resíduos anterior à aprovação da PNRS pode ser um fator complicador, já que será preciso harmonizar a normatização entre os três níveis federativos. De acordo com Ylä-Mella et al. (2014), países como a Suécia, que já possuíam legislação e sistema de LR de REEE em vigor, enfrentaram dificuldades para harmonizar suas leis com a Diretiva WEEE, atrasando a atualização legislativa nos parâmetros da UE.

Nesse cenário, o estado de São Paulo se destaca, pois foi o único a criar uma lei específica sobre resíduos tecnológicos, Lei $\mathrm{n}^{\circ}$ 13.576/2009, de acordo com Xavier et al. (2013). Para esta pesquisa é importante ressaltar que o Estado de São Paulo se destacou na questão da 
gestão dos REEE e avançou na implantação de sistemas de LR em diversos setores. O setor de telefonia móvel, por exemplo, assinou o termo de compromisso em junho de 2012, mas nenhuma empresa fabricante de EEE efetivou uma proposta com o Estado (AUGUSTO, 2014).

Outro progresso importante do Estado de São Paulo para viabilizar a LR foi a descaracterização dos REEE como perigosos, desde que não sejam submetidos à etapa de separação. Essa medida permite seu transporte primário ao ponto de coleta e o armazenado temporário, incluindo o transporte secundário, com o encaminhamento à unidade de beneficiamento ou tratamento, sem necessidade de obtenção do Certificado de Movimentação de Resíduos de Interesse Ambiental (CADRI), de acordo com a CETESB (2016). Entretanto, esses avanços não acontecem em nível nacional e muitos desafios ainda persistem para que seja possível a viabilização da LR de REEE no Brasil.

Muitos desses desafios, no entanto, estão relacionados à motivação dos atores para participarem da LR de REEE. Entre eles figuram a falta de vontade dos fabricantes, importadores e do governo de cooperarem entre si (MIGLIANO, 2012; OLIVEIRA; BERNANDES; GERBASE, 2012; DEMAJOROVIC; AUGUSTO; SOUZA, 2016), principalmente no que se refere a repartir custos (DEMAJOROVIC; AUGUSTO; SOUZA, 2016), além da falta de conscientização do consumidor sobre a importância do descarte correto do seu dispositivo eletrônico ao final de vida (AUGUSTO, 2014; OLIVEIRA; BERNANDES; GERBASE, 2013), já que, segundo Oliveira, Bernardes e Gerbase (2012), um dos fatores críticos para o sistema de coleta é a colaboração do consumidor para realizar o descarte correto do REEE.

A falta de interesse e a ausência de capacitação das cooperativas de catadores para atuarem com REEE é o outro desafio que precisa ser vencido (AUGUSTO, 2014), pois, de acordo com Mendes et al. (2016), a participação do setor informal nos países em desenvolvimento tem sido consenso, porque os trabalhadores informais costumam ser responsáveis pela maior parte do volume de REEE coletado. Demajorovic, Augusto e Souza (2016), por sua vez, afirmam que a participação destes atores na cadeia reversa pode gerar inovação, ganhos ambientais e econômicos, além de inclusão social.

Nesse sentido, para Xavier et al. (2013), as cooperativas poderiam se beneficiar econômica e socialmente ao agregar valor na gestão dos REEE, realizando atividades de préprocessamento, como na recuperação de metais que podem ser extraídos dos fios e cabos, desmontagem dos equipamentos para separar os materiais ou até mesmo dando uma segunda vida aos EEE. Uma experiência na China, mostrou que a a exclusão dos trabalhadores informais do sistema pode afetar significativamente a sustentabilidade do projeto (WANG et al., 2012). 
Apesar das cooperativas de catadores, serem responsáveis pela maior parte do material coletado e triado para reciclagem no Brasil, os dados conhecidos não incluem os REEE, pois as cooperativas não vêm valor nesse resíduo (OLIVEIRA; BERNARDES; GERBASE. 2012; AUGUSTO, 2014; DEMAJOROVIC; AUGUSTO; SOUZA, 2016). De fato, a sua participação na cadeia reversas dos REEE exige precaução para garantir que todo o processo seja feito de forma ambientalmente correta (OLIVEIRA; BERNARDES; GERBASE, 2012), pois os catadores carecem de capacitação em gestão administrativa e operacional para lidar com os REEE (DEMAJOROVIC; AUGUSTO; SOUZA, 2016). Nesse cenário, um dos pontos mais inovadores da PNRS pode não ser efetivado, devido à falta de interesse do setor de EEE em cooperar com a capacitação e inclusão dos catadores de materiais recicláveis na LR de REEE.

Os desafios descritos aqui são relativos à vontade de cada ator participar de forma cooperativa na LR de REEE. Com efeito, a vontade de participar é um dos atributos essenciais para a efetivação de parcerias, pois, mesmo havendo um fator que determina a necessidade de operar a LR de REEE, se não houver disposição, dificilmente a cooperação ou colaboração se iniciam (HORD, 1981; POLENSKE, 2004).

Nenhuma das barreiras ou desafios apresentados foram resolvidos até o momento (DEMAJOROVIC; AUGUSTO; SOUZA, 2016; MENDES et al., 2016). Existem apenas expectativas de mudanças de comportamento (MENDES et al., 2016) e encaminhamento de questões que o governo precisa resolver (ABINEE, 2015). A falta de empresas de reciclagem, assim como a conscientização do consumidor sobre a importância do descarte, só deve ser resolvida com a efetivação da LR de REEE, segundo Mendes et al. (2016). As questões sobre a periculosidade dos REEE, transporte primário e secundário e postos de coletas só foram resolvidas no Estado de São Paulo (CETESB, 2016). Em nível nacional, de acordo com a ABINEE (2015), as questões de periculosidade dos resíduos, do transporte fronteiriço e da titularidade do bem eletrônico foram encaminhadas para o Ministério do Meio Ambiente (MMA) e aguardam definição.

A questão de bitributação das taxas para financiamento do sistema, que devem ser cobradas no momento da venda do produto novo, por exemplo, só será tratada pelo governo após a assinatura do acordo setorial (AUGUSTO, 2014). No entanto, representantes da Associação Brasileira da Indústria Elétrica e Eletrônica (ABINEE) encarregados de tentar resolver todas as barreiras apontadas por eles mesmos antes de assinarem o AS, não conseguiram nem encaminhar a questão da taxa, intitulada de "ecovalor", para o Ministério da Fazenda (ABINEE, 2015). De fato, a bitributação pode onerar o valor do produto final e criar mais um problema, como a busca do consumidor por produtos contrabandeados, mais baratos 
e sem garantias de funcionamento, de segurança e à saúde e ao meio ambiente. Esses fatores podem afetar a sustentação financeira da operacionalização da LR e do setor de EEE brasileiro (DEMAJORIVIC; AUGUSTO; SOUZA, 2016). Outros desafios estão relacionados à forma como se deve implementar a LR, suas definições prévias e as exigências de conteúdo mínimo, que serão discutidas no item a seguir e relacionadas aos atributos estruturantes de colaboração e cooperação.

Nesse cenário, após oito anos da aprovação da PNRS, não se conseguiu chegar a um consenso e estabelecer um modelo de LR de REEE possível no Brasil (AUGUSTO, 2014; DEMAJOROVIC; AUGUSTO; SOUZA, 2016; MENDES et al., 2016). Assim, entender quais são as exigências da lei para balizar a construção do sistema de LR de REEE, os desafios que precisam ser superados e como estão sendo construídas as relações e a base para estruturar a sua operacionalização pode explicar como a colaboração e a cooperação podem impactar na sua efetivação e manutenção.

\subsubsection{Instrumentos para implementação da LR de REEE}

A PNRS instituiu a LR, responsabilidade compartilhada, acordo setorial e inclusão social como instrumentos para gestão dos RS.

No Brasil, optou-se pela responsabilidade compartilhada para implementar a LR, que determina aos fabricantes, importadores, distribuidores, comércio varejista e consumidores a responsabilidade pelo ciclo de vida do produto (BRASIL, 2010a). Assim, para abranger todos os atores, ela deve ser implementada de forma individualizada e encadeada. A operacionalização de um processo, realizada de forma individualizada, em etapas, é uma das características essenciais para a cooperação, pois cada ator é responsável por sua parte, podendo dar o melhor de si, sem perder sua soberania no processo (HORD, 1981; POLENSKE, 2004; SILVA, 2007). Esse instrumento objetiva: compatibilizar os interesses dos agentes envolvidos; reduzir a geração e o desperdício de resíduos; promover o aproveitamento dos resíduos devolvendo-os para cadeia produtiva; incentivar o uso de substâncias menos tóxicas; e estimular o desenvolvimento de um mercado de produção e consumo de produtos reciclados e recicláveis, por meio do aprimoramento da responsabilidade socioambiental e boas práticas (BRASIL, 2010a).

A Lei define quem deve fazer parte da responsabilidade compartilhada, mas não declara onde começa e onde termina a obrigação de cada membro. Mas é justamente a falta de papéis claros que gera tantos conflitos de interesse na discussão da implantação da LR, pois cada um 
dos atores envolvidos tenta diminuir ao máximo os custos que lhe cabem, reduzindo o seu papel (MIGLIANO, 2012; AUGUSTO, 2014). Contudo, a operacionalização de um processo é uma das características determinantes da cooperação, mas exige papéis claros, atividades separadas e resultados tangíveis para todos (POLENSKE, 2004). A diferença entre responsabilidade compartilhada e REP adotada em países como Suécia, Noruega, Finlândia, Itália e outros países da UE é que a responsabilidade compartilhada sobre o ciclo de vida do produto recai sobre todas as partes envolvidas e a REP apenas sobre o produtor (MENDES et al., 2016). Nesse caso, a responsabilidade do fabricante é clara, e a cooperação entre os outros membros é negociável, de forma a atender os objetivos individuais de cada um na participação do processo.

Apesar do governo não ter conseguido efetivar a colaboração dos atores envolvidos na elaboração da PNRS, ele escolheu o AS como principal instrumento para implementar a responsabilidade compartilhada, pois pretende alcançar o equilíbrio através do diálogo e a troca de informações sempre que possível. Tido como um dos elementos centrais da gestão compartilhada, o acordo setorial poderá ser firmado, através de contrato entre fabricantes, importadores, distribuidores e varejistas e o poder público, tendo como objetivo assegurar a implantação da responsabilidade compartilhada pelo ciclo de vida dos produtos, podendo ter abrangência nacional, regional, estadual ou municipal (BRASIL, 2010a; BRASIL, 2010b). Caso não seja possível, a LR de REEE poderá ser implementada também por meio de Termo de Compromisso ou Decreto (BRASIL, 2010a).

A elaboração do acordo setorial é uma atividade tipicamente colaborativa e o seu desenvolvimento tem respeitado a maioria dos atributos de colaboração, com a formação de GTs, que se reúnem presencialmente para discutir os termos do AS e fomentar a troca de informação. Entretanto, objetivos individuais não parecem convergir para o atendimento do objetivo comum, que consiste em estabelecer um AS para LR de REEE por meio de responsabilidade compartilhada, garantindo a isonomia de todos (AUGUSTO, 2014; ABINEE, 2015; DEMAJOROVIC; AUGUSTO; SOUZA, 2016). Segundo a ABINEE (2015), as reuniões dos GTs têm possibilitado discussões sobre as barreiras e permitido o encaminhamento das questões que não podem ser resolvidas por seus membros aos Ministérios referentes. A ABINEE (2015) afirma que o AS não será assinado antes de resolver os entraves legislativos. Segundo Ansell e Gash (2008), a governança colaborativa valida as decisões tomadas pelo grupo devido a sua participação, facilitando a implementação de leis complexas e inovadoras, pois cada membro se sente responsável pelo resultado final.

No caso da LR de REEE, o AS iniciou-se pelo Edital de Chamamento 01/2013 (MMA, 2013) que estabelece os objetivos, características, interessados, prazos e requisitos mínimos 
para o Acordo Setorial. No entanto, dois dos pontos mais conflitantes sobre os requisitos mínimos são as metas de coleta, estabelecidas em 17\% sobre os EEE colocados no mercado no ano anterior à assinatura do AS, e a quantidade mínima de pontos fixos de coletas, que não deve ser inferior a 1 por cada 25 mil habitantes.

Além disso, o conteúdo mínimo do AS prevê a possibilidade de contratação titular do serviço público de limpeza urbana e de manejo de resíduos sólidos em diversas etapas da LR de REEE, desde que determinada previamente a remuneração para execução do processo. Isto abarca a possibilidade de contratação de uma organização gestora para a operacionalização das etapas propostas no sistema a ser implantado, incluindo a possibilidade de participação de cooperativas (MMA, 2013).

Segundo o Instituto Ethos (2014), em 2014 o setor de EEE, em conjunto com a ABINEE, a Associação Nacional de Fabricantes de Produtos Eletroeletrônicos (Eletros), a Confederação Nacional do Comércio de Bens, Serviços e Turismo (CNC), a Associação Brasileira de Supermercados (Abras), o Instituto para Desenvolvimento do Varejo (IDV), a Associação Brasileira dos Distribuidores de Tecnologia da Informação (Abradisti) e o Sindicato Nacional das Empresas de Telefonia e de Serviços Móvel, Celular e Pessoal (SindiTelebrasil), representando, respectivamente, fabricantes, comércio, distribuidores e operadoras de celular, entregou uma proposta unificada ao MMA, que foi acolhida e avaliada como uma evolução do processo ao unificar as quatro propostas do setor apresentadas no ano anterior. O documento trata ainda de seis pontos pendentes, apresentados no Quadro 10. Entretanto, segundo o Instituto Ethos (2014), o MMA solicitou que fossem encaminhados ofícios para os outros ministérios do Comitê Orientador (CORI), pois os assuntos extrapolam as questões ambientais.

Quadro 10 - Seis pontos pendentes para o Acordo Setorial de LR de REEE

\begin{tabular}{|c|}
\hline $\mathrm{s}) \mathrm{Cl}$ \\
\hline $\begin{array}{l}\text { Reconhecimento da não periculosidade dos produtos eletroeletrônicos pós-consumo enquanto } \\
\text { não haja alteração das suas características físico-químicas }\end{array}$ \\
\hline $\begin{array}{l}\text { Criação de documento autodeclaratório de transporte com validade em território nacional de } \\
\text { forma a documentar a natureza e origem da carga, dispensando quaisquer outros documentos } \\
\text { para sua movimentação }\end{array}$ \\
\hline $\begin{array}{l}\text { Reconhecimento de que o descarte no sistema de logística reversa dos produtos eletroeletrônicos } \\
\text { implica a perda da propriedade }\end{array}$ \\
\hline $\begin{array}{l}\text { Envolvimento vinculante de todos os atores do ciclo de vida dos produtos eletroeletrônicos não } \\
\text { signatários do acordo setorial }\end{array}$ \\
\hline $\begin{array}{l}\text { Participação pecuniária, ainda em estudo, do consumidor para custeio da logística reversa, } \\
\text { destacada do preço e isenta de tributação, bem como instrumentos e mecanismos de compensação } \\
\text { e custeio para produtos órfãos }\end{array}$ \\
\hline
\end{tabular}

Fonte: Instituto Ethos, 2014, p. 1 
Entretanto, apenas dois desses entraves tiveram uma resolução. As associações dos produtores já criaram suas OGs - Operadoras Gestoras (ABINEE, 2016a; ABREE, 2016) e o governo federal publicou o Decreto 9.177/2017, estabelecendo que todas as empresas do setor de EEE terão as mesmas obrigações estabelecidas no AS, ainda que não sejam signatárias do Acordo, garantindo isonomia ao setor (ABINEE, 2017).

Em maio de 2018, as entidades representativas dos setores de varejo e indústria de EEE entregaram uma nova proposta de AS de LR de REEE, visando atender à PNRS (ABINEE, 2018).

\subsubsection{O modelo de LR de REEE proposto e o projeto piloto.}

Augusto (2014) descreve o modelo brasileiro de LR de REEE que está sendo discutido entre o governo e membros do setor. De acordo com a autora, no Brasil, o governo deverá desempenhar o papel de normalizador, criando as leis que atendem às especificidades do setor de REEE. O governo ainda deve criar incentivos fiscais, creditícios e financeiros para a implantação da LR de REEE com base na PNRS. As empresas vão criar uma OG, para operacionalização de toda a LR de REEE. Segundo Augusto (2014), ela será contratada no mercado brasileiro, com as etapas da LR sendo executada por ela ou por terceiros contratados para esse fim. Com o intuito de dar transparência ao processo, será criada uma entidade para auditar todas as empresas do processo reverso, assim como os resultados obtidos. Nesse modelo, o consumidor será responsável por entregar seus REEE sem custo nem incentivo, nos postos de coletas. O consumidor também pagará uma taxa no momento da compra de um novo produto, que será repassada à OG. Esse ainda é um ponto crítico, pois, como apontado anteriormente, não se conseguiu sequer encaminhar a questão da bitributação para o Ministério da Fazenda. Dessa forma, segundo a autora, essa questão só deve ser discutida após a assinatura e implantação da LR e depois de aferidos os resultados iniciais. No primeiro momento, a taxa ficará embutida no custo do produto.

O fluxo do material será iniciado com o descarte do REEE pelo consumidor nos pontos de coleta instalados no varejo. A retirada e transporte do ponto de coleta ao de consolidação será de responsabilidade da OG. É no ponto de consolidação que será feita a separação por marcas dos produtos, bem como o pré-armazenamento. Nas centrais de transbordo, os REEE serão descaracterizados e destinados à reciclagem, descontaminação e eliminação do rejeito final. O modelo discutido, contudo, não apresenta indícios de que incluirá as cooperativas (AUGUSTO, 2014). 
Além disso, alguns atores envolvidos na LR de REEE defendiam a criação de um projeto piloto para levantar dados sobre a quantidade de REEE que deverá ser gerado e descartado pelos consumidores, a fim de verificarem se as metas propostas pelo governo são exequíveis, mas o tema não era considerado pelo governo até então.

Esse é justamente a ausência que uma iniciativa do governo japonês, por meio do Agência de Cooperação Internacional do Japão - JICA, quis cobrir com a efetivação de um acordo de cooperação entre o governo federal brasileiro e a Prefeitura de São Paulo (ABINEE, 2016b). Esse acordo de cooperação foi firmado entre a JICA e o Ministério do Desenvolvimento, Indústria e Comércio Exterior (MDIC), o Ministério do Meio Ambiente (MMA), a Agência Brasileira de Cooperação (ABC) e a Prefeitura Municipal de São Paulo em 2014 (ABINEE, 2016b).

De acordo com Mendes et al. (2016), o governo brasileiro recebeu o apoio do JICA com o objetivo de levantar dados sobre a coleta de REEE de uso doméstico. Dessa forma será possível estimar a quantidade de REEE que podem ser coletadas, bem como sobre custo da operação, comportamento do consumidor, além de propor ações de melhoria na implementação da LR de REEE no país.

O acordo entrou em operação em 2014, com previsão de três anos de duração. Na primeira etapa, foi feita uma pesquisa para levantar dados sobre a geração de REEE e a situação das atividades de reciclagem. A segunda etapa, realizada em 2015, consistiu na elaboração do projeto piloto Descarte ON (PREFEITURA DE SÃO PAULO, 2014). Sua implementação foi realizada em maio de 2016 (ABINEE, 2016b). A última etapa foi realizada em 2017, na qual foi feita a avaliação dos resultados do projeto piloto, que darão subsídio técnico para a definição do modelo, estruturas envolvidas, custos e outros do modelo de LR de REEE a ser implementado na cidade de São Paulo. Serão igualmente oferecidas sugestões de melhorias a serem entregues ao governo federal do Brasil ao final das etapas (PREFEITURA DE SÃO PAULO, 2014; ABINEE, 2016b).

O projeto de acordo de cooperação do JICA com o Brasil poderá ajudar a entender quais são as motivações dos atores para cooperarem na LR de REEE no Brasil, quais foram os desafios enfrentados para o estabelecimento e a manutenção das relações, quais os atributos mais importantes para a definição do modelo a ser seguido na LR e quais os resultados aferidos por cada ator, conforme metodologia estabelecida no capítulo 4. 


\section{METODOLOGIA}

Segundo Vergara (2004), a ciência busca oferecer explicações para fenômenos de forma racional, mas discutível, pois não se trata de dogma. Por meio dela é possível construir uma estrutura que revela as suposições acerca de um tema. A presente pesquisa parte do princípio de que a escolha por colaborar ou cooperar pode trazer resultados diferentes nos processos de implantação e operacionalização da LR de REEE no Brasil, desde a elaboração da lei à sua execução. As suposições têm implicações diretas de ordem metodológica, direcionando a pesquisa à metodologia mais adequada (VERGARA, 2004). Dessa forma, o método dialético pode contribuir para o entendimento do impacto da colaboração e cooperação da LR de REEE no Brasil, já que o fenômeno é estudado dentro do seu contexto, que se configura como a totalidade do cenário da cadeia reversa dos REEE no país. É a contradição entre as teorias de colaboração e cooperação e seus resultados em outras áreas que permite a superação do uso delas como sinônimos, como observado ao longo da história dessas pesquisas (VERGARA, 2004). Assim, procura-se dar embasamento para o uso correto desses conceitos no contexto estudado, dadas as características dos processos de elaboração da lei e sua natureza, assim a implantação e operacionalização da LR de REEE comparando-os aos atributos descritos e diferenciados no referencial teórico de colaboração e cooperação.

\subsection{NATUREZA DA PESQUISA, FINS E MEIOS DE INVESTIGAÇÃO}

A pesquisa tem natureza qualitativa. No que se refere a tipos, usou as taxonomias de Vergara (2004) com fins exploratórios e descritivos e aplicou múltiplos estudos de caso como meios de investigação.

Para Godoi e Balsini (2010), a pesquisa qualitativa permite o entendimento de fenômenos sociais com o menor afastamento possível do ambiente, para que se possa compreender as motivações e intenções para agir dos agentes envolvidos, sem tentar enumerar ou encontrar regularidade nos drivers presentes. A escolha por uma abordagem qualitativa justifica-se para este projeto, pois seu objetivo consiste em entender o que motiva os atores da LR de REEE no Brasil a colaborar ou cooperar na elaboração e implementação da LR, viabilizando sua operação em um ambiente complexo, com interesses conflitantes (AUGUSTO, 2014). Além disso, pretende-se entender como essas relações colaborativas e cooperativas impactam os resultados da LR. 
A pesquisa exploratória é adequada para áreas que têm pouco conhecimento acumulado e sistematizado e a abordagem explicativa visa elencar as características de determinado fenômeno, estabelecendo correlações com suas variáveis e sua natureza, de acordo com Vergara (2004). Apesar do farto material encontrado sobre colaboração e cooperação na literatura, alguns textos datando de 1937 (PALMER, 1937), e da abrangência de áreas abordadas, não foram localizadas pesquisas que tratam desses conceitos na LR de REEE. Além disso, a literatura sobre LR de REEE no Brasil, Espanha e Portugal é muito escassa, justificando o caráter exploratório da pesquisa. Entretanto, poucos autores se dedicaram a diferenciar os conceitos de colaboração e cooperação, por suas características ou resultados, sendo que a grande maioria os trata como similares ou sinônimos (POLENSKE, 2004) sem o compromisso com a natureza conceitual nas áreas de economia, administração e marketing. Na LR de REEE, nenhum dos artigos que usava explicitamente as palavras colaboração e cooperação o fazia com a devida diferenciação. Nesse cenário, levantar quais são os fatores que compõem cada conceito, descrevê-los sistematicamente, relacionando-os à sua natureza, foi essencial para a pesquisa, dada a essência colaborativa do processo de elaboração e desenvolvimento de leis e a cooperativa da operacionalização da LR de REEE, conforme foi possível levantar durante a revisão bibliográfica, de acordo com a metodologia descritiva da pesquisa (VERGARA, 2004).

Para Yin (2005), o estudo de caso é adequado quando se precisa lidar com condições contextuais estritamente relacionadas ao fenômeno estudado e se trata de uma situação tecnicamente única, com muito mais variáveis de interesse como resultado. A estratégia permite o detalhamento e o aprofundamento nas relações, assim como a percepção das motivações para decisões, efetivação da ação, resultados esperados e alcançados (VERGARA, 2004; YIN, 2005). A pesquisa pode se dar tanto por meio de estudo de caso único, como de casos múltiplos (YIN, 2005), sendo que sua "unidade" pode ser definida por uma pessoa, família, empresa, órgão público ou até um país (VERGARA, 2004).

O presente estudo, justifica o uso da metodologia do estudo de casos múltiplos pela necessidade da identificação aprofundada das características dos fenômenos colaboração e cooperação na LR de REEE, no Brasil, Espanha, Portugal e Suíça. Nos três países europeus, foi possível analisar os resultados de um sistema de LR de REEE em funcionamento formalmente, o que trouxe elementos enriquecedores para os resultados, pois dois deles atendem às exigências legais da Diretiva de REEE da UR, e o outro, a Suíça, foi o primeiro país no mundo a implementar a LR de REEE, mesmo sem uma lei que a estabelecesse. Dessa forma, será possível comparar o cenário de países que já elaboraram suas leis e implementaram a LR de REEE, com o caso brasileiro, que ainda está em fase de elaboração do AS. 
A operacionalização da LR de REEE no Brasil será observada a partir do projeto Descarte ON. Esse projeto piloto é uma iniciativa inédita de LR de REEE no Brasil (ABINEE, 2016b), que atende ao caráter de situação tecnicamente única da metodologia de estudo de caso. O projeto faz parte de um acordo de cooperação entre o governo japonês, por meio do Japan International Cooperation Agency (JICA), o Ministério do Desenvolvimento, Industria e Comércio Exterior (MDIC), o Ministério do Meio Ambiente (MMA), a Prefeitura de São Paulo, por meio da Secretaria de Serviços e da Autoridade Municipal de Limpeza Urbana (AMLURB) e a Agência Brasileira de Cooperação (ABC), com apoio técnico da ABINEE.

As unidades escolhidas permitiram identificar os valores que assumem os atributos de colaboração e cooperação, as motivações para sua execução e os impactos que esses conceitos tiveram na LR de REEE nesses 4 países. Assim, os estudos de casos permitiram fazer uma descrição comparativa entre os países estudados, sistematizando os valores que cada atributo assumia dentro das 4 dimensões da colaboração e a cooperação, definidas a partir do marco teórico, para entender como motivação, delimitação de escopo e estrutura estabelecida para atuarem em parceria impactam nos resultados da LR de REEE no Brasil, Espanha, Portugal e Suíça (SAMPIERI; COLLADO; LUCIO, 2006). A Figura 7 representa a estrutura lógica da pesquisa fundamentando a escolha pelo estudo de caso:

Figura 7 - Estrutura lógica da tese

\begin{tabular}{|c|c|c|c|}
\hline \multicolumn{4}{|c|}{$\begin{array}{l}\text { Pergunta de Pesquisa: Como a colaboração e cooperação estão influenciando a } \\
\text { implementação do modelo de LR de REEE no cenário europeu e brasileiro? }\end{array}$} \\
\hline \multicolumn{4}{|c|}{$\begin{array}{l}\text { Objetivo Principal: discutir o impacto da colaboração e cooperação na } \\
\text { implementação do modelo de LR de REEE no Brasil }\end{array}$} \\
\hline \multicolumn{4}{|c|}{ Objetivos Específicos } \\
\hline $\begin{array}{c}\text { Discutir os } \\
\text { principais atributos } \\
\text { dos termos } \\
\text { colaboração e } \\
\text { cooperação }\end{array}$ & $\begin{array}{c}\text { Identificar os } \\
\text { elementos da } \\
\text { colaboração e } \\
\text { cooperação nos } \\
\text { modelos } \\
\text { internacionais de LR } \\
\text { de REEE } \\
\end{array}$ & $\begin{array}{l}\text { Aplicar os fatores } \\
\text { determinantes da } \\
\text { colababoração. e } \\
\text { cooperaçãp da LR de } \\
\text { REEE nos modelos } \\
\text { brasileiro e europeus }\end{array}$ & $\begin{array}{c}\text { Comparar os } \\
\text { modelos a partir dos } \\
\text { resultados de forma } \\
\text { a entender o impacto } \\
\text { da colaboração e } \\
\text { cooperação no } \\
\text { modelo brasileiro. }\end{array}$ \\
\hline \multicolumn{4}{|c|}{ Revisão da Literatura } \\
\hline & $\begin{array}{r}\text { Metodologia } \\
\text { Qualitativa, Explo } \\
\text { Estudo de Ca }\end{array}$ & $\begin{array}{l}\text { de Pesquisa } \\
\text { ratória e Descritiva } \\
\text { sos Múltiplos }\end{array}$ & \\
\hline \multicolumn{4}{|c|}{ Apresentação dos Resultados Categorizados } \\
\hline \multicolumn{4}{|c|}{ Discussão dos Resultados } \\
\hline \multicolumn{4}{|c|}{ Considerações Finais } \\
\hline
\end{tabular}

Fonte: Autora, 2018 
A pergunta de pesquisa tem como foco entender como a colaboração e a cooperação influenciam a implementação do modelo de LR de REEE. De fato, segundo Yin (2005), o estudo de caso é uma estratégia adequada para pesquisas para as quais se quer fazer perguntas com "como" ou "por que" sobre um conjunto de acontecimentos contemporâneos, sobre o qual o pesquisador não tem quase ou nenhum controle. A pergunta do presente trabalho atende ao primeiro componente do estudo de caso. Os objetivos específicos que visam elencar e discutir os atributos de colaboração e cooperação e identificá-los nos modelos internacionais de LR de REEE são atendidos pelo caráter exploratório e descritivo da pesquisa. Novamente segundo Yin (2005), o estudo de caso não é uma metodologia excludente, podendo ser complementar às abordagens exploratória e descritiva. Nesse contexto, é a delimitação das unidades para o estudo de caso múltiplo que permite atender ao terceiro objetivo específico. De forma complementar com as metodologias adotadas, elas atenderão o objetivo geral, permitindo responder à pergunta de pesquisa. Antes de passar para as etapas da coleta de dados e da estratégia de análise dos dados resultantes do campo, apresenta-se a estratégia de seleção de artigos para a construção da revisão da literatura, fundamental para a construção das categorias analíticas desta pesquisa.

\subsection{O PROCESSO DE SELEÇÃO DA LITERATURA}

A pesquisa bibliográfica realizada de forma sistematizada em material publicado em livros, revistas e redes eletrônicas forneceu o material para fundamentação teóricometodológica deste trabalho (VERGARA, 2004). Assim, foi possível criar um marco teórico sobre colaboração e cooperação, ajudando a prevenir erros cometidos em outras pesquisas, como a adoção dos conceitos como sinônimos, orientar sobre a forma de realização do estudo, com as definições dos elementos determinantes de cada tipo de parceria, e definir os pressupostos, que foram submetidos à prova nos 4 países estudados (SAMPIERI; COLLADO; LUCIO, 2006).

Antes de começar a pesquisa bibliográfica com base nas etapas iniciais da revisão sistemática da literatura, a pesquisadora recebeu quatro indicações de textos sobre colaboração e cooperação, sendo uma tese (GATTAZ, 2010) e três artigos (POLENSKE, 2004; ANSELL; GASH, 2008; WINCKLER; MOLINARI, 2011) que demonstraram a importância de entender a diferença entre os conceitos e seu impacto na elaboração de leis, bem como na implantação e operacionalização de processos, elementos essenciais para o tema central da pesquisa.

À luz da pergunta de pesquisa, iniciou-se uma busca nas bases de dados Proquest, Ebscoo e Science Direct. 
Nelas, primeiro foi feita uma busca que incluiu, nas palavras chaves, colaboração ou cooperação, alem de LR de REEE, assim como todos os seus sinônimos em português e inglês, conforme apresentado no Apêndice D, permitindo que o próprio sistema buscasse por palavras similares àquelas definidas. A pesquisa restringiu-se a artigos revisados, com textos completos, e aos campos título, resumo e palavra-chave. Entretanto, as pesquisas nas três bases de dados, Proquest, Ebscoo e Science Direct, não apresentaram nenhum resultado para esta busca.

Assim, testou-se buscar apenas por colaboração e cooperação, usando as mesmas restrições anteriores. Desta vez, retornaram mais de 60 mil resultados. Quando se repetiu, no entanto, a inserção de LR de REEE com o operador “AND” à mesma definição de busca, novamente não houve retorno para pesquisa em todas as três bases de pesquisa.

Dessa forma, dividiu-se a pesquisa da revisão sistematizada da literatura em duas etapas, uma que atenderia ao primeiro objetivo específico, discutir os principais atributos de colaboração e cooperação, e a outra levantaria modelos de LR de REEE que tivessem conteúdo suficiente para traçar seus modelos em países com alta performance nos resultados de sua implementação.

Para a primeira etapa, levantou-se duas proposições; a primeira definiu que a evolução das parcerias delimitou o escopo dos dois conceitos, colaboração e cooperação, que poderia explicar sua diferenciação. Esse fator estabeleceu a não determinação de um período de tempo nas buscas nas bases de dados, permitindo a construção dos conceitos a partir de uma revisão histórica sobre o tema. A segunda estabeleceu que as áreas de atuação dos temas precisariam ter alguma similaridade com a LR de REEE possibilitando a transposição analógica dos atributos de cada conceito aos modelos de LR de REEE. Nesse caso, foi levado em consideração que LR é uma cadeia reversa, que tem fluxos parecidos às cadeias de suprimentos de forma inversa, pertence ao setor de EEE, e, invariavelmente, trata da elaboração e implementação de uma política pública ou lei. Abriu-se, assim, o campo de pesquisa para essas áreas. Esses fatores, permitiram determinar as palavras chaves para a busca, conforme apresentado no Apêndice E.

Com a determinação das palavras-chaves e das restrições para resultado de artigos revisados, com textos completos, e aos campos título, resumo ou palavra-chave padronizou-se a busca nas três bases de dados, usando o operador booleano "AND" apenas entre os conceitos colaboração e cooperação e as áreas afins de LR de REEE, conforme apresentado no Apêndice F.

A busca retornou um total de 1912 artigos, distribuídos conforme a Quadro 11. O procedimento seguinte foi baixar e tabular todos os artigos. Cada texto foi identificado em uma 
linha da planilha por seu título, autores, ano, palavras chaves, área de estudo, periódico, resumo, país e um campo que identificava se fazia ou não diferenciação entre os conceitos de colaboração e cooperação.

Quadro 11- Resultado da pesquisa sobre colaboração e cooperação nas bases de dados

\begin{tabular}{l|c}
\hline \multicolumn{1}{c|}{ Base de dados } & Qtd. de Artigos \\
\hline Proquest & 1361 \\
\hline Ebscoo Host & 339 \\
\hline Science Direct $\quad$ Total & 212 \\
\hline & $\mathbf{1 9 1 2}$ \\
\hline
\end{tabular}

Fonte: Autora, 2016

Após a tabulação, foi realizada uma pré-seleção dos artigos, excluindo temas na área de saúde, alimentação e artigos repetidos. Optou-se, contudo, por manter artigos na área de educação, devido à necessidade de transferência de conhecimento na implantação da LR de REEE e de conscientização sobre sua importância. Após essa etapa, selecionou-se 122 artigos que abordavam em seus títulos ou resumos temas sobre redes de colaboração ou cooperação, supply chain, logística, logística reversa, revisão histórica dos conceitos, teorias, gestão participativa/colaborativa, modelos de colaboração e cooperação que determinassem fatores críticos de sucesso, construtos ou métricas, além de artigos que abordassem a indústria de EEE ou REEE.

Entretanto, a busca mostrou o que os textos iniciais já tinham apresentado: poucos autores diferenciam os conceitos. Dessa forma, foram feitas mais duas buscas, uma no Google Scholar, que resultou em 15 artigos novos, e em outra na base de dados CAPES, com mais 19 textos. Em ambos os casos, as buscas se restringiram ao uso das palavras-chaves colaboração e cooperação, com o operador booleano "AND" entre elas e o "OR" entre os pares de seus sinônimos em português e inglês.

O capítulo de revisão da literatura sobre os conceitos colaboração e cooperação foi dividido em dois grandes itens basicamente: de um lado, a revisão histórica das pesquisas sobre o tema, que ofereceu uma visão ampla de como eles têm sido tratados desde o século XIX e, de outro, a diferenciação entre os conceitos e a discussão dos seus atributos.

A segunda etapa das buscas para construção do referencial teórico tratou dos modelos de LR de REEE implementados no mundo. Nessa etapa, usou-se como palavras-chaves: REEE “OR” Resíduos de Equipamentos Eletro Eletrônicos “OR” Waste Electrical and Electronic Equipment “OR” WEEE “OR” lixo eletrônico “OR” e-waste “OR” Electronic Waste. Sempre 
com o operador booleano "OR" para aumentar o potencial da busca, mas mesmas bases de dados: Proquest, Ebscoo, Science Direct e CAPES. O resultado das buscas foi classificado por países. E, em seguida, verificou-se quais países possuíam material suficiente para identificar o modelo de implementação e operação e os atributos sobre colaboração e cooperação. Apenas Suécia apresentou conteúdo suficiente para atender ao segundo objetivo específico: identificar os atributos de colaboração e cooperação nos modelos internacionais, pois os outros países deixavam muitas lacunas na matriz dos conceitos, devido à falta de literatura sobre esse tema, apresentada no capítulo 2 .

\subsection{COLETA DE DADOS}

De acordo com Vergara (2004), o método de pesquisa define a forma como serão coletados os dados na pesquisa. No caso da pesquisa fenomenológica ou dialética, os dados são coletados durante a observação, nas histórias de vida, em entrevistas e questionários não estruturados, em países, empresas, organizações em geral, em conteúdo de textos; em tudo que lhe possibilite refletir sobre as interações e processos. Para Yin (2005), a observação e as entrevistas com as pessoas envolvidas no momento do acontecimento diferenciam-na dos estudos históricos, oferecendo ampla variedade de técnicas de coletas de dados.

Para a presente pesquisa, optou-se por coletar os dados primários por meio de estudo de caso múltiplo, com observação de campo, análise de documentos e leis, e entrevistas em profundidade a partir de roteiro semi-estruturado.

A observação de campo na Espanha e Portugal se deu nos departamentos acadêmicos de pesquisa que estudam sobre o tema, no comércio local, em lojas e supermercados que poderiam ou deveriam receber REEE, nos pontos de coleta seletiva municipais, assim como nos departamentos responsáveis pela gestão desses resíduos em instituições universitárias e órgãos municipais, para entender como a estrutura de LR foi construída e entendida por esses atores e como os consumidores se comportam diante dela.

No Brasil, essa observação foi realizada com dois grupos: os atores que discutem a LR de REEE no AS e os membros envolvidos na elaboração e operacionalização do PP. Uma fonte importante de dados para esta pesquisa foi a participação da autora na comissão de estudos CE 111 do Comitê Brasileiro de Eletricidade e da Associação Brasileira de Normas Técnicas (ABNT), que retomou suas atividades em novembro de 2016 com o objetivo de tratar da elaboração de normas e documentos específicos para a cadeia reversa de REEE e para controle de substâncias perigosas nos EEE. Para potencializar os resultados dessa ação, a pesquisadora 
participou dos dois Grupo de Trabalho (GT) formados na ocasião da reabertura do CE 111, o GT sobre LR de REEE e a respeito da RoHS em EEE. O primeiro grupo, de LR de REEE, discute a revisão da ABNT NBR 16156:2013 que regula as atividades de remanufatura de EEE com o objetivo de criar um guia para uso da norma. O segundo discute normas de análise química para determinação de presença das substâncias restritas pela Diretiva Européia RoHS. Estes espaços também são importantes como fontes de material documental. Para esta pesquisa, acompanhar estes grupos foi fundamental, uma vez que a comissão é composta por vários membros do Acordo de cooperação com o JICA para implementação da LR de REEE no Brasil e do Acordo Setorial de LR de REEE, representantes do governo federal, estadual e municipal, fabricantes de EEE e representantes das atividades relacionadas à cadeia de EEE, como varejistas, recicladores e cooperativas de catadores de materiais recicláveis, assim como representantes das associações que representam os atores mencionados, além de institutos de pesquisas e da academia. A participação nessas comissões permitiu o aprofundamento dos elementos abordados nos objetivos específicos, para ajudar a responder à pergunta de pesquisa, além da aproximação com os membros do acordo de cooperação do JICA e a identificação de atores que participam do acordo setorial, mas não faziam parte do projeto. No caso do JICA, como a observação de campo ocorreu depois da execução da parte prática do PP, foi possível observar as reuniões dos comitês do DescarteON, que visavam apresentar os resultados de sua operacionalização e levantar insights sobre os aprendizados obtidos nelas para sugerir propostas de melhorias ao AS.

Nos quatro países escolhidos foram estudados documentos cedidos pelos principais atores e órgãos públicos envolvidos na LR de REEE, como relatórios de operacionalização, informações sobre os resultados das etapas de implementação de infraestrutura da LR e mapeamento de cenários, propostas de projetos e leis em andamento, bem como diários oficiais que continham leis e normas sobre a gestão dos REEE. As entrevistas foram feitas com atores envolvidos no processo de decisão ou operacionalização da LR dos quatro países e expandindo para consumidores na Espanha e Portugal.

O Quadro 12 apresenta a relação de atores que foram entrevistados por setores, instituições ou papeis e países na LR de REEE. 
Quadro 12 - Relação dos atores entrevistados

\begin{tabular}{|c|c|c|c|}
\hline $\begin{array}{l}\text { Sigla } \\
\text { Ator }\end{array}$ & Brasil & Instituições ou Papéis & Qtd. \\
\hline BGF & Governo Federal & MDIC, CTI & 2 \\
\hline BGE & Governo Estadual & CETESB & 2 \\
\hline BGM & Governo Municipal & AMLURB & 1 \\
\hline BPD & Produtores, Distribuidores e Associações de EEE & ABINEE, ELETROS & 3 \\
\hline $\mathrm{BCV}$ & Comércio e Associações Varejistas & APAS, Pão de Açúcar, FAST & 3 \\
\hline $\mathrm{BRC}$ & $\begin{array}{l}\text { Entidades Gestoras, Recicladores e Cooperativas } \\
\text { de Catadores de Materiais Recicláveis }\end{array}$ & $\begin{array}{l}\text { Entidade Gestora X e Y, ONIX, } \\
\text { FOX }\end{array}$ & 4 \\
\hline $\mathrm{BJC}$ & Japan International Cooperation Agency & JICA & 2 \\
\hline \multicolumn{4}{|c|}{ Espanha } \\
\hline EGF & Governo Nacional & MAPAMA, MINECO & 2 \\
\hline EGM & Governo Municipal & $\begin{array}{l}\text { Consejeria de Medio Ambiente } \\
\text { San Vicente del Raspeig }\end{array}$ & 1 \\
\hline ERC & $\begin{array}{l}\text { Entidades Gestoras, Recicladores e Cooperativas } \\
\text { de Catadores de Materiais Recicláveis }\end{array}$ & $\begin{array}{l}\text { Braceli, Ecotic, Ferrovial, } \\
\text { Recyclia }\end{array}$ & 6 \\
\hline EAC & Universidades/ Institutos de Pesquisa & Pesquisadores de REEE & 3 \\
\hline \multicolumn{4}{|c|}{ Portugal } \\
\hline PGF & Governo Federal & APA & 1 \\
\hline PGM & Governo Municipal & Câmara Municipal de Lisboa & 2 \\
\hline PRC & $\begin{array}{l}\text { Entidades Gestoras, Recicladores e Cooperativas } \\
\text { de Catadores de Materiais Recicláveis }\end{array}$ & AMB3E & 1 \\
\hline PAC & Universidades/Institutos de Pesquisa & Pesquisadores de REEE & 2 \\
\hline \multicolumn{4}{|c|}{ Suíça } \\
\hline SGF & Governo Federal & $\begin{array}{l}\text { FOEN (Federal Office for the } \\
\text { Environment)/ Municipal Waste } \\
\text { Section, EMPA (Swiss Federal } \\
\text { Laboratories for Materials } \\
\text { Science and Technology) }\end{array}$ & 2 \\
\hline $\mathrm{SRC}$ & $\begin{array}{l}\text { ORP (Organizações de Responsabilidade do } \\
\text { Produtor) }\end{array}$ & SENS, SWICO & 2 \\
\hline
\end{tabular}

Fonte: Autora, 2018

Não houve uma definição do número exato de entrevistas a serem realizadas, sem a preocupação de representatividade estatística, por se tratar de uma pesquisa qualitativa. De acordo com Godoi e Mattos (2010), a relação de participantes do processo de estudo deve ter como base o desenvolvimento do trabalho teórico, de tal forma que, caso necessário, o pesquisador possa elencar novos entrevistados ou aprofundar as questões de entrevistas com os participantes e voltar a campo para melhorar a compreensão analítica sobre o tema.

Definidos os setores, o acesso aos entrevistados ocorreu primeiramente por telefone ou mensagem eletrônica personalizada, com o objetivo de agendar uma entrevista pessoalmente com o responsável nomeado de cada setor envolvido no projeto de cooperação com o JICA e o AS, no caso do Brasil, e nos sistemas de LR de REEE em Portugal, Espanha e Suíça. No Brasil, além dos atores envolvidos no AS e no PP, foram entrevistados representantes dos setores elencados na lei, mas que não participaram do AS ou do projeto JICA, seja porque não quiseram ou porque não tiveram a oportunidade de fazê-lo. Após a anuência, cada candidato recebeu por e-mail o resumo e os objetivos da pesquisa, com exceção dos consumidores. As observações 
do estudo de caso foram realizadas nas lojas responsáveis pelo recebimento dos REEE, na cooperativa, nas recicladoras, nos pontos de coleta de REEE em todos os países estudados, além de contarem com a participação da pesquisadora nas reuniões do projeto de cooperação do JICA e em seminários relativos ao tema no Brasil e na Espanha.

Um roteiro preliminar de entrevista semi-estruturado foi elaborado para elencar e descrever os atributos de colaboração e cooperação existentes nos casos brasileiro, português, espanhol e suíço. O roteiro foi construído a partir das quatro dimensões da colaboração e cooperação: motivação, escopo do projeto, estrutura e impactos na LR de REEE definidas a partir da revisão sistemática da literatura, por meio do cruzamento dos principais elementos da LR desse setor e dos fatores que compõem os dois conceitos no âmbito da administração, pesquisa e educação. Em cada país, foi investigado o histórico que determinou a adoção do modelo de LR de REEE e sua operação. No caso do Brasil, devido à falta de efetivação da LR de REEE, adotou-se o DescarteON, Projeto de Cooperação do JICA para o estudo da cooperação. No caso da investigação sobre colaboração foi analisado o processo de desenvolvimento da PNRS e a elaboração do AS de EEE. Dessa forma, foi possível entender como os dois conceitos foram utilizados no processo de formulação da legislação e na operacionalização dos sistemas de LR de REEE. A análise permitiu revelar o impacto da colaboração e cooperação nos casos estudados no Brasil, Portugal, Espanha e Suíça. O roteiro foi desenvolvido para servir de guia nas entrevistas dentro do tema proposto, proporcionando ao entrevistado flexibilidade em suas respostas, de forma a incorporar novas questões e interpretações da realidade pesquisada (GODOI; MATTOS, 2010). O Quadro 13 define o foco de identificação de cada atributo dentro das dimensões. 
Quadro 13 - Roteiro de pesquisa

\begin{tabular}{|c|c|c|}
\hline \multicolumn{3}{|c|}{ Atributos Motivacionais comuns à colaboração e cooperação } \\
\hline Dimensões & Atributos & Foco \\
\hline \multirow[t]{3}{*}{ Motivação } & $\begin{array}{l}\text { Necessidade } \\
\text { ou desejo de } \\
\text { fazer algo }\end{array}$ & $\begin{array}{l}\text { Entender qual a motivação para a ação: elaboração da lei, implementação da } \\
\text { LR de REEE ou projeto piloto. }\end{array}$ \\
\hline & $\begin{array}{l}\text { Percepção } \\
\text { de } \\
\text { oportunidade } \\
\text { em uma } \\
\text { parceria }\end{array}$ & $\begin{array}{l}\text { Entender porque foram envolvidos atores diferentes ao invés de desenvolver } \\
\text { a atividade isoladamente. Levantar as expectativas de cada um sobre como } \\
\text { os outros atores envolvidos no ambiente de LR de REEE no país estudado } \\
\text { podem facilitar a execução ou aprimorar os resultados caso atuem } \\
\text { conjuntamente. O que levou os atores a realizar a parceria. Levantar quais } \\
\text { oportunidades foram visualizadas com o estabelecimento da parceria. Caso } \\
\text { ela não tem ocorrido, quais benefícios ou desafios sua ausência trouxe. }\end{array}$ \\
\hline & $\begin{array}{l}\text { Tem } \\
\text { disposição } \\
\text { ou vontade } \\
\text { para atuar na } \\
\text { parceria }\end{array}$ & $\begin{array}{c}\text { Levantar os elementos que evidenciam a disposição para trabalhar em } \\
\text { conjunto e como as relações de parceria são avaliadas como possíveis e } \\
\text { positivas, apesar de sua complexidade, motivando os atores a interagir com } \\
\text { os outros e a superar os desafios. } \\
\text { Levantar quem são os atores que demonstraram mais disposição para atuar } \\
\text { em parceria e colocaram as necessidades do projeto acima das suas } \\
\text { individuais, superando as divergências. } \\
\text { Quais foram as maiores barreiras para efetivar a parceria e como } \\
\text { conseguiram superá-los? } \\
\text { E quais fatores foram mais decisivos para a efetivação da parceria e } \\
\text { superação da complexidade característica da atuação em conjunto de atores } \\
\text { de setores e empresas diferentes? }\end{array}$ \\
\hline \multicolumn{3}{|c|}{$\begin{array}{l}\text { Atributos do escopo do projeto (base estratégica) são diferentes para colaboração e cooperação. } \\
\text { Identificar cada atributo e checar com qual conceito ele se relaciona. E como os atributos delimitaram o } \\
\text { projeto e definiram a qual tipo de relações de parcerias pertenciam. }\end{array}$} \\
\hline \multirow[t]{4}{*}{ Escopo } & Natureza & $\begin{array}{l}\text { Verificar o que cada ator pensa que irá executar. É uma ação mais mental, } \\
\text { de planejamento, desenvolvimento, inovação ou uma decisão estratégica de } \\
\text { operacionalização externa de um processo, mecanização, serviço, etapa, com } \\
\text { a criação ou não de uma organização para sua execução junto com outros } \\
\text { atores? Todos os atores têm a mesma percepção? }\end{array}$ \\
\hline & Objetivo & $\begin{array}{l}\text { Entender o que o objetivo atende e como. O objetivo é o mesmo para todos, } \\
\text { ou cada um tem um objetivo predominante, mas o resultado atende aos } \\
\text { objetivos de todos do grupo? }\end{array}$ \\
\hline & Resultados & $\begin{array}{l}\text { Verificar quem e como recebem os resultados. Ambos recebem algo, mas os } \\
\text { resultados não são obrigatoriamente tangíveis para todos, com resultados } \\
\text { intangíveis motivando a participação do outro, ou; Gera resultados tangíveis } \\
\text { para ambos. Elencar e classificar os resultados, separando-os por tangíveis e } \\
\text { intangíveis e quais são mais importantes. Esses resultados são maiores do } \\
\text { que se estivessem atuando sozinhos. }\end{array}$ \\
\hline & Atores & $\begin{array}{l}\text { Identificar que atores estão participando. Quais são os riscos de } \\
\text { relacionamento com cada ator. São de setores diferentes ou não? São } \\
\text { concorrentes? }\end{array}$ \\
\hline
\end{tabular}




\begin{tabular}{|c|c|c|}
\hline \multicolumn{3}{|c|}{$\begin{array}{l}\text { Atributos da estrutura são diferentes para colaboração e cooperação. Identificar cada atributo e checar } \\
\text { com qual conceito ele se relaciona. Visa entender como se estruturam as atividades. }\end{array}$} \\
\hline \multirow[t]{6}{*}{ Estrutura } & Atividades & $\begin{array}{l}\text { Verificar como executam as atividades: trabalham juntos, na mesma } \\
\text { atividade, simultaneamente, em forma de apoio, contribuição, ou separados, } \\
\text { cada um fazendo uma etapa de forma complementar e recíproca ou com a } \\
\text { criação de uma nova organização para execução do processo. }\end{array}$ \\
\hline & Recursos & $\begin{array}{l}\text { Levantar como é feito o uso dos recursos. Quais são, de quem são, quem usa } \\
\text { e como usa. Os recursos humanos, físicos e financeiros são compartilhados, } \\
\text { uso mútuo e as informações são compartilhadas, ou fazem uso do seu } \\
\text { próprio recurso, criando fundos para estruturação das ações e reportam as } \\
\text { informações e resultados. }\end{array}$ \\
\hline & $\begin{array}{l}\text { Comunicaçã } \\
\text { o }\end{array}$ & $\begin{array}{l}\text { Entender como se dá a comunicação. Quais são seus canais; intensa, aberta, } \\
\text { presencial; tentam limitar ao que quer cada ator, ou limitadas ao processo; é } \\
\text { por relatórios periódicos, faz uso de TIC síncrona ou assíncrona }\end{array}$ \\
\hline & Poder & $\begin{array}{l}\text { Com quem fica o poder de decisão sobre as ações. Mútuo, ou centralizado } \\
\text { em cada organização }\end{array}$ \\
\hline & Controle & $\begin{array}{l}\text { Quais são os mecanismos de controle necessários e os existentes. Sente-se } \\
\text { falta de algum mecanismo ou eles existem em excesso? São formais ou } \\
\text { informais; ou mecanismos de controles estruturados e contratos formais? }\end{array}$ \\
\hline & Risco & $\begin{array}{l}\text { Levantar os riscos de cada ator, o que aumenta ou diminui os riscos em cada } \\
\text { caso. Como pode ser afastado o perigo. Entender se ele é mútuo ou dividido } \\
\text { e como, onde e por que. }\end{array}$ \\
\hline \multicolumn{3}{|c|}{$\begin{array}{l}\text { Atributos de impacto. Entender como a colaboração e cooperação impactou a elaboração de leis e } \\
\text { modelos de LR de REEE e na sua operacionalização nos quatro países estudados e como a sua ausência } \\
\text { em determinados momentos funcionou como barreira para melhores resultados. Identificar como cada } \\
\text { definição dos atributos das dimensões escopo e estrutura impactou os resultados. }\end{array}$} \\
\hline Impactos & $\begin{array}{l}\text { Resultados } \\
\text { da } \\
\text { Presença/Au } \\
\text { sência da } \\
\text { parceria }\end{array}$ & $\begin{array}{l}\text { Quais foram os resultados positivos da atuação em parceria nas atividades? } \\
\text { O que foi realizado em parceria que não poderia ser realizado isoladamente? } \\
\text { Por quê? } \\
\text { Quais foram os fatores que atuaram como barreira na parceria? }\end{array}$ \\
\hline
\end{tabular}

Fonte: Autora, 2018

Ao final foram 39 entrevistas realizadas, sendo 35 gravadas, resultando em 30 horas e 38 minutos gravados, posteriormente transcritas para a etapa de análise dos dados.

\subsection{ANÁLISE DOS DADOS}

Para Eisenhardt (1989), o processo de análise é o elemento essencial da pesquisa qualitativa. Para o tratamento dos dados, a pesquisa usará a técnica de análise de conteúdo, devido a sua característica flexível no uso de diferentes técnicas para tratamento dos dados coletados. De acordo com Bardin (2011), a análise de conteúdo é um conjunto de técnicas que utiliza procedimentos sistemáticos para garantir uma descrição objetiva do conteúdo dos dados. Segundo Vergara (2005), a análise de conteúdo objetiva entender o que está sendo dito sobre um assunto. Já para Silva, Gobbi e Simão (2005), a análise de conteúdo serve como ferramenta para construir os significados que os atores sociais externalizam em suas falas. 
Suas principais etapas incluem a pré-análise, com a transcrição das entrevistas; exploração e análise do material, com a leitura das transcrições, seleção e definição de enumeração e categorias de análise; e interpretação do conteúdo, nessa etapa dá-se a redação do texto com a discussão dos resultados encontrados (VIEIRA; ZOUAIN, 2005).

Um elemento central para a análise do conteúdo é a construção das categorias de análise. Nesse sentido, as categorias iniciais compõem uma grade aberta que, segundo Vergara (2005), são redefinidas no processo de entrevistas até que se obtenha um conjunto final.

Figura 8 - Categorias de análise com base no referencial teórico

\section{Categorias de análise}

\section{Pergunta de Pesquisa}

Como a colaboração e cooperação estão influenciando a implementação do modelo de LR de REEE no cenário europeu e brasileiro?

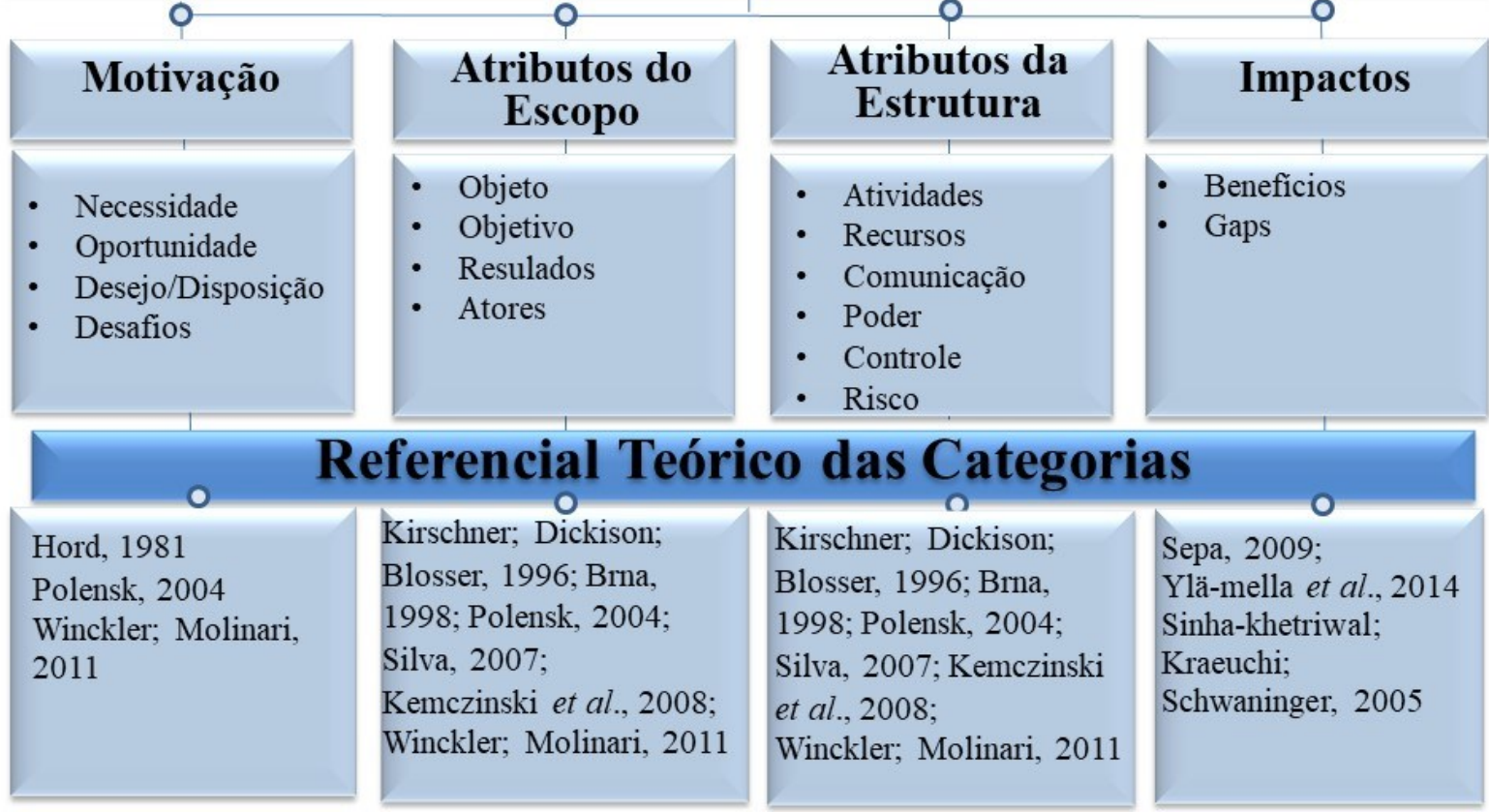

Fonte: Autora, 2018

Conforme apresentado na Figura 8, foram definidas quatro categorias preliminarmente baseadas no referencial teórico, com o objetivo de responder e se aprofundar na pergunta de pesquisa e objetivos específicos do trabalho.

A seguir, o Quadro 14 apresenta a finalidade de cada categoria e suas subcategorias. 
Quadro 14 - Finalidade das categorias

\begin{tabular}{|c|c|c|}
\hline Categoria & Focos & Finalidades \\
\hline $\begin{array}{l}\text { A. Motivação } \\
\text { para atuar em } \\
\text { parceria }\end{array}$ & $\begin{array}{l}\text { 1.1 Desejo ou necessidade } \\
\text { 1.2 Oportunidades e expectativas } \\
\text { 1.3 Disposição para se relacionar } \\
\text { e superar os desafios }\end{array}$ & $\begin{array}{l}\text { Discutir e identificar se existem elementos que } \\
\text { motivam os atores a buscar parcerias } \\
\text { colaborativas ou cooperativas. Entender quais } \\
\text { são suas expectativas e levantar se têm } \\
\text { disposição para atuar em sistemas complexos de } \\
\text { parcerias e superar os desafios }\end{array}$ \\
\hline $\begin{array}{l}\text { B. Atributos do } \\
\text { escopo da } \\
\text { colaboração e } \\
\text { cooperação }\end{array}$ & $\begin{array}{l}\text { 2.1 Objeto } \\
\text { 2.2 Objetivo } \\
\text { 2.3 Resultados } \\
\text { 2.4 Atores envolvidos }\end{array}$ & $\begin{array}{l}\text { Identificar os atributos de escopo na elaboração } \\
\text { das leis e implementação da LR de REEE nos } \\
\text { cenários brasileiro e europeu. Fazer uma } \\
\text { comparação dos elementos encontrados em cada } \\
\text { um dos processos com os atributos que } \\
\text { caracterizam a colaboração e cooperação } \\
\text { definidos pela literatura para entender se eles } \\
\text { atendem às características da natureza da } \\
\text { atividade }\end{array}$ \\
\hline $\begin{array}{l}\text { C. Atributos da } \\
\text { estrutura da } \\
\text { colaboração e } \\
\text { cooperação }\end{array}$ & $\begin{array}{l}\text { 3.1 Atividades } \\
\text { 3.2 Recursos } \\
\text { 3.3 Comunicação } \\
\text { 3.4 Poder } \\
\text { 3.5 Controle } \\
\text { 3.6 Riscos }\end{array}$ & $\begin{array}{l}\text { Identificar os atributos que estruturam os } \\
\text { processos de elaboração das leis e } \\
\text { operacionalização dos sistemas de LR de REEE } \\
\text { no Brasil e na Europa. Verificar se os atributos } \\
\text { desta categoria foram estabelecidos conforme } \\
\text { definido pelo referencial teórico e entender } \\
\text { como eles atuaram e impactaram a gestão das } \\
\text { atividades estabelecidas. }\end{array}$ \\
\hline D. Impactos & $\begin{array}{l}\text { 4.1 Benefícios } \\
\text { 4.2 Desafios } \\
4.3 \text { Avaliação dos atores sobre o } \\
\text { efeito da colaboração e } \\
\text { cooperação e forma de condução } \\
\text { das relações } \\
4.4 \text { Fatores críticos }\end{array}$ & $\begin{array}{l}\text { Identificar e discutir quais são os principais } \\
\text { benefícios e desafios da colaboração ou } \\
\text { cooperação no cenário brasileiro e europeu de } \\
\text { LR de REEE, do ponto de vista de cada ator. } \\
\text { Identificar quais fatores funcionaram como } \\
\text { barreiras, quais facilitaram as relações conjuntas } \\
\text { e o que precisa ser alterado para melhorar ou } \\
\text { efetivar a colaboração e cooperação na LR de } \\
\text { REEE. }\end{array}$ \\
\hline
\end{tabular}

Fonte: Autora, 2018

Por fim, foi realizado o processo final de triangulação das informações analisando pontos convergentes e divergentes presentes nas entrevistas e correlacionando-os com os documentos analisados. 


\section{APRESENTAÇÃO DOS RESULTADOS E DISCUSSÃO}

Esse capítulo pretende apresentar os resultados obtidos na pesquisa por meio de entrevistas, documentos, relatórios e observação de campo. Eles foram organizados, primeiramente, respeitando as unidades de caso por país: Suíça, Portugal, Espanha e Brasil. Cada unidade de estudo segue a cronologia dos fatos e a ordem das categorias de análise, que refletem as quatro dimensões apresentadas na matriz de determinantes da cooperação e colaboração: motivação, escopo, estrutura e impactos. Estes resultados atendem ao segundo objetivo da tese: identificar os elementos da colaboração e cooperação presentes na implementação da legislação e operacionalização dos sistemas de LR de REEE nos países estudados.

\subsection{ESTUDO DE CASO DA LR DE REEE NA SUÍÇA}

Está seção apresenta o processo de elaboração e implementação da LR de REEE na Suíça para mostrar quais foram os fatores que motivaram a implementação da LR de REEE, descrever como foi definido o escopo e a estrutura para estabelecerem o processo de negociação e discussão entre os atores envolvidos nessa cadeia e o governo, assim como de que forma isso aconteceu na operacionalização da LR, verificar como esses elementos impactaram na efetivação da colaboração e cooperação e quais resultados foram obtidos nesse cenário.

\subsubsection{Os atributos da dimensão "Motivação" na LR de REEE na Suíça}

Está seção apresenta os atributos da dimensão "Motivação": necessidade, oportunidade e disposição na elaboração e implementação da LR de REEE na Suíça.

\subsubsection{Necessidade}

A coleta de REEE na Suíça começou de forma voluntária, bem antes da aprovação da Portaria sobre Retorno, Coleta e Eliminação de Equipamento Elétrico e Eletrônico - (ORDEE - Ordinance on the Return, Taking Back and Disposal of Electrical and Electronic Equipment - tradução nossa). Um dos fatores motivacionais para a implementação do sistema de LR de REEE por parte dos fabricantes foi a necessidade de mitigar e prevenir os possíveis impactos ambientais dos REEE gerados no processo pós consumo dos produtos fabricados por eles e 
descartados de qualquer forma pelo consumidor. Um exemplo disso foi a contaminação dos lençóis freáticos por substâncias químicas contidas em alguns resíduos, como os REEE de grande porte.

SGF2 - Um dos fatores motivacionais no início do sistema foi a contaminação de lençóis freáticos por algumas substâncias perigosas, mas isso estava mais relacionado a equipamentos de grande porte, como geladeiras, essas coisas. E esses EEE terminavam nos bosques.

Naquela época, em 1990, quase todos os produtores de EEE faziam algum tipo de coleta, oferecida como um serviço extra. Na verdade, além de evitar que os REEE causassem impactos ambientais ou fossem parar junto aos resíduos comuns, a LR era vista como uma oportunidade dos produtores recuperarem recursos valiosos contidos nesses resíduos, que estavam sendo dispensados como lixo. Para isso, era cobrada do consumidor uma taxa pós consumo no momento do descarte, como garantia de destinação ambientalmente adequada do seu REEE. Contudo, nem todos os consumidores queriam pagar para jogar fora seu EEE antigo e nem todos os fabricantes estavam interessados em coletar REEE que tivesse baixo valor agregado, como era o caso das geladeiras. Assim, esses resíduos eram muitas vezes descartados nos bosques.

SGF2 - Viram que muitos EEE se perdiam nos resíduos comuns, e isso não era a ideia. Eles sabiam que os EEE tinham seu valor, têm seus recursos, e precisavam buscar soluções para a recuperação dos recursos.

SRC1 - Antes deles criarem organizações como SENS ou SWICO, todos estavam fazendo algo que dava retorno ou não. Quando você compra uma geladeira nova, apenas paga a geladeira. Então você tem que descartar a antiga, e você tem que pagar de novo pela geladeira antiga? E o que acontecia na época, é que essas antigas geladeiras eram descartadas na natureza. Então isso não era um jeito bom e ecológico de se fazer a reciclagem. [...] Alguns produtos eram reciclados, mas apenas os que tinham vários tipos de metais e rendiam dinheiro.

Mas, há mais de 20 anos, um pequeno grupo de grandes produtores se reuniu para buscar uma solução para a destinação dos seus REEE. Eles estavam preocupados com os impactos ambientais causados pelos bens que produziam e com o reflexo disso em suas marcas. Eles também perceberam a oportunidade de criar o seu próprio modelo de LR de REEE para se antecipar à criação de uma lei, prevenindo-se de exigências mais pesadas. Nesse contexto, no início da década de 1990, eles criaram a ORP SENS e depois a SWICO, responsáveis pela gestão dos grandes EEE e dos equipamentos de escritórios, respectivamente. Mas, no começo, enfrentaram diversos desafios, pois não tinham volume, nem todos os atores da indústria de EEE tinham aderido aos sistemas, faltava padronização e era muito caro. No caso da SENS, 
que trata dos grandes EEE, a situação era mais evidente, pois o custo era maior e ainda se cobrava a taxa de reciclagem no momento do descarte. Nesse cenário, quando a SWICO começou sua operação, ela já veio com a cobrança da TAR (Taxa Antecipada de Reciclagem).

\begin{abstract}
SGF2 - Na Suíça tudo começou há mais de 20 anos, com a iniciativa de alguns produtores. Os produtores grandes de EEE como a HP, começaram por eles mesmo, pois viram a necessidade de desenvolver um programa de coleta, sem a pressão da lei, pois não havia lei, não havia regras. Mas eles começaram a buscar soluções de como eles poderiam desenvolver um sistema de coleta de REEE. Então as marcas se juntaram.

SRC2 - Naquele ponto algo aconteceu. Algo que é bem típico pra Suíça, ao invés de se esperar por uma lei, a associação dos importadores e fabricantes [...] como HP, Cannon, Xerox. Então, eles disseram: Ok! Vamos achar uma solução! E é melhor fazermos essa solução sozinhos do que esperar por uma lei que vai vir com obrigações mais pesadas, vamos fazer nós mesmos. [...] Então, em 90-94, vários produtores de TI começaram com um sistema comum, gerenciado pela SWICO e nós antecipamos a taxa de reciclagem.
\end{abstract}

Esse sistema cresceu rapidamente nos primeiros anos, pois, além da adesão das grandes marcas, o consumidor começou a preferir comprar marcas de EEE que tivessem a TAR incluída do seu valor na Nota Fiscal. Como a TAR tinha um valor muito pequeno, ela causava um impacto positivo no consumidor em relação à marca que não a cobrava, pois era a garantia de que seus REEE seriam tratados de forma ambientalmente correta. Dessa forma, criou-se uma massa crítica que forçou as outras marcas a aderirem às Organizações de Responsabilidade do Produtor (ORP). Além disso, os responsáveis pelas ORP começaram se reunir com as outras marcas para pressioná-las a ingressarem nos sistemas coletivos, argumentando que era melhor eles tomarem essa iniciativa do que esperar o governo exigir outro tipo de solução para resolver o problema dos REEE que não estavam sendo reciclados.

SGF2 - Então esse sistema cresceu bastante nos primeiros anos, e eles começaram a convencer outras marcas a entrar no sistema e finalmente se tinha um sistema muito grande. Então, ele iniciou com os maiores produtores. [...] Até certo ponto, os pequenos fabricantes de EEE sofreram uma pressão dos próprios consumidores para que eles entrassem no sistema também. Pois a TAR era visível há 15 anos, nas notas fiscais. O consumidor via que ela era cobrada só em alguns marcas. Era um valor pequeno, um par de dólares, que assegurava que daqui a uns 4, 5 anos, quando eu descartar esse EEE, ele será reciclado.

SRC1 - Então, nosso presidente estava realmente começando a sentar com essas pessoas numa mesa e dizer: Cavalheiros, vocês devem ser responsáveis por seus resíduos e o governo vai querer resolver isso, de uma forma ou de outra. Então é melhor que façam algo que já sabem como funciona.

Então, com o sistema constituído e funcionando, os fabricantes começaram a pressionar o governo para legislar sobre a LR de REEE, obrigando todos os atores da cadeia a executá-la. 
Assim, o governo se uniu aos produtores, que ajudaram a desenvolver a ORDEE de 1998, que determinava que todas empresas de EEE, fossem elas fabricantes, importadores ou supermercados que tinham suas próprias marcas, fizessem a coleta e reciclagem de seus EEE ao final de seu ciclo de vida. Da mesma forma, o consumidor seria obrigado a fazer o descarte correto do seu REEE, levando-o a um ponto de coleta.

SGF2 - Depois de um tempo, o governo suíço começou a fazer a LR de REEE como lei, como regras. Antes os produtores já tinham criado o sistema.

SGF1 - Então eles pediram ao governo para transformar em obrigação, o fato de que o consumidor tenha que trazer de volta seu REEE, em um ponto de coleta. [...] E isso foi realmente ideia de uma organização do produtor, que queria ter uma boa imagem, então eles queriam fazer algo pelo meio ambiente quanto à geladeira, aos EEE.

Já a participação do governo municipal na coleta de REEE foi motivada pela necessidade de atender à demanda da população por esse tipo de serviço e a oportunidade de aumentar a coleta desses resíduos. Os importadores e fabricantes, por meio das ORP, queriam potencializar os resultados das coletas, e por isso incentivaram os municípios a incluirem seus canais de coletas nesses sistemas. A população também não estava feliz, queria fazer o descarte correto. Mas queria a mesma comodidade que tinha para fazer o descarte dos outros tipos de resíduos, nos mesmos pontos de coleta municipais.

\footnotetext{
SGF1 - Então, a idéia é ter o máximo de participantes e REEE coletado. Dessa forma, o fabricante e o importador, por meio das organizações SENS e SWICO, motivaram a municipalidade a receber os REEE. [...] Na Suíça, você sempre tem, em todo o município, alguns pontos de coleta, onde as pessoas podem trazer todos os seus resíduos. [...] Eles também trazem REEE. Então é bem impossível que a municipalidade diga para uma pessoa: Ah! Eu não aceito REEE. Porque a pessoa diria: Ei! Eu gostaria de trazer o EEE aqui, então você precisa aceitar.

SRC2 - Cada vez mais as pessoas perceberam o problema do descarte incorreto dos REEE, é claro. Houve também discussões políticas, as pessoas não estavam felizes com a situação, com esse descarte selvagem de eletrônicos na natureza.
}

De acordo com documentos cedidos por SRC2, como há escassez de recursos naturais no país, é importante que se faça um uso consciente deles. Por esse motivo, desde a década de 1990, o país assumiu o compromisso de adotar um modelo econômico baseado na sustentabilidade. Além disso, ele reconhece a importância do papel da reciclagem, tanto para economia de recursos naturais, como para geração de riquezas na criação de novos empregos e demandas de mercado. Esse fator parece impulsionar os atores a cooperar e colaborar em prol da gestão dos REEE no país. Eles demonstram predisposição para atuar em questões sustentáveis, pois desejam se transformar em líderes mundiais no setor de reciclagem. 
Precisamos reduzir a níveis ecologicamente corretos, e é por isso que, na Rio +20 , a Conferência das Nações Unidas sobre Desenvolvimento Sustentável, a idéia de uma economia verde foi apresentada como nossa direção econômica de longo prazo. $\mathrm{O}$ objetivo é uma abordagem sustentável para a economia e a reciclagem desempenha um papel importante neste conceito, recuperando matérias-primas valiosas e reintegrando-as no ciclo de materiais (SENS, 2015, p.1).

\subsubsection{Oportunidade}

Mediante a necessidade de legislar sobre a LR de REEE, o governo se uniu com os representantes das marcas que já operavam esse sistema para contar com seu conhecimento, além de chamar outros atores interessados no tema para envolvê-los na elaboração da lei. Para o governo suíço, a participação de stakeholders no desenvolvimento de qualquer lei é vista como uma oportunidade de garantir seu engajamento desde o inicio, aumentando as chances de sucesso na implementação do projeto em questão.

SGF1 - Porque se nós conseguirmos garantir o stakeholder no começo, então teremos mais chance que a lei ou projeto será implementado. Isso é mais geral, porque nós temos parcerias e colaboração, entre governo e produtor.

Salienta-se ainda que o governo visa melhorar os resultados de processos da administração pública quando atua conjuntamente com os stakeholders. No caso da coleta dos REEE, pode-se garantir um sistema de coleta mais eficaz, com mais opções para o consumidor, além de ser capaz de receber uma quantidade maior de REEE, já que grande parte dos consumidores entregaria seus resíduos nesses postos, ao invés do varejista.

SGF1 - Isso ajuda o produtor e o importador também, porque nem todo o resíduo está indo para o varejista. Então, para o importador e fabricante, isso tem um objetivo de se ter o máximo de REEE coletado. [...] Cerca de 50\% dos REEE estão sendo coletados pela municipalidade.

As ORP compartilham os pontos de coletas e trabalham juntas no controle e gerenciamento dos recicladores para auferir melhores resultados na LR de REEE.

SRC1 - Mas, no lado da reciclagem, cada ponto de coleta os dois tipos de produtos. Ok, faz sentido, nós trabalhamos juntos lá, todos... digamos, todos os recicladores. Não reciclar apenas um produto, geralmente dois ou três produtos. Então faz sentido que a SENS e a SWICO trabalhem juntas também. 


\subsubsection{Disposição para atuar em conjunto}

A disposição do governo para atuar de forma conjunta com os principais stakeholders de um determinado processo é cultural e apontada como o fator principal para que as leis funcionem bem no país. O objetivo é buscar sempre o consenso entre as partes, para que todos os atores se sintam atendidos pela lei, tanto o governo federal, quanto a indústria e o município. Afinal, segundo SGF2, as leis existem para serem executadas, por isso é importante consultar as partes e obter um consenso. Por isso, o governo e as ORP se ajudam da elaboração da lei e no desenvolvimento de critérios de qualidade, aproveitando o que já foi construído e acrescentado o que acham importante.

SGF2 - Em um país pequeno como a Suíça, os processos de elaboração de leis normalmente são colaborativos. Então se o estado está elaborando uma lei, há uma consulta dos interessados. Então há uma cultura de colaboração e dos termos que são aceitáveis à indústria, aos municípios e aos consumidores. Há uma cultura de buscar o consenso entre as partes interessadas e finalmente, isso é uma das razões porque funciona. Pois o estado está buscando uma lei que se possa ser executada, com o mínimo de oposição possível.

SRC2 - Então, toda a auditoria técnica feita pelo EMPA foi realizada com base no que nós desenvolvemos, em nome da SWICO e de todo o sistema. [...] E em certo momento o estado disse ok, mas eu gostaria que vocês tivessem um nível máximo de mercúrio. Então, eles também editaram algumas regras, mas basicamente o jeito que os recicladores são auditados é basicamente o que fizemos.

\subsubsection{Os atributos da Dimensão Escopo na LR de REEE na Suíça}

Está seção apresenta os atributos da dimensão "Escopo": natureza, objetivo, resultados e atores na elaboração e implementação da LR de REEE na Suíça.

\subsubsection{Natureza}

No caso da Suíça foi a operacionalização da LR de REEE, iniciada por um pequeno grupo de grandes empresas de EEE, que impulsionou o desenvolvimento e implementação da lei que regulamenta, padroniza e imputa a todos os produtores de EEE a obrigação de fazer a correta gestão dos resíduos ORDEE de 1998. 


\subsubsection{Objetivos}

Para os fabricantes e importadores de EEE, o objetivo da operacionalização da LR de REEE era assegurar que os produtos vendidos por eles não fossem descartados de forma incorreta pelos consumidores ao final do seu ciclo de vida, contaminando o meio ambiente. Assim como queriam recuperar os materiais contidos nesses aparatos, devido à escassez desses recursos. Com essa atitude, eles pretendiam evitar danos à sua imagem, causados pela a associação do consumidor com os impactos ambientais, resultantes da gestão inadequada dos resíduos gerados no pós consumo de seus produtos.

Já o governo, no que tangia ao desenvolvimento da legislação de REEE, queria atender às reivindicações, tanto da população, quanto dos fabricantes que iniciaram o sistema LR de REEE no país, por meio de uma lei que obrigasse todas as marcas a fazer a gestão correta dos seus REEE de forma padronizada e o mais eficiente possível, como apontado nos fatores motivacionais. Sua decisão de participar do processo de coleta dos resíduos ocorreu para melhorar os resultados da LR de REEE, facilitando o seu descarte pelo cidadão suíço, além de atender a seus anseios por uma administração eficiente e sustentável, pois ele tem um alto nível de conscientização, além de participar ativa e criticamente da política.

SGF1 - Então, a idéia é ter o máximo de participantes e REEE coletado.

SGF2 - Cada participante do sistema tem o seu objetivo, que talvez possa ser parecido com a motivação do outro. As marcas, a sua primeira preocupação é que elas não queriam sujar a sua imagem. Eles queriam mostrar que eles cuidam do meio ambiente e que seus EEE, depois do final da sua vida útil, terminam em um processo de reciclagem com recuperação dos metais e a descontaminação. Essa era a motivação principal das marcas.

\subsubsection{Resultados esperados}

Assim como os objetivos dos atores envolvidos na LR de REEE eram claros e complementares, os resultados esperados por eles com a implementação desse sistema também estavam bem definidos. O governo esperava evitar a contaminação no meio ambiente pelas substâncias tóxicas dos EEE e recuperar materiais nobres e raros com a efetivação da LR, além de mostrar para a população que os REEE têm um valor positivo, alimentando a economia circular e preservando os recursos naturais. Já os representantes das marcas de EEE esperavam manter a sua imagem positiva diante dos consumidores. 
SGF2 - O governo tinha mais interesse em não perder recursos e mostrar que EEE tem um valor positivo também. E temos uma escassez de recursos cada vez maior e que a recuperação dos metais, por exemplo, nesses EEE é uma contribuição importante à economia circular. Então dessa forma não era um término, mas a motivação principal era evitar a contaminação do meio ambiente, por parte do governo. E, ao mesmo tempo, apoiar a recuperação dos materiais.

O EMPA, órgão do governo responsável por auditar o sistema de LR de REEE, além de receber pelo processo de auditoria, esperava ter acesso a informações relevantes sobre as empresas, que lhes permitissem desenvolver novos projetos de investigação.

SGF2 - O EMPA audita e recebe por isso. Mas ele também tem muitas vantagens, pois, com a auditoria, ele tem acesso às empresas e às informações muito interessantes que nos possibilita formular projetos de investigação.

No modelo suíço, nem o governo, nem os fabricantes precisam cumprir metas de coleta ou reciclagem. Assim, cumprir metas não seria um resultado esperado a ser alcançado pelos atores envolvidos na LR de REEE. Entretanto, apesar de não ter metas, todos trabalham conjuntamente para fazer o melhor sistema de LR possível.

SGF2 - Aqui é diferente, não somos como os países da UE que têm uma certa obrigação de recolher um \% do que ele coloca no mercado. Então estamos num nível mais alto que a Europa, sem a necessidade da pressão de cotas mínimas. Nunca tivemos nenhuma taxa, desde o princípio, aliás não sei porque isso não ocorreu.

Outra preocupação que não existe no sistema de LR da Suíça é a de evitar o transbordo ilegal de REEE para países em desenvolvimento. De fato, além de não ter acesso ao mar, o país possui um sistema de fiscalização muito forte para evitar esse tipo de situação.

SGF2 - Além disso também não temos problema de levar esses equipamentos ao porto em direção à África, à Ásia, pois somos um país que não tem acesso ao mar. Então somos um sistema bastante fechado e também temos uma fiscalização muito forte de exportação de resíduos. Então o que se gera na Suíça, o resíduo fica na Suíça.

\subsubsection{Atores}

Nesse cenário, participam da LR de REEE na Suíça os fabricantes ou importadores de EEE, por meio das ORP, SWICO, SENS e SLRS (Swiss Lighting Recycling Foundation Fundação Suíça de Reciclagem de Iluminação, tradução nossa) que organizam toda a gestão desses resíduos por meio de empresas contratadas por elas. Também participam os governos 
municipais e os varejistas como pontos de coleta. Além desses atores, o EMPA tem o papel de auditar as ORP e as empresas que prestam serviços à elas.

SGF1 - Para EEE, a obrigação de trazer de volta é apenas do fabricante e importador. E o que eles fizeram, os produtores e importadores? Eles têm uma fundação para cada tipo de EEE e existem três delas no total, Swico, SENS e SLRS. Eles representam o produtor e o importador e eles organizam para eles toda a coleta do sistema de LR. [...] Eles motivam a municipalidade a participar da coleta também.

SFG2 - Então os atores que participam da logística reversa são o município que tem pontos de coleta, sobretudo, nas zonas rurais, porque lá não tem tanta densidade de lojas. Os municípios também oferecem pontos de coletas e, nesses pontos de coleta, os REEE vão direto para o sistema. Além disso, tem o varejista que vende os EEE e as empresas contratadas pelas ORP. Mas somente as empresas prestadoras de serviços de LR que foram auditadas pelo EMPA podem participar do sistema. Isso é como uma proteção do mercado. Isso é para garantir que as empresas que querem participar atendem a todos os requisitos de qualidade necessários.

Apesar de existirem três ORP na Suíça, eles não são concorrentes, pois seus fluxos de gestão são distintos e complementares. A SWICO é responsável pelos equipamentos de escritório e TI, a SLRS pelas luminárias e lâmpadas e a SENS pelo restante dos REEE domésticos. Além disso, as organizações mantêm relações cooperativas entre elas, de acordo com o relatório técnico unificado das três ORP (SWICO; SENS; SLRS, 2017) que, de agora em diante, será apresentado como SOG1. Como exemplo desta cooperação, é possível citar a forte parceria existente entre a SLRS e a SENS que, além de fornecer a coleta e transporte por meio de seu sistema, também realiza reciclagem, monitoramento e relatórios referentes a lâmpadas e equipamentos de iluminação em uma base operacional.

SGF2 - SWICO, SENS e SLRS são organizações dos produtores, que assumem atender aos produtores de forma coletiva. Elas se completam. SWICO é uma empresa de reciclagem de tecnologia da informação e equipamentos de escritório, SLRS de luminária e lâmpadas e SENS dos demais eletrodomésticos. São fluxos que se complementam e não que competem.

SRC2 - Estou falando de assegurar a qualidade técnica, eu penso que a Suíça não é parte da UE e o nosso sistema é diferente porque nós temos ferramentas e sistemas que não estão uns contra os outros. Eles não estão competindo, mas eles fazem tipos diferentes de produtos. No resto da Europa, você geralmente tem sistemas diferentes competindo entre si e o produtor pode escolher em qual sistema ele quer ir.

Em contrapartida, há competição entre os operadores de gestão de reciclagem. E isso é uma forma de melhorar o sistema.

SRC2 - Isso é essencial, os Operadores Gestores de Reciclagem (OGR) serem concorrentes, porque aí colocamos o mercado para agir. 
Os atores entrevistados afirmam não contar com a participação do setor informal, pois a população em geral tem um poder econômico satisfatório, não obrigando a nenhuma pessoa a sobreviver da coleta de resíduo. Nesse caso, a Suíça não precisa tomar nenhum tipo de ação para incluir ou excluir esse setor na coleta dos REEE, pois ele é inexistente no país. Entretanto, mais da metade das empresas de desmontagem que prestam serviços à SWICO e à SENS são organizações de integração social, que visam ajudar na inclusão de jovens e pessoas mais maduras que estão prestes a se aposentar, mas não conseguem recolocação no mercado e pessoas com necessidades especiais, tais como pessoas com deficiência físicas ou mentais, presos ou condenados a prestar serviços comunitário e requerentes de asilo.

\begin{abstract}
SGF1 - Não temos setor informal. Não há pessoas que precisam viver de coletar lixo nas ruas. Não temos pessoas nessa situação, então, isso deixa as coisas mais fáceis, nesse aspecto.

Geralmente existem dois tipos de empresas de desmantelamento: empresas privadas e organizações de integração social. [...] Mais de 50 empresas de desmontagem combinam suas atividades com a integração social. [...] Quase mil pessoas trabalham nessas empresas de desmontagem na integração social como empregados de tempo parcial, em tempo integral, temporários ou permanentes na Suíça. [...] Enquanto algumas instituições trabalham muito com jovens, outras se concentram nos desempregados de longa duração. Esses indivíduos vão se aposentar em breve e raramente são capazes de encontrar um novo emprego. Pessoas que não são capazes de trabalhar em um ambiente de trabalho tradicional encontram uma rotina diária estruturada e um ambiente social de mente aberta em uma empresa de desmontagem. Isso se aplica, por exemplo a: pessoas com deficiência mental ou física; pessoas com dependência de álcool ou drogas; prisioneiros ou pessoas condenadas ao serviço comunitário; requerentes de asilo (SENS, SWICO, SLRS, 2017)
\end{abstract}

\title{
5.1.3 Os atributos da Dimensão "Estrutura” na LR de REEE na Suíça
}

Está seção apresenta os atributos da dimensão "Estrutura": atividade, recursos, comunicação, poder, mecanismos de controle e riscos na elaboração e implementação da LR de REEE na Suíça.

\subsubsection{Atividades}

Toda a gestão dos REEE na Suíça é feita pelas ORP SENS, SWICO e SLRS. Elas são responsáveis por atender às obrigações dos fabricantes e importadores, organizando toda a cadeia reversa por meio de pontos de coletas e da contratação de empresas de transporte e reciclagem. A SLRS gerencia apenas o fundo financeiro da LR, mas toda sua gestão técnica é feita pela SENS. 
SGF1 - A obrigação de trazer de volta é apenas do fabricante e importador. E o que eles fizeram, os produtores e importadores? Eles têm uma fundação e existem três delas no total, SENS, SWICO e SLRS. E eles representam o produtor e o importador e organizam para eles toda a coleta do sistema de LR.

SGF2 - Toda a gestão dos REEE é feita pelas ORP. São essas organizações suíças que se responsabilizaram por toda a organização do sistema de LR de REEE. E são organizações que representam os seus membros, suas empresas, distribuidores, os supermercados também, porque os supermercados têm marcas próprias de EEE aqui. Os sistemas são coletivos e as ORP é que tem a responsabilidade.

SRC1 - A SLRS é uma fundação e ela faz um pouco do que a SENS faz, mas eles estão apenas gerenciando o fundo. Então, a SENS está gerenciando o sistema de LR por ela.

Para aumentar a eficiência do sistema e reduzir os custos, SWICO E SENS atuam conjuntamente nos pontos de coleta, logística, auditorias e controle dos recicladores, pois muitas vezes usam o mesmo OGR.

SRC2 - Basicamente nós temos auditorias em comum, e as logísticas são geralmente juntas, porque o transporte é geralmente organizado para que a coleta seja junta, pois o ponto de coleta geralmente vai trabalhar junto com o reciclador. Então nós pagamos o reciclador, e o pagamos pela reciclagem e também pelo transporte, e também pelo ponto de coleta. E é claro que ele vai então tentar não apenas coletar os nossos resíduos, mas também os da SENS, para que então tudo seja feito junto. A única diferença é quando você tem geladeiras porque geladeiras têm um lugar diferente onde são recicladas. Então sempre tentamos minimizar os custos de logística e burocracia.

SRC1 - E o controle do plano de reciclagem eles fazem juntos, isso é mais eficiente. Elas trabalham juntas em controlar, gerenciar seus recicladores e, gerenciando os pontos de coleta.

As empresas de varejo que vendem EEE têm obrigação de fazer a coleta dos REEE, independentemente do consumidor ter comprado um novo equipamento. A única restrição feita é que cada loja só recebe o mesmo tipo de EEE que vende. Para isso, ela deve ceder um espaço no estabelecimento para colocar um coletor de REEE.

SGF2 - A loja que vende EEE tem por lei a obrigação de receber REEE sem obrigação da pessoa comprar um novo equipamento. É tudo muito fácil, é consumer-friendly. Então esse é o sistema muito importante, porque nós chegamos à cota de $16 \mathrm{~kg}$ de REEE por habitante por ano. Então as lojas têm obrigação de ceder espaço para colocar os coletores de REEE onde um consumidor pode devolver seu equipamento. A única condição é que a loja venda o mesmo produto que ela coleta, só.

SRC2 - Agora nós temos um jeito diferente, todos os comerciantes são obrigados por lei a recolher os resíduos. Então você pode ir em uma loja e dizer olha, esse é o meu rádio, pega de volta. você não precisa comprovar a compra, você não precisa ter comprado nessa loja, indiferentemente da marca. 
Apesar da municipalidade não ter a obrigação de coleta os REEE, ela também participa desse processo. Ela integrou os pontos de coleta seletiva com a coleta de REEE, para facilitar seu descarte. Nesse cenário, a municipalidade coleta a maior parte dos REEE descartados no país.

SGF1 - A municipalidade está coletando o REEE, mas, na verdade, não é obrigatório para eles. [...] A municipalidade tem outras obrigações de outros resíduos, por exemplo, resíduo urbano, embalagens de vidro, têxteis, papel, mas não para EEE. Mas os REEE são coletados nos pontos de coletas do município também. Então o cidadão traz para postos de coleta do município e eles (ORP) vão coletar ali.

SRC2 - Agora, a maior parte dos eletrônicos é trazido de volta para os pontos de coleta da municipalidade. E por conta das pessoas também trazerem jornais e garrafas, o que seja. Esses pontos de coleta não são obrigados por lei a recolher, então nós pagamos ele por tonelada. Nós estamos pagando a eles algo por tonelada, e então, é claro, eles também podem transportar eles mesmos, e nós pagamos a eles por isso, ou podemos organizar o transporte dependendo da situação e então é feito por nós e basicamente o transporte é pago por nós.

Além das lojas e pontos municipais, as ORP têm parceria com empresas, escolas e grandes entidades, que cedem espaço para que seus funcionários possam descartar seus REEE. Entretanto, não são pontos para fazer campanhas de conscientização envolvendo as crianças, como ocorre em outros países, pois eles não concordam com essa abordagem.

SRC2 - Nós também temos grandes locais onde várias pessoas estão trabalhando. Isso pode ser uma escola ou um grande edifício com vários escritórios. Eles geralmente têm um local reservado para descartar os materiais recicláveis, então isso tudo fica em um só lugar. É claro que também iremos buscar. Na Suíça, as escolas não usam crianças para reciclar EEE, isso é algo mais cultural.

A retirada dos REEE dos pontos de coletas do varejo e município é feita pelas empresas de transporte e reciclagem contratadas pelas ORP. Assim que um desses pontos atinge uma determinada quantidade de REEE, tanto a municipalidade, como o varejo ligam para a empresa responsável pela coleta para solicitar a retirada do coletor ou contêiner de resíduos do seu estabelecimento.

SGF1 - A pessoa do posto de coleta vai ligar para a ORP e dizer, sim, está conosco um contêiner de REEE, envie a companhia de transporte. E a ORP vai organizar o transporte e a reciclagem. Eles estão fazendo o mesmo trabalho que eles fariam para o varejista, para o produtor.

SGF2 - Quando as lojas recebem os REEE já têm uma quantidade suficiente, elas se conectam com as recicladoras ligadas à SWICO, SENS ou SLRS para ir retirá-los. 
Os pontos de coletas instalados nas lojas pertencem à SENS ou à SWICO mas, para ampliar as opções desses pontos e facilitar o descarte para o consumidor, as ORP cooperam entre si, aceitando todos os tipos de REEE nos seus pontos. Entretanto, nas outras etapas da LR, cada organização executa a parte que lhe cabe, reciclando apenas os tipos de REEE que representam, por meio dos seus terceiros. Já as empresas de transporte e de reciclagem são concorrentes e podem atuar com os REEE das três ORP.

SGF2 - Na Suíça, há cooperação entre elas. Os pontos de coleta. por exemplo, são da SENS ou da SWICO, mas para os consumidores isso não interessa. Na parte da logística não há cooperação, porque cada um faz o seu. Já as empresas de reciclagem entre elas há competição sim, porque elas podem reciclar tanto um tipo de resíduo quanto o outro.

Depois de retirarem os REEE dos pontos de coletas, as ORP os levam para os seus centros de desmontagem. Nesse local, primeiro é feito o processo manual, com a retirada das baterias, cabos e a desmontagem para retirada de componentes tóxicos ou valiosos quando possível. Além de remover os componentes nocivos, a triagem é realizada em frações, permitindo que parte dos metais não passe pelo processo de trituração. O restante desses resíduos é triturado e separado por diferentes tecnologias. Uma fração desses resíduos vai para as fundições que estão na Bélgica e na Suécia, que separam e retiram os metais contidos nesses resíduos, como ouro, prata e cobre. Dessa forma, toda a gestão primária é feita na Suíça.

SGF2 - Depois de retirar os REEE nos pontos de coletas, as ORP levam para o centro próprio para a empresa de reciclagem onde eles fazem um dos processos manuais que é retirar as baterias, os cabos ou fazem uma desmontagem manual, para depois tirar os componentes tóxicos ou, quem sabe, talvez alguns componentes valiosos. E depois disso levam a uma trituração e depois a uma separação com diferentes tecnologias e algumas dessas frações que se produzem disso terminam em uma fundição na Suíça. Por exemplo, os cartões que contém muitas substâncias valiosas vão para a Bélgica ou Suécia. Então a gestão primária, as empresas de reciclagem fazem na Suíça. É claro que as fundições de metais são feitas na Bélgica, na Suécia, onde tem os grandes fornos para isso.

O governo tem o papel de legislar, monitorar e auditar todo o sistema de LR de REEE. Tanto as ORP quanto as empresas que são contratadas por elas são auditadas pelo EMPA (Eidgenössische Materialprüfungs und Forschungsanstalt), Laboratórios Federais Suíços de Ciência e Tecnologia de Materiais. As empresas de fundição que estão na Bélgica e Suécia são igualmente auditadas pelo EMPA, para verificar se todos os requisitos para garantir a segurança e sustentabilidade dos processos estão sendo atendidos. 
SGF2 - Nós, do EMPA, fazemos a auditoria do sistema de reciclagem faz muito tempo. Eu sou o auditor líder de um grupo de quatro auditores. Auditamos as empresas de reciclagem da Suíça e também vamos auditar as empresas de fundição na Bélgica e Suécia.

Nesse cenário, o papel do consumidor é pagar a taxa que assegura a reciclagem antecipadamente ao comprar o seu novo EEE e fazer o descarte ambientalmente correto nos pontos de coleta.

SGF2 - O papel do consumidor é pagar a taxa ao comprar o novo produto e fazer o descarte nos locais certos.

\subsubsection{Recursos}

Todo o sistema de LR de REEE na Suíça é financiado pela TAR paga pelo consumidor, que forma o fundo de reciclagem das ORP. O valor dessa taxa é transferido pelo varejista para os produtores que o repassam às organizações ou Voluntary Sistems (sistemas voluntários tradução nossa), conforme apresentado na Figura 9, que representa o Sistema de Financiamento Suíço para a reciclagem dos REEE. Os produtores e importadores repassam esses valores com base na quantidade de produtos que colocaram no mercado e no tipo de EEE, pois cada item EEE tem um valor de taxa de reciclagem definido pela ORP. Com essa taxa, as ORP pagam o município pelos REEE coletados em seus pontos de coletas, bem como pelo transporte e pela reciclagem, todos processos que não geram receitas. Os processos de extração de metais ou plásticos com valor econômico não necessitam de repasse, pois, essa atividade gera renda por si só. Além disso, o repasse para os recicladores é indexado pelo valor das matérias-primas, garantindo que eles sempre recebam o suficiente para ter lucro e não queiram sair do sistema. Dessa forma, se o valor do ouro cair, as ORP pagam mais pela reciclagem para compensar a queda e vice e versa.

SGF1 - As organizações SWICO, SENS e SLRS mandam pagar a municipalidade, pelo trabalho que fazem. [...] A ideia é que o produtor precisa pagar pela reciclagem e também precisa pagar por todos os custos que a municipalidade teve.

SGF2 - Todo financiamento do sistema é feito por uma tarifa antecipada de reciclagem que o consumidor paga quando compra seu equipamento novo. Essa taxa vai para o sistema. E no sistema tem um fundo com o qual eles podem financiar as atividades não rentáveis, como a logística, auditoria. E com isso paga as empresas de reciclagem pelos resíduos que não recebem ingressos pela venda de metais ou pelas vendas de alguns bons plásticos que contém esses equipamentos, pois eles têm que também descontaminar os equipamentos, por isso que eles recebem, eles têm que tirar as substâncias perigosas que existem nesses equipamentos. Tudo isso são atividades dessas empresas de reciclagem que têm um custo. 
SRC2 - Conforme a renda da reciclagem vai fluindo, dependendo dos preços das matérias-primas. Se alumínio e cobre estão com o preço subindo, então ele vai ter mais dinheiro quando ele vender isso. E nós temos um index nos nossos preços, que vai diminuir o que pagamos ao reciclador. E se o preço das matérias-primas diminuir nós iremos pagar mais a ele.

Figura 9 - Sistema de Financiamento Suíço para a reciclagem dos REEE

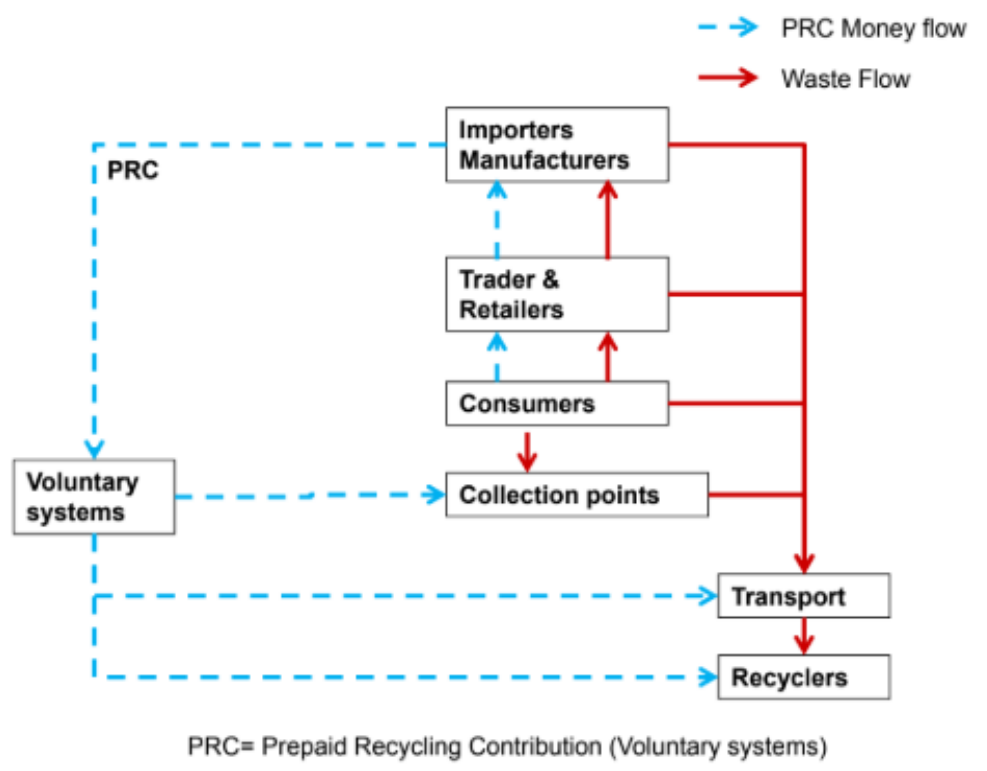

Fonte: BAFU, 2012, p.1

Além de financiar os serviços prestados pelo municípios e empresas contratadas para o transporte e reciclagem, a TAR paga as atividades de auditoria realizadas pelo EMPA.

SGF2 - Com as auditorias a gente também recebe um pagamento desses fundos. A SWICO tem aproximadamente 40 milhões de francos suíços anualmente neste fundo.

Por lei, os lojistas não recebem nenhum pagamento por ceder espaço no seu estabelecimento para colocar coletores de REEE, mas a SENS decidiu dar um prêmio a eles, por uma determinada quantidade de REEE que eles recebem, pois seus resíduos são grandes. Dessa forma, eles recebem como os outros pontos de coletas.

SFG2 - Eles [lojistas] não recebem nenhum pagamento por isso [ceder espaço para colocar coletores de REEE].

SRC1 - Quando eles recebem de volta tantos materiais eles recebem um prêmio. Então o comerciante recebe o mesmo que um ponto de coleta por tonelada de material.

\subsubsection{Comunicação}


Todos os resíduos recolhidos são reportados aos sistemas das suas respectivas ORP pelas empresas de reciclagem. Elas devem comunicar a quantidade de material recolhido, por categorias de equipamentos, informar quais produtos foram gerados com a reciclagem e seu destino. Relatam, por exemplo: foram gerados tantos quilos de ouro com a reciclagem dos equipamentos de pequeno porte e eles foram vendidos para um determinado produtor de EEE. O governo tem acesso a todos esses dados, já que é responsável pela auditoria das organizações.

SGF2 - O controle do que foi recolhido é feito pelos sistemas da SENS e da SWICO. As cifras estatísticas da coleta nós estamos verificando porque faz parte da auditoria que fazemos. As empresas de reciclagem que fazem parte do sistema de LR de EEE da Suíça precisam reportar a quantidade de material recebido e diferentes grupos de materiais, grandes EEE, pequenos EEE e têm que entregar também os produtos que produzem, por exemplo, tantos metais desse tipo e reportar para onde vão seus produtos.

De acordo com SENS, SWICO, SLRS (2017), os relatórios de reciclagem não têm apenas a função de quantificar os REEE reciclados e apresentar a viabilidade econômica do sistema, mas mostrar se o sistema de reciclagem e seus requisitos são ambientalmente benéficos.

O objetivo é, portanto, não só manter um olho nos custos financeiros no interesse das partes interessadas envolvidas, mas também para manter um equilíbrio em termos do impacto ambiental. Conhecimentos científicos, técnicos e práticos consideráveis são necessários para saber se algo é ambientalmente benéfico. É por isso que faz sentido que a lista dos autores deste relatório técnico seja como "quem é quem" de especialistas técnicos suíços neste campo. Sem a sua perícia, não seria possível lidar com o desenvolvimento dos requisitos para uma boa reciclagem de tal forma que eles fizessem tanto sentido financeiro quanto ambiental. (SENS, SWICO, SLRS, 2017)

\subsubsection{Poder}

Dessa forma, as ORP têm o poder sobre a gestão do REEE, desde que respeitem os requisitos estabelecidos pelos conselhos de cada entidade, formados pelos produtores, e demonstrem ao governo que os seguem por meio das auditorias.

\subsubsection{Mecanismos de controle}

Ainda que o poder fique centralizado em cada entidade, todo o sistema é controlado de forma bastante rígida pelo EMPA, por meio das auditorias. Nesse caso, são feitos testes que 
determinam a quantidade esperada de materiais gerados pela reciclagem de cada tipo de REEE e que ajudam a controlar todos os fluxos desses resíduos.

\begin{abstract}
SGF2 - Nós, da parte da auditoria, controlamos e fazemos ensaios de lotes e verificamos a quantidade de produtos que podem sair de cada um deles. Nós também vamos nas empresas de reciclagem fora do país para verificar se elas também estão fazendo os processos corretamente. Nós auditamos todo o sistema. Assim nós temos um controle bastante rígido referente a todos os fluxos de material. Isso tudo está sendo gerido pela SWICO e pela SENS, mas por trás tem a gente.
\end{abstract}

Esses testes são tão precisos que são capazes de terminar a porcentagem de REEE, por tipo e toneladas, que vão para as plantas de reciclagem, a quantidade de plástico que não poderá ser vendido e irá para a incineradoras e qual a porcentagem que será utilizada, por exemplo, na mistura do concreto.

SGF2 - A taxa de reciclagem é variável dependendo do tipo de REEE. Então, para saber o valor dessa taxa nós fazemos um ensaio. Por exemplo: vamos processar 10 toneladas de grandes EEE, e o que resulta disso é que 7 toneladas vão para a planta de reciclagem, uma certa porcentagem de plástico vai para incineradoras, pois não se pode vendê-lo, e uma certa porcentagem tem que depositar, por exemplo, no concreto.

Com todo esse controle baseado nos ensaios das amostras, é possível calcular as taxas de reciclagem e valorização dos REEE, usando como referência as normas da União Europeia. Dessa forma, é possível saber se as empresas de reciclagem estão atendendo às taxas mínimas exigidas por lei.

SGF2 - Tendo todas essas cifras, podemos calcular as taxas de valorização e reciclagem segundo as normas que existem neste tema. As normas europeias, que determinam claramente como devemos calcular essas cifras. E verificamos se uma empresa está com as suas taxas de reciclagem do mínimo exigido pela lei.

Todo esse rigor e acompanhamento dos resultados da coleta e reciclagem nos últimos 20 anos, permitiu que o governo constatasse que, nos últimos 10 anos, o uso de metais na composição dos EEE diminuiu muito, e, por outro lado, a quantidade de plástico aumentou a ponto de ter mais plástico do que metais nos EEE.

SGF2 - Como temos as quantidades dos últimos 20 anos, tanto dos resíduos coletados como das substâncias que os compõem, podemos dizer que a parte reciclável que são os metais, diminuiu muito nos últimos 10 anos, e tem muito mais plástico e menos metais. 
Esse controle é muito importante, já que um dos maiores objetivos da LR de REEE é a recuperação de materiais com o aumento da taxa de reciclabilidade. Para isso, os testes para determinar a composição dos REEE são repetidos a cada dois anos. Dessa forma, é possível fazer uma pressão na indústria para que ela melhore a qualidade dos plásticos utilizados nos seus EEE e evite que sejam contaminados por retardantes de chama, viabilizando uma taxa de reciclagem melhor.

SFG2 - A cada dois anos nós fazemos um teste para saber como está a composição dos EEE. E o que se pode realmente reciclar, por exemplo, em relação ao plástico, existe uma pressão forte, para que eles possam ser reciclados, pois para poder chegar à maior taxa de reciclabilidade é necessário que os plásticos também o sejam. Pois alguns não podem ser reciclados por ser de má qualidade ou por conter retardantes de chama.

\subsubsection{Riscos}

Com todo esse controle e papéis bem definidos, nenhum dos entrevistados apresentou dados referentes a riscos nos processos da LR de REEE.

\subsubsection{Os atributos da Dimensão "Impactos" na LR de REEE na Suíça}

A colaboração e a cooperação são apresentadas como fatores chaves para o sucesso da LR de REEE e motivo pelo qual tudo funciona melhor na Suíça. A solidariedade entre os atores da indústria foi o ponto de partida para a busca da criação dos sistemas de LR. Nesse sentido, a palavra solidariedade surge como sinônimo para a vontade a atuar junto com pessoas com as quais já se tem afinidade para realizar algo que, sozinho, não se seria capaz de fazer. Além disso, na Suíça, o governo tem a cultura de cooperar e colaborar nos processos da administração pública, para melhor atender a população, sob a pena de ter suas leis ou atos contestados pelos cidadãos que podem atuar com a criação de um referendo.

SGF2 - A cooperação é fator chave, é uma das razões porque aqui as coisas funcionam melhor do que nos outros países. Existe essa cultura de colaboração da parte do governo central principal até o município pois sabem que teremos votação de muitas coisas. [...] Então, os políticos têm sempre que buscar soluções que são aceitáveis para a população.

SRC2 - O ponto relevante foi o produtor, todo o resto veio depois e veio mais tarde. Então o ponto relevante é que você tenha uma solidariedade entre produtores. 
Dois resultados claros da cooperação e da colaboração na LR de REEE da Suíça são, respectivamente, os números dos sistemas de reciclagem e a elaboração da lei de LR de REEE. Atualmente, coleta-se cerca de $16 \mathrm{~kg}$ per capita por ano de REEE, devido às parcerias das ORP com a municipalidade e os recicladores. Nesse contexto, a colaboração entre governo e ORP normatizou a obrigatoriedade dos consumidores fazerem o descarte dos REEE e das empresas de EEE participarem de um sistema de LR.

SGF2 - O sucesso da LR de REEE é reflexo dessa cooperação entre os atores. Hoje, coletamos cerca de $16 \mathrm{~kg}$ de REEE por habitante por ano aqui no nosso país, muito além do que atingem a maioria dos países da União Europeia.

SGF1 - Isso (a Lei que obriga que o consumidor faça corretamente o descarte do REEE) foi resultado da colaboração entre o governo e a organização (ORP).

O desenvolvimento do volume de REEE processados na Suíça pela SWICO e SENS pode ser visto na Figura 10, separados por categorias. De 2003 a 2016, esse volume passou de 38.000 toneladas para cerca de 131.800 toneladas, um incremento de $288 \%$ em 13 anos. A categoria que teve a maior redução foi a NON-ORDEE, que pertence aos REEE que não estão incluídos nas listas da ORDEE.

Figura 10 - O volume de REEE processados na Suíça pela SWICO e SENS de 2003 até 2016

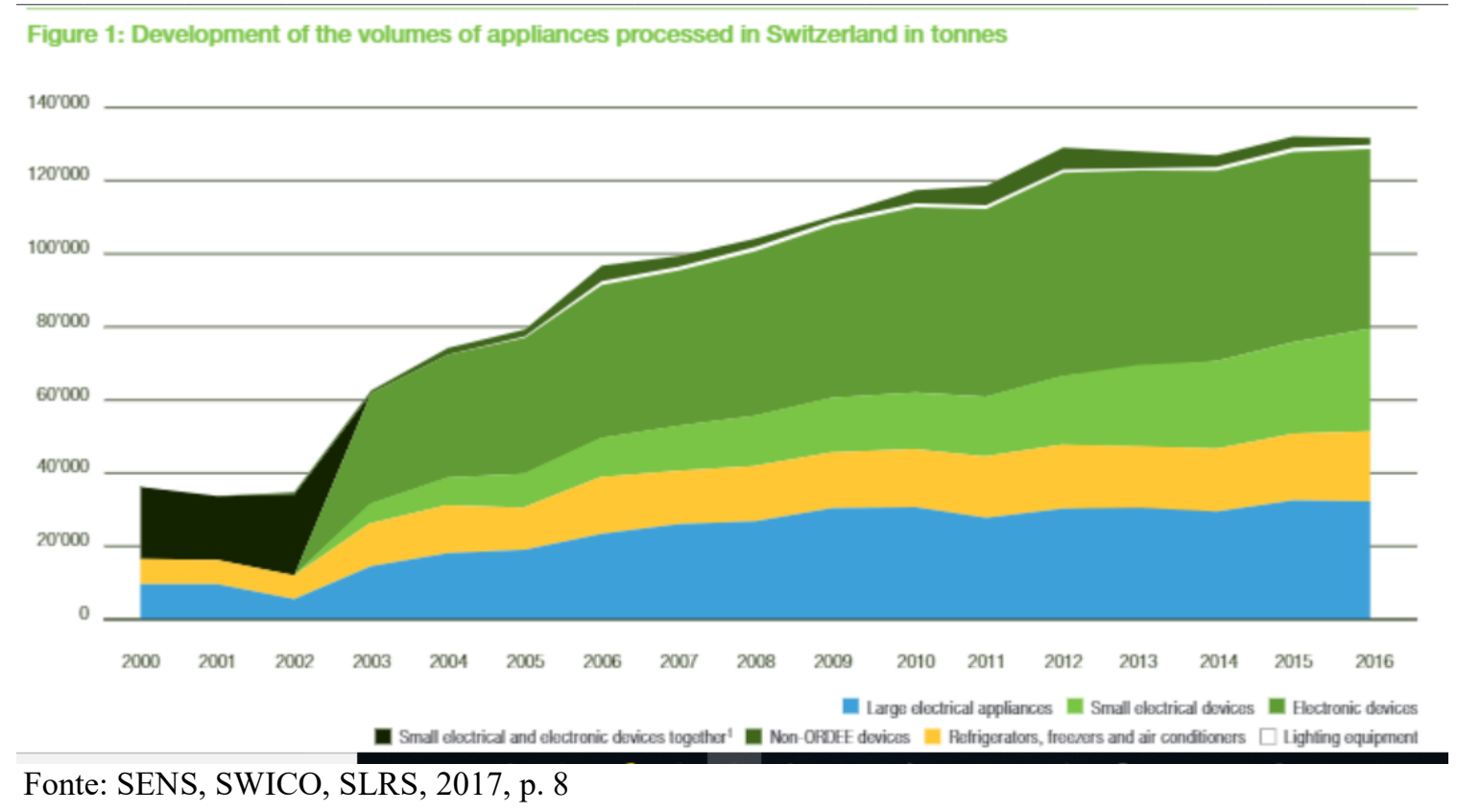

Nesse cenário, dois fatores atuaram como facilitadores para a adesão da indústria ao sistema coletivo de LR de REEE: o senso de comunidade e a pressão das grandes marcas e do governo sobre atores que ainda não tinham se juntado à ORP. 
SGF2 - É claro que alguns dos produtores não se sentiam obrigados a entrar nesse sistema de LR, mas a pressão aumentou com as marcas grandes pressionado as marcas que não se juntaram. Assim como o governo também as pressionou ao fazer com que elas se juntassem ao sistema coletivo.

SRC2 - Foi bem fácil e simples, porque eles se conheciam por serem membros da SWICO, então já havia um senso de comunidade. Eu digo isso porque é um ponto muito importante e isso é muito difícil hoje, [...] É muito difícil conseguir todos no mesmo lugar. Porque no nosso sistema, que é voluntário, é importante ter a maior parte dos produtores do seu lado, para que possa pressionar quem não é parte.

A capilaridade foi uma das estratégias adotadas pelas ORP que ajudou nos resultados atuais. De fato, desde o começo foram criadas parcerias com os supermercados e com varejistas para atuarem como postos de coleta. Soma-se a esse sistema todos os pontos de coletas de resíduos municipais, que atuam de forma voluntária, assim como os postos sediados nas empresas de reciclagem. Toda essa capilaridade do sistema de LR facilita o descarte para o consumidor, de tal forma que ele não precise ir muito longe para efetuá-lo.

SGF2 - Uma das razões principais para esse resultado é que, desde o começo, eles integraram supermercados ao sistema de LR. Então o consumidor não precisa ir muito longe, porque em cada esquina tem uma loja de EEE. Mas também os municípios têm seus pontos de coletas, algumas empresas de reciclagem também têm pontos de coleta. Isso é um dos fatores. [...] E o sucesso também é porque eles ofereceram a coleta dos REEE nas lojas.

Nesse cenário, os esforços voluntários das empresas em buscar soluções coletivas para a questões dos REEE são reconhecidos como um fator muito importante na primeira etapa de formação do sistema de LR de REEE no país. Foi feita muita propaganda para os supermercados e para os municípios sobre as vantagens e importância dos sistemas voluntários.

SGF2 - Mas assim, com muitas propagandas para supermercados e os municípios começaram a criar um sistema. Um passo muito importante dessa primeira fase era a disponibilidade voluntária dessas empresas na busca de soluções.

Salienta-se ainda que, além da capilaridade oferecida pelos sistemas voluntários, o alto nível de conscientização ambiental da população contribuiu para os resultados atuais. Reciclar e cuidar do ambiente externo, como sendo extensão da sua casa, é algo natural para o cidadão suíço. Esses dois fatores diminuem a necessidade de investimento em educação ambiental para incentivar o descarte.

SGF2 - Outro fator é que a Suíça é um país muito pequeno, onde já temos uma disciplina de reciclagem muito bem estabelecida pois coletamos tudo já faz muitos 
anos: papel, vidro, tudo. E temos números muito altos, existe uma cultura de reciclagem, que se manifesta com altas taxas de coleta.

SRC2 - O ponto é que existem tantos lugares onde você pode descartar, que seria muito mais difícil ir jogar na natureza, mais perigoso, seria criminoso. Você teria um peso na consciência e seria um infortúnio, porque com esse sistema de coleta, nós temos 6000 lugares no país onde você pode descartar as coisas. [...] Então o que realmente não faz sentido é não fazer o certo. E é claro que isso é algo que foi desenvolvido com o tempo, e agora absolutamente não é um problema, e nós não precisamos fazer grandes campanhas, ou falar para não jogar fora, porque ninguém faria isso

Outro fator forte é a predisposição em ser sustentável e o orgulho de fazer a coisa certa, da melhor forma possível, se tornando referência.

SRC2 - Nossas regras funcionam como uma base a ser desenvolvida no resto da Europa. Porque os esquemas estão trabalhando juntos e agora isso se juntou à norma europeia EN 50625. Que é uma norma europeia, com várias sub-normas em que são reguladas a coleta, o transporte, e também todas as coisas que falamos, também regras técnicas. É certamente um documento interessante para pessoas que estão procurando quais são os níveis de qualidade necessários para a reciclagem de REEE.

Além do aumento da quantidade coletada pelo sistema, outro resultado positivo da LR de REEE no país é o aumento da rentabilidade no processo de reciclagem devido à diminuição de substâncias tóxicas na composição dos EEE, como nas televisões de tela plana, que não contém mais mercúrio.

SGF2 - Por exemplo, há menos componentes tóxicos. Agora temos telas planas que não contém mercúrio. Além disso, os tubos de raio catódico dos televisores pesados também estão desaparecendo. Há uma evolução tanto da quantidade, quanto da composição dos EEE que são coletados e o rendimento econômico das empresas de reciclagem está se desenvolvendo, está melhorando.

Mesmo com os resultados elevados da coleta de REEE, a falta de um sistema mais eficaz de financiamento da reciclagem, a ausência de tecnologias para reciclar alguns metais, como neodímio e cobalto, entre outros, e a necessidade de aumentar a taxa de reciclabilidade são apontados como desafios para a LR no país. Com efeito, para aumentar a reciclabilidade, é preciso investir em novas tecnologias e isso encarece o sistema. Por outro lado, os produtores não querem aumentar a TAR, pois, desse modo, acreditam que estariam incentivando os consumidores a comprar mais EEE na UE do que já ocorre atualmente. Esse fator agrava o modelo atual de financiamento da reciclagem, pois quando uma pessoa compra seu EEE fora do país, mas o descarta no sistema suíço, a diferença entre a TAR arrecada e os REEE coletados no sistema de LR aumenta, sobrecarregando e encarecendo o custo da reciclagem do sistema 
de LR de REEE da Suíça. A conscientização e predisposição para ser sustentável do consumidor inspirou a criação de um aplicativo que possibilita o pagamento voluntário da TAR ao sistema de LR do país, como forma de minimizar o problema dos EEE comprados fora.

\begin{abstract}
SGF1 - Os desafios são reciclar mais material [...] Neodímio, cobalto e todos esses tipos de metais que precisamos achar um jeito de reciclar. Temos que ter um financiador para um sistema de reciclagem mais eficaz, que é o consumidor, mas se ele não paga a taxa de reciclagem, porque ele compra o equipamento na UE, e isso é um problema. O consumidor está comprando EEE fora da Suíça, então ele não paga a taxa de reciclagem. A gente gostaria de reciclar mais, mas temos que motivar o produtor a ter uma maior TAR, de modo a pagar a reciclagem desses metais. Mas ele não quer ter uma TAR mais alta, porque se não, o consumidor compra o equipamento da EU.

SRC1 - A Suíça é bem cara, então todos vão comprar produtos além da fronteira, na Alemanha ou na Itália. E eles não pagam nenhuma taxa de reciclagem. Nós temos um aplicativo pelo qual você pode voluntariamente pagar a taxa de reciclagem de produtos adquiridos fora da Suíça que você traz para cá. Outro problema que nós temos é com compras online. Compras online têm crescido bastante e ainda não achamos uma solução. Estamos rastreando dois diferentes problemas: por exemplo, que o governo vá atrás de cobrar a taxa de um produto importado adiantadamente, e o segundo problema são os serviços postais, que eles também podem fazer o serviço, e é dessas duas coisas que estamos indo atrás.
\end{abstract}

Além disso, a legislação sobre REEE não aborda a necessidade dos produtores desenvolverem seus EEE baseados no ecodesign. Dessa forma, quase não se percebe o investimento em tecnologias para melhorar a reciclagem, nem a reciclabilidade dos REEE, de acordo com SFG1.

SGF1 - Acho que tem menos impacto no ecodesign porque nós não o vimos ainda. Nós gostaríamos de colocar alguns aspectos do ecodesign mas é realmente difícil, porque não está na Lei [de LR de REEE], não é regulamentada para isso.

Outro problema que pode afetar a TAR são os free riders. Ainda que eles sejam apenas dois e conhecidos pelo sistema, sua existência parece incomodar muito os atores da LR na Suíça. Por isso, com o objetivo de alertar a população sobre o mau comportamento desses dois comerciantes de REEE, foi feita uma lista negra de empresas que não aderiram a nenhuma ORP e que, portanto, não contribuem para o bom funcionamento do sistema de LR de REEE.

SRC1 - Nós temos free riders, temos dois grandes free riders. Eles são comerciantes, estão na Suíça, e fizemos uma lista negra. Fizemos uma lista de todos os que estão usando, mas não estão dividindo o sistema. E isso é público. 


\subsection{ESTUDO DE CASO DA LR DE REEE EM PORTUGAL}

Esta seção apresenta o processo de elaboração e implementação da LR de REEE em Portugal, com o objetivo de levantar quais foram os fatores motivacionais para a implementação da LR de REEE e descrever como foi definido o escopo e estrutura para estabelecerem o processo de negociação e discussão entre os atores envolvidos nessa cadeia e o governo. Além disso, será analisado como este processo se deu na operacionalização da LR, verificado como esses elementos impactaram na efetivação da colaboração e cooperação e quais resultados foram obtidos nesse cenário.

\subsubsection{Os atributos da Dimensão "Motivação" na LR de REEE em Portugal}

Está seção apresenta os atributos da dimensão "Motivação": necessidade, oportunidade e disposição na elaboração e implementação da LR de REEE em Portugal.

\subsubsection{Necessidade}

Segundo todos os entrevistados, a LR de REEE foi implementada em Portugal pela necessidade de atender à Diretiva de REEE da União Europeia: o Decreto-Lei n. ${ }^{\circ}$ 230/2004 que transpunha a Diretiva 2002/96/CE de REEE, aprovada em 27 de janeiro de 2002.

\footnotetext{
PGF1 - A LR de REEE iniciou por causa da diretiva.

PAC1 - O grande propulsor da LR de REEE na Europa são as diretivas comunitárias, que todos os estados membros têm que cumprir. E, portanto, quem não cumprir é penalizado. Isso é o motor que faz todos fazerem. A necessidade é política, dentro de uma lógica de sistema organizado. Então, aqui em Portugal foi mesmo por causa da
} diretiva.

De acordo com PGF1, Portugal tem suas próprias iniciativas no tema ambiental, como a LR de pneus. Tais iniciativas mostram seu desejo de ter uma gestão sustentável, para mitigar o impacto de seus resíduos no meio ambiente. Assim, o entrevistado acredita que não é apenas para atender o diretiva que Portugal legislou sobre os REEE e implementou a sua LR de REEE, mas também pelo desejo de preservar o meio ambiente.

PGF1 - É claro que a gente tem a UE por trás da gente, mas nós temos as iniciativas portuguesas, como no caso dos pneus, que, em 2001, nós já tínhamos leis para a LR deles, antes da UE. Nós fizemos a lei porque achávamos que precisava e funcionou bastante bem. 
Outro elemento que corrobora a vontade do governo de fazer uma gestão sustentável dos seus resíduos é o Decreto-Lei n. ${ }^{\circ}$ 20/2002, de 30 de janeiro de 2002, que versa sobre a gestão integrada dos resíduos, em especial dos REEE, e foi publicado apenas três dias depois da primeira diretiva sobre o mesmo resíduo, a Diretiva 2002/96/CE. No decreto, estava previsto que o sistema de gestão dos REEE seria baseado no princípio da responsabilidade do produtor, consonante com as Diretivas da UE, e deveria ser implementado e ter as metas atendidas até 31 de dezembro de 2003. A lei também previa a criação de entidades gestoras, organizadas pelos produtores, que seriam responsáveis pela gestão do REEE, desde a coleta até a sua destinação ambientalmente correta. $\mathrm{O}$ decreto também previa a participação dos municípios na coleta de REEE, que, por sua vez, teriam que disponibilizar locais para descarte desses resíduos. A meta, no entanto, era a metade daquela exigida pela UE, apenas 2kg/hab/ano (MAOT, 2002). Observa-se que o decreto não foi citado por nenhum dos atores entrevistados. Eles citam apenas o Decreto-Lei 230/2004, que transpunha a Diretiva de REEE de 2002.

PGF2 - Cabe ao Estado, através do departamento governamental com atribuições na área do ambiente e organismos sob sua tutela, garantir que os sistemas de recolha de REEE, que, nos termos do presente diploma, devem ser constituídos até 13 de Agosto de 2005 , cumprem os requisitos estabelecidos no artigo $11^{\circ}$, tendo em conta o objetivo fixado no $\mathrm{n}^{\mathrm{o}} 10$ do presente artigo.

Para a Câmara de Lisboa, contudo, a gestão dos REEE é uma obrigação legislativa da municipalidade, já que ela sempre foi responsável pelos resíduos urbanos. Entende-se, portanto, que a necessidade de atender à legislação obriga-a a atuar na LR de REEE. Para isso, a Câmara de Lisboa se baseia no arcabouço legislativo de Portugal que começou a ser criado da década de 1970 e que, na década de 1980, instituiu a coleta seletiva. Vale ressaltar, entretanto, que os REEE não constavam dessas legislações. Para PGM1 e PGM2, no entanto, os REEE são considerados resíduos recicláveis e domiciliares, portanto precisam ser coletados pela Câmara também. Por isso, atualmente eles fazem parte dos sistemas de coletas dos REEE.

\footnotetext{
PGM1 - Em Portugal, já fazem muitos anos que a recolha dos resíduos urbanos é de responsabilidade das câmaras municipais. Nós definimos que a partir de 11001/dia são os grandes produtores de resíduos, e já não tem mais que ser o município a recolher. As câmaras sempre assumiram a recolha dos resíduos da sua área, inclusive a dos REEE, então, no fundo, isso tem a ver com uma base legal, essa participação da Câmara Municipal na recolha dos REEE.
}

Outro aspecto levantado pela Câmara de Lisboa para sustentar a importância da sua participação na coleta dos REEE, é que o serviço de coleta necessita de proximidade com a 
população. PAC1 corrobora a necessidade da Câmara fazer parte da coleta para garantir a capilaridade do sistema.

PGM1 - O serviço de recolha é um serviço de proximidade com o cidadão, então deve ser feito por quem tem essa proximidade com o cidadão.

PAC1 - Quando você coloca a Câmara, as lojas e as EG para fazer a coleta, isso aumenta a capilaridade do sistema.

Além dos fatores legais e da proximidade com a população, a Câmara está preocupada também com problemas ambientais que podem ser gerados pela má gestão desses resíduos. Dessa forma, pretende evitar que os REEE, que contêm substâncias tóxicas e metais preciosos, sejam descartados junto com os resíduos urbanos, que são incinerados, contaminando o solo e o ar, assim como perdendo a oportunidade de recuperar os materiais valiosos que estão contidos neles.

PGM1 - É, portanto, para evitar ao máximo jogar no indiferenciado, depois ir para incineração. E tem os problemas ambientais com as substâncias tóxicas nos REEEs e a perda dos metais valiosos que são valorizáveis, ou fatalmente se eles forem para aterros, com todos esses problemas ambientais, a Câmara tem que ter mecanismos alternativos para os munícipes.

\subsubsection{Oportunidade}

Para atender à Responsabilidade Ampliada do Produtor sobre os REEE, os fabricantes e importadores de EEE em Portugal optaram por um sistema coletivo de gestão dos seus resíduos, executado pelas EG. O Decreto-Lei no 230/2004, que legisla sobre os REEE, prevê e ampara a criação tanto de sistemas coletivos, para que os produtores e importadores de EEE transfiram a responsabilidade da gestão dos REEE para uma EG, como permite que uma empresa crie seu próprio sistema de LR de forma individual. A maior motivação para isso encontra-se claramente nas oportunidades econômicas desse modelo, que viabiliza a LR de REEE, diminuindo os custos operacionais e aumentando a capilaridade. Entretanto, algumas empresas, como a Apple, chegaram a propor sistemas de LR de REEE individuais, mas nenhuma delas seguiu adiante.

PGF1 - Das duas uma, ou organizam-se em um sistema integrado, que é uma EG, ou vão ao mercado por meio de um sistema individual. Hoje, em Portugal, nós não temos sistemas individuais, porque é muito caro fazer isso. Nós tivemos duas ou três propostas de sistemas individuais, mas as empresas não tiveram pernas para fazer isso. 
Uma delas era da Apple. A Apple queria fazer isso para todos os países, era um mega sistema.

PAC1 - Esse fluxo baseia-se no princípio da responsabilidade alargada do produtor. Eles foram buscar parcerias por causa das sinergias. E, dessa forma, eles conseguem criar sistemas, em termos logísticos e mesmo em termos econômicos, mais viáveis economicamente. O sistema coletivo é melhor do que um sistema individual.

Outra vantagem dos sistemas operados pelas EG é que eles garantem maior capilaridade de pontos e formas de coleta. Dessa forma, diminuem a resistência dos consumidores para entregarem os seus REEE, pois diminuem as distâncias a serem percorridas por eles até um posto de coleta. O consumidor também pode entregar seu EEE de grande porte com o sistema de coleta em casa.

PGF1 - É mais fácil ter uma coleta com as gestoras, pois ela coleta de vários atores e garante várias metas. Dessa forma também se garante capilaridade.

PRC1 - Eu preciso ter uma capilaridade grande, pois o meu consumidor não anda mais que um quarteirão para entregar seu mix. [...] Nós procuramos expandir e estamos com a rede sempre crescendo. [...] Tentando angariar mais parceiros e mais tipos de parceiros.

Além disso, para PGF1, os resíduos representam uma oportunidade para gerar divisas. Dessa forma, quanto maiores as metas de reciclagem e o engajamento de todos, melhor.

PGF1 - Os REEE têm valor econômico. Todos os REEE dão retorno, não apenas os computadores e celulares.

O governo federal costuma chamar os atores de um determinado setor para conversar e colaborar nos processos de formulação de leis, transposição de Diretivas ou planejamentos de SI que estruturam o funcionamento de algumas normas ou decretos. No caso dos REEE, existe uma Comissão de Acompanhamento da Gestão dos Resíduos (CAGER), que é convocada sempre para debater sobre as novas leis nacionais ou suas alterações, nesse tema. Além disso, são chamadas as ONGs e as Câmaras que fazem parte da Associação Nacional de Municípios Portugueses, para colaborarem em todas as leis elaboradas em Portugal.

PGF1 - Sempre que transpomos uma diretiva ou novas leis, elas têm que ir aos interessados. No REEE, a gente tem uma comissão chamada CAGER (Comissão de Acompanhamento da Gestão de Resíduos). Eles podem dar opinião sobre o que está sendo elaborado, são considerados parceiros. Mesmo em nível de sistemas de informação a gente envolve, as vezes dizem coisas que são boas, e a gente acata e faz. Outras vezes não. 
PGM1 - Nós sempre somos chamados para dar a nossa opinião sobre as novas leis. Damos nosso parecer oral e por escrito. É porque nós, da Câmara de Lisboa, fazemos parte da Associação Nacional de Municípios Portugueses.

Esse envolvimento dos stakeholders na elaboração de leis é muito importante, pois garante que os atores se sintam parte do processo e possam opinar. Dessa forma, eles validam o processo. Para PGF1, os atores envolvidos com o tema de LR de REEE se sentem ouvidos em suas proposições, embora isso ocorra muito mais fortemente hoje, do que antigamente. Assim, observa-se que a participação e o interesse desses stakeholders é muito maior atualmente, talvez pelo fato da comunicação social ser mais efetiva.

PGF1 - Certamente eles sentem que sua opinião tem impacto. Mas eu acho que agora nota-se mais a ação deles do que antigamente. Naquela época, as coisas publicavamse e não havia sucessões. Uma ONG ou outra que falavam alguma coisa, mas agora tem muito mais ONGs.

PGM1 - É muito importante que nós sejamos ouvidos, que nós possamos contribuir. Mas não sabemos até que ponto vamos ser ouvidos, é muito importante estar lá, é muito importante a partilha e o envolvimento de várias entidades. Essa parceria é importante, os municípios interagirem uns com os outros.

Esse mecanismo participativo no processo de elaboração de leis e estruturas permite que os atores não só opinem, mas ampliem a visão de todos sobre o tema a partir da experiência de cada um. Esta estratégia também pode ajudar a fazer com que percebam a importância de elementos contidos na nova lei ou em sua alteração que, no princípio, não parece beneficiar a todos. Dessa forma, durante o processo de construção da lei, com o passar do tempo, os stakeholders entendem a necessidade daquele ponto e o validam. A participação os ajuda a sensibilizar outros atores que ainda estão contrários às mudanças. Assim, hoje os operadores de reciclagem atuam como intermediários entre o governo e o produtor, e são considerados aliados do governo. Mas PGF1 salienta que é importante envolvê-los desde o princípio para aferir esse benefício.

PGF1 - Temos o hábito de envolver. Se eles se envolvem desde o início e perceberem o porquê estamos fazendo aquilo, acatam. Por exemplo, uma guia eletrônica, uma guia de papel, eles reclamavam que isso ia atrasar, ia atrapalhar. Então houve um tempo que eles só viam os pontos negativos, mas ao longo do tempo, começaram a perceber que havia benefícios. E hoje em dia, os operadores são nossos veículos de comunicação com os produtores de resíduos, somos aliados.

PGM1 - Muitas vezes as entidades a nível nacional pensam num ponto de vista mais teórico, a ideia é boa, mas nós temos um ponto de vista mais empírico. Porque nós tivemos a prática, que resulta bem. Pois é muito importante que o plano teórico seja alinhado com o plano local. 
Esses resultados têm motivado a participação de um número cada vez maior de atores. A maioria é convidada pelo governo, mas outros se candidataram para participar desses processos espontaneamente. No ambiente da legislação, a admissão desses candidatos é feita pelo CAGER. Já as entidades ouvidas são escolhidas pelo governo federal.

PGF1 - Aumentou muito o número de stakeholders participando desse processo. Alguns foram captados, convidados pela gente, outros se ofereceram pra participar. No início, na verdade, fomos nós que procuramos eles, mas com o passar do tempo nós fomos procurados por um outro ator, que vem perguntar "eu posso participar também?". No ambiente da legislação, é uma comissão, que é a CAGER, que é responsável.

Essa motivação se reflete no aumento da disposição para incluir os atores em outros processos, inclusive incentivando que eles apresentem as suas propostas para que depois eles aceitem o que for acordado.

PGF1 - Agora, com as novas licenças, eles terão que padronizar isso. Estamos implementando um novo modelo de licenciamento desde 2015. Em vez deles colocarem para nossa aprovação as tabelas, eles têm que primeiro colocar todos os inputs, e depois o valor. Eles podem ir alterando isso ao longo da licença e se for $10 \%$, não precisa de aprovação. E é mais transparente.

\subsubsection{Disposição para atuar em conjunto}

Entretanto, nem sempre é fácil conciliar os desejos e garantir a satisfação de todos. De acordo com PGF1, o processo de negociação com os atores exige diálogo e envolvimento. No “início não é fácil garantir a satisfação de todos”, mas depois, quando os diversos atores vão entendendo os motivos para as novas demandas, eles mesmos ajudam a promover a ideia. Mas isso leva um tempo e disposição para negociar, segundo o entrevistado. Nesse cenário, nos recentes processos de elaboração de leis e diretrizes do novo licenciamento para REEE tem sido gerado um certo desconforto nas discussões, pois os stakeholders não concordam com as novas metas, e tampouco sentem que sua opinião está refletida no resultado final.

PRC1 - Agora estamos num processo de argumentação sobre as licenças dos EEE. Mas tipicamente os decretos de lei que têm relevância na nossa atividade e mesmo as próprias licenças, a APA nos envia as propostas para que nós possamos avaliar. Em nossa última experiência nesse processo de licenciamento, nós não tivemos margem para alterações do que foi proposto. Tivemos obviamente abertura para propor aquilo que achávamos mais adequado, sobre alterações. Mas depois, a decisão final, eu posso dizer que não espelhou as nossas considerações. 
Mesmo assim, Portugal parece apresentar uma disposição para atuar em conjunto. Segundo PGF1, o país é dividido em 23 sistemas para gestão dos resíduos, nos quais cada um é formado por um grupo de municípios, visando criar sinergia para operar melhor. Além disso, a colaboração dos diversos atores na elaboração de leis está garantida por lei em Portugal, de acordo com PGF1, pois todos os projetos de lei precisam passar por consulta pública.

PGF1 - A responsabilidade de gestão dos RS é dos Municípios. Mas os municípios se organizaram em 23 sistemas. Então, eles se juntam em um conjunto de câmaras (municípios) e criam seus sistemas. [...] Elas se juntam para criar sinergia e formam uma empresa responsável. Eles criaram, cooperação entre si.

PAC1 - Aqui, para qualquer projeto de lei é obrigatório a consulta pública. Todos os stakeholders participam.

Embora as leis favoreçam o parecer de todos os envolvidos, os fabricantes e importadores não costumam questionar nenhuma transposição de Diretiva ou lei. Além disso, desde que o país entrou na UE, acatou tudo o que foi definido pela comissão da UE, sem ressalvas.

PGF1 - Aqui, a gente nunca teve os fabricantes fazendo um movimento contra a lei. Além do mais, é uma Diretiva comunitária. Portugal, desde que está na UE, aceita tudo que a comissão define.

\subsubsection{Os atributos da Dimensão "Escopo" na LR de REEE em Portugal}

Está seção apresenta os atributos da dimensão "Escopo": natureza, objetivos, resultados, e atores na elaboração e implementação da LR de REEE em Portugal.

\subsubsection{Natureza}

O caso de Portugal apresenta as problemáticas da colaboração na elaboração de leis e planejamento da estrutura de apoio dos sistemas criados por elas, assim como permite entender como ocorre a cooperação na operacionalização da LR de REEE.

PCA2 - A cooperação é importante na execução e a colaboração é importante no planejamento estratégico, na ativação de uma série de leis e por aí afora. 


\subsubsection{Objetivos}

O objetivo principal dos atores que participam da operacionalização da LR de REEE em Portugal é atender à Diretiva de REEE da UE, embora cada ator apresente objetivos secundários ao estabelecer parcerias para sua execução. O governo federal quer, além de atender às metas da UE, criar sistemas que garantam a transparência e o controle de toda a cadeia, da produção e venda do EEE à sua destinação final, seja ela o reaproveitamento ou o descarte ambientalmente correto. A Câmara de Lisboa quer garantir que esses resíduos não vão parar em seus aterros ou incineradores, assim como assegurar a saúde ambiental do distrito e a revalorização das substâncias valiosas dos REEE. As entidades gestoras, que representam os fabricantes e importadores, querem atender às metas estabelecidas na lei, assim como garantir a LR de REEE ao menor custo possível. E os OGR, que são contratadas pelos OG, querem garantir a sua participação nesse mercado, visando lucro.

No processo de elaboração de lei, por sua vez, cada um dos atores parece ter um objetivo principal e um secundário compartilhado por todos. Com exceção do governo federal que quer estabelecer as estruturas jurídicas, tecnológicas e físicas para viabilizar a LR de REEE. Os outros atores parecem querer defender seus interesses primeiro. É interessante notar, contudo, que, apesar de ter objetivos próprios mais fortes do que os do grupo, não parecem impor a sua vontade, aceitando as decisões superiores do governo federal. Nesse cenário, as EG querem evitar metas que consideram impossíveis, os OGR querem evitar sistemas que sejam complexos e deem mais trabalho para operar a LR de REEE e as Câmaras querem ajudar a elaborar uma política ou estrutura exequível que atenda à sua realidade e reflita a sua opinião.

PRC1 - Nós, enquanto EG, podemos contribuir para alcançar a meta nacional, mas não alcançamos. A meta é também a do país. Se nós não conseguirmos alcançar as metas, pois são muito exigentes, nós não vamos cumprir, mas o país também não.

\subsubsection{Resultados esperados}

Na operacionalização da LR de REEE, os resultados são quase todos tangíveis e estão estabelecidos por lei e contratos. No caso dos parceiros das EG, as contrapartidas estão estabelecidas pelos acordos que cada uma tem com a EG. Nesse caso, tanto as câmaras, quanto as escolas e bombeiros, sabem o que vão receber desde o princípio, assim como os prestadores de serviços. 
$\mathrm{Na}$ elaboração das leis, os resultados não são tangíveis para todos. De fato, alguns atores esperam melhorias da sua imagem, prestígio por participar e ser ouvido nesses processos, e outros querem estabelecer vantagens futuras, conseguindo influenciar as leis ou estruturas, no momento da sua elaboração. Esses elementos foram todos percebidos também como oportunidades, conforme apresentado na seção anterior.

\subsubsection{Atores}

A LR de REEE foi o primeiro setor a ter mais de uma EG atuando com os mesmos tipos de REEE em Portugal como concorrentes. Além disso, com a nova lei, elas poderão competir pelo mesmo fabricante ou importador, pois estes podem aderir a mais de uma EG para tratarem seus diferentes tipos de REEE. Um dos entrevistados mostra essa diferença de comportamento de mercando comparando seu modelo competitivo, com o da Suíça, que tem quatro EG que trabalham de forma complementar e cooperativa. Mas esse modelo não é apresentado de forma negativa pela AMB3E: ao contrário, a entidade gestora se diz acostumada com a competição e acredita que ela traz benefícios para o sistema por meio da competitividade.

\footnotetext{
PGF1 - Nós, em Portugal, temos duas entidades gestoras a AMB3E e a ERP. Mas vai entrar uma terceira no mercado, que é a WEEEcycle. Foram dois outros operadores que se zangaram com as EG anteriores e resolveram formar a WEEEcycle.

PRC1 - Agora, com essa nova lei, uma empresa pode ser atendida por mais de uma EG. Um produtor que coloca TVs e geladeiras pode aderir a uma EG para geladeiras e outra para TVs. Diferente da Suíça, onde a SENS e a SWICO trabalham de forma cooperativa, aqui é competição. Para nós, é natural trabalhar em concorrência. Os EEE foi o primeiro setor a ter mais de uma EG trabalhando desde o início. Do ponto de vista de mercado, é óbvio que a concorrência introduz competitividade.
}

Além das EG responsáveis pela gestão, participam da LR de REEE, os OGR licenciados para fazer o transporte dos pontos de coleta e a reciclagem. Da coleta, por sua vez, participam as lojas, as escolas e os bombeiros, em parceria com as EG. A Câmara também faz parte do sistema de coleta, pois o considera importante para os resultados da LR de REEE, já que Portugal é um país pequeno.

PGF1 - A Câmara ajuda na coleta dos REEE, pois Portugal é um país pequeno

Já na elaboração das leis e estruturas para a LR de REEE, participam os membros da CAGER e as Câmaras que pertencem à Associação Nacional de Municípios Portugueses. Além desses atores, participam ONGs e entidades envolvidas com o tema discutido, que são 
convidadas ou aceitas pelo Governo Federal. Se for no âmbito da legislação, quem decide sobre a admissão desses atores é a CAGER.

\subsubsection{Os atributos da Dimensão "Estrutura" na LR de REEE em Portugal}

Está seção apresenta os atributos da dimensão "Motivação": necessidade, oportunidade e disposição na elaboração e implementação da LR de REEE em Portugal.

\subsubsection{Atividades}

A operacionalização da LR de REEE em Portugal iniciou-se em 2005 com papeis bem definidos pelo Decreto-Lei 230/2004, que transpunha a Diretiva de REEE da UE. Dessa forma, cada ator sabe onde começam e terminam suas atribuições.

Nesse cenário, a APA, que representa o governo federal, tem o papel de legislar e transpor as Diretivas de REEE dando apoio ao Ministério do Ambiente. Além disso, ela registra os EEE colocados no mercado, licencia as EG e acompanha suas ações e relatórios no que tange à gestão dos REEE e seus fluxos. Como a APA não tem papel fiscalizador, sempre que ela tem dúvida sobre a idoneidade de algum EEE em circulação ela pede para Autoridade de Segurança Alimentar e Econômica (ASAE) verificar, pois é a responsável pela fiscalização dos produtos colocados no mercado.

Os OGP, fornecedores das EG, são licenciados e fiscalizados pela CCDR (Comissão de Coordenação e Desenvolvimento Regional), outra instituição do governo federal, que atua de forma independente nas regiões do país. Portugal conta com mais dois agentes fiscalizadores para os REEE: a Guarda Nacional Republicana (GNR) e a Polícia de Segurança Pública (PSP), ambas responsáveis pela fiscalização dos diplomas (certificados) da APA. Dentro dessas entidades há as brigadas, SEPNA (Serviço de Proteção da Natureza e do Ambiente) e BriPAs (Brigadas de Proteção Ambiental), Elas são responsáveis por fiscalizar ocorrências ambientais no território português e, entre os crimes que fiscaliza, estão os de descarte ou de gestão incorretos dos REEE.

PGF1 - Agora você tem também o governo, que pela APA responde pelo licenciamento das EG. Mas os prestadores de serviços de reciclagem não são licenciados por nós, são licenciados pela CCDR (Comissão de Coordenação e Desenvolvimento Regional). A vantagem da CCDR é que ela licencia e fiscaliza e APA só licencia as EG. A APA dá apoio técnico ao Ministério do Ambiente para elaborar as leis, supervisiona os fluxos de informação, mas não pode fiscalizar. 
Fiscalizar ou é a CCDR ou é a Inspeção-Geral da Agricultura, do Mar, do Ambiente e do Ordenamento do Território (IGAMAOT). Essa Inspeção Geral faz sob a tutela de vários ministérios. A APA está sob a tutela só do MA. Depois temos os CCDR, e depois GNR (Guarda Nacional Republicana) e PSP (Polícia de Segurança Pública), todos os nossos diplomas ou certificados são fiscalizados pelos GNR e PSP, cada um dependendo da sua área. Isso tem a ver com regras do governo da parte interna. Dentro dessas forças, há brigadas próprias. Brigadas de meio ambiente. Dentro das GNR, há o SEPNA (Serviço de Proteção da Natureza e do Ambiente) e dentro da PSP há as BriPA (Brigadas de Proteção Ambiental). A colocação no mercado é fiscalizada pela ASAE (Autoridade de Segurança Alimentar e Econômica).

Nesse contexto legislativo, os fabricantes de EEE respondem por seus resíduos à REP. Portanto, para que cada marca possa colocar seus EEE no mercado, ela precisa estar associada a uma EG pelo menos, de modo a transferir a responsabilidade pela gestão dos seus REEE a elas, ou criar um sistema individual para fazer essa gestão. Como apontado anteriormente, em Portugal, optou-se apenas pelas soluções coletivas. Nesse caso, depois de associada a uma EG, a empresa precisa registrar seus EEE na APA para obter o número de registro, chamado de PT. Esse número prova que o produtor atende à legislação dos REEE e deve ser colocado na fatura de venda emitida ao distribuidor.

PGF1 - Para a marca poder colocar seu EEE no mercado, ela tem que estar associada a uma EG e tem que estar registrada, antes com a ANREEE, agora conosco, para ter um número que nós chamamos de $\mathrm{PT}$, e este número tem que vir na fatura de venda ao distribuidor. Esse número prova ao distribuidor que ele está trabalhando com alguém que está cumprindo a lei neste caso. Isso tudo está dentro de um sistema de informação integrado. É o mesmo sistema que eles cadastram os EEE quando gerados, dessa forma temos quase todos os dados dos EEE.

Em Portugal, existem duas entidades gestoras, até esse momento, conforme citado acima: a AMB3E e a ERP. Em breve serão três, pois a WEEEcycle também está sendo licenciada para operar com REEE.

PRC1 - Quem faz a gestão dos REEE são as duas gestoras, a AMB3E e a ERP. As associações de produtores não fazem nada disso.

As EG foram criadas para atender à Diretiva 2002/96/EC. Uma delas, a AMB3E, surgiu como resposta da Associação Empresarial dos Sectores Eléctrico, Eletrodoméstico, Fotográfico, Electrónico (AGEFE) à diretiva. A AMB3E foi licenciada em 2005 para atuar com os REEE, após apresentar um caderno de encargos para a APA. Na mesma época, a ERP, que já atuava em diversos países na Europa, decidiu licenciar-se separadamente, sendo licenciada em janeiro de 2006. 
PRC1 - A AMB3E começou em 2005. Nós temos uma associação em Portugal que se chama AGEFE. É uma associação portuguesa de produtores de EEE que acompanhou a implementação e discussão das diretivas comunitárias. No âmbito e questão dos REEE, foi no centro dessa associação que o conjunto de produtores de EEE se juntou e desenvolveu o primeiro caderno de encargos, submeteu-o à APA, e, desta forma, teve a licença para gestão de REEE. Então é aí que está a AMB3E.

As EG são responsáveis por atender a todos os objetivos, metas e requisitos impostos à gestão dos REEE. Para operacionalizar a LR de REEE, as EG contratam os OGR. Essas empresas fazem desde o transporte do ponto de coleta, armazenagem e consolidação, triagem, pré-processamento, reciclagem, até o tratamento ambientalmente correto desses resíduos. A mineração dos metais valiosos não é feita em Portugal por nenhuma delas, pois não existe essa tecnologia no país. Então, após o pré-processamento, esse material é enviado pela empresa recicladora, para uma planta de usinagem, onde é feita essa separação. As EG controlam esses fluxos por relatórios de rastreamento, mas não têm contato com os terceiros, contratados pelo OGR, como no caso da usina de mineração.

PAC1 - Essas EG têm uma rede de recicladoras que tem que cumprir os parâmetros de qualidade e que não ponham em perigo a saúde pública.

PGF1 - No caso dos REEE, as EG não têm um centro de consolidação, um armazém próprio. Elas têm contratos com esses operadores de gestão de resíduos que estão licenciados para receber esses códigos de REEE. É nos OGR que os REEE serão tratados ou serão armazenados para ser feita a triagem

PRC1 - Nós não temos contato direto com quem faz a usinagem. Nós temos relações contratuais com as empresas que fazem a distribuição para fazer o tratamento desses materiais $[\ldots]$ e acompanhamos a destinação.

Além dos OGR, as EG precisam criar uma rede de coleta com capilaridade, garantindo que todos os cidadãos possam fazer o descarte do seu REEE corretamente. Apesar de diferentes, elas fazem a coleta de forma similar. Para isso, criam parcerias com lojas, distribuidores, escolas e pontos estratégicos, onde deixam seus coletores de diversos tamanhos para atender às categorias de REEE de médio e pequeno porte. Nesse cenário, a AMB3E tem o Electrão e a ERP, o Depositrão, ambos coletores vermelhos.

PGF1 - Essas entidades formam uma rede de recolha, para que cada um dos cidadãos e das empresas possa entregar seus REEE. Elas têm equipamentos, nestes locais. Aqui na APA tem o Electrão, da AMB3E, e o Depositrão que é da ERP, onde nós podemos deixar os pequenos EEE. [...] As EG são diferentes entre si, mas parecidas na forma de recolha. Elas têm contratos com os distribuidores de EEE, com varejistas, fazendo protocolos com escolas, para deixar os equipamentos que são contentores. 
Os varejistas são obrigados por lei a cooperar com a coleta dos REEE conforme definido pelo Artigo 68 do Decreto-Lei 152-D/2017 de 11 de dezembro, que apresenta a obrigação dos distribuidores comerciantes, à luz da diretiva da UE. Eles podem, portanto, atender a essa exigência de duas formas. A primeira é disponibilizando um espaço na loja para a EG colocar os contentores para coletar REEE de pequeno e médio porte, quando essa tem uma área de $400 \mathrm{~m}^{2}$ ou mais. Nesse caso, o consumidor não é obrigado a comprar um equipamento novo para fazer o descarte, basta levar, por exemplo, seu secador de cabelo e descartar. As EG buscam disponibilizar esses equipamentos de coleta, de forma a que se adequem à necessidade do parceiro. Esses REEE são retirados pela EG, que tem um sistema de coleta porta a porta para lojas parceiras, roteirizado. A outra forma dos varejistas atenderem à lei é com a coleta umpara-um de grandes EEE. Ou seja quando o varejista vende e vai entregar uma geladeira, por exemplo, ele recolhe a outra veja sem cobrar nada, leva para seu depósito e quando atingir um determinado volume, chama a OGP contrata pela EG parceira.

\begin{abstract}
PRC1 - Nós temos parcerias com as lojas. Nós disponibilizamos tipicamente aquilo que eles nos solicitam. Normalmente, dentro da loja nós disponibilizamos caixas de papelão para lâmpadas, pilhas. Temos dois tipos de parcerias com lojas, ou a frente de loja ou o armazém. Muitas vezes, essas lojas funcionam em cadeia e fazem elas próprias a LR para seus armazéns. Então, nós vamos buscar lá no armazém, quando eles atingem um determinado volume e nos chamam. Também vamos à frente de loja, pois tem muitas lojas onde temos rotas já delimitadas, e vamos a elas fazer a coleta.
\end{abstract}

PGF1 - Os comerciantes têm a obrigação de receber um para um. Então, quando vão entregar um grande EEE, eles já buscam o antigo, como TV, geladeira, máquina de lavar roupa. Ele também tem que receber os pequenos EEE, como mix, mesmo, sem que eu compre um novo na loja dele. [...] Na verdade, os distribuidores comerciantes dão um espaço para se colocar os contentores que realizam essa coleta, quando a loja é maior que $400 \mathrm{~m}^{2}$, que são fornecidos pelas EG.

A rede de coleta de REEE das EG também é composta pelos municípios. Nesse caso, o consumidor pode deixar seu REEE na porta de casa, para ser atendido pelo sistema de coleta seletiva, com dias e horários preestabelecidos para cada região, ir a um dos pontos de descarte nos Ecopontos ou ligar na Câmara e pedir para retirarem seu REEE na sua casa, com horário agendado, todos sem nenhum custo extra. As EG mandam buscar esses resíduos nos locais mantidos pelos municípios e responsabilizam-se por eles desse momento em diante. Nesse cenário, de acordo com a maioria dos atores, garante-se uma cobertura mais ampla e flexível do sistema de coleta dos REEE, evitando sua chegada no aterro ou sejam descartados de forma inadequada. 
PGM1 - Os sistemas integrados de REEE visam evitar ao máximo que as pessoas depositem REEE no lixo comum porque são resíduos perigosos e valorizados. [...] Apesar dos sistemas um-para-um dos varejistas, a pessoa pode querer descartar a máquina antiga e não querer comprar uma máquina nova, porque agora está na moda compartilhamento desses equipamentos. Então nós damos outras alternativas para esse consumidor. Esses mecanismos são: recolha porta a porta com itinerários, o próprio munícipe pode se deslocar a um posto da Câmara e entregá-los, depositar lá sem qualquer custo ou ligar para a Câmara para ela buscar na sua casa, pois são resíduos urbanos também, e porque a câmara tem obrigação de recolher. Portanto, no fundo é garantir que a cobertura seja 100\% da recolha de REEE nesse caso.

Além dos sistemas de parceria com o município e os varejistas, que funcionam intermitentemente, as EG se juntam também às escolas e aos bombeiros para aumentar a capilaridade e conscientizar sobre a importância do descarte correto de REEE, sem criar conflito com as iniciativas existentes. Nesse caso, a coleta é incentivada por meio de campanhas que premiam os atores que mais trazem REEE. Umas das EG é reconhecida pelo forte trabalho que faz junto às escolas (PGF1, PAC1). De acordo com alguns entrevistados, dessa forma é possível transmitir a mensagem para toda a família do aluno e ao seu entorno, sendo uma das formas mais eficientes de conscientização (PAC1, PAC2). Para PRC1, tanto as parcerias com os bombeiros, quanto com as escolas, representam um potencial muito forte devido à proximidade e interação dessas instituições com a comunidade.

PRC1 - Quando nós buscamos parcerias com as escolas e com os bombeiros, nós queríamos criar mecanismos complementares de recolha, que não conflitassem com as iniciativas das Câmaras nem das freguesias. [...] Nós trabalhamos com estes atores, que, no fundo, têm muito potencial não só de interação com o meio social, mas também de recolha. [...] E aí criamos campanhas onde esses atores participam de concursos e premiamos quem recolhe mais.

O consumidor, por sua vez, tem a obrigação, estabelecida por lei, de descartar seus REEE de forma correta, em qualquer uma das opções oferecidas. Caso ele não realize o descarte corretamente, a lei prevê uma multa. De acordo com PGF1, contudo, isso dificilmente ocorrerá, devido à falta de fiscalização.

PGF1 - O papel do consumidor é devolver o REEE nos pontos adequados, pelos canais adequados. Caso ele não faça isso pela lei, ele pode ser multado, mas nós não temos fiscais para isso, então acaba não ocorrendo a multa.

Além dos atores previstos em lei, Portugal conta com a atuação do setor informal, à revelia de todos os atores da LR de REEE. Essas pessoas, que não têm um número de identificação fiscal e, portanto, não compõem o setor formal, atravessam o sistema de coleta seletiva das Câmaras. Elas passam antes do caminhão de coleta, furtando os REEE deixados na 
rua pelos munícipes no dia estipulado para seu descarte. Outro problema similar ocorre com os pontos de coleta em Ecopontos e pontos comerciais. Embora, nem sempre sejam visíveis para a população, são frequentemente furtados. Depois de desviados do sistema de coleta formal, esses REEE são levados para oficinas onde se retira suas partes valiosas que são vendidas para sucateiros de metais e o restante desses resíduos é descartado de qualquer forma, sem o devido cuidado com as substâncias tóxicas contidas neles. Esses sucateiros conseguem, de alguma forma, legalizar esse material, após fazê-lo passar por vários intermediários e fazer com que sejam comprados pelas EG por meio dos grandes recicladores, que são seus fornecedores.

PRC1 - Essas pessoas [setor informal que recolhe os REEE nas ruas antes das Câmaras], eu acredito que não tenham um NIF (número de identificação físcal). O que seguramente acontece é que nós não trabalhamos diretamente com esses atores. Nós trabalhamos com entidades que já transacionaram esses resíduos, alguns já com outros agentes. Acredito que seja uma cadeia alimentar que vai do menor, que passa por cima do sistema da Câmara, e que repassa para um maior, e assim por diante.

PGM1 - O que acontece, os mercados paralelos só estão interessados na parte de valor do REEE e deixam as partes que não têm valor nas vias públicas. Há problemas com CRCs, e por uma questão ambiental não queremos que isso aconteça.

A falta de leis que promovam a inclusão do setor informal na Europa é um dos fatores que vincula a existência desse ator na cadeia reversa dos REEE de forma clandestina. Outro motivo, elencado pelo setor de reciclagem, é a forte dependência que o sistema tem com grandes recicladores para alcançar as metas da LR de REEE e os baixos resultados dos sistemas municipais e intermunicipais de coleta de resíduos.

PRC1 - Na Europa, não há cultura de inclusão do mercado informal. As leis é que não estão formatadas para a inclusão desse setor. Nós, em Portugal, temos uma particularidade nos REEE: nós temos uma porcentagem bastante reduzida de resíduos recolhidos através de sistemas intermunicipais. Por contraponto temos uma porcentagem bastante elevada de recolha a nível de grandes recicladoras. Esses grandes recicladores já fazem a consolidação desses pequenos recicladores que estão no mercado informal. Se nós fôssemos entrar somente na parte municipal e intermunicipal, nossos números seriam diferentes do que são porque esse setor informal existe, e está atuando no nosso país.

Desde 2016, a meta é coletar 45\% do peso médio dos EEE colocados no mercado pelo produtor ou importador, nos últimos 3 anos. Mas isso vai aumentar para 65\% em 2019.

PGF1 - De 2016 para cá é 45\% do peso médio dos colocados no mercado nos últimos 3 anos. Antes era um valor por habitante. O nosso reporte do ano passado já é baseado nessa meta. A partir de 2019 , será $65 \%$ do peso médio dos EEE colocados em mercado. É uma meta ambiciosa. 
Para uma marca atingir a sua cota, ela não precisa necessariamente ter coletado REEE seus. Basta que a EG à qual ela está associada tenha coletado resíduos suficientes para atingir à sua meta.

PRC1 - Ou seja, nós, dentro do universo da recolha, nós não separamos por marca e não dizemos separamos $\mathrm{X}$ de Philips, Toshiba. Nós não fazemos isto. $\mathrm{O}$ que fazemos é: se a Samsung tem uma cota de mercado de X dentro do universo da AMB3E, o que nós fazemos no total de recolhas que nós tivemos podemos alocar esta parte para a Samsung ou a Philips.

\subsubsection{Recursos}

Todo esse sistema é financiado pelo produtor, por meio do Ecovalor, uma taxa destinada a pagar a LR de REEE. O fabricante ou importador paga à EG, no momento em que gera o EEE, o montante referente a sua cota de reciclagem, conforme estabelecido pela lei. A EG estabelece o valor do Ecovalor por categoria e cobra conforme seu modelo de gestão aprovado no licenciamento do seu sistema pela APA, ou seja, pode ser por unidade ou por peso, dependa da EG.

PFG1 - É, no fundo, quem coloca no mercado, o produtor do bem, que paga a prestação financeira para a EG fazer a sua gestão. Essa prestação financeira é paga quando o produtor coloca o bem no mercado. Algumas pagam semestralmente, outras anualmente.

Uma TAR é cobrada do consumidor, no momento que ele compra seu novo EEE. Mas ela não precisa ser declarada na nota fiscal do produto. Por isso, a maioria dos consumidores nem sabem que estão pagando esse serviço antecipadamente.

PGF1 - No caso dos EEE, não é obrigatório vir a taxa declarada na fatura. Pagar, eles pagam sim, só não sabem. Nos pneus é obrigatório vir na fatura o valor do Ecovalor, nos EEE é opcional. Nas pilhas portáteis é proibido. Cada fluxo tem suas regras. E é proibido pela Comissão Europeia.

Embora, de acordo com PGF1, a TAR não vá para o Estado como tributo, mas sim para as EG, não foi possível esclarecer se ela sofre tributação por estar embutida na NF, aumentando seu valor. No entanto, o Ecovalor, que deve ser coberto pela TAR, era muito mais elevado no início do que atualmente, pois, além de ser um sistema novo, era menos eficiente e sem escala (PRC1). De fato, a taxa precisava cobrir os REEE dos equipamentos que haviam sido vendidos 
antes da lei. Atualmente, o Ecovalor para uma geladeira é de 1,85 Euros e de um computador portátil, 0,07 Euros (PGF1).

PGF1 - Isso é separado porque esse dinheiro não entra para o Estado, esse dinheiro da taxa, eles entregam para a EG e é com este valor que organizam a sua rede e financiam o tratamento do resíduo. Quer dizer, pagam para a EG que é sem fins lucrativos. Então eu, como consumidora, vou à uma loja, compro meu EEE, e pago junto a taxa de reciclagem que está embutida. [...] Mas, no início, esse Ecovalor, que o consumidor paga para reciclagem junto com o aparelho, era muito mais alta., pois era justamente para cobrir os EEE antigos, anteriores, que foram vendidos anteriores à lei. Nós não temos mais esse problema.

PRC1 - No começo, as taxas de Ecovalor eram mais caras, porque era um sistema juvenil, as coisas não eram bem estipuladas. Depois, você consegue ganhos de escala e fomos conseguindo preços mais significativos com o amadurecimento do sistema.

Com os Ecovalores repassados às EG, elas pagam todos os prestadores de serviços e parceiros, como os bombeiros, algumas lojas que fazem parte da LR, sistemas municipais e intermunicipais de coleta, conforme o volume coletado.

PGF1 - Os varejista e distribuidores têm os valores de contrapartida quando recolhem os REEE na casa do consumidor e disponibilizam para a EG.

PRC1 - Nós temos algumas contrapartidas financeiras para grandes produtores de resíduos. Ou seja, acima de determinada quantidade, nós temos condições comerciais mais favoráveis. Por exemplo, para os bombeiros temos uma contrapartida específica para eles. Temos contrapartidas para os sistemas municipais e intermunicipais e também para alguns produtores de resíduos.

\subsubsection{Comunicação}

A comunicação entre os atores é feita periodicamente por meio de relatórios, trocas de e-mails e sistemas de informação. Nesse contexto, as EG entregam relatórios anuais para a ANREE e, a partir de 2018, para a APA. Neles, precisam comprovar o cumprimento de metas de coleta, reutilização e valorização, assim como os valores gastos com investigação, desenvolvimento e conscientização ambiental, além de quanto arrecadaram para o fundo do Ecovalor.

PGF1 - As EG têm que entregar um relatório anual até 31 de março. Depois têm que evidenciar o cumprimento de meta de recolha/coleta, reutilização e valorização e também têm que gastar dinheiro com a investigação e desenvolvimento e a conscientização. E têm que dizer o Ecovalor que vão angariando, isto é o desempenho delas, dizer o fundo do Ecovalor. Esse relatório de atividades deve estar com muitas informações. 
Além disso, as EG fazem relatórios anuais personalizados para os produtores com os dados de coleta e o valor da cota perante ao valor de mercado desse serviço. Mas as empresas podem solicitar um novo relatório a qualquer momento. Em contrapartida, os produtores e importadores precisam declarar as vendas no sistema integrado da EG, na área do cliente, trimestralmente. Já os OGR declaram diariamente dados da coleta de REEE, na área do fornecedor.

\begin{abstract}
PRC1 - No início deste ano, nós temos os reports, mas fazemos relatórios personalizados ao produtor. Fazemos um relatório para cada um deles, para transmitir quais foram os resultados principais da nossa associação, ou qual é a cota ou tributo, face à cota do mercado, que eles têm aqui dentro no universo das recolhas e do tratamento, e fazemos divulgação numa base anual para grandes produtores. Ou seja, proativamente, nós anualmente fazemos esse report. Se algum desses produtores pedir algum relatório, nós enviamos. Trimestralmente, o produtor tem que declarar as vendas na área de clientes. $\mathrm{Na}$ área de fornecedor, todos os dias é colocado a recolha. Anualmente fazemos o report que transmitimos a fornecedores $\mathrm{e}$ aos clientes/empresas.
\end{abstract}

As EG também apresentam relatórios anuais para seus fornecedores, com os resultados apurados sobre as taxas e resíduos perigosos. Além de disponibilizar os relatórios de atividades no site, dando transparência ao processo.

PRC1 - Para operadores de tratamento, que são também outros parceiros importantes, também transmitimos os resultados, quais são as taxas que nós apuramos, quais são os resíduos perigosos que nós apuramos. Ou seja, nós, antes de divulgar os resultados à APA, reportamos a eles. Além disso, temos no nosso site os relatórios de atividades publicados. Tem todos os tipos de recolhas, tem todas as quantidades desde 2007.

A comunicação feita pelas EG ao consumidor tem o objetivo de oferecer educação ambiental sobre a importância da LR de REEE e informações de como o resíduo pode ser descartado. Esse processo, assim como a pesquisa e desenvolvimento para soluções em REEE, é determinado por lei e o orçamento para realizá-lo é baseado em um percentual do Ecovalor arrecadado. Para atender as exigências relativas à comunicação, as EG fazem campanhas em escolas, junto aos corpos de bombeiros, e em locais públicos, com palestras, cartazes, distribuição de materiais didáticos, jogos e premiações para incentivar o descarte, bem como propagandas nas rádios e televisão, mesmo que estas se limitem a datas específicas. De acordo com alguns atores, o canal mais utilizado pelas EG e que alcança maior êxito são aqueles dirigidos para as escolas. Entretanto, esses esforços não têm sido suficientes. Alguns consumidores, que não estão relacionados com o universo escolar, só conhecem os serviços fornecidos pelas Câmaras, que recolhem resíduos volumosos, tanto o de porta em porta, como 
através do telefone para agendamento de retiradas desses REEE, e acreditam que este é o lugar para descartar pequenos eletrônicos, e não os contentores amarelos, que aceitam embalagens, plásticos e metais, distribuídos pelos municípios, para a coleta seletiva.

PRC1 - Somos obrigados a gastar dinheiro com comunicação e desenvolvimento. [...] Em termos de comunicação, nós temos vários meios de comunicação, um deles associado à vertente da escola, o Electrão. Fazemos palestras em todas as escolas, fazemos material de comunicação, material didático, com Quiz. Falamos sobre os resíduos perigosos, o que causa, quais são as vantagens de recolher e entregar nos locais apropriados. Portanto as escolas são veículos muito importantes na nossa vertente de comunicação. Depois temos outros canais, obviamente, voltados para produtores, distribuidores e instaladores, que também transmitem informação que é necessário fazer a recolha e entregar nos pontos apropriados. Já tivemos campanhas publicitárias na televisão, e [...] conseguimos transmitir a mensagem do ponto Electrão.

PAC1 - As EG têm a obrigação, na licença que lhes foi autorizada, de investir um percentual na comunicação e informação e outra porcentagem em investigação. Portanto, compete a elas fazer esse esforço. Mas, na minha visão, elas deixam muito a desejar.

\subsubsection{Poder}

Nesse cenário, com todos os atores tendo seus papéis bem definidos, o poder se mantém no âmbito da operação e cada organização controla seu processo, dentro dos requisitos estabelecidos por leis e contratos. Ainda que o governo demonstre ter força na definição de processos, ele não interfere na operação dos atores, nem os impõe compulsoriamente, apenas exerce o papel de legislador e fiscalizador.

\subsubsection{Mecanismos de controle}

Para garantir a transparência e o cumprimento de todas as regras, todos os stakeholders precisam enviar seus dados ao sistema do governo federal. No caso das EG, todos os dados enviados ao sistema precisam ser auditados, assim como precisa ser comprovado o nível de eficiência dos investimentos feitos em comunicação, baseado em critérios mínimos estabelecidos por lei.

PGF1 - Para comprovar, eles têm que enviar as fichas de projetos completos com indicadores, como, por exemplo, público alcançado. Se o indicador for baixo, nós não aprovamos. Nosso nível de campanha de comunicação tem spots na rádio, na televisão. 
Os fabricantes e importadores precisam estar vinculados a uma EG licenciada e possuir o registro do produtor, que é tirado na APA, pelo SILiAmb (Sistema de Licenciamento Integrado Ambiental). Desse modo, fica garantido que todos os EEE que entram no mercado já possuam a garantia de serem geridos corretamente ao final do seu ciclo de vida pelo sistema de coleta ao qual a marca aderiu, além de estarem registrados na APA. Com isso, o sistema de LR de REEE tem quase todos os registros dos EEE, pois hoje o único controle que não possuem é quando o EEE é vendido pelo varejista (PGF1).

Os REEE não precisam de um licenciamento especial, nem emissão de guias, pois não são caracterizados como perigosos. No caso do transporte primário feito pelo varejista, entre a casa do consumidor e a loja, ou mesmo nos pontos de coleta ou na armazenagem preliminar do varejista, por menos de um ano, também não há necessidade de emissão de guias, nem licenciamento. Eles precisam apenas obedecer aos critérios de armazenamento definidos por lei que prevêem, entre outros requisitos, uma área coberta e livre da chuva. Somente os OGR precisam de guia a partir da retirada das lojas.

\begin{abstract}
PGF1 - Agora, as lojas de comércio eletrônico só coletam ou vão buscar na minha casa o antigo, então não precisa de guia para este transporte. Mas quando o OGR, vai buscar no armazém dessas lojas, ela já precisa dessa guia. Os REEE não requerem licenciamento especial como se fossem perigosos. Como a gente obriga eles a coletar e armazenar, por isso a gente não requer licenciamento, só se for armazenar por mais de um ano. Então, se for considerado armazenamento preliminar, por menos de um ano, não requer licenciamento. Os pontos de recolha não precisam de licenciamento, mas precisam atender os requisitos mínimos que estão no anexo 3 . Tem que ter balança para medir os pesos, tem que estar protegido da chuva.
\end{abstract}

\title{
5.2.3.6 Riscos
}

Com o poder descentralizado em cada ator e todos os processos sendo controlados por sistemas integrados online, contratos e leis, o risco da operação também está centrado no ator que executa aquela etapa do processo de LR. De acordo com PRC1, contudo, existe uma zona cinzenta no processo, que está entre o momento em que o consumidor descarta seu REEE na rua e a sua coleta pelo sistema de coleta da Câmara. Este é justamente o momento em que o REEE encontra-se mais vulnerável ao furto pelo setor informal. Nesse caso, o ator acredita que a responsabilidade é de todos.

PRC1 - Não conseguimos fazer um controle porta a porta das entregas, portanto nós não podemos garantir às câmaras municipais ou intermunicipais. A partir do momento em que esse resíduo está no local do município e nos chamam para recolher esse resíduo, nós garantimos que eles serão encaminhados para os locais de reciclagem e que o rastreio de todas as ações de tratamento é feito corretamente. Então essa área 
cinzenta, entre a disponibilização do REEE pelo consumidor e a coleta pela Câmara, nós não conseguimos garantir. Portanto, acredito que a responsabilidade seja de todos.

\subsubsection{Os elementos da Categoria "Impactos" na LR de REEE em Portugal}

As parcerias estabelecidas para a operacionalização da LR de REEE em Portugal tem ajudado a aumentar o número dos pontos de coleta, oferecendo mais alternativas de descarte aos munícipes, informações sobre os REEE por canais e atores diferentes, como por exemplo, a Câmara e a APA, que criam campanhas e treinamento para gerar conscientização ambiental. Essa sinergia impacta diretamente os resultados da LR de REEE que, desde 2010, tem ultrapassado as metas da EU de $4 \mathrm{~kg}$ de REEE/hab/ano, coletando 4,4 kg/hab/ano.

PGM1 - O impacto da colaboração entre a Câmera e a AMB3E é o aumento dos pontos de coleta, os munícipes têm mais alternativas, evita-se que os resíduos cheguem nos aterros. É que, na verdade, os munícipes associam coleta de resíduos com a Câmara e nós fazemos campanhas de conscientização que mostram quais são os canais de coleta para os consumidores.

PGF1 - Desde 2010 nós já cumpríamos as metas. A meta era 4kg, nós recolhíamos $4,4 \mathrm{~kg}$.

Os resultados dos relatórios de 2010 a 2015 fornecidos pela APA mostram que os números continuam melhorando. Em 2015, foram coletados 5,1 kg de REEE por habitante. Além disso, todos os objetivos mínimos de valorização e preparação para reutilização e reciclagem foram atendidos, conforme relatório de 2015, apresentado nas Figuras 11 e 12.

PGF1 - Nesses documentos e no site, tem a parte das licenças das EG, tem os dados da gestão de 2010 a 2015. Ainda não tem de 2017, porque 2016 só esse ano que vai se reportar à comissão, pois o prazo para publicar é 30 de junho, sempre um ano e meio para trás. Então, tem uma outra meta que nós não cumprimos em todos, são os objetivos mínimos da gestão por categoria. 
Figura 11 - Taxa de Reciclagem por objetivos mínimos de valorização, reutilização e reciclagem em Portugal

\begin{tabular}{|c|c|c|c|c|}
\hline & \multicolumn{2}{|c|}{ Valorização } & \multicolumn{2}{|c|}{$\begin{array}{l}\text { Preparação para } \\
\text { reutilizacão e reciclagem }\end{array}$} \\
\hline & Taxa & Objetivo $^{(2)}$ & Taxa & Objetivo $^{(2)}$ \\
\hline 1. Grandes eletrodomésticos & $94 \%$ & $85 \%$ & $80 \%$ & $80 \%$ \\
\hline 2. Pequenos eletrodomésticos & $93 \%$ & $75 \%$ & $80 \%$ & $55 \%$ \\
\hline 3. Equipamentos informáticos e de telecomunicações & $92 \%$ & $80 \%$ & $82 \%$ & $70 \%$ \\
\hline 4. Equipamentos de consumo & $87 \%$ & $80 \%$ & $81 \%$ & $70 \%$ \\
\hline 5. Equipamento de iluminação & $90 \%$ & $75 \%$ & $80 \%$ & $55 \%$ \\
\hline 5.1 Lâmpadas de descarga & N.A. & N.A. & $84 \%$ & $80 \%$ \\
\hline 6. Ferramentas elétricas e eletrónicas & $91 \%$ & $75 \%$ & $79 \%$ & $55 \%$ \\
\hline 7. Brinquedos e equipamentos de desporto e lazer & $92 \%$ & $75 \%$ & $79 \%$ & $55 \%$ \\
\hline 8. Aparelhos médicos & $93 \%$ & $75 \%$ & $81 \%$ & $55 \%$ \\
\hline 9. Instrumentos de monitorização e controlo & $91 \%$ & $75 \%$ & $79 \%$ & $55 \%$ \\
\hline
\end{tabular}

Fonte: APA, 2016, p. 1

Figura 12 - Valorização Global dos REEE e resumo da gestão dos REEE 2015 em Portugal
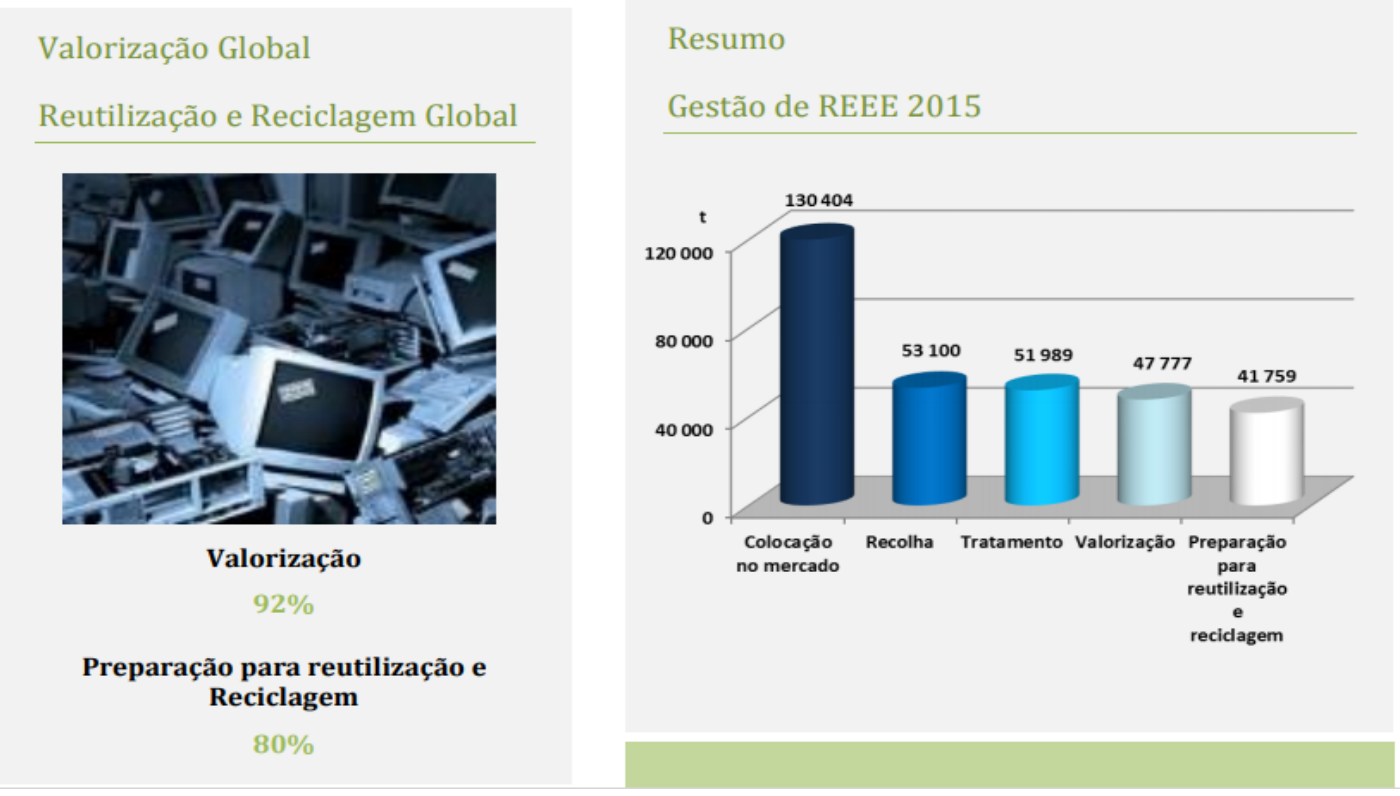

Fonte: APA, 2016, p. 1

Outra vantagem auferida pelo trabalho conjunto entre os atores da LR de REEE é a diminuição dos custos de operação, que se reflete diretamente no Ecovalor.

PGF1 - Outra vantagem em trabalharem juntos [...] é quanto ao Ecovalor, que já foi muito mais caro. Hoje, por exemplo, a taxa do seu gravador é 0,07 Euros, o celular, 0,02 Euros. 
A elaboração das leis e estruturas para a gestão da LR de REEE também trouxe benefícios com o envolvimento dos atores nesses processos. Entre eles estão a simplificação dos relatórios exigidos das EG e as melhorias na plataforma de registros das operações de LR de REEE, que antes eram feitos pela ANREE e agora passaram para a APA. Tudo é feito de forma consensual e satisfatória, segundo PGF1. Essas mudanças foram possíveis graças à participação dos atores que tinham conhecimento sobre o processo e à vontade do governo de sua a validação por parte dos atores que seriam afetados pelas leis e estruturas de gestão.

PGF1 - Por causa da participação dos atores, temos feito várias alterações. Com as
EG, nós temos feito várias simplificações de relatório. Agora, temos o registro das
operações feitas por nós, porque havia uma grande pressão que fosse feito pela APA
e não pela ANREEE, além do modo como a plataforma foi desenvolvida. Os
resultados não poderiam ter sido melhores, pois era tudo do conhecimento deles.
Superamos nossas dificuldades, conseguimos construir uma coisa de raiz que satisfez
todas as partes, o que é difícil ao início, porque tem uma questão de mudança de
hábitos.

Esses resultados positivos da colaboração, fazem com que PGF1 acredite ser possível envolver os varejistas na apuração dos EEE vendidos, para fecharem todo o mapeamento dos EEE colocados no mercado. Dessa forma, será possível estabelecer a meta sobre os EEE que foram vendidos com maior precisão, não pela média do que foi produzido nos últimos três anos.

PGF1 - O que a gente não conseguiu ainda é fazer com que o vendedor preste contas para o nosso sistema, mas eu acho que, se a gente se unir, a gente vai conseguir. E a nossa meta é com base nos três anos anteriores, do que ele gerou de EEE, não do que foi vendido.

Os resultados positivos obtidos com o trabalho conjunto entre os atores os têm incentivado a criar outros mecanismos na operacionalização da LR de REEE, principalmente no momento em que as metas aumentam. Um exemplo destes novos mecanismos é a intenção de criar uma câmara de compensação de REEE, com o objetivo de alcançarem as metas por categorias, intercambiando os resíduos coletados pelas EG de acordo com suas necessidades. Dessa forma, elas teriam mais chances de atingir as novas metas que serão publicadas que, além de serem mais audaciosas, passam a ser igualmente por categorias. Essa iniciativa também visa criar sinergia entre as EG, que até o momento trabalham isoladas uma da outra. Para isso, deve ser criada uma legislação que possibilite a criação da câmara de compensação de REEE. Essa é uma iniciativa do próprio governo federal, que tem sido recebida com simpatia entre as EG.

Outra parceria que deve aumentar a sinergia, é a parceria entre as EG e a Câmara de Lisboa para melhorar a coleta porta a porta dos REEE, que também visa diminuir os furtos. 
Para isso, estuda-se o pagamento de melhores contrapartidas financeiras à Câmara para cobrir os custos com as alterações que precisaram ser feitas para atender esse objetivo. Segundo membros da academia que estudam os REEE, a cooperação entre os atores é boa para todos. Nesse sentido, acrescentam que, se as EG cooperassem entre elas, poderiam melhorar muito o sistema de coleta, aumentando sua capilaridade, compartilhando postos de descarte e resultados do sistema de LR, já que têm objetivos e metas comuns.

PRC1 - A questão da compensação eu acho que é uma coisa positiva, assim como a parte eletrônica que vai dar um pouquinho de trabalho, mas é desejável.

PGF1 - A ideia é legalizar um mecanismo de compensação de REEE entre as EG. Dessa forma, se uma recolheu além da cota de uma determinada categoria e a outra ainda não atingiu a sua cota, elas podem trocar entre elas esse resíduo. A ERP vem amanhã para falarmos disso. Tem muita coisa para tratarmos. Como isso será feito? Fisicamente, ou apenas no sistema? Ainda não sabemos, mas vamos tentar viabilizar.

PGM1 - Nesse momento já começam a falar em contrapartidas para incentivar também o aumento das recolhas desses fluxos, porque como é um fluxo que também tem valor econômico, as pessoas passam antes e recolhem. Então surgem negócios paralelos de furto de material. E para nós que queremos evitar isso ao máximo, para que não saia fora do sistema municipal, então a AMB3E está disposta a pagar para que a câmara trabalhe mais, eventualmente até numa recolha porta a porta [...] para evitar o desvio ao máximo e terem o máximo de retorno.

PAC1 - Com a cooperação todos ganham. Uma outra coisa, é a câmara de compensação, pois cada uma tem cotas de licença, por exemplo, essa tem que coletar $70 \%$ desse tipo de resíduo, a outra $50 \%$ do outro tipo de resíduo, se essa obtiver mais que os $70 \%$ e a outra menos do que a cota determinada, elas podem trocar e compensar. Porque seria bom que uma EG, que tem o mesmo objetivo que a outra, tivesse um pouco mais de cooperação. Seria importante que eles pudessem cooperar entre si, até mesmo compartilhar postos ou resultados.

Outra ação que as EG estão realizando para aumentar a proximidade entre as OGR e eliminar o furto de REEE é a premiação dos grandes recicladores. Dessa forma, eles recebem valores maiores quando entregam lotes padronizados, em melhores condições, com REEE completos e embalados individualmente, para que se possa conferi-los adequadamente. Com essa campanha, espera-se que a mensagem de que não se deve comprar partes dos REEE ou seus restos chegue aos seus fornecedores, recicladores menores, e o fornecimento de base seja melhor. Além de buscar qualidade nos REEE para obter retorno econômico, a EG está premiando seus principais players pela entrega de resíduos que contenham substâncias perigosas, para que se possa garantir o tratamento ambientalmente correto desses resíduos. Espera-se, assim, que esses players recebam e armazenem essas categorias de REEE e as entreguem à EG. 
PRC1 - Premiamos a colocação de REEE intactos e em boas condições. Tentamos que esses agentes de maiores dimensões, junto de seus fornecedores, também transmitam essa mensagem para que, quando eles levem os resíduos, não levem enfardados, ou sem compressores, mas sim de forma individualizada e que nós possamos ter algum retorno. E também, fomentamos a entrega de resíduos perigosos, pois esses players recebem diferentes tipos de EEE e nós tentamos que eles concentrem, por exemplo, frigoríficos, lâmpadas, e que nos entreguem.

A atuação em parceria tem gerado muitos novos insights, inclusive com experiências na operacionalização das LR de outros tipos de fluxos específicos, pois muitos atores estão envolvidos em mais de um deles. Nesse sentido, tem-se percebido que incentivos financeiros podem motivar a participação dos atores na LR, como no caso das baterias. Nesse modeloo consumidor recebe um voucher quando entrega a sua bateria velha na loja. De acordo com PGF1, o modelo de campanhas de coletas de REEE nas escolas é similar ao das baterias e tem surtido um efeito parecido. Nesse caso, as mães dão seus EEE antigos a seus filhos para que participem das gincanas promovidas em suas escolas pela AMB3E, que premia o aluno que traz mais REEE com um computador.

PGF1 - Aqui tem uma corrente que acha que as pessoas devolveriam mais, se recebessem incentivos financeiros ao entregar. Aqui temos esse sistema na venda de baterias. Você compra a bateria, leva para casa, quando precisar trocar você mesmo troca a bateria do carro, e quando você devolve a sua bateria velha no revendedor, você recebe um voucher, ou um valor, alguma coisa assim. É o mesmo que temos agora: as mães dão para os seus filhos celulares ou outros resíduos antigos que eles levam para a escola para ganhar as gincanas que são realizadas pela AMB3E.

Esse fato é corroborado com a criação do projeto da Amb3E, Academia Electrão, que visa envolver as universidades na busca por soluções para a gestão dos REEE, premiar os melhores trabalhos acadêmicos e eventualmente viabilizar a execução desses projetos.

PRC1 - Na parte de desenvolvimento nós vamos lançar um projeto que se chama Academia Electrão, que vai premiar trabalhos acadêmicos feitos na área de REEE, pilhas e acumuladores e embalagens. E o que nós vamos fazer é consultar a academia toda, nacional, e promover essa iniciativa com o objetivo de surgirem trabalhos e, eventualmente, equacionar a viabilização da execução de algum projeto.

Outra lição que já está clara para alguns atores é a importância de responsabilizar o consumidor por meio de conscientização para obter melhores resultados na LR de REEE. Segundo PGF1, os consumidores não entenderem que seus hábitos de consumo e descarte têm impactos diretos sobre eles, aumentado o custo das taxas de saneamento público. Assim, eles precisam cooperar, saindo de suas casas para fazer o descarte correto do seus EEE pequenos e 
médios, e que não adianta só esperarem que façam isso por eles, como acontece do descarte um-para-um, dos grandes EEE. Só assim será possível contar com eles na LR de REEE.

PGF1 - Eu costumo dizer em palestras de conscientização que o ambiente é nossa casa. Então, se eu não faço a separação dos resíduos, isso vai parar em um aterro que contamina o solo e o lençol freático. Eu vou beber essa mesma água. Tudo que eu faço em casa volta para mim.

PAC1 - Mas é mais fácil quando você faz a coleta do grande um-para-um, como aqui em Portugal, do que conseguir fazer a coleta dos menores [...]. Porque ele, o consumidor, precisa levar o resíduo até o posto de coleta. Sim, é mais complicado, então o pequeno e o médio eletrodomésticos, os brinquedos, mixer, batedeiras, essas coisas.

A falta de investimentos na educação ambiental dificulta ainda mais o envolvimento dos consumidores na LR de REEE, além de exigir maior esforço coordenado entre os atores, de acordo com PAC1. De fato, o consumidor precisa saber por que, como e onde fazer o descarte de REEE. Ainda segundo PAC1, é muito importante que as EG se esforcem mais para oferecer e fazer chegar a todos a mensagem de conscientização sobre as questões do REEE, assim como é necessário que o governo federal participe desse processo mais ativamente.

\footnotetext{
PAC1 - Aqui as pessoas não têm consciência do impacto do seu comportamento quando elas colocam os seus resíduos nos contentores indiferenciados, ao invés dos [contentores] da coleta seletiva. Falta investir mais em consciência ambiental. [...] Portanto, compete a eles [EG] fazer esse esforço. Mas, na minha visão, eles deixam muito a desejar. E as autoridades nacionais podiam ter um papel mais ativo, pois ultimamente não se tem investido muito em educação ambiental.
}

PGF1 - Muitas vezes o cidadão não sabe que ele pode depositar, porque ele não lê a lei, mas, em regra, esse dinheiro da taxa de reciclagem também deveria pagar a comunicação e a conscientização desses consumidores. Olha, eu vou ser sincera, a semana que passou, a minha máquina de lavar quebrou, então eu comprei uma nova, e, quando foram levar na minha casa, [...] a transportadora quis cobrar para levar a minha máquina antiga. [...] Eu disse: não. [...] No dia seguinte, a loja ligou para nós, pediu desculpas pelo transtorno e que isso foi uma ação isolada do transportador que eles contrataram.

Outra questão que tem causado um desconforto e uma atitude reativa dos atores da LR de REEE é a falta de compreensão sobre a importância ou necessidade de alguma nova exigência legislativa. Muitas vezes esse comportamento é causado pela sensação de que um novo processo dará muito mais trabalho sem retorno aparente ou de que o ator está sendo exigido acima de sua capacidade. Esses fatos ocorrem, respectivamente, com a mudança das guias manuais para eletrônicos dos REEE e com mudanças nas regras de licenciamento para as EG, com metas mais elevadas do que as da UE. 
PRC1 - O problema é que estão sendo equacionadas as metas em nível nacional, sem haver reflexo quanto à diretiva comunitária, pois é maior. Ou seja, a perspectiva é que, em termos de licença, os objetivos sejam muito mais ambiciosos e, francamente, em alguns casos, impossíveis. Isso não está refletido em nenhuma legislação. Ficamos sem entender o porquê de aqui ser tão exigente. E operacional e tecnicamente não exequível. [...] Se nós não conseguirmos alcançar as metas, pois são muito exigentes, nós não vamos cumprir, mas o país também não.

A dificuldade para gerir questões mais complexas ou sistemas novos configura-se como outro elemento que não tem facilitado a cooperação entre os atores. Essa deficiência pode impedir resultados mais significativos na reciclabilidade de REEE, que poderiam ser obtidos por meio de investimento das marcas em Ecodesign. Para PRC1, mesmo que as empresas invistam em projetos de EEE mais fáceis para desmontar ou para separar os materiais, os fornecedores das EG não teriam como atender às inovações, pois não possuem equipamentos para desmontar os equipamentos de forma diferente, tampouco criar mecanismos que tratem as marcas inovadoras de forma diferenciada.

PRC1 - Os sistemas de reciclagem não estão preparados para tanta especificidade, tampouco teremos equipamentos para desmontar cada tipo de REEE.

PGF1 afirma que alguns fabricantes têm se mostrado receptivos para investir em ecodesign e acredita que eles podem ser bonificados se conseguirem a redução do seu Ecovalor. Entretanto, isso não parece viável para as EG, conforme apresentado anteriormente.

PGF1 - A gente já tem alguns produtores pensando em ecodesign, em ser mais fácil desmontar, para facilitar a reciclagem, e, atualmente, esses fabricantes são bonificados quando eles conseguem ter Ecovalores mais baixos.

Nessa perspectiva, PAC2 acredita que, se a legislação não é suficiente para criar pressão sobre a indústria, para que repense seus produtos, é necessário criar mecanismos de pressão social, como um rótulo negro para a empresas relativo a suas práticas. Esse tipo de ação tem gerado excelentes impactos em outras áreas de consumo, segundo o ator.

PAC2 - A pressão sobre as empresas é dada de forma legislativa e elas se sentem mais ou menos compelidas a fazer isso. Mas nós não podemos esquecer que quem trabalha nas empresas são pessoas, e se começar a haver um movimento popular de rotulagem e declaração de rótulo negro pra empresa $\mathrm{A}, \mathrm{B}$ e $\mathrm{C}$ relativo à suas práticas, quando este movimento acontece, tem de fato uma força enorme. 
Outro problema grave enfrentado pelo sistema de LR de REEE em Portugal, citado anteriormente, mas sem a devida ênfase, é o furto desses resíduos. Apesar das Juntas de Freguesias cooperarem na coleta dos REEE, atores que não estão incluídos na cadeia reversa, como os sucateiros, dificultam a gestão correta desses resíduos.

PGF1 - O problema é que essas coletas de porta a porta, os caminhões têm um determinado horário para passar, e como esses resíduos normalmente têm valor, tem sempre alguém que passa primeiro para recolher isso nas portas. São como sucateiros, que pegam geladeiras, retiram os compressores, sem nenhum cuidado, pondo em risco a saúde e o meio ambiente.

A exclusão de atores informais na cadeia reversa em Portugal tem contribuído para a piora da qualidade dos resíduos coletados pelos agentes oficiais. O maior problema desse desvio de resíduos, no ponto de vista de entrevistados, é que eles são canibalizados, retirando-se a parte valiosa e descartando a parte sem valor, que muitas vezes contém agentes tóxicos, em qualquer lugar. Isto deixa o processo de reciclagem mais caro e põe em risco a saúde pública.

PRC1 - Então nós, conjuntamente com o sistema integrado, deveríamos promover as funções para que esse setor informal conseguisse entrar no sistema e não prejudicasse a qualidade do resíduo, pois eles canibalizam os resíduos que coletam nas ruas.

PAC1 - As vezes, [...] depois que tiram as peças que têm valor, [acabam] jogando em contentores normais, misturando com os outros resíduos comuns. Isso é um problema que as EG enfrentam. Tem até vídeo no Youtube de como recuperar ouro, essas coisas, desses materiais.

Esse problema é agravado devido à falta de capacidade das Juntas de Freguesias em conseguirem fiscalizar a coleta. Além disso, pouco se consegue fazer, pois a legislação não prevê a inclusão desses atores na cadeia reversa dos REEE.

PGF1 - O problema é que essas Juntas de Freguesia não conseguem fiscalizar, porque elas chegam sempre depois, então elas não conseguem autuar. Se esses resíduos estão na via no dia da coleta porta a porta, eles pertencem à Junta de Freguesia.

PAC1 - O governo não consegue fazer a fiscalização nas ruas, do momento que o resíduo é deixado na porta do cidadão até a hora de passar o caminhão de coleta, por isso acontecem os furtos dos REEE.

Outro problema relatado juntamente com o problema de controlar o mercado informal foi a exportação ilegal desses resíduos, disfarçados de EEE para segundo uso, para países em desenvolvimento, como Uganda. Esses destinos não têm condições de fazer a reciclagem correta desses resíduos, contaminando solo, água e ar com seus processos rudimentares para extração de metais valiosos. 
PCA1 - Como também é difícil outro problema, que é a exportação desse tipo de resíduos para outros tipos de países, subdesenvolvidos, que t6em uma questão moral e ética. Nosso problema é que muitas vezes eles vão disfarçados. Esse é um problema grave aqui e em outros países mais desenvolvidos, pois esses resíduos vão parar nos lixões da Guiné, Uganda, aqueles enormes lixões de EEE que vão ser queimados.

\subsection{ESTUDO DE CASO DA LR DE REEE NA ESPANHA}

Esta seção apresenta o processo de implementação da LR de REEE na Espanha, e pretende levantar quais foram os fatores motivacionais para a implementação da LR de REEE, descrever como foi definido o escopo e a estrutura para estabelecerem a operacionalização da LR, verificar como esses elementos impactaram a efetivação da colaboração e da cooperação e quais resultados foram obtidos nesse cenário.

\subsubsection{Os atributos da Dimensão "Motivação" na LR de REEE na Espanha}

Está seção apresenta os atributos da dimensão "Motivação": necessidade, oportunidade e disposição na elaboração e implementação da LR de REEE em Espanha.

\subsubsection{Necessidade}

A LR de REEE começou na Espanha pela necessidade de atender à Diretiva de REEE da UE. Como Estado Membro, o país precisa alinhar as suas leis às diretivas estabelecidas pela UE, sob pena de sanções e até mesmo de ser retirada do bloco que a compõe. Para atender à Diretiva, o governo estabeleceu o Real Decreto (RD) de 208/2005, que trata sobre a Gestão Integrada de REEE em 25 de fevereiro de 2005. Os fabricantes e importadores, por sua vez, aderiram ao Sistema Integrado de Gestão (SIG) para transferir a responsabilidade estendida do produtor, para que esses sistemas coletivos fizessem a gestão dos seus REEE, que lhes foi imputada pelo RD.

ERC4 - Aqui? Para atender à Diretiva da UE. E os fabricantes nos contratam para transferir a responsabilidade estendida do produtor pelos REEE.

Em 2003, o governo federal, por meio do Ministério do Meio Ambiente, se reuniu com os principais atores da LR de REEE para juntos iniciarem a elaboração do RD 208/2005, de acordo com Martinez (2015). 
Em 2003, na Espanha, estava em uma situação de preparação antes da transposição da Diretiva 2002/96/CE relativa aos REEE. As organizações relacionadas com o gerenciamento desses resíduos, bem como produtores de EEE, a quem sob o princípio da RAP da Diretiva era responsável pela consecução dos objetivos de coleta e reciclagem de REEE, estavam trabalhando juntos com o Ministério do Meio Ambiente na preparação do que seria mais tarde o Decreto Real 208/2005 sobre EEE e a gestão de seus resíduos. (MARTINEZ, 2015)

Umas das iniciativas realizadas para construção de um modelo de gestão integrada mais adequada à realidade da Espanha foi a execução do primeiro "Estudo sobre REEE na Espanha", em colaboração com os fabricantes de EEE, por meio da Associação Nacional de Fabricantes e Importadores de Eletrodomésticos (ANFEL), da Associação Nacional de Fabricantes de Pequenos Eletrodomésticos (FAPE) e da Federação Espanhola de Recuperação e Reciclagem (FER). Para o representante da FER era importante que não se ignorasse o modelo já existente no país, executado por recicladores e sucateiros. Embora esse sistema não fosse regulado nem tampouco reconhecido, ele funcionava baseado no valor residual do produto.

É assim que o Primeiro Estudo sobre Resíduos de Equipamentos Elétricos e Eletrônicos [REEE] na Espanha, em colaboração entre a ANFEL e a FAPE (mais tarde representado pela Fundação ECOLEC) e pela FER, que tive o prazer de dirigir e levar até o final. E isso permitiu projetar qual seria o modelo de aplicação e gerenciamento de REEE que a ECOLEC colocou em operação nos 10 anos seguintes. (MARTINEZ, 2015).

Além da obrigatoriedade de criar um sistema de LR de REEE dada pela Diretiva da UE, recicladores que já operavam antes do RD 208/2005 afirmavam que era necessário mitigar os impactos ambientais com a gestão desses resíduos. EGM1 explica que, para o município, é importante garantir que esses resíduos sejam descartados pelos canais corretos, principalmente tendo em conta que a população não tem o hábito de reciclar. Além disso, é preciso garantir que ELES não sejam enviados para países em desenvolvimento como se fosseM EEE de segunda mão, mas com o objetivo claro de economizar com o descarte ambientalmente correto dos REEE, pois eles têm parâmetros de reciclagem mais baratos e menos exigentes.

ERC1 - Essa questão da LR começou pela questão ambiental mesmo.

EGM1 - Por que fazemos? porque somos conscientes que as pessoas reciclam pouco e a pressão mundial está muito forte para os países da China e de terceiro mundo que estão recebendo essas coisas. Certamente queremos que vá tudo pelos canais oficiais, não que vão para estes países como coisas de segunda mão, mas que na verdade são REEE. 
Outro fator que motiva o governo municipal a atuar na LR de REEE é a possibilidade de evitar que eles cheguem ao aterro, pois a prefeitura é cobrada pela quantidade de lixo enviada.

EGM1 - Posso gerir de duas maneiras: coloca tudo dentro de uma caixa, todas as caixas iguais, e levo tudo para um aterro, e nesse local, me cobram segundo o que eu levei. Ou posso ter uma conscientização com equipe de governos, e técnicos e funcionários que queremos fazer a coleta seletiva.

Com cotas de reciclagem cada vez maiores e o sistema de coleta das lojas e municípios coletando apenas $1 / 3$ da quantidade necessária, os SIG têm buscado recicladores menores para completar suas metas. O novo RD 110/2015, que incorpora a Diretiva 2012/19/UE ao ordenamento jurídico da Espanha, traz a hierarquia para a gestão dos REEE baseada na prevenção e na preparação para sua reutilização. Isto significa que será necessário prevenir a geração de REEE e preparar os EEE descartados para receberem uma segunda vida sempre que possível. Os EEE recondicionados farão parte das novas metas de reciclagem. Para isso, o RD prevê a criação dos Centros de Preparação para a Reutilização (CRP). Nesse cenário, os recicladores menores que já são auditados pelo governo e possuem Código LER (Lista Europeia de Resíduos) para atuar com os REEE estão buscando o seu credenciamento para atuarem como CRP também. Atualmente, só existem dois CRP cadastrados no país. Esse fator intensificou a busca dos SIG por fornecedores de REEE que lhes permitam cumprir as novas exigências legislativas para seus associados.

ERC2 - Agora, na Espanha, eles estão começando a fazer os cadastros de CPR, que são os Centros de Preparação para a Reutilização dos REEE. Nós somos a segunda empresa a ter um CPR na Espanha, só tem duas por enquanto. Aqui veio um SIG para REEE para ver o nosso CPR, porque agora eles estão interessados nisso, devido às metas de reutilização.

\subsubsection{Oportunidade}

Nesse cenário diversos atores visualizaram novas oportunidades. O governo nacional espera gerar novos empregos verdes, já que o setor de reciclagem de resíduos representa a maior parcela desse setor, com $27 \%$ dos postos de trabalhos verdes, assim como fomentar a economia circular.

As empresas de reciclagem, fornecedoras de REEE para as SIG, perceberam a importância e a oportunidade de atuarem em parceria com outras recicladoras, pois, dessa forma, se sentem mais fortalecidas, ganham volume, aumentam sua rentabilidade e 
competitividade. Esses tipos de recicladores recebem das SIG uma compensação financeira pelos REEE que trataram, valorizaram ou reciclaram. Para aumentar o volume de REEE tratados por eles, contudo, estabelecem parceria com outros tipos de recicladoras, especializadas em resíduos diferentes, mas que eventualmente recebem de seus clientes resíduos que não estão autorizadas a processar, como no caso de um reciclador que opera com embalagens, vidros e papelão, mas tem clientes que geram demanda de gestão de REEE periodicamente. Para atender aos clientes da melhor maneira e firmar contratos mais abrangentes, essas empresas fazem parcerias com recicladores de REEE e vice-e-versa. Dessa forma, cada um pode se especializar em um tipo de resíduo e ter acesso aos outros, pois todos ganham.

ERC1 - No final, o que nós temos que fazer são essas parcerias entre os agentes recicladores. Porque eu me especializo em um tipo de resíduo, mas muitas vezes vou ter acesso a outro, como, por exemplo, me especializo em REEE e tenho acesso a embalagem, e a outra empresa se especializou em embalagens, mas também recebe sempre REEE, lâmpadas. Essas parcerias permitem que a gente troque resíduos aumentando o nosso ganho, com volume.

ERC5 - Nas parcerias que temos entre recicladores que tem Códigos LER diferentes, cada um dá o que tem de melhor, ou seja, eu reciclo e ganho volume com os meus parceiros de REEE, ao mesmo tempo em que eu viabilizo negócios para outros parceiros que não poderiam trabalhar com REEE, quando eu aceito os seus resíduos. Dessa forma, podemos abranger um leque maior de coisas que podemos fazer e contratos que firmamos, para fazer a gestão dos resíduos de algumas empresas.

\subsubsection{Disposição para atuar em conjunto}

Apesar do RD de 2015 obrigar as lojas com uma zona de venda de no mínimo $400 \mathrm{~m}^{2}$ a receberem REEE de pequeno porte de forma gratuita, algumas lojas não parecer estar dispostas a cooperar de fato. No caso do El Corte Inglés, uma grande rede de magazines espanhola, em Alicante, por exemplo, os coletores fornecidos pela Ecotic estão alocados no estacionamento do estabelecimento e a maioria dos seus colaboradores nem sabem da sua existência. Da mesma maneira, en San Vicente del Raspeig, funcionários de alguns supermercados se recusaram a colocar coletores de REEE em suas lojas, depois de já terem aceitado recebê-los em seus estabelecimentos com a desculpa que não tinham autorização dos seus superiores.

EGM1 - Queríamos também os grandes supermercados. Essas pessoas que a princípio nos tinham dito sim, mas quando fomos levar os coletores, eles disseram que tinham que ter permissão dos seus chefes de não sei onde. 


\subsubsection{Os atributos da Dimensão "Escopo" na LR de REEE na Espanha}

Está seção apresenta os atributos da dimensão "Escopo": natureza, objetivos, resultados e atores na implementação da LR de REEE na Espanha.

\subsubsection{Natureza}

O estudo de caso da Espanha visa apresentar apenas como está ocorrendo a operacionalização da LR de REEE no país, pois não foi possível coletar elementos suficientes para entender o processo de elaboração das leis. Ainda que documentos cedidos pelo Ministerio de Economía y Competitividad (MINECO) e a pesquisa de Martinez (2015) demonstrem que, no período de elaboração da lei, diversos atores, como a indústria e os recicladores, foram chamados para debater sobre o melhor modelo de gestão dos REEE, eles não contêm todos os dados para avaliar o escopo, estrutura e impacto da colaboração neste processo.

\subsubsection{Objetivos}

Os produtores de EEE e os SIG têm como objetivo atender ao RD que estabelece as obrigações sobre os REEE. Governo federal e estatal visam respeitar a Diretiva de REEE da União Europeia. Com efeito, as prefeituras querem que os REEE sigam os fluxos corretos evitando que sejam enviados para os aterros ou países em desenvolvimento e os pequenos recicladores querem ampliar seu mercado de reciclagem participando da LR de REEE.

\subsubsection{Resultados esperados}

Nesse cenário, cada ator espera por um resultado, mas todos são tangíveis. O governo federal precisa atender à Diretiva; a prefeitura quer diminuir o volume de lixo enviado para o aterro garantindo que os REEE não cheguem lá; as empresas precisam cumprir suas cotas de reciclagem e por isso contratam as SIG, pois, com sistemas coletivos têm custos mais econômicos.

EAC1 - Por serem sistemas coletivos, os sistemas integrados de gestão são mais econômicos. É claro que todos querem economizar. Apesar que alguns pouquíssimos produtores preferem sistemas individuais, mas é por questão estratégica, pois essas empresas fabricam produtos de uso industrial. 


\subsubsection{Atores}

No processo de elaboração do RD 208/2005, participaram os produtores de EEE, a ANAFEL, a FAPE, Ministério de Meio Ambiente e FER (MARTINEZ, 2015).

De acordo com MAPAMA (2018), a Espanha conta com onze SIG autorizados pelos governos das Comunidades Autônomas (CCAA). Entretanto, nem todas as SIG estão em todas as comunidades, pois para cada uma delas é necessário que se apresente toda a documentação ao seu órgão competente, que, depois de avaliada sua legitimidade, encaminhará os documentos à Comissão de Coordenação em Matéria de Resíduo que, por sua vez, dará seguimento à autorização e condições específicas para o exercício da atividade de gestão integrada dos REEE. Como CCAA, elas podem ter critérios diferentes, desde que atendam à Lei 22/2011 sobre os Resíduos e Solos Contaminados (BOE, 2016).

No caso da Comunidade Valenciana, por exemplo, apenas nove SIG autorizadas firmaram o Convênio Marco com o Ministério do Meio Ambiente, Água, Urbanismo e Habitação da Generalitat Valenciana, em 29 de maio de 2008. São elas: Fundación Ecolec, Fundación Ecotic, European Recycling Platform (ERP), Fundación Ecoasimelec, Fundación Ecofimatica, Fundación Tragamovil, AMBILAMP, Fundación Ecolum e Fundación EcoRAEEs (GENERALITAT VALENCIANA, 2008). Todas estão registradas na OfiRAEE, plataforma informática online estatal que congrega as SIG que podem atuar na comunidade e junto às prefeituras na gestão dos RAEE local, de acordo com EGM1.

EAC1 - A ERP é um dos sistemas integrados de gestão com o qual as empresas gestoras de resíduos fecham contratos para prestar serviços.

ERC2 - Nós não temos autorização para tratar os monitores com tubo, nem as lâmpadas fluorescentes. Essas nós enviamos à AMBLAMB, que é o SIG autorizado para fazer a gestão desse REEE e tem contrato com as empresas que tratam deles.

\subsubsection{Os atributos da Dimensão "Estrutura" na LR de REEE na Espanha}

Está seção apresenta os atributos da dimensão "Estrutura": atividade, resultados, comunicação, poder, mecanismos de controle riscos na implementação da LR de REEE em Espanha. 


\subsubsection{Atividades}

A legislação sobre os REEE na Espanha atende aos conceitos centrais das diretivas de REEE. Ela estabelece, portanto, a responsabilidade ampliada do produtor sobre seus produtos ao final do ciclo de vida, obrigando-o a estabelecer um sistema de LR de forma individual ou coletiva. Os sistemas coletivos são operados por fundações sem fins lucrativos, criadas pelos próprios produtores, chamados de Sistema Integrado de Gestão (SIG). Cada SIG está autorizada a trabalhar com uma ou mais das 10 categorias de REEE. Assim, o produtor pode eleger o sistema ao qual deseja aderir, desde que o SIG atue com o tipo de EEE que ele produz ou importa e esteja cadastrado na região onde a empresa colocou EEE no mercado. Ao se associar a um SIG, o produtor transfere sua responsabilidade de gestão desses resíduos à essa entidade.

EGM1 - Os produtores criam e se associam às SIG, que são sem fins lucrativos, para fazer a gestão desses resíduos.

Nesse cenário, os SIG são responsáveis por toda a gestão de REEE. Para tanto, contratam empresas de transporte e recicladoras, que coletam os REEE nos pontos de coleta e os enviam para empresas de reciclagem responsáveis por descontaminar, valorar, reciclar, reaproveitar e dar o destino ambientalmente adequado às partes que não podem voltar para a cadeia de consumo. Eles também fornecem equipamentos de coleta para lojas e municípios, e fazem sua manutenção.

EGM1 - As frações de resíduos têm gestores diferentes, mas todos seguem mais ou menos o mesmo modelo de gestão.

EAC1 - Há empresas que se encarregam de recolher esses resíduos e separam suas partes. Plástico para um lado, cobre para outro, alumínio para outro e os separam. E o que se pode reutilizar se reutiliza. Essas empresas são pagas pelo SIG.

Já no caso dos varejistas, apenas as lojas que tenham uma área destinada à venda de EEE superior a $400 \mathrm{~m}^{2}$ estão obrigadas por lei a disponibilizar espaço para colocar um coletor de REEE em seus estabelecimentos ou em um local próximo. O varejista deve receber pequenos REEE sem custo, desde que suas dimensões externas não superem $25 \mathrm{~cm}$, mesmo que o cliente final não tenha comprado um EEE novo (BOE, 2015). Essa limitação é justificada por EGM1, pois, para ele, as empresas não têm a obrigação de ser em "lixeiras de resíduos". Além disso, o entrevistado argumenta que as pequenas lojas nem têm espaço para colocar os coletores. Já os EEE que se encaixem nas condições de coleta $1 \times 1$, os equipamentos de grande porte, como 
geladeiras e microondas, devem ser retirados gratuitamente da casa do consumidor pelo distribuidor, independentemente do tamanho do seu estabelecimento, sempre que for comprado um EEE novo do mesmo tipo.

EAC1 - Todas as empresas, pequenas e grandes que vendem EEE retiram o velho quando te entregam o novo, mas poucas empresas pequenas recolhem REEE nas suas lojas.

EGM1- Eles não são depósitos de resíduos. Se eu comprar um secador novo, aí deposito o velho. Mas eles não têm porque ser uma lixeira de resíduos. As lojas pequenas não têm nem lugar onde colocar coletores.

As prefeituras também têm algumas obrigações estabelecidas por lei. Elas precisam cooperar com a LR de REEE, seja passando informação, realizando campanhas de conscientização ou recebendo os resíduos em seus postos de coleta. Para isso, firmam convênio com as CCAA, para fazerem parte da plataforma estatal OfiRAEE, que automatiza a integração dos Ecopontos das prefeituras com os SIG autorizados na região.

EGM1 - O único que nós fazemos é dizer que vamos cooperar ou pôr os meios para que se selecione de maneira seletiva. Por exemplo, já há um ecoparque onde se recolhe os resíduos do município e deixamos colocar as jaulas para os REEE.

Assim, a prefeitura fornece algumas opções para o cidadão, que pode pegar o seu REEE e levá-lo até um Ecoparque ou Pontos Limpos, aguardar o dia da semana no qual o Ecoponto estará em seu bairro para descartá-lo, solicitar por telefone a retirada gratuita na sua porta com horário agendado ou chamar o serviço para coletar resíduos volumosos, como um fogão, uma geladeira ou um microondas.

Entre os coletores seletivos distribuídos pela cidade não tem um coletor específico para REEE, apenas para vidro, embalagens plásticas, metais, papelão e o cinza, para os não recicláveis. Entretanto, se um cidadão descartar seu REEE em um desses coletores, a empresa terceirizada responsável pela coleta de RSU fará a separação e o encaminhamento desses resíduos para os Ecoparques. Nos pontos de coleta pode ser feito descarte de todos os tipos de REEE e o cidadão conta com a orientação de um funcionário que indica em qual jaula ele tem que descartar cada tipo de resíduo. No final, todos os REEE coletados por algum dos serviços de coleta da prefeitura, são encaminhados para o Ecoparque e separados por tipos nas jaulas. Quando uma das jaulas atinge um determinado volume, o operador liga para a empresa de transporte contratada pelo SIG para que o retire os resíduos do local e os encaminhe para a reciclagem. 
EAC1 - Em San Vicente, você tem o Ecoponto Limpo onde pode descartar qualquer reciclável, inclusive os REEE. Ali tudo fica separado por tipo de resíduo. Não existem caixas de coleta seletiva, como para vidro e plástico, destinadas à coleta dos REEE. Isso é, falando dos municípios.

EGM1 - Então as empresas contratadas pelas prefeituras transportam todas as coisas e levam aos aterros ou aos gestores autorizados. [...] Todos os restos eletrônicos eles levam para os Ecoparques nas distintas jaulas. Os pequenos computadores, os toners. Cada pequena jaula é de um tipo que tem um SIG que faz a sua gestão. São eles que fornecem as jaulas, fazem a manutenção.

Apesar das várias alternativas fornecidas pelas prefeituras, os fabricantes e importadores estão cientes de que os cidadãos não fazem o descarte correto dos seus REEE. Por isso, criaram um projeto piloto de cooperação com as lojas e supermercados, para colocar um coletor em seus estabelecimentos. A princípio, foram selecionados 16 estabelecimentos, mas, quando os coletores com adesivos vermelhos foram enviados aos supermercados, todos se recusaram a aceitá-los, pois os funcionários alegaram que não tinham autorização de seus superiores. Apenas as oito lojas que vendem EEE disponibilizaram espaço para esses coletores. A ideia é que o consumidor descarte sua calculadora, seu secador, sem precisar comprar um novo obrigatoriamente no estabelecimento. Caso o projeto tenha sucesso, a prefeitura de San Vicente del Raspeig aumentará o número de coletores disponibilizado. Além disso, para divulgar o projeto e aumentar a sua atratividade para as lojas participantes, foi feito um mapa de onde estão os pontos de coleta, publicado no site da prefeitura.

EGM1 - Como nós somos conscientes de que muita gente não vai aos Ecoparques
jogar seus REEE, acabamos de lançar uma experiência piloto na qual criamos uns
coletores com cores chamativas e uma etiqueta vermelha. E vamos colocar isso nas
lojas para que as pessoas quando forem comprar seus EEE possam levar seus
secadores, seus REEE para descartá-los. Coisas pequenas. Então colocamos coletores
de $250 \mathrm{~L}$, muito pequenos e pedimos que as lojas cooperem tendo eles ali e quando
eles ficam cheios, chamam por telefone as empresas de resíduos que os recolhem e
levam ao Ecoparque. [...] Esta é uma experiência piloto. Até o momento, oito
estabelecimentos cooperaram. Eram 16 , mas os supermercados desistiram depois dos
coletores estarem prontos. Em nossa página web, publicamos a iniciativa e um mapa
para que as pessoas saibam onde eles estão. Se tiver sucesso vamos estender ao resto
da cidade.

Os SIG têm procurado empresas de reciclagem que estejam autorizadas a trabalhar com os mesmos Códigos LER dos seus associados, para atender suas cotas de coleta, valorização e reciclagem de REEE. Essas empresas compram REEE de pessoas físicas e jurídicas para processar e vender a outras empresas as partes separadas desses equipamentos. Elas fazem um serviço parecido ao dos sucateiros no Brasil e são auditadas pelo governo. Quando uma pessoa 
ou empresa quer vender o seu resíduo, ela o leva até a recicladora, que preenche o cadastro desse resíduo no sistema, com Código LER, marca e peso, e faz o cálculo do valor a ser pago por ele. Dependendo do tipo e volume do resíduo, ele tem um valor por quilo. Por exemplo, uma CPU que pesa $10 \mathrm{~kg}$ vale cerca de 2,5 Euros como resíduo. Com os dados dos REEE processados, quando uma SIG chega a sua sede, passa um relatório completo do lote que o sistema precisa, detalhando o que foi valorizado, reciclado ou descartado como rejeito, e para onde foi enviada cada parte de todos esses REEE.

ERC2 - Por exemplo, temos uma quantidade $\mathrm{x}$ de computadores descartados aqui. Aí a Ecotic veio e eu passei o relatório de que foi tratado $80 \%$ do que eu tenho aqui, e ela não precisa mais disso, então eu posso repassar os outros $20 \%$ para a Ecofirmática se ela precisar. Então, eu passo os relatórios para eles, com todos os dados, para eles lançarem no sistema deles. Nós aqui só processamos o REEE que temos autorização.

ERC3 - Pode ser pessoa física ou empresa autorizada que traz os REEE aqui, pois é melhor que uma pessoa traga sua lavadora aqui do que descarte em qualquer lugar. Esse resíduo gera um ticket com o código LER, o peso, a marca. A marca porque a Europa quer saber quem vende mais, quem recolhe mais, quem cuida mais. E nós pagamos por esse resíduo.

Para melhorar seu desempenho, essas empresas de reciclagem investem em marketing para conscientizar a população sobre a importância de reciclar e as vantagens financeiras de entregar a elas os seus REEE.

ERC5 - A gente faz campanha de marketing para que as pessoas possam trazer seus resíduos em bom estado aqui e dizemos que elas podem ganhar dinheiro com seus resíduos, que eles são valorizados aqui.

Outro papel que já começa a ser executado por essas empresas de reciclagem, para atender ao RD de 2015, é o de CPR. Parte dos REEE que chegam às empresas cadastradas como CRP estão sendo remanufaturados e vendidos como equipamentos de segunda mão. Nesse processo, quando o cliente vai entregar seu computador velho, por exemplo, o técnico que o recebe pergunta o motivo do descarte e qual é o defeito que ele tem. Em seguida, esse equipamento vai para uma oficina, onde é testado, consertado, tem seus dados apagados por um software e é posto à venda em uma loja. Dessa forma, esse REEE para a ser denominado EEE usado, conforme previsto na lei. Para a empresa de reciclagem, a remanufatura é muito mais lucrativa. Já o governo pretende aumentar o ciclo de vida dos EEE e incentivar uma atividade que gera mais empregos do que a reciclagem, fomentando a economia circular. 
uma peça, e, de vários computadores, por exemplo, ele faz um para ser vendido como um equipamento de segunda mão.

Nesse cenário, o consumidor tem a obrigação de pagar a taxa de reciclagem antecipada no momento da compra do seu novo EEE e fazer o descarte correto do seu REEE.

EAC1 - Aqui, quando os consumidores compram um EEE, já pagam uma taxa para que ele seja reciclado depois. Então quando você se desfaz do seu EEE, você tem a obrigação de descartar corretamente. Você pode descartar nos pontos de coleta seletiva.

Para facilitar o papel do consumidor, os SIG têm criado parcerias e iniciatiavas. A ERP, por exemplo, tem buscado por parcerias com hospitais, escolas e empresas para colocar seus coletores nesses locais (ERP-ES, 2018). Já a Ecolec criou um buscador online de pontos de coletas, no qual é possível encontrar pontos limpos municipais, pontos de venda e o \#GreenShop mais próximos de sua casa, colocando seu código postal (RESIDUOS PROFEISIONAL, 2018). O \#GreenShop é um programa da Ecolec em parceria com o Federación Española de Comerciantes de Electrodomésticos (FECE - Federação Espanhola de Comerciantes de Eletrodomésticos - tradução nossa) que visa certificar as lojas que se associam à iniciativa. Ela diferencia esses estabelecimentos dos outros, pois põe um selo do programa na frente do estabelecimento, atestando que aquele local ajuda os consumidores a fazer o descarte correto colocando cartazes com informação, além de terem coletores no local.

Outro exemplo das buscas de parceria vem da ECOTIC, que tem feito companhas em escolas com jogos e criou o programa Ecoinstalador. Esse programa é realizado desde 2011, em parceria com a associação de instaladores de ar condicionado. O projeto visa capacitar esses profissionais para fazerem o descarte correto desses EEE e oferece uma compensação econômica para cobrir os custos de logística e armazenagem desses profissionais (ECOTIC, 2018). De acordo com Recyclia (2018), os SIG continuam alcançando novas parcerias colaborativas que têm ajudado na coleta dos REEE e na conscientização dos consumidores.

Entretanto, parece que poucos consumidores cumprem sua obrigação de descartar corretamente seu REEE, seja por falta de informação, seja por falta de vontade, seja porque querem doá-los. Para EGM1, falta cultura para o descarte ainda para boa parte da população. Alguns entrevistados afirmaram manter seu EEE antigo guardado, como reserva para caso o novo tenha algum problema de funcionamento ou dão uma segunda vida a ele, doando para um filho ou até mesmo para usos cenográficos, como faz EAC2 que participa de um grupo de teatro. 
Na verdade, cumprir a obrigação de descartar seu REEE não é fácil, nem para quem tem conhecimento sobre o assunto ou desejo, como constatado pela pesquisadora. Depois de ir a várias lojas que vendiam EEE, em apenas uma encontrou um ponto de coleta de REEE, no El Corte Inglés, uma grande loja de departamentos com oito pisos, um deles exclusivo para venda de EEE. Nessa loja, enquanto comprava um EEE, perguntou ao vendedor se havia um ponto de descarte para seu celular no local. Ele, primeiro, hesitou para responder, mas depois disse que tinha um coletor no subsolo, sem explicar como chegar lá. Vale ressaltar que só o vendedor de EEE tinha essa informação, pois enquanto a pesquisadora descia para tentar encontrar o coletor, nenhum outro atendente conseguiu dar informações sobre o assunto. Alguns atendentes, inclusive, afirmavam categoricamente que isso não existia ali. Depois de descer os oito andares sem ter visto nenhuma sinalização e chegar no subsolo, encontrou três coletores da Ecotic, um para pilhas e acumuladores, um para lâmpadas e outro um pouco maior, com aproximadamente $1,5 \mathrm{~m}^{3}$, para REEE.

EAC1 - Elas também guardam os REEE nas suas casas, eu mesmo guardo, porque funcionam, porque eu não sei se vou precisar dele amanhã, porque sim. [...] Eu acredito que só as pessoas que têm um pouquinho mais de interesse nessas coisas de reciclagem é que sabem como descartar os REEE, essas coisas, mas são poucas. Creio que a maior parte vai para a lixeira. Só quando vão levar um equipamento grande na casa da pessoa que ela entrega para a reciclagem.

EAC2 - Eu, os meus equipamentos antigos, velhos, eu levo para um grupo de teatro que eu faço parte, para a gente usar nas cenas, eu dou uma segunda vida para eles.

Nesse contexto, o governo federal tem o papel de legislar e criar os sistemas previstos em lei para controle da gestão dos REEE. Já os governos das Comunidades Autônomas, que são como os governos estaduais, fazem o cadastramento e as auditorias das SIG, assim como firmam os acordos com as prefeituras para cooperarem na LR de REEE.

\subsubsection{Recursos}

Os SIG recebem os valores correspondentes às TAR dos produtores e importadores, que lhes pagam ao declarar os EEE colocados naquele trimestre no mercado. Esse valor pago é referente à cota de REEE que tem que ser reciclada, conforme determinado por lei. Com esse valor, os SIG pagam toda a gestão dos REEE: empresas de transporte, recicladores, fornecedores de REEE, prefeituras ou empresas que prestam serviços de gestão de RSU a elas e investimentos com infraestrutura e campanhas de conscientização. Entretanto, a lei não 
apresenta nenhuma meta de investimento para as campanhas, apenas define que elas precisam ser feitas.

EAC1 - O fluxo financeiro é assim: o consumidor paga para as lojas na hora da compra do EEE. A loja repassa isso para o produtor junto com o valor do produto, que investe no SIG.

De modo geral, os SIG pagam para as prefeituras o valor correspondente às toneladas de REEE processadas por elas. Os equipamentos utilizados nos Ecoparques para coletar e armazenar os REEE são fornecidos pelos SIG, mas o investimento em projeto e campanhas de conscientização ambiental para esse tipo de resíduo é suportado pela prefeitura e obrigatório, segundo o RD. Um exemplo disso é o projeto de cooperação realizado pela prefeitura de San Vicente del Raspeig em parceria com algumas lojas cuja estrutura e divulgação são pagas pela prefeitura. Quando alguma prefeitura não tem recursos financeiros para cooperar na LR de REEE, a Generalitat financia essas ações. Assim como os SIG, contudo, as prefeituras não possuem um valor pré-estipulado para investir em conscientização, apenas têm determinado que essas ações devem ser executadas.

EGM1 - Em 2017, foi coletado ali [Ponto Limpo] 74 toneladas. Por essas toneladas, nós temos um pequeno auxílio financeiro, uma subvención, deste SIG, muito pequeno para ajudar a cobrir os gastos da coleta seletiva. Então, a prefeitura contrata uma empresa que faz toda a coleta do município e essa subvención é repassada para eles. Mas eles não pagaram pelo projeto piloto pelas lojas, isso foi tudo o município. A propaganda no rádio, os contenedores, os adesivos, as coisas que incluímos na web, foram todos custos para nós.

\subsubsection{Comunicação}

A comunicação entre todos os atores da LR é basicamente feita por sistemas de informação, que não são integrados. Dessa forma, os SIG normalmente disponibilizam para seus clientes um sistema online para que declarem os EEE postos trimestralmente no mercado e para que façam o cálculo e emitam a fatura da taxa que cobrirá a gestão desses equipamentos quando chegarem ao final do ciclo de vida.

ERC6 - As empresas aderentes a qualquer um dos SIG da RECYCLIA devem completar as Declarações Trimestrais de dispositivos elétricos e eletrônicos [EEE] colocados no mercado no referido período, que terão o objetivo de calcular a contribuição das empresas para cada SIG, bem como obter as informações necessárias para a realização de estatísticas e relatórios a serem entregues às Administrações Públicas. 
As prefeituras, por sua vez, usam o OfiRAEE, uma plataforma online do governo federal para a coordenação logística da gestão de REEE dos pontos municipais de limpeza. A Figura 13 mostra o mapa de atuação da OfiRAEE. Nela estão todos os principais agentes envolvidos na reciclagem: SIG, entidades locais e Pontos Limpos. Nesse sistema, o Ecoparque ou Ponto Limpo faz a solicitação de retirada de REEE pela internet ou por telefone ao OfiRAEE, que processa e atribui automaticamente esse pedido a um SIG determinado para que ele gestione a retirada dos resíduos e seu tratamento. Em seguida, o OfiRaee emite a fatura da entidade local ao SIG. Dessa forma, o sistema automatiza a gestão e a coleta dos REEE movimentados entre prefeituras e SIG, para obter e gerar informações consolidadas e confiáveis sobre a quantidade de REEE coletada e gerida a partir dos pontos municipais de limpeza nos níveis local, regional e estadual. (OFIRAEE, 2018).

EGM1 - Nós, do ajuntamento, somos a menor estrutura do sistema. Nós temos firmado um sistema de cooperação com o Sistema Integrado de Gestão Estatal, que depois se assina com cada CCAA, e se chama OfiRAEE. [...] Nós, como ajuntamento, apenas aderimos à Generalitat Valenciana. E a Generalitat Valenciana aderiu à estatal.

Figura 13 - Mapa de Atuação OfiRAEE

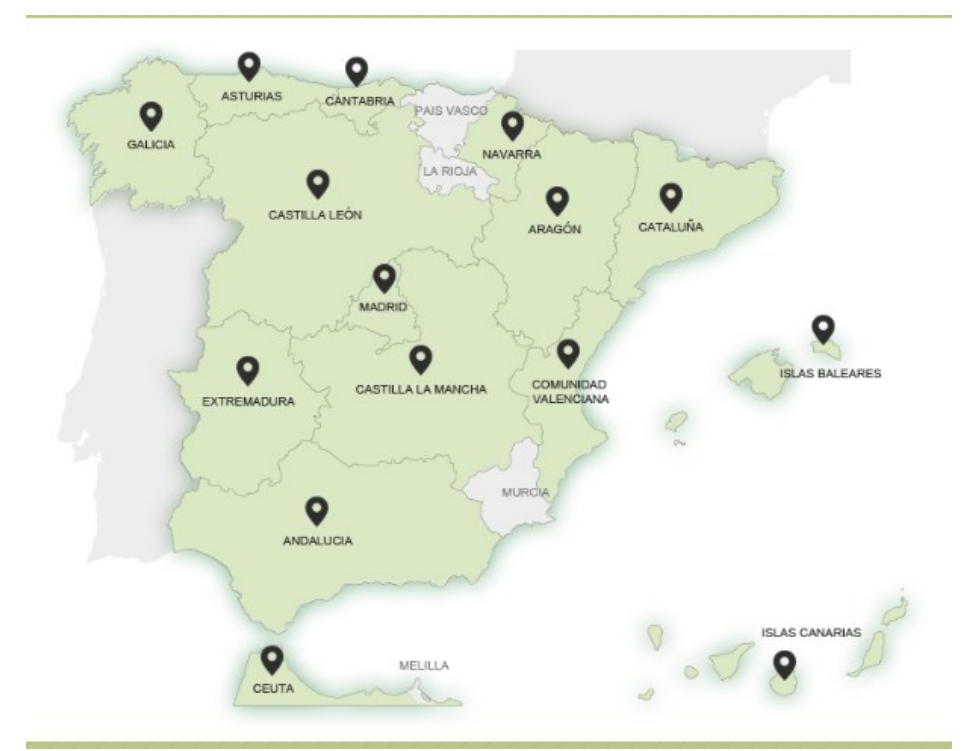

Fonte: OFIRAEE, 2018, p.1

Já o governo federal tem um sistema online para os produtores de EEE, o Registro Integrado Industrial - Aparatos Eléctricos y Electrónicos (RII-AEE) ou Registro Integrado Industrial - Equipamentos Elétricos e Eletrônicos (tradução nossa). Esse sistema permite a inscrição das empresas no registro dos produtores, a atribuição do número de identificação aos produtores no momento da inscrição, a declaração trimestral dos EEE colocados no mercado, a 
definição da cota de mercado para cada produtor ou SIG sobre os resíduos e o acesso público às informações sobre os produtores e EEE que eles colocam no mercado.

EGF1 - Mas já temos o sistema RII, no qual os produtores declaram a quantidade de EEE produzidos.

Até o momento, no entanto, não existe um site do governo no qual se tenha informações sobre a quantidade de REEE coletada pelas SIG, apesar de isto estar previsto no RD 110/2015. Com efeito, a plataforma encontra-se em fase de testes e desenvolvimento, e deve entrar em funcionamento em outubro de 2018. Estima-se que só a partir de 2019 os SIG serão obrigados a declarar nela seus dados sobre a gestão dos REEE. O objetivo é que, no futuro, todos os atores da LR de REEE estejam integrados a esse sistema, tanto os varejistas de EEE, como os pontos municipais de coleta de acordo com EGF1 e o MTE (2018).

ERC4 - Não tem um site do governo onde você possa encontrar essas informações consolidadas. Tem a lei que diz que temos que ter o site, sim. Eles estão fazendo campanhas de informações para as empresas envolvidas, mas ele ainda não está pronto.

\begin{abstract}
A Direção Geral de Biodiversidade e Qualidade Ambiental do Ministério da Transição Ecológica está desenvolvendo esta ferramenta, que será de uso obrigatório para os gestores de REEE, em sua primeira fase de implementação. Posteriormente, esta obrigação será estendida aos distribuidores de EEE e aos pontos de limpeza municipais. A plataforma eletrônica de REEE está atualmente em fase de testes (ambiente de pré-produção) e entrará em produção em $1^{\circ}$ de outubro de 2018 . Seu uso é estimado como obrigatório para os gerentes no início de 2019. (MTE, 218)
\end{abstract}

EGF1 - Ainda não temos um sistema de declaração de REEE, conforme previsto em lei. Ele está em fase de desenvolvimento.

Segundo EGF2, o governo federal está trabalhando em três plataformas: a plataforma integrada para declaração dos REEE coletados, um sistema de gestão do fluxo dos REEE, por meio de etiquetas eletrônica e o RII. Contudo, somente o RII, responsável pelo registro dos EEE postos no mercado já está funcionando. Além de receber trimestralmente a declaração dos EEE, o RII também atribui o número de identificação do produtor e a cota de mercado para o produtor ou SIG que o representa, e dá acesso público a informações referentes ao produtor e aos EEE colocados no mercado.

EGF2 - Um sistema de informação que permite: a inscrição no Registo de Produtores; a atribuição do número de identificação aos produtores ou ao seu representante autorizado no momento da inscrição; a declaração trimestral de dispositivos elétricos e eletrônicos colocados no mercado; atribuição de cota de mercado para cada produtor ou sistema coletivo de responsabilidade alargada do produtor [anteriormente SIG] para o estabelecimento de responsabilidades sobre os resíduos; acesso público a 
informações relevantes sobre os produtores e os dispositivos que eles colocam no mercado.

O terceiro sistema de informação mapeará totalmente o fluxo de REEE do momento do descarte até sua destinação final. É um sistema baseado em etiquetas de leitura eletrônica, como código de barras ou $Q R$ Code, que serão introduzidas nos REEE no momento da primeira entrega nos Pontos Limpos, nas lojas e nos gestores de coleta, de acordo com EGF2. Entretanto, conforme decidido pelo governo federal, ele não tem data estabelecida para ser implementado, pois depende da criação de toda a infraestrutura para sua efetivação.

EGF2 - Os REEE, no momento da entrega e primeira coleta, serão identificados com etiquetas que possam ser lidas eletronicamente e que garantam seu controle e rastreabilidade. Os rótulos serão desenvolvidos em conjunto com a plataforma eletrônica de dados de REEE, que será implementada pelo MAGRAMA (atual MAPAMA) e seu uso será implementado assim que a plataforma estiver em andamento e de acordo com o formato considerado adequado para garantir seu funcionamento adequado.

Dessa forma, fica claro o momento de transição pelo qual o sistema de LR de REEE espanhol está passando. Com os dois sistemas que controlam os resultados da coleta em fase de implementação, um com previsão de uso obrigatório para 2019 e outro sem data, o governo só deverá ter o controle total do fluxo após o período de transição definido na lei, conforme o RD 110/2015.

\subsubsection{Poder}

Nesse cenário, com todos os atores tendo seus papéis bem definidos, o poder se mantém dentro de cada organização. Mesmo com o governo sendo legislador, seu poder se limita a garantir que se cumpra o que está definido nas obrigações de cada um. Além disso, com onze SIG credenciadas para atuar em todo o país, com adesão a critério da indústria, a concorrência não afere a liderança do sistema a nenhuma delas. Dessa forma, por atuarem complementarmente, todos os atores são co-responsáveis pelo resultado da LR de REEE.

\subsubsection{Mecanismos de controle}

O controle sobre as obrigações de cada ator é garantido por sistemas de informação online, por contratos entre os atores envolvidos e por leis que determinam as metas a serem efetivadas e seus mecanismos de controle. Para tanto, a partir de 2016, o governo federal passou 
a editar uma resolução anual sobre os objetivos de coleta de REEE, já que as metas de coletas foram alteradas pelo RD 110/2015, de $4 \mathrm{~kg}$ de REEE por ano por habitante, para um percentual progressivo sobre a quantidade de EEE colocados no mercado, conforme o Quadro 15. A partir de 2019, haverá duas opções de meta de coleta que ainda serão decididos pelo governo (BOE, 2015).

Quadro 15 Objetivos de coleta de REEE definidos pelo RD 110/2015

\begin{tabular}{|l|l|l|}
\hline Ano & $\begin{array}{l}\text { Meta de coleta de } \\
\text { REEE }\end{array}$ & Referência para cálculo \\
\hline 2015 & $\begin{array}{l}4 \mathrm{~kg} \text { por habitante } \\
\text { ao ano }\end{array}$ & $\begin{array}{l}\text { A quantidade por categoria será baseada nos EEE colocados no mercado } \\
\text { em } 2014\end{array}$ \\
\hline 2016 & $45 \%$ & Média anual dos EEE colocados no mercado entre 2013 e 2015 \\
\hline 2017 & $50 \%$ & Média anual dos EEE colocados no mercado entre 2014 e 2016 \\
\hline 2018 & $55 \%$ & Média anual dos EEE colocados no mercado entre 2015 e 2017 \\
\hline $\begin{array}{l}\text { A partir } \\
\text { de } 2019\end{array}$ & $65 \%$ & $\begin{array}{l}\text { Opção 1: percentual sobre o peso médio dos EEE introduzidos no mercado } \\
\text { nos três anos anteriores }\end{array}$ \\
\hline $\begin{array}{l}\text { A partir } \\
\text { de } 2019\end{array}$ & $85 \%$ & $\begin{array}{l}\text { Opção 2: percentual sobre os REEE gerados, uma vez que a Comissão } \\
\text { Europeia estabelece a metodologia para a estimativa dos resíduos gerados. }\end{array}$ \\
\hline
\end{tabular}

Fonte: Autora, "adaptado de" BOE, 2015, p. 14237.

\subsubsection{Riscos}

Não foram relatados riscos.

\subsubsection{Os elementos da Categoria "Impactos" na LR de REEE na Espanha}

Segundo dados do Eurostat, de 2006 a 2015, a Espanha atendeu ao objetivo mínimo de coleta de REEE, de 4 kg per capita. Em 2007, 2008, 2013 e 2015, coletou 5,97 kg, 6,23 kg, 4,33 $\mathrm{kg}$ e 4,61 kg respectivamente. Entretanto, os dados de 2006 a 2008 estão baseados em estimativas, conforme alerta o Eurostat (2018). De acordo com Martinez (2015), no entanto, os objetivos de coleta deixaram de ser alcançados a partir de 2009, quando as CCAA passaram a não incluir os REEE coletados por recicladores e sucateiros na apuração dos dados. Com efeito, segundo o autor, esse setor é responsável por dois terços dos resíduos coletados no país, sendo que a maior parte é referente a resíduos da linha branca, volumosos. Esse resultado pode ser observado na Figura 14. 
Figura 14 - Volume de REEE coletados na Espanha de 2006 a 2015

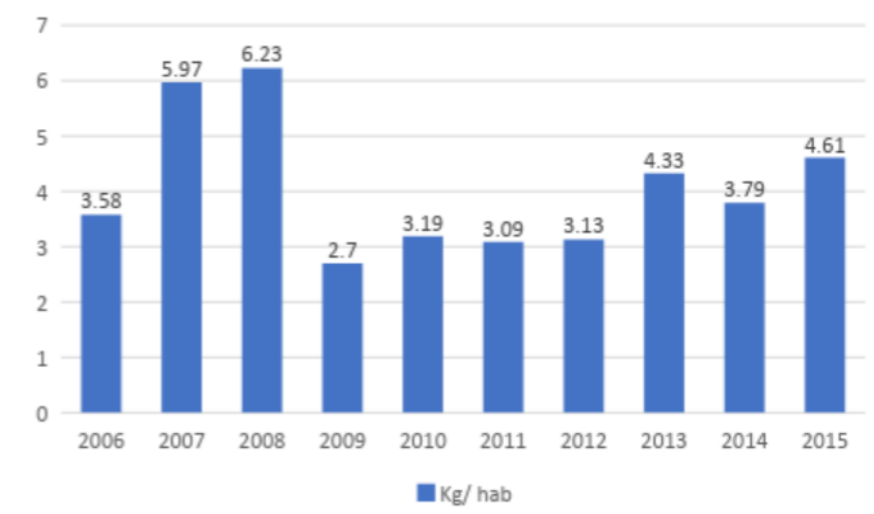

Fonte: Eurostat, 2018, p.1

A evolução dos resultados mostra que a Espanha tem deixado de cumprir as metas da primeira Diretiva por diversos anos. Esse fato é mais preocupante quando se transforma os dados de coleta de 2015 em percentual do que foi coletado com base na média dos EEE colocados no mercado nos últimos, pois ficava abaixo dos $45 \%$ que seriam exigidos em 2016 , conforme apresentado na Figura 15

Figura 15 - Total de REEE coletados em 2015 por países na UE, comparado com a média percentual de $45 \%$ e $65 \%$.

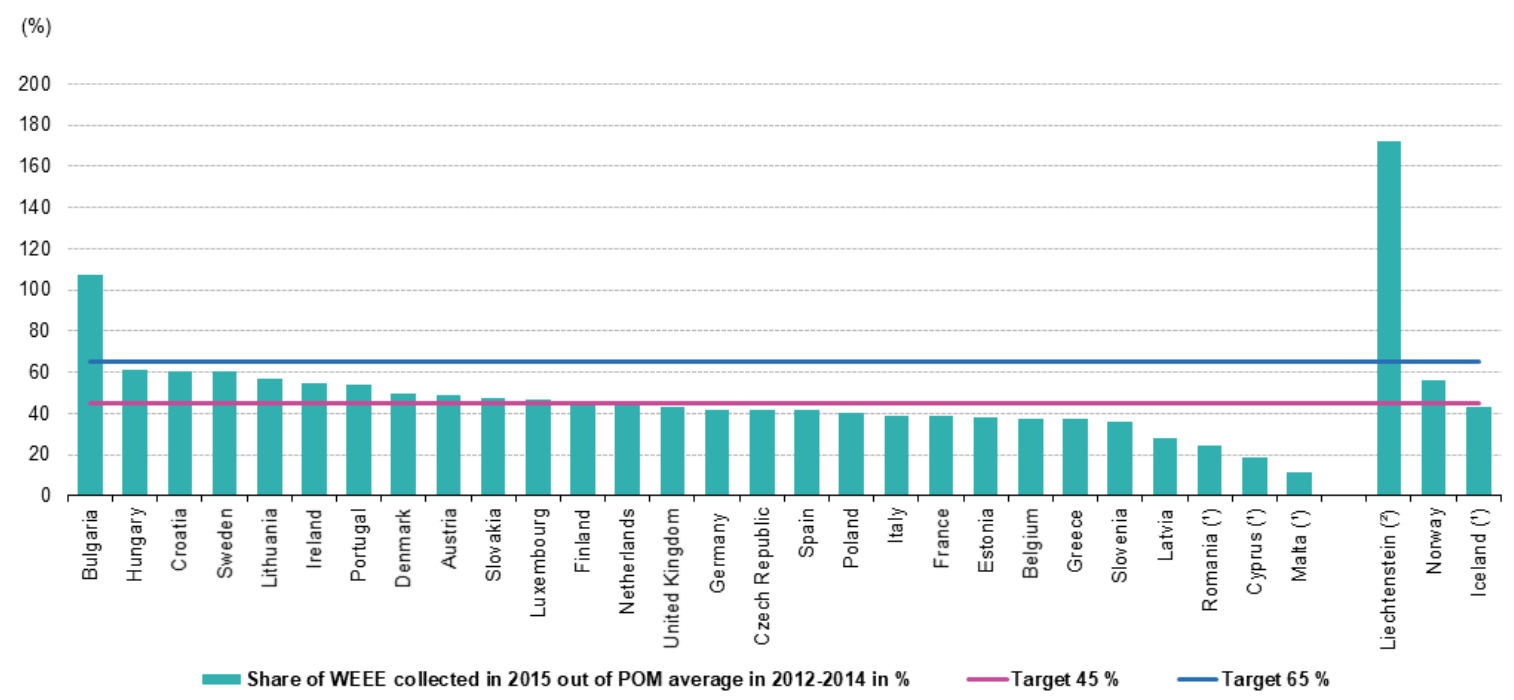

Note: ranked on 'Share of WEEE collected...' data.

(') 2015: 2014 data instead and average 2011 - 2013.

(2) Waste collected definition differs, see metadata.

Source: Eurostat (online data code: env_waselee)

Fonte: EUROSTAT, 2015, p. 1

Entretanto, de acordo com ERC5, a Espanha vem alcançando as metas na média, embora certamente isso não ocorra em todas as categorias. Outro ator do setor de reciclagem considera que dificilmente o país alcançará as futuras metas, pois, na Espanha, é comum que os objetivos 
não sejam alcançados logo início. Um representante da academia acredita que o país atingirá seu objetivo quando for obrigatório, referindo-se a esse período transitório, definido desta forma pela RD de REEE de 2015 até 31 de dezembro de 2018.

ERC4 - Não cumprimos as metas de todas as categorias de REEE. De alguns sim, de outros não. Na média, acho que chegamos, mas não em tudo.

ERC1 - Creio, sinceramente, que não aqui [Não vamos cumprir as metas dos REEE]. Pelo menos na Espanha, no momento não, é impossível que se cumpra isso [nova meta para agosto, de 55\%], é impossível! Pelo menos agora no início, porque não tem essa cultura.

EAC3 - A Espanha vai atingir as metas de reciclagem de REEE, quando realmente for obrigatório.

Um dos principais fatores relacionados à falta de cooperação do consumidor na LR de REEE é a baixa conscientização ambiental da população. Esse elemento surgiu repetidamente, em vários momentos das entrevistas com todos os atores e, muitas vezes, a falta de comprometimento com a LR de REEE foi generalizada para todos os resíduos. Alguns atores acreditam que se trata de um fator cultural, pois esse é um tema recente na Espanha. De acordo com atores de GM, a coleta seletiva tem apenas seis anos no município estudado (qual município?). Além disso, os espanhóis adultos não foram educados para reciclar, separar seus resíduos, diferentemente das crianças que começam a aprender sobre reciclagem nas escolas desde o ensino infantil. ERC1 faz uma comparação entre sua geração, que tem em média 45 anos, com a dos seus filhos, que tem entre 5 e 12 anos, ao argumentar sobre a dificuldade de sensibilizar as pessoas mais velhas, de fazer com que elas internalizem a necessidade de separar, de reciclar. E conclui que será preciso investir muito mais recursos em publicidade para sensibilizá-las.

EAC1 - As pessoas na Espanha não têm muita consciência ambiental, porque você pode ver geladeiras, por exemplo, jogadas nas caixas de coleta seletiva. [...] Isso é cultural. [...] Somos de uma geração que não recebeu nenhum tipo de publicidade para isso, não temos isso interiorizado. Para minha geração, tem que gastar mais dinheiro com publicidade, para que interiorize a necessidade de reciclar, de separar.

EGM1 - Tentamos sensibilizar as pessoas para que coloquem cada coisa em cada local. As pessoas não cooperaram. Mas não podemos fazer outra coisa. [...] Fazem cinco ou seis anos que existe coleta seletiva aqui, as pessoas não sabiam o que era coleta seletiva. Não entendiam que tinham várias caixas de lixo.

Já para EGM1, a sensação de impunidade é outro fator cultural que dificulta o comprometimento com os objetivos da LR de REEE no país, pois sempre que não se atinge uma meta, é o governo federal que arca com a sanção. Nesse caso, nem prefeitura, nem cidadão 
sentem que estão sendo cobrados por não terem cumprido as metas. Além disso, muitos atores não têm disposição para atuar em parceria nas coletas de REEE se não forem obrigados por lei, como foi o caso dos supermercados, que aceitaram participar do projeto piloto no município de San Vicente del Raspeig, e desistiram no momento da entrega dos coletores.

EGM1 - Aqui na Espanha sempre acontece o mesmo com as metas. Chega o dia, não as cumprimos e eles nos põem uma sanção. E como é o governo federal que paga, não o município, então é como se não pagássemos. Como as pessoas não percebem que estão pagando mais pelas coisas que não cumprem, então não reclamam.

Para ERC1, a falta de informação sobre REEE se deve ao fato de que os municípios decidiram priorizar os resíduos que lhes trazem mais impactos e investir na conscientização sobre a coleta seletiva de papelão, embalagens, vidros e orgânicos, resíduos que se acumulam mais no dia a dia das pessoas e com os quais elas têm mais contato.

ERC1 - Eu vejo que, no final, temos que começar por algo. Então, estamos começando pelos orgânicos, papéis, plásticos, são coisas que você tem mais contato e que se acumulam mais na sua casa.

EGM1 - Na verdade, nós estamos mais preocupados com os outros resíduos, que nos impactam mais, como as embalagens, as podas de árvores, os móveis.

Outro desafio enfrentado pelos sistemas de coleta é o roubo de REEE nos Ecoparques ou nas ruas nos dias de coleta seletiva, antes do caminhão da prefeitura passar para recolhê-los. Esse fenômeno é resultado do desemprego e da falta de programas para a inclusão do setor informal de catadores, formado principalmente por imigrantes ilegais. Como o REEE tem valor econômico e pode ser vendido às empresas de reciclagem, as pessoas em estado de vulnerabilidade econômica roubam-nos para poder sobreviver. Esata ação resulta em riscos à saúde e ao meio ambiente, pois os catadores separam as partes dos REEE com maior valor econômico para vender, sem se preocupar com o perigo de contaminação pelas substâncias tóxicas que eles contêm. Para evitar esse processo, alguns recicladores se recusam a receber REEE que não estejam íntegros, na tentativa de evitar que os resíduos sejam desmontados de forma inadequada. Entretanto, isso não resolve a questão dos roubos, nem a falta de inclusão dessas pessoas na cadeia reversa dos EEE.

ERC5 - Aqui acontece igual a Portugal: tem os caminhões dos municípios que passam para fazer a coleta seletiva, e, antes, passam essas pessoas, como os ciganos, recolhendo os resíduos que têm valor para vendê-los. [...] E se falamos que não aceitamos esses resíduos pela metade, eles não trazem mais assim, já no dia seguinte trazem eles inteiros. Essas pessoas são pessoas com necessidade, elas têm fome. 
EGM1 - De fato, estão roubando esse tipo de resíduo nos Ecoparques. As pessoas sem recursos saltam ali e levam computadores, as partes das geladeiras. Nos roubam muito. A economia está muito mal e as pessoas buscam a vida e roubam ali.

O alto custo da reciclagem e a falta de volume de REEE para se obter lucro com sua gestão geram um problema ético e moral mais sério ainda, a exportação ilegal desses resíduos para países em desenvolvimento. Com efeito, eles são enviados para países africanos, disfarçados de EEE de segunda mão, para burlar o custo da reciclagem ambientalmente correta.

ERC1 - Aqui estão exportando bastante para a África. É como passar a batata quente para eles.

EGM1 - Esses tipos de resíduos são uma fração muito pequena do que a gente recebe lá. [...] Na verdade, o grande problema, o grande volume deste resíduo vai para outro país, nos barcos que vão para a China.

\subsection{ESTUDO DE CASO DA LR DE REEE NO BRASIL, DA ELABORAÇÃO DO ACORDO SETORIAL À IMPLEMENTAÇÃO DO PROJETO PILOTO DE COOPERAÇÃO DESCARTEON.}

Esta seção apresenta o processo de elaboração do Acordo Setorial de EEE e implementação do Projeto Piloto DescarteON (PP), e visa levantar quais foram os fatores motivacionais para a implementação da LR de REEE, descrever como foi definido o escopo e a estrutura para o processo de negociação entre os atores envolvidos nessa cadeia e o governo, verificar como esses elementos impactaram a efetivação da colaboração e da cooperação e que resultados foram alcançados nessas ações, no cenário brasileiro.

\subsubsection{Acordo Setorial da LR de REEE no Brasil}

Esta seção apresenta o processo de elaboração do Acordo Setorial de EEE no Brasil

\subsubsection{Os atributos da Dimensão “Motivação” no AS de LR de REEE do Brasil}

Nesta seção o processo de elaboração do Acordo Setorial de EEE no Brasil será apresentado à luz das dimensões da colaboração.

O setor de EEE é formado por empresas que atuam no mercado global, com sede e atuação em países nos quais muitas vezes já possuem a obrigação de implementar a LR de REEE. No Brasil, muitas dessas empresas já possuem seus sistemas de LR, uns para atender 
apenas clientes empresariais, outros que englobam os REEE de uso doméstico. Entretanto, essas empresas não atuam para influenciar o mercado a criar um sistema amplo, que conte com a participação de todos os fabricantes e distribuidores, como ocorreu na Suíça. Esse comportamento tem intrigado alguns atores desse cenário.

GF1 - Interessante é que algumas empresas fazem isso aqui no Brasil. [...] E por que essas empresas que já fazem, como é o caso por exemplo da DELL, por que elas não conseguem influenciar uma transformação no mercado?

\subsection{Necessidade}

A elaboração do Acordo Setorial do setor de EEE, deve ser realizada para atender à obrigação imposta pela PNRS aos atores desse setor para depois implementar a LR de REEE por meio da responsabilidade compartilhada. BRC2 ressalta que o processo de criar um Grupo para discutir o AS não foi colaborativo, não houve uma construção de parceria. Ao contrário, foi impositivo, nos termos da lei, com pressão governamental, para que os atores discutam as questões técnicas, cheguem a um consenso, assinem o documento e assumam a responsabilidade da cadeia reversa.

BRC2 - O processo de elaboração e aprovação não foi colaborativo. E não adianta a gente querer dizer que houve uma construção de parceria. Na verdade, é bastante impositivo! Em todo lugar do mundo, sempre começa com uma pressão governamental para que os atores [...] entrem em um consenso, para formação desse processo. [...] Nada mais é do que uma discussão prévia à assinatura de um documento.

Alguns entrevistados reconhecem a importância de implementar a LR de REEE por meio da elaboração do AS (BGF1, BGE1, BRC1, BRC2). Para BPD1, todos os envolvidos, tanto do setor privado, como do setor público, desejam que o AS seja definido. Por outro lado, alguns entrevistados acreditam que o setor privado não concorda com sua obrigação plena na gestão de REEE, recusando-se a reconhecer a validade da lei na íntegra. Nesse sentido, segundo BGF1, o setor de EEE concorda em implementar a LR, mas não se acha obrigado a custear o sistema. O descompasso entre o discurso e a prática é corroborado pelo fato de que, até o momento, não se chegou a um consenso sobre como será desenvolvido o sistema de LR.

BPD1 - É um desejo do setor privado que saia [o Acordo Setorial]. Acho que não só do setor privado, mas do próprio governo também. 
BGF1 - Eu acredito que o setor de EEE não se sinta obrigado a implementar a LR de REEE. Na verdade, eles tentam dizer que está previsto na lei que eles são obrigados a implementar, mas que eles não são obrigados a custear.

Para BGE1, contudo, a resistência para implementar a LR de REEE tem diminuído ao longo do tempo, visto que os atores do setor privado têm claro que a lei criou uma obrigação e eles terão que cumpri-la, cedo ou tarde. Sendo assim, acredita que, para os atores que têm a responsabilidade de implementar a LR, o melhor é participar da discussão e da definição do AS para poder se antecipar a uma possível decisão unilateral, por parte do governo, que não domina todos os aspectos de operacionalização da LR de REEE.

BGE1 - Em 2011, houve muita gente de diversos setores, inclusive do eletroeletrônico, que tinha o seguinte discurso: Olha, nós não reconhecemos a responsabilidade compartilhada pelos resíduos, da PNRS, no artigo 33. [...] Mas, hoje, todos se dispõem, não sei se todos querem, é diferente, às vezes você não quer fazer uma coisa, mas faz porque é necessário. Então tem de separar o desejo da obrigação/necessidade. Eu acho que todos já entenderam que têm uma responsabilidade e que cedo ou tarde terão que responder por isso. [...] Digo para eles: a gente vai ter que discutir em algum momento a sua responsabilidade, e eu estou aqui para a gente tentar se antecipar a qualquer maluquice que alguém possa fazer e te dar oportunidade de dialeticamente chegar a uma construção que seja interessante, e, inclusive possa te trazer alguma oportunidade além da responsabilidade e dos riscos que já existem na Lei, que são claros e vão ter que ser assumidos.

\subsection{Oportunidade}

Membros do governo afirmam que foi priorizada a elaboração do modelo brasileiro por meio de AS, devido à expectativa de contar com a colaboração dos atores envolvidos no ciclo de vida do EEE e dizem que o governo definirá de forma unilateral a LR de REEE por meio de Decreto só em último caso.

BGF1 - Ele tomou essa decisão de priorizar mesmo o acordo setorial. O decreto seria usado assim em última análise, como último recurso, caso não houvesse acordo entre as partes, que precisam estar colaborando para implementação.

O governo federal percebeu que pode haver ganhos significativos com a participação do setor, inclusive com a diminuição dos riscos de ser questionado judicialmente pela inviabilidade de algum aspecto da efetivação do sistema, caso optasse por um decreto.

BGF1 - É porque você melhora a eficiência dos processos quanto coloca todo mundo para conversar e definir alguns parâmetros. Você acaba fazendo com que o processo seja o mais eficiente possível, ao passo que, por um decreto, normalmente o governo não tem todas as variáveis necessárias e acaba por impor coisas que não necessariamente são as que causam menos impacto para a economia como um todo. 
Membros do setor de EEE também elegeram o AS como melhor mecanismo para estabelecer a LR. As opiniões pareçem ser distintas, no entanto, quando se aborda a visão de construção de parceria entre os atores da LR de REEE. Enquanto para um a discussão do AS é uma relação de parceria entre os atores, para o outro é apenas uma forma de atender a uma obrigação legal, ainda que considere a participação dos atores na discussão do modelo de LR como elemento chave do AS. Ambos, contudo, concordam que ele trará oportunidades, ao permitir que os atores possam opinar e ajudar a resolver os entraves.

De acordo com BPD2, um dos resultados da discussão do AS é a definição da gestão da LR por Entidades Gestoras (EG), que serão formadas por fabricantes e distribuidores de EEE e trarão redução de custos e padronização dos processos para atender a Lei. Já para BPD1, o AS não só facilitará as negociações, como permitirá criar um modelo de LR de REEE que funcione e que seja capaz de contribuir para preservar o meio ambiente e reduzir a extração de matéria prima para produção de EEE. Para BGF2, a proteção ao meio ambiente é o fator mais importante para o governo federal querer implementar a LR de REEE, além da dimensão econômica atrelada à LR de REEE, devido ao seu potencial para gerar renda e empregos, como foi observado na experiência japonesa.

BPD2 - O melhor mecanismo oferecido pela PNRS é o AS, com toda certeza! [...]
Porque você consegue discutir, mesmo ele sendo um contrato, e demonstrar quais são
os entraves para que ocorra esse mecanismo. Aí busca-se junto a solução desses
entraves. Então esse é o maior desafio. [... [AS] é um contrato entre poder público e
iniciativa privada, para que pudessem solucionar uma questão que envolve política
pública.

BPD1 - O AS nada mais é do que essa parceria para facilitar a negociação da LR. [...] Além da necessidade de se fazer algo pelo planeta, criar um sistema de LR para parar a extração de matérias primas, a gente quer fazer uma coisa que realmente funcione, que seja sustentável e isso poderá ser viável pelo AS.

BGF2 - O que mais motivou o governo federal a implementar a LR de REEE foi a preservação do meio ambiente. Isso é fundamental! No mundo inteiro foi isso. Foi o maior motivo. [...] Na Dimensão Econômica logicamente você pode criar empregos e renda.

Por outro lado, apesar da indústria de EEE reconhecer as oportunidades que a elaboração do AS traz para a implementação da LR de REEE, ela não se sente motivada a agir proativamente na elaboração da proposta, pois, segundo BGF1, acredita que a LR só vai gerar mais custos e, por isso, tenta postergar ao máximo a assinatura do AS.

BGF1 - Na verdade, a grande alegação do setor privado é que isso é mais custo para indústria, mais custo para o comércio. Então isso acaba sendo uma razão para eles 
protelarem. Acho que o que se busca com isso é ganhar tempo, de modo a reduzir o custo o quanto puder.

\subsection{Disposição para atuar em conjunto}

Parece não haver consenso nas opiniões dos entrevistados sobre a disposição dos atores para atuarem de forma sinergética na definição do AS. Os atores da LR de REEE não demonstram vontade verdadeira e não atendem com a celeridade necessária para a aprovação do AS. Alguns entrevistados são categóricos sobre a falta de motivação dos membros envolvidos no AS (BGF1, BRC1). Refletindo sobre o comportamento desses atores, eles observam que o grupo é composto por pessoas que estão defendendo interesses próprios, ao invés de priorizar a elaboração do AS e a implementação da LR de REEE, postergando o quanto puderem sua efetivação. BGF1 acredita que esses atores não se sintam pressionados suficientemente a definir o AS, devido à ausência de prazo para estabelecimento da LR. Esse fator leva a outra reflexão: será que o fato do governo federal não ter dado um deadline por considerar a gestão dos REEE complexa, não teria aumentado a procrastinação ao invés de viabilizar a colaboração entre os atores? A falta de iniciativa dos atores privados corrobora a opinião de alguns dos entrevistados sobre a falta de vontade de agirem em parceria, pois não desejam acelerar o processo, e, por isso, não pressionam com veemência o governo, como o fazem quando têm interesse sobre a resolução de alguma questão que os envolva. BGF1 corrobora seu posicionamento sobre resistência do setor privado quando declara que seus representantes apelam para recursos jurídicos para retardar o andamento do progresso da proposta de AS.

BGE1 - Eu vejo que todos estão dispostos a participar, mas, na maior parte dos casos, falta o interesse verdadeiro de fazer a coisa da forma ou na velocidade ou intensidade com que deveria ser feita.

BGF1 - A falta de prazo é, a princípio, por causa da complexidade da LR de REEE [...]. E quando há um prazo, na verdade, o próprio setor pressiona o governo a resolver algumas pendências. Nesse caso, eu não vejo o setor privado com essa motivação. Ele [setor privado] tem se defendido, judicialmente, no sentido de que ainda há coisas que precisam ser feitas para a implementação da LR por parte do governo e que ficam bastante confortáveis nessa posição.

O setor privado reconhece a disposição do MMA para contribuir para o AS, para trabalhar junto, ouvindo todas as partes, tentando conciliar os interesses para chegar a uma solução que possa superar os entraves apresentados para a efetivação na LR de LEEE. Ainda assim, pleitos como a taxa de reciclagem ou a definição de periculosidade de EEE, que 
dependem outros órgãos do governo federal, não encontram a mesma receptividade. O setor privado precisou provar tecnicamente que suas demandas por ajustes legais e financeiros eram válidas, e não desculpas para postergar o AS.

De acordo com BGF1, o governo federal tem dificuldade em avançar e atuar de forma proativa e colaborativa, pois a Lei não exauriu todos os aspectos técnicos e legais que envolvem a LR de REEE. A complexidade da LR e todas as possibilidades de interpretações da Lei diante das especificidades do tema, "engessam as respostas do governo" para os numerosos questionamentos feitos pelo setor de EEE, que não foram tratados nem na Lei 12.305/2010, nem no Decreto Federal 7.404/2010. Além disso, técnicos do governo federal, responsáveis por responder à demanda gerada, principalmente pelo setor privado de EEE, “ficam muito presos à letra da lei e às possíveis interpretações", deixando o processo mais moroso e ineficiente.

BGF1 - É um pouco mais complexo, pois uma das premissas básicas do funcionário público é que o governo não pode fazer, nem deixar de fazer algo, senão em virtude de lei. Então, muitas vezes, apesar dos técnicos, dos dirigentes terem essa visão, de entenderem essa necessidade de abrirem mão de algumas coisas, ficam muito presos à letra da lei.

Alguns atores acreditam que a lentidão do AS se deve à falta de prioridade que o governo federal atribui à LR de REEE (PD1, RC1). No entanto, para que ocorra a colaboração efetivamente é importante que todos os atores estejam dispostos a se empenharem e superarem as barreiras.

BPD1 - O governo tem sentado para conversar [...]. Pelo menos por parte do
Ministério do Meio Ambiente (MMA), eles têm deixado a gente discutir. Eles têm
boa vontade, ideias, e pelo menos ouvem a gente. Teve uma carta em 2014-2015 em
que o MMA reconheceu que todos os quatro pleitos são legítimos. Houve um avanço,
já que no começo eles achavam que a gente queria enrolar, e que era um absurdo o
que estávamos pedindo. Tivemos que provar tecnicamente. [...] A única explicação
que a gente consegue encontrar é que não é uma prioridade para outros ministérios
como é para o MMA.
BRC1 - Eu acho que existe o desejo de postergar ao máximo, de todos os lados,
inclusive do governo federal, por uma questão de impacto econômico. [...] Eu acredito
que o governo federal, no momento que nós estamos vivendo, possui várias outras
prioridades.

Diante disso, percebe-se que, apesar dos atores visualizarem possíveis oportunidades ao participar da elaboração do acordo setorial e concordarem que é necessário implementar a LR por meio do AS, a falta de senso de urgência, prioridade e necessidade para sua efetivação não os motiva. Isso se reflete na falta de disposição para atuarem em parceria, fazerem concessões e atuarem de forma sinergética na elaboração do AS e na resolução dos problemas, pois cada 
um tenta priorizar seus próprios interesses. Isso é corroborado nas entrevistas dessa pesquisa, assim como pelo tempo em que se arrasta a discussão de como e quem irá fazer a gestão dos REEE.

Além disso, os atores não parecem estar dispostos a incluir outros membros na discussão, mesmo que concordem que eles possam contribuir dado seu conhecimento no tema, como pesquisadores, recicladores que atuam ativamente nessa cadeia, ou até mesmo varejistas que já fazem uma parte da LR de REEE. Nesse sentido, alegam que eles podem atrapalhar o processo, deixando-o mais moroso. Por outro lado, os atores excluídos acreditam que essas os atores que participam da elaboração do AS tenham medo que os novos atores contrariem o discurso atual, de que determinada coisa não dá para fazer, quando a experiência deles mostra o contrário.

BGF1 - Eu acho que, em algum momento, é interessante você ter participação, por exemplo da academia, como um meio que pensa fora dos interesses privados. Mas também, ao envolver esses novos membros, acaba deixando o processo um pouco mais tumultuado, isso acontece mesmo.

BCV1 - A gente não foi envolvido nesse debate [do Acordo Setorial]. Eu tentei entrar em contato com a Fecomércio, na época, mas ninguém se posicionou. Eu queria muito falar para eles que dá para trabalhar com cooperativa e que vou continuar fazendo assim.

No caso da colaboração, é preciso ter persistência para que as relações de confiança se estabeleçam. Além disso, é necessário que o escopo do projeto e a estrutura que o apoia sejam definidos de forma a apoiar a atuação em parceria. Esses elementos na LR de REEE foram estabelecidos pelo Decreto da PNRS e pelo edital de chamamento desse setor. A seguir eles serão apresentados à luz da segunda e terceira categorias, com o objetivo de levantar como foram construídos o escopo e a estrutura para discussão do AS.

\subsubsection{Os atributos da Dimensão "Escopo" no Acordo Setorial da LR de REEE no Brasil}

Está seção apresenta os atributos da dimensão "Escopo": natureza, objetivos, resultados e atores na elaboração do AS da LR de REEE no Brasil.

\subsection{Natureza}

A elaboração do AS é um processo de natureza mental, que visa contar com a colaboração dos atores envolvidos. 
BPD2 - O governo chama o setor empresarial para conversar, cria um grupo técnico, discute quais são as regras que devem ser aplicadas, o que, para quem, como, quanto tempo, qual é a meta estrutural, qual é a meta quantitativa, como será feito.

\subsection{Objetivos}

No final de 2012, o governo federal aprovou o edital de chamamento que estabelece as diretrizes do AS do setor de EEE, mas sem definir papéis nem onde começa e onde acaba a responsabilidade dos atores. Apenas traçou metas mínimas e algumas condições para validar a proposta. Dessa forma, esperava que os atores chegassem a um consenso e validassem o modelo de LR de REEE por meio desse mecanismo, já que tem claro que a lei não é bem vista pelos atores envolvidos (GF1).

BGF1 - Eu acho que o governo federal tem esse objetivo, esse desafio realmente de conseguir implementar uma lei que levou vinte e um [grifo da autora] anos para ser aprovada. É bom a gente ter sempre em mente que, na verdade, essa lei não é uma lei popular, muito distante disso.

Percebe-se que os atores têm objetivos diferentes, muitas vezes não congruentes e incompatíveis com processos colaborativos. Apesar de declararem que querem criar uma proposta de acordo com as metas do edital de chamamento, transferem para a vontade do consumidor ou dos atores que vão operar a LR a responsabilidade de atingir as metas. Dessa forma, minimizam o seu papel na cadeia reversa, atuando apenas na construção da infraestrutura da LR, mas não tendo responsabilidade de garantir sua eficiência, e mostrando que seu objetivo não é atender a lei e criar a melhor proposta de AS, mas tentar defender seus próprios interesses, acima de tudo. Esse comportamento se reflete nas opiniões de outros atores envolvidos no AS, pois o discurso é antagônico à ação. Para alguns representantes do governo, tanto federal, como estadual, o setor privado tem como objetivo principal reduzir ao máximo a sua responsabilidade e, por consequência, os custos que recairão sobre ele.

PD1 - Nosso objetivo é criar o sistema que seja capaz de receber e destinar $17 \%$ dos REEE. Mas se nós vamos coletar $17 \%$ ou não, só Deus sabe. Vai depender muito da conscientização do consumidor, pois o produto está na casa dele, é dele, e ele faz o que ele quiser. Vai depender talvez da cooperação de alguns outros atores, que já trabalham com LR, por interesses econômicos.

GE1 - Cada um tem seus objetivos individuais, até porque em parte esses objetivos individuais vão atender a sua parcela de responsabilidade. Então, por exemplo, o fabricante tem que assegurar a coleta, a devida destinação etc. e tal. Ele tem que ter 
como objetivo que isso aconteça, num sistema de LR dentro de um acordo setorial, e ele também reduz o custo desse sistema.

Além do objetivo de reduzir custos, o setor privado parece ter percebido que seria interessante econômica e estrategicamente fazer a gestão dos REEE. Dessa forma, com o objetivo de garantir que o benefício será aferido por ele, criou EG para operarem a LR de REEE, quando o AS for assinado. O setor privado apresenta suas EG como a solução para a LR de REEE, inserindo-as como modelo de gestão na discussão e proposta do AS.

BGF2 - Algumas associações criaram suas EG depois da visita ao Japão, pois viram que, se bem feita, a LR de REEE gera oportunidades. Todos saímos do Japão com uma visão diferente sobre a LR de REEE. Nós estamos desenvolvendo um processo para extração dos metais valiosos aqui no país.

BPD2 - Essas associações representam esse objetivo, que é um objetivo comum entre esses membros, que são concorrentes. Então o objetivo comum, por exemplo dessa entidade gestora, como a ABREE, é a discussão de uma política que atenda todos os fabricantes e importadores.

\subsection{Resultados esperados}

Para os atores, os novos conhecimentos adquiridos, a melhoria da imagem ou a sensação de fazer algo importante para o planeta com a implementação da LR de REEE foram considerados como ganhos na discussão sobre o AS. O governo federal, por sua vez, espera definir o AS sem questionamento posterior sobre sua validade, atribuir responsabilidade a quem de fato é responsável pela geração dos REEE, desonerar os municípios dessa obrigação, gerar menor impacto ao meio ambiente, diminuir o envio dos REEE para aterros ou locais ilegais, reduzir a necessidade de extração de matéria prima, diminuir o envio de divisas para outros países que atualmente detém a tecnologia de mineração das placas de CI, gerar novos empregos, ampliar o mercado de reciclagem de REEE e trazer para a formalidade o mercado informal.

BGF1 - Tem uma oportunidade de novos mercados, de novos negócios, ou de uma melhoria do setor de reciclagem, o que é muito importante. É claro que tem um impacto positivo com relação ao meio ambiente. [...] Um ponto importante para a gente refletir é que quem está negociando o AS, na verdade, não é quem vai ser mais beneficiado pelo acordo, que são justamente os governos municipais. Eles não participaram, eles foram chamados para participar, mas acabaram se abstendo e não participando de nenhum processo de construção. Talvez uma parte do governo federal, talvez o Ministério da Fazenda, pense um pouco nisso [criar outras fontes de receita ou vagas de emprego].

BGE1 - Garantir a correta destinação. [...] É trazer para a formalidade o mercado informal, é regular um mercado que hoje está solto. Agora, o grande resultado de logística, na minha opinião, é a transferência da responsabilidade de municípios e 
cidadãos para fabricantes, importadores, distribuidores e comerciantes. Então, acredito eu que disso decorram todos os outros resultados secundários.

BGF2 - Acredita-se que a LR de REEE bem feita evitará a extração de matérias primas, com o aprimoramento desse processo biolixiviação que o CTI criou. Com um mercado bem desenvolvido, espera-se poder fazer a extração de metais nobres, como ouro e cobre, no Brasil. Isso irá reduzir a evasão de divisas e commodities. Seremos capazes de aferir melhor se estas empresas de mineração internacionais estão pagando corretamente pelo que tem nas placas de CI. Para isso, basta fazer um teste de uma pequena amostra do material enviado para elas.

Os entrevistados consideram, porém que o governo federal e os ministérios envolvidos no AS, não parecem perceber ou ter interesse em resultados tangíveis, como o aumento da arrecadação tributária, caso novos negócios surjam no setor de reciclagem para atender a demanda da LR de REEE. Segundo BGF1, a preocupação do governo está focada na efetiva implementação da LR e na proteção do meio ambiente. Entretanto, até o momento, o governo federal não desonerou nenhuma parte da LR de REEE, conforme solicitado pelo setor de EEE, atitude que não corrobora a afirmação anterior.

BGF1 - Esse ponto de receber novos tributos com os novos mercados e empregos não é essencial, nem é tão relevante. Até porque muitas das coisas que foram estudadas foram justamente para desonerar os impostos com relação a esse novo modelo.

Já a indústria e o comércio afirmam que esperam por resultados tangíveis, como criar uma política com o menor impacto econômico, reduzindo custos e impostos sobre todas as etapas da LR de REEE, desburocratizando o fluxo reverso nos pontos de coleta, no transporte e, por fim, diminuindo o quanto for possível o seu papel nesse sistema. Muitos desses pleitos estavam velados e nem sempre eram benéficos para o resultado do AS, como apresentado anteriormente. Além de defender seus interesses econômicos, queriam demonstrar que não eram contrários à política, nem contrários à LR de REEE, e que estavam dispostos a ajudar a construir esse sistema, mas que não era justo terem que assumir toda a responsabilidade. Essa preocupação estava calcada no desejo de não desgastar a sua imagem pública, nem junto ao governo, nem junto aos consumidores.

BCV2 - Espera-se construir um AS que impacte o quanto menos no valor do produto. Conseguir que a LR ganhe escala para diminuir cada vez mais o custo da LR.

BCV1 - Tem também a questão da imagem, pois o cliente vai lá na loja e descarta o seu aparelho velho e já pode comprar um novo na loja, mas isso funciona apenas para os pequenos EEE. Isso é bom! Você faz ações ambientais e seu cliente vê isso.

BPD2 - É uma corda que cada um tem uma ponta e puxa obviamente para defender minimamente alguns pleitos ou necessidades que devem ser mencionadas ou 
acordadas dentro desse acordo. É claro que o resultado é muito mais intangível, não deixa de ser um resultado político.

Diante dos elementos de escopo apresentados é necessário entender como foi estruturado o processo para a elaboração do AS, já que o processo colaborativo precisa de mais tempo para construir a confiança entre os pares, não usa mecanismos de controle e exige disponibilidade para reuniões presenciais.

\subsection{Atores}

Além de ser importante que os atores tenham um objetivo comum, processos colaborativos não são adequados entre concorrentes, o que gera outro desafio para efetivar a colaboração entre os atores da LR. De fato, a Lei 12305 define que todos os atores da indústria e comércio de EEEE devem fazer parte do AS e convida à participação recicladores e cooperativas de catadores que possam atuar na LR de REEE.

Assim, a indústria reconhece a importância do comércio participar, mesmo que exista concorrência entre os atores desses dois setores. Todavia, os atores da indústria têm uma visão peculiar sobre concorrência nesse caso. Segundo eles, a indústria não se vê como concorrente dentro do GT de EEE, já que está representada pelas associações que defendem seus interesses, assim como defendem que é importante que as EG participem da discussão do AS.

BRC2 - A ABREE é uma entidade gestora que participa da elaboração do AS. Ela é um ator dentro do GT, um ator do setor industrial, do setor empresarial.

BPD2 - Apesar de serem concorrentes, vão representados por entidades que os representam, para defender o interesse comum de todos.

BPD1 - Em uma reunião com o governo, nós vamos todos como ABINEE, e não tenho ali a marca X Y Z, isso daí institucionalmente. [...] A indústria e o comércio que são os dois grandes atores.

Entretanto, indústria e comércio não acham interessante que recicladores, estudiosos da academia sobre os REEE, cooperativas e até mesmo empresas que já fazem sua LR de REEE participem. Alguns desses atores, ainda que previsto em lei, afirmam que não lograram êxito na tentativa de compor o GT, como é o caso de recicladores e varejistas. Esses últimos, em especial, não sentem sua vontade representada pelas associações. Nesse cenário, o discurso quanto aos riscos da atuação de atores concorrentes no GT parece conflitante, pois as EG têm participado da elaboração do AS por meio de seus representantes, que são os mesmos que 
representam as associações da indústria, defendendo os interesses de ambas as instituições, enquanto os recicladores não conseguem encontrar espaço para participar da discussão.

BPD2 - Reciclador vai participar? Não necessariamente da elaboração do acordo. Quem decide isso é a própria lei, então por mais que haja uma contribuição ou outra, o olhar é sempre dos que são diretamente focados ou responsabilizados por essa cadeia.

BRC1 - Sim, gostaria de participar da elaboração do AS. Estou tentando. Se você conseguir que eu faça parte do GT de EEE, tenha certeza que eu vou com maior prazer. [...] Agora, você ter associações que estão falando de gestoras, ligadas a fabricantes, criadas por elas, que estão dentro da negociação do AS, como associações de fabricantes e que estão abrindo recicladoras, é no mínimo confuso.

Vale ressaltar que o consumidor, um ator reconhecidamente importante para a LR de REEE, não foi representado por nenhuma associação na discussão do AS. Segundo BGF2, esse player será comunicado por meio da mídia, para que seja sensibilizado e informado sobre como fazer o descarte do seu REEE.

BGF2 - O consumidor tem uma participação fundamental, muito bem declarado pela PNRS, na qual está muito claro essa participação. Tanto que que assim que a política for instalada, uma das metas é a divulgação, na televisão, na mídia geral, sobre os pontos de coleta, para sensibilizar o consumidor.

\subsubsection{Os atributos da Dimensão "Estrutura” no Acordo Setorial da LR de REEE no}

\section{Brasil}

Está seção apresenta os atributos da dimensão "Estrutura": atividades, recursos, comunicação, poder, mecanismos de controle e riscos na elaboração do AS da LR de REEE no Brasil.

\subsection{Atividades}

A estrutura para definir o AS foi criada pelo governo federal, por meio de Edital de Chamamento, que definiu as diretrizes para a aprovação da proposta do Sistema de LR de REEE. O GT foi formado pelas associações representantes da indústria de EEE, varejistas, MMA, MDIC, Ministério da Fazenda (MF), Ministério da Saúde (MS), governos estaduais e municipais. Entretanto, os dois últimos quase não participaram das reuniões. Com os atores e requisitos mínimos definidos, o governo federal iniciou as convocações do GT para tratar do AS em Brasília durante todo processo de discussão. 
BPD2 - Quem criou a estrutura do GT foi o próprio governo, para elaboração do AS. O marco regulatório para começar a discussão desse grupo técnico foi a publicação do edital de chamamento. Lá tem tudo. Quem fez a gestão, quem administrou o processo? O governo federal. [...] O governo administrou esse processo, de ponta a ponta. Ele que faz a convocação, ele que administra os recursos.

Nas reuniões presenciais com todos os atores, trata-se da pauta estabelecida, apresentase as novas propostas sobre assuntos tratados na reunião anterior, traz-se material técnico para embasar os posicionamentos, estrutura-se o texto base e depois ele é levado para ser discutido nas instituições. Nada é, contudo, efetivamente decidido na primeira vez em que um tema era posto. As reuniões presenciais com todos os atores ocorrem duas vezes por ano. Em paralelo, de forma presencial ou por videoconferência, dependendo da complexidade do assunto, ocorrem ao longo do ano reuniões entre a indústria e o comércio.

BPD2 - O que acontece dentro desse GT? Só a discussão do texto do acordo? Não, existe também a apresentação de conteúdo técnico, que vai fomentar o conteúdo do acordo [...] ou cases internacionais, ou informação de LR, o que deu certo em algum estado, em algum município.

BGF1 - Na verdade, poderiam ser substituídas por e-mails ou ofícios, porque nas reuniões o que se apresenta são novas possibilidades ou novas propostas e aí as partes voltam para os seus devidos lados e, enfim, avaliam e depois raramente uma decisão é tomada numa reunião.

BGE1 - Cada vez mais tenho a convicção de que é fundamental o encontro presencial. Porém, não é no encontro que você concebe, é no encontro que você discute eventuais alterações.

Os papéis de cada ator não estavam bem definidos, assim como na lei. Apenas o MMA tem um papel de mediador mais claramente definido, com o propósito de assegurar um objetivo geral comum para todos e tentar atender aos pleitos de todas as partes, para viabilizar a LR de REEE. Dessa forma, todos contribuem e colaboram no texto base.

BGE1 - Eu entendo que o papel do MMA, principalmente, como mediador do processo, é assegurar que haja um objetivo geral que seja comum a todos, e que depois cada um possa ter seus objetivos específicos atendidos de diferentes formas.

\subsection{Recursos}

Nesse cenário, cada ator arcava com seus custos de participação, tais como locomoção, recursos humanos e estruturais. Quando os custos eram mais elevados, como no caso dos estudos técnicos, os atores que tinham interesse naquela informação assumiam o ônus. $\mathrm{O}$ 
governo arcou com o custo do estudo de viabilidade técnica da LR de REEE e a indústria e o comércio ratearam o estudo sobre o Visible Fee, para entender qual seria o custo da taxa de reciclagem de cada equipamento.

\begin{abstract}
BGE1 - Cada qual arca com sua parte. Do ponto de vista da colaboração é homem/hora. Você tem uma sala de reunião, serve o cafezinho, e o resto é homem/hora.

BPD1 - Custos que a gente tem é a hora que cada empresa disponibiliza de seus profissionais para participarem das reuniões, nas respectivas associações e as associações recebem dinheiro para representar seu conjunto de empresas. [...] $\mathrm{O}$ principal custo que foi rateado entre todas as associações foi um estudo sobre a Visible Fee que a gente pagou. [...] E o governo fez um estudo, que foi o estudo de viabilidade técnico e econômico, foi pago pelo governo.
\end{abstract}

\title{
5.4.1.3.3 Comunicação
}

O fluxo de informação não foi muito intenso no AS dos REEE. Com poucas reuniões presenciais entre todos os atores, o GT parece ter dois grandes grupos distintos, o setor privado e o governo, como se fosse um contra o outro. Dentro do setor privado, o fluxo de e-mails era mais intenso, com o objetivo de levar um posicionamento unificado para as reuniões e decidir o que seria aceito ou o que se continuaria pleiteando. Entretanto, nem todas as informações eram compartilhadas entre a indústria e o varejo, pois tinham interesses distintos em alguns pontos.

Já entre os ministérios, a informação sempre seguia os ritos burocráticos e legais, que muitas vezes engessavam o processo de decisão. Nem sempre eficientes, não resultavam em solução ou posicionamento, deixando os membros do setor privado sem resposta.

BPD1 - Quando você chega em um momento de decisão, a comunicação é presencial. Agora já discutimos tudo que tinha pra discutir por email. Chegou a hora da decisão, então vamos botar o texto aqui e ver o que a gente decide.

BGF1 - Por ser uma relação setor privado versus governo, e o governo ser sempre muito reativo ou reticente ao contato, pode ser por isso que essas coisas presenciais não funcionem tão bem quanto deveriam.

\subsection{Poder}

No AS, o governo federal tem o poder de decidir se aceita as propostas apresentadas, de que forma e quando a discussão se encerra. Entre as instituições do governo federal, o poder está dividido conforme a alçada de cada ministério. Entre os outros membros do grupo, as 
relações acontecem de forma horizontal, sem hierarquia. Dessa forma, pode-se afirmar que o poder está centralizado no governo, já que a decisão final é dele.

BPD2 - Quem controla a atividade, o recurso, comunicação, poder é o governo federal. [...] Obviamente quem controla prazo, quem controla cumprimento disso ou não, se essa discussão vai ficar num âmbito ambiental ou se ela tem um âmbito mais amplo. Quem tem que endereçar para um outro ministério, é o MMA. Ele recebe e ele endereça os assuntos, que não são só assuntos ambientais e saem da competência do MMA.

BGF1 - Eu acho que não tem ninguém que centraliza o poder. Eu acho que ali é bem descentralizado. Mas no governo federal, o MMA concentra o poder da informação. Eles são os que estão mais próximos do setor privado. Mas, por outro lado, o MMA não concentra o poder da decisão, porque muitas das decisões que precisam ser tomadas, dos pleitos, são atribuições de outros ministérios. O que faz com que também do lado do governo não seja simples essa gestão. E, nas reuniões, o governo não leva pessoas que tenham o poder de decisão, nem o setor privado leva.

BPD1 - Não é que tem poder. Pois eu vou querer gastar o mínimo possível, você também vai querer gastar o mínimo possível. Mas a gente tenta chegar numa equação que cause o melhor impacto para todos. Principalmente indústria e comércio, é uma relação de fornecedor e cliente

\subsection{Mecanismos de controle}

Quase não se notam mecanismos de controle, como contrato, acordos assinados, relatórios periódicos ou sistemas de informação, com os dados padronizados, no que tange às relações do GT. Como instrumento balizador, o GT segue o edital de chamamento, mas seus membros não assinaram nenhum contrato com regras, nem colocaram todas as informações em um sistema de informação. Aliás, nem o SINIR (Sistema Nacional de Informação de Resíduos) funciona como previa a lei. Entretanto, isso não parece aborrecer os membros, mas não favorece a celeridade das decisões, já que não tem prazos definidos ou cláusulas de sanções por qualquer tipo de ação. Os fatos ocorrem dentro da discussão do AS no GT.

BGF1 - A partir do momento que você vai tendo reuniões e conhecendo as pessoas, você vai conhecendo com quem você pode falar de uma maneira menos protocolar ou menos formal ou pessoas que estão mais dispostas a ajudar. [...] Não tem contratos, mecanismos de controle. O que tem na verdade é o edital de chamamento, ali, o governo já delineia algumas regras, que vão valer para o AS.

BGE1 - Alguns mecanismos de controle não estão muito bem definidos, existe até uma ideia de que haja, mas não está. Não existe por exemplo, um sistema de informação como o SINIR prometia ser, que controle fluxos, valores, dados, como a gente gostaria. 


\title{
5.4.1.3.6 Riscos
}

Com relações mais próximas do que o habitual, percebe-se, entre os membros do GT, o medo de passar mais dados do que o necessário, ter uma informação fornecida durante uma conversa, usada contra eles ou não poder garantir o melhor AS em uma perspectiva individual. O intuito do AS, no entanto, é minimizar o risco para todos, segundo BPD2.

\begin{abstract}
BPD2 - O risco é você redigir um texto que não esteja claro, com toda a necessidade tanto do setor empresarial e também do setor governamental, porque o governo também tem risco de um AS mal feito. Mas cada AS, ele tem uma característica de minimizá-lo.

BPD1 - Existe muitas vezes o medo da informação que se tem ser usada contra o processo. Você corre um risco de falar algo e ser generalizado e se serve pra esse, serve pra qualquer um.
\end{abstract}

Nesse cenário, contudo, percebe-se que um desdobramento das discussões do AS, que é a operacionalização da LR por meio de uma EG, pode diminuir o risco para todos, visto que ela deverá responder pelos resultados.

BPD1 - É, se a entidade gestora estiver operando, significa que já tem um acordo e que as partes já chegaram num ponto comum. Aí o risco teoricamente se reduz para todos. [...] Então quem vai ser cobrado inicialmente vão ser as EG.

\subsubsection{Os elementos da Categoria “Impactos” no Acordo Setorial da LR de REEE no Brasil}

A forma colaborativa que se elegeu para determinar o modelo de LR de REEE, o AS, ajudou os atores a se conhecerem melhor e a entenderem as necessidades de cada um, assim como possibilitou mapear como os atores poderiam colaborar para desenhar o modelo da LR. Dois desdobramentos interessantes dessa discussão por parte do governo federal, segundo BGF2, foram a elaboração de uma norma ABNT para padronizar os critérios de qualidade dos recicladores de REEE e um decreto que garante que os atores que não participaram ou não assinarem o AS terão que participar da LR de REEE no modelo estabelecido pelo GT.

Outro ator que contribuiu com a finalidade de atender uma das demandas do setor privado, foi o governo do estado de São Paulo que criou um regulamento estadual com o objetivo de classificar como não perigoso os REEE antes de serem desmontados, simplificando questões como a implementação de postos de coleta e transporte até um local de consolidação, 
de acordo com BGE1 e BGE2. Esse modelo de classificação do REEE deve ser seguido pelo governo federal, que já trabalha nesta lei.

BGF2 - Ano passado, aconteceu uma coisa muito importante. Foi feito o decreto sobre os importadores e sobre todos os outros atores, que os obriga a também fazerem a logística reversa, mesmo se eles não assinaram o acordo. Isso era uma solicitação da indústria nacional.

BPD1 - A iniciativa do governo do estado de São Paulo de regulamentar sobre os REEE como não perigosos impactou positivamente a decisão do governo federal, que atualmente trabalha na legislação sobre eles em nível nacional.

No processo de discussão do AS, a indústria, por sua vez, adquiriu novos conhecimentos sobre o potencial do mercado de REEE e os benefícios dos sistemas coletivos de LR, por meio de estudos apresentados no GT e da visita ao Japão para conhecer o sistema local. Depois disso, ela elegeu a criação das EG como um dos principais avanços para a efetivação da LR de REEE no Brasil. A iniciativa das associações que representam a indústria de EEE contou com a colaboração de empresas do setor que ajudaram a estruturar e financiar seu desenvolvimento. Esse fator ganha destaque, pois mostra a disponibilidade de algumas empresas para efetivar a LR de REEE, já que poucos atores têm participado diretamente da elaboração do AS, preferindo apenas acompanhar os resultados à distância.

BPD1 - Agora, talvez o principal passo que a ABINEE deu no ano retrasado foi a decisão de criar uma EG, para seus associados e não associados, para fazer a implantação desse sistema de LR no Brasil. [...] Hoje, temos várias empresas já associadas com a Green Eletro [...], algumas tem nos auxiliado, e entraram antes, ajudaram a estruturar ou bancaram alguma coisa. [...] No mundo inteiro, eu nunca vi alguém que implantasse o sistema de LR por si próprio.

De acordo com BPD1, a criação das duas EG representantes das duas associações de EEE poderá trazer mais resultados positivos, caso elas trabalhem de forma complementar, ajudando-se mutuamente, cooperando na coleta e troca de serviços com o objetivo de ambas atingirem as metas. Como as duas EG representam, muitas vezes, os mesmos fabricantes, que usam os mesmos canais de distribuição, em vez de competir elas podem aliar os esforços para aumentar a capilaridade da rede de coleta e fazer a troca dos REEE coletados por uma que pertencem ao escopo da outra.

BPD1 - Existem duas, a Green Eletro e a ABREE. Uma foi criada no âmbito da ABINEE e a outra pela Eletros. As entidades gestoras trabalham com produtos diferentes, elas não são competidoras, elas se complementam, inclusive tem associados que estão dentro das duas. [...] Mas as duas entidades têm que se ajudar. 
A criação das EG foi influenciada pela participação desses atores no PP, encomendado pelo MMA ao JICA, como meio de coletar informações sobre a realidade brasileira e ajudar na elaboração do AS. Esse projeto será abordado mais detalhadamente na próxima seção. Além disso, os atores têm aprendido com os resultados dos AS de outros setores, que já foram assinado e encontram-se em vigor.

Outro elemento que tem contribuído para o aprendizado é o resultado da experiência de alguns deles ao implementar a coleta de REEE em seus estabelecimentos. Esses fatores têm impactado igualmente a postura dos atores no AS, pois percebem que juntando forças será possível melhorar o modelo de LR e implementá-la. Como consequência, poderão educar os cidadãos para fazerem o descarte do seu REEE e gerar mais vendas, atraindo mais consumidores para suas lojas.

\begin{abstract}
BPD3 - Eu acho que está todo mundo entendendo um pouco mais de LR, dos desafios reais. Estão aprendendo com os acordos que já foram assinados em outros setores. Alguns atores que tinham uma reatividade maior a participar tanto do lado da indústria como do comércio [...]. Mas dá para fazer um negócio bem feito com a colaboração de todos os participantes. Vários deles, indústria e comércio, que já começaram a fazer algo por conta própria, porque estão entendendo que tem vantagem nisso, seja em se posicionar como uma marca de fato responsável que assuma suas responsabilidades ou claramente, como algumas já falaram pra gente, que isso leva clientes para loja dele.
\end{abstract}

Entretanto, apesar da indústria parecer ter encontrado um modelo capaz de executar a LR de REEE, a incorporação de todo esse conhecimento exigiu mais de cinco anos de discussão do AS, sem que se tenha concluído a etapa de elaboração. Uma das demandas não definidas até o momento, por exemplo, é a desoneração da taxa de reciclagem antecipada, que será cobrada no momento da compra do EEE, para o pagamento da sua LR, chamada pelos atores da indústria de Visible Fee. Outras pendências importantes que não avançaram ou estão no campo de análise ou planejamento, segundo BPD1, são: a criação de incentivos financeiros ou fiscais para a LR de REEE, previstos em Lei, mas sem nenhuma proposta até o momento; a elaboração e aprovação de uma norma unificada nacionalmente para o transporte de REEE sem tributação; a própria normatização do REEE como não perigoso, já que até o momento, só o governo estadual de São Paulo resolveu essa questão.

BPD1 - Não necessariamente, a gestora acaba com todas as demandas de todos os atores para viabilizar a LR, e principalmente com a questão de custos. [...] Restam quatro pontos ainda. Um deles é uma definição clara se o eletroeletrônico é considerado um resíduo perigoso ou não, dentro do sistema de logística reversa. [...] Outra questão seria a criação de um documento simplificado para transporte desses 
REEE entre os estados, pois hoje tem diferentes legislações, cobrança de ICMS aqui. E que não tenha uma tributação, isso daí é algo que a gente pede para o CONFAS [...] porque isso já existe em pilhas e baterias, portanto seria uma extensão somente. E o último ponto seria uma forma de financiamento de todo esse sistema. Nosso pleito era a criação de uma taxa visível, que possa ser destacada da nota fiscal na hora da compra do produto e que fosse livre de tributação.

Além disso, as metas sobre coleta e quantidade de postos de coleta de REEE são pontos polêmicos para os atores. Para eles, não é certo que seja possível coletar $17 \%$ do que foi colocado no mercado, devido à falta de cultura da população para descarte. E, com relação aos postos de descarte de REEE, não é um percentual de pontos de coletas pelo número de habitantes, que garante um sistema de coleta eficaz. Mas essas são questões que o governo federal parece não reconhecer como pleito.

\begin{abstract}
BPD1 - Metas são uma dúvida bastante grande. A meta traz uma quantidade de pontos, o que a gente não concorda que seria o ideal. Quantidade de pontos não significa efetividade de sistema. As vezes, pode ter uma campanha uma vez por mês ou a cada 2 meses em que você consegue uma efetividade de coleta muito maior do que ficar criando um ponto em cada esquina para ficar lá às moscas, ou ainda correndo o risco de extravio. A meta de se coletar $17 \%$ e destinar, essa é uma incógnita mortal.
\end{abstract}

Nesse cenário, a falta de colaboração entre os atores em alguns momentos da discussão do AS funcionou como barreira para o avanço da proposta. Percebe-se que nem todos os atores sentem a necessidade de atuar colaborativamente e de efetivar o AS, pois, no Brasil, eles não se sentem pressionados pelo consumidor final, nem acreditam que a falta de proatividade para ter um processo sustentável possa afetar sua imagem.

BPD2 - Quando eu falo da ausência de colaboração em determinados momentos, ele funciona como algo que impede a evolução do próprio conteúdo do AS. [...] Em determinados momentos, ela funcionou como barreira para melhores resultados, ele funciona como impeditivo, ela tem um efeito suspensivo.

BGF1 - Não se tem preocupação com relação à imagem ou com relação à pressão do consumidor.

Embora haja alguns avanços, a colaboração apresenta desafios importantes para sua efetivação, que precisam ser superados

\title{
5.4.2 O caso $P P$
}

Nesta seção o caso do Projeto Piloto do JICA, DescarteOn (PP), será apresentado à luz das dimensões da cooperação. 


\subsubsection{Os atributos da Dimensão “Motivação" no PP}

Está seção apresenta os atributos da dimensão "Motivação": necessidade, oportunidade e disposição na implementação do PP.

\subsection{Necessidade}

Já que a maioria dos desafios apontados pelos atores do setor privado estão baseados em projeções de custos da LR e estimativas de coletas de REEE, e não em resultados práticos da operacionalização da LR no Brasil, verificou-se a necessidade de levantar dados reais. O governo brasileiro, por meio do Ministério da Indústria, Comércio Exterior e Serviços (MDIC), solicitou ao Japão a implementação de um projeto de cooperação técnica, a ser realizado pela JICA, a fim de criar o PP. Assim, com base nas análises dos resultados do PP, espera-se conseguir o consenso entre os atores da LR de REEE para a assinatura do AS, de acordo com JC2 e JC4.

BJC2 - Houve a solicitação de ajuda do governo brasileiro, do MDIC e do MMA, para dar o andamento no AS, pois o Japão já tem uma certa experiência com esse assunto [LR de REEE]. Então, foi através dessa solicitação que aconteceu esse projeto.

BGF2 - O governo federal assinou um acordo de cooperação com o Japão, por meio da JICA. O objetivo era realizar o PP e conseguir dados da realidade brasileira para balizar e validar as negociações no AS e finalizar a sua proposição. Enfïm, assinar o AS e implementar a LR dos REEE.

A prefeitura de São Paulo, apesar de não ter a obrigação legal de fazer a LR de REEE, sentiu a necessidade de criar alguma alternativa para a gestão correta dos REEE, pois existem problemas de descarte desses resíduos em vias públicas e cidadãos questionando sobre onde podem entregá-los de forma segura. Como o município é responsável pela gestão dos outros tipos de resíduos, achou importante participar do projeto que permita dar uma resposta aos munícipes sobre os REEE.

BGM1 - A gente tem problema de descarte de EEE irregular na via pública, tem uma demanda enorme de munícipes que nos procuram para perguntar onde descartar. Então a gente está aqui para servir a população, e ainda que não seja nossa obrigação inicial, a Amlurb, como responsável pelo gerenciamento dos resíduos da cidade, tem por obrigação de informar de forma adequada o nosso munícipe. Então, acho que são basicamente esses três pontos, a questão do descarte na via pública, proporcionar para o munícipe uma alternativa de descarte eficiente, prático, com facilidade e ter certeza 
da destinação correta, ou seja, dar uma resposta pro munícipe que nos procura. E essa questão da responsabilidade compartilhada mesmo, que a gente tem responsabilidade, a gente só tem que entender até onde.

\subsection{Oportunidade}

A necessidade de criar o PP foi percebida como oportunidade para levantar dados reais por todos os atores envolvidos no AS de EEE. Para o setor privado, o fato do projeto mensurar os custos operacionais da LR de REEE, levantar o potencial real de coleta e entender o comportamento do consumidor em relação ao descarte era fundamental para evidenciar que as metas iniciais da LR exigidas pelo governo eram superdimensionadas. Além disso, os riscos financeiros para os atores adquirirem tal conhecimento era ínfimo, já que todo o projeto foi financiado pelo JICA, facilitando a decisão de todos por participar cooperativamente. Desde o GFB, até as empresas de reciclagem, todos desejavam aprender com a experiência japonesa.

BRC4 - Eu acho que o que motivou os atores a participarem do PP foi o investimento muito baixo.

BPD3 - Eles enxergaram lá atrás, quando surgiu esse convênio, a possibilidade de aprender justamente como é operacionalizada a LR em um país que já faz isso há algum tempo.

BGM1 - Todos fomos ao Japão para poder conhecer o modelo de logística. Tudo financiado pela JICA.

Alguns desses desafios são comuns aos dilemas apresentados para a falta de definição do AS no Brasil. Entre eles figuram questões como o valor das taxas de reciclagem e a falta de conscientização dos consumidores, a falta de comprometimento dos varejistas com a LR e a procrastinação para sua total implementação.

BJC1 - Lá nós tivemos problemas no início também. As pessoas às vezes que não queriam pagar a taxa e também não queriam deixar dentro de casa. Aí começaram a jogar até em aterros informais. [...] Então, também existem exemplos que aconteceram no Japão que o próprio varejista, ao invés de ele passar para o fabricante, ele acabava também jogando em aterro informal. Isso aconteceu no Japão. Mas se as autoridades locais encontrarem, eles realmente aplicam a multa neles.

Além do conhecimento empírico, a JICA possui forte vocação para transferência de conhecimento acumulado com a experiência do próprio país e outras obtidas em projetos de cooperação em países em desenvolvimento, podendo ajudar a sanar os conflitos dos atores brasileiros envolvidos na negociação do AS de LR de REEE. O Japão também vislumbrou oportunidades nessa parceria, pois o potencial de geração de REEE no Brasil pode abastecer 
suas usinas de mineração urbana, assim como a criação de novos mercados, com a inserção de pequenas e médias empresas japonesas no mercado brasileiro de REEE. Assim, o PP conseguiu alinhar interesses de atores brasileiros e japoneses pela parceria.

BJC2 - Existe essa parte da essência da JICA, que é o órgão de cooperação internacional do Japão, que já vem sempre apoiando países em desenvolvimento. Juntamente com isso, existe a questão de beneficiar também o Japão. Além de ter só a motivação pelo lado da JICA, tem os benefícios para indústria japonesa também. Por exemplo, aumento de empresas de reciclagem japonesas, que utilizam o sistema de reciclagem do Japão, ou até a expansão de negócios para os fabricantes japoneses.

Outra oportunidade que a participação no PP trouxe para a prefeitura foi a possibilidade de dar visibilidade para as cooperativas de catadores na LR, incluindo-as no projeto. Dessa forma, foi possível testar novos modelos de negócio e provar a capacidade desses novos atores para atuar com os REEE, quando capacitados. Por conseguinte, a inserção de catadores na LR de REEE, poderá melhorar sua remuneração e gerar novos postos de trabalho. Eles conseguiram incluir a Coopermiti, que já era especializada em REEE, mas que ainda não tinha tido a experiência de trabalhar como ponto de consolidação de REEE. Até então, toda a renda dessa cooperativa vinha da coleta, separação e venda dos REEE. Para BGM1, a abertura desse mercado para as cooperativas poderá torná-las autossuficientes, já que, até hoje, essas entidades têm seus gastos de água, luz e galpão custeados pelo município.

BGM1 - A gente tem uma cooperativa especializada em EEE na cidade que é amparada pela prefeitura, a Coopermiti. Nós pagamos o aluguel, luz e água. A fonte de renda dela é coletar eletrônicos, desmontar e vender as partes. No projeto, usamos a Coopermiti com outra finalidade. Ela se transformou num centro de consolidação. [...] A cooperativa achou uma oportunidade de negócio simples, mas é mais uma oportunidade dela ter recurso, porque o objetivo da Amlurb é que as cooperativas sejam independentes. Nós vamos pagar o aluguel delas até quando? [...] E para isso o mercado tem que tomar conhecimento disso, a LR tem que tomar conhecimento das cooperativas e tem que incluí-las.

\subsection{Disposição para atuar em conjunto}

O PP contou com a participação dos principais atores envolvidos na LR de REEE no Brasil, governo federal e setor privado, de forma positiva, sem apresentarem comportamento resistivo. Isso se refletiu em suas declarações de planos futuros, pois vários desses atores estão se preparando para atuar conjuntamente, em outros projetos pilotos, com o objetivo de analisar outras exigências estabelecidas. 
Outro ponto interessante que deve ser destacado para explicar esse comportamento são os baixos custos e investimentos exigidos de cada parte, já que o projeto foi financiado pela JICA.

BPD3 - A gente entende que a cooperação faz todo sentido nessa questão de LR, principalmente entre os atores. O comércio participando lá também, já abriu portas para gente inclusive negociar o próximo projeto piloto que estamos fazendo como Green Eletro, agora.

\subsubsection{Os atributos da Dimensão "Escopo" no PP}

Está seção apresenta os atributos da dimensão “Escopo": natureza, objetivos, resultados, e atores na implementação do PP.

\subsection{Natureza}

O PP foi a primeira iniciativa de operacionalização da LR de REEE no Brasil que envolveu conjuntamente os atores definidos pela Lei 12305/10. Ele foi implementado na cidade de São Paulo, na região da Lapa, com a finalidade de coletar REEE residenciais, excluindo pilhas e baterias. O tempo de duração do projeto foi de três anos, iniciado em outubro de 2014 e concluído em setembro de 2017.

BPD1 - O objetivo deles era fazer o projeto piloto na zona oeste de SP, criando pontos de coleta em lojas do comércio.

\subsection{Objetivos}

O PP tinha como objetivo apresentar um plano para a melhoria da implementação da LR (BJC1). De acordo com membros do JICA, esse objetivo estava dividido em dois objetivos maiores. O primeiro era levantar dados sobre custos, controle, formas de coleta e modalidades mais adequadas para a realidade brasileira para efetivação do descarte. O segundo pretendia conscientizar a população sobre a importância do descarte dos REEE (BJC2). Já os atores da indústria e o governo municipal queriam verificar como a LR funcionaria no Brasil e obter conhecimento sobre esse mercado (BPD1). Os varejistas, por sua vez, precisavam entender como a sua atuação como ponto de coleta impactaria em seu negócio (BCV1; BCV2). Alguns dos atores do setor de reciclagem queriam mostrar que tinham competência para atuarem nesse mercado (BRC1; BRC2). 
BJC2 - São dois grandes objetivos. Primeiro é a coleta de dados, inclusive na questão de custos e tudo mais, e a forma de coleta, que realmente essa coleta que está sendo feita é a mais adequada ou não.

BPD3 - Nosso objetivo era aprender com a experiência da equipe da JICA, o que eles tinham para oferecer sobre LR. De fato, a gente teve esse treinamento. [...] Para a ABINEE, a JICA foi um meio de aprendizagem.

BRC4 - Então seria uma maneira de divulgar o nome da empresa e abranger os novos negócios. [...] O objetivo do PP foi levantar dados, para escalonar esse projeto, fazer grande escala envolvendo todo o Brasil.

Outro objetivo da JICA, que pode ser detectado nas entrelinhas das falas dos entrevistados e observado por outros atores do PP, foi a intenção de conhecer melhor o potencial do mercado de REEE brasileiro, para ampliar o processo de mineração urbana e aumentar o mercado de reciclagem de REEE no Japão. Atualmente, apenas 10\% do que é processado nas usinas de mineração japonesas é proveniente do próprio país. Dos outros $90 \%, 80 \%$ vem da Ásia e 10\% dos EUA.

BGF2 - O JICA quer ampliar o seu mercado de reciclagem de REEE. E quer buscar esses resíduos fora do país. Ele quer comprar o REEE do Brasil.

\subsection{Resultados}

Os resultados do projeto foram todos preestabelecidos no contrato inicial, chamado de Registro de Discussões (R/D) e entregues conforme combinado para cada parte. De acordo com o R/D e a JICA, os resultados esperados eram:

Resultado 1: Situação atual da geração de resíduos eletroeletrônicos, cadeia de valores da LR e atividades de reciclagem do estado de São Paulo. Resultado 2: Serão extraídas lições aprendidas referentes à criação da LR em nível federal a partir do Projeto Piloto de sistema de Logística Reversa no estado de São Paulo. Resultado 3: Será proposto um sistema de monitoramento e preparação de relatório da LR no âmbito da "Lei da Política Nacional de Resíduos Sólidos”. (JICA, 2017, p. 1)

Durante toda a execução do PP foram realizadas reuniões mensais para discutir os resultados obtidos e planejar as ações de correção quando necessário, bem como novas estratégias (BRC2). Ao final do projeto, a JICA analisou e compilou todos os dados no relatório de conclusão, no qual sugere algumas orientações para a elaboração do AS (JICA, 2017). Nesse sentido, é unânime entre os atores do PP que o resultado mais importante foi o conhecimento 
sobre o mercado de REEE no Brasil, embora outros resultados tenham sido obtidos de forma indireta.

\begin{abstract}
BJC2 - Teve dois pontos importantes, a gente aprendeu muita coisa. Eles aprenderam muitas coisas, porque essa questão da taxa a ser cobrada lá no Japão é uma coisa normal todos pagarem pela taxa, mas viram essa diferença que é aqui no Brasil, que não é dessa forma. Agora pelo lado brasileiro, muitos perceberam a eficiência da estrutura com centro de consolidação, que ela é mais barata do que sem o centro de consolidação. Então teve um aprendizado dos dois lados.

BGM1 - O governo federal, estadual e municipal, eu acho que o ganho de ver na prática o que era só teoria. [...] Esse teve um super aprendizado, nós temos que criar uma estratégia para conversar com o setor privado.
\end{abstract}

\title{
5.4.2.2.4 Atores
}

O PP foi firmado entre a JICA, MDIC, MMA e AMLURB. Nesse cenário, atores públicos e privados representados por suas associações, incluindo os do mesmo setor, puderam participar do PP como parceiros, com o objetivo de efetivar o projeto piloto de forma cooperativa (BRC3). As empresas que operacionalizaram a comunicação e a LR foram selecionadas por editais pela JICA. Entretanto, alguns dos atores que operacionalizaram o PP foram convidados por sugestão de outros membros do grupo, como foi o caso da Coopermiti, após demonstrar que possuia as competências exigidas. Ela participou de todas as etapas, inclusive do treinamento dado no Japão e das reuniões (BGM1), ainda que esse tipo de organização não exista na realidade japonesa (BJC1). Posteriormente, a ABREE também participou do programa de coleta residencial de geladeiras e grandes EEE, por indicação da Eletros. A Figura 16 apresenta a Estrutura de implementação do PP completa.

BJC2 - A contratação desses centros de consolidação, transporte secundário, e a parte de relações públicas. Tudo através de licitação. [...] O centro de consolidação foi a Coopermiti, porque não tinha outra capacitada a fazer isso, uma licitação nomeada através de indicação. [...] Porque já existia um vínculo com a prefeitura antes do nosso projeto.

BPD1 - No projeto da JICA, a ABINEE participou, mas $\boldsymbol{n} \tilde{\boldsymbol{a}} \boldsymbol{o}$ a Green Eletro, pois não tinha sido constituída ainda.

BGM1 - Brasília entendeu que SP seria o local ideal para fazer o teste porque todos os desafios você encontra aqui.

BJC1 - Essa é a estrutura do projeto: a gente, o time da JICA, a AMLURB, a gestão do MDIC e MMA. 
Figura 16 - Estrutura de implementação do PP

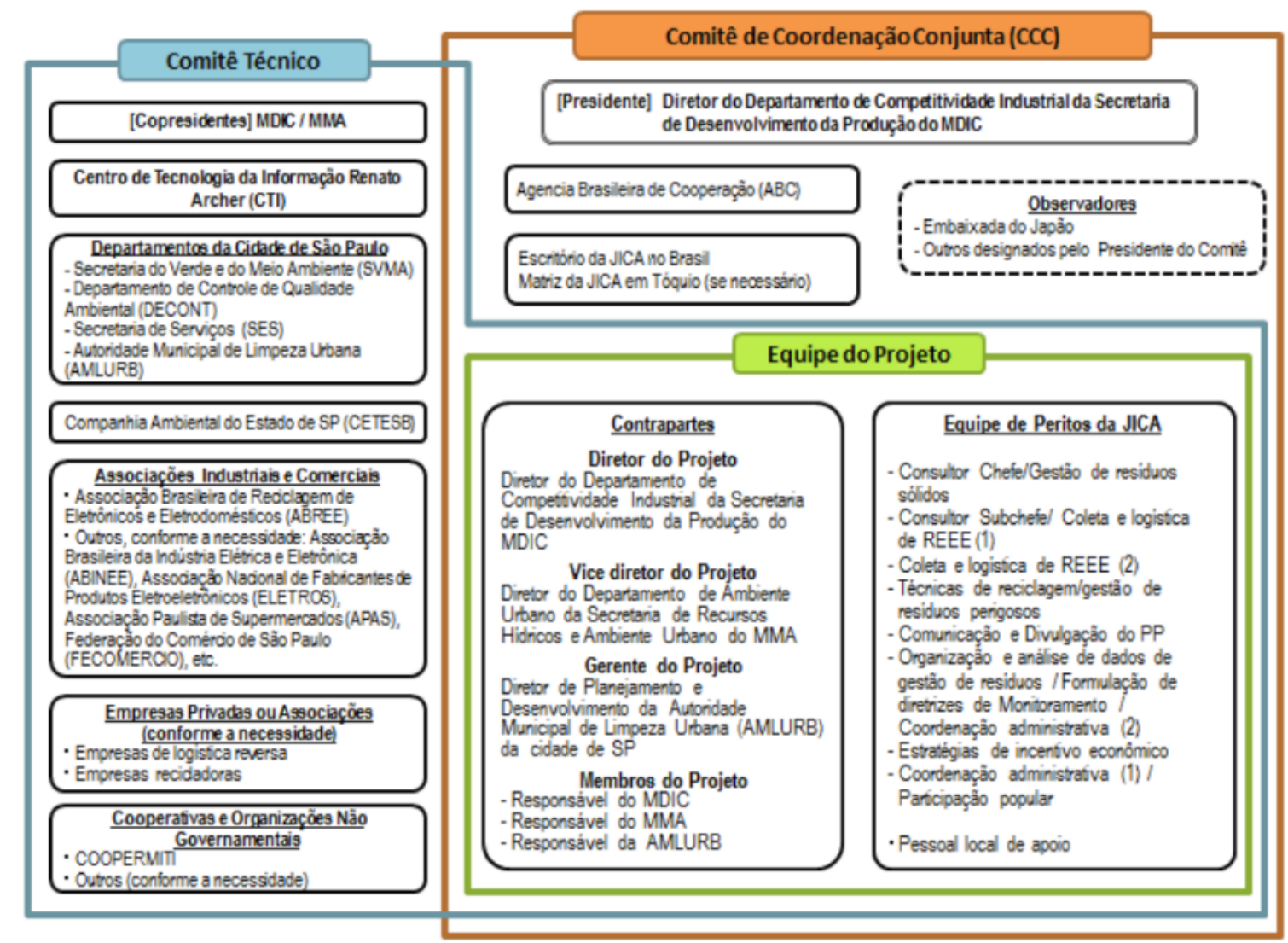

Fonte: JICA, 2017, p. 3

\subsubsection{Os atributos da Dimensão "Estrutura" no PP.}

Está seção apresenta os atributos da dimensão "Estrutura": atividades, recursos, comunicação, poder, mecanismos de controle e riscos na implementação do PP.

\subsection{Atividades}

A primeira etapa do PP foi o planejamento e a coleta de dados. Depois definiu-se como seria a estrutura e como seria feita a identificação das partes interessadas. Nessa etapa, ainda foram feitas a licitação e a contratação das empresas de consolidação, transporte secundário e relações públicas, pela JICA, com apoio da AMLURB e do governo federal. Na sequência, deuse a execução da LR de REEE, e, por último, foram feitas a análise dos resultados e elaboração do relatório final.

BJC2 - Foi assim: primeiro pensamos no operacional. Como vai ser a estrutura e, depois, através de licitações fomos escolhendo os atores. Nós ficamos responsáveis aqui pela contratação desses centros de consolidação, transporte secundário e a parte de relações públicas. Tudo através de licitação. [...] A gente já tinha uma previsão, 
mas aí fomos aprofundando a conversa com a AMLURB e com o governo federal para definir os membros. [..] Nós fomos a cada loja, fomos buscando as opiniões dos varejistas, essas campanhas promocionais foram feitas diretamente.

Os resultados demonstram que tanto o escopo do projeto como a estrutura foram bem delimitadas no R/D. Todos os atores tiveram seus papéis definidos previamente, com a divisão das atividades. Participaram do planejamento estratégico, por parte do governo federal, o MDIC e o MMA, juntamente com a JICA, e, no âmbito municipal, participou a AMLURB. Além de fazer parte do corpo estratégico, a AMLURB foi responsável por mapear e contactar os atores que deveriam fazer parte dos comitês técnicos, bem como mediar a participação de cada um (BGM1). O governo do estado de São Paulo, por meio da Companhia de Controle Ambiental do Estado de São Paulo, ficou responsável por emitir as licenças necessárias ao PP e assessorálo, à luz das leis estaduais (JICA, 2017).

BGM1 - Primeiro, nós funcionamos como um facilitador entre os atores, porque o governo japonês, a JICA, e o ministério, colocaram para a AMLURB essa função para agregar os atores, de identificar quem são os atores. [...] A AMLURB fez essa facilitação entre os atores, toda essa interlocução com os governos, com a CETESB, era tudo feito através de AMLURB. Outro papel da AMLURB foi ajudar na divulgação. Eu ia junto com a JICA nas escolas. A gente fez apresentação do projeto na faculdade de moda Santa Marcelina e na faculdade Rio Branco, todas ali da região da Lapa.

Após a etapa de planejamento, na estruturação do PP, pode-se destacar quatro tipos de atores que operacionalizaram a LR: as associações de varejistas e as lojas que cooperaram sem receber remuneração, os prestadores de serviços contratados pela JICA, recicladores e cooperativas, que recebiam conforme o contrato, e a ABREE que executou um piloto de coleta.

As associações de varejo ajudaram a intermediar a inclusão dos varejistas da região da Lapa, que participaram como pontos de coleta. Para tanto, as lojas disponibilizavam espaço para colocarem as caixas coletoras. Alguns varejistas tardaram a participar, pois dependiam de adaptações no projeto que respeitassem as características da sua marca, por isso iniciaram as atividades em tempos diferentes.

Já a ABREE, que é a EG da Eletros, operacionalizou o serviço "Coleta na sua casa", que oferecia a coleta de EEE de grande porte da linha branca para quem comprasse um novo, pelo valor de R $\$ 10,00$, subsidiados pela JICA. Esse modelo de coleta foi um piloto executado em parceria com as lojas do Pão de Açúcar.

A Coopermiti atuou como Central de Consolidação (CC), fez o transporte primário das lojas à sua central, na qual fazia a segregação e contagem por tipologia do material coletado. A empresa contratada para dar o tratamento ambientalmente adequado dos resíduos, a Oxil, coletava os REEE na $\mathrm{CC}$, realizava o transporte secundário desses resíduos, da Coopermiti ao 
seu ponto de consolidação, que ficava mais afastado da cidade de São Paulo. Lá ela processava e dava destinação adequada aos REEE. Uma vez por mês era feita uma reunião com todos os atores para apresentar os resultados e corrigir alguma ação, se necessário.

\begin{abstract}
BPD1 - Eram onze ou doze pontos de coleta. Tinha uma empresa que fazia coleta desses resíduos, a triagem, e algumas empresas que davam alguma destinação e a reciclagem, a Coopermiti. A própria JICA foi a empresa gestora, como se fosse a gestora. Era para tudo ser operacionalizado pela Coopermiti. Então, a JICA fechou contrato com as lojas, onde colocaria seus coletores. A Coopermiti faria o processo de coleta desses produtos e levaria até o galpão deles, faria a triagem, contagem e tal. E seria feito um relatório e enviaria isso aí para as empresas que iriam fazer a desmontagem e a reciclagem. Só que no meio disso, já existia a ABREE, entidade gestora da ELETROS, e eles disseram que eles queriam operar, que não queriam que a Coopermiti operasse. Aí eles criaram um sistema deles, para pegar basicamente produtos grandes, que seriam as geladeiras. Existia o processo também de coleta das geladeiras da Coopermiti, mas a ABREE e o Pão de Açúcar fecharam uma parceria com as lojas do Pão de Açúcar, e não com todos os pontos, para se fazer esse piloto. Então ficaram esses dois sistemas com eles.

BRC4 - A Oxil participava de todas as reuniões, que eram chamadas de comitê técnico, e eram realizadas uma vez ao mês. [...] Fizemos toda a parte de manufatura reversa, e contratação do transporte secundário.
\end{abstract}

As associações da indústria de EEE ficaram responsáveis por monitorar e inspecionar as empresas recicladoras, juntamente com a JICA, e cooperar na divulgação do PP em seus sites e revistas (BRC2). Já o consumidor deveria descartar seus REEE nos postos de coleta distribuídos nas lojas de varejo, sem pagar nenhuma taxa, ou solicitar a retirada de EEE de grande porte pelo serviço “Coleta em casa", mediante o pagamento da taxa de R $\$ 10,00$.

BPD3 - A nossa participação foi só o acompanhamento e aprendizado com os resultados que eles traziam. E vez ou outra, ir em um comitê técnico, sugerir uma ação. Agente acabou apresentando vários dados no início, para ajudar eles nas estimativas que estavam tentando levantar. Mas, no mais, foi bem por aí, bem mais recebendo dados e resultados prontos. [...] Mas para a gente foi claro que a gente ia participar como observador e aprendiz nesse processo.

\title{
5.4.2.3.2 Recursos
}

Todo o projeto foi financiado pela JICA, desde o treinamento dos atores envolvidos no projeto e a viagem feita ao Japão para conhecerem a experiência de LR de REEE do país, a operacionalização da LR, à comunicação e divulgação do PP. Apenas nas reuniões do comitê técnico alguns membros cediam espaço e infraestrutura para o encontro, e cada ator arcava com os custos da participação dos seus representantes. A AMLURB cedeu espaço para instalação da equipe da JICA, durante os três anos do projeto. 
BPD3 - Foi a JICA quem pagou tudo. A gente cedia o espaço para reuniões, quando a gente, como equipe, ia participar também para discutir algo sobre o projeto, cada representante de sua instituição ia. A equipe técnica que fez os cálculos, acompanhamentos e relatórios eram japoneses inclusive.

BGM1 - A gente oferecia a infraestrutura de uma sala, com mobília. Assim, o ônus de todo o projeto foi da JICA. A comunicação, eles contrataram uma empresa, com critérios próprios, contrataram a recicladora, todos os pagamentos de insumos usados aqui, tudo por conta deles. Nosso treinamento e viagem para o Japão foi toda bancada por eles.

\subsection{Comunicação}

A troca de informações ocorria nas reuniões mensais, por meio de relatórios periódicos e troca de e-mails, sempre formalmente, dentro dos critérios estabelecidos pela JICA. No início, as reuniões serviam para levantar dados e decidir como seria operacionalizada a LR de REEE do PP e, em seguida, para apresentação dos resultados de cada etapa aos participantes do PP e discussão dos pontos críticos.

Um dos pontos mais discutidos tratava da identidade visual dos coletores e dos impactos nas lojas que participaram da coleta, pois muitas vezes feriam seus padrões de cores.

BPD3 - Era uma reunião de apresentação de resultados, não gerava tanto debate. Lógico, a primeiras tiveram um pouco mais de complicação, até pra decidir como é que ia ser a própria identidade visual, quais cores utilizar. Pois você ia mexer nas lojas e você tem uma loja que não pode usar vermelho, que é a cor do concorrente.

Mas a comunicação com o principal ator da LR de REEE, o consumidor, só melhorou no final do projeto, depois dos baixos números da coleta. Nesse momento, percebeu-se que deveria haver uma comunicação mais direta e massiva, focada no descarte. Somente dessa forma, a população passou a participar mais ativamente do projeto.

BRC4 - Foi quando eles investiram pesado no marketing. Eles falaram que iam fazer uma ação para a Black Friday e próximo ao Natal. Foi onde aumentou o descarte, eles iam aumentar os promotores nas lojas.

\subsection{Poder}

O poder de decisão estava todo centralizado nos dois atores proponentes do PP, a JICA e o governo federal, mas tudo tinha que ser reportado para a JICA. E se o acordo de cooperação 
não previsse um relatório, como no caso das lojas, os representantes da JICA faziam o monitoramento pessoalmente.

BJC1 - A decisão final era da presidência do comitê técnico que era o MMA e o MDIC, por uma questão de controle. O relatório de cada empresa que vinha para gente, a gente ficava sabendo. E se não tinha relatório, a gente fazia o monitoramento daqui mesmo, a gente ia para as lojas para saber o que estava acontecendo.

Segundo alguns membros, no entanto, todas as decisões passavam pela avaliação do comitê técnico e eram alinhadas com a indústria. E, apesar de eles terem considerado as especificidades dos varejistas para redefinir o modelo de comunicação nas lojas, os gestores do projeto não se demonstravam flexíveis às mudanças depois de definido o processo. Nas falas dos entrevistados fica evidente que a JICA exercia uma liderança unilateral no PP e eles declararam que gostariam de participar mais dos processos de decisão e operacional, para efetivarem melhor aprendizado sobre as EG no Brasil, já que esse era um dos objetivos do PP.

BJC2 - É sempre alinhado com a indústria, é como se fosse o nosso comitê aqui.

BPD3 - A gente acabou negociando um pouco com as lojas, como seria a parte de comunicação, quais materiais poderiam ser utilizados ou não. [...] Mas não tinha mais uma outra opção de participação, era mais um acompanhamento depois que o projeto já começou a rodar. [...] Se, por exemplo, fosse chamada uma equipe nossa para participar mais de uma tomada de decisão ou ter escolhas mais ativas, seria bom.

\subsection{Mecanismos de controle}

Todas as atividades do PP eram balizadas pelo R/D assinado por MMA, MDIC, AMLURB e JICA. Todos os atores contratados para operacionalizar a LR assinavam um contrato formal e sua contratação era realizada por meio de um edital. Os outros participantes assinaram uma carta de adesão. Os contratos e as atas de reuniões funcionavam como mecanismo de controle para assegurar que os objetivos e resultados esperados seriam entregues pela equipe da JICA. Nenhuma ação, decisão ou comunicação acontecia se não fosse fiscalizada pela JICA.

BPD3 - Eram contratos formais mesmo. Eles abriram edital para alguns serviços, como comunicação e logística, e algumas empresas mandaram as suas propostas e eles fizeram contratação.

BGM1 - Os participantes do projeto fizeram uma carta de adesão e a recicladora, a Coopermiti, e a empresa de publicidade, que é a Xiza, elas foram contratadas num contrato comercial, que a JICA fez a licitação com os critérios dela e tudo mais. 
Os relatórios das atividades elaborados pelos atores contratados para operar a LR do PP também seguiam o mesmo rigor de controle. A recicladora, por exemplo, precisou relatar todos os itens que compunham o lote de REEE que havia coletado, inclusive os parafusos dos equipamentos. Não era permitido nenhum percentual de diferença entre o volume coletado na Coopermiti e o volume processado na Oxil.

BRC4 - Eles queriam que pesasse até o parafuso. Eles queriam um balanço de massa $100 \%$. Imagina ter que desmontar uma geladeira e ter que guardar os parafusinhos, numa área de produção. [...] sem nenhum percentual de erro. Porque assim, as vezes, quando pesava na balança da Coopermiti e dava diferença de 500-600g para balança da Oxil, eles queriam que repesasse tudo.

\subsection{Riscos}

A estrutura definida para o PP minimizou os riscos de cada um dos parceiros, pois cada um tinha seu papel e suas responsabilidades definidos. Dessa forma, o risco ficava restrito à parte cada um executava.

BPD3 - Não, não enxergava como um risco mútuo para todos, uma vez que até a gestão em si estava na mão da JICA. As lojas têm essa exposição maior de estar recebendo com o coletor dentro dela.

\subsubsection{Os elementos da categoria "Impactos" no Projeto Descarte ON}

A categoria "Impactos da cooperação" buscou entender como a construção das parcerias impactou os resultados do projeto.

Os atores da JICA ressaltam a importância da cooperação entre os participantes na execução do PP e acrescentam que, sem ela, não será possível efetivar a responsabilidade compartilhada, nem implementar a LR de REEE no Brasil. Para isso ocorrer, segundo eles, todos os atores precisam assumir a sua parte na responsabilidade compartilhada. A indústria precisa entender que haverá custo, mas ele será para todos, e o governo precisa se posicionar diante das pendências e exercer seu papel como legislador.

BJC2 - Na verdade, a forma mais dinâmica de ter um sistema de LR é com cooperação. É a forma mais realista. Mas dentro disso, existe, como foi mencionado, esse receio da indústria, pela questão de aumento de custos e tudo mais. Diante disso o governo também precisa tomar uma posição. Aí volta nesse mesmo assunto de responsabilidade compartilhada, e é justamente nesse ponto que está o entrave. A responsabilidade tem que ser de todos. 
Entretanto, apesar dos membros da JICA reconhecerem que os produtores de EEE tem um papel de destaque na implementação da LR de REEE, junto com o governo federal, a sua participação do PP foi limitada a de espectadores. Esse fator parece ter desmotivado os atores do setor, que, ao final do projeto, demonstraram ter suas expectativas frustradas, pois esperavam participar mais ativamente do processo de decisão e operacionalização da LR de REEE.

BRC4 - Dos principais atores que precisam assinar o AS, muitos não colocaram a mão na massa porque o PP forneceu tudo: coletor, quem fazia a logística era uma outra empresa, também a Coopermiti foi bancada pelo governo japonês. Nós não tivemos que investir nada, foi apenas o tempo.

Nesse contexto, os resultados de coleta auferidos pelo PP foram abaixo da expectativa. Um levantamento feito pela JICA para estimar o potencial de LR de REEE na cidade de São Paulo mostrou, que em 2014, foram geradas 72 mil toneladas de REEE. Cerca de 15\% desse volume foi parar nos aterros sanitários, junto com os RSUs, e 50\% foi processado por ferrosvelhos e sucateiros, aumentando as chances de tratamento inadequado e contaminação do meio ambiente. Apenas 2\% dos REEE residenciais foram coletados e tratados adequadamente.

É importante notar que esses dados são de um período que não contava com nenhuma iniciativa organizada de LR de REEE na cidade. Entretanto, os resultados auferidos pelo PP não foram diferentes dessa estimativa. Do total de REEE gerados na subprefeitura da Lapa, estimados pela JICA, o PP coletou cerca de 2\% a 3\% no sistema de coleta nas lojas e menos de $1 \%$ no sistema de Coleta na sua Casa. Foram coletadas 3.781 unidades ou 4.050,02 kg de REEE de pequeno e médios porte pelas lojas (Drop-off). Já o sistema Coleta na sua Casa (Trade-in) para REEE de grande porte coletou 19 unidades, 873,4 kg. A Figura 17 apresenta quanto de REEE foi coletado no PP, nos sistemas Drop-off e Trade-in, em dois gráficos, por unidade e peso, respectivamente. 
Figura 17 - Resultado da coleta de REEE, por forma de coleta [Esquerda: Unidades, Direita: Peso]
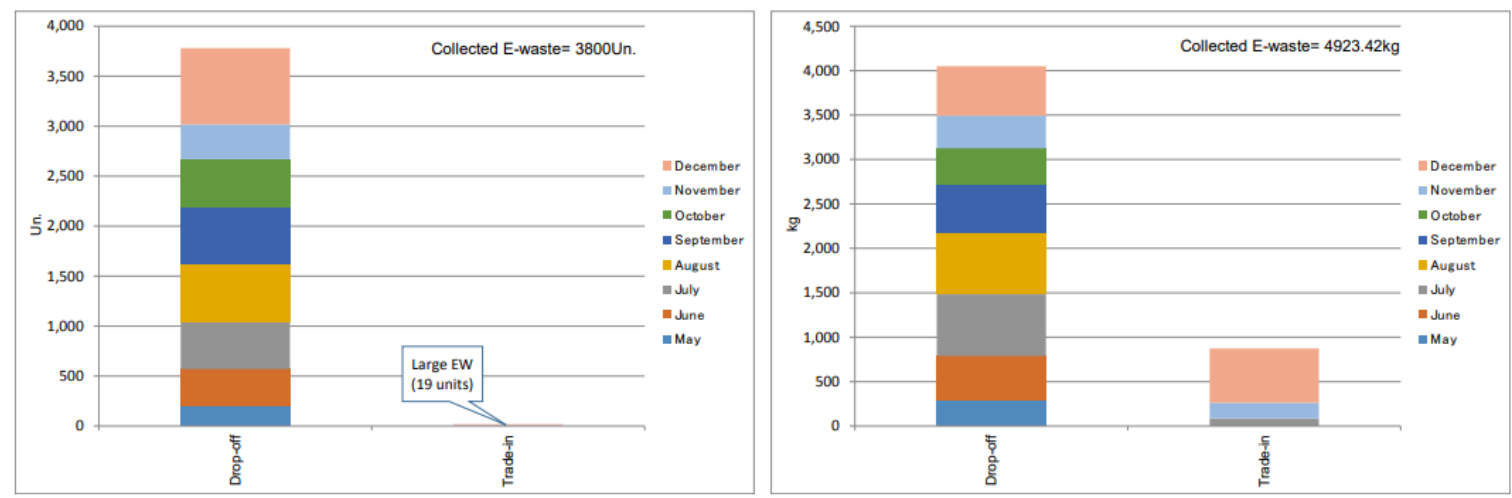

Fonte: JICA, 2017, p. 16

Esses resultados são atribuídos pela JICA (2017) ao número limitado de lojas da Subprefeitura da Lapa e ao curto período de coleta de REEE de grande porte. A coleta nas lojas começou no final de abril e foi até o último dia da etapa de operacional do PP, 31 de dezembro de 2016. Já a distribuição do formulário para solicitar a coleta em casa iniciou no final de junho nas lojas Walmart e, no início de outubro, pelas lojas do GPA, ambas indo até 31 dezembro de 2016

Segundo alguns atores, no entanto, um dos problemas foi a adesão tardia ao PP por parte de algumas das maiores redes do varejo na região da Lapa, como o Walmart e GPA. A Figura 18 mostra os resultados consolidados das coletas Drop-off e Trade-in, por unidades e percentual. Nelas é possível observar um aumento significativo no mês de julho, depois uma queda forte que se inicia em setembro e a retomada do crescimento em novembro.

Figura 18 - Resultado da coleta de REEE, por mês [Esquerda: Unidades, Direita: Peso]
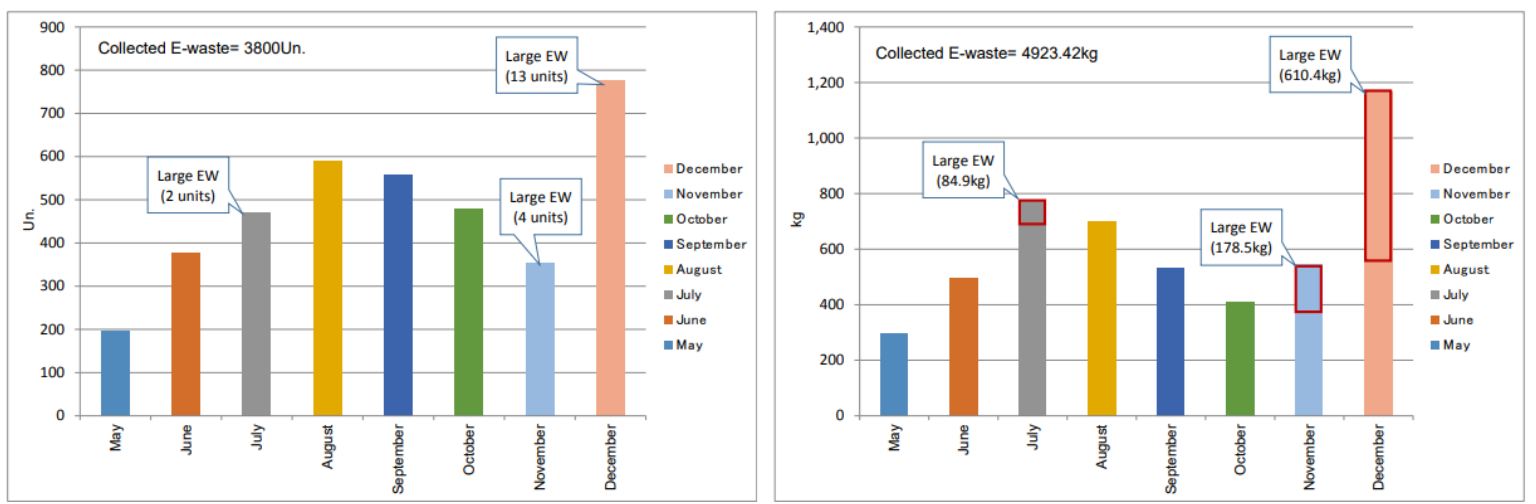

Fonte: JICA, 2017, p. 17 
A resistência dos varejistas, no entanto, estava relacionada à comunicação visual das caixas coletoras, pois não respeitavam restrições específicas de suas marcas. Após muita negociação, a JICA decidiu encontrar uma solução para essa questão, adotando layouts específicos para cada parceiro. Depois disso, a adesão espontânea foi quase total, o que garantiu seu envolvimento. Os varejistas passaram a se comprometer com os resultados tanto que, ao perceberem a queda na coleta de REEE em suas lojas, investiram em treinamento para seus funcionários e, em novembro, fizeram campanhas publicitárias para incentivar o descarte de REEE.

BGM1 - Na hora de fazer o banner, por exemplo, no GPA não entra nada com vermelho no cartaz. Aí no Walmart não entra nada com verde. Então teve um grupo de trabalho específico para a parte de comunicação. Então assim é complicado porque você tem marcas com conceitos muito próprios. [...] Mas eu acho que depois o varejo contribuiu muito [...] Então, o varejo, eu tenho a maior tranquilidade em dizer que se engajou bastante, forneceu espaço, treinou seus funcionários.

BRC4 - No primeiro momento, sim [faltou treinamento dos vendedores que recebiam os REEE]. Então, eles [varejistas] investiram em treinamento dos promotores e em mais informações do que seria feito com o material descartado. Mas, mesmo assim, se chegaram a 50 celulares em 8 meses de projeto, foi muito.

Outro resultado interessante apresentado na Figura 19, foi o volume coletado diferenciado nos grandes supermercados e na megastore do Ponto Frio em relação às lojas de rua. Para a JICA (2017), no caso dos supermercados, esse resultado pode ser atribuído ao fato dessas lojas venderem produtos de uso diário, inclusive alimentos, o que aumenta a frequência com que os clientes vão a essas lojas, sem contar com a comodidade de haver grandes estacionamentos. Para alguns atores da indústria, o resultado está atrelado ao fato desses locais que tiveram maior volume de coleta não serem lojas de rua e terem estacionamentos para o cliente. 
Figura 19 - Resultado da coleta de REEE, por loja [Esquerda: Unidades, Direita: Peso]
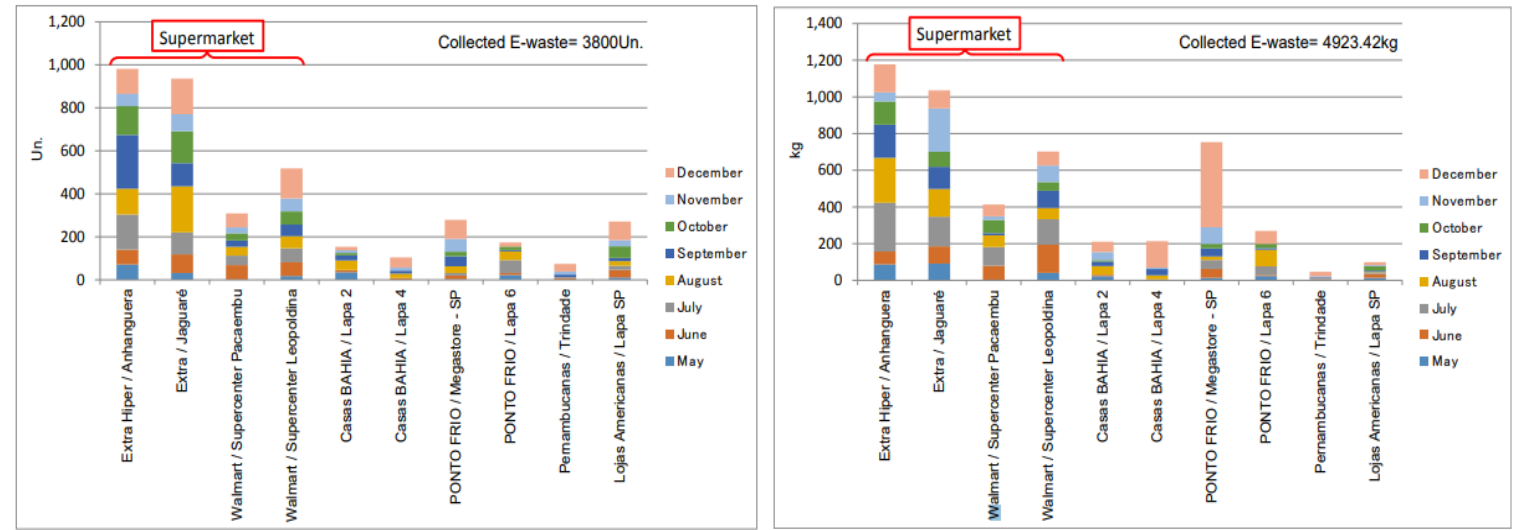

Fonte: JICA, 2017, p. 18

Contudo, os baixos resultados da coleta não foram vistos como um problema, e sim como uma oportunidade de aprendizado, pois mostraram como funciona a realidade brasileira e ensinaram lições valiosas.

BGF2 - Eu não vejo que o projeto-piloto foi uma solução, pois ele mostrou todos os problemas que nós vamos ter, esse era o objetivo. Se desse certo da primeira vez, a gente ia achar que ia acertar sempre.

Umas das principais lições tiradas dessa experiência, segundo BRC4, é que a LR de REEE é viável no Brasil, pois há empresas capacitadas para executá-la. Além disso, mostrou ao governo que é importante ter leis mais claras e objetivas para efetivar a implementação da LR de REEE no país.

BRC4 - Foi bom para o governo perceber que realmente precisa de leis mais claras e mais objetivas porque se não tiver nada que obrigue a fazer, não vai ser feito. E nós vimos que esse modelo sim é funcional, dá pra fazer, nós temos capacidade para atingir grandes volumes de reciclagem, basta ter o descarte. Tem como transportar, tem como segregar, tem como reciclar, mas não tem o descarte.

O PP também trouxe contribuições importantes sobre o comportamento do consumidor e os fatores que impactam o descarte de REEE no Brasil. De acordo com BGF2, a conscientização do consumidor para participar do sistema de LR é um elemento que leva tempo, por isso é necessário desenvolver campanhas massivas e mais longas para sensibilizar para o descarte de REEE, já que os resultados mostraram aumento da entrega desses resíduos só ao final dos 7 meses da etapa de coleta do PP.

Além disso, é necessário levar em conta a relação do consumidor com o seu EEE antigo, pois ele não tem o hábito de descartá-lo quando compra outro. Em pesquisa realizada pela JICA 
no comércio da região, identificou-se que este consumidor tenta dar uma segunda vida a seu REEE, enviando para a casa de praia ou doando para pessoas do seu entorno que tenham menor poder aquisitivo ou para instituições de caridade. Isso ocorre mesmo quando o EEE não está funcionando, pois ele acha mais nobre doar algo nessas condições, do que dar a destinação ambientalmente correta.

Nesse cenário, o consumidor só descarta mesmo aquilo que não tem nenhum valor percebido por ele, como copo de liquidificador, brinquedos destruídos, CD, TV de tubo. Nesse sentido, a JICA precisou criar uma nova categoria, chamada "outros", para computar os resíduos que não se encontravam em nenhuma das quatro categorias determinadas pelo PNRS. Esse fato pode ser visto na Figura 20, que apresenta os resultados da coleta por tipo de REEE e inclui a categoria “outros". É justamente essa categoria que apresenta o maior resultado.

BGF2 - Ele demonstrou que tem defíciência na comunicação, no marketing, na sensibilização da população. É uma coisa muito importante. Você vê que a divulgação foi feita e que resultado demora um tempo. Você não divulga hoje e amanhã as pessoas descartam.

BGM1 - Aprendizado de como a gente se comunica com as pessoas, qual é a reação delas diante disso. Tem uns resultados do trabalho: conhecer o hábito do brasileiro. [...] Então aqui, quando você ia perguntar para a pessoa: Ah! Mas, o senhor está comprando, o senhor quer descartar? Ele respondia: Não, eu vou dar pra minha vizinha, vou levar para a praia, vou levar paro o sítio, ou vou doar. Então, olha que interessante, a pessoa acha que é nobre dar, não é nobre descartar.

Figura 20 - Resultado da coleta de REEE, por categorias [Esquerda: Unidades, Direita: Peso]
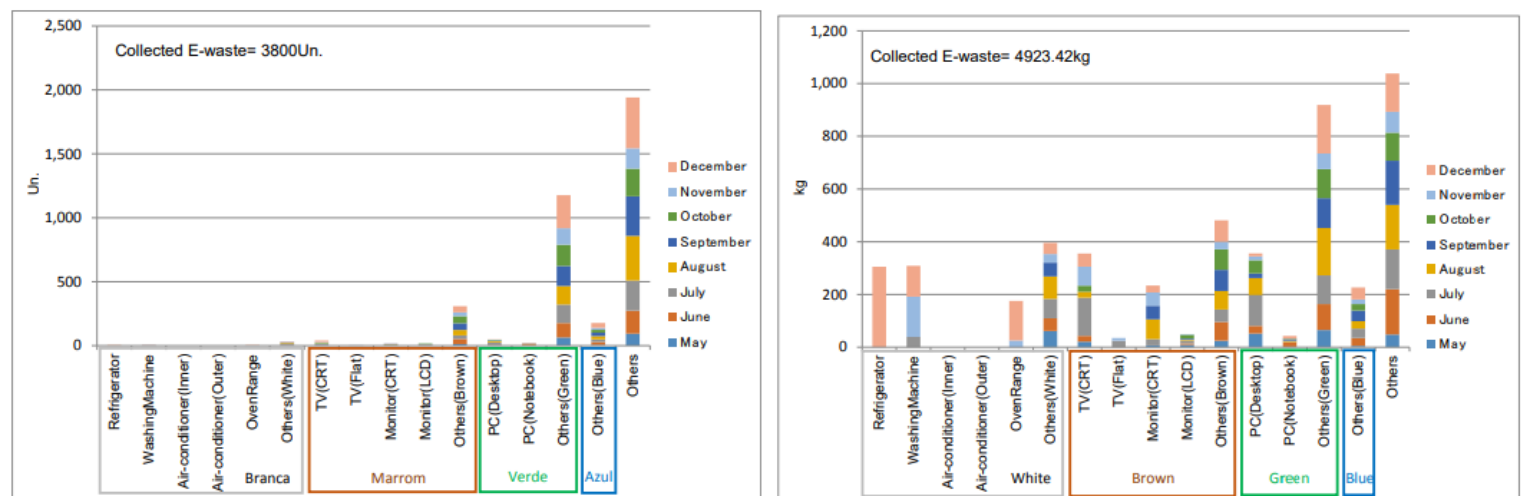

Fonte: JICA, 2017, p. 17

Uma das análises feitas sobre esse comportamento do consumidor brasileiro é que talvez seja necessário criar incentivos financeiros para ele descartar seu REEE quando for adquirir um novo, oferecendo um desconto na compra. 
BCV2 - Talvez, para obter a colaboração aqui, se eu tivesse condições de valorizar esse produto, que foi o que eu lembro em uma das propostas. $\mathrm{O}$ cliente ao comprar uma nova, eu [comércio] te pago 50 reais, mas te entrego e retiro a geladeira velha.

Para BGF2, contudo, o modelo de pontos de descarte não é o mais adequado para a realidade brasileira. Para ele, seria mais eficiente fazer campanhas pontuais em escolas e eventos. Já para BPD1, o que não funciona são pontos de descarte em lojas de rua, pois o consumidor precisa de locais com estacionamento para facilitar o descarte dos REEE. De acordo com BGM1, um dos pontos críticos sobre o descarte em lojas é a falta de capacitação e conscientização dos promotores de vendas. Para resolver essa questão, BGM1 acredita que os atendentes precisam ter alguma motivação para cooperar e incentivar o descarte, pois a maior parte de sua renda depende da comissão de venda.

BGF2 - Eles fizeram um modelo de coleta, mas o que a gente tem visto no Brasil, é que isso não funciona. $\mathrm{O}$ que funciona são campanhas em escolas, eventos como este aqui, o Greenk.

BPD1 - O ponto de coleta em lojas de rua é uma coisa que não funciona. O que funciona é você ter pontos de coleta em locais onde você tenha um espaço suficiente pra alguém chegar com seu veículo, parar e levar esses produtos. Todos esses resultados da JICA mostram que as lojas que participaram de rua ficaram dois ou três meses sem receber um produto.

BGM1 - Se o funcionário não estiver engajado. E, detalhe, ele não ganhava nada para vender esse voucher, que é um problema, porque parte do salário do vendedor, é a venda. Então é difícil você estimular alguém, cujo DNA já é esse, de dizer você tem que vender esse voucher só que você não vai ganhar nada por isso.

Embora o PP tenha indicado uma série de fragilidades para efetivar a implementação da LR no Brasil, mostrou também oportunidades para novos negócios para todos os atores envolvidos na implantação da LR de REEE no país. Por isso, para a maioria dos membros, o PP superou as expectativas. De acordo com BGF2, ver a experiência do Japão, um país pequeno que construiu um mercado próspero de reciclagem com mais de 40 empresas, foi motivador, já que $90 \%$ do REEE processados por eles vem de fora, sendo que $80 \%$ vem dos EUA e $10 \%$ da Ásia. Para ele, o PP mostrou que, ao contrário do que se acreditava, a LR de REEE pode dar lucro, quando organizada de forma apropriada. Nesse cenário, a experiência permitiu que os atores da LR de REEE visualizassem o potencial que se tem no Brasil para esse mercado.

BGF2 - A gente esperava ver uma coisa razoável, mas nós tivemos uma coisa excelente! Você vê no Japão, um país com dimensões pequenas, ver eles construírem mais de 40 indústrias de reciclagem. [...] E eles fizeram 40 empresas gerarem renda, empregos, criaram um novo setor de economia. Para você ver a ousadia deles, a coragem deles, é que $80 \%$ de tudo que eles processam vem dos Estados Unidos, $10 \%$ da Ásia e apenas $10 \%$ do próprio país. Elas vão buscar esses resíduos fora do país. O 
projeto mostrou muito claramente, na prática, ao empresário brasileiro, comerciante, para o governo, que a solução é possível e o custo é investimento. Se for bem investido, bem organizado, pode dar lucro, pode dar emprego e deixar divisa no Brasil.

Outro desdobramento do PP, foi a criação de um novo projeto piloto pela Green Eletron, que visa, a partir do conhecimento adquirido com o DescarteON, testar novas formas de comunicação, pontos de coleta e coletores. O novo projeto objetiva ser a base para a assinatura do termo de compromisso da LR de REEE no estado de SP com a CETESB.

BRC3 - Nosso projeto piloto já está rodando, a gente começou no final de abril (2017), com alguns pontos que estão sendo instalados. Ele vai fazer parte do termo de compromisso que já está para fechar aqui no estado de SP. É lógico que ele já traz uma série de aprendizados que a gente teve com o projeto JICA como, por exemplo, o tipo de coletor que a gente está fazendo. É completamente diferente do que foi feito pela JICA, para testar uma coisa nova.

Um dos legados mais importantes do PP, segundo BPD3, foi que ele possibilitou superar uma das principais controvérsias presentes na discussão do AS, que se refere à periculosidade dos REEE. Com o envolvimento de todos os atores na operacionalização da LR, foi possível entender que os REEE não precisam ser tratados como perigosos a partir do momento do descarte, pois ainda não oferecem riscos e, assim, facilita-se sua coleta, triagem e transporte até as plantas de reciclagem. Essa conclusão culminou com uma iniciativa da CETESB de normatizar sobre a periculosidade dos REEE no estado de SP com o objetivo de ajudar a viabilizar o PP. Essa normativa deve ser ampliada para o âmbito federal.

BPD1 - Um exemplo claro disso foi a publicação pelo Estado de São Paulo da decisão Diretoria G120, que fala que, para fins de LR, o REEE não é um resíduo perigoso e não deve ser tratado como tal. [...] Aqui em São Paulo, a CETESB também está participando do projeto JICA, viu que era uma necessidade e conseguiu encontrar uma solução. Isso foi muito positivo, pela colaboração, pela participação de todo mundo, ouvindo, não só na teoria e tentar chegar num texto com um acordo.

O reconhecimento da capacidade da Coopermiti para operar na LR de REEE foi outro resultado positivo. Dessa forma, membros da indústria já consideram inclúíla em seu próximo projeto piloto e sensibilizar seus associados sobre sua competência para operar.

BPD3 - É exatamente assim que a gente vê, até pelo que o próprio Alex já explicou para gente, que as próprias cooperativas não o olham como uma cooperativa, pelo fato dele estar tão bem estruturado, ter as certificações que ele já tem. Ele tem ali um nível de qualidade muito elevado, então quanto a isso a gente não vê problema. A gente está tentando inclusive trazer isso para os associados, para que eles possam conhecer mais desse universo. 
A partir dos dados apresentados, nota-se que os países estudados têm pontos bastantes diferentes em relação aos aspectos da colaboração e cooperação, com resultados igualmente distintos. A seguir discute-se esses resultados com a revisão da literatura realizada. 


\section{DISCUSSÃO DOS RESULTADOS}

Nesse capitulo será discutido os resultados da pesquisa à luz da literatura.

\subsection{A MOTIVAÇÃO PARA BUSCA DE PARCERIAS NA IMPLEMENTAÇÃO DA LR DE REEE NA ESPANHA, PORTUGAL, SUÍÇA E BRASIL}

De acordo com Brna (1998), é importante entender quais são os fatores que motivam os atores a atuarem em parceria para que se possa garantir sua efetiva participação nesse processo. Para tanto, serão discutidos os resultados da categoria "Motivação" à luz da revisão da literatura sobre colaboração ou cooperação apresentada no capítulo 2 .

\subsubsection{Necessidade e Desejo}

A necessidade de Portugal e Espanha atenderem à Diretiva de REEE da UE fez com que os atores envolvidos com a LR de REEE nesses países buscassem parcerias para implementála. De fato, tratava-se de uma atividade nova, que envolvia stakeholders de diversos setores, quase todos acostumados apenas com o fluxo direto de mercadoria. Esse fato mostra que as organizações buscam por parcerias justamente quando percebem a necessidade de executar uma atividade complexa ou que está além de seus recursos (HORD, 1981; POLENSKE, 2004), como é o caso da LR de REEE (LAU; WANG, 2009; MIGLIANO, 2012; AUGUSTO, 2014; DEMAJOROVIC; AUGUSTO; SOUZA, 2016), ou quando sofrem uma pressão coercitiva, como a obrigação de atender à Diretiva da UE (SCHERMERHORN, 1975).

No caso da Suíça, no entanto, o elemento motivador inicial foi o desejo de um pequeno grupo de produtores de EEE, que, visando se antecipar à pressão dos consumidores, se uniu em prol da gestão ambientalmente correta dos REEE, preservando suas marcas. Assim, foi a necessidade de manter a competitividade e de atender às novas demandas mercadológicas que impulsionou essas organizações a procurar por atores do mesmo setor para efetivar parcerias cooperativas (POLENSKE, 2004; SILVA, 2007; WINCKLER; MOLINARI, 2011).

Nesse contexto, observa-se que todos esses países têm em comum a percepção clara de sua responsabilidade na implementação do fluxo reverso dos EEE, seja por força da lei ou por pressão de uma sociedade com alto nível de conscientização ambiental, reunindo os fatores básicos motivacionais para a efetivação de parceria, ou seja, a necessidade ou o desejo de fazer 
algo além das suas competências ou recursos (SCHERMERHORN, 1975; POLENSKE, 2004; SILVA, 2007; WINCKLER; MOLINARI, 2011).

Entretanto, no caso brasileiro, apesar de haver a obrigatoriedade de implementar a LR de REEE, dada a aprovação da PNRS em 2010, nenhum dos atores parece se sentir imbuído do seu dever em efetivá-la (MIGLIANO, 2012; AUGUSTO, 2014; DEMAJOROVIC; AUGUSTO; SOUZA, 2016). Esse fator compromete a efetivação do comportamento cooperativo e colaborativo no Brasil (HORD, 1981; POLENSKE, 2004).

Nesse cenário, a partir da demanda legislativa e de mercado, uma série de outros elementos motivaram a busca por parcerias entre os atores da LR de REEE nos três países europeus estudados. Na Espanha e em Portugal, os governos federais envolveram os principais atores da LR, produtores e associações de recicladores, na elaboração de suas legislações em âmbito nacional, com o objetivo de adaptar a Diretiva europeia à realidade de cada país, garantindo sua viabilidade e validação por parte dos atores envolvidos. Com efeito, é importante que todos os envolvidos tenham consenso sobre a importância do que precisa ser feito e estejam de acordo sobre como as ações devem ser executadas para contar com sua colaboração (HORD, 1981; POLENSKE, 2004; ANSELL; GASH, 2008).

No caso da Suíça, a cooperação entre os atores se deu baseada no consenso sobre a problemática a ser resolvida (POLENSKE, 2004), assim como na forma de solucioná-la por meio da criação de uma ORP (HORD, 1986). Apesar do sistema ter crescido rapidamente com a adesão voluntária de outros fabricantes, era importante que toda a indústria de EEE tivesse a obrigação legal de aderir a uma ORP. Dessa forma, seria possível garantir a destinação ambientalmente adequada dos REEE de forma padronizada e obrigar todos consumidores a entregá-los nos pontos de coletas. Para isso, os produtores suíços buscaram apoio do governo federal, visando validar o modelo coletivo em funcionamento e obter respaldo jurídico com a elaboração da lei LR de REEE no país (BAUMGART, 1974; ANSELL; GASH, 2008).

Baumgart (1974), de fato, ressalta a importância das parcerias entre um conjunto de organizações e o governo para resolver questões de senso comum. Nesse tipo de relação colaborativa, o governo é capaz de entender e defender o posicionamento de um conjunto empresas do mesmo setor que estão pleiteando alteração ou criação de uma lei, ao mesmo tempo em que visa proporcionar benefícios para a população. Na Suíça, a pressão da indústria de EEE e da população, que começou a contestar o fato de apenas alguns produtores cobrarem a TAR e darem a garantia de reciclagem dos seus produtos, impeliu o governo federal a criar a ORDEE em 1998. 
Além disso, os governos municipais desses três países precisavam atuar na LR de REEE devido à sua obrigação de fazer a gestão dos RSU que, na opinião de todos, também incluía esse tipo específico de resíduo. Com efeito, a sociedade já relacionava naturalmente a coleta de resíduos aos serviços prestados pelo município. Assim, os governos municipais se viram obrigados a atender a essa demanda da população, ofertando soluções que viabilizassem o descarte em todo o seu território, adequadas às distintas necessidades da população e às particularidades de cada categoria de REEE (SCHERMERHORN, 1975; HORD, 1981; POLENSKE, 2004). Para atender às demandas ambientais da população, esses municípios estabeleceram parcerias com as SIGs para coletar REEE por meio dos canais de coleta seletiva já existentes, que deveriam armazená-los até a sua retirada por um dos operadores contratados pelo sistema. De fato, segundo Schermerhorn (1975), a demanda ambiental é um dos fatores determinantes para os tomadores de decisão decidirem cooperar com outras organizações. Além disso, segundo Baumgart (1974), o governo é capaz de melhorar o atendimento ao cidadão por meio da cooperação com o setor privado, criando canais de relacionamento que respeitem suas necessidades, e nesse caso, apenas aproveitando a infraestrutura já existente.

Em Portugal e na Espanha, os SIGs precisaram buscar parcerias com os recicladores e sucateiros para atingir as metas de coleta estabelecidas pela lei (SCHERMERHORN, 1975; HORD, 1981; POLENSKE, 2004). Na Espanha, a exclusão dos recicladores e sucateiros do sistema de coleta oficial de REEE pelas CCAA a partir de 2009 fez com que eles se unissem para garantir volume de coleta e competitividade (SCHERMERHORN, 1975; HORD, 1981; POLENSKE, 2004). Nesse caso, cada reciclador processa o tipo de resíduo que está autorizado, mas pode coletar todas as categorias, apenas direcionando os outros resíduos para um parceiro habilitado, ampliando o leque de empresas que pode atender. Nesse cenário, a percepção da fragilidade na infraestrutura e na competência, aliada com a limitação de poder processar apenas alguns tipos de resíduos de acordo com as licenças que cada um possuía, que atuou como fator determinante na decisão de cooperar desses atores (SCHERMERHORN, 1975; SILVA, 2007; WINCKLER; MOLINARI, 2011).

No Brasil, ainda que os atores não se sintam responsáveis pela efetivação da LR de REEE e tenham prolongado sua discussão por mais de duas décadas sem ainda ter concluído esse processo (BRASIL, 2010a; REVEILLEAU, 2011; YOSHIDA, 2012), pode-se elencar alguns elementos que têm ajudado a progredir na elaboração do AS, com um pouco mais de celeridade, bem como no desenvolvimento de parcerias nos últimos três anos.

É importante destacar que governo federal reconhece não ter todas as competências necessárias para determinar o modelo de LR de REEE a ser implementado no país, e por isso 
tem buscado meios colaborativos e cooperativos para tentar efetivá-lo, corroborando Schermerhorn (1975), Polenske (2004) e Winckler e Molinari (2011). Para esses autores, de fato, a falta de expertise é um dos elementos determinantes para impulsionar a busca por parcerias. A primeira vez que isso ocorreu com o governo federal brasileiro foi quando ele definiu o AS como instrumento principal para elaborar e implementar o modelo de LR de REEE, esperando contar com a colaboração dos diversos atores envolvidos na confecção da proposta (ANSELL; GASH, 2008). Entretanto, o governo brasileiro não se demonstrou tão empenhado quando o governo português, que mostrou determinação para manter os principais pontos do sistema, como a definição das metas acima das exigidas pela UE, mesmo não tendo a aprovação de todos, e flexibilidade para negociar ou mostrar a importância de superar pontos conflituosos. Mesmo assim, depois de muitos impasses entre os atores da LR de REEE no Brasil, o governo brasileiro buscou auxílio junto ao governo do Japão, por meio da JICA, com a qual assinou um acordo de cooperação para implementar o PP no Brasil e evoluir na proposta do AS, com base em dados reais e nas recomendações que seriam extraídas do projeto.

A prefeitura de São Paulo e o governo do estado de São Paulo participaram do projeto, ambos motivados pelas demandas ambientais e pelo desejo de dar uma resposta à sociedade sobre essa questão (SCHERMERHORN, 1975). Nesse caso, as motivações do estado e do município de São Paulo são as mesmas dos municípios europeus estudados nessa pesquisa, corroborando Schermerhorn (1975), Hord (1981), Brna (1998) e Polenske (2004) sobre a importância dos fatores motivacionais que antecedem o ato de cooperar e colaborar. Com efeito, quando há interesse é mais fácil contar com participação das empresas em processos cooperativos (SCHERMERHORN, 1975). Assim, os atores do setor privado brasileiro também aceitaram participar do PP. Para eles, destaca-se como fator determinante de sua participação a necessidade de validar suas queixas sobre a coleta e custo da reciclagem de REEE, baseadas em dados reais extraídos do PP. Outro elemento importante para o aumento da sua participação no PP e busca por melhores soluções para os entraves da LR foi a constatação de que cedo ou tarde teriam que implementá-la, com ou sem a sua colaboração no AS, por imposição da lei (SCHERMERHORN, 1975).

Um elemento que surgiu como insight nas entrevistas e análise dos resultados sobre a motivação para colaborar e cooperar foi a predisposição de algum ator para fazer determinada coisa. Na revisão da literatura, o valor mais próximo assumido por esse atributo foi o "histórico de colaboração" como condição inicial na governança colaborativa apontado por Ansell e Gash (2008, p. 550). Entretanto, não foi encontrado nenhum autor que falasse sobre a importância da 
predisposição para agir ou legislar em prol da sustentabilidade, como observado nos resultados dessa pesquisa.

No caso de Portugal, o governo federal demonstrou sua predisposição para legislar em prol da sustentabilidade quando argumentou que não era só por força das Diretivas da UE que tinha implementado esse tipo de legislação, posto que o vinha fazendo em outras áreas, como no caso da lei sobre LR de pneus. Além disso, o Decreto-Lei 20/2002 de 30 de janeiro de 2002, primeira lei portuguesa que regula os REEE, foi publicada apenas três dias depois da publicação da primeira Diretiva europeia sobre REEE. Além disso, as metas de gestão dos REEE reguladas pela lei portuguesa era, mais expressivas do que as da UE.

A Suíça também apresenta essa predisposição para atuar de forma sustentável de várias formas. De fato, declarou que a economia verde seria sua meta balizadora na Rio +20 e um grupo de importadores e produtores de EEE começou a operar a LR anos antes da formulação da lei, para evitar os impactos ambientais dos seus resíduos e para atender a uma parcela dos consumidores no final da década de 1980 que passaram a pressionar os produtores e o próprio governo por medidas de responsabilização pós consumo, de forma a viabilizar o retorno dos EEE ao final da vida útil. Três outros fatores podem explicar essa predisposição na Suíça: a consciência de governo, indústria e consumidor sobre as limitações territoriais e de recursos naturais do país; o desejo de se tornar líder mundial em reciclagem; e a cultura participativa da população na gestão pública.

\subsubsection{Oportunidade}

Portugal, Suíça e Brasil elegeram a colaboração no desenvolvimento do modelo de LR de REEE como elemento essencial para legislar sobre ela. Esses governos queriam garantir o envolvimento dos atores na construção do modelo e na efetivação desse sistema com sucesso. De fato, segundo Ansell e Gash (2008), a participação dos stakeholders na discussão e elaboração de políticas públicas facilita sua implementação, pois os membros se sentem responsáveis pelo resultado final. Esse resultado é principalmente potencializado quando se trata de uma lei complexa e inovadora, como aquelas que tratam da LR de REEE. Nesse sentido, Portugal e Suíça envolveram os principais stakeholders na discussão sobre Decreto-lei 230/2004 e a ORDEE de 1998 desde o inicio. Esse tipo de relação na elaboração de leis é comum nos dois países.

No caso do Brasil, o governo federal primeiro criou um arcabouço legislativo sobre os REEE, bem como as metas e parâmetros para sua gestão, e depois chamou os atores para debater 
o melhor modelo de LR, por meio do AS. Entretanto, a maior parte das divergências entre governo e setor privado estão baseadas nos elementos que já haviam sido definidos pela PNRS ou pelo edital de chamamento desse setor.

O histórico de colaboração entre o governo e os atores do setor privado em Portugal e na Suíça atua como fator de condição inicial para o desenvolvimento de uma governança colaborativa, aumentando as chances de sucesso desses governos no engajamento e validação da lei (ANSELL; GASH, 2008). Já o Brasil optou por incluir os atores na discussão só mais tarde. Parte dessa decisão se deve ao fato dos atores convidados não terem um histórico positivo de relações colaborativas na formulação de leis (ANSELL; GASH, 2008).

Além de garantir o envolvimento dos atores com os resultados do projeto, a colaboração na elaboração de uma lei pode evitar os altos custos gerados por leis conflituosas e por problemas de contestação (ANSELL; GASH, 2008). Esse é um dos riscos que o governo brasileiro tenta afastar ao privilegiar o AS como principal ferramenta para a implementação da LR de REEE no país, ao invés do decreto, que seria uma decisão unilateral, como foi o caso da PNRS e o edital de chamamento. Esse é um dos motivos que tem causado o prolongamento das discussões sobre o AS há mais de seis anos (AUGUSTO; DEMAJOROVIC; MELGAREJOMORENO, 2018).

A possibilidade de negociar sobre os elementos que compõem a legislação é visto por todos os atores como outra importante oportunidade para estabelecer parcerias interorganizacionais em Portugal, Suíça e Brasil (BALESTRIN; VARGAS, 2004). Um dos exemplos disso, em Portugal, foi participação efetiva dos diversos atores na elaboração do sistema de informação para gestão dos REEE, na qual os operadores foram acatados em suas sugestões sobre o melhor layout da plataforma. Mesmo que às vezes seus pleitos não sejam atendidos, os atores se sentem ouvidos, o que corrobora a importância de assegurar pequenas vitórias para garantir o comportamento colaborativo e o engajamento de todos no processo, de acordo com Ansell e Gash (2008).

Na Suíça, a abertura do governo para participação colaborativa possibilitou a criação da lei baseada no sistema de LR de REEE que já estava em funcionamento, permitindo que os produtores validassem o modelo e ajudassem a criar mecanismos legislativos para melhorá-lo. Nesse sentido, sua participação na elaboração da lei assegurou a participação de todos os atores do setor de EEE em algum sistema de LR de REEE, mesmo que fosse de forma individual e a obrigação do consumidor descartar seus REEE de forma ambientalmente correta. Essas condições foram essenciais para atingir os resultados atuais na coleta e reciclagem dos REEE 
no país. Nesse cenário, todos ganham, já que cada um pode contribuir com o que tem de melhor, de acordo com Das e Teng (1998).

No Brasil, todos os atores consideram que a possibilidade de participar da construção do AS é uma oportunidade, ainda que as mudanças ocorram mais devagar do que o necessário. De fato, eles têm conquistado vitórias significativas, como a criação de um PP para coletar dados reais e confrontá-los com as metas mínimas estabelecidas pelo governo, ou o reconhecimento por parte do governo sobre algumas barreiras apresentadas ao setor privado. Esse reconhecimento é importante para fortalecer as relações de parceria, pois, de acordo com Ansell e Gash (2008), o processo de negociação ajuda na construção de conhecimento necessário para o desenvolvimento de políticas públicas e no reconhecimento das competências do outro para atuar efetivamente na parceria, estimulando o comprometimento com os resultados.

De acordo com Balestrin e Vargas (2004), o lobby praticado pelos atores do setor privado pode ajudar a conquistar vantagens econômicas junto ao governo. No caso brasileiro, este lobby é representado pela ação colaborativa de fabricantes e setor de varejo de forma a postergar a implementação da LR por meio do AS e ao mesmo tempo modificá-lo de forma a atender seus interesses econômicos, com revisão das metas e incentivos fiscais e financeiros.

A possibilidade de negociar que os atores têm nas relações de parceria gera outro tipo de oportunidade para aqueles envolvidos na LR de REEE, que é desenvolver empatia pelo outro, compreendendo os desafios enfrentará devido às novas exigências, metas ou mudanças no processo de gestão (SCHERNERHORN, 1975; ANSELL; GASH, 2008; DAS; TENG, 1998).

O governo de Portugal acredita que, ao envolver os atores nas discussões sobre as metas de coleta e reciclagem dos REEE acima do estipulado pela UE e sobre os novos mecanismos de controle e gestão de resíduos, ele pode sensibilizá-los sobre a importância desses elementos na gestão de um sistema realmente eficiente para esse tipo de resíduo. Para isso, tem conversado com pequenos grupos, visando gerar empatia sobre essas questões e mostrar a importância deles entenderem os novos mecanismos, além de suas próprias limitações, pensando no bem-estar da população e na gestão sustentável da cadeia. Dessa forma, tem conseguido não só sensibilizar esses grupos, como fazer com que eles ajudem a convencer os outros atores sobre a importância da LR de REEE, diminuindo sua resistência deles frente aos novos mecanismos.

Na Suíça, foi o setor privado que viu a oportunidade de envolver outras empresas de EEE na LR de REEE, por meio da empatia. Nesse caso, foram mostrados os benefícios de se antecipar à lei, tendo um sistema de LR em funcionamento, moldado por eles, para atender à 
crescente demanda da população por uma forma de descarte correta dos REEE, pois, dessa forma, aumentariam as chances de ter uma lei de LR de REEE baseada em um modelo factível para todos e adaptada às suas condições (DAS; TENG, 1998; ANSELL; GASH, 2008).

No caso da Espanha, esse elemento não emergiu na pesquisa, pois, apesar de existirem metas e desafios dos novos sistemas de informação para a gestão integrada da LR de REEE, os diferentes atores encontram-se em um estágio de transição, segundo o RD 110/2015, o que significa que não sofrem sanções por não o cumprir as metas, atenuando a pressão sobre necessidade de mostrar a importância desses requisitos até o momento.

Já no Brasil, a implementação do PP a pedido do governo federal teve ampla adesão do setor privado, uma vez que os setores público e privado entenderam como oportunidade a possibilidade de sensibilizar a outra parte sobre a importância do seu ponto de vista. Nesse caso, os dois lados tentam usar o recurso da empatia para enfrentar o mesmo problema. Assim, enquanto o governo federal tenta mostrar que a LR de REEE é exequível mesmo no cenário atual, por meio da criação do PP, a indústria quer justamente o oposto: ao participar do projeto, pretende constatar que não é possível implementar a LR sem que sejam feitas nas leis as alterações anteriormente solicitadas. Nesse caso, parece que ambos querem que a outra parte perceba seu problema, sem querem perceber o do outro. Esse desequilíbrio pode comprometer a efetivação da cooperação entre eles, de acordo com Das e Tang (1998).

Dessa forma, só Portugal e Suíça puderam usufruir da oportunidade gerada pela empatia, ao perceberam que as relações de parceria permitem que uma das partes sensibilize as outras sobre a importância de fazer algo desafiante, ampliando as perspectivas dos atores para além das suas limitações e criando senso comum sobre o problema, elemento essencial para a atuação conjunta (SCHERNERHORN, 1975; ANSELL; GASH, 2008).

Uma das oportunidades amplamente discutida na literatura, corroborada com o resultado das entrevistas, é o aumento das competências por meio de parcerias colaborativas ou cooperativas (BALESTRIN; VARGAS, 2004; POLENSKE, 2004; SILVA, 2007; ANSELL; GASH, 2008; VERSCHOORE; BALESTRIN, 2008). Nesse contexto, todos os entrevistados apontaram como um dos fatores motivacionais para estabelecer parcerias a oportunidade de aumentar alguma de suas competências. Na Suíça e Brasil, o acesso ao conhecimento de atores que já executam a LR de REEE foi determinante para que os governos buscassem parcerias. Na Suíça, o governo estabeleceu parceria com as empresas que já executavam a LR de REEE para moldar a ORDEE. E, no Brasil, o governo federal estabeleceu um acordo de cooperação com o governo japonês para implementar o PP, visando aprender com ele a realizar a LR e levantar 
dados sobre o cenário brasileiro, como comportamento do consumidor, potencial de coleta, capacidade das empresas de LR de REEE para atender a nova demanda e custos operacionais.

Espanha, Portugal e Suíça aumentaram o volume de REEE coletado e reciclado devido às parcerias dos OGR com os sistemas de coletas de resíduos municipais, aumentando a capilaridade na coleta, facilitando o acesso da população a esse serviço e diminuindo o custo da LR e exigência de mais infraestrutura. Nesses casos, o ganho percebido pelo acesso à infraestrutura foi incrementado pela expertise dos municípios sobre o comportamento de descarte e necessidades específicas da população, dada sua localidade e faixa etária (BALESTRIN; VARGAS, 2004; POLENSKE, 2004; SILVA, 2007; ANSELL; GASH, 2008; VERSCHOORE; BALESTRIN, 2008).

$\mathrm{Na}$ Espanha, os recicladores e sucateiros que não pertencem formalmente aos SIG, também se uniram para ganhar volume na coleta, maior rentabilidade e competitividade, ao usar a expertise e infraestrutura de outro reciclador para atrair clientes que não estariam dentro do seu escopo de acordo com as permissões de LER que possuíam. Nesse caso, o aumento das competências de um desses atores espanhóis permitiu que ele fosse credenciado como CPR de REEE pelo governo para explorar um novo mercado, que visa prolongar a vida dos EEE, gerar renda com a venda de EEE remanufaturados e criar postos de trabalho. De acordo com Verschoore e Balestrin (2008), o acesso a novos mercados e redução de custos operacionais estão entre as oportunidades geradas pela cooperação mais lembrada pelos atores envolvidos nela.

Com efeito, a oportunidade de criar novos mercados, postos de trabalho e aumentar as divisas com a exploração dos REEE também foi fator motivacional para que Portugal e Suíça buscassem fortalecer a LR de REEE e aumentar o seu volume. O governo brasileiro também visa aproveitar essa oportunidade ao implementar a LR. Além dele, a indústria de EEE, que se uniu para criar as EGs, e o Japão também se motivaram a cooperar no PP devido ao potencial futuro de explorar esse novo mercado no país. De fato, as empresas podem usufruir dos resultados obtidos na cooperação para criar novas oportunidades para si (HORD, 1981; POLENSKE, 2004).

Outro fator motivacional determinante para as empresas atuarem de forma cooperativa é a expectativa de melhorar sua imagem diante da pressão social (SCHERMERHORN, 1975), como ocorreu com as empresas suíças. Já a recicladora e a cooperativa de catadores brasileiras visam mostrar sua capacidade de atuar nesse mercado. Contrastando com a literatura sobre cooperação e colaboração, que normalmente mostra que as empresas se juntam para adquirir competência, ou são procuradas porque a têm (SCHERMERHORN, 1975; HORD, 1981; 
POLENSKE, 2004), no caso brasileiro, cooperativa de catadores de materiais recicláveis e as recicladoras queriam mostrar sua competência ao operarem no PP. Além disso, a mitigação de impacto ambiental e recuperação de materiais raros e valiosos também surgem em todos os países estudados como elemento decisivo para colaborar e cooperar para operacionalizar a LR de REEE.

É interessante notar que, nessa pesquisa, o atributo oportunidade assume valores diferentes dos encontrados na literatura, pois esse é um campo novo de estudo, com estrutura distinta das apresentadas no referencial teórico. Entre esses valores figuram: aumento da capilaridade; volume da coleta de REEE; expertise em reciclagem de REEE; diminuição do impacto ambiental; e recuperação de materiais raros e valiosos,

Todos os países estudados apresentaram motivações que geram alguma vantagem para efetivação de alianças (POLENSKE, 2004; SILVA, 2007; WINCKLER; MOLINARI, 2011), tão importantes no processo de decisão por cooperar ou colaborar (SCHERMERHORN, 1975; HORD, 1981; POLENSKE, 2004), ainda que, em algumas situações, a motivação de um ator fosse de encontro à oportunidade percebida pelo outro, como ocorreu no Brasil.

\subsubsection{Disposição}

Para completar o processo de decisão de cooperar ou colaborar, contudo, é igualmente importante que a instituição ou pessoa tenha disposição para atuar em parceria. Nesse caso, as necessidades e oportunidades descritas anteriormente precisam ser mais importantes do que os riscos e esforços enfrentados para efetivar a parceria (HORD, 1981; POLENSKE, 2004).

A cultura colaborativa suíça é apontada pelos stakeholders da LR de REEE como fator determinante para sua disposição de atuar em parceria na busca de consenso e sucesso na efetivação das leis (ANSELL; GASH, 2008). Essa disposição pode ser apreciada nos diversos níveis políticos, assim como entre os membros dos setores envolvidos na LR, pois todos querem vencer as barreiras para atuar em prol da sociedade, atendendo suas necessidades (HORD, 1981; POLENSKE, 2004).

Nesse cenário, Portugal também se demonstra disposto a colaborar e cooperar para o sucesso da LR de REEE. O governo português tem conseguido aprovar até as medidas menos populares, como metas e mudanças nos sistemas de informação para controle da LR de REEE (HORD, 1981; POLENSKE; 2004, ANSELL; GASH; 2008). Esse sucesso se deve à disposição do governo em mostrar ao grupo a importância de uma determinada medida e os benefícios que gera para todos, tornando-o aliado para convencer o restante dos atores envolvidos no processo. 
Isso tem estimulado o governo português a ampliar a quantidade de stakeholders que traz para as discussões, assim como aprofundar sua participação incentivando-os a apresentar propostas de melhorias. Assim como na Suíça, em Portugal, tanto os municípios, quanto os atores do setor privado têm demonstrado disposição para atuar em parceria e superar as barreiras.

Já na Espanha, iniciativas voluntárias dos municípios para ajudar no aumento da coleta dos REEE separados dos RSU demonstram sua disposição para atuar em prol da LR de REEE. Um exemplo disso, que vai além de aceitar os REEE nos canais de coleta seletiva, é o projeto piloto do ajuntamento de San Vicente del Raspeig, que buscou envolver pequenas lojas de EEE e supermercados na coleta de REEE. Entretanto, apenas as lojas pequenas aceitaram colocar os coletores em seus estabelecimentos.

Outro exemplo que ilustra a fraca disposição das lojas para participar da LR é do El Corte Inglés, uma grande loja de departamentos, que possui um andar exclusivo para a venda de EEE e, por lei, é obrigada receber os REEE. A observação in loco, porém, mostrou que a loja mantém os coletores, fornecidos por uma das SIGs, em um canto do estacionamento, sem nenhuma informação para clientes e colaboradores, o que certamente pouco contribui para sua participação no processo de LR. Entre os três países europeus, de fato, a Espanha é o único que não conta com a participação da população no descarte correto de REEE. Além disso, ao contrário da Suíça e de Portugal, não existe senso de urgência para a efetivação da LR de REEE, pois o país encontra-se no período de transição, mais tolerante ao não atendimento das metas.

O Brasil, por sua vez, conta com um cenário muito distinto do europeu quanto à disposição dos diversos atores em estabelecer parcerias para elaborar a Lei sobre REEE e com um comportamento contraditório na implementação do PP. Nem o governo federal, nem os atores do setor privado demonstram disposição para atuarem juntos na superação das barreiras para aprovação do AS. Cada um espera que o outro ceda na sua posição, enquanto tenta provar que tem razão nas suas demandas. $O$ governo federal não prioriza o assunto, nem pressiona o setor de EEE a firmar o AS. Este, sem se sentir pressionado, evolui pouco nas propostas, não pressiona o governo a tomar uma atitude em relação às barreiras apresentadas e usa recursos jurídicos para não precisar atender ao governo ou à lei. Sem se sentirem responsáveis por arcar com a LR, não importando o quão seja difícil implementá-la, os atores do setor de EEE não demonstram motivação para buscar suporte em outras organizações para executá-la (SCHERMERHORN, 1975; HORD, 1981; POLENSKE, 2004). Além disso, não estão dispostos a deixar entrar novos atores na discussão, mesmo que esses possam contribuir de forma positiva a partir de sua experiência ou conhecimento, como no caso de recicladores, membros da academia especializados no tema ou varejistas que já fazem a coleta dos REEE de 
forma eficiente. Nesse cenário, apenas o MMA parece engajado na busca por consenso na elaboração do modelo de LR de REEE, mas não possui autonomia para resolver a maioria dos impasses.

Apesar de toda a resistência dos atores para participarem efetivamente da elaboração do AS de LR de REEE, o PP teve adesão total de todos. Com efeito, todos concordaram com o objetivo de levantar dados reais sobre a LR de REEE no Brasil e demonstraram disposição para atuar conjuntamente. Até os varejistas, um dos setores mais resistentes, participou e teve disposição para negociar sobre os coletores, testar o modelo de coleta de grandes EEE na casa do consumidor e ajudar a melhorar a comunicação sobre o projeto. Nesse cenário, como o PP era organizado e financiado pela JICA, os participantes se sentiram menos inseguros para aderir, pois seu risco financeiro era muito pequeno e o projeto era percebido como uma oportunidade de validar seu ponto de vista. De acordo com Das e Tang (1998), quanto maior o risco envolvido em uma atividade, maior será o esforço empregado para a construção da confiança para que sejam estabelecidas relações de parcerias. Para os autores, a definição de metas e estrutura facilita a confiança na cooperação, com ocorreu no PP.

Nesse contexto, pode-se inferir que os países que têm senso de urgência para executar a LR de REEE estão mais propensos a superar os desafios inerentes aos processos colaborativos e cooperativos de forma a efetivar a LR. Da mesma forma, outros atores da cadeia reversa, tais como recicladores, mesmo que ainda não sejam considerados parte efetiva do sistema de LR, entendem que a cooperação pode fortalecer a sua ação de forma a se credenciar como fornecedores de serviços de coleta e reciclagem para as organizações gestoras (HORD, 1981; POLENSKE, 2004).

O Quadro 16, apresenta a compilação dos atributos da dimensão Motivação encontrados e discutidos à luz da literatura. 
Quadro 16 - Resumo dos Atributos da dimensão Motivação no Brasil e países europeus

\begin{tabular}{|c|c|c|c|c|c|c|}
\hline \multicolumn{7}{|c|}{ Dimensão Motivação } \\
\hline Atributo & Espanha & Portugal & Suíça & Brasil & Valores do Atributo & Referências \\
\hline \multirow{2}{*}{ 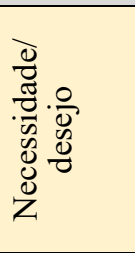 } & $\begin{array}{c}\text { Atender Leis (Diretiva e } \\
\text { RD de REEE). Diminuir o } \\
\text { impacto dos REEE. }\end{array}$ & $\begin{array}{l}\text { Atender Leis (Diretiva e } \\
\text { Decreto de REEE). } \\
\text { Consenso. Diminuir o } \\
\text { impacto dos REEE. }\end{array}$ & $\begin{array}{c}\text { Atender pressão do } \\
\text { mercado. Consenso. } \\
\text { Prevenir impactos dos } \\
\text { REEE. Imagem da marca }\end{array}$ & $\begin{array}{c}\text { Atender a PNRS. Atores } \\
\text { não se sentem } \\
\text { obrigados. Atender a } \\
\text { população. Diminuir } \\
\text { impactos REEE }\end{array}$ & $\begin{array}{l}\text { Escassez de recursos ou } \\
\text { demandas de mercado } \\
\text { que estão além de suas } \\
\text { competências. }\end{array}$ & $\begin{array}{c}\text { Schermerhorn } \\
\text { (1975), Hord (1981); } \\
\text { Polenske (2004) }\end{array}$ \\
\hline & & $\begin{array}{l}\text { Predisposição para ser } \\
\text { sustentável*. }\end{array}$ & $\begin{array}{l}\text { Predisposição para ser } \\
\text { sustentável*. }\end{array}$ & & $\begin{array}{l}\text { Predisposição para ser } \\
\text { sustentável. }\end{array}$ & N/A \\
\hline \multirow{7}{*}{ 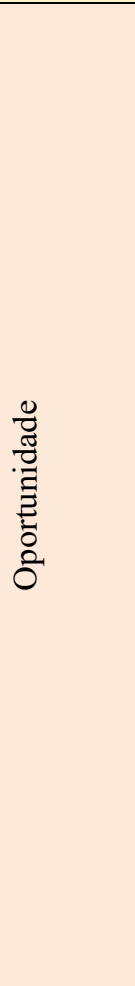 } & & Validar e efetivar a lei. & Validar e efetivar a lei. & Validar e efetivar o AS. & $\begin{array}{l}\text { Engajamento para } \\
\text { validar as decisões. }\end{array}$ & $\begin{array}{c}\text { Ansell e Gash } \\
(2008)\end{array}$ \\
\hline & & & & $\begin{array}{l}\text { Diminuir risco de } \\
\text { contestação. }\end{array}$ & $\begin{array}{l}\text { Evitar custos de criar } \\
\text { políticas conflituosas. }\end{array}$ & $\begin{array}{c}\text { Ansell e Gash } \\
(2008)\end{array}$ \\
\hline & & $\begin{array}{l}\text { Lobby por melhor } \\
\text { cenário. }\end{array}$ & $\begin{array}{l}\text { Lobby para validar o } \\
\text { modelo executado. }\end{array}$ & $\begin{array}{l}\text { Lobby por melhor } \\
\text { cenário e reduzir } \\
\text { custos. }\end{array}$ & $\begin{array}{l}\text { Lobby por melhor } \\
\text { cenário para si. }\end{array}$ & $\begin{array}{c}\text { Balestrin e Vargas } \\
(2004)\end{array}$ \\
\hline & $\begin{array}{l}\text { Não há urgência. } \\
\text { Período de transição, } \\
\text { pelo R/D de } 2005 \text {. }\end{array}$ & $\begin{array}{c}\text { Sensibilizar atores sobre } \\
\text { a importância das novas } \\
\text { metas acima da UE e } \\
\text { novas ferramentas. }\end{array}$ & $\begin{array}{c}\text { Sensibilizar empresas } \\
\text { sobre a importância de } \\
\text { todos aderirem às } \\
\text { ORPs. }\end{array}$ & $\begin{array}{c}\text { Sensibilizar sobre } \\
\text { metas acima do factível } \\
\text { superdimensionadas } \\
\text { (PD). Sensibilizar } \\
\text { sobre viabilidade das } \\
\text { metas (GF). }\end{array}$ & $\begin{array}{c}\text { Sensibilizar sobre a } \\
\text { importância de algo } \\
\text { negociar para ter } \\
\text { consenso }^{2} \text {; preservação } \\
\text { da equidade; adaptação } \\
\text { intra-firmas }{ }^{3} \text {. }\end{array}$ & $\begin{array}{c}\text { Schernerhorn } \\
\text { (1975); Ansell e } \\
\text { Gash (2008); Das e } \\
\text { Tang (1998) }\end{array}$ \\
\hline & & & $\begin{array}{l}\text { Aprender com ORP } \\
\text { para elaborar a lei. }\end{array}$ & $\begin{array}{l}\text { Aprender com o PP } \\
\text { para efetivar AS. }\end{array}$ & $\begin{array}{c}\text { Acessar conhecimento } \\
\text { para melhorar eficiência } \\
\text { ou consultorias } \\
\text { compartilhadas. }\end{array}$ & $\begin{array}{c}\text { Balestrin e Vargas } \\
\text { (2004); Polenske } \\
\text { (2004); Silva (2007); } \\
\text { Verschoore e } \\
\text { Balestrin (2008) }\end{array}$ \\
\hline & $\begin{array}{c}\text { Capilaridade e volume: } \\
\text { parceria com GM; } \\
\text { competitividade: uso } \\
\text { da expertise e } \\
\text { infraestrutura de outro. }\end{array}$ & $\begin{array}{c}\text { Capilaridade e volume: } \\
\text { parcerias com escolas e } \\
\text { municípios. }\end{array}$ & $\begin{array}{l}\text { Capilaridade e volume: } \\
\text { parceria na coleta entre } \\
\text { ORPs, ORP e GM, } \\
\text { ORP e outros. }\end{array}$ & $\begin{array}{l}\text { PP financiado pela } \\
\text { JICA. }\end{array}$ & $\begin{array}{c}\text { Acesso à estrutura de } \\
\text { algum ator ou criação } \\
\text { de uma nova entidade } \\
\text { para aumentar a } \\
\text { eficiência do processo. }\end{array}$ & $\begin{array}{c}\text { Balestrin e Vargas } \\
\text { (2004); Polenske } \\
\text { (2004); Silva (2007); } \\
\text { Verschoore e } \\
\text { Balestrin }(2008)\end{array}$ \\
\hline & $\begin{array}{l}\text { Mercados de segunda } \\
\text { mão (CRP) e aumento } \\
\text { de empregos e divisas. }\end{array}$ & $\begin{array}{l}\text { Aumento de divisas com } \\
\text { a reciclagem de REEE, } \\
\text { quanto maior a meta. }\end{array}$ & $\begin{array}{l}\text { Recuperar materiais } \\
\text { raros e valiosos. } \\
\text { Explorar o valor dos } \\
\text { REEE (RC). }\end{array}$ & $\begin{array}{l}\text { Mercado de REEE para } \\
\text { cooperativas, postos de } \\
\text { trabalho e maior renda. } \\
\text { Novos mercados e } \\
\text { aumento de divisas. }\end{array}$ & $\begin{array}{c}\text { Explorar novos } \\
\text { mercados, gerar novos } \\
\text { empregos e aumentar } \\
\text { rentabilidade }\end{array}$ & $\begin{array}{c}\text { Balestrin e Vargas } \\
\text { (2004); Polenske } \\
\text { (2004); Silva (2007); } \\
\text { Verschoore e } \\
\text { Balestrin (2008) }\end{array}$ \\
\hline
\end{tabular}




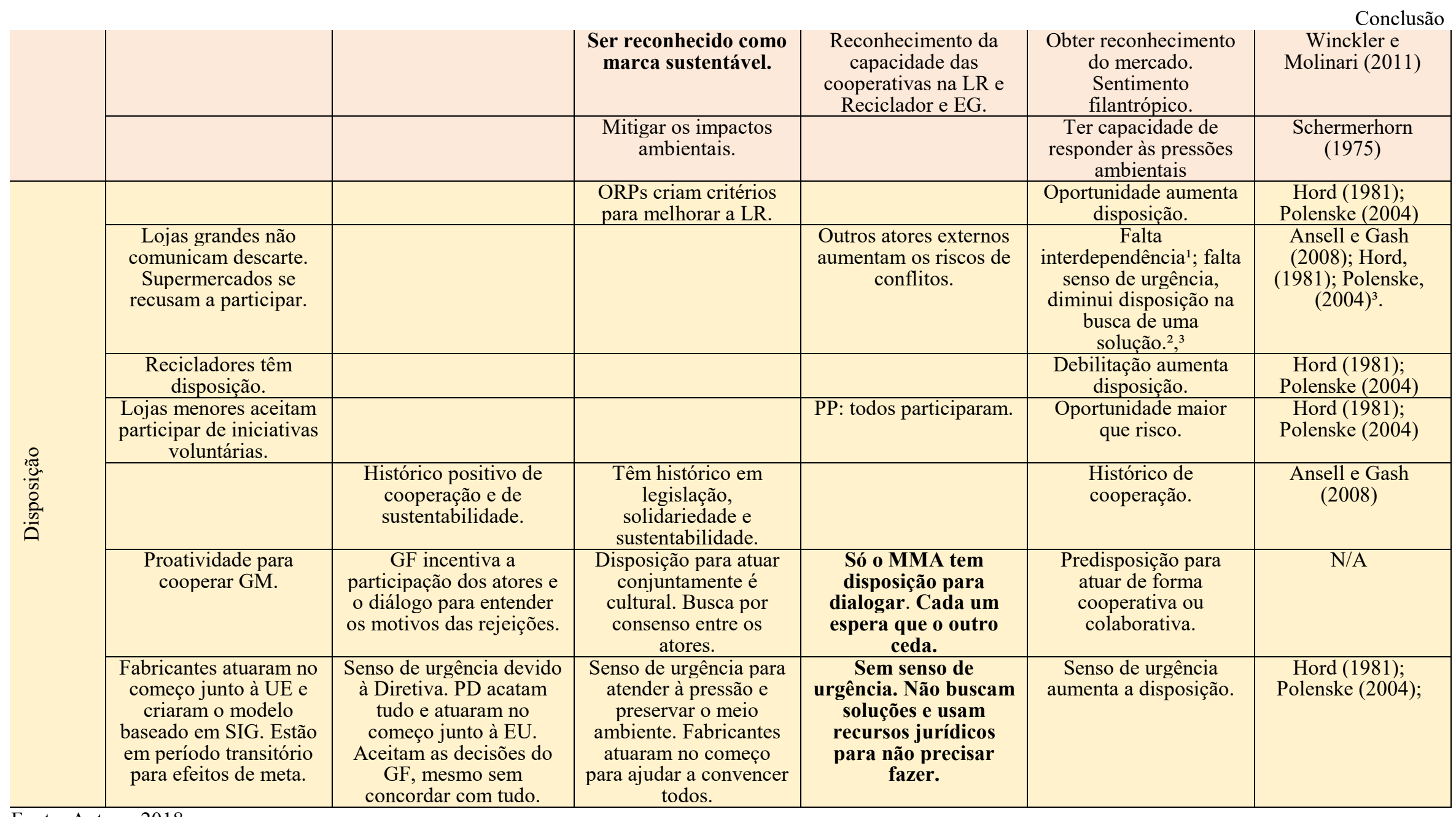




\subsection{ESCOPO}

Os atributos do Escopo são fundamentais para definir o modelo de parceria que se deve estabelecer, diante da natureza da operação (HORD, 1981; POLENSKE, 2004), dos objetivos e resultados esperados (HORD, 1981), e dos atores envolvidos, dado que esses podem ser concorrentes ou não (POLENSKE, 2004), pois cooperação e colaboração possuem abordagens distintas para que as instituições possam trabalhar juntas com sucesso (HORD, 1981).

\subsubsection{Natureza}

Nos estudos de caso realizados, todos os países atuam mediante os dois tipos de parcerias: colaborativas e cooperativas. Nesse sentido, colaboram quando trabalham na elaboração das leis e no desenvolvimento de mecanismos para dar suporte e controle à gestão dos REEE, que são atividades tipicamente mentais (KEMCZINSKI et al., 2008), e cooperam quando criam uma organização especializada na gestão de REEE para operar a LR por eles, como no caso da Espanha, com onze SIG, Portugal com duas EG e Suíça com duas ORP, ou se unem para operacionalizar um PP, como ocorreu no Brasil (SILVA, 2007; KEMCZINSKI et al., 2008; WINCKLER; MOLINARI, 2011). É interessante notar, contudo, que, diferentemente dos outros países, na Suíça a cooperação ocorreu antes da colaboração, com a efetivação da LR de REEE.

\subsubsection{Objetivos}

No caso de processos mentais, como elaboração e planejamento de políticas e estruturação de sistemas de controle e gestão, é importante que os atores envolvidos tenham claro quais são seus objetivos e haja consenso sobre o que será feito (HORD, 1981; BRNA, 1998; POLENSKE, 2004; KEMCZINSKI et al., 2008; ANSELL; GASH, 2008; WINCKLER; MOLINARI, 2011).

Nesse sentido, na Espanha e em Portugal, estava claro para os atores que o objetivo comum era desenvolver a legislação e a estrutura necessárias para transpor a Diretiva de REEE da UE. Ainda que no caso de Portugal, os objetivos individuais das EG e dos Recicladores Autorizados do Sistema (RAS) fossem conflitantes com o objetivo do grupo, eles não eram mais importantes do que os do grupo (KEMCZINSKI et al., 2008; ANSELL; GASH, 2008). Apesar das EG não quererem metas maiores do que as da UE, em dissonância com o desejo do 
governo federal, e dos RAS serem contrários à digitalização do sistema de controle da gestão dos REEE, eles acatariam a decisão final do governo, mesmo que ambos acreditassem que essas medidas inviabilizariam o sistema. Na Suíça, todos os atores tinham como objetivo comum a elaboração da Lei de REEE e, ainda que também tivessem objetivos individuais, eles eram complementares ao do grupo. No Brasil, entretanto, apesar do objetivo comum ser a elaboração do AS para atender à PNRS com base no edital de chamamento, todos os atores envolvidos têm objetivos individuais antagônicos a ele. Esse fator, por si só, deveria inviabilizar a colaboração no desenvolvimento do AS, pois, segundo Ansell e Gash (2008), os atores não poderão perceber pequenas vitórias intermediárias, indispensáveis em relações colaborativas.

Para Hord (1981), Polenske (2004), Kemczinski et al. (2008) e Winckler e Molinari (2011), na cooperação é fundamental que os objetivos individuais de todos os atores sejam atendidos para que ela seja efetivada com sucesso. Os países pesquisados mostram que essa condição foi contemplada em todos eles, na operacionalização da LR de REEE, inclusive no Brasil, ainda que cada ator tivesse um objetivo diferente para atuar de forma cooperativa.

Produtores e importadores espanhóis e portugueses queriam atender à legislação da forma mais econômica possível, os municípios queriam garantir a gestão sustentável dos REEE e diminuir o impacto e custo da gestão dos RSU, os recicladores almejavam aumentar o mercado de reciclagem de metais e o governo federal, além de atender à UE, visava criar novos postos de trabalhos com essa operação e gerar divisas para seus países.

$\mathrm{Na}$ Suíça ocorreu o mesmo fenômeno, pois os governos municipal e federal puderam atender às demandas socioambientais da população e gerar mais postos de trabalho, a indústria de EEE pode preservar a sua imagem ao menor custo possível e garantir a valoração e recuperação dos metais valiosos e raros contidos nos REEE, e os recicladores puderam potencializar seu lucro com o aumento da demanda e do suporte financeiro dado pelas ORPs.

No caso do Brasil, ainda que todos quisessem aprender como operacionalizar a LR de REEE por meio do PP e da experiência japonesa, os atores tinham finalidades próprias e específicas para esse aprendizado. O governo federal queria viabilizar o AS com o mínimo de mudanças possíveis na legislação, a indústria queria aprender a executar a LR e negociar metas e incentivos com o governo, com base nos dados do projeto, os varejistas queriam conhecer o impacto da coleta nos seus estabelecimentos e testar outros modelos de coleta junto com as OGs e o governo japonês queria conhecer o potencial de coleta de REEE do mercado brasileiro para gerar novos negócios para seu setor de reciclagem. As recicladoras Oxil e Coopermiti também estavam interessadas nos dados no cenário brasileiro de REEE, além de quererem demonstrar sua capacidade de atuar nesse novo mercado. Dessa forma, mesmo que não haja necessidade 
de se ter um objetivo comum na cooperação (HORD, 1981; POLENSKE, 2004; KEMCZINSKI et al., 2008; WINCKLER; MOLINARI, 2011), no caso brasileiro, ele permitiu atender todos os outros objetivos individuais.

\subsubsection{Resultados Esperados}

Os resultados esperados entre os atores que colaboraram na elaboração das leis e normas em Portugal, na Suíça e no Brasil não são simétricos (POLENSKE, 2004; WINCKLER; MOLINARI, 2011), mas são mútuos em todos os casos, pois cada ator esperava obter algo ao participar desses processos (BALANCIERI, 2004; ANSELL; GASH, 2008; WINCKLER; MOLINARI, 2011).

Entretanto, nem todos atores nesses países podem descrever resultados tangíveis (POLENSKE, 2004; WINCKLER; MOLINARI, 2011). Nesse sentido, o ator que aparece sempre com algum resultado tangível é o governo federal, em todos os casos. Dessa forma, em Portugal, só o governo federal relata resultados tangíveis, relacionados à efetivação da lei e à redução do impacto ambiental dos REEE. Suíça e Brasil possuem, entre os atores que podem tangibilizar os resultados, o governo federal e a indústria de EEE. Embora os dois atores suíços almejem a mesma coisa, que é efetivar a lei de forma consensual para garantir a participação de todos e a padronização do sistema de gestão de REEE, no Brasil, eles desejam quase o oposto, pois o governo quer efetivar o AS, conforme estabelecido pela lei e edital de chamamento, e reduzir as obrigações dos municípios na gestão de resíduos, enquanto a indústria de EEE quer minimizar os impactos econômicos e a responsabilidade que recaem sobre ela nessa cadeia. Além disso, os atores do CV também esperam reduzir os custos e responsabilidades atribuídos a eles. Assim, o Brasil é o país que mais teve resultados tangíveis enumerados, ainda que seja o único que não tenha efetivado a LR de REEE até o momento. Entretanto, a falta de resultados tangíveis para todos não é considerada um problema nesse tipo de relação, já que, para alguns atores, a percepção de resultados intangíveis é suficiente para compensar sua participação nesses processos (POLENSKE, 2004; WINCKLER; MOLINARI, 2011). Além disso, os resultados esperados não foram previamentes estipulados por um contrato ou acordo formal, dessa forma, são apenas frutos da expectativa de cada ator (BRNA, 1998).

Em compensação, quanto aos resultados intangíveis da colaboração nos países estudados, a pesquisa revelou que, em processos de colaboração, o atributo "resultados intangíveis" pode assumir outro valor, não narrado na literatura, o "poder de influenciar". 
No caso de Portugal, o governo descreve esse poder de influenciar como a disposição para convencer os atores sobre a importância de cada medida que quer adotar. Já os atores que atuam da operacionalização da LR, como os EG e os RAS, querem influenciar o governo na elaboração de normas e leis para evitar processos que complexifiquem suas atividades, ou, como no caso das EG, a criação de metas acima da UE, que eles considerem que possam pôr em risco a capacidade de atender seus associados. Produtores e importadores, por sua vez, não se envolveram na elaboração de normas, tendo atuado apenas na discussão da Diretiva de REEE, na qual decidiram criar as EG para transferir sua responsabilidade da gestão dos EEE pós consumo. Na Suíça, produtores e ORP também buscam influenciar a modelagem das leis e os critérios de qualidade baseados no seu modus operandi.

Esse valor surge, assim, nos três países europeus estudados, para quase todos os atores, com exceção do GF da Suíça, que o define como processo de negociação, enfatizando sua cultura colaborativa e predisposição para chegar a um consenso que atenda às necessidades dos stakeholders, sem impor sua posição. Além disso, todos os atores desejam criar uma imagem de entidade ou nação sustentável como resultado do processo colaborativo.

No caso do Brasil, os resultados para cada ator estão limitados ao poder de influência que exercerão no AS, como em uma disputa de cabo de aço, na qual cada um tenta puxar as vantagens para o seu lado, e ao conhecimento adquirido pelos atores durante todo o processo. Um exemplo de difusão do conhecimento proporcionado pela discussão do AS é o fato de que todos os estudos e levantamentos de dados feitos por atores de diferentes setores para barganhar seu ponto de vista foram compartilhados com o GT. Balancieri (2004) reforça este importante aspecto da colaboração no qual o compartilhamento de conhecimento é distribuído de forma igualitária entre todos os envolvidos. A questão da imagem como potencial ganho intangível, no entanto, não aparece como um ponto importante, pois foi pouco valorizada pelos entrevistados.

No caso da cooperação, todos os atores envolvidos na operacionalização da LR de REE, em todos os países, receberam resultados tangíveis. De acordo com Hord (1981), Polenske (2004) e Winckler e Molinari (2011), a percepção desse benefício é importante em parcerias cooperativas. De fato, embora não necessitem ser assimétricos (POLENSKE, 2004; WINCKLER; MOLINARI, 2011), é imprescindível que todos possam tangibilizar os resultados auferidos (HORD, 1981; POLENSKE, 2004; WINCKLER; MOLINARI, 2011), que devem ser preestabelecidos de forma clara e formal no início da parceria (KEMCZINSKI et al., 2008; WINCKLER; MOLINARI, 2011). Todas essas características foram atendidas nos quatro países estudados. 
No Brasil, o resultado tangível mais esperado por todos os atores que participaram do PP foi o relatório com os dados reais sobre a quantidade de REEE que será coletada, quais os canais de descarte mais eficientes para as quatro categorias de EEE, o comportamento do consumidor, o custo da logística e da reciclagem e as considerações da equipe da JICA sobre qual o melhor modelo de LR para atender o país. Nesse cenário, apenas os atores de reciclagem e a agência de marketing receberam alguma contrapartida financeira por participar do PP, conforme acertado em contrato. Contudo, todos os atores sabiam que resultados poderiam esperar do PP, além do conhecimento sobre a realidade brasileira, sistematizados no relatório final entregue a eles. Dessa forma, no PP, os resultados foram relatados e divididos conforme acertado, corroborando Hord (1981) e Polenske (2004). Entre os resultados tangíveis esperados estão alguns desdobramentos que serão apurados apenas quando a LR de REEE estiver em operação no país e são praticamente os mesmos esperados com a efetivação do AS, já que era essa a finalidade do PP.

Assim como no Brasil, todos os parceiros que atuam na coleta e gestão dos REEE nos três países europeus, como municípios, escolas, bombeiros e recicladores, têm claro as contrapartidas financeiras que receberão. Além de resultados financeiros diretos, todos os municípios buscavam diminuir o custo da gestão dos RSU e atender à população. Já os sistemas coletivos de gestão dos REEE, de responsabilidade dos produtores na Espanha, Portugal e Suíça buscam reduzir o custo com esse modelo e atender as metas dos PD.

Sobre os resultados intangíveis esperados, pode-se apontar a melhoria da imagem dos governos municipais e federais nos países europeus e do GE e GM no Brasil. Esses atores relatam a sensação de dever cumprido, por estarem garantindo a gestão sustentável desses resíduos e atendendo às demandas da população. O GE no Brasil destaca a importância de poder mostrar para os atores do GF que é possível legislar para facilitar a LR de REEE no país. Nesse cenário, em todos os países estudados, percebe-se que os atores tinham certo que receberiam resultados tangíveis ao cooperarem na operacionalização da LR de REEE e quais eram os resultados intangíveis que poderiam ser auferidos (HORD, 1981; POLENSKE, 2004; WINCKLER; MOLINARI, 2011).

\subsubsection{Atores}

Polenske (2004) afirma que colaboração e cooperação podem ser estabelecidas entre membros de qualquer setor e até mesmo na mesma empresa. Mas Winckler e Molinari (2011) alertam para os riscos de atores concorrentes participarem de processos colaborativos, pois 
podem gerar involuntariamente vantagens competitivas para a outra parte ou deixar vazar informações secretas sobre a empresa, devido à proximidade das relações.

Contrariando a literatura revista, em todos os processos colaborativos estudados existia a presença de atores concorrentes. Nenhum dos atores, contudo, se mostrou preocupado com a participação de outras empresas do mesmo setor, pois todos afirmaram que, durante as discussões para a elaboração das leis e normas, não atuavam como concorrentes, mas se uniam para fazer lobby sobre os pontos com os quais não concordavam nesse processo (BALESTRIN; VARGAS, 2004).

Além disso, a maior parte das vezes, esses atores participam por meio de representantes de suas associações de classe ou pelas OG. Surge assim no Brasil outro elemento divergente da literatura analisada sobre a possibilidade de haver colaboração entre setores diferentes. A indústria e o comércio parecem atuar como concorrentes, escondendo informações e defendendo pontos de vistas distintos, o que tem dificultado as negociações do AS. Ademais, ambos os setores evitam a entrada de qualquer outro membro na discussão do AS, como no caso de recicladores, varejistas e academia. No caso do varejo, não foram integrados aqueles que já têm seus próprios sistemas de LR e que muitas vezes incorporam cooperativas de catadores. A perspectiva da academia, por sua vez, frequentemente não coincide com os pontos de vista da indústria ou do varejo. Embora esses atores não sejam concorrentes da indústria, nem do varejo, trazem argumentos que desconstroem algumas das barreiras apresentadas pela indústria, como a viabilidade de incluir cooperativas de catadores na cadeia reversa de REEE.

Considera-se, por outro lado, que a cooperação é compatível com todos os tipos de atores, concorrentes ou não, por se tratar de um processo mais estruturado, com atividades, objetivos e resultados predefinidos, sem a necessidade de uma convivência muito próxima (BALESTRIN; VARGAS, 2004). Nesse caso, a maior parte dos países não fazem restrição aos atores que desejam cooperar na operação da LR, exceção feita à inclusão do setor informal. As entrevistas indicaram a resistência da integração deste segmento em Portugal, Espanha e Brasil. Ainda que o assunto não seja discutido abertamente, os atores da LR não parecem dispostos a criar medidas que os incluam, ao contrário.

Com efeito, esses atores são marginalizados e não recebem nenhum tipo de incentivo para operar formalmente na coleta dos REEE. Dessa forma, o índice de roubo de REEE em pontos de descarte tem incomodado os governos municipais na Espanha e emPortugal. Já a Suíça não possui setor informal, mas faz da reciclagem de REEE uma porta de inclusão para os desempregados jovens sem experiência e para os mais velhos, por meio de empresas sociais e 
privadas que mantêm programas de capacitação para essa mão de obra visando incluí-la nos processos de desmontagem de REEE.

No Brasil, apesar das cooperativas de catadores não poderem ser caracterizadas como setor informal, pois são organizações formais, regulamentadas por leis, ainda assim há grande resistência do setor privado, particularmente da indústria, em integrá-las na cadeia reversa de REEE. A Coopermiti só participou do PP porque o governo municipal insistiu junto à equipe da JICA para incluí-los, com o objetivo de superar o preconceito do setor privado em relação a esse ator. Para o município de São Paulo, era importante dar visibilidade a esse setor na LR de REEE e mostrar que ele poderia atuar nessa cadeia de diversas formas, como na coleta, transporte, triagem e central de consolidação dos REEE.

O Quadro 17 apresenta um resumo dos valores que cada atributo assumiu nos quatro casos estudados, comparando-os com a coluna "Atributo base". Essa coluna apresenta os valores que cada atributo assume na literatura. Dessa forma, foi possível verificar quais casos apresentavam não conformidade em relação aos atributos. Eles são divididos em suas características mais fortes, para que seja possível aprofundar a análise, e repetidos de acordo com sua natureza e vocação para colaboração ou cooperação. 
Quadro 17 - Escopo da colaboração e cooperação na LR de REEE nos países europeus e no Brasil

\begin{tabular}{|c|c|c|c|c|c|c|}
\hline Atributo & Espanha & Portugal & Suíça & Brasil & Atributo base & Referência \\
\hline \multirow{2}{*}{ 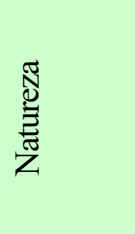 } & $\begin{array}{l}\text { Elaborar lei e sistemas de } \\
\text { gestão e controle }\end{array}$ & $\begin{array}{l}\text { Elaborar lei e sistemas de } \\
\text { gestão e controle }\end{array}$ & $\begin{array}{c}\text { Elaborar lei e critérios de } \\
\text { qualidade }\end{array}$ & $\begin{array}{c}\text { Definir modelo de LR de } \\
\text { REEE para atender à PNRS }\end{array}$ & Colaboração: Elaboração & Kemczinski et al. (2008) \\
\hline & $\begin{array}{c}\text { Criou SIG para fazer a gestão } \\
\text { da LR }\end{array}$ & $\begin{array}{c}\text { Criou EG para fazer a gestão } \\
\text { da LR }\end{array}$ & $\begin{array}{c}\text { Criou ORP p/ fazer a gestão a } \\
\text { LR }\end{array}$ & Operacionalizou o PP & Cooperação: Operação & $\begin{array}{c}\text { Kemczinski et al. (2008); } \\
\text { Winckler e Molinari } \\
\text { (2011) }\end{array}$ \\
\hline 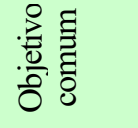 & Atender à Diretiva & Atender à Diretiva & $\begin{array}{c}\text { Atender à demanda do } \\
\text { mercado, padronização da LR } \\
\text { de REEE }\end{array}$ & Atender à PNRS & $\begin{array}{l}\text { Colaboração: Claro e com } \\
\text { senso comum do que será } \\
\text { feito }\end{array}$ & $\begin{array}{c}\text { Brna (1998); Ansell e } \\
\text { Gash (2008); Polenske } \\
\text { (2004) }\end{array}$ \\
\hline 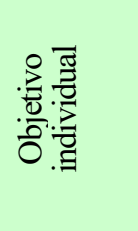 & $\begin{array}{c}\text { A base dos objetivos } \\
\text { individuais é igual ao comum }\end{array}$ & $\begin{array}{c}\text { A base dos objetivos } \\
\text { individuais é igual ao comum. } \\
\text { Alguns objetivos individuais } \\
\text { dos EGs e RAS são } \\
\text { conflitantes com GF e não os } \\
\text { impõem. }\end{array}$ & $\begin{array}{c}\text { A base dos objetivos } \\
\text { individuais é igual ao comum., } \\
\text { além de complementares e } \\
\text { parecidos com a motivação do } \\
\text { outros. }\end{array}$ & $\begin{array}{l}\text { Diferentes e conflitantes, se } \\
\text { sobrepões ao comum. }\end{array}$ & $\begin{array}{c}\text { Colaboração: Comum ao } \\
\text { grupo, o individual não se } \\
\text { sobrepõe ao comum }\end{array}$ & $\begin{array}{c}\text { Hord (1981); Brna } \\
\text { (1998); Polenske (2004); } \\
\text { Kemczinski et al. (2008); } \\
\text { Winckler e Molinari } \\
\text { (2011) }\end{array}$ \\
\hline 宽芯 & $\begin{array}{l}\text { Operar a LR de REEE, para } \\
\text { atender a diretiva as Leis }\end{array}$ & $\begin{array}{l}\text { Operar a LR de REEE, para } \\
\text { atender as Leis }\end{array}$ & $\begin{array}{c}\text { Operar a LR de REEE, para } \\
\text { atender demandas do mercado }\end{array}$ & $\begin{array}{l}\text { Aprender com o PP, para } \\
\text { propor uma proposta de AS } \\
\text { baseada em dados reais sobre } \\
\text { custo e canais de coleta }\end{array}$ & $\begin{array}{c}\text { Cooperação: Objetivo claro } \\
\text { é Estado, são pré- } \\
\text { estipulados }\end{array}$ & \begin{tabular}{|} 
Hord (1981); Polenske \\
(2004); Kemczinski et al. \\
(2008); Winckler e \\
Molinari (2011)
\end{tabular} \\
\hline 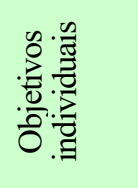 & $\begin{array}{c}\text { Objetivos individuais são } \\
\text { diferentes e garantidos pelo } \\
\text { comum. Membros externos } \\
\text { podem ser atendidos pelo } \\
\text { objetivo comum. }\end{array}$ & $\begin{array}{l}\text { Objetivos individuais são } \\
\text { diferentes e garantidos pelo } \\
\text { objetivo comum. }\end{array}$ & $\begin{array}{c}\text { Objetivos individuais são } \\
\text { convergentes aos dos outros } \\
\text { atores e atendidos pelo comum }\end{array}$ & $\begin{array}{l}\text { Objetivos individuais são } \\
\text { atendidos pelo comum, mas } \\
\text { há conflito de interesses } \\
\text { entre os atores. }\end{array}$ & \begin{tabular}{|c|} 
Cooperação: Objetivos \\
Individuais são garantidos \\
pelo comum. São \\
importantes. Não precisam \\
ser iguais.
\end{tabular} & $\begin{array}{c}\text { Hord (1981); Polenske } \\
\text { (2004); Kemczinski et al. } \\
\text { (2008); Winckler e } \\
\text { Molinari (2011) }\end{array}$ \\
\hline
\end{tabular}


Conclusão

\begin{tabular}{|c|c|c|c|c|c|c|}
\hline 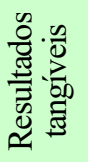 & & GF aufere & GF, ORP e PD auferem & $\begin{array}{l}\text { GF, PD e CV esperam esse } \\
\text { tipo de resultado }\end{array}$ & $\begin{array}{l}\text { Colaboração: Todos } \\
\text { recebem algo, mas não } \\
\text { precisa ser tangível para } \\
\text { todos }\end{array}$ & $\begin{array}{c}\text { Balancieri (2004); Ansell } \\
\text { e Gash (2008); Winckler } \\
\text { e Molinari (2011). }\end{array}$ \\
\hline 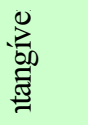 & & Todos recebem & Todos recebem & $\begin{array}{l}\text { Todos têm expectativa de } \\
\text { receber }\end{array}$ & $\begin{array}{c}\text { Colaboração: Compensam } \\
\text { a ausência de resultados } \\
\text { tangíveis }\end{array}$ & $\begin{array}{c}\text { Balancieri (2004); Ansell } \\
\text { e Gash (2008); Winckler } \\
\text { e Molinari (2011). }\end{array}$ \\
\hline 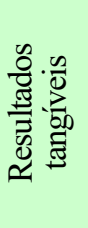 & $\begin{array}{l}\text { Todos recebem: GF, GM, } \\
\text { PD, SIG, recicladores e } \\
\text { sucateiros }\end{array}$ & $\begin{array}{l}\text { Todos recebem GF, GM, } \\
\text { parceiros, EG e PD }\end{array}$ & $\begin{array}{l}\text { Todos recebem: GF, EMPA, } \\
\text { PD, ORP, GM, RAS }\end{array}$ & $\begin{array}{c}\text { Todos recebem: GF, GE, GM, } \\
\text { PD, CV, RC }\end{array}$ & \begin{tabular}{|} 
Cooperação: Ambos \\
recebem resultados \\
tangíveis $1,2,3$; são relatados \\
e divididos ${ }^{1,2}$ de forma \\
clara e formal acertado \\
previamente \\
3,4
\end{tabular} & $\begin{array}{c}\text { Hord (1981); Polenske } \\
\text { (2004); Winckler e } \\
\text { Molinari (2011); } \\
\text { Kemczinski et al. (2008) }\end{array}$ \\
\hline 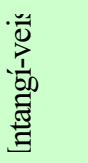 & GM & GF, GM & GF, EMPA, GM, PD e SIG & $\begin{array}{l}\text { Todos recebem: resultado } \\
\text { mais importante, } \\
\text { conhecimento sobre a } \\
\text { realidade brasileira }\end{array}$ & $\begin{array}{l}\text { Cooperação: Imagem, } \\
\text { influência, sentimento de } \\
\text { altruísmo }\end{array}$ & $\begin{array}{l}\text { Hord (1981); Polenske } \\
\text { (2004); Winckler e } \\
\text { Molinari (2011) }\end{array}$ \\
\hline \multirow[t]{2}{*}{$\frac{\mathscr{0}}{\stackrel{0}{*}}$} & $\begin{array}{c}\text { Setores diferentes, mas há } \\
\text { atores concorrentes unidos } \\
\text { ou representados por } \\
\text { associações }\end{array}$ & $\begin{array}{l}\text { Setores diferentes, mas há } \\
\text { atores concorrentes unidos } \\
\text { ou representados por } \\
\text { associações }\end{array}$ & $\begin{array}{l}\text { Setores diferentes, mas há } \\
\text { atores concorrentes unidos } \\
\text { ou representados por } \\
\text { associações }\end{array}$ & $\begin{array}{c}\text { Setores diferentes, mas há } \\
\text { atores concorrentes unidos } \\
\text { ou representados por } \\
\text { associaç̃̃es. Atores de setores } \\
\text { distintos competem. } \\
\text { Restringem atores externos, } \\
\text { mesmo sem ser concorrentes. }\end{array}$ & $\begin{array}{c}\text { Colaboração: Pode ser entre } \\
\text { qualquer setor }{ }^{1} \text { e não } \\
\text { devem ser concorrentes } \\
\end{array}$ & $\begin{array}{c}\text { Polenske (2004); } \\
\text { Winckler e Molinari } \\
\text { (2011) }\end{array}$ \\
\hline & $\begin{array}{c}\text { Setores diferentes e } \\
\text { concorrentes, mas não } \\
\text { incluem setor informal. SIGs } \\
\text { são concorrentes }\end{array}$ & $\begin{array}{c}\text { Setores diferentes e } \\
\text { concorrentes, mas não incluem } \\
\text { setor informal. EGs são } \\
\text { concorrentes. }\end{array}$ & $\begin{array}{l}\text { Setores diferentes e } \\
\text { concorrentes, mas não incluem } \\
\text { setor informal. ORPs são } \\
\text { complementares. }\end{array}$ & $\begin{array}{c}\text { Setores diferentes e } \\
\text { concorrentes, mas não querem } \\
\text { incluir as cooperativas. }\end{array}$ & $\begin{array}{c}\text { Cooperação: Pode ser entre } \\
\text { qualquer setor }{ }^{1} \\
\text { concorrentes }^{2,3}\end{array}$ & $\begin{array}{c}\text { Polenske (2004); Hord } \\
\text { (1981); Winckler e } \\
\text { Molinari (2011) }\end{array}$ \\
\hline
\end{tabular}

Fonte: Autora, 2018

Nota: Conformidade com a literatura $\square$ Apresenta alguma desconformidade 
Segundo Hord (1981), ficam evidentes as diferenças de objetivos e resultados entre cooperação e colaboração, já que o escopo de cada uma é distinto. Enquanto, para a primeira, é essencial atingir resultados tangíveis para todos, para a segunda resultados intangíveis são suficientes para compensar a fala de resultados concretos. Além disso, para a autora, fica claro quais são os conflitos que surgem quando não se tem a definição clara de qual modelo de processo deverá ser adotado, comprometendo o resultado final.

Nessa pesquisa, com relação a essa dimensão, percebe-se que há clareza na natureza do processo, mas existem objetivos e resultados que não atendem à necessidade do grupo, principalmente no Brasil. Outro fator que chama a atenção é que, quando os atores concorrentes se comportam como uma unidade, unidos para fazer lobby ou representados por uma associação, a sua participação fica harmoniosa até em processos colaborativos, ao contrário do que apresenta a literatura.

\subsection{ESTRUTURA}

Após definir os atributos que compõem o Escopo, é necessário estabelecer a estrutura correta que suporte esse tipo de relacionamento e garanta seus ganhos (HORD, 1981; POLENSKE, 2004).

\subsubsection{Atividades}

$\mathrm{Na}$ colaboração, é importante que os atores realizem as atividades conjuntamente (HORD, 1981; BALANCIERI, 2004; POLENSKE, 2004; WINCKLER; MOLINARI, 2011; ANSELL; GASH, 2008) de forma interdependente, sem papéis muito delimitados para garantir a flexibilidade e facilitar a criatividade e sinergia na busca de resolução para problemas (BRNA, 1998; HORD, 1981; KEMCZINSKI et al., 2008; ANSELL; GASH, 2008).

Nesse cenário, a colaboração nos países estudados se dá de formas distintas. A Suíça parece ser o país que tem a melhor estrutura para colaborar, pois seus atores trabalham conjuntamente na elaboração da lei e dos critérios de qualidade para a LR de REEE, permitindo que cada um contribua com o que tem de melhor, sem limitar os papéis dos atores ou sinalizar quem irá definir ao final, pois todos buscam o consenso e a melhor solução para o país (HORD, 1981; BALANCIERI, 2004; POLENSKE, 2004; KEMCZINSKI et al., 2008; WINCKLER; MOLINARI, 2011; ANSELL; GASH, 2008). 
Já Portugal e Brasil diferem da literatura quanto ao modo como trabalham conjuntamente, mas de formas diferentes. No Brasil, apesar de todos os atores envolvidos na discussão do AS participarem das reuniões, seus representantes não podem decidir com autonomia algo novo, apenas atuam como porta-vozes de suas instituições, relatando o que foi decidido sobre a última reunião e coletando as novas propostas, para que cada organização discuta internamente sobre elas. Além disso, nos encontros para o AS, o governo federal, que deveria liderar as discussões, não tomava iniciativa na resolução dos impasses, nem pressionava nenhum ator para que o fizesse. Indústria e varejo brasileiros, por outro lado, se encontram fora das reuniões do AS para discutirem os pontos conflitantes que têm com o governo e tentam chegar a um consenso no que é melhor para ambas, mas não necessariamente para o AS.

Já em Portugal, o governo trabalha a discussão das lei e normas de forma separada, aos pares, com os diversos atores, algumas vezes, apenas de forma consultiva. O caso mais relevante é o das EGs que preferem conversar separadamente com o governo para tratar do mesmo assunto. Um dos exemplos dessa atuação é o fato de que ambas as EGs discordam das metas estabelecidas, mas não se unem para sentar com o governo e negociar. O outro exemplo trata da elaboração da câmara de compensação de REEE, que o governo quer criar para que as EGs possam atingir as metas de coleta por categoria mais facilmente, potencializando o resultado de ambas. Embora uma das EGs não demonstre interesse na sua efetivação, a discussão com o governo é feita de forma isolada.

Além disso, o governo federal português assume o papel de líder, o que gera uma diferença de poder frente aos outros atores, as Câmaras Municipais, as EGs e os OGRs, podendo gerar descontentamento entre os atores no processo. Nesse contexto, o governo português tenta convencer alguns atores, para obter sua aliança na persuasão de todos sobre os pontos conflitantes, como quando tenta mostrar os benefícios e ia mportância dos novos requisitos para a licença e sistemas de controle. Embora o governo português acredite estar fazendo a coisa certa, corre o risco de gerar conflitos de confiança, que podem criar barreiras para a negociação leal e efetivação da colaboração no seu sentido mais amplo, de engajamento a favor de um objetivo comum (ANSELL; GASH, 2008). Nesse contexto, alguns atores mostram-se um pouco desmotivados nas negociações, pois não se sentem sempre ouvidos.

Isto difere do caso suíço e brasileiro. No primeiro caso, a liderança se dá de forma muito mais compartilhada entre os atores, diminuindo a possibilidade de conflitos. Já no segundo caso, é interessante notar que, embora o governo brasileiro tenha um papel formal na liderança do AS, ele não exerce este poder de forma a conduzir os atores para a construção final do acordo. Ansell e Gash (2008) alertam para o risco de hierarquização pelo poder nas relações de 
colaboração, pois podem gerar manipulação do processo pela parte mais forte. Assim, a Suíça é a única que consegue os melhores resultados da atuação conjunta dos atores dentro processo de elaboração de leis porque o consenso é construído efetivamente (HORD, 1981; BALANCIERI, 2004; POLENSKE, 2004; KEMCZINSKI et al., 2008; WINCKLER; MOLINARI, 2011; ANSELL; GASH, 2008).

No processo de cooperação, por outro lado, as atividades são realizadas em etapas (BRNA, 1998), cada qual executando a sua parte dentro da própria organização ou com a criação de uma entidade externa para executar o processo (POLENSKE, 2004; KEMCZINSKI et al., 2008; WINCKLER; MOLINARI, 2011), garantindo sua independência nas relações (KEMCZINSKI et al.,2008).

Nos quatro países analisados, as atividades da LR de REEE eram divididas em etapas (BRNA, 1998) executadas separadamente, com divisão clara de papéis (POLENSKE, 2004; KEMCZINSKI et al., 2008; WINCKLER; MOLINARI, 2011). Além disso, foram criadas OGs para realizar a gestão da LR e assumir a responsabilidade dos produtores de EEE nos três países europeus. Entretanto, como dito antes, as OGs na Espanha e em Portugal são concorrentes e cada ator da indústria de EEE pode escolher uma ou mais dentre elas para atender a suas cotas anuais de coleta, valorização e reciclagem de REEE. O sistema de coleta é composto pelos municípios que disponibilizam seus canais para a coleta do REEE, por parceiros, como escolas e empresas que participam de campanhas de conscientização, pelos canais de distribuição das lojas que coletam no sistema 1x1 no momento da entrega do EEE de grande porte, e pelas lojas de EEE com mais de $400 \mathrm{~m}^{2}$ que devem disponibilizar espaço para receber os coletores para REEE de pequeno porte. Além disso, ambos os países contam com a participação de grandes recicladores que ajudam a complementar as cotas de coletas, pois os sistemas municipais e do varejo somam uma parte muito pequena do total que se precisa coletar. Na Espanha, os grandes recicladores contribuem com cerca de $2 / 3$ de tudo que é coletado.

A Suíça, entretanto, apresenta uma série de particularidades em relação ao sistema de LR de REEE dos outros dois países europeus. As OGs atuam de forma complementar, assim, os postos de coleta de REEE, a logística e a auditoria dos recicladores contratados são compartilhados. Da mesma forma, a Suíça não tem meta mínima para a LR de REEE. Nesse caso, o importante é coletar tudo o que foi descartado pelo consumidor, maximizando a reciclagem. Além disso, quanto mais os recicladores contratados reciclam, mais eles ganham. Nesse contexto, para proteger o mercado e garantir a qualidade da LR, somente recicladores contratados e auditados podem participar do sistema de reciclagem. A coleta de REEE é realizada pelos canais de coleta seletiva das municipalidades, pelas lojas e instituições parceiras, 
como escolas, empresas e hospitais e na própria sede dos recicladores contratados. Vale destacar que só as municipalidades são responsáveis por mais de 50\% da coleta dos REEE. No caso das lojas, independentemente do seu tamanho, todas são obrigadas a receber REEE do mesmo tipo dos EEE que vendem. Outro diferencial do país é que, apesar de existirem parcerias com escolas, as crianças não participam de gincanas que visam aumentar a quantidade de resíduos coletados.

O caso brasileiro se diferencia dos outros principalmente porque a LR de EEE foi realizada no contexto de um PP e não foi criada uma OG, pois a JICA assumiu esse papel. É interessante notar que, diferentemente da PNRS, que atribui a responsabilidade compartilhada pelo ciclo de vida do produto, sem definir papéis, o PP já foi iniciado com todas as atividades distribuídas para cada ator, conforme definido em contrato. Nesse sentido, o PP resolveu um dos principais entraves brasileiros para efetivar a cooperação na LR de REEE, que é definir papéis claros para cada ator, tão importante para efetivar a cooperação (POLENSKE, 2004; KEMCZINSKI et al., 2008; WINCKLER; MOLINARI, 2011). Nesse sentido, o GFB atuou na elaboração do PP, junto à JICA, o GESP ficou responsável pelo licenciamento dos operadores da LR e normatizou sobre a definição da periculosidade dos REEE no Estado de SP, para facilitar as etapas de coleta e transporte até o pré-processamento. O GM apoiou a JICA em todas as questões e cedeu espaço de trabalho para sua equipe. A indústria de EEE, por meio de suas associações, forneceu dados para levantamento estatístico da JICA e atuou na inspeção dos recicladores. A Coopermiti fez o transporte dos REEE dos pontos de coleta das lojas e casas dos consumidores e atuou como CC. A Oxil coletou os resíduos na CC e deu a destinação ambientalmente correta. Com a entrada da ABREE, como operador do PP, todas a coletas em casa proveniente das lojas do GPA foram realizadas por ela. O consumidor tinha o papel de descartar nas lojas sem nenhum custo ou comprar o voucher para retirada do REEE de grande porte em sua residência. Apesar dos papéis bem definido, entretanto, os atores não tiveram autonomia total no desenvolvimento de suas atividades, pois a JICA controlava tudo, contradizendo a literatura sobre a importância de cada organização manter independência e controle centrado nela (HORD, 1981; POLENSKE, 2004; KEMCZINSKI et al., 2008). De fato, caso um determinado ator quisesse fazer a divulgação do PP em seu site ou por e-mail, atividade que estava no escopo todos membros, precisava da aprovação anterior do texto pela JICA para publicá-lo.

Dentre os quatro países estudados, só o Brasil apresenta não conformidade com a literatura como pode ser observado no apêndice G. Nesse caso, a divergência da literatura está associada ao excesso de controle exercido pela JICA. Esse comportamento pode afetar os 
resultados da cooperação, pois tira a soberania das empresas sobre o seu processo (HORD, 1981; POLENSKE, 2004) e limita a reciprocidade e engajamento na execução das atividades (POLENSKE, 2004; KEMCZINSKI et al., 2008; WINCKLER; MOLINARI, 2011).

\subsubsection{Recursos}

No caso da colaboração, as competências precisam ser assimétricas e os atores compartilham seus recursos humanos (HORD, 1981; KEMCZINSKI et al., 2008; ANSELL; GASH, 2008), físicos e financeiros (HORD, 1981). Dessa forma, todos os atores nos três países europeus demonstravam conhecimentos e habilidades complementares, capazes de enriquecer as discussões sobre as leis e normas, conforme discutido na revisão da literatura. Muitas vezes esses atores traziam documentos, relatórios ou testemunhos sobre o tema que estava sendo decidido, para contribuir com a discussão (HORD, 1981; KEMCZINSKI et al., 2008; ANSELL; GASH, 2008). Entretanto, no Brasil, os atores não tiveram atitudes colaborativas, pois, apesar de compartilharem o conhecimento, atuavam para atender a seus objetivos individuais. Interessante ressaltar que as pessoas indicadas pelas diferentes organizações para participar das reuniões não tinham autonomia para decidir modificações no AS, limitando os encontros à leitura do que havia sido decidido pelas instituições que elas representavam referente às reuniões anteriores. Quando possível, os representantes das organizações envolvidas acrescentavam a decisão à proposta do AS ou levavam um novo questionamento para suas sedes, sem decidir nada de novo na reunião.

Com relação aos recursos financeiros, diferentemente do que descreve Hord (1981), em nenhum dos casos verificou-se o compartilhamento de custos ou financiamento da ação por meio de empréstimo coletivo. No Brasil, em Portugal e na Suíça, percebe-se que a colaboração se beneficiou do compartilhamento do conhecimento entre os atores e das reflexões sobre os fatores que afetam a eficiência da LR de REEE. Na Suíça e em Portugal, a construção de conhecimento coletivo viabilizou a definição de normas e leis mais harmoniosas e consensuais (ANSELL; GASH, 2008). No Brasil, houve um amadurecimento dos atores sobre o tema, indicando novas perspectivas para aquilo que, a princípio, só parecia gerar mais custos operacionais para o setor privado, além de ter impulsionado a decisão do governo de realizar um PP para entender melhor a realidade do país.

$\mathrm{Na}$ cooperação, as competências também precisam ser assimétricas, mas os atores não compartilham os recursos físicos ou financeiros: cada um usa o seu ou se cria uma entidade que 
irá operar por eles e um fundo para sustentar a operação (HORD, 1981; KEMCZINSKI et al., 2008; POLENSKE, 2004; SILVA, 2007),

Os sistemas de LR de REEE na Espanha, Portugal e Suíça são custeados pela TAR, cobrada do consumidor no momento da compra do EEE, mas não vem destacada na nota, pois está embutida no produto. Esse valor é repassado para as OGs quando o produtor ou importador do EEE declara a quantidade de produtos que colocou no mercado.

Portugal e Espanha só repassam para as OGs o valor referente às cotas de coleta e reciclagem de que precisam para cumprir a lei. Na Suíça, como não há meta, o valor pago às ORP pela indústria é sobre $100 \%$ dos produtos colocados no mercado no trimestre anterior. Nesse caso, o objetivo das ORP é coletar o máximo de REEE possível, portanto, não está limitada a um percentual mínimo. Dessa forma, as OG pagam os serviços de coleta prestados pelos municípios e parceiros.

Em Portugal, as EG pagam os varejistas que coletam grandes volumes de EEE, assim como existe uma contrapartida especial para os bombeiros por esses serviços prestados. $\mathrm{Na}$ Suíça, todos os varejistas são obrigados a receber REEE do mesmo tipo que vendem em seus estabelecimentos, sem receber nada por isso. A SENS, contudo, decidiu premiar os estabelecimentos que coletam REEE de grande porte, da mesma forma que paga a um operador que executa a mesma função.

Na Espanha, alguns SIG certificam profissionais de instalação de EEE e pagam pelo transporte e armazenamento dos REEE. Além disso, devido à baixa performance dos fluxos de coletas municipais e do varejo, Espanha e Portugal dependem de recicladores que não atuam no sistema para completar suas cotas. Nesses casos, as OG dão uma contrapartida financeira para cobrir os custos de coleta e reciclagem dessas empresas. Em contrapartida, os recicladores emitem um relatório em favor da $\mathrm{OG}$, especificando quanto e como foi tratado cada tipo de REEE, para que elas possam lançar a informação em seus sistemas.

Apesar de toda a LR de REEE ser financiada pela TAR, as iniciativas de conscientização do governo são suportadas por eles sem nenhuma contrapartida das OG nos três países europeus. No caso da Espanha, quando algum município não consegue arcar com os custos da coleta dos REEE, a Generalitat daquela CCAA arca com esse valor. O sistema de repasse para os recicladores contratados na Suíça está atrelado a um índice que flutua de forma inversamente proporcional à cotação dos metais contidos nos REEE. Essa variação visa garantir o equilíbrio do sistema e a rentabilidade dos recicladores.

No caso brasileiro, todo o PP foi financiado pela JICA, conforme estabelecido no contrato firmado pelo entre os governos do Brasil e do Japão. Apenas algumas despesas, como 
translado, recursos humanos ou infraestrutura cedida para reuniões, foram custeadas pelos outros atores envolvidos no projeto. Já o consumidor que quisesse descartar uma geladeira, ou outro EEE de grande porte, precisava comprar o voucher de coleta, mas não pagava nada para descartar os pequenos EEE nos pontos de coleta das lojas parceiras. Apesar da peculiaridade do PP ser financiada por uma entidade, a JICA atuou como uma EG e o recurso financeiro funcionou como os fundos criados pelas OG. Desse modo, percebe-se que todos os casos estão de acordo com a revisão da literatura, usando recursos próprios e criando um fundo para custear as operações (HORD, 1981; KEMCZINSKI et al., 2008; POLENSKE, 2004; SILVA, 2007).

\subsubsection{Comunicação}

Em processos colaborativos, a comunicação precisa ocorrer de maneira intensa, presencial e com uso de tecnologias síncronas, como chat e videoconferências, por se tratar de um processo mental, que busca resolver algum problema. Dessa forma, será possível melhorar a eficiência dos resultados (HORD, 1981; KEMCZINSKI et al., 2008).

Diferentemente da literatura, Suíça e Portugal praticamente não relatam informações sobre seus canais de comunicação em suas respostas sobre efetivação das leis e normas de forma colaborativa. Ambos os países focam no fato de que buscam a colaboração dos membros para obterem consenso na proposição de leis e normas, independentemente da forma como se comunicam. Nesse sentido, os atores suíços enfatizam que colaboram para atender às necessidades da população e do mercado, sempre respeitando o modelo de economia verde apresentado pelo governo como estratégia econômica de longo prazo na Rio+20. Nesse cenário, o mais importante não é a quantidade de reuniões são necessárias, nem se a comunicação é presencial, online ou síncrona, mas sim a obtenção do consenso e o respeito as necessidades da população, independentemente do esforço que isso exija. A Suíça reconhece que o objetivo maior do governo é legislar em prol do país, que possui cidadãos com alto nível de conscientização e preocupação com os recursos ambientais escassos.

Portugal segue na mesma linha por busca de consenso, sem se preocupar com a quantidade de encontros necessários para isso. Mas os diferentes atores enfatizam a importância das reuniões com para buscar soluções e sensibilizar todos sobre a importância de aspectos conflituosos, corroborando Ansell e Gash (2008) no que tange à importância de sensibilizar e conseguir consenso na criação de lei e normas harmoniosas. Além disso, para esses autores, a forma como a comunicação se dá não é um elemento essencial para a governança colaborativa, pois é o histórico positivo de colaboração e os níveis de confiança entre os atores que 
determinarão a estrutura necessária para a efetivação da colaboração e aferição dos seus resultados.

Já o Brasil apresenta divergências com a literatura, como o uso frequente de e-mails e os encontros esporádicos. Nenhum dos atores envolvidos na discussão do AS parece entender a definição de consenso, já que buscam por objetivos individuais. Nesse cenário, com dois lados distintos, as discussões do AS seguem de forma paralela, nos diversos subgrupos, cada qual com seu mecanismo de comunicação. De um lado, há o setor público, com governo e seus ministérios e, do outro, o setor privado, formado pela indústria e varejo, como se fossem grupos rivais.

No grupo composto por todos os atores que devem discutir o AS, GF, Ministérios e setor privado, a discussão acontece de forma presencial, mas esporádica, com troca de e-mails ao longo do ano. Já o grupo de setor público, que deveria resolver os entraves legislativos, segue os ritos burocrático da legislação, com troca de petições e arguições, usando mecanismos indiretos e assíncronos. Esses são elementos totalmente opostos ao esperado em comunicações de processos colaborativos (HORD, 1981; KEMCZINSKI et al., 2008). Entre os atores do setor privado, contudo, as reuniões são mais frequentes e presenciais e as pendências que ficam dos encontros são esgotadas com a troca de e-mails. Nesse caso, os dois atores principais do setor privado se unem para buscar consenso entre si e defender seu ponto de vista diante do governo.

No entanto, nem sempre esses atores revelam todas as suas intenções no processo de comunicação, com medo de expor seus reais interesses e, com isso, ser combatido pelo outro. Esse comportamento reforça o que Ansell e Gash (2008) discutem sobre a importância de construir a confiança com mecanismos mais transparentes e de controle, em ambientes onde ela não ocorre por si só. Já, em um processo colaborativo, como é a discussão do AS, essas lacunas de tempos e comunicação realizada de forma indireta é prejudicial ao resultado (HORD, 1981; KEMCZINSKI et al.,2008). Além disso, os atores brasileiros reconhecem que comunicação presencial é crucial em processos de decisão, ainda que dificilmente decidam algo novo nas reuniões. Nesse processo, outro ponto que diverge da literatura é o fato de não haver uma comunicação franca e aberta entre todos (KEMCZINSKI et al., 2008).

De fato, a comunicação em processos cooperativos precisa atender as exigências de estruturas bem definidas, com processos transparentes, baseados em sistemas que permitam o registro e o controle dos dados. Não precisam ser frequentes, nem presenciais, mas devem respeitar uma periodicidade (HORD, 1981; KEMCZINSKI et al., 2008).

Os papeis bem definidos nos três países europeus ajudaram a criar uma estrutura de comunicação mais organizada, baseada em SI assíncronos e sem necessidade de reuniões 
presenciais. Esses elementos são apontados como essenciais para a efetivação da cooperação (HORD, 1981; KEMCZINSKI et al., 2008). Nesse contexto, vale destacar pequenas diferenças nos sistemas desses países. A Suíça concentra a comunicação nos SI das ORPs, que dão publicidade a todos os dados por meio de relatórios em seus sites, garantindo a transparência da gestão dos REEE. Dessa forma, a indústria comunica às ORPs a quantidade de EEE que colocou no mercado nos últimos três meses e paga o valor correspondente à sua reciclagem. Os recicladores contratados informam sobre os REEE coletados por tipo, os produtos gerados da sua reciclagem e seu destino. Esses dados são usados pelo governo para fazer as auditorias. Esses relatórios não visam apenas dar transparência para o valor cobrado pela TAR, mas mostrar que o processo é benéfico ambientalmente.

Já em Portugal, a comunicação é centrada no governo, por meio de SI também. O produtor precisa declarar para o governo todo os EEE que colocou no mercado, no mesmo sistema no qual se cadastra para obter o número do registro PT, que garante que está credenciado a alguma EG ou tem seu próprio sistema de coleta. Esse código permite que ele comercialize seus produtos e deve ir registrado na fatura de venda ao distribuidor. As EGs apresentam à APA um relatório anual com o valor arrecadado de seus associados, os dados de coleta, quantidade de materiais tóxicos apurada nesses resíduos, sua destinação e os custos com a LR. Precisam comprovar em seus relatórios que cumpriram de forma adequada as metas de investimento em educação ambiental e P\&D. Nesse cenário, o governo objetiva dar transparência para os resultados financeiros e os investimentos para melhoria da LR de REEE. As EG também garantem a transparência de seus processos para seus fornecedores e associados por meio de relatórios e SI. Para isso, a indústria declara trimestralmente os valores e a quantidade de EEE colocados no mercado e paga o valor referente a sua cota de reciclagem. Os recicladores contratados, por sua vez, declaram diariamente dados sobre os REEE coletados. Para cumprir as metas de investimento em educação ambiental e comunicação, as EG investem em campanhas de divulgação em escolas, com palestras, gincanas para descarte de REEE e quiz. Entretanto, apesar de alguns atores gostarem da proposta de conscientizar os pais por meio das crianças, eles acham que falta esforço e investimento por parte das organizações, pois o mecanismo não está sendo efetivo. Há alguns anos atrás, investiram em mídia massiva, mas, apesar dos resultados positivos, esse recurso não tem sido usado. Um dos possíveis motivos é que eles consideram todo investimento em comunicação como um gasto. Nesse contexto, o único elemento que diverge da literatura é a forma de comunicação eleita pelas EG como elemento principal para efetivar a cooperação dos consumidores: as palestras e campanhas em escola, que precisam de encontros presenciais (KEMCZINSKI et al., 2008). 
Apesar da comunicação na Espanha ser toda feita por SI, os sistemas não são integrados e cada um acompanha um fluxo da cadeia reversa ou parte dele. O Sistema OfiRAEE é uma plataforma estatal que cuida dos fluxos municipais de coleta de REEE para as CCAA. Já o governo federal tem sistema online, no qual o produtor se registra e registra o produto que colocou no mercado trimestralmente, o RII-AEE. Assim como em Portugal, o cadastro nesse SI garante que o produtor aderiu a algum SIG. Por meio dele, o governo emite anualmente um comunicado com as cotas de coleta de cada SIG e produtor. Ainda não há um sistema no qual os SIG ou empresas declarem os REEE coletados e tratados, para que seja público. Já os SIG emitem relatórios para o governo e para os produtores sobre os REEE coletados e os custos, mas esses dados não são públicos e só são acessados por meio de área restrita no portal. Para se comunicar com o consumidor, os SIG usam estratégias diferentes, como os selos na frente das lojas que recebem REEE e o desenvolvimento de Apps e sistemas online, que visam facilitar a busca do consumidor por pontos de descarte. Esses sistemas, no entanto, incluem apenas os pontos municipais e dos seus próprios parceiros. Percebe-se que a Espanha usa os recursos de comunicação conforme descritos pela literatura, de forma assíncrona ou por sistemas offline, como os selos de certificação. Mas a falta de integração dos SI e da publicidade dos dados prejudicam a ampla transparência para a população (KEMCZINSKI et al., 2008).

O Brasil é o país que mais apresenta não conformidades com a literatura, com reuniões mensais periódicas e visitas pessoais para levantar dados em fornecedores. Nesse cenário, todas as informações estavam centradas na JICA e no SI fornecido por ela, garantindo que tudo passasse por ela, antes de ser divulgado ou executado. Para transmitir informações e resultados sobre o PP, a JICA realizava reuniões, que depois eram documentadas em atas e transmitidas aos membros do projeto. Além das reuniões presenciais, a JICA lançou mão de outro procedimento não previsto em processos cooperativos, pois visita com frequência os fornecedores ou parceiros, que não eram obrigados a emitir relatórios por contrato, para checar se tudo estava sendo realizado como previsto. Após a visita, relatavam as informações coletas para todos. Já a comunicação com o consumidor não foi tão intensa, nem suficiente para sensibilizá-lo durante quase todo o período de coleta. Nesse contexto, apenas quando os varejistas investiram em campanhas em canais de comunicação de massa para incentivar o descarte dos REEE na época da Black Friday e do Natal, é que houve aderência aos pontos de coleta nas lojas e um aumento significativo no programa Coleta em Casa. Isso ocorreu, contudo, quase no final do PP, alterando pouco os resultados finais da coleta.

Um dos resultados que surgiu no Brasil, na Espanha e em Portugal, e que não tinha sido encontrado na literatura sobre colaboração e cooperação, é a relevância da comunicação em 
massa para sensibilizar o consumidor sobre a importância da reciclagem e garantir a sua cooperação no sistema de LR de REEE. Na literatura sobre LR de REEE, Demajorovic et al. (2012) chamam a atenção para a importância da comunicação clara e de fácil acesso nos canais de informação das empresas de EEE, com o objetivo de viabilizar a participação do consumidor na LR de REEE. Entre os países estudados, a Suíça foi a única que não apresentou nenhuma não conformidade com a literatura sobre a estrutura de comunicação na cooperação, nem revelou a necessidade de campanhas massivas para conscientização da população sobre o descarte de REEE.

\subsubsection{Poder}

Na colaboração, o poder é mútuo (HORD, 1981; BALANCIERI, 2004; ANSELL; GASH, 2008) ou hierarquizado a partir da parte mais forte da relação (WINCKLER; MOLINARI, 2011). Entretanto, Ansell e Gash (2008) alertam para os impactos oriundos das diferenças de poder nas relações colaborativas, pois pode afetar a confiança entre os diferentes atores. Dessa forma, percebe-se que, na Suíça, o poder é exercido de forma mútua, pois todos decidem conjuntamente em busca de consenso (HORD; 1981; BALANCIERI, 2004; ANSELL; GASH, 2008). Já no Brasil e em Portugal, o poder é hierarquizado, devido à diferença de forca entre o governo federal e os outros atores (POLENSKE, 2004; KEMCZINSKI et al., 2008; WINCKLER; MOLINARI, 2011), mas não apresentam discrepâncias fortes. Apenas se tem claro que os governos têm o poder de decisão, caso queiram exercê-lo. No Brasil, contudo, o GB não usou seu poder nem para liderar o GT e dar maior celeridade à discussão do AS.

A estrutura de poder na operacionalização da LR de REEE nos países europeus se apresenta basicamente da mesma forma, centrada na organização que executa a atividade, garantindo sua soberania delas (HORD, 1981; POLENSKE, 2004). Um dos fatores que contribui para isso é a definição clara de papéis de cada ator (POLENSKE, 2004). Já no Brasil, todo o poder e liderança do processo estavam centrados na JICA, embora o GFB tivesse o direito de exercê-lo garantido por contrato. Mesmo que a JICA compartilhasse com todos os atores os processos de decisão e demonstrasse interesse em suas opiniões, era evidente para a maioria que a decisão final seria dela. Para alguns atores, esta situação fazia parte do acordo e não era vista como um problema. Entretanto, outros membros se sentiam incomodados com a supervisão e interferência em seus processos, pois, segundo Hord (1981) e Polenske (2004), as definições de como executar a tarefa já haviam sido definidas previamente e o ator que lidera o processo deve respeitar a individualidade do outro. 


\subsubsection{Mecanismos de Controle}

Devido à estrutura flexível dos processos colaborativos é importante que não haja muitos mecanismos de controle e que a colaboração seja construída a partir de contratos informais (BRNA, 1998) para facilitar a interação entre os pares, bem como a flexibilidade e a criatividade no processo de criação e solução de problemas complexos, facilitando até mesmo a aprovação de leis inovadoras (HARGROVE, 1998).

Nesse cenário, nos três países europeus, onde foi estudada a colaboração, percebe-se que o processo de elaboração das leis e normas está de acordo com a literatura (BRNA, 1998), pois não foi regido por contratos formais ou sistemas de informação específicos para gerir esse processo. As relações eram baseadas apenas nas expectativas de atingir determinados objetivos, sem a criação de mecanismos de controle (HORD, 1981; BRNA, 1998).

Entretanto, no cenário brasileiro, a confiança requerida para evitar a exigência de mecanismos de controle não se efetivou, mesmo após o largo tempo de discussão dedicado ao AS. Alguns atores dizem que, com o tempo, até foi possível saber em quem confiar e quem eram as pessoas mais dispostas a ajudar. Mas isso não se refletiu em seu comportamento. Segundo Das e Teng (1998), nesses casos é necessário que se construa a confiança por meio de mecanismos de controle, gradativamente, para não prejudicar a estrutura da parceria. Uma das formas de fazer isso é definir metas claras, criando menos expectativas entre os membros e garantindo os efeitos positivos da colaboração. Assim, a falta de prazos, metas e sansões para a definição do AS não favoreceram a celeridade do processo no país. Embora Ansell e Gash (2008) alertem para a necessidade de muito tempo para estabelecer parcerias colaborativas, o Brasil já discute o AS a mais de 5 anos, com poucos avanços, mostrando que, neste caso, problema não é tempo, mas talvez a ausência mecanismos de controle e liderança.

Devido às características da cooperação, a estrutura referente aos mecanismos de controle é essencial para aferição dos benefícios da relação, pois ela que garante a formalização dos papéis, obrigações, direitos e critérios de controle e qualidade para todos os atores envolvidos (HORD, 1981; POLENSKE, 2004; KEMCZINSKI et al., 2008; DAS; TENG, 1998). Dessa forma, todos os países criaram mecanismos de controle bem estruturados, baseados em SI, em contratos e auditorias.

É interessante notar, contudo, que apesar da Suíça não ter metas referentes à quantidade de REEE coletados, todos os operadores têm contratos com cláusulas rígidas de qualidade e auditorias, embasadas nos resultados dos testes de amostra, capazes de prever a quantidade de 
todos os tipos de substâncias que compõem cada tipo de REEE. A preocupação com o meio ambiente e com a recuperação de materiais dos REEE faz com que todo o sistema suíço vise potencializar ao máximo os resultados da LR, voltando toda a sua atenção para os critérios de qualidade desse processo.

Portugal se destaca pelo desenvolvimento de um SI para controlar toda cadeia reversa dos REEE. Hoje, os SIs do governo português permitem saber quem são os fabricantes e importadores, a que EG eles estão afiliados, quantos EEE colocaram no mercado, quanto eles pagam de TAR, quais deles foram para cada distribuidor, quantos REEE foram coletados, quanto foi recuperados de matéria prima, qual foi a quantidade de resíduos contaminados tratados e qual sua destinação final, quem se responsabilizou por cada etapa do processo e todo os custos envolvidos na cadeia reversa. Da mesma forma, o governo sabe como e quanto foi gasto com educação e $\mathrm{P} \& \mathrm{D}$, tudo de forma integrada. O próximo passo é saber quando e para quem o EEE foi vendido no varejo.

Apesar da Espanha não ter os SIs integrados e não ter concluído a fase de teste da plataforma que vai controlar a quantidade de REEE coletados, ela possui sistemas capazes de automatizar toda a coleta dos municípios, inclusive com a emissão de boleto para o SIG fazer o pagamento da coleta ao município. Além disso, o país tem sistemas de cadastro dos produtores e de seus produtos, auditorias e credenciamento dos SIG e já começa a auditar os CPR para a nova fase da lei. Todas as relações são regidas por contratos e os recicladores fornecedores são auditados pelo Código LER que possuem. A Espanha cumpre, portanto, toda a exigência de mecanismos de controle para atuar de forma cooperativa. No entanto, o mesmo não se pode dizer a respeito do processo de transparência. Diferente da Suíça e de Portugal onde os dados do sistema de coleta são públicos e facilmente acessados nas bases digitais de governos e OG, na Espanha esta informação não é disponibilizada para o público em geral. Com a implementação do SI que está em fase de teste, contudo, essa necessidade deve ser atendida da forma como defendem Ansell e Gash (2008) sobre a importância da transparência nos processos de governança colaborativa.

No Brasil, por sua vez, o processo de controle formal atende rigorosamente ao debate na literatura. De fato, todos os processos e relações no PP são controlados por contratos. Todos os operadores precisam emitir relatórios detalhados e serem inspecionados e auditados com o objetivo de manter a qualidade e a padronização da operação. Assim, construiu-se uma estrutura forte de controle, garantindo que tudo fosse centralizado na JICA. 
Os resultados apresentados mostram que todos os países estudados criaram estruturas de controle adequadas para a necessidade desse tipo de operação. No entanto, vale destacar que, no caso brasileiro, o acesso às informações sistematizadas está restrito aos envolvidos no PP.

\subsubsection{Riscos}

Somente os atores brasileiros relataram riscos no processo de colaboração e cooperação, sendo que os riscos elencados na elaboração do AS são inerentes aos processos colaborativos, devido à proximidade das relações (HORD, 1981; POLENSKE, 2004). Nesse sentido, todos têm medo de passar mais dados do que o necessário, principalmente com medo de se sentirem reféns da própria fala. Alguns temem redigir o AS com falhas, sem pensar em todos os detalhes ou possibilidades, deixando brechas que possam prejudicá-los no futuro, atribuindo mais custos ou responsabilidades do que gostariam de assumir, por exemplo. De toda forma, todos os riscos relatados ameaçam a busca pelos objetivos individuais, que giram em torno de diminuir custos e responsabilidades.

No caso da cooperação, os atores brasileiros acreditam que os riscos foram minimizados pela estrutura criada pela JICA, tanto pela divisão de papéis (POLENSKE, 2004), quando pelo suporte financeiro oferecido por ela. Quando se considera quem pode ser mais afetado pelo risco, conforme Hord (1981), percebe-se que ele pode atingir mais diretamente a parte responsável pelo processo. Assim. os lojistas e operadores de LR estavam mais vulneráveis do que os setores da indústria e do governo, pois esses não participaram diretamente da operação da LR. Esses dados demonstram a importância de uma estrutura bem definida para efetivar a cooperação.

\subsection{IMPACTOS DA COLABORAÇÃO E DA COOPERAÇÃO}

A colaboração facilita a elaboração de soluções para questões complexas, como a criação de leis inovadoras (HARGROVE, 1998), promovendo o engajamento dos stakeholders na busca de consenso e melhores resultado para todos, reduzindo o investimento com a formulação de políticas contraditórias e normas inovadoras (ANSELL; GASH, 2008). Os resultados das ações colaborativas são potencializados pelo uso do conhecimento multidisciplinar dos integrantes do grupo, promovendo aprendizado coletivo e acelerado (HARGROVE, 1998; ANSELL; GASH, 2008). 


\subsubsection{Impactos, benefícios e desafios da colaboração}

Os países europeus têm aferido diversos benefícios com a colaboração entre os atores. A Suíça foi capaz de aprovar a ORDEE, de criar mecanismos de controle e qualidade rigorosos e de se tornar referência mundial na LR de REEE, atendendo às demandas da população e das empresas que já realizavam a LR, graças à parceria entre os atores da indústria de EEE e o governo, tudo de forma consensual. Nesse caso, o governo suíço contou com o conhecimento da indústria de EEE para embasar os termos da lei e o aprimoramento dos padrões de reciclagem de REEE. O comportamento proativo dos atores da LR e a predisposição do governo suíço para legislar em prol da população têm criado um arcabouço de conhecimento e legislativo capaz de atender às complexas demandas da LR. Todos esses esforços transformaram o país em referência mundial em LR de REEE e têm servido de inspiração para as diretivas da UE. A norma suíça EN 50625-1: 2014, por exemplo, que define os critérios de qualidade de reciclagem dos REEE, será usada para balizar as novas mudanças na Diretiva de REEE. De acordo com Ansell e Gash (2008), a colaboração acelera o processo de conhecimento coletivo, trazendo benefícios para todos os envolvidos e facilitando o processo de criação e inovação.

Em Portugal, o governo tem buscado a participação colaborativa dos atores na elaboração dos Decretos-Lei sobre REEE, das propostas de licença das EGs e OGRs e dos sistemas de controle da LR. Por meio de mecanismos participativos, o governo tem aprendido sobre as necessidades de cada ator e mostrado a eles a importância dos requisitos legais. Dessa forma, foi possível aprovar leis e mecanismos de controle de forma consensual, mesmo nas questões mais complexas. Um exemplo disso é a melhoria do SI de registro dos REEE, que automatizou diversos processos e que, no início, foi muito combatido pelos atores que o usariam. Hargrove (1998) explica que a colaboração permite ampliar as perspectivas dos atores sobre um determinado problema e sensibilizá-los sobre a importância de medidas muitas vezes controversas, facilitando seu entendimento e aceitação.

O histórico positivo de colaboração incentivou o governo português a buscar mais parcerias para a discussão de sistemas de controle e de leis que possam melhorar os resultados da LR de REEE. Dessa forma, quer que o varejo participe do sistema de controle de LR de REEE, fazendo com que as lojas registrem os EEE vendidos para poder balizar as metas da LR nos EEE vendidos de fato. Atualmente, esses valores são calculados pela quantidade de EEE fabricados, o que pode causar discrepâncias entre a projeção de descarte e os EEE que foram consumidos. 
Além disso, o governo português tem procurado as EGs a fim de elaborarem uma lei que estabeleça uma Câmera de compensação de REEE entre elas, criando um arcabouço legislativo para facilitar a cooperação na operação da LR.

Os resultados positivos de ambos os países reforçam as colocações de Ansell e Gash (2008) sobre a importância da colaboração na construção de políticas públicas coerentes e em prol do interesse de todos. Mostram também que esses governos estão preocupados com a criação de leis que facilitem a cooperação entre as empresas que vão operar conjuntamente a LR de REEE, pois, segundo Verschoore e Balestrin (2008), a falta de estrutura legislativa que suporte esse tipo de parceria pode dificultar a sua efetivação.

No Brasil, apesar do governo ter escolhido um mecanismo colaborativo para discutir o modelo de LR de REEE, não foi possível efetivar a colaboração até o momento. De fato, depois de mais de 5 anos de discussão para implementar a LR de REEE, não se chegou a um consenso sobre os termos do AS. Mesmo assim, a atuação conjunta no AS permitiu que os atores recebessem benefícios oriundos do processo colaborativo. Assim, os atores passaram a entender melhor a necessidade de cada um, ampliando sua perspectiva sobre o potencial do outro (HARGROVE, 1998), a identificar as respectivas competências dos atores, para saber em que cada um poderia ajudar mais (HORD, 1881; POLENSKE, 2004) e a adquirir novos conhecimentos sobre o processo de LR e o mercado de REEE, resultado da aprendizagem coletiva (ANSELL; GASH, 2008). Nesse sentido, a indústria percebeu que pode criar suas EGs, pois, além de atender à PNRS, a LR pode trazer lucro, resultado característico desse processo. Com efeito, segundo Hargrove (1998), a colaboração ajuda na criação de novos produtos e serviços como resposta a questões complexas, como é o caso da operação da LR de REEE.

Outro benefício do aprendizado coletivo no caso brasileiro foi o entendimento sobre as barreiras para a efetivação da LR. O governo estadual de São Paulo, por exemplo, entendeu a importância de legislar sobre a periculosidade do REEE para que a LR seja mais facilmente exequível e, para isso, estabeleceu uma norma a fim de facilitar o descarte e transporte dos REEE e inspirou o governo federal a fazer o mesmo em nível nacional.

O governo federal brasileiro, por sua vez, estabeleceu o decreto que determina que todos os atores do setor de EEE deverão aderir ao sistema de LR definido pelo AS, ainda que não tenham participado das discussões ou assinado o AS, um dos pleitos importantes da indústria.

Ainda que a maioria das barreiras para a efetivação da LR de REEE não tenha sido vencida, a participação em um processo colaborativo fez com que os membros do grupo contribuíssem com seus conhecimentos e habilidades distintas para avançar em diversas pendências (HARGROVE, 1998). 
Apesar dos benefícios apresentados nos casos da Suíça e de Portugal e dos avanços obtidos no Brasil, alguns desafios ficam evidentes para a efetivação da colaboração e aferição dos seus impactos positivos. No caso de Portugal, o poder exercido pelo governo nas negociações das políticas pode gerar conflitos de confiança no grupo, que pode não se sentir ouvido no processo e perder a motivação para colaborar. Já no Brasil, a quantidade de desafios encontrados é muito maior. Na contramão de Portugal, o governo brasileiro não exerce a liderança inerente ao seu papel no AS, sendo incapaz de estimular a busca pela resolução dos problemas e a sinergia entre os membros (HORD, 1981). Esse comportamento reflete-se na inércia dos atores do governo federal para resolver os entraves legislativos que podem viabilizar a operação da LR e criar incentivos fisscais. Além disso, alguns pleitos, como a revisão da meta de $17 \%$ de coleta de REEE e a quantidade de postos de coleta que devem ser implementados para operacionalizar a LR, parecem ser fatores inegociáveis. Essa morosidade do governo em atender às demandas dos atores do AS e sua ausência de flexibilidade na negociação prejudicam o engajamento do grupo, pois esse não se sente atendido em nenhum de seus pleitos (ANSELL; GASH, 2008). Nesse contexto, os atores do setor privado não reconhecem como legal a sua obrigação de implementar a LR de REEE por meio da responsabilidade compartilhada. Dessa forma, eles potencializam o maior desafio enfrentado para efetivar a colaboração no cenário brasileiro, a falta de senso de urgência para operacionalizar a LR de REEE no país.

A escolha correta da estrutura que adotada em processos de colaboração ou cooperação é muito importante para seu sucesso (BRNA, 1998). Dessa forma, uma análise feita a partir dos atributos de motivação, escopo e estrutura na colaboração desses três países mostrou que o Brasil é o país que mais tem não conformidades com a literatura, conforme mostrado no Quadro 18.

Quadro 18 - Síntese das não conformidades na colaboração

\begin{tabular}{|c|c|c|c|}
\hline Portugal & Suíça & Brasil & \\
\hline $\begin{array}{l}\text { Motivação }=0 / 3 \\
\text { Escopo }=1 / 4 * \\
\text { Estrutura }=2 / 9 * *\end{array}$ & $\begin{array}{l}\text { Motivação }=0 / 3 \\
\text { Escopo }=1 / 4 * \\
\text { Estrutura }=1 / 9 * *\end{array}$ & $\begin{array}{l}\text { Motivação }=3 / 3 \\
\text { Escopo }=2 / 4 * \\
\text { Estrutura }=5 / 9 * *\end{array}$ & $\begin{array}{ll}\text { Quantidade de } & \text { não } \\
\text { conformidades } & \text { por } \\
\text { dimensão } & \end{array}$ \\
\hline $\begin{array}{l}\text { Efetivação da lei e } \\
\text { superação dos resultados }\end{array}$ & 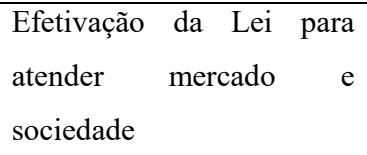 & $\begin{array}{l}\text { Não efetivou o AS, nem } \\
\text { conseguiu consenso }\end{array}$ & \\
\hline
\end{tabular}

Fonte: Autora, 2018

Nota1: Os dados desse quadro foram extraídos do Apêndice $\mathrm{H}$.

Nota2: * indica que uma das não conformidades "concorrentes atuam na colaboração" é igual para os três países.

Nota3: ** indica que a não conformidade "cada um arca com seus custos” é igual para os três países. 
Talvez essa abordagem explique a quantidade de desafios que o Brasil enfrenta, em relação a Portugal e à Suíça. No caso do Brasil, dos 16 atributos que compõem as três dimensões que descrevem as características do processo de colaboração, dez apresentam "não conformidade" com a literatura, ou seja, seus valores não estão de acordo com os autores de referencial teórico. Além disso, a maioria dos valores assumidos pelos atributos são característicos de processo de cooperação, como pode ser observado no Quadro 19. Nesse caso, a categoria Motivação, que representa os motivos para iniciar a parceria colaborativa é a mais afetada e apresenta não conformidades relativas à falta de desejo e necessidade, à percepção de oportunidade em atuar conjuntamente e à disposição para superar os desafios e atuar conjuntamente nos três atributos. Percebe-se, assim, que os atores só continuam atuando conjuntament, porque esse foi o mecanismo escolhido pelo governo. Ainda que o setor privado ache importante estar no grupo, seus representeantes têm como objetivo defender seus pleitos, sobrepondo-os aos objetivos comuns, como pode ser notado na segunda categoria, Escopo. A terceira categoria, Estrutura, é aquela que apresenta mais divergências com a literatura e é responsável pela forma como as tarefas são divididas, como as relações são tratadas, como os recursos são disponibilizados e quais são os mecanismos para construir a confiança no grupo.

$\mathrm{Na}$ sequência, vem Portugal, com três não conformidades e um desafio. Neste caso, contudo, o desafio levantado, apesar de estar diretamente relacionado a uma das não conformidades, ainda não afeta as relações, embora os atores já demonstrem descontentamento com a forma como o poder é exercido pelo governo português na elaboração das leis e normas e reclamem por nem sempre ter seus pleitos aceitos. Entretanto, declaram que o governo acata algumas de suas sugestões, garantindo pequenas vitórias, tão importantes manter o engajamento dos membros em situações de governança colaborativa, de acordo com Ansell e Gash (2008).

E, por último, a Suíça, com duas não conformidades e nenhum desafio relatado para auferir os resultados positivos da colaboração. Nesse caso, observa-se que os atores que atuam conjuntamente são motivados pelo desejo de serem sustentáveis e trabalhar em prol da comunidade e, portanto, agem com proatividade, criando voluntariamente os mecanismos necessários para auferir os melhores resultados da LR. Além disso, desde o início, a LR de REEE foi vista como oportunidade pelos atores da indústria de EEE, por se tratar de um resíduo valioso, pela oportunidade de preservar o meio ambiente e pelo impacto positivo que ela causaria em sua imagem.

Vale ressaltar que duas dessas não conformidades identificadas na Suíça e em Portugal são comuns aos três países e não parecem influenciar os resultados da colaboração, anulando o seu efeito: uma delas trata da atuação entre concorrentes e a outra do financiamento da ação. 
Na primeira situação, surge uma nova reflexão para o caso da colaboração na LR de REEE e na elaboração de políticas públicas. Diferentemente do que a literatura aponta para outros campos do conhecimento, como pesquisa e educação (HORD, 1981; BRNA, 1998; POLENSKE, 2004), nos quais a colaboração não é aconselhada entre membros concorrentes, na LR de REEE ela se apresenta possível entre concorrentes, pois eles atuam como bloco de setor, para resolver uma questão comum: o impacto que seu modelo de negócio causa ao meio ambiente.

Na segunda situação, a não conformidade está atrelada ao atributo recursos financeiros. Segundo a literatura, ele deve ser compartilhado ou se cria um fundo ou se pede um empréstimo conjunto para financiar as ações no processo de colaboração (HORD, 1981; POLENSKE, 2004). No caso da colaboração na elaboração de leis e normas de LR de REEE, no entanto, a fala de todos atores suíços mostra que é natural que cada um arque com a sua parte das despesas de locomoção ou recepção de um grupo em sua organização, sem a necessidade de que isso seja financiado coletivamente.

Poder-se-ia dizer, portanto, que a Suíça não tem nenhuma não conformidade, Portugal uma e o Brasil oito, e que esses valores, nesses dois atributos, não afetam os resultados finais da colaboração. Dessa forma, é necessário rever a matriz de fatores determinantes da colaboração para que ela se adeque à realidade desta área de conhecimento, pois ela foi elaborada a partir da revisão da literatura, que não incluía nenhum caso de colaboração em LR de REEE. Para tanto, a matriz de atributos determinantes para a colaboração foi refeita, considerando os resultados da presente pesquisa, alterando os valores que os dois atributos relatados podem assumir e incluindo o valor "predisposição para ser sustentável” no atributo disposição. O Quadro 19 mostra o resultado aferido nos três países e seus impactos no processo, já com as alterações referidas.

Quadro 19 - Matriz do impacto da colaboração em Portugal, Suíça e Brasil

\begin{tabular}{|c|c|c|c|c|}
\hline Portugal & Suíça & Brasil & $\begin{array}{c}\text { Valores dos } \\
\text { atributos }\end{array}$ & Ref. \\
\hline \multicolumn{5}{|c|}{ Dimensão Escopo da Colaboração } \\
\hline Necessidade de atender às leis & Desejo de atender à sociedade & Não sentem obrigação & Necessidade/Desejo & 1,6 \\
\hline $\begin{array}{l}\text { Oportunidade de gerar divisas. } \\
\text { Ter consenso }\end{array}$ & $\begin{array}{l}\text { Ter consenso. Padronizar para } \\
\text { todos. Recuperar materiais }\end{array}$ & $\begin{array}{l}\text { Lobby para diminuir a } \\
\text { responsabilidade }\end{array}$ & Oportunidade & 1,6 \\
\hline $\begin{array}{l}\text { Histórico positivo de } \\
\text { colaboração. Senso de } \\
\text { urgência }\end{array}$ & $\begin{array}{l}\text { Iniciativa voluntária. } \\
\text { Predisposição em ser } \\
\text { sustentável }\end{array}$ & $\begin{array}{l}\text { Não tem disposição, nem } \\
\text { senso de urgência }\end{array}$ & Disposição & $1,6,8$ \\
\hline
\end{tabular}


Conclusão

\begin{tabular}{|c|c|c|c|c|}
\hline \multicolumn{5}{|c|}{ Dimensão Escopo da Colaboração } \\
\hline $\begin{array}{l}\text { Elaborar lei e sistemas de gestão e } \\
\text { controle }\end{array}$ & Elaborar lei e critérios de qualidade & Elaborar AS & $\begin{array}{c}\text { Natureza: Elaboração } \\
\text { de algo }\end{array}$ & 7 \\
\hline Objetivo do grupo & Objetivo do grupo & Objetivo individual & Objetivo do Grupo & $\begin{array}{c}1,3 ; 6 ; 8 \\
9\end{array}$ \\
\hline Tangíveis e intangíveis & Tangíveis e intangíveis & Tangíveis e intangíveis & $\begin{array}{c}\text { Resultados Tangíveis } \\
\text { ou intangíveis }\end{array}$ & $5 ; 8 ; 9$ \\
\hline $\begin{array}{l}\text { Concorrentes representados por } \\
\text { associações }\end{array}$ & $\begin{array}{l}\text { Concorrentes representados por } \\
\text { associações }\end{array}$ & $\begin{array}{l}\text { Concorrentes representados por } \\
\text { associações. Restringem atores }\end{array}$ & $\begin{array}{c}\text { Concorrentes são } \\
\text { permitidos em grupo } \\
\text { ou associação }\end{array}$ & $6 ; 9$ \\
\hline \multicolumn{5}{|c|}{ Dimensão Estrutura da colaboração } \\
\hline $\begin{array}{l}\text { Trabalham em pares. Tenta } \\
\text { manter a dependência. } \\
\text { Governo lidera as discussões }\end{array}$ & $\begin{array}{l}\text { Em conjunto; } \\
\text { Interdependência }\end{array}$ & $\begin{array}{l}\text { Trabalham separados; } \\
\text { Reuniões paralelas; Não } \\
\text { têm interdependência }\end{array}$ & $\begin{array}{l}\text { Trabalham juntos, } \\
\text { internamente; } \\
\text { Interpendência }\end{array}$ & $\begin{array}{l}1 ; 5 ; \\
6 ; 7 ; \\
8 ; 9 ;\end{array}$ \\
\hline Contribuição & Contribuição & Contribuição & $\begin{array}{c}\text { De apoio, } \\
\text { contribuição }\end{array}$ & $\begin{array}{c}1 ; 5 \\
9 ; 7\end{array}$ \\
\hline $\begin{array}{l}\text { Compartilhado. Os atores iam } \\
\text { na reunião com o governo. }\end{array}$ & $\begin{array}{l}\text { Compartilhado. Os atores } \\
\text { iam para as reuniões. }\end{array}$ & $\begin{array}{l}\text { Compartilhado; Não tinham } \\
\text { poder de decisão; reunião } \\
\text { nas sedes e governo }\end{array}$ & $\begin{array}{l}\text { Recurso: } \mathrm{RH} \text { e } \\
\text { estrutura } \\
\text { compartilhados }\end{array}$ & 1 \\
\hline Cada qual arca com a sua parte & $\begin{array}{l}\text { Cada qual arca com a sua } \\
\text { parte }\end{array}$ & $\begin{array}{l}\text { Cada qual arca com a sua } \\
\text { parte }\end{array}$ & $\begin{array}{c}\text { Recurso } \\
\text { Financiado } \\
\text { Arca com a sua } \\
\text { participação }\end{array}$ & 1 \\
\hline Não surgiu & Compartilha informação & Compartilha informação & $\begin{array}{l}\text { Recurso } \\
\text { informação: } \\
\text { compartilhado }\end{array}$ & 6 \\
\hline Até esgotar o assunto & Até obter consenso & Esporádicas & $\begin{array}{c}\text { Comunicação } \\
\text { intensa }\end{array}$ & $1 ; 7$ \\
\hline Mútuo, hierarquizado GF & Mútuo & Mútuo. Hierarquizado GF & Poder Mútuo & 7,9 \\
\hline Ñ têm contratos & Ñ têm contratos & $\begin{array}{l}\text { Não tem mecanismos, nem } \\
\text { confiança por si só; } \tilde{N} \text { tem } \\
\text { contrato }\end{array}$ & $\begin{array}{l}\text { Controle: poucos } \\
\text { mecanismos; } \\
\text { informal } \\
\end{array}$ & $1 ; 3$ \\
\hline Não foram relatados riscos & Não foram relatados riscos & Todos têm um risco & $\begin{array}{c}\text { Risco } \\
\text { compartilhado }\end{array}$ & $\begin{array}{c}1 ; 2 \\
6\end{array}$ \\
\hline \multicolumn{5}{|c|}{ Dimensão: Impactos da Colaboração } \\
\hline Efetivação da lei & Efetivação da lei & Não efetivou ainda o AS & Resultado Direto & \\
\hline $\begin{array}{c}\text { Lei consensual. Superação das } \\
\text { divergências. Melhoria dos SI } \\
\text { do governo. Motivação para } \\
\text { criar parcerias }\end{array}$ & $\begin{array}{l}\text { Lei consensual. Referência } \\
\text { mundial na LR de REEE e } \\
\text { critérios de qualidade para a } \\
\text { EU. Aprendizado coletivo }\end{array}$ & $\begin{array}{l}\text { Entenderam as necessidades } \\
\text { dos outros. Aprendizagem } \\
\text { coletiva. Possibilitou } \\
\text { identificar as competências }\end{array}$ & Benefícios & \\
\hline Não exceder no uso do poder, & & $\begin{array}{c}\text { Falta senso de } \\
\text { obrigatoriedade que } \\
\text { potencializa todos os outros. } \\
\text { Não tem consenso, não } \\
\text { reconhecem os pleitos; falta } \\
\text { de incentivos fiscais }\end{array}$ & Desafios & \\
\hline
\end{tabular}

Fonte: Autora, 2018

Nota1: Legenda das Referências: Hord $(1981)^{1}$; Hord $(1986)^{2}$; Brna $(1998)^{3}$; Das e Teng $(1998)^{4}$; Balancieri (2004) $)^{5}$; Polenske (2004) $)^{6}$; Kemczinski et al. (2008) ${ }^{7}$; Ansell e Gash (2008) ${ }^{8}$; Winckler e Molinari (2011) ${ }^{9}$.

Legenda: As cores mais fortes nos quadros foram utilizadas para marcar algum tipo de não conformidade. $\mathrm{O} X$ vermelho marca os atributos que têm características do processo de cooperação. O contorno vermelho assinala quais foram os valores de atributos que assumiram outros valores, baseados nos resultados de pesquisa

Além da quantidade elevada de não conformidades e da ausência de fatores motivacionais, o Quadro 19 apresentado evidencia os atributos que assumiram valores característicos de cooperação, no caso brasileiro. Nesse contexto, Polenske (2004) alerta para o problema da eleição de uma estrutura inadequada para atuar com um dos dois conceitos, pois isso pode dificultar a elaboração de políticas públicas ou criar um clima de insegurança entre 
os atores, pois cada um deles prevê um tipo de comportamento, uso de recursos e resultados alcançáveis. Nesse contexto, além da dimensão motivação que está totalmente em desacordo com processos colaborativos, no Escopo, os objetivos dos atores são individuais, não do grupo. Na dimensão Estrutura, o grupo não aproveitou a sinergia característica gerada em reuniões frequentes e presenciais, além de ter se dividido em dois blocos, que atuavam como adversários. Esses elementos fragilizaram mais a confiança do grupo, exigindo mecanismos de controle formais, como a garantia por decreto, de que as empresas que não participaram do AS teriam que aderir obrigatoriamente ao modelo de LR de REEE eleito por ele. Esses fatos corroboram Hord (1981) e Polenske (2004) sobre a importância de construir um modelo adequado à natureza do processo, respeitando seus atributos.

\subsubsection{Impactos, benefícios e desafios da cooperação}

A cooperação, quando respeita o escopo e a estrutura necessários para sua efetivação, traz entre seus benefícios, o aumento exponencial do conhecimento, a complementariedade das competências e recursos, o aumento da capacidade de atender a novos mercados e a redução dos custos (POLENSKE, 2004; SILVA, 2007).

Nesse cenário, a cooperação na LR de REEE na Espanha e em Portugal tem permitido que as metas de reciclagem sejam superadas nesses países. No caso da Suíça, apesar do país não ter meta, a cooperação entre os atores a tornou referência mundial na LR de REEE e em critérios de qualidade para reciclagem de REEE. Com quase três décadas de funcionamento, na Suíça, o sistema coleta hoje cerca de 3 vezes mais REEE do que Espanha e Portugal, com uma média de $16 \mathrm{~kg}$ por pessoa em 2016. Portugal tem ultrapassado as metas de coleta de $4 \mathrm{~kg}$ de REEE /por pessoa/ano desde de 2010, e, em 2015 coletou 5,1 kg. A Espanha, por sua vez, superou a meta em 2015, coletando 4,61 kg. Esses dados mostram que, por meio da cooperação, bons resultados são possíveis. Dessa forma, percebe-se que a cooperação permite que os atores atendam a demandas mais urgentes e maiores do que a capacidade atual (KIRSCHNER; DICKINSON; BLOSSER, 1996; BALESTRIN; VARGAS, 2004; POLENSKE, 2004).

Nesse cenário, é nítida a superioridade do sistema de LR de REEE suíço. Esse desempenho está relacionado à forma cooperativa com que os atores da LR de REEE atuam, impactando positivamente os resultados do sistema. O primeiro ponto a destacar é o compartilhamento dos pontos de coleta entre as ORPs, pois elas não são concorrentes. Esse mecanismo duplica as possibilidades de coleta para ambas as ORPs. Dessa forma, a rede de coleta é formada pelos canais de coleta seletiva da municipalidade, pelo mecanismo de coleta 
das lojas que vendem EEE e pelos postos de coleta dos recicladores contratados, que atuam em parceria com as ORP. Destaca-se que, na Suíça, todas as lojas que vendem EEE, independentemente do tamanho do estabelecimento, devem coletar o REEE do mesmo tipo que vendem. Essas parcerias aumentam a capilaridade do sistema de coleta de REEE, tão importante para a LR (LEITE; LAVEZ; SOUZA, 2009), garantindo mais de 6000 pontos de descarte. Esse fator facilita a participação do consumidor no descarte, pois ele não precisa se locomover muito para fazê-lo, aumentando o volume de REEE coletado. Além disso, o compartilhamento de pontos de coleta gera benefícios também para os recicladores contratados pelo sistema, que otimizam o transporte, atendendo as três associações em uma única viagem. Assim, todos os atores cooperam para potencializar os resultados da LR, aumentando a coleta de REEE, valorizando e reciclando a maior parcela possível de substâncias contidas nesses dispositivos, aumentando a rentabilidade dos recicladores e diminuindo os custos de reciclagem e o valor da TAR. Esse esforço se converte em outros benefícios, como o fomento à economia verde, a redução de resíduos enviados para aterros ou sistemas de incineração, a preservação dos recursos naturais do planeta e a melhoria da imagem das instituições que participam da LR.

Espanha e Portugal também receberam benefícios por atuarem de forma cooperativa na LR de REEE. Em ambos os países, os esforços das OGs na busca por parcerias com municípios, lojas e entidades, como empresas e escolas, garantiram uma maior capilaridade da LR, menor custo da reciclagem, redução do volume dos resíduos enviados aos aterros e diminuição do impacto e risco ambientas devido ao descarte correto dos REEE. Além disso, a LR de REEE fomenta o mercado formal das recicladoras de metais e dos sucateiros, que recebem contrapartidas financeiras das OGs pelos relatórios do processamento e destinação ambientalmente corretos dos REEE. Na Espanha, essas empresas se juntam a outras do mesmo setor que atuam com Códigos LER diferentes para ampliar seu mercado de atuação e ganhar mais competividade. Nesse cenário, os atores de ambos os países relataram que entre os elementos que potencializam o impacto da cooperação do consumidor figuram os incentivos financeiros para o descarte de REEE, as campanhas que envolvem a família por intermédio dos filhos em idade escolar, e a publicidade em canais de massa, como anúncios na TV e nas rádios.

No Brasil, a cooperação dos atores envolvidos no AS ajudou a implementar o PP. No entanto, os resultados de coleta ficaram muito aquém das expectativas, pois foram coletados apenas cerca de $2 \%$ da projeção de resíduos gerados no local em que foi implementado o PP. As particularidades do PP, um projeto que teve início, meio e fim, transformam resultados insatisfatórios em oportunidade de aprendizado. Dessa forma, a maior impacto da cooperação no contexto do PP foi o aprendizado coletivo acelerado (HARGROVE, 1998; ANSELL; 
GASH, 2008), pois possibilitou que os atores envolvidos aprendessem muito sobre o cenário brasileiro e o comportamento do consumidor em um curto período. Apesar do PP ter durado cerca de dois anos, a operacionalização da LR ocorreu em apenas oito meses. Assim, parte dos baixos resultados da coleta do PP são atribuídas à tardia adesão de algumas lojas de varejo, pois o material de comunicação do PP conflitava com as especificidades das marcas. A resistência inicial das lojas é explicada por Polenske (2004), que afirma que, em processos de cooperação, é importante respeitar a individualidade dos atores e sua forma de operar. Além disso, o curto período do PP não permitiu que os consumidores se acostumassem com o sistema de coleta e se habituassem a descartar. Ainda assim, o PP deixou como legado a regulamentação, em nível estadual, sobre a periculosidade dos REEE, o reconhecimento da capacidade operacional da Coopermiti e o potencial de mercado da LR de REEE.

Apesar do aprendizado que todos os países estudados tiveram nas parcerias de cooperação da LR de REEE e dos benefícios que afetaram positivamente a competividade desses atores nos países europeus, diversos desafios precisam ser superados nos quatro países estudados.

A Suíça, país que mais relatou benefícios relacionados à cooperação entre seus atores, ainda precisa superar os problemas que podem afetar o custo da reciclagem, pela falta de cooperação. Nesse contexto, três desafios se destacam: a presença de free riders, a importação de EEE pelo consumidor sem o pagamento da TAR e a falta de investimento em ecodesign. Os free riders, que representam menos de $2 \%$ do universo de empresas que atuam no mercado de EEE na Suíça e os EEE importados afetam os custos da reciclagem, pois não contribuem para o sistema de LR, mas seus REEE são encaminhados a ele. Dessa forma, a quantidade de REEE que precisam ser tratados aumenta sem aumentar a arrecadação, pois não há restrição por marca do momento da coleta. Já a falta de investimento em ecodesing pelos fabricantes poderia ser superada pelo investimento em $\mathrm{P} \& \mathrm{D}$, mas isso impactaria nos preços da TAR, ampliando o problema de importação, pois o custo dos EEE na Suíça é mais alto do que nos países vizinhos. Dessa forma, apesar de desejarem resolver a situação, não foi possível chegar a uma solução. A única alternativa criada até o momento para mitigar esse problema foi o desenvolvimento de um aplicativo que permite o pagamento voluntário da TAR pelo consumidor, quando ele comprar algum EEE em outro país. Entretanto, essa iniciativa é recente, e por isso não foi possível saber se o consumidor aderiu à ideia.

Portugal e Espanha enfrentam desafios semelhantes no que tange a questões como a participação do consumidor no descarte de REEE, a ausência de inclusão social do setor informal e a exportação ilegal de REEE devido aos altos custos da reciclagem. Ambos precisam 
de mais investimento em campanhas de conscientização para o consumidor sobre a importância do descarte correto dos REEE. Nessa questão, o problema é mais grave na Espanha, pois a coleta seletiva é recente no país e os municípios ainda não conseguiram nem sensibilizar os consumidores para o descarte dos recicláveis comuns. Dessa forma, apesar do governo ser penalizado pela UE por não cumprir as cotas de coleta, o consumidor não se sente afetado por isso, pois não relaciona o aumento das taxas ao fato dele não participar do sistema de coleta. Nesse cenário, para que o consumidor coopere, é importante que ele sinta a necessidade ou desejo de fazer o descarte correto (HORD, 1981; POLENSKE, 2004), e para isso, precisa ser melhor sensibilizado.

Além disso, nos dois países, o sistema de coleta sofre com os roubos dos REEE nos canais oficiais. Trabalhadores do setor informal invadem pontos de coleta dos municípios ou passam antes dos caminhões de coleta para furtarem os REEE, desmontá-los e vender apenas a parte que tem valor. Esse problema é agravado, pois o sistema de coleta seletiva na Espanha e em Portugal contribui com menos do que as OGs precisam para completar as cotas de reciclagem de seus clientes. Assim, elas recorrem a recicladores formais, que compram os REEE das pessoas que vão até sua empresa ou de recicladores menores, que muitas vezes aceitam receber equipamentos fragmentados, oriundos do setor informal. Esse ciclo, associado à falta de fiscalização dos pontos de coleta e à ausência de políticas públicas de inclusão social, fomenta o mercado paralelo. Ainda que essa solução ajude as OGs a atingirem suas metas gerais, os dois países não atendem a todas as metas por categorias. Além disso, o alto custo da reciclagem de REEE tem motivado a exportação ilegal de REEE para países em desenvolvimento. O problema do alto custo da reciclagem é agravado, pois Portugal e Espanha não conseguiram motivar a indústria de EEE a investir em ecodesing. A falta de investimento em ecodesing é comum aos três países europeus.

No caso do Brasil, entre os desafios que antecedem ao PP, mas foram elencados como primordiais pelos membros da JICA, estão a necessidade de tanto o setor público quanto o privado assumirem sua responsabilidade sobre a obrigação de implementar a LR, para que ela possa ser efetivada. Sem essa motivação inicial, a LR não será efetiva no Brasil (HORD, 1981; POLENSKE, 2004). Além disso, o PP mostrou que a falta de definição clara dos papéis na legislação não permite que a cooperação seja efetivada para a LR de REEE no país (BALANCIERI, 2004; POLENSKE, 2004; KEMCZINSKI et al., 2008), pois os atores continuam tentando minimizar suas obrigações. Entre os desafios que precisarão ser enfrentados, quando a LR de REEE começar no país, figuram a falta de hábito do consumidor de descartar seus REEE, pois ele tenta dar uma segunda vida para seus EEE ou outra finalidade 
que ele ache mais nobre do que descartá-lo. Dessa forma, será necessário investir em campanhas de conscientização e propaganda de massa para motivar o consumidor a participar da LR, pois ele precisa sentir que é importante e necessário cooperar nesse processo. Além disso, é importante facilitar o acesso para o descarte em locais com estacionamento e com venda de produtos do dia-a-dia, para que ele se lembre de descartar sempre que for ao mercado fazer suas compras cotidianas. Nesse contexto, percebe-se que a motivação para participar da LR tem que existir para todos, apesar da literatura não ter incluído o consumidor final em nenhum dos textos utilizado pelo referencial teórico.

Nesse cenário, no qual objetivos, resultados esperados e papéis precisam ser bem definidos para aferir os impactos positivos da cooperação (BRNA, 1998), é necessário entender como esses elementos foram construídos nos quatro países. Assim, foi feita uma análise dos atributos nas três dimensões nos países estudados e ela novamente mostrou que o Brasil é o país que tem mais não conformidades com a literatura, conforme mostrado no Quadro 20.

Quadro 20- Síntese das não conformidades na cooperação

\begin{tabular}{|l|l|l|l|l|}
\hline Espanha & Portugal & Suíça & Brasil & \\
\hline Motivação $=1 / 3$ & Motivação $=0 / 3$ & Motivação $=0 / 3$ & Motivação $=2 / 3$ & Quantidade de não \\
Escopo $=0 / 4$ & Escopo $=0 / 4$ & Escopo $=0 / 4$ & Escopo $=1 / 4$ & conformidades por \\
Estrutura $=0 / 8$ & Estrutura $=0 / 8$ & Estrutura $=0 / 8$ & Estrutura $=3 / 8$ & dimensão \\
\hline
\end{tabular}

Fonte: Autora, 2018

Nota1: O apêndice G mostra o detalhamento das não conformidades de cada atributo.

$\mathrm{Na}$ cooperação, só o Brasil e a Espanha apresentam não conformidade com a literatura. No caso da Espanha, ela está relacionada com a falta de motivação para alcançar as metas antes do término do período de transição da lei, pois não há sansões da UE. Esse fator, contudo, não afeta os outros atributos da motivação, nem está relacionado a um valor de colaboração.

Já no caso brasileiro, os atributos que apresentam não conformidade na dimensão motivação estão relacionados ao comportamento oportunista e à procrastinação, pois os atores da indústria, apesar de reconhecerem as competências da JICA para executar o PP e de ter interesse no aprendizado que a ação iria proporcionar, queriam usar esse conhecimento para mostrar ao governo que seus pleitos eram válidos e que sem eles não seria possível realizar a LR de REEE no país. Essa linha de raciocínio do setor privado afetou a dimensão Escopo no atributo "objetivos individuais", pois, apesar de ser importante, o objetivo do grupo não seria capaz de satisfazer todos os membros, posto que são conflituosos entre si. De fato, enquanto o governo quer provar com o PP que é possível realizar a LR, o setor privado quer o oposto. 
Entretanto, ter suas necessidades atendidas e transparência sobre os objetivos de cada um é uma condição sine qua non para aferir resultados positivos na cooperação (POLENSKE, 2004; KEMCZINSKI et al., 2008; WINCKLER; MOLINARI; 2011).

$\mathrm{Na}$ dimensão Estrutura, dois atributos surgiram com valores divergentes da literatura, com características mais próximas da definição de colaboração, mas com diferenças que não permite afirmar com precisão que as estruturas foram trocadas, como ocorreu em alguns atributos no processo de colaboração. De fato, as tarefas são realizadas separadamente, de acordo com a literatura de cooperação (HORD, 1981; POLENSKE. 2004), mas os atores não têm liberdade para agir e todo o poder fica centralizado na JICA. Dessa forma, as empresas não conseguiam manter a soberania sobre seu papel e processo, pois precisavam realizar a atividade exatamente como a equipe da JICA havia definido que seria melhor e muitas vezes sob sua supervisão. Como em alguns casos não estava previsto a obrigação do parceiro fazer relatórios, a equipe da JICA ia direto à empresa para inspecionar como estava sendo feito aquela etapa do PP. Processos de controle são importantes na cooperação, mas, em excesso, eles tiram a liberdade da empresa e prejudicam o clima de confiança (DAS; TENG, 1998). A descrição dos atributos das quatro dimensões e as não conformidades pode ser vista no Quadro 21 e seu detalhamento no apêndice $H$, com a síntese de todos os impactos.

Quadro 21- Matriz do impacto da cooperação na Espanha, Portugal, Suíça e Brasil.

\begin{tabular}{|c|c|c|c|c|c|}
\hline Espanha & Portugal & Suíça & Brasil & Atributos & Ref. \\
\hline \multicolumn{6}{|c|}{ Dimensão Escopo da Cooperação } \\
\hline Atender às leis & $\begin{array}{c}\text { Atender às leis e } \\
\text { imagem sustentável }\end{array}$ & $\begin{array}{l}\text { Atender ao mercado e } \\
\text { imagem sustentável }\end{array}$ & Aprovar AS & Necessidade/Desejo & $1 ; 6$ \\
\hline $\begin{array}{c}\text { Segunda vida do EEE, } \\
\text { aumento da } \\
\text { capilaridade e divisas }\end{array}$ & $\begin{array}{c}\text { Capilaridade e } \\
\text { volume, aumento de } \\
\text { divisas }\end{array}$ & $\begin{array}{l}\text { Recuperar materiais, } \\
\text { capilaridade, diminuir } \\
\text { custos e impactos }\end{array}$ & $\begin{array}{c}\text { Sensibilizar para as } \\
\text { metas, aprender com } \\
\text { PP, sem custo }\end{array}$ & Oportunidade & $1 ; 6$ \\
\hline $\begin{array}{l}\text { Proatividade, sem } \\
\text { senso de urgência }\end{array}$ & Senso de urgência & Iniciativa voluntária & $\begin{array}{l}\text { Sem senso de } \\
\text { urgência }\end{array}$ & Disposição & $1 ; 6 ; 8$ \\
\hline \multicolumn{6}{|c|}{ Dimensão Escopo da Cooperação } \\
\hline Operacionalizar LR & Operacionalizar LR & Operacionalizar LR & Operacionalizou PP & Natureza: Operação & $7 ; 9$ \\
\hline Objetivos individuais & Objetivos individuais & Objetivos individuais & $\begin{array}{l}\text { Objetivos individuais, } \\
\text { conflito de interesses }\end{array}$ & $\begin{array}{c}\text { Objetivos Individuais } \\
\text { são garantidos } \\
\text { pelo grupo }\end{array}$ & $1 ; 6 ; 7 ; 9$ \\
\hline Tangíveis: Todos & Tangíveis: Todos & Tangíveis: Todos & Tangíveis e intangíveis & Resultados tangíveis & $1 ; 6 ; 7 ; 9$ \\
\hline $\begin{array}{l}\text { Concorrentes. Sem } \\
\text { setor informal }\end{array}$ & $\begin{array}{c}\text { Concorrentes. Sem setor } \\
\text { informal }\end{array}$ & $\begin{array}{l}\text { Atores concorrentes. } \\
\text { ORPs complementares }\end{array}$ & $\begin{array}{l}\text { Concorrentes. Sem } \\
\text { cooperativas. }\end{array}$ & Concorrentes & $1 ; 9$ \\
\hline
\end{tabular}


Conclusão

\begin{tabular}{|c|c|c|c|c|c|}
\hline \multicolumn{6}{|c|}{ Dimensão: Estrutura da Cooperação } \\
\hline $\begin{array}{l}\text { Separados, com SIG. } \\
\text { Independentes }\end{array}$ & $\begin{array}{l}\text { Separados, com EG. } \\
\text { Independentes }\end{array}$ & $\begin{array}{c}\text { Separados, com } \\
\text { ORP. Independentes }\end{array}$ & $\begin{array}{l}\text { Separados; não têm } \\
\text { autonomia para } \\
\text { alterar nada }\end{array}$ & $\begin{array}{c}\text { Trabalham } \\
\text { separados, ou } \\
\text { criam OG; } \\
\text { independentes. }\end{array}$ & $\begin{array}{c}1 ; 6 ; 7 ; \\
9\end{array}$ \\
\hline Não compartilha & Não compartilha & Não compartilha & Não compartilha & $\begin{array}{l}\text { Recursos físicos e } \\
\text { humano: não } \\
\text { compartilha }\end{array}$ & $1 ; 6$ \\
\hline $\begin{array}{l}\text { Criam fundo com a } \\
\text { TAR. GM arca com } \\
\text { custo de campanhas }\end{array}$ & $\begin{array}{l}\text { Criam fundo com a } \\
\text { TAR. GM arca com } \\
\text { custo de campanhas. }\end{array}$ & $\begin{array}{c}\text { Criam fundo com a } \\
\text { TAR }\end{array}$ & JICA financiou o PP & $\begin{array}{l}\text { Recursos } \\
\text { financeiros: criam } \\
\text { fundos, não } \\
\text { compartilham } \\
\end{array}$ & $6 ; 7 ; 10$ \\
\hline $\begin{array}{c}\text { Relata sobre o } \\
\text { processo }\end{array}$ & $\begin{array}{c}\text { Relata sobre o } \\
\text { processo }\end{array}$ & $\begin{array}{c}\text { Relata sobre o } \\
\text { processo }\end{array}$ & $\begin{array}{c}\text { Relata sobre o } \\
\text { processo }\end{array}$ & \begin{tabular}{|c|} 
Informação: relata \\
sobre o processo \\
\end{tabular} & \\
\hline $\begin{array}{l}\text { Esporádicas e por } \\
\text { relatórios e SI }\end{array}$ & $\begin{array}{l}\text { Esporádicas e por } \\
\text { relatórios e SI }\end{array}$ & $\begin{array}{l}\text { Esporádicas, por } \\
\text { relatórios e SI }\end{array}$ & $\begin{array}{c}\text { Reuniões } \\
\text { presenciais mensais, } \\
\text { relatórios } \\
\end{array}$ & $\begin{array}{c}\text { Comunicação: } \\
\text { Esporádica e com } \\
\text { SI } \\
\end{array}$ & $1 ; 6$ \\
\hline $\begin{array}{l}\text { Centrado nas } \\
\text { organizações }\end{array}$ & $\begin{array}{l}\text { Centrado nas } \\
\text { organizações }\end{array}$ & $\begin{array}{l}\text { Centrado nas } \\
\text { organizações }\end{array}$ & $\begin{array}{c}\text { Centrado no JICA e } \\
\text { no GF }\end{array}$ & \begin{tabular}{|c|} 
Poder: Centrado na \\
organização
\end{tabular} & $1 ; 6$ \\
\hline $\begin{array}{c}\text { Contrato com todos e } \\
\text { TIC }\end{array}$ & $\begin{array}{c}\text { Contrato com todos e } \\
\text { TIC }\end{array}$ & $\begin{array}{c}\text { Contrato com todos e } \\
\text { TIC }\end{array}$ & Contrato com todos & $\begin{array}{l}\text { Mecanismos de } \\
\text { controle formal }\end{array}$ & $7 ; 10$ \\
\hline $\begin{array}{l}\text { Dividido por etapa } \\
\text { está operando }\end{array}$ & $\begin{array}{l}\text { Fica para quem está } \\
\text { operando }\end{array}$ & $\begin{array}{c}\text { Fica para quem está } \\
\text { operando. }\end{array}$ & $\begin{array}{l}\text { Fica para quem está } \\
\text { operando }\end{array}$ & $\begin{array}{c}\text { Risco dividido, fica } \\
\text { para quem está } \\
\text { operando. }\end{array}$ & $1 ; 6 ; 7$ \\
\hline \multicolumn{6}{|c|}{ Impactos da Cooperação } \\
\hline $4,61 \mathrm{~kg} / \mathrm{pessoa} / 2015$ & $5,1 \mathrm{~kg} /$ pessoa $/ 2015$ & $16 \mathrm{~kg} / \mathrm{pessoa} / 2016$ & 2\% dos REEE & Resultado Direto & \\
\hline $\begin{array}{l}\text { Alcançou metas, } \\
\text { capilaridade, redução } \\
\text { de custo, impacto e } \\
\text { riscos ambientais }\end{array}$ & $\begin{array}{l}\text { Alcançou metas, } \\
\text { capilaridade, redução } \\
\text { de custo, impacto e } \\
\text { riscos ambientais }\end{array}$ & $\begin{array}{l}\text { Capilaridade: }>6000 ; \\
\text { redução de custo, } \\
\text { impacto e riscos } \\
\text { ambientais, imagem. } \\
\text { Maior rentabilidade } \\
\text { na reciclagem }\end{array}$ & $\begin{array}{l}\text { Aprendizado. } \\
\text { Regulamentação dos } \\
\text { REEE; } \\
\text { reconhecimento da } \\
\text { Coopermiti; } \\
\text { potencial de } \\
\text { mercado. Novos PPs } \\
\text { da indústria. } \\
\end{array}$ & Benefício & \\
\hline $\begin{array}{c}\text { Incentivos } \\
\text { financeiros para o } \\
\text { consumidor fazer o } \\
\text { descarte }\end{array}$ & & $\begin{array}{l}\text { A colaboração nas } \\
\text { leis. Pressão de outro } \\
\text { ator. Senso de } \\
\text { comunidade. } \\
\text { Solidariedade e } \\
\text { confiança. } \\
\text { Propaganda para os } \\
\text { supermercados. } \\
\end{array}$ & & $\begin{array}{l}\text { Beneficios: } \\
\text { Fatores que } \\
\text { facilitam }\end{array}$ & \\
\hline $\begin{array}{l}\text { Comportamento do } \\
\text { consumidor. Setor } \\
\text { informal. } \\
\text { Roubo e exportação } \\
\text { ilegal de REEE }\end{array}$ & \begin{tabular}{|c|} 
Falta de investimento \\
em conscientização e \\
ecodesing. Setor \\
informal. Fiscalização. \\
Roubo e exportação \\
ilegal de REEE
\end{tabular} & $\begin{array}{c}\text { Free Riders e } \\
\text { importação EEE sem } \\
\text { TAR. TAR que } \\
\text { financie ecodesing }\end{array}$ & $\begin{array}{l}\text { Assumirem sua } \\
\text { responsabilidade. } \\
\text { Leis claras e } \\
\text { objetivas. } \\
\text { Comportamento do } \\
\text { consumidor } \\
\end{array}$ & Desafio & \\
\hline
\end{tabular}

Fonte: Autora, 2018

Nota 1: Legenda das Referências: Hord $(1981)^{1}$; Hord $(1986)^{2}$; Brna $(1998)^{3}$; Das e Teng $(1998)^{4}$; Polenske $(2004)^{6}$; Kemczinski et al. $(2008)^{7}$; Ansell e Gash $(2008)^{8}$; Winckler e Molinari (2011) ${ }^{9}$; Silva (2007) ${ }^{10}$

Nota 2: As células com tons mais escuros foram usadas para sinalizar atributos com "não conformidades" com a literatura.

Nesse cenário, o Quadro 21 mostra que todos os casos optaram pela estrutura adequada para cooperar, conforme a literatura, ainda que no Brasil o excesso de poder e controle de um dos atores tenha comprometido alguma das características importantes para efetivar a cooperação. Entretanto, pode-se afirmar que os quatro países tiveram êxito no processo de cooperação, pois atingiram seu objetivo principal. Dessa forma, percebe-se a importância da 
definição da estrutura adequada para cada tipo de processo, além da importância de respeitar as características dos seus atributos para não dificultar sua implementação ou criar desconfiança e descontentamentos entre os membros do grupo. No caso do Brasil, esse resultado ganha relevância, pois o PP foi a primeira iniciativa para operar a LR de REEE de forma organizada. Além disso, contou com a participação voluntária de todos os atores que discutem o AS.

Entretanto, dois fatores chamam atenção no impacto da cooperação: a diferença de REEE coletados pelos países estudados e os desafios para obter melhores resultados com a contribuição do consumidor. Alguns fatores podem ser levantados sobre a diferença de REEE coletados. Primeiro, existe uma diferença entre o tempo de existência dos sistemas de LR de REEE e suas características. O sistema tem quase três décadas de funcionamento na Suíça e a motivação para iniciar a LR foi a vontade de um grupo de fabricantes e a necessidade de atender o consumidor. Além disso, suas ORPs não competem e não possuem metas de coleta. Dessa forma, além da diferença de tempo entre os sistemas, a motivação para implementar a LR de REEE nos outros países foi por força da lei, os modelos de LR são baseados na concorrência e o consumidor só aparece na matriz como desafio a ser vencido. Esse último fato leva à reflexão do próximo fator que destoou entre a Suíça e os outros países: a presença do desejo do consumidor na dimensão Motivação. Ao contrário da Suíça, que economiza com educação ambiental devido ao alto nível de conscientização do seu cidadão, os outros países precisam investir alto em propaganda de massa se quiserem sensibilizar o consumidor para participar da LR de REEE de forma cooperativa. 


\section{CONSIDERAÇÕES FINAIS}

O acelerado crescimento do uso dos EEE e a obsolescência programada e perceptiva têm contribuído para o aumento exponencial do descarte dos seus resíduos ao final de vida, além de ampliar os riscos socioambientais no caso da ausência na destinação adequada. A presente pesquisa mostra que uma resposta para este desafio tem sido proposta em programas de LR.

Nesse cenário, a Europa surge como exemplo de implementação da LR de REEE devido a sua efetivação exitosa em diversos países. A maior parte dos países europeus a implementou para atender à Diretiva de REEE de 2002, que estabelece normas e metas para o descarte correto de REEE em todos os países membros da UE.

Este estudo mostra, no entanto, que é preciso analisar os modelos de LR a partir de uma perspectiva mais ampla que possibilite entendê-los para além do papel da legislação, uma vez que o nível de efetividade deste processo varia considerando os países estudados. Para esta pesquisa, adotou-se o pressuposto de que os modelos de LR podem se beneficiar e atingir maior efetividade quando a cooperação e a colaboração entre os atores envolvidos estão presentes. Interessante notar que, mesmo considerando que as características colaborativas e cooperativas sejam intrínsecas a sistemas de LR de REEE, poucos estudos se aprofundaram nesta temática ao discutir tais modelos.

O estudo mostrou que, de fato, colaboração e cooperação são conceitos diferentes, mas muitas vezes complementares, já que, quando atuam de forma intercalada nos processos para implementação de LR, potencializam a efetivação da cadeia reversa de REEE.

Em alguns momentos, a colaboração permite a elaboração de leis mais efetivas, de sistemas de controle e de qualidade, e o desenvolvimento de novas tecnologias que facilitem a LR. Em outros momentos, a cooperação garante capilaridade, aumento do volume de REEE coletados e redução do custo da LR. Dessa forma, não é possível dizer se a colaboração vem antes da cooperação ou vice-e-versa, corroborando Kemczinski et al. (2008), que defendem uma visão ampla dos conceitos, de forma que eles possam ser executados separadamente ou intercalados, sem ordem certa, mas respeitando as características do processo a ser executado no momento. Quando são usados adequadamente, portanto, eles conferem resultados mais efetivos ao processo de LR de REEE.

O presente trabalho mostrou também que o exemplo mais concreto desssa dinâmica é o caso da Suíça, pois é o país que menos apresenta não conformidades com a literatura e os 
melhores resultados na LR de REEE, sendo referência mundial no tema. A Suíça mostra elementos da colaboração e cooperação muito claros. No caso da colaboração, os atores envolvidos participam conjuntamente no desenvolvimento das leis, normas e sistemas para melhorar a LR, sempre buscando o consenso entre eles e a melhor solução para o problema, em um processo de melhoria contínua. O governo suíço atua como facilitador desse processo, normatizando os sistemas criados e ampliando seu escopo, quando entende que isso pode melhorar os resultados, mas sempre de forma consensual. Além disso, a maioria dos atores da indústria se mantêm próximos às ORPs, para auxiliar na busca de soluções, unidos por um senso de comunidade. Esse fator se deve a uma particularidade do país, seu tamanho. A proximidade geográfica entre atores facilita o processo de colaboração, de acordo com Balancieri (2004), pois permite maior sinergia entre os membros e compartilhamento de competências.

Destaca-se, para essa pesquisa, que não foi encontrado um vínculo semelhante entre os membros da indústria e as ORPs em nenhum dos outros casos estudados. Quanto aos aspectos operacionais ligados à cooperação, o sistema de LR de REEE tem papéis claros para todos, com mecanismos que asseguram a transparência dos processos, focados na busca pelos melhores resultados possíveis. Para atestar a eficiência do sistema e a motivação dos atores envolvidos na coleta, as ORPs desenvolveram um sistema de contrapartida financeira bem delineado, para remunerá-los proporcionalmente aos seus resultados, assegurando maior lucratividade no processo. Para Hord (1981), de fato, é importante entender quais são os fatores motivacionais dos atores, para que se possa estimulá-los e motivar sua efetiva participação na ação. Além disso, a pesquisa mostrou um valor novo para os atributos de motivação: a predisposição suíça para ser sustentável, que surgiu tanto como necessidade ou desejo, quanto como oportunidade e disposição para atuar em parceria. Esse fator estimula a busca por parcerias, sempre que se percebe a oportunidade ou necessidade de melhorar algo no sistema.

Nesse cenário, as ORPs criaram um sistema de coleta compartilhado, com alta capilaridade, construído por meio das parcerias com o sistema de coleta seletiva da municipalidade, supermercados e dos OGRs. Esse sistema facilita a operação e reduz seus custos, o que confere uma TAR reduzida ao consumidor. Dessa forma, a Suíça reúne uma série de fatores que facilitam a colaboração e a cooperação no país, garantindo o aprimoramento constante da LR de REEE. É também o único caso que relatou a motivação do consumidor para atuar na LR de REEE. Garante, portanto, o elemento seminal para que todos os atores sejam motivados a participar dela.

Destaca-se que nenhum dos outros três países apresentou um modelo de LR de REEE com tantos elementos da colaboração e cooperação em harmonia com a estrutura descrita pela 
literatura quanto a Suíça, com fatores motivacionais baseados no desejo e na oportunidade de todos os atores em executá-las. Ressalta-se que, no caso suíço, medidas voluntárias, ainda que pontuais, são potencializadas pela legislação, traduzindo-se em um movimento forte de cooperação e colaboração.

Já nos casos da Espanha e de Portugal, os modelos de LR de REEE se iniciam por força mandatória da Diretiva da UE, que exige que os países que compõem o bloco atendam aos resultados determinados por ela (EUR-LEX, 2015). Percebe-se que a Diretiva impactou mais fortemente na cooperação do que na colaboração, ainda que em níveis diferentes. Especificamente no caso de Portugal, verifica-se que a legislação influenciou de maneira acentuada o processo de cooperação, que se traduziu em atributos fortes, como a estrutura adequada com papéis bem definidos e SIs centralizados do governo, para garantir o controle e transparência do processo, além da sinergia entre os atores. Nesse cenário, Portugal é o país que está mais próximo da Suíça em termos de resultados e de estrutura para facilitar a colaboração e cooperação. Depois do modelo suíço, é o caso que apresenta menos não conformidades com a literatura, nos dois conceitos. Dessa forma, aufere o segundo lugar nos resultados de coleta entre os países estudados, mas longe dos $16 \mathrm{~kg}$ por habitante da Suíça.

Desde 2010, Portugal consegue atingir as metas estabelecidas pela UE e vem aumentando gradativamente seus resultados de coleta. Esses fatores corroboram a literatura no que tange à importância do escopo e estrutura para efetivar a cooperação na operacionalização de sistemas complexos, como a LR de REEE. Quanto aos valores de REEE coletados, é importante ressaltar que, para os atores que operam a LR em Portugal, a métrica de sucesso do sistema está baseada nas cotas de coleta e no atendimento dos requisitos de investimento em P\&D e educação ambiental, pois esse é o resultado esperado por seus associados. Assim, sua motivação é a necessidade de atender às metas estabelecidas pela lei, dentro do que foi estabelecido pela Diretiva de REEE, e não as superar. Dessa forma, pode-se inferir que esses atores se limitam a fazer o que a Diretiva determina, tanto que a maior resistência das EGs está relacionada às metas mais exigentes de Portugal, acima das que a UE estabeleceu para LR de REEE.

Nesse contexto, no que tange a colaboração, dois fatores se destacam na diferença com que Suíça e Portugal lidam com a motivação e o poder nessas relações. Primeiro, ainda que o governo português demonstre desejo de ser sustentável, a lei de LR de REEE foi elaborada para atender à Diretiva de REEE, e, portanto, não foi motivada pela iniciativa de nenhum dos atores do setor de EEE, nem do próprio governo. Segundo, apesar do governo desejar consenso entre os atores, ele busca as parcerias colaborativas para validar suas propostas por meio da 
conscientização dos atores sobre a importância de superar determinados pontos conflituosos e da necessidade de esforços que todos têm que fazer para melhorar a gestão dos REEE. De acordo com Ansell e Gash (2008) nenhum desses comportamentos destoa da colaboração, pois permitem que o governo valide a sua proposta. Os autores advertem, entretanto, para o risco do governo usar o seu poder para persuadir os outros atores, gerando conflitos de confiança no grupo e, assim, desmotivar a participação colaborativa.

Apesar destas considerações, Portugal tem um nível muito bom de efetivação das leis e sistemas de gestão dos REEE, pois tem conseguido implementar tudo o que foi necessário, em um curto período. Embora ainda haja reclamações sobre a forma como o governo português conduziu as negociações na elaboração de leis e regulamentos, os atores envolvidos continuam a contribuir com os processos de planejamento das leis e com os sistemas de controle, pois percebem que o governo demonstra interesse em suas opiniões e, às vezes, cede frente às contestações. De toda forma, este mecanismo enriquece o resultado do processo e permite que todos alcancem pequenas vitórias, tão importantes para validar as parcerias colaborativas.

No entanto, no caso espanhol, ainda que a força externa fosse a mesma, os arranjos sociais se limitaram às atividades de cooperação, não sendo possível verificar elementos que permitissem entender se a colaboração se efetivou de forma adequada no país. A Espanha é o país com o menor resultado de coleta entre os três países europeus e o que mais teve dificuldades para alcançar as metas até o momento. Nesse sentido, foi o caso que mais relatou não conformidades com a literatura sobre cooperação. Esses fatores evidenciam a importância de escolher a estrutura mais adequada para a natureza da atividade que será realizada, assim como entender quais são os elementos motivacionais que a antecedem.

Nesse contexto, o modelo de LR de REEE não apresenta, na dimensão motivação na cooperação, nenhuma citação sobre os consumidores, que apresentam baixa conscientização ambiental no que tange à coleta seletiva e à gestão de RSU. Esse fato se agrava quando se trata dos REEE, pois, para o consumidor, os REEE têm valor econômico e, portanto, não devem ser “jogados no lixo". Entretanto, é fundamental que esse consumidor seja motivado a participar da LR de REEE. Dessa forma, é necessário que se invista em propaganda de massa, para que o consumidor seja convencido da importância de fazer o descarte, assim como é motivado para comprar um produto novo. Além disso, o sistema do município não conta com coletores específicos para REEE, junto aos pontos de descarte. Existem jaulas específicas para os REEE apenas em Ecopontos, mas esses locais ficam mais afastados dos centros comerciais, afetando a capilaridade da LR. Esse fator não facilita o acesso ao descarte, nem a lembrança para descartar os REEE. Resulta disso que o sistema municipal coleta apenas 1/3 dos resíduos 
coletados pelos SIGs. Dessa forma, os SIGs se tornaram dependentes de recicladores fornecedores, que compram esses resíduos de qualquer pessoa, inclusive daquelas que os roubam nos pontos de coleta municipais, para vender e sobreviver, devido à sua vulnerabilidade social.

Ainda relacionado com a dimensão motivação, na Espanha, os atores envolvidos parecem dar pouca relevância para as metas atuais, principalmente as específicas por categoria, pois a legislação está em período de transição até 2019, durante o qual é aceitável que não sejam cumpridos os objetivos anuais. Em contrapartida, os recicladores fornecedores perceberam nos SIGs uma forma de aumentar sua receita, pois, além de vender os metais contidos nos REEE, atividade já realizada por eles, podem receber recursos por emitir relatórios de gestão desses resíduos. Para se fortalecer e melhorar esses resultados, esses recicladores buscam parcerias com recicladores com Código LER diferentes, ampliando o seu escopo e ganhando vantagem competitiva, além de investirem em marketing para atrair mais clientes que vendam seus REEE. Esses fatores reforçam a importância da motivação em parcerias de cooperação (HORD, 1981; POLENSKE, 2004).

No Brasil, por sua vez, a lentidão dos resultados pode ser explicada pela fragilidade das estratégias de colaboração e cooperação no país. De fato, ao mesmo tempo em que elas podem potencializar os resultados da LR, sua ausência pode explicar menores níveis de efetividades nesses sistemas. Com efeito, é no caso brasileiro que se encontra o maior número de não conformidades com a literatura sobre colaboração e cooperação, além dos menores resultados na coleta de REEE e nos avanços incipientes na legislação para implementá-la, posto que, após oito anos da aprovação da PNRS, o AS ainda não foi firmado.

Enquanto a colaboração, no Brasil, é praticamente inexistente por causa da falta de atributos de motivação, objetivos convergentes e estrutura com valores divergentes à natureza do processo, a cooperação é limitada em função das características do único caso de implementação da LR de REEE que envolve os atores do setor. Alguns fatores podem ser elencados para explicar melhor porque a colaboração não se efetiva na elaboração do AS.

De fato, os elementos centrais para iniciar a busca por parcerias para resolver problemas complexos, como a elaboração de um modelo de LR de REEE, não aparecem no Brasil, pois os atores envolvidos, como governo, indústria e comércio, não têm senso de urgência, nem prioridade, tampouco desejo de implementar a LR de REEE, pois a consideram como apenas um custo. Além disso, a única oportunidade que visualizam ao participarem do GT é a de tentar diminuir suas responsabilidades pelo processo e reduzir os custos da LR. Não buscam por complementariedade de competências ou aumento das suas capacidades, contrariando os 
preceitos básicos para iniciar a colaboração. Dessa forma, evitam que outros atores que tenham perspectivas diferentes da sua, mas conhecimentos que poderiam ajudar a viabilizar a LR, participem do AS, pois temem que esses atores levantem as bandeiras que eles têm tentado evitar, como a inclusão das cooperativas na LR e a viabilidade econômica da operação sem a isenção de impostos sobre a TAR.

Assim, nenhum dos atributos da motivação foi atendido, ainda que os atores envolvidos afirmem que é importante poder participar do AS e o governo brasileiro queira diminuir os impactos ambientais dos REEE e validar o modelo de LR de forma colaborativa. Sem desejo ou necessidade, a parceria se torna muito mais complexa e difícil de se efetivar. No caso do Brasil, os objetivos individuais sobrepõem-se aos do grupo e a expectativa de resultados tangíveis é maior do que dos intangíveis, além de serem incompatíveis com os resultados esperados pelos outros atores. De fato, Poleske (2004) adverte para a importância do objetivo do grupo, que tem que ser maior que os interesses pessoais para efetivar a colaboração.

Com motivação e escopo comprometidos, conforme refletido pelas não conformidades da literatura, a estrutura escolhida para discutirem o AS não favoreceu aspectos como sinergia e facilitação da inovação, pois as atividades foram desenhadas para serem realizadas fora do grupo, com reuniões esporádicas. Após as reuniões gerais, os membros do grupo que prepara o AS se dividiam em dois subgrupos, setor privado e governo, e discutiam separadamente, ao longo do semestre, os assuntos do seu interesse para se prepararem para a reunião seguinte. Assim, muitas vezes agiam como adversários. Esse comportamento deteriorou qualquer possibilidade de criação de confiança entre os membros do grupo. A troca de informação com o grupo geral, o GT, era feita por mecanismos de comunicação assíncronos e os representantes das organizações enviados para as reuniões tinham o papel de representar sua instituição apenas como porta-vozes. Portanto, foi usada estrutura cooperativa em um processo tipicamente mental e colaborativo. Esse caso permite inferir sobre a importância do uso adequado da estrutura a partir dos fatores determinantes para colaboração ou cooperação.

O processo cooperativo analisado - o PP, por outro lado, teve apenas oito meses de operacionalização, limitando o alcance de seus resultados. Além disso, ele foi executado por um ator externo ao contexto brasileiro, a JICA, que centralizou todo o poder de decisão. Ainda que o PP tenha conseguido garantir a motivação dos atores que estavam interessados em aprender sobre como a LR de REEE funcionaria no Brasil e ter acesso ao conhecimento da equipe da JICA, foram atitudes oportunistas que motivaram sua adesão. Nesse caso, os atores, assim como no AS, viam a oportunidade de comprovar seu ponto de vista com os resultados do projeto, para diminuir sua parte da responsabilidade. Os objetivos eram individuais, o que é 
característico de um processo de cooperação, e parte deles estava declarada, como obter o conhecimento sobre o cenário brasileiro, mas parte do que esperavam receber desse aprendizado era que ele confirmasse os pontos de vista de cada ator. A expectativa desse resultado individual, contudo, foi omitido no grupo. Sabe-se, entretanto, que em processos cooperativos é importante que todos os resultados desejados sejam declarados para garantir a confiança entre os membros. E, por último, ainda que as tarefas e papéis tenham sido definidos de forma clara, o excesso de controle do proponente do projeto centralizou o poder e tirou a autonomia das empresas, gerando desmotivação e descontentamento na maioria dos participantes. Esse fator é corroborado pela atuação dos varejistas, que aumentaram os resultados de coleta quando conseguiram ter mais controle sobre a operação de coleta de REEE em suas lojas, criando campanhas de descarte.

Assim, para a colaboração se efetivar no Brasil, em primeiro lugar o governo e o setor privado precisam assumir a sua responsabilidade pela implementação da LR de REEE, atendendo o atributo "necessidade". Além disso, precisam ser capazes de visualizar as vantagens que a LR pode gerar para todos, como criar divisas, novos negócios e empregos com a efetivação da reciclagem. Dessa forma, seria possível obter um valor positivo para o atributo "oportunidade", o que facilitaria a disposição para atuarem em parceria, na busca pelo melhor modelo. Depois de desenvolver os fatores motivacionais, seria necessário que os atores tivessem como objetivo comum a definição de um modelo de LR de REEE factível para todos. E, por último, seria importante que aproximassem as relações entre os atores envolvidos no AS por meio de reuniões presenciais, disponibilizando representantes capazes de articular as mudanças legislativas necessárias para criar mecanismos que facilitem a cooperação na operação de LR.

Naturalmente, a quantidade de países estudados limita a pesquisa, no que tange à generalização dos fatores determinantes para a escolha da estratégia mais adequada para definir a estrutura de parceria a ser adotada. Além disso, como visto na pesquisa, a realidade dos países fez surgir novos valores para alguns atributos. Sem a investigação de um universo maior, contudo, não foi possível esgotar todas as possibilidades de valores que os atributos podem assumir, para sua aplicação em sistemas de LR de REEE. Para pesquisas futuras, recomendase a ampliação da quantidade de países analisados e uma abordagem que inclua o consumidor, para entender a diferença de elementos que motivam seu comportamento e como ele pode ser afetado, visando a melhor construção de um modelo conceitual e o fomento de políticas públicas que incentivem a sua participação. Além disso, após levantar os valores que os atributos podem assumir em outros países, seria interessante fazer um estudo quantitativo que permitisse definir 
em que grau os fatores determinantes da colaboração e da cooperação impactam sobre a implementação da LR de REEE.

Mesmo considerando os limites apresentados, acredita-se que esse estudo lança um novo olhar para entender os desafios enfrentados para a implementação da LR de REE na realidade brasileira ao interpretar o fenômeno a partir das limitações dos processos de colaboração e cooperação entre os atores envolvidos. Além disso, foi possível criar uma matriz conceitual com os fatores determinantes para definir qual é o tipo de parceria mais adequado. A pesquisa possibilitou levantar outros valores para atributos da dimensão Motivação, como a "predisposição para ser sustentável", "histórico positivo em colaboração" e, na dimensão Estrutura, no atributo recursos financeiros, "cada um arca com o seu custo". Dessa forma, a pesquisa pode contribuir para facilitar a implementação da LR de REEE no setor privado e fomentar políticas públicas e sistemas de controle para facilitar a cooperação e a colaboração entre os diversos atores envolvidos. 


\section{REFERÊNCIAS}

ABINEE - ASSOCIAÇÃO BRASILEIRA DA INDÚSTRIA ELÉTRICA E ELETRÔNICA. Abinee apoia Projeto Descarte ON. 26/abr /2016b. Disponível em:

$<$ http://www.abinee.org.br/noticias/com46.htm>. Acesso em: 07 dez. 2016.

. Abinee entrega proposta para Acordo de Logística Reversa. 2018. Disponível em: $<$ http://www.abinee.org.br/noticias/com311.htm>. Acesso em: 10 de ago. 2018.

. Green Eletron: Uma realidade. 2016a. Disponível em:

$\overline{<\mathrm{http}: / /}$ www.abinee.org.br/noticias/com38.htm>. Acesso em: 08 dez. 2016.

Decreto assegura isonomia no cumprimento de obrigações na Logística Reversa. 2017. Disponível em: < http://www.abinee.org.br/noticias/com62.htm>. Acesso em: 10 ago. 2018.

em:

O exemplo japonês. Revista ABINEE. Ano 18, n. 83, p.29, out. 2015. Disponível

$<$ http://www.abinee.org.br/informac/revista/83/files/assets/common/downloads/revista\%20abi nee\%2083.pdf>. Acesso em: 07 dez. 2016.

ABREE - ASSOCIAÇÃO BRASILEIRA DE RECICLAGEM DE ELETROELETRÔNICOS E ELETRODOMÉSTICOS. Associação. 2016. Disponível em: <

http://abree.org.br/associacao/>. Acesso em: 08 dez. 2016.

ANSELL, C.; GASH; A. Collaborative governance in theory and practice. Journal of public administration research and theory, Oxoford, v. 18, n. 4, p. 543-571, out, 2008.

APA - ASSOCIAÇAO PORTUGUESA DO AMBIENTE. Resíduos de Equipamentos Elétricos e Eletrónicos (REEE): Principais Resultados de Gestão 2015. 2016. Disponível em:

$<$ https://www.apambiente.pt/_zdata/Politicas/Residuos/FluxosEspecificosResiduos/REEE/Res ultados_REEE_2015_Portal.pdf $>$. Acesso em: 10 ago. 2018.

ARAUJO, F. S. et al. Estratégias de Ecodesign aplicadas às atividades da logística reversa. REBRAE. Revista Brasileira de Estratégia, Curitiba, v. 5, n. 1, p. 105-116, jan./abr. 2012.

AUGusto, E. E. F. Logística Reversa de Computadores e Celulares: desafios e perspectivas para o modelo brasileiro. 2014. 157 f. Dissertação (Mestrado em Admnistração de Empresas) - Centro Universitário FEI, São Paulo, 2014.

AUGUSTO, E. E. F.; DEMAJOROVIC, J.; MELGAREJO-MORENO, J. The impact of cooperation on the implementation of the 'Descarte on' WEEE reverse logistics pilot project in Brazil. WIT Transactions on The Built Environment, v. 179, p. 269- 280, 2018.

BAFU - SWISS FEDERAL OFFICE FOR THE ENVIRONMENT. Swiss financing system for the recycling of WEEE. 2012 (Documento escaneado). 
BALANCIERI, R. Análise de redes de pesquisa em uma plataforma de gestão em ciência e tecnologia: uma aplicação à Plataforma Lattes. 2004. 117 f. Dissertação (Mestrado em Engenharia de Produção) - Universidade Federal de Santa Catarina, Florianópolis, 2004. Disponível em:

$<$ https://repositorio.ufsc.br/bitstream/handle/123456789/87468/224645.pdf? sequence=1>. Acesso em: 07 ago. 2016.

BALANCIERI, R. et al. A análise de redes de colaboração científica sob as novas tecnologias de informação e comunicação: um estudo na Plataforma Lattes. Ciência da Informação, Brasília, v. 34, n. 1, p. 64-77, jan. 2005. Disponível em:

$<$ http://www.scielo.br/scielo.php?script=sci_arttext\&pid=S0100-

19652005000100008\&lng=en\&nrm=iso>. Acesso em: 08 ago. 2016.

BALDÉ, C. P. et al. E-waste statistics: Guidelines on classifications, reporting and indicators. Bonn: United Nations University, IAS-SCYCLE, 2015. Disponível em: $<$ https://i.unu.edu/media/ias.unu.edu-en/project/2238/E-waste-

Guidelines_Partnership_2015.pdf $>$. Acesso em: 08 ago. 2016

BALESTRIN, A.; VARGAS, L. M. A dimensão estratégica das redes horizontais de PMEs: teorizações e evidências. Revista de Administração Contemporânea, Curitiba, v. 8, p. 203227, Edição especial, 2004. Disponível em: <http://dx.doi.org/10.1590/S141565552004000500011>. Acesso em: 08 ago 2016.

BALESTRIN, A.; VERSCHOORE; J. R.; REYES JUNIOR, E. O campo de estudo sobre redes de cooperação interorganizacional no Brasil. RAC-Revista de Administração Contemporânea, Curitiba, v. 14, n. 3, p. 459-477, mai/jun, 2010. Disponível em: < http://www.scielo.br/pdf/rac/v14n3/v14n3a05.pdf>. Acesso em: 08 ago 2016.

BARDIN, L. Análise de conteúdo. São Paulo: Almedina, 2011.

BAUMGART, G. Industrywide cooperation for consumer affairs. California Management Review, Berkeley, v. 16, n. 3, p. 52-57, abr., 1974. Disponível em: < https://journals.sagepub.com/doi/10.2307/41164508>. Acesso em: 09 jul 2016. https://doi.org/10.2307/41164508

BERNSTAD, A.; LA COUR JANSEN, J.; ASPEGREN, H. Property-close source separation of hazardous waste and waste electrical and electronic equipment-A Swedish case study. Waste Management, Amesterdã, v. 31, n. 3, p. 536-543, 2011.

BERNSTEIN, E. M. British Policy and a World Economy. The American Economic Review, v. 35, n. 5, p. 891-908, 1945.

BOE - BOLETÍN OFICIAL DEL ESTADO. Ley 22/2011, de 28 de julio, de residuos y suelos contaminados. 15 maio 2016. Disponivel em: <https://www.boe.es/buscar/act.php?id=BOEA-2011-13046>. Acesso em: 24 jul. 2018.

Real Decreto 110/2015, de 20 de febrero, sobre residuos de aparatos eléctricos y electrónicos. 21 fev 2015. Disponivel em: https:/www.boe.es/eli/es/rd/2015/02/20/110>. Acesso em: 24 jul. 2018. 
BRASIL. Decreto 7.404 de 23 de dezembro de 2010. Regulamenta a Lei n. 12.305 de 02 de agosto de 2010, que institui a Política Nacional de Resíduos Sólidos, cria o Comitê Interministerial da Política Nacional de Resíduos Sólidos e o Comitê Orientador para a implantação dos Sistemas de Logística Reversa, e dá outras providências. Brasíla, Planalto, Casa Civil, 2010b. Disponível em: <http://www.planalto.gov.br/ccivil_03/_Ato20072010/2010/Decreto/D7404.htm> Acesso em 03 jun. 2011.

\section{Lei 12.305 de 02 de agosto de 2010. Institui a Política Nacional de Resíduos} Sólidos; altera a Lei n. 9.605, de 12 de fevereiro de 1998; e dá outras providências. DF, Brasília, Planalto, Casa Civil, 2010a. Disponível em:

$<$ http://www.planalto.gov.br/ccivil_03/_Ato2007-2010/2010/Lei/L12305.htm>. Acesso em: 03 jun. 2011.

BRNA, P. Models of Collaboration. Revista Brasileira de Informática na Educação, Porto Alegre, n. 3, 1998. Disponível em: <http://br-

ie.org/pub/index.php/rbie/article/view/2298/2060>. Acesso em: 15 maio 2016.

CARROLL, D. C. Man-machine cooperation on planning and control problems. IMR;

Industrial Management Review, Massachusetts, v. 8, n. 1, p. 145-165, 1966.

CETESB - COMPANHIA AMBIENTAL DO ESTADO DE SÃO PAULO. Decisão de diretoria n⿳ 120/2016/C, de 01 de junho de 2016. 2016. Disponível em:

$<$ http://www.cetesb.sp.gov.br/wp-content/uploads/sites/11/2014/12/DD-120-2016-C010616.pdf>. Acesso em: 20 dez. 2016.

DAS, T. K.; TENG, B. Between trust and control: Developing confidence in partner cooperation in alliances. Academy of management review, New York, v. 23, n. 3, p. 491512, jul., 1998.

DEMAJOROVIC, J.; MIGLIANO, J. E. B. Política nacional de resíduos sólidos e suas implicações na cadeia da logística reversa de microcomputadores no Brasil. Gestão \& Regionalidade, [S.1.], v. 29, n. 87, p. 64-80, dez. 2013. Disponível em: < http://dx.doi.org/10.13037/gr.vol29n87.2155>. Acesso em: 28 jan. 2015.

DEMAJOROVIC, J.; AUGUSTO, E. E. F.; SOUZA, M. T. S. de. Logística reversa de reee em países em desenvolvimento: desafios e perspectivas para o modelo brasileiro. Ambiente \& Sociedade, São Paulo, v. 19, n. 2, p. 119-137, jun. 2016.

DEMAJOROVIC, J. et al. Logística reversa: como as empresas comunicam o descarte de baterias e celulares? RAE-Revista de Administração de Empresas, São Paulo, v. 57, n. 2, p. 165-178, abr. 2012. Disponível em:

$<$ http://rae.fgv.br/sites/rae.fgv.br/files/artigos/10.1590_s0034-75902012000200004.pdf>. Acesso em: 16 ago. 2012.

DRURY, J. C. Consumers' Cooperation. Journal of Marketing, Chicago, v. 1, n. 4, p. 385 389, abr. 1937. Disponível em: <https://www.jstor.org/stable/1246794>. Acesso em: 19 abr. 2016.

ECOTIC. Ecotic reciclando para recrear. 2018 Disponivel em: $<$ http://www.ecotic.es/es/246569/Publicos.htm>. Acesso em: 10 ago. 2018. 
EISENHARDT, K. M. Building theories from case study research. Academy of Management Review, Califórnia, v. 14, n. 4, p. 532-550, out. 1989.

EL-KRETSEN. El-Kretsen: Portals and files. 2017. Disponível em: < http://www.elkretsen.se/english/portals >. Acesso em: 12 jan. 2017.

El-Kretsen: Collection. 2016. Disponível em: $<$ http://www.elkretsen.se/english/collection>. Acesso em: 12 dez. 2016.

ELRETUR. Sweden: world leader in WEEE collection and treatment. [2010?]. Disponível em: $<$ http://www.avfallsverige.se/fileadmin/uploads/elretur_eng.pdf $>$. Acesso em: 03 mar. 2013.

ERP-ES. Puntos de recogida. 2018. Disponível em: < https://erp-recycling.org/es-es/puntosde-recogida/>. Acesso em: 10 ago. 2018.

EUR-LEX. Diretivas da União Europeia. 2015. Disponível em: $<$ https://eurlex.europa.eu/legal-content/PT/ALL/?uri=URISERV:114527>. Acesso em: 29 set. 2018.

Directive 2012/19/eu of the european parliament and of the council of 4 July 2012 on waste electrical and electronic equipment (WEEE) (recast). 2012. Disponível em: < http://eur-lex.europa.eu/legal-content/PT/TXT/?uri=CELEX\%3A32012L0019>. Acesso em: 05 out 2015.

EUROSTAT. EEE put on the market and WEEE collected in the EU. 2015. Disponível em: $<$ https://ec.europa.eu/eurostat/statistics-explained/index.php?title=Waste_statistics__electrical_and_electronic_equipment\#EEE_put_on_the_market_and_WEEE_collected_in_th e_EU>. Acesso em: 18 ago. 2016.

. Overview. 2016. Disponível em: $<$ http://ec.europa.eu/eurostat/about/overview $>$. Acesso em: 07 dez. 2016.

Summary document of the Waste electrical and electronic equipment rates and targets. 2012. Disponível em:

$<$ http://appsso.eurostat.ec.europa.eu/nui/submitViewTableAction.do>. Acesso em: 07 dez. 2016.

View table Action. 2018. Disponível em:

$<$ http://appsso.eurostat.ec.europa.eu/nui/submitViewTableAction.do>.. Acesso em: 08 ago. 2018 .

GATTAZ, C. C. Um modelo de referência de formação e gestão de redes organizacionais: o caso do sistema de C, T\&I do setor aeroespacial brasileiro. 2010. 201 f. Tese (Doutorado em Engenharia de Produção). Escola Politécnica da Universidade de São Paulo. São Paulo. 2010 .

GAULT, E. H. Cooperation by business groups. Journal of Marketing, Chicago, v. 1, n. 4, p. 396-400, abr. 1937. 
GENERALITAT VALENCIANA. Convenio Marco entre la Conselleria del Medio Ambiente, Agua, Urbanismo Y Vivendas Y Las Entidades Gestoras de Los Sistemas Integrados de Gestión de Residuos de Aparatos Eléctricos Y Electrónicos. 29 maio 2008. (Documento escaneado).

GIGANTE, L. C.; RIGOLIN, C. C. D.; MARCELO, J. F. Redes sociais de produção e colaboração tecnológica para o descarte de resíduos de equipamentos elétricos e eletrônicos. AtoZ: novas práticas em informação e conhecimento, [S.1.], v. 1, n. 2, p. 52-64, nov. 2012. Disponível em: < doi:http://dx.doi.org/10.5380/atoz.v1i2.41312>. Acesso em: 28 jan. 2016.

GODOI, C.K.; BALSINI, C. P. V. A pesquisa qualitativa nos estudos organizacionais brasileiros: uma análise bibliométrica. In: GODOI, C.K.; BANDEIRA-DE-MELLO, R.; SILVA, A. B. da (Orgs.). Pesquisa, estratégia e métodos. 2. ed. São Paulo: Saraiva, 2010. cap. 2, p. 53-87.

GODOI, C.K.; MATTOS, P. L. C. L. Entrevista qualitativa: instrumento de pesquisa e evento de dialógico. In: GODOI, C.K.; BANDEIRA-DE-MELLO, R.; SILVA, A. B. da (Orgs.).

Pesquisa, estratégia e métodos. 2. ed. São Paulo: Saraiva, 2010. cap. 10, p. 301-323.

GUARNIERI, P. Logística Reversa: em busca do equilíbrio econômico e ambiental. 2. ed. São Paulo: Clube de autores, 2011.

HARGROVE, R. Colaboração criativa: a interação de talento e diversidade para obter resultados positivos. São Paulo: Editora Cultrix, 1998.

HARRIGAN, K. R. Joint ventures and competitive strategy. Strategic management journal, New Jersey, v. 9, n. 2, p. 141-158, mar/abr. 1988.

HART, L. C. Essentials of Successful Marketing: A Case History in Manufacturer-Distributor Collaboration. Journal of Marketing, Chicago, v. 13, n. 2, p. 195-201, out. 1948.

HISCHIER, R; WÄGER, P; GAUGLHOFER, J. D. WEEE recycling make sense from an environmental perspective? The environmental impacts of the Swiss take-back and recycling systems for waste electrical and electronic equipment (WEEE). Environmental Impact Assessment Review, St. Gallen, v. 25, p. 525-539, jul. 2005. Disponível em: $<$ http://www.ewasteguide.info/files/Hischier_2005_EIAR_0.pdf $>$. Acesso em: 16 maio 2012.

HOOD, J. N.; LOGSDON, J. M.; THOMPSON, J. K.. Collaboration for social problemsolving: A process model. Business and Society, Toronto, v. 32, n. 1, p. 1-17, jun. 1993.

HORD, S. M. A Synthesis of Research on Organizational Collaboration. Educational Leadership, Alexandria, v. 43, n. 5, p. 22-26, Feb 1986. Disponível em:

$<$ http://www.ascd.org/ASCD/pdf/journals/ed_lead/el_198602_hord.pdf $>$. Acesso em: 20 set. 2016.

Working Together: Cooperation or Collaboration? Educational Resources Information Center (ERIC). Austrian, Report n. 3123, 1981. Disponível em: $<$ http://files.eric.ed.gov/fulltext/ED226450.pdf $>$. Acesso em: 12 set. 2016. 
INSTITUTO ETHOS. Seis pontos a vencer. 2014. Disponível em: $<$ https://www3.ethos.org.br/cedoc/seis-pontos-a-vencer/\#.W7LOLuhKjIU>. Acesso em: 23 jan. 2015.

JANG, Y.-C. Waste electrical and electronic equipment (WEEE) management in Korea: generation, collection, and recycling systems. Journal of Material Cycles and Waste Management, Tokyo, v. 12, n.4,p. 283-294, nov. 2010. Disponível em: $<$ http://link.springer.com/article/10.1007\%2Fs10163-010-0298-5>. Acesso em: 01 jul. 2012.

JANSE, B.; SCHUUR, P.; BRITO, M. P. de. A reverse logistics diagnostic tool: the case of the consumer electronics industry. The International Journal of Advanced Manufacturing Technology, Berlim, v. 47, p. 495-513, nov. 2009. Disponível em: < https://doi.org/10.1007/s00170-009-2333-z >. Acesso em: 17 dez 2013.

JAYARAMAN, V; LUO, Y. Creating competitive advantages through new value creation: e reverse logistics perspective. Academy Management Perspective, New York, v. 1, n. 2, p. 56-73, maio 2007.

JICA - JAPAN INTERNATIONAL COOPERATION AGENCY. Projeto para Melhoria da Logística Reversa de REEE no Brasil Relatório de Conclusão do Projeto (Versão Resumida). São Paulo: JICA, 2017. (Arquivo em PDF).

KEBKER, Vant. A Note on" Consumer Actions and Nonprofit Co-Operation". Journal of Marketing, Chicago, v. 15, n. 4, p. 457-462, abr. 1951.

KEMCZINSKI, A. et al. Colaboração e cooperação - pertinência, concorrência ou complementaridade. Revista Produção Online, Florianópolis, v. 7, n. 3, p.1-15, jul. 2008. ISSN 16761901. Disponível em: <https://producaoonline.org.br/rpo/article/view/68>. Acesso em: 15 nov. 2016. doi:http://dx.doi.org/10.14488/1676-1901.v7i3.68.

KHETRIWAL, D.S; KRAEUCHI, P.; WIDMER, R. Producer responsibility for e-waste management: key issues for consideration e learning from the swiss experience. Journal of Environmental Management, Sint-Katelijne-Waver, v. 90, n.1, p. 153-165, jan. 2009.

KIRSCHNER, B. W.; DICKINSON, R; BLOSSER, C. From cooperation to collaboration: The changing culture of a school/university partnership. Theory into practice, Londres, $\mathrm{v}$. 35, n. 3, p. 205-213, nov. 1996.

KOGA, G. A. et al. Comportamento do usuário em relação ao descarte e à reciclagem de aparelhos celulares no Estado de São Paulo. Future Studies Research Journal: Trends and Strategies, São Paulo, v. 6, n. 2, p. 3-29, jul/dez. 2014.

KOLBUS, D. Building a collaborative advantage. Work Study, Bingley, v. 41, n. 1, p. 10-15, 1992.

LANDECKER, W. S. International Relations as Intergroup Relations. American Sociological Review, Londres, v. 5, n. 3, p. 335-339, jun. 1940. Disponível em: $<$ https://www.jstor.org/stable/2084035?seq=1\#page_scan_tab_contents $>$. Acesso em: 16 jul. 2016. 
LANDRY, S.; TRUDEL, Y.; DIORIO; M. O. Just-in-time supply: cooperation, competition, and abuse. Competitiveness Review: An International Business Journal, Bingley, v. 8, n. 1, p. 37-45, 1998.

LAU, K. H.; WANG, Y. Reverse logistics in the electronic industry of China: a case study. Supply Chain Management: An International Journal, Bingley, v. 14, n. 6, p. 447-465, 2009. Disponível em:

$<$ https://www.emeraldinsight.com/doi/abs/10.1108/13598540910995228>. Acesso em: 25 out 2013.

LEE-MORTIMER, A. A dynamic collaboration. The TQM Magazine, Bingley, v. 5, n. 1, 1993. Disponível em: < https://www.emeraldinsight.com/doi/abs/10.1108/eb059546>. Acesso em: 25 out 2013.

LEITE, P. R.; LAVEZ, N.; SOUZA, V. M. de. Fatores da logística reversa que influem no reaproveitamento do "lixo eletrônico" - um estudo no setor de informática. In: SIMPOI. 2009, São Paulo. Anais eletrônico... p. 1-16. Disponível em: < http://www.webresol.org/textos/e2009_t00166_pcn20771.pdf>. Acesso em: 04 mar. 2011.

LIU, Peide; ZHANG, X. Research on the supplier selection of a supply chain based on entropy weight and improved ELECTRE-III method. International Journal of Production Research, Londres, v. 49, n. 3, p. 637-646, fev. 2011.

MANOMAIVIBOOL, P.; VASSANADUMRONGDEE, S. Extended producer responsibility in Thailand prospects for policies on waste electrical and electronic equipment. Journal of Industrial Ecology, Lund, v. 15, n. 2, p. 185-205, mar. 2011.

MAOT - MINISTÉRIO DO AMBIENTE E DO ORDENAMENTO DO TERRITÓRIO. Decreto-Lei n.o 20/2002 de 30 de Janeiro. Diário da República, n. 25/2002, Série I-A de 2002, 30 jan. 2002. Disponível em: < https://dre.pt/pesquisa//search/276215/details/maximized $>$. Acesso em: 17 ago. 2018.

MAPAMA - MINISTERIO DE AGRICULTURA Y PESCA, ALIMENTACIÓN Y MEDIO AMBIENTE. Responsabilidad ampliada del productor. 2018. Disponível em: $<$ https://www.mapama.gob.es/es/calidad-y-evaluacion-ambiental/temas/prevencion-y-gestionresiduos/flujos/responsabilidad-ampliada/> Acesso em: 20 jul. 2018.

MARTINEZ, A. R. Análisis comparado de la aplicación del principio europeo de responsabilidad ampliada del productor en envases, vehículos fuera de uso y residuos de aparatos eléctricos y electrónicos. 387 f. 2015. Tese (Doutorado em Economía Internacionaly Desarrollo). Universidad Complutense de Madrid, Madrid, 2015. Disponível em: $<$ http://eprints.ucm.es/40706/1/T38196.pdf>. Acesso em: 17 ago 2018.

MENDES, H. M. R. et al. Gestão da Logística Reversa de Eletroeletrônicos: Conceitos, Princípios e Desafios. Revista em Gestão, Inovação e Sustentabilidade, Brasilia, v. 2, n. 1, jun. 2016.

MIGLiAnO, J. E. B. Política Nacional de Resíduos Sólidos (PNRS): Perspectivas, Desafios e Oportunidades da Logística Reversa para a Indústria Nacional de Computadores. $124 \mathrm{f}$. 
2012. Dissertação (Mestrado em Administração) - Centro Universitário da FEI, São Paulo. 2012.

MMA - MINISTÉRIO DO MEIO AMBIENTE. Chamamento para a Elaboração de Acordo Setorial para a Implantação de Sistema de Logística Reversa de Produtos Eletroeletrônicos e seus Componentes: Edital No 01/2013. 2013. Disponível em:

$<$ http://www.mma.gov.br/images/editais_e_chamadas/SRHU/fevereiro_2013/edital_ree_srhu _18122012.pdf>. Acesso em: 24 jul. 2015.

MORROW, J. D. Modeling the forms of international cooperation: distribution versus information. International Organization, Cambridge, v. 48, n. 03, p. 387-423, maio 1994.

MTE - MINISTÉRIO PARA A TRANSIÇÃO ECOLÓGICA. Jornadas divulgativas sobre la plataforma electrónica RAEE. 2018. Disponível em:

$<$ https://www.mapama.gob.es/es/calidad-y-evaluacion-ambiental/temas/prevencion-y-gestionresiduos/notaresumenjornadasplataformaelectronicaraee_tcm30-456016.pdf $>$. Acesso em: 20 jul. 2018.

ODLE, T. Entrepreneurial cooperation on the Great Lakes: the origin of the methods of American grain marketing. Business History Review, Cambridge, v. 38, n. 04, p. 439-455, dez. 1964.

OFIRAEE. OFIRAEE. 2018. Disponível em: <http://www.ofiraee.es/>. Acesso em: 10 ago. 2018.

OLIVEIRA, C. R. de; BERNARDES, A. M.; GERBASE, A. E. Collection and recycling of electronic scrap: A worldwide overview and comparison with the Brazilian situation. Waste Management, Amesterdã, v. 32, p. 1592-1610, ago. 2012.

OLIVEIRA, M. L. et al. Bibliometric Analysis of International Literature on Collaboration in Supply Chain. BASE - Revista de Administração e Contabilidade da UNISINOS, São Leopoldo, v. 13, n. 1, p. 32-52, jan/mar. 2016.

PALMER, J. L. Can Consumer Cooperation Correct Important Defects in Marketing? Journal of Marketing, Chicago, v. 1, n. 4, p. 390-395, abr. 1937.

POLENSKE, K. Competition, collaboration and cooperation: an uneasy triangle in networks of firms and regions. Regional Studies, Abingdon, v. 38, n. 9, p. 1029-1043, 2004.

PREFEITURA DE SÃO PAULO. São Paulo inicia a implementação do Projeto Piloto em Logística Reversa. dez. 2014. Disponível em:

$<$ http://www.prefeitura.sp.gov.br/cidade/secretarias/servicos/amlurb/noticias/?p=187800>. Acesso em: 08 dez. 2016.

RECYCLIA. España cumple con los objetivos europeos de reciclaje de residuos electrónicos en 2017. Econoticias: Resumen de las atividades. jun. 2018. Disponível em: $<$ https://www.recyclia.es/econoticias/027ECONOTICIAS.pdf >. Acesso em: 10 ago. 2018. 
REVEILLEAU, A. C. A. de A. Política nacional de resíduos sólidos: aspectos da responsabilidade dos geradores na cadeia do ciclo da vida do produto. Revista Internacional de Direito e Cidadania (RIDC), São Paulo, n. 10, p. 163-174, jun. 2011.

RESIDUOS PROFEISIONAL. Ecolec lanza un buscador online de puntos de recogida de residuos electrónicos en toda España. 17 maio 2018. Disponível em:

$<$ https://www.residuosprofesional.com/buscador-puntos-recogida-raee $>$. Acesso em: 10 ago 2018.

ROGERS, D. S.; TIBBEN-LEMBKE, R. S. Going backwards: reverse logistics trends and practices. 1. ed. Reno: Reverse Logistics Executive Council, 1999.

ROSAS, J.; CAMARINHA-MATOS, L. M. An approach to assess collaboration readiness. International Journal of Production Research, Londres, v. 47, n. 17, p. 4711-4735, jun. 2009.

ROTTER, V. S.; CHANCEREL, P.; SCHILL, W. P. Practicalities of individual producer responsibility under the WEEE directive: experiences in Germany. Waste Mangement \& Research, Wien, v. 29, n. 9, p. 931-944, set. 2011.

SAMPIERI, R. H.; COLLADO, C. F.; LUCIO, P. B. Metodologia de pesquisa. $3^{a}$ ed. São Paulo: McGraw-Hill, 2006.

SCHERMERHORN, J. R. Determinants of interorganizational cooperation. Academy of management Journal, New York, v. 18, n. 4, p. 846-856, nov. 1975.

SCHLUEP, M. et al. Recycling from e-waste to resources: sustainable innovation and technology transfer industrial sector studies. Bonn: UNEP-UNU, Solving the E-waste Problem (STEP), 2009. Disponível em: $<$ http://www.unep.org/PDF/PressReleases/EWaste_publication_screen_FINALVERSION-sml.pdf>. Acesso em: 02 nov. 2012.

SENS. 25 years of SENS: Mora than 7 golden gate bridges. 2015. (Documento escaneado)

SENS; SWICO; SLRS. Technical Report 2016. 2016. Disponível em:

$<$ https://www.google.com.br/url?sa=t\&rct=j\&q=\&esrc=s\&source=web\&cd=2\&cad=rja\&uact $=8 \& v e d=0$ ahUKEwjd-

PvWztHRAhVEDZAKHUJkA_4QFgglMAE\&url=http\%3A\%2F\%2Fwww.swicorecycling.ch $\% 2$ Fdownloads\%2Fdokumente $\% 2$ Ftechnical-report-

2016.pdf\%2F3837\&usg=AFQjCNHITIIobSwG2gODxE34dXa7NO4pIQ>. Acesso em: 24 maio 2012.

. Technical Report 2017. 2017. Disponível em:

$<$ http://www.swicorecycling.ch/downloads/dokumente/technical-report-swico-sens-slrs2017.pdf/4598>. Acesso em: 17 ago. 2018.

SEPA - SWEDISH ENVIRONMENTAL PROTECTION AGENCY. WEEE directive in sweden: evaluation with future study. nov. 2009. Disponível em:

$<$ http://www.naturvardsverket.se/Documents/ publikationer/978-91-620-8421-9.pdf $>$. Acesso em: 24 maio 2012. 
SILVA, Cristiane Rocha; GOBBI, Beatris Christo; SIMÃO, A. A. O uso da análise de conteúdo como uma ferramenta para a pesquisa qualitativa: descrição e aplicação do método. Organizações Rurais \& Agroindustriais, Lavras, v. 7, n. 1, p. 70-81, 2005.

SILVA, D. H. DA. Cooperação internacional em ciência e tecnologia: oportunidades e riscos. Revista Brasileira de Política Internacional, Brasília, v. 50, n. 1, p. 5-28, jun., 2007.

Disponível em: < http://dx.doi.org/10.1590/S0034-73292007000100001>. Acesso em: 24 jun. 2016.

SINHA-KHETRIWAL, D.; KRAEUCHI, P; SCHWANINGER, M. A comparison of electronic waste recycling in Switzerland and in India. Environmental Impact Assessment Review, Amesterdã, n. 25, p.492, jul. 2005.

SLRS. History. 2008. Disponível em:

$<$ http://212.113.88.1/att/members/info_DRAFT\%202\%20pagerSLRS_def_60.pdf $>$. Acesso em: 07 dez. 2016.

THOMAS, K. W.; JAMIESON, D. W.; MOORE, R. K. Conflict and collaboration: Some concluding observations. California Management Review, Berkeley, v. 21, n. 2, p. 91-95, dez. 1978.

TORRETTA, V. et al. Management of waste electrical and electronic equipment in two EU countries: A comparison. Waste Management, Amesterdã, v. 33, n. 1, p. 117-122, jan. 2013.

VERGARA, S. C. Método de pesquisa em administração. São Paulo: Atlas, 2005.

Projetos e relatórios de pesquisa em administração. 5. ed. São Paulo: Atlas, 2004.

VERSCHOORE, J. R; BALESTRIN, A. Ganhos competitivos das empresas em redes de cooperação. Revista de Administração USP-Eletrônica, São Paulo, v. 1, n. 1, p. 1-21, 2008. Disponível em:

$<$ https://www.researchgate.net/profile/Jorge_Verschoore/publication/268870412_Ganhos_co mpetitivos_das_empresas_em_redes_de_cooperacao/links/5479bbfc0cf293e2da2b59c0.pdf $>$. Acesso em: 14 nov. 2016.

VIEIRA, J. G. V. Avaliação do estado de colaboração logística entre indústria de bens de consumo e redes de varejo supermercadista. 235 f. 2006. Tese (Doutorado em Engenharia de Produção) - Universidade de São Paulo, São Paulo, 2006.

VIEIRA, M. M. F.; ZOUAIN, D. M. Pesquisa qualitativa em administração: teoria e prática. Rio de Janeiro: FGV, 2005.

VIVALDINI, M.; SOUZA, F. B. de; PIRES, S. R. I. O relacionamento colaborativo na cadeia de suprimentos do McDonald's. Revista Gestão Industrial, Ponta Grossa, v. 3, n. 02, p. 2844, 2007.

WANG, F. et al. The Best-of-2-Worlds philosophy: Developing local dismantling and global infrastructure network for sustainable e-waste treatment in emerging economies. Waste Management, Amesterdã, v. 32, n. 11, p. 2134-2146, nov. 2012. Disponível em: $<\mathrm{http}$ ://www.ewasteguide.info/files/Wang_2012_Bo2W_0.pdf $>$. Acesso em: 28 fev. 2013. 
WINCKLER, N. C. e G. T. MOLINARI. Competição, colaboração, cooperação e coopetição: revendo os conceitos em estratégias interorganizacionais. Revista ADMpg Gestão Estratégica, Ponta Grossa, v. 4, n. 1, p. 1-12, 2011.

XAVIER, L. H. et al. Sistema de Logística Reversa de Equipamentos Eletroeletrônicos: Breve Análise da Gestão no Brasil e na Espanha. In: FORUM INTERNACIONAL DE RESÍDUOS SÓLIDOS, 4., 2013, Porto Alegre, RS. Anais eletrônicos... 2013. Disponível em: <http://www.institutoventuri.org.br/ojs/index.php/firs/article/view/572>. Acesso em: 10 ago. 2018.

YLÄ-MELLA, J. et al. Overview of the WEEE Directive and its implementation in the Nordic countries: national realisations and best practices. Journal of Waste Management, London, v. 2014, p. 1-18, out. 2014.

YIN, R. K. Estudo de caso: planejamento e métodos. 3. ed. Porto Alegre: Bookman, 2005.

YOSHIDA, C. Competência e as diretrizes da PNRS: conflitos e critérios de harmonização entre as demais legislações e normas. In: PHILIPPI Jr., A. (Coord). Política nacional, gestão e gerenciamento de resíduos sólidos. São Paulo: Manole, 2012. cap. 1, p. 3-38. 
APÊNDICE A - Atributos de colaboração 
Quadro 22 - Atributos de colaboração

\begin{tabular}{|c|c|c|c|}
\hline \multicolumn{4}{|c|}{ Atributos do Escopo } \\
\hline $\begin{array}{c}\text { Descrição dos } \\
\text { Atributos }\end{array}$ & $\mathbf{N}^{\circ}$ & Definição Colaboração & Referência Colaboração \\
\hline Natureza & 1.1 .1 & $\begin{array}{l}\text { Criação, desenvolvimento ou } \\
\text { elaboração de algo (ação mental) }\end{array}$ & Kemczinski et al. (2008) \\
\hline \multirow{3}{*}{$\begin{array}{l}\text { Objetivo: A quem } \\
\text { atende }\end{array}$} & 1.1 .2 & Objetivo comuns ao grupo & $\begin{array}{l}\text { Hord (1981); Hord (1986); Brna (1998); } \\
\text { Hargrove (1998); Balancieri (2004); Polenske } \\
\text { (2004); Winckler e Molinari (2011) }\end{array}$ \\
\hline & 1.1 .2 & Problemas comuns & Hargrove (1998) \\
\hline & 1.1 .2 & $\begin{array}{c}\text { Objetivos claros para ambos - } \\
\text { necessidade }\end{array}$ & Ansell e Gash (2008) \\
\hline Objetivo: Meta & 1.1 .3 & Metas compartilhadas com grupo & Hargrove (1998) \\
\hline \multirow{6}{*}{ Resultados } & 1.2 & Mútuos & $\begin{array}{l}\text { Hargrove (1998); Balancieri (2004); Ansell e } \\
\text { Gash (2008); Winckler e Molinari (2011) }\end{array}$ \\
\hline & 1.2 & Assimétricos & Polenske (2004); Winckler e Molinari (2011) \\
\hline & 1.2 & Percepção de ganhos mútuos, & Hord (1981); Hord (1986) \\
\hline & 1.2 & $\begin{array}{c}\text { Compartilham Resultados dos projetos } \\
\text { em que os atores estão envolvidos }\end{array}$ & Balancieri (2004) \\
\hline & 1.2 & $\begin{array}{l}\text { Baseados em expectativas devido à } \\
\text { falta de contrato formal }\end{array}$ & Brna (1998) \\
\hline & 1.2 & Interesse elevado nos resultados & Hord (1981); Hord (1986) \\
\hline $\begin{array}{l}\text { Resultados: } \\
\text { Tangíveis }\end{array}$ & 1.2.1.1 & Não precisa ser mútuo & Polenske (2004); Winckler e Molinari (2011), \\
\hline $\begin{array}{l}\text { Resultados: } \\
\text { Intangíveis }\end{array}$ & 1.2.1.2 & Compensa a falta do tangível & Polenske (2004); Winckler e Molinari (2011), \\
\hline Base: Atores & 1.3 & Não é compatível entre concorrentes & Winckler e Molinari (2011) \\
\hline \multicolumn{4}{|c|}{ Atributos da Estrutura } \\
\hline $\begin{array}{c}\text { Descrição dos } \\
\text { Atributos }\end{array}$ & $\mathbf{N}^{\circ}$ & Definição Colaboração & Referência Colaboração \\
\hline Atividade & 2.1 & Estado & Brna (1998) \\
\hline \multirow[t]{2}{*}{ Trabalham juntos } & 2.1 .1 & Trabalham junto & $\begin{array}{l}\text { Hord (1981); Hord (1986); Brna (1998); } \\
\text { Balancieri (2004); Polenske (2004); } \\
\text { Kemczinski et al. (2008); Winckler e } \\
\text { Molinari (2011) }\end{array}$ \\
\hline & 2.1 .1 & Esforço coordenado, sinergia & Balancieri (2004); Ansell e Gash (2008) \\
\hline $\begin{array}{l}\text { Atividade: Como } \\
\text { trabalham }\end{array}$ & 2.1 .1 & Realizada mutuamente & $\begin{array}{l}\text { Brna (1998); Hord (1981); Hord (1986); } \\
\text { Kemczinski et al. (2008) }\end{array}$ \\
\hline Atividade: Papéis & 2.1 .2 & Não delimitados & $\begin{array}{l}\text { Kirschner; Dickinson e Blosser (1996); } \\
\text { Kemczinski et al. (2008); Ansell e Gash } \\
\text { (2008) }\end{array}$ \\
\hline
\end{tabular}


Continuação

\begin{tabular}{|c|c|c|c|}
\hline \multirow{3}{*}{$\begin{array}{l}\text { Atividade (tipos de } \\
\text { atuação) }\end{array}$} & 2.1 .3 & Compartilhada & Hord (1981); Hord (1986) \\
\hline & 2.1.3 & Apoio, Contribuição & $\begin{array}{l}\text { Balancieri (2004); Winckler e Molinari } \\
\text { (2011); Kemczinski et al. (2008) }\end{array}$ \\
\hline & 2.1 .3 & Interdependentes & $\begin{array}{l}\text { Hord (1981); Hord (1986); Ansell e Gash } \\
\text { (2008); Kemczinski et al. (2008) }\end{array}$ \\
\hline \multirow{3}{*}{$\begin{array}{c}\text { Atividade } \\
\text { (forma/sentido) }\end{array}$} & 2.1 .4 & Horizontal & Kemczinski et al. (2008) \\
\hline & 2.1 .4 & Vertical & Polenske (2004) \\
\hline & 2.1 .4 & Vertical ou horizontal & Winckler e Molinari (2011), \\
\hline $\begin{array}{l}\text { Atividade: } \\
\text { Concorrência }\end{array}$ & 2.1 .5 & A competitividade quase não é afetada & Wincler e Molinaria (2011). \\
\hline Recurso: $\mathrm{CHA}[\mathrm{CH}]$ & $\begin{array}{c}2.2 .1 .1 \\
1\end{array}$ & Assimétricas & $\begin{array}{l}\text { Balancieri (2004); Ansell e Gash (2008); } \\
\text { Hord (1981); Hord (1986); Hargrove (1998); } \\
\text { Polenske (2004). Brna (1998); Kemczinski et } \\
\text { al. (2008) }\end{array}$ \\
\hline \multirow{5}{*}{ Recurso: CHA[A] } & $\begin{array}{c}2.2 .1 .1 \\
2\end{array}$ & $\begin{array}{c}\text { Atitude Colaborativa, } \\
\text { compartilhamento, Trabalho em } \\
\text { equipe }\end{array}$ & $\begin{array}{l}\text { Hord (1981); Hord (1986); (1986); } \\
\text { Kemczinski et al. (2008) }\end{array}$ \\
\hline & $\begin{array}{c}2.2 .1 .1 \\
2\end{array}$ & Oportunismo & Brna (1998) \\
\hline & $\begin{array}{c}2.2 .1 .1 \\
2\end{array}$ & Comprometimentos de todos & Ansell e Gash (2008) \\
\hline & $\begin{array}{c}2.2 .1 .1 \\
2\end{array}$ & Paciência, tolerância a mudança & Hord (1981); Hord (1986) \\
\hline & $\begin{array}{c}2.1 .1 \\
2\end{array}$ & Forte Empatia. Saber ouvir & Hord (1981); Hord (1986) \\
\hline Recurso: RH & 2.2 .1 .2 & Compartilham (Pessoas) & Hord (1981); Hord (1986) \\
\hline $\begin{array}{c}\text { Recurso: } \\
\text { Infraestrutura }\end{array}$ & 2.2 .2 & Compartilham (equipamentos) & Hord (1981); Hord (1986) \\
\hline Recurso: Financeiro & 2.2 .3 & $\begin{array}{l}\text { Compartilham (recursos financeiros e } \\
\text { fundos) }\end{array}$ & Hord (1981); Hord (1986) \\
\hline Recurso: Tempo & 2.2 .4 & Precisa de muito tempo & $\begin{array}{l}\text { Hord (1981); Hord (1986); Ansell e Gash } \\
\qquad(2008)\end{array}$ \\
\hline Recurso: Informação & 2.2.5.1 & Troca intensa & $\begin{array}{l}\text { Hord (1981); Hord (1986); Ansell e Gash } \\
\text { (2008); Kemczinski et al. (2008) }\end{array}$ \\
\hline Recurso: Informação & 2.2 .5 .2 & Limitadas ao que se quer oferecer & Polenske (2004) \\
\hline $\begin{array}{c}\text { Recurso: } \\
\text { Capilaridade de rede }\end{array}$ & 2.2 .6 & Quanto mais, melhor & Balancieri (2004) \\
\hline Comunicação & 2.3 .1 & Constante inteiração. Aberta & Kemczinski et al. (2008) \\
\hline $\begin{array}{l}\text { Comunicação } \\
\text { (Intensidade) }\end{array}$ & 2.3.1 & Muitas reuniões presenciais - Intensa & $\begin{array}{l}\text { Hord (1981); Hord (1986); Kemczinski et al. } \\
\qquad(2008)\end{array}$ \\
\hline
\end{tabular}

Contunua... 
Conclusão

\begin{tabular}{|c|c|c|c|}
\hline $\begin{array}{c}\text { Comunicação } \\
\text { (Intensidade/Níveis) }\end{array}$ & 2.3.1.1 & Muitas reuniões, em todos os níveis & Hord (1981); Hord (1986) \\
\hline $\begin{array}{l}\text { Comunicação } \\
\text { (Canais) }\end{array}$ & 2.3 .2 & Dialogo presencial, essencialmente & Ansell e Gash (2008) \\
\hline $\begin{array}{c}\text { Comunicação } \\
\text { (Forma: Síncrono ou } \\
\text { Assíncrono) }\end{array}$ & 2.3 .3 & $\begin{array}{l}\text { Síncrona (Videoconferência, Chat, } \\
\text { ICQ, Teleconferência), uso de } \\
\text { Sistemas online, }\end{array}$ & Kemczinski et al. (2008) \\
\hline Poder & 2.4 .1 & Mútuo, decidem em conjunto & Kemczinski et al. (2008) \\
\hline Poder & 2.4 .1 & Hierarquizado & Winckler e Molinari (2011), \\
\hline Poder & 2.4 .1 & Liderança mútua & $\begin{array}{l}\text { Polenske (2004); Kemczinski et al. (2008); } \\
\text { Winckler e Molinari (2011) }\end{array}$ \\
\hline $\begin{array}{c}\text { Poder: } \\
\text { Responsabilidade }\end{array}$ & 2.4 .2 & Mútua & $\begin{array}{l}\text { Hord (1981); Hord (1986); Balancieri (2004); } \\
\text { Ansell e Gash (2008) }\end{array}$ \\
\hline $\begin{array}{c}\text { Controle } \\
\text { (mecanismos) }\end{array}$ & 2.5 & Mecanismos Internos & Polenske (2004) \\
\hline Controle & 2.5 & $\begin{array}{l}\text { Frágil, falta de estrutura da relação } \\
\text { afeta a confiança }\end{array}$ & Brna (1998) \\
\hline Controle & 2.5 & $\begin{array}{l}\text { Importante, fortalecimento da relação } \\
\text { de segurança, }\end{array}$ & $\begin{array}{l}\text { Hord (1981); Hord (1986); Ansell e Gash } \\
\qquad(2008)\end{array}$ \\
\hline Controle & 2.5 & Construída por si só & Das e Teng (1998) \\
\hline Controle & 2.5 & Pouco usado & Brna (1998); Polenske (2004) \\
\hline Controle: Contratos & 2.5 .1 & Não são formais & Brna (1998) \\
\hline Risco & 2.6 & Mútuo & Hord (1981); Hord (1986) \\
\hline $\begin{array}{l}\text { Risco: Como é para } \\
\text { cada um }\end{array}$ & 2.6.1 & Assimétricos & Polenske (2004) \\
\hline
\end{tabular}

Fonte: Autora, 2016 
APÊNDICE B - Atributos de cooperação 
Quadro 23 - Atributos de cooperação

\begin{tabular}{|c|c|c|c|}
\hline \multicolumn{4}{|c|}{ Atributos do Escopo } \\
\hline Descrição dos Atributos & $\mathbf{N}^{\mathbf{0}}$ & Definição Cooperação & Referência Cooperação \\
\hline Natureza & 1.1 .1 & $\begin{array}{l}\text { Operacionalização de processo, serviço, } \\
\text { ou aprimoramento de algo }\end{array}$ & Kemczinski et al. (2008) \\
\hline Objetivo: A quem atende & 1.1 .2 & Objetivos Individuais & $\begin{array}{l}\text { Hord (1981); Hord (1986); } \\
\text { Polenske (2004); Kemczinski } \\
\text { et al. (2008); Winckler e } \\
\text { Molinari (2011) }\end{array}$ \\
\hline Objetivo: A quem atende & 1.1 .2 & Não precisam ser iguais & $\begin{array}{l}\text { Hord (1981); Hord (1986); } \\
\text { Winckler e Molinari (2011) }\end{array}$ \\
\hline Objetivo: A quem atende & 1.1 .2 & Claros - estado & $\begin{array}{l}\text { Hord (1981); Hord (1986); } \\
\text { Polenske (2004); Kemczinski } \\
\text { et al. (2008); Winckler e } \\
\text { Molinari (2011) }\end{array}$ \\
\hline Resultados & 1.2 & Mútuo & $\begin{array}{l}\text { Polenske (2004); Kemczinski } \\
\text { et al. (2008); Winckler e } \\
\text { Molinari (2011) }\end{array}$ \\
\hline Resultados & 1.2 & Assimétricos & $\begin{array}{c}\text { Hord (1981); Hord (1986); } \\
\text { Polenske (2004); Winckler e } \\
\text { Molinari (2011) }\end{array}$ \\
\hline Resultados & 1.2 & Quem opera fica com os resultados & Hord (1981); Hord (1986) \\
\hline Resultados & 1.2 & $\begin{array}{c}\text { Resultados são relatados a quem } \\
\text { coopera permitindo a pesquisa, projeto }\end{array}$ & $\begin{array}{l}\text { Hord (1981); Hord (1986); } \\
\text { Polenske (2004) }\end{array}$ \\
\hline Resultados & 1.2 & $\begin{array}{l}\text { Resultados esperados, definidos de } \\
\text { forma clara e explicita antecipadamente }\end{array}$ & $\begin{array}{l}\text { Kemczinski et al. (2008); } \\
\text { Winckler e Molinari (2011) }\end{array}$ \\
\hline Resultados & 1.2 & Resultados que contemplem o coletivo & $\begin{array}{l}\text { Kemczinski et al. (2008); } \\
\text { Winckler e Molinari (2011) }\end{array}$ \\
\hline Resultados: Tangíveis & 1.2.1.1 & $\begin{array}{c}\text { De quem opera, e quem estava } \\
\text { planejado ficar }\end{array}$ & $\begin{array}{c}\text { Hord (1981); Polenske } \\
\text { (2004); Winckler e Molinari } \\
\text { (2011) }\end{array}$ \\
\hline Resultados: Intangíveis & 1.2.1.2 & $\begin{array}{l}\text { Pode compensar a falta do tangível, } \\
\text { sentimento de altruísmo }\end{array}$ & Hord (1981); Hord (1986) \\
\hline Base: Atores & 1.3 & É compatível & $\begin{array}{l}\text { Hord (1981); Hord (1986); } \\
\text { Winckler e Molinari (2011) }\end{array}$ \\
\hline
\end{tabular}


Continuação

\begin{tabular}{|c|c|c|c|}
\hline \multicolumn{4}{|c|}{ Atributos de Estrutura } \\
\hline Descrição dos Atributos & $\mathbf{N}^{\mathbf{0}}$ & Definição Cooperação & Referência Cooperação \\
\hline Atividade & 2.1 & Processo & Brna (1998) \\
\hline Trabalham juntos & 2.1 .1 & Trabalham separados & $\begin{array}{l}\text { Hord (1981); Hord (1986); } \\
\text { Polenske (2004); Kemczinski } \\
\text { et al. (2008); Winckler e } \\
\text { Molinari (2011) }\end{array}$ \\
\hline Atividade: Como trabalham & 2.1 .1 & $\begin{array}{l}\text { Divisão clara e executada } \\
\text { separadamente }\end{array}$ & $\begin{array}{l}\text { Hord (1981); Hord (1986); } \\
\text { Polenske (2004); Kemczinski } \\
\text { et al. }(2008)\end{array}$ \\
\hline Atividade: Papéis & 2.1 .2 & Delimitados & $\begin{array}{l}\text { Hord (1981); Hord (1986); } \\
\text { Silva (2007); Kemczinski et } \\
\text { al. (2008) }\end{array}$ \\
\hline Atividade (tipos de atuação) & 2.1 .3 & $\begin{array}{l}\text { Complementar, complementam a tarefa } \\
\text { de outro }\end{array}$ & $\begin{array}{c}\text { Polenske (2004); Kemczinski } \\
\text { et al. (2008) }\end{array}$ \\
\hline Atividade (tipos de atuação) & 2.1 .3 & $\begin{array}{l}\text { Reciprocidade - cada um oferece o que } \\
\text { tem de melhor }\end{array}$ & Winckler e Molinari (2011) \\
\hline Atividade (tipos de atuação) & 2.1 .3 & Individualizado & Kemczinski et al. (2008) \\
\hline Atividade (forma/sentido) & 2.1 .4 & Horizontal & $\begin{array}{c}\text { Polenske (2004); Kemczinski } \\
\text { et al. (2008); Winckler e } \\
\text { Molinari (2011) }\end{array}$ \\
\hline $\begin{array}{l}\text { Atividade (sentido ou } \\
\text { forma) }\end{array}$ & 2.1 .4 & $\begin{array}{l}\text { Podem criar uma organização, como } \\
\text { uma cooperativa }\end{array}$ & Polenske (2004) \\
\hline Atividade: Concorrência & 2.1 .5 & Gera vantagem competitiva & $\begin{array}{c}\text { Polenske (2004); Silva } \\
\text { (2007); Winckler e Molinari } \\
\text { (2011) }\end{array}$ \\
\hline Atividade: Concorrência & 2.1 .5 & $\begin{array}{l}\text { Aumenta a competitividade de médio e } \\
\text { longo prazo }\end{array}$ & Winckler e Molinari (2011) \\
\hline Recurso: $\mathrm{CHA}[\mathrm{CH}]$ & $\begin{array}{c}2.2 .1 .1 \\
1\end{array}$ & Assimétricas & $\begin{array}{l}\text { Hord (1981); Hord (1986); } \\
\text { Polenske (2004); Kemczinski } \\
\text { et al. (2008); Winckler e } \\
\text { Molinari (2011) }\end{array}$ \\
\hline Recurso: CHA[A] & $\begin{array}{c}2.2 .1 .1 \\
2\end{array}$ & Complementar & $\begin{array}{l}\text { Polenske (2004); Kemczinski } \\
\text { et al. (2008); Winckler e } \\
\text { Molinari (2011) }\end{array}$ \\
\hline Recurso: RH & 2.2.1.2 & $\begin{array}{c}\text { Não compartilha, são de quem está } \\
\text { operando a tarefa }\end{array}$ & $\begin{array}{l}\text { Hord (1981); Hord (1986); } \\
\text { Polenske (2004) }\end{array}$ \\
\hline Recurso: Infraestrutura & 2.2 .2 & $\begin{array}{c}\text { Não compartilha, são de quem está } \\
\text { operando a tarefa }\end{array}$ & $\begin{array}{l}\text { Hord (1981); Hord (1986), } \\
\text { Polenske (2004) }\end{array}$ \\
\hline Recurso: Financeiro & 2.2 .3 & Contribuem, ambos investem & $\begin{array}{c}\text { Silva (2007); Kemczinski et } \\
\text { al. (2008) }\end{array}$ \\
\hline
\end{tabular}


Continuação

\begin{tabular}{|c|c|c|c|}
\hline \multicolumn{4}{|c|}{ Atributos de Estrutura } \\
\hline Descrição dos Atributos & $\mathbf{N}^{\mathbf{0}}$ & Definição Cooperação & Referência Cooperação \\
\hline Recurso: Financeiro & 2.2 .3 & $\begin{array}{c}\text { Não compartilha, são de quem está } \\
\text { operando a tarefa }\end{array}$ & $\begin{array}{l}\text { Hord (1981); Hord (1986), } \\
\text { Polenske (2004) }\end{array}$ \\
\hline Recurso: Tempo & 2.2 .4 & Menos tempo & $\begin{array}{l}\text { Hord (1981); Hord (1986); } \\
\text { Polenske (2004); Kemczinski } \\
\text { et al. }(2008)\end{array}$ \\
\hline Recurso: Informação & 2.2.5.1 & Trocas Esporádicas & $\begin{array}{l}\text { Hord (1981); Hord (1986); } \\
\text { Polenske (2004); Kemczinski } \\
\text { et al. }(2008)\end{array}$ \\
\hline Recurso: Informação & 2.2.5.2 & Limitadas ao Processo & $\begin{array}{l}\text { Hord (1981); Hord (1986); } \\
\text { Polenske (2004); Kemczinski } \\
\text { et al. (2008) }\end{array}$ \\
\hline Recurso: Informação & 2.2.5.2 & $\begin{array}{l}\text { Não excludente, pois todos têm acesso } \\
\text { aos resultados da cooperação }\end{array}$ & Polenske (2004) \\
\hline $\begin{array}{c}\text { Recurso: Capilaridade de } \\
\text { rede }\end{array}$ & 2.2 .6 & Quanto mais, melhor & Kemczinski et al. (2008) \\
\hline Comunicação & 2.3 .1 & Inconstante Inteiração & Kemczinski et al. (2008) \\
\hline Comunicação (Intensidade) & 2.3 .1 & Poucas Reuniões presenciais & $\begin{array}{l}\text { Hord (1981); Hord (1986); } \\
\text { Polenske (2004) }\end{array}$ \\
\hline Comunicação (Canais) & 2.3 .2 & Relatórios/TI & Kemczinski et al. (2008) \\
\hline $\begin{array}{l}\text { Comunicação (Forma: } \\
\text { Síncrono ou Assíncrono) }\end{array}$ & 2.3 .3 & $\begin{array}{l}\text { Assíncrona (e-mail, lista de discussão, } \\
\text { fórum, FAQ- Perguntas Frequentes), } \\
\text { uso de sistemas off-line, }\end{array}$ & Kemczinski et al. (2008) \\
\hline Poder & 2.4 .1 & $\begin{array}{l}\text { Controle se mantém centrado em cada } \\
\text { organização }\end{array}$ & Hord (1981); Polenske (2004) \\
\hline Poder & 2.4 .1 & Hierarquizado & Winckler e Molinari (2011) \\
\hline Poder & 2.4 .1 & $\begin{array}{l}\text { Liderança Unilateral, por parte da } \\
\text { empresa que lidera o processo. }\end{array}$ & Hord (1981); Polenske (2004) \\
\hline Poder: Responsabilidade & 2.4 .2 & Corresponsáveis pelo produto e sucesso & Hord (1981); Hord (1986) \\
\hline Controle (mecanismos) & 2.5 & Externas & $\begin{array}{c}\text { Polenske (2004); Kemczinski } \\
\text { et al. (2008) }\end{array}$ \\
\hline Controle & 2.5 & $\begin{array}{l}\text { Mais forte, devido mecanismos de } \\
\text { controle, e definição prévia de tarefas, } \\
\text { papeis e resultados }\end{array}$ & $\begin{array}{c}\text { Hord (1981); Hord (1986); } \\
\text { Polenske (2004); Kemczinski } \\
\text { et al. (2008) }\end{array}$ \\
\hline Controle & 2.5 & Construída por mecanismos & Das e Teng (1998) \\
\hline Controle & 2.5 & Necessário & $\begin{array}{l}\text { Hord (1981); Hord (1986); } \\
\text { Winckler e Molinari (2011) }\end{array}$ \\
\hline
\end{tabular}

Continua 
Conclusão

\begin{tabular}{|c|c|c|c|}
\hline Controle: Contratos & 2.5 .1 & Formais & $\begin{array}{c}\text { Hord (1981); Hord (1986); } \\
\text { Silva (2007); Kemczinski } \text { et } \\
\text { al. (2008) }\end{array}$ \\
\hline Risco & 2.6 & Dividido & $\begin{array}{c}\text { Polenske (2004); Kemczinski } \\
\text { et al. (2008) }\end{array}$ \\
\hline Risco: Como é para cada um & 2.6 .1 & Unilateral & Hord (1981); Hord (1986) \\
\hline
\end{tabular}

Fonte: Autora, 2016 
APÊNDICE C - Análise dos atributos de colaboração e cooperação 
Quadro 24 - Análise dos atributos de colaboração e cooperação

\begin{tabular}{|c|c|c|c|c|}
\hline \multicolumn{3}{|c|}{ Legenda } & \multirow{2}{*}{\multicolumn{2}{|c|}{1}} \\
\hline \multicolumn{3}{|c|}{ Excludente: ou é uma coisa ou outra } & & \\
\hline \multicolumn{3}{|c|}{ Diferente/ Única } & & \\
\hline \multicolumn{3}{|c|}{ Iguais } & & \\
\hline \multicolumn{5}{|c|}{$\begin{array}{l}\text { Antagônica ao conjunto e não sustentada pela pesquisa do } \\
\qquad \text { autor }\end{array}$} \\
\hline $\begin{array}{c}\text { Referência } \\
\text { Colaboração }\end{array}$ & Definição Colaboração & Atributos & $\begin{array}{c}\text { Definição } \\
\text { Cooperação }\end{array}$ & $\begin{array}{l}\text { Referência } \\
\text { Cooperação }\end{array}$ \\
\hline $\begin{array}{l}\text { Kemczinski et al. } \\
\text { (2008) }\end{array}$ & $\begin{array}{l}\text { Mútuo, decidem em } \\
\text { conjunto }\end{array}$ & \multirow{3}{*}{$\begin{array}{c}\text { Poder: } \\
\text { mútuo, } \\
\text { hierarquiza } \\
\text { do }\end{array}$} & $\begin{array}{l}\text { Controle se mantém } \\
\text { centrado em cada } \\
\text { organização }\end{array}$ & $\begin{array}{l}\text { Hord (1981); } \\
\text { Polenske (2004) }\end{array}$ \\
\hline $\begin{array}{l}\text { Winckler e } \\
\text { Molinari (2011) }\end{array}$ & Hierarquizado & & Hierarquizado & $\begin{array}{c}\text { Winckler e } \\
\text { Molinari (2011) }\end{array}$ \\
\hline $\begin{array}{l}\text { Polenske (2004); } \\
\text { Kemczinski et al. } \\
\text { (2008); Winckler } \\
\text { e Molinari (2011) }\end{array}$ & Liderança mútua & & $\begin{array}{l}\text { Liderança Unilateral, por } \\
\text { parte da empresa que } \\
\text { lidera o processo. }\end{array}$ & $\begin{array}{l}\text { Hord (1981); } \\
\text { Polenske (2004) }\end{array}$ \\
\hline $\begin{array}{l}\text { Kemczinski et al. } \\
\text { (2008) }\end{array}$ & Horizontal & Sentido & Horizontal & $\begin{array}{l}\text { Polenske (2004); } \\
\text { Kemczinski et al. } \\
\text { (2008); Winckler e } \\
\text { Molinari (2011) }\end{array}$ \\
\hline Polenske (2004 & Vertical & & & \\
\hline $\begin{array}{l}\text { Winckler e } \\
\text { Molinari (2011) }\end{array}$ & Vertical ou horizontal & & & \\
\hline $\begin{array}{l}\text { Balancieri (2004); } \\
\text { Hord (1981); Hord } \\
(1986) \text {; Winckler } \\
\text { e Molinari (2011), } \\
\text { Kemczinski et al. } \\
\text { (2008); Brna } \\
(1998)\end{array}$ & Trabalham junto & $\begin{array}{l}\text { Atuação: } \\
\text { junto, } \\
\text { separada }\end{array}$ & Trabalham separados & $\begin{array}{l}\text { Hord (1981); Hord } \\
\text { (1986); Polenske } \\
\text { (2004); Kemczinski } \\
\text { et al. }(2008) ; \\
\text { Winckler e } \\
\text { Molinari (2011) }\end{array}$ \\
\hline
\end{tabular}

Continua... 
Continuação

\begin{tabular}{|c|c|c|c|c|}
\hline $\begin{array}{l}\text { Hord (1981); Hord } \\
\text { (1986) }\end{array}$ & Compartilhada & & $\begin{array}{l}\text { Complementar, } \\
\text { complementam a tarefa } \\
\text { de outro }\end{array}$ & $\begin{array}{l}\text { Polenske (2004); } \\
\text { Kemczinski et al. } \\
\text { (2008) }\end{array}$ \\
\hline \multirow[t]{2}{*}{$\begin{array}{l}\text { Balancieri (2004); } \\
\text { Winckler e } \\
\text { Molinari (2011); } \\
\text { Kemczinski et al. } \\
(2008)\end{array}$} & Apoio, Contribuição & & $\begin{array}{l}\text { Reciprocidade - cada um } \\
\text { oferece o que tem de } \\
\text { melhor }\end{array}$ & $\begin{array}{l}\text { Winckler e } \\
\text { Molinari (2011) }\end{array}$ \\
\hline & & & $\begin{array}{l}\text { Podem criar uma } \\
\text { organização, como uma } \\
\text { cooperativa }\end{array}$ & Polenske (2004) \\
\hline $\begin{array}{l}\text { Balancieri (2004); } \\
\text { Ansell e Gash } \\
\text { (2008) }\end{array}$ & $\begin{array}{c}\text { Esforço coordenado, } \\
\text { sinergia }\end{array}$ & & & \\
\hline $\begin{array}{l}\text { Hord (1981); Hord } \\
\text { (1986); Ansell e } \\
\text { Gash (2008); } \\
\text { Kemczinski et al. } \\
(2008)\end{array}$ & Interdependentes & \multirow{4}{*}{$\begin{array}{c}\text { Relações: } \\
\text { interdepen } \\
\text { dente, } \\
\text { independen } \\
\text { te, intensa, } \\
\text { externas }\end{array}$} & Externas & $\begin{array}{l}\text { Polenske (2004); } \\
\text { Kemczinski et al. } \\
\text { (2008) }\end{array}$ \\
\hline \multirow[t]{3}{*}{$\begin{array}{l}\text { Kemczinski et al. } \\
\text { (2008) }\end{array}$} & Constante inteiração & & & \\
\hline & & & Aliança Estratégica & $\begin{array}{l}\text { Silva (2007); } \\
\text { Kemczinski et al. } \\
\text { (2008) }\end{array}$ \\
\hline & & & $\begin{array}{l}\text { Não excludente, pois } \\
\text { todo tem acesso aos } \\
\text { resultados da cooperação }\end{array}$ & Polenske (2004) \\
\hline $\begin{array}{l}\text { Balancieri (2004); } \\
\text { Ansell e Gash } \\
\text { (2008); Hord } \\
\text { (1981); Hord } \\
\text { (1986); Hargrove } \\
\text { (1998); Polenske } \\
\text { (2004). Brna } \\
\text { (1998); } \\
\text { Kemczinski et al. } \\
\text { (2008) }\end{array}$ & Assimétricas & \multirow[t]{2}{*}{$\begin{array}{c}\text { Competênc } \\
\text { ias: (CHA), } \\
\text { simétricas, } \\
\text { assimétrica, } \\
\text { complemen } \\
\text { tares }\end{array}$} & Assimétricas & $\begin{array}{l}\text { Hord (1981); Hord } \\
\text { (1986); Polenske } \\
\text { (2004); Kemczinski } \\
\text { et al. }(2008) ; \\
\text { Winckler e } \\
\text { Molinari (2011) }\end{array}$ \\
\hline $\begin{array}{l}\text { Hord (1981); Hord } \\
\text { (1986); (1986); } \\
\text { Kemczinski et al. } \\
(2008)\end{array}$ & $\begin{array}{c}\text { Atitude Colaborativa, } \\
\text { compartilhamento, Trabalho } \\
\text { em equipe }\end{array}$ & & Complementar & $\begin{array}{l}\text { Polenske (2004); } \\
\text { Kemczinski et al. } \\
\text { (2008); Winckler e } \\
\text { Molinari (2011) }\end{array}$ \\
\hline
\end{tabular}

Continua.. 
Continuação

\begin{tabular}{|c|c|c|c|c|}
\hline Brna (1998) & Oportunismo & & & \\
\hline $\begin{array}{l}\text { Ansell e Gash } \\
(2008)\end{array}$ & Comprometimento de todos & & & \\
\hline $\begin{array}{l}\text { Hord (1981); Hord } \\
(1986)\end{array}$ & $\begin{array}{c}\text { Paciência, tolerância a } \\
\text { mudança }\end{array}$ & & & \\
\hline Brna (1998) & Estado & & Processo & Brna (1998) \\
\hline $\begin{array}{l}\text { Hord (1981); Hord } \\
(1986)\end{array}$ & Forte Empatia. Saber ouvir & & É um comportamento & $\begin{array}{l}\text { Polenske (2004); } \\
\text { Winckler e } \\
\text { Molinari (2011) }\end{array}$ \\
\hline $\begin{array}{l}\text { Hord (1981); Hord } \\
(1986) ; \\
\text { Kemczinski et al. } \\
(2008)\end{array}$ & $\begin{array}{l}\text { Muitas reuniões presenciais } \\
\text { - Intensa }\end{array}$ & \multirow{4}{*}{$\begin{array}{c}\text { Comunicaç } \\
\text { ão }\end{array}$} & $\begin{array}{l}\text { Poucas Reuniões } \\
\text { presenciais }\end{array}$ & $\begin{array}{l}\text { Hord (1981); Hord } \\
\text { (1986); Polenske } \\
(2004)\end{array}$ \\
\hline $\begin{array}{l}\text { Hord (1981); Hord } \\
(1986)\end{array}$ & $\begin{array}{l}\text { Muitas reuniões, em todos } \\
\text { os níveis }\end{array}$ & & & \\
\hline $\begin{array}{l}\text { Kemczinski et al. } \\
\text { (2008) }\end{array}$ & $\begin{array}{c}\text { Síncrona (Videoconferência, } \\
\text { Chat, ICQ, Teleconferência), } \\
\text { uso de Sistemas online, }\end{array}$ & & $\begin{array}{l}\text { Assíncrona (e-mail, lista } \\
\text { de discussão, fórum, } \\
\text { FAQ- Perguntas } \\
\text { Frequentes), uso de } \\
\text { sistemas off-line, }\end{array}$ & $\begin{array}{l}\text { Kemczinski et al. } \\
\text { (2008) }\end{array}$ \\
\hline $\begin{array}{l}\text { Ansell e Gash } \\
(2008)\end{array}$ & $\begin{array}{c}\text { Dialogo presencial, } \\
\text { essencialmente }\end{array}$ & & Relatórios & \\
\hline Brna (1998) & $\begin{array}{l}\text { Frágil, falta de estrutura da } \\
\text { relação afeta a confiança }\end{array}$ & \multirow[t]{2}{*}{ Confiança } & $\begin{array}{l}\text { Mais forte, devido } \\
\text { mecanismos de controle, } \\
\text { e definição prévia de } \\
\text { tarefas, papeis e } \\
\text { resultados }\end{array}$ & $\begin{array}{l}\text { Hord (1981); Hord } \\
(1986) ; \text { Polenske } \\
(2004) ; \text { Kemczinski } \\
\text { et al. }(2008)\end{array}$ \\
\hline $\begin{array}{l}\text { Hord (1981); Hord } \\
\text { (1986); Ansell e } \\
\text { Gash (2008) }\end{array}$ & $\begin{array}{l}\text { Importante, fortalecimento } \\
\text { da relação de segurança, }\end{array}$ & & & \\
\hline $\begin{array}{l}\text { Hord (1981); Hord } \\
\text { (1986); }\end{array}$ & Mútuo & \multirow{2}{*}{$\begin{array}{l}\text { Riscos: } \\
\text { mútuo, } \\
\text { dividido, } \\
\text { unilateral }\end{array}$} & Dividido & $\begin{array}{l}\text { Polenske (2004); } \\
\text { Kemczinski et al. } \\
\text { (2008) }\end{array}$ \\
\hline Polenske (2004) & Assimétricos & & Unilateral & $\begin{array}{l}\text { Hord (1981); Hord } \\
\text { (1986) }\end{array}$ \\
\hline
\end{tabular}

Continua... 
Continuação

\begin{tabular}{|c|c|c|c|c|}
\hline $\begin{array}{l}\text { Hord (1981); } \\
\text { Hord (1986); } \\
\text { Ansell e Gash } \\
\text { (2008); } \\
\text { Kemczinski et al. } \\
\text { (2008) }\end{array}$ & Troca intensa & \multirow{3}{*}{ Informação } & Esporádicas & $\begin{array}{l}\text { Hord (1981); Hord } \\
\text { (1986); Polenske } \\
\text { (2004); Kemczinski } \\
\text { et al. (2008) }\end{array}$ \\
\hline $\begin{array}{l}\text { Kemczinski et al. } \\
\text { (2008) }\end{array}$ & Troca aberta & & & \\
\hline Polenske (2004) & $\begin{array}{c}\text { Limitadas ao que se quer } \\
\text { oferecer }\end{array}$ & & Limitadas ao Processo & $\begin{array}{l}\text { Hord (1981); Hord } \\
(1986) ; \text { Polenske } \\
(2004) ; \text { Kemczinski } \\
\text { et al. }(2008)\end{array}$ \\
\hline \multirow[t]{2}{*}{ Brna (1998) } & Não são formais & Contratos & Formais & $\begin{array}{l}\text { Hord (1981); Hord } \\
\text { (1986); Silva } \\
(2007) ; \text { Kemczinski } \\
\text { et al. }(2008)\end{array}$ \\
\hline & & $\begin{array}{c}\text { Financeiros } \\
\text {, fundos }\end{array}$ & $\begin{array}{l}\text { Contribuem, ambos } \\
\text { investem }\end{array}$ & $\begin{array}{l}\text { Silva (2007); } \\
\text { Kemczinski et al. } \\
\text { (2008) }\end{array}$ \\
\hline $\begin{array}{l}\text { Hord (1981); Hord } \\
\text { (1986) }\end{array}$ & Compartilham & $\begin{array}{l}\text { Financeiros } \\
\text {, fundos }\end{array}$ & $\begin{array}{l}\text { Não compartilha, são de } \\
\text { quem está operando a } \\
\text { tarefa }\end{array}$ & $\begin{array}{l}\text { Hord (1981); Hord } \\
\text { (1986), Polenske } \\
(2004)\end{array}$ \\
\hline $\begin{array}{l}\text { Hord (1981); Hord } \\
\text { (1986) }\end{array}$ & Compartilham & $\begin{array}{c}\text { Equipamen } \\
\text { tos }\end{array}$ & $\begin{array}{l}\text { Não compartilha, são de } \\
\text { quem está operando a } \\
\text { tarefa }\end{array}$ & $\begin{array}{l}\text { Hord (1981); Hord } \\
\text { (1986), Polenske } \\
(2004)\end{array}$ \\
\hline $\begin{array}{l}\text { Hord (1981); Hord } \\
\text { (1986) }\end{array}$ & Compartilham & $\begin{array}{c}\text { Infraestrut } \\
\text { ura }\end{array}$ & $\begin{array}{l}\text { Não compartilha, são de } \\
\text { quem está operando a } \\
\text { tarefa }\end{array}$ & $\begin{array}{l}\text { Hord (1981); Hord } \\
\text { (1986), Polenske } \\
(2004)\end{array}$ \\
\hline \multirow[t]{2}{*}{$\begin{array}{l}\text { Hord (1981); Hord } \\
\text { (1986) }\end{array}$} & Compartilham & Pessoas & $\begin{array}{l}\text { Não compartilha, são de } \\
\text { quem está operando a } \\
\text { tarefa }\end{array}$ & $\begin{array}{l}\text { Hord (1981); Hord } \\
\text { (1986); Polenske } \\
(2004)\end{array}$ \\
\hline & & \multirow{2}{*}{$\begin{array}{c}\text { Competitivi } \\
\text { dade }\end{array}$} & $\begin{array}{l}\text { Gera vantagem } \\
\text { competitiva }\end{array}$ & $\begin{array}{l}\text { Polenske (2004); } \\
\text { Silva (2007); } \\
\text { Winckler e } \\
\text { Molinari (2011) }\end{array}$ \\
\hline $\begin{array}{l}\text { Winckler e } \\
\text { Molinari (2011), }\end{array}$ & Quase não é afetada & & $\begin{array}{l}\text { Aumenta a } \\
\text { competitividade de } \\
\text { médio e longo prazo }\end{array}$ & $\begin{array}{l}\text { Winckler e } \\
\text { Molinari (2011) }\end{array}$ \\
\hline
\end{tabular}


Continuação

\begin{tabular}{|c|c|c|c|c|}
\hline $\begin{array}{l}\text { Winckler e } \\
\text { Molinari (2011) }\end{array}$ & $\begin{array}{l}\text { Não é compatível entre } \\
\text { concorrentes }\end{array}$ & & É compatível & $\begin{array}{l}\text { Hord (1981); Hord } \\
(1986) \text {; Winckler e } \\
\text { Molinari (2011) }\end{array}$ \\
\hline $\begin{array}{l}\text { Winckler e } \\
\text { Molinari (2011), }\end{array}$ & Quase não é afetada & & Não é afetada & $\begin{array}{l}\text { Hord (1981); Hord } \\
\text { (1986) }\end{array}$ \\
\hline $\begin{array}{l}\text { Brna (1998); } \\
\text { Polenske (2004) }\end{array}$ & Pouco usado & $\begin{array}{c}\text { Mecanismo } \\
\text { s de } \\
\text { Controle }\end{array}$ & Necessário & $\begin{array}{l}\text { Hord (1981); Hord } \\
\text { (1986); Winckler e } \\
\text { Molinari (2011) }\end{array}$ \\
\hline $\begin{array}{l}\text { Hord (1981); Hord } \\
\text { (1986); Ansell e } \\
\text { Gash (2008) }\end{array}$ & Precisa de muito tempo & $\begin{array}{c}\text { Tempo: } \\
\text { exige mais } \\
\text { ou menos }\end{array}$ & Menos tempo & $\begin{array}{l}\text { Hord (1981); Hord } \\
\text { (1986); Polenske } \\
\text { (2004); Kemczinski } \\
\text { et al. }(2008)\end{array}$ \\
\hline $\begin{array}{l}\text { Brna (1998); Hord } \\
\text { (1981); Hord } \\
(1986) \text {; } \\
\text { Kemczinski et al. } \\
(2008)\end{array}$ & $\begin{array}{l}\text { Realizada mutuamente, sem } \\
\text { divisão clara }\end{array}$ & $\begin{array}{c}\text { Tarefas: } \\
\text { divisão } \\
\text { clara ou } \\
\text { tênue, } \\
\text { executada } \\
\text { separadam } \\
\text { ente ou } \\
\text { junto }\end{array}$ & $\begin{array}{l}\text { Divisão clara e executada } \\
\text { separadamente }\end{array}$ & $\begin{array}{l}\text { Hord (1981); Hord } \\
\text { (1986); Polenske } \\
\text { (2004); Kemczinski } \\
\text { et al. }(2008)\end{array}$ \\
\hline $\begin{array}{l}\text { Kirschner; } \\
\text { Dickinson e } \\
\text { Blosser (1996); } \\
\text { Kemczinski et al. } \\
\text { (2008); Ansell e } \\
\text { Gash (2008) }\end{array}$ & Não delimitados & $\begin{array}{c}\text { Papeis: } \\
\text { delimitados } \\
\text { ou não } \\
\text { delimitados }\end{array}$ & Delimitados & $\begin{array}{l}\text { Hord (1981); Hord } \\
\text { (1986); Silva } \\
\text { (2007); Kemczinski } \\
\text { et al. (2008) }\end{array}$ \\
\hline $\begin{array}{l}\text { Hord (1981); } \\
\text { Hord (1986); Brna } \\
\text { (1998); Hargrove } \\
\text { (1998); Balancieri } \\
\text { (2004); Polenske } \\
\text { (2004); Winckler } \\
\text { e Molinari (2011) }\end{array}$ & Objetivo comuns ao grupo & $\begin{array}{l}\text { Objetivos/ } \\
\text { Metas: } \\
\text { Comuns ao } \\
\text { grupo ou } \\
\text { individuais }\end{array}$ & Objetivos Individuais & $\begin{array}{l}\text { Hord (1981); Hord } \\
(1986) \text {; Polenske } \\
(2004) ; \text { Kemczinski } \\
\text { et al. }(2008) ; \\
\text { Winckler e } \\
\text { Molinari (2011) }\end{array}$ \\
\hline Hargrove (1998) & Problemas comuns & & & \\
\hline
\end{tabular}

Continua... 
Continuação

\begin{tabular}{|c|c|c|c|c|}
\hline $\begin{array}{l}\text { Ansell e Gash } \\
\text { (2008) }\end{array}$ & $\begin{array}{c}\text { Objetivos claros para ambos } \\
\text { - necessidade }\end{array}$ & & Claros - estado & $\begin{array}{l}\text { Hord (1981); Hord } \\
(1986) ; \text { Polenske } \\
(2004) ; \text { Kemczinski } \\
\text { et al. }(2008) ; \\
\text { Winckler e } \\
\text { Molinari (2011) }\end{array}$ \\
\hline & & & Não precisam ser iguais & $\begin{array}{l}\text { Hord (1981); Hord } \\
\text { (1986); Winckler e } \\
\text { Molinari (2011) }\end{array}$ \\
\hline Hargrove (1998) & $\begin{array}{l}\text { Metas compartilhadas com } \\
\text { grupo }\end{array}$ & & & \\
\hline $\begin{array}{l}\text { Hargrove (1998); } \\
\text { Balancieri (2004); } \\
\text { Ansell e Gash } \\
\text { (2008); Winckler } \\
\text { e Molinari (2011) }\end{array}$ & Mútuos & \multirow{7}{*}{$\begin{array}{c}\text { Resultados: } \\
\text { mútuos } \\
\text { (todos } \\
\text { ganham, } \\
\text { similares), } \\
\text { unilateral, } \\
\text { assimétrico } \\
\text { s (ganhos } \\
\text { tangíveis } \\
\text { para uns, e } \\
\text { intangíveis } \\
\text { para outro) }\end{array}$} & Mútuo & $\begin{array}{l}\text { Polenske (2004); } \\
\text { Kemczinski et al. } \\
\text { (2008); Winckler e } \\
\text { Molinari (2011) }\end{array}$ \\
\hline $\begin{array}{l}\text { Polenske (2004); } \\
\text { Winckler e } \\
\text { Molinari (2011) }\end{array}$ & Assimétricos & & Assimétricos & $\begin{array}{l}\text { Hord (1981); Hord } \\
\text { (1986); Polenske } \\
\text { (2004); Winckler e } \\
\text { Molinari (2011); }\end{array}$ \\
\hline $\begin{array}{l}\text { Hord (1981); Hord } \\
\text { (1986) }\end{array}$ & $\begin{array}{l}\text { Percepção de ganhos } \\
\text { mútuos, }\end{array}$ & & $\begin{array}{l}\text { Quem opera fica com os } \\
\text { resultados }\end{array}$ & $\begin{array}{l}\text { Hord (1981); Hord } \\
\text { (1986) }\end{array}$ \\
\hline Balancieri (2004) & $\begin{array}{l}\text { Compartilham Resultados } \\
\text { dos projetos em que os } \\
\text { atores estão envolvidos }\end{array}$ & & $\begin{array}{l}\text { Resultados são relatados } \\
\text { a quem coopera } \\
\text { permitindo a pesquisa, } \\
\text { projeto }\end{array}$ & $\begin{array}{l}\text { Hord (1981); Hord } \\
\text { (1986); Polenske } \\
(2004)\end{array}$ \\
\hline \multirow[t]{2}{*}{ Brna (1998) } & $\begin{array}{l}\text { Baseados em expectativas } \\
\text { devido à falta de contrato } \\
\text { formal }\end{array}$ & & $\begin{array}{l}\text { Resultados esperados, } \\
\text { definidos de forma clara } \\
\text { e explicita } \\
\text { antecipadamente }\end{array}$ & $\begin{array}{l}\text { Kemczinski et al. } \\
\text { (2008); Winckler e } \\
\text { Molinari (2011) }\end{array}$ \\
\hline & & & $\begin{array}{l}\text { Operacionalização de } \\
\text { decisão estratégica }\end{array}$ & $\begin{array}{l}\text { Winckler e } \\
\text { Molinari (2011); } \\
\text { Silva (2007) }\end{array}$ \\
\hline $\begin{array}{l}\text { Hord (1981); Hord } \\
\text { (1986) }\end{array}$ & $\begin{array}{l}\text { Interesse elevado nos } \\
\text { resultados }\end{array}$ & & & \\
\hline
\end{tabular}

Continua... 
Conclusão

\begin{tabular}{|c|c|c|c|c|}
\hline & & & $\begin{array}{l}\text { Resultados que } \\
\text { contemplem o coletivo }\end{array}$ & $\begin{array}{l}\text { Kemczinski et al. } \\
\text { (2008); Winckler e } \\
\text { Molinari (2011) }\end{array}$ \\
\hline $\begin{array}{l}\text { Polenske (2004); } \\
\text { Winckler e } \\
\text { Molinari (2011) }\end{array}$ & Não precisa ser mútuo & $\begin{array}{l}\text { Resultados } \\
\text { tangíveis }\end{array}$ & $\begin{array}{l}\text { De quem opera, e quem } \\
\text { estava planejado ficar }\end{array}$ & $\begin{array}{l}\text { Hord (1981); } \\
\text { Polenske (2004); } \\
\text { Winckler e } \\
\text { Molinari (2011) }\end{array}$ \\
\hline $\begin{array}{l}\text { Polenske (2004); } \\
\text { Winckler e } \\
\text { Molinari (2011) }\end{array}$ & Compensa a falta do tangível & $\begin{array}{c}\text { Resultados } \\
\text { intangíveis: } \\
\text { Imagem, } \\
\text { sentimento } \\
\text { filantrópico }\end{array}$ & $\begin{array}{l}\text { Pode compensar a falta } \\
\text { do tangível, sentimento } \\
\text { de altruísmo }\end{array}$ & $\begin{array}{l}\text { Hord (1981); Hord } \\
\text { (1986) }\end{array}$ \\
\hline $\begin{array}{l}\text { Hord (1981); Hord } \\
\text { (1986); Balancieri } \\
\text { (2004); Ansell e } \\
\text { Gash (2008) }\end{array}$ & Mútua & $\begin{array}{c}\text { Responsabi } \\
\text { lidade } \\
\text { mutua, } \\
\text { unilateral }\end{array}$ & $\begin{array}{l}\text { Co-responsáveis pelo } \\
\text { produto e sucesso }\end{array}$ & $\begin{array}{l}\text { Hord (1981); Hord } \\
\text { (1986) }\end{array}$ \\
\hline Balancieri (2004) & Quanto mais, melhor & $\begin{array}{l}\text { Capilarida } \\
\text { de de rede }\end{array}$ & Quanto mais, melhor & $\begin{array}{l}\text { Kemczinski et al. } \\
\text { (2008) }\end{array}$ \\
\hline
\end{tabular}

Fonte: Autora, 2016 
APÊNDICE D - Esquema de palavras para busca de colaboração, cooperação E LR de REEE 
Quadro 25 - Esquema de palavras para busca de colaboração, cooperação e LR de REEE

\begin{tabular}{|c|c|c|}
\hline Palavra-chave & $\begin{array}{l}\text { Operador } \\
\text { booleano }\end{array}$ & Palavra-chave \\
\hline $\begin{array}{l}\text { (Colaboração "OR" Cooperação } \\
\text { "OR" Collaboration "OR" } \\
\text { Cooperation "OR" Colaborar "OR" } \\
\text { Cooperar "OR" Collaborate "OR" } \\
\text { Cooperate) }\end{array}$ & "AND" & $\begin{array}{l}\text { (REEE “OR" Resíduos de Equipamentos Eletro } \\
\text { Eletrônicos "OR” Waste Electrical and } \\
\text { Electronic Equipment "OR” WEEE “OR” lixo } \\
\text { eletrônico "OR” e-waste "OR” Electronic } \\
\text { Waste) }\end{array}$ \\
\hline
\end{tabular}

Fonte: Autora, 2016 
APÊNDICE E - Palavras-chaves para colaboração, cooperação, e áreas a fins de LR de REEE 
Quadro 26 - Palavras-chaves para colaboração, cooperação e áreas a fins de LR de REEE

\begin{tabular}{|c|c|}
\hline Áreas & Palavras chaves e sinônimos \\
\hline Colaboração ou Cooperação & $\begin{array}{l}\text { (Colaboração "OR" Cooperação "OR" Collaboration "OR" Cooperation "OR" } \\
\text { Colaborar "OR" Cooperar "OR" Collaborate "OR" Cooperate) }\end{array}$ \\
\hline LR & $\begin{array}{l}\text { Logística reversa “OR” LR “OR” Reverse Logistic “OR” RL “OR” Cadeia } \\
\text { Reversa “OR” Reverse Chain }\end{array}$ \\
\hline REEE & $\begin{array}{l}\text { REEE “OR" Resíduos de Equipamentos Eletro Eletrônicos "OR" Waste } \\
\text { Electrical and Electronic Equipment "OR" WEEE “OR” lixo eletrônico "OR" } \\
\text { e-waste "OR" Electronic Waste }\end{array}$ \\
\hline EEE & 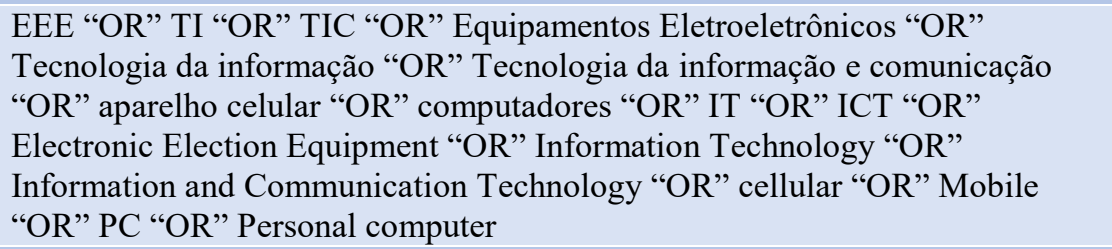 \\
\hline LEIS & $\begin{array}{l}\text { Políticas Públicas “OR” Leis “OR” Inclusão Social “OR” Setor Informal “OR” } \\
\text { Public Policies "OR" Laws "OR" Social Inclusion "OR" Informal Sector }\end{array}$ \\
\hline Cadeia de Suprimentos & Cadeia de Suprimento "OR" Supply Chain \\
\hline
\end{tabular}

Fonte: Autora, 2016 
APÊNDICE F - Conjunto de palavras-chaves com operadores booleanos 
Quadro 27 - Conjunto de palavras-chaves com operadores booleanos

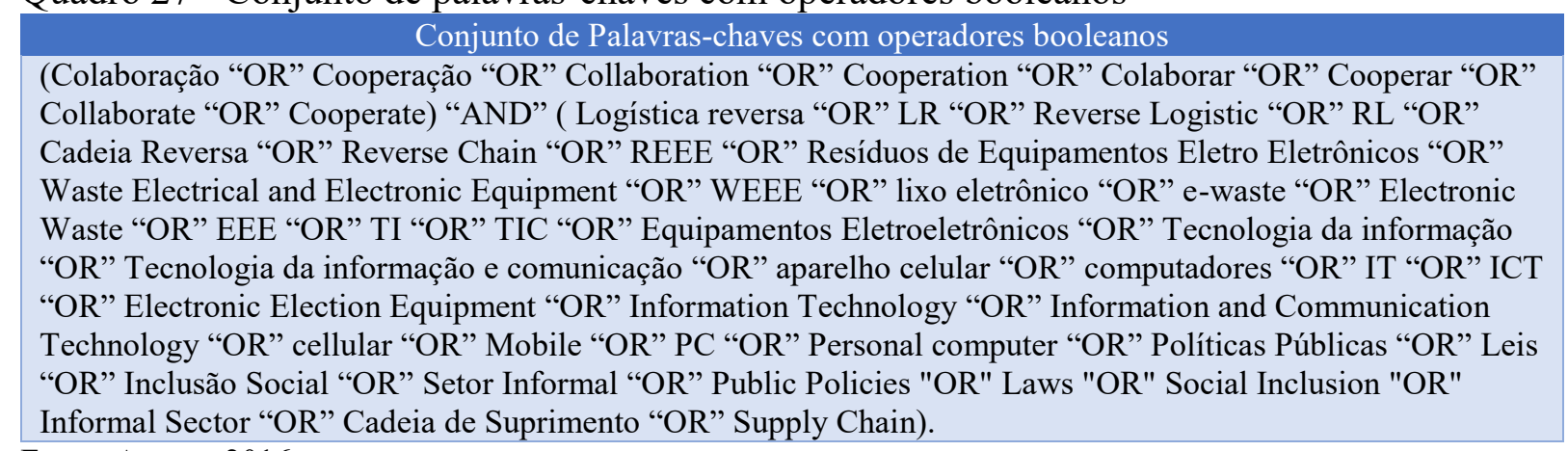

Fonte: Autora, 2016 
APÊNDICE G - Matriz detalhada do impacto da cooperação na Espanha, Portugal, Suíça e Brasil 
Quadro 28 - Matriz detalhada do impacto da cooperação na Espanha, Portugal, Suíça e Brasil

\begin{tabular}{|c|c|c|c|c|c|}
\hline Espanha & Portugal & Suíça & Brasil & Atributos & Ref. \\
\hline \multicolumn{6}{|c|}{ Dimensão Escopo da Cooperação } \\
\hline Atender às leis & $\begin{array}{c}\text { Atender às leis e imagem } \\
\text { sustentável }\end{array}$ & $\begin{array}{l}\text { Atender ao mercado e imagem } \\
\text { sustentável }\end{array}$ & Aprovar AS & Necessidade/Desejo & $1 ; 6$ \\
\hline $\begin{array}{c}\text { Segunda vida do EEE, aumento da } \\
\text { capilaridade e divisas }\end{array}$ & $\begin{array}{c}\text { Capilaridade e volume, aumento } \\
\text { de divisas }\end{array}$ & $\begin{array}{c}\text { Recuperar materiais, capilaridade, } \\
\text { diminuir custos e impactos }\end{array}$ & $\begin{array}{l}\text { Sensibilizar sobre metas, } \\
\text { aprender com o PP, sem custo }\end{array}$ & Oportunidade & $1 ; 6$ \\
\hline $\begin{array}{c}\text { Proatividade, sem senso de } \\
\text { urgência }\end{array}$ & Senso de urgência & Iniciativa voluntária & Sem senso de urgência & Disposição & $1 ; 6 ; 8$ \\
\hline & \multicolumn{5}{|c|}{ Dimensão Escopo da Cooperação } \\
\hline Operacionalizar LR de REEE. SIG & Operacionalizar LR de REEE. EG & Operacionalizar LR de REEE. ORP & Operacionalizou o PP & Natureza: Operação & $7 ; 9$ \\
\hline $\begin{array}{l}\text { Objetivos individuais são diferentes e } \\
\text { garantidos pelo objetivo do grupo }\end{array}$ & $\begin{array}{l}\text { Objetivos individuais são diferentes e } \\
\text { garantidos pelo objetivo do grupo }\end{array}$ & $\begin{array}{c}\text { Objetivos individuais são convergentes } \\
\text { aos dos outros atores e atendidos pelo } \\
\text { do grupo }\end{array}$ & $\begin{array}{c}\text { Objetivos individuais são atendidos } \\
\text { pelo do grupo, mas há conflito de } \\
\text { interesses entre os atores }\end{array}$ & $\begin{array}{l}\text { Objetivos individuais são } \\
\text { garantidos } \\
\text { pelo objetivo do grupo }\end{array}$ & $1 ; 6 ; 7 ; 9$ \\
\hline $\begin{array}{l}\text { Tangíveis: Todos } \\
\text { Intangíveis: GM }\end{array}$ & $\begin{array}{c}\text { Tangíveis: Todos } \\
\text { Intangíveis: GF e GM }\end{array}$ & $\begin{array}{c}\text { Tangíveis: Todos } \\
\text { Intangíveis: GF, EMPA, GM, PD e } \\
\text { SIG } \\
\end{array}$ & $\begin{array}{l}\text { Tangíveis: Todos } \\
\text { Intangíveis: Todos }\end{array}$ & & $1 ; 6 ; 7 ; 9^{4}$ \\
\hline $\begin{array}{l}\text { Atores e SIG concorrentes; não incluem } \\
\text { setor informal. }\end{array}$ & $\begin{array}{l}\text { Concorrentes, mas não incluem setor } \\
\text { informal. EGs são concorrentes }\end{array}$ & $\begin{array}{l}\text { Atores concorrentes. ORPs são } \\
\text { complementares }\end{array}$ & $\begin{array}{l}\text { Setores diferentes e concorrentes. } \\
\text { Sem cooperativas. }\end{array}$ & Concorrentes & $1 ; 9$ \\
\hline \multicolumn{6}{|c|}{ Dimensão: Estrutura da Cooperação } \\
\hline $\begin{array}{c}\text { Trabalham separados, SIG. } \\
\text { Independentes, atendem ao plano } \\
\text { e contrato. }\end{array}$ & $\begin{array}{c}\text { Trabalham separados, EG. } \\
\text { Independentes, atendem ao plano } \\
\text { e contrato. }\end{array}$ & $\begin{array}{c}\text { Trabalham separados; ORP. } \\
\begin{array}{c}\text { Independentes, atendem ao plano } \\
\text { e contrato. }\end{array}\end{array}$ & $\begin{array}{l}\text { Trabalham separados; não têm } \\
\text { autonomia para alterar nada }\end{array}$ & $\begin{array}{c}\text { Trabalham separados ou } \\
\text { criam OG; } \\
\text { independentes. }\end{array}$ & $1 ; 6 ; 7 ; 9$ \\
\hline $\begin{array}{c}\text { Cada qual opera com seu RH e } \\
\text { estrutura }\end{array}$ & $\begin{array}{c}\text { Cada qual opera com seu RH e } \\
\text { estrutura }\end{array}$ & $\begin{array}{c}\text { Cada qual opera com seu RH e } \\
\text { estrutura }\end{array}$ & $\begin{array}{c}\text { Cada qual opera com seu RH e } \\
\text { estrutura }\end{array}$ & $\begin{array}{l}\text { Recurso físico e humano: } \\
\text { não compartilha }\end{array}$ & $1 ; 6$ \\
\hline $\begin{array}{l}\text { Criam fundo com a TAR. GM } \\
\text { arca custos de campanhas. }\end{array}$ & $\begin{array}{l}\text { Criam fundo com a TAR. GM } \\
\text { arca custos de campanhas. }\end{array}$ & Criam fundo com a TAR. & JICA financiou o PP & $\begin{array}{l}\text { Recursos financeiros: } \\
\text { criam fundos, não } \\
\text { compartilham }\end{array}$ & $\begin{array}{l}1 ; 6 ; 7 \\
10\end{array}$ \\
\hline Relata sobre o processo & Relata sobre o processo & Relata sobre o processo & Relata sobre o processo & $\begin{array}{c}\text { Informação: relata sobre } \\
\text { o processo }\end{array}$ & \\
\hline
\end{tabular}




\begin{tabular}{|c|c|c|c|c|c|}
\hline & \multirow{2}{*}{$\begin{array}{c}\text { Continuaça } \\
1 ; 6\end{array}$} \\
\hline Esporádicas, por relatórios e SI & Esporádicas, por relatórios e SI & Esporádicas, por relatórios e SI & $\begin{array}{l}\text { Reuniões presenciais mensais, } \\
\text { relatórios }\end{array}$ & $\begin{array}{c}\text { Comunicação: } \\
\text { esporádica e com SI }\end{array}$ & \\
\hline Centrado nas Organizações & Centrado nas Organizações & Centrado nas Organizações & Centrado no JICA e GF & $\begin{array}{l}\text { Poder: centrado na } \\
\text { organização }\end{array}$ & $1 ; 6$ \\
\hline Contrato com todos e TIC & Contrato com todos e TIC & Contrato com todos e TIC & Contrato prévio com todos & $\begin{array}{l}\text { Mecanismos de controle } \\
\text { formal }\end{array}$ & $1 ; 7 ; 10$ \\
\hline $\begin{array}{l}\text { Dividido por etapa, fica para } \\
\text { quem está operando }\end{array}$ & Fica para quem está operando & Fica para quem está operando. & Fica para quem está operando & $\begin{array}{l}\text { Risco dividido, fica para } \\
\text { quem está operando. }\end{array}$ & $1 ; 6 ; 7$ \\
\hline \multicolumn{6}{|c|}{ Impactos da Cooperação } \\
\hline $4,61 \mathrm{~kg} /$ pessoa $/ 2015$ & $5,1 \mathrm{~kg} /$ pessoa $/ 2015$ & $\begin{array}{c}16 \mathrm{~kg} / \text { pessoa } / 2016 \\
131.800 \text { toneladas REEE } / 2016\end{array}$ & $\begin{array}{l}2 \% \text { dos REEE colocados no } \\
\text { mercado }\end{array}$ & Resultado Direto & \\
\hline $\begin{array}{l}\text { Alcance das metas, capilaridade, } \\
\text { diminuição do custo de } \\
\text { operação, diminuição do impacto } \\
\text { e risco ambientais pelo descarte } \\
\text { correto dos REEE. }\end{array}$ & $\begin{array}{l}\text { Alcance das metas, capilaridade, } \\
\text { diminuição do custo de operação, } \\
\text { diminuição do impacto e risco } \\
\text { ambientais pelo descarte correto } \\
\text { dos REEE. }\end{array}$ & $\begin{array}{l}+6000 \text { - Capilaridade; redução } \\
\text { de custos da reciclagem e com } \\
\text { conscientização. }\end{array}$ & $\begin{array}{l}\text { Regulamentação dos REEE; } \\
\text { reconhecimento da competência } \\
\text { da Coopermiti; potencial de } \\
\text { mercado da LR de REEE. Novos } \\
\text { PPs, financiados pela indústria. }\end{array}$ & Benefício & \\
\hline $\begin{array}{l}\text { Incentivos financeiros para o } \\
\text { consumidor fazer o descarte. }\end{array}$ & & $\begin{array}{l}\text { A colaboração na elaboração das } \\
\text { leis e normas criou um sistema } \\
\text { eficiente, que permite seu } \\
\text { aprimoramento constante e } \\
\text { aumento da rentabilidade da } \\
\text { reciclagem. Pressão/influência } \\
\text { de outro ator } \\
\text { Senso de comunidade } \\
\text { Solidariedade e confiança entre } \\
\text { os produtores } \\
\text { Muita propaganda para os } \\
\text { supermercados participarem da } \\
\text { LR de REEE. }\end{array}$ & & $\begin{array}{c}\text { Beneficios: } \\
\text { Fatores que facilitam }\end{array}$ & \\
\hline
\end{tabular}




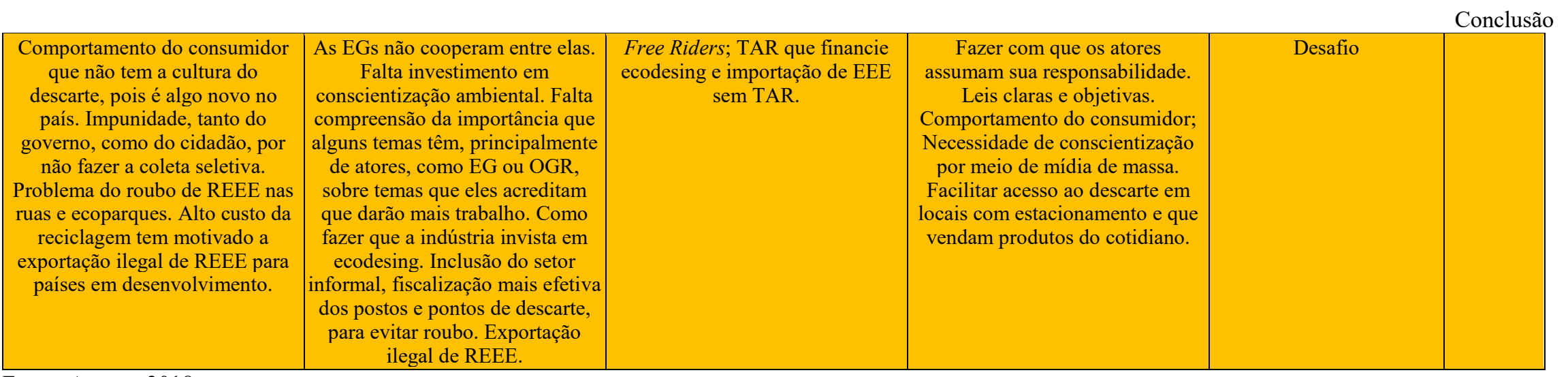

Fonte: Autora, 2018

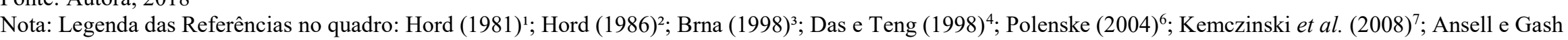
$(2008)^{8}$; Winckler e Molinari (2011) ${ }^{9}$; Silva (2007) 
APÊNDICE H - Matriz detalhada do impacto da colaboração em Portugal, Suíça e Brasil 
Quadro 29 - Matriz detalhada do impacto da colaboração em Portugal, Suíça e Brasil

\begin{tabular}{|c|c|c|c|c|}
\hline Portugal & Suíça & Brasil & Valores dos atributos & Ref. \\
\hline \multicolumn{5}{|c|}{ Dimensão Escopo da Colaboração } \\
\hline $\begin{array}{l}\text { Atender à Diretiva e evitar o impacto do } \\
\text { REEE }\end{array}$ & $\begin{array}{l}\text { Atender ao consumidor/mercado e evitar o } \\
\text { impacto do REEE }\end{array}$ & $\begin{array}{c}\text { Atender à PNRS. Atores não se sentem } \\
\text { obrigados }\end{array}$ & Necessidade/Desejo & $1 ; 6$ \\
\hline $\begin{array}{c}\text { Gerar divisas com REEE. Sensibilizar atores } \\
\text { sobre a importância dos objetivos }\end{array}$ & $\begin{array}{l}\text { Recuperar materiais dos REEE. Lobby para } \\
\text { padronizar a LR para todos }\end{array}$ & $\begin{array}{l}\text { Lobby para melhorar cenário para si e } \\
\text { diminuir sua parte da responsabilidade }\end{array}$ & Oportunidade & $1 ; 6$ \\
\hline $\begin{array}{l}\text { Histórico positivo em colaboração. Senso de } \\
\text { urgência }\end{array}$ & $\begin{array}{l}\text { Iniciativa voluntária da indústria de EEE. } \\
\text { Predisposição para ser sustentável }\end{array}$ & $\begin{array}{l}\text { Não tem disposição, nem senso de } \\
\text { urgência }\end{array}$ & Disposição & $1 ; 6, ; 8$ \\
\hline \multicolumn{5}{|c|}{ Dimensão Escopo da Colaboração } \\
\hline Elaborar lei e sistemas de gestão e controle & Elaborar lei e critérios de qualidade & $\begin{array}{c}\text { Definir modelo de LR de REEE para atender à } \\
\text { PNRS }\end{array}$ & Natureza: Elaboração de algo & 7 \\
\hline $\begin{array}{l}\text { Objetivo do grupo. Alguns objetivos individuais } \\
\text { conflitantes, mas não se sobrepõem }\end{array}$ & Objetivo do grupo: comum. & Objetivo individual se sobrepõe ao grupo & Objetivo do Grupo & 1,$3 ; 6 ; 8,9$ \\
\hline $\begin{array}{c}\text { Tangíveis: GF } \\
\text { Intangíveis: Todos }\end{array}$ & $\begin{array}{l}\text { Tangíveis: GF, ORP e PD } \\
\text { Intangíveis: Todos }\end{array}$ & $\begin{array}{l}\text { Tangíveis: GF, PD e CV } \\
\text { Intangíveis: Todos }\end{array}$ & $\begin{array}{l}\text { Resultados tangíveis ou } \\
\text { intangíveis }\end{array}$ & $5 ; 8 ; 9$ \\
\hline Concorrentes representados por associações & Concorrentes representados por associações & $\begin{array}{c}\text { Concorrentes representados por associações; } \\
\text { setores distintos competem. Restringem atores }\end{array}$ & Não concorrentes ${ }^{2}$ & $6 ; 9$ \\
\hline \multicolumn{5}{|c|}{ Dimensão Estrutura da colaboração } \\
\hline $\begin{array}{c}\text { Trabalham em pares alternados. Tenta } \\
\text { manter a dependência. Governo lidera as } \\
\text { discussões }\end{array}$ & Em conjunto; interdependência. & $\begin{array}{c}\text { Trabalham externamente ao grupo. } \\
\text { Reuniões paralelas entre PD e CV; não } \\
\text { tem interdependência }\end{array}$ & $\begin{array}{l}\text { Trabalham juntos, } \\
\text { internamente; } \\
\text { interpendência }\end{array}$ & $\begin{array}{l}1 ; 5 ; 6 ; 7 \\
8 ; 9\end{array}$ \\
\hline Contribuição & Contribuição & Contribuição & De apoio, contribuição & $1 ; 5 ; 9 ; 7$ \\
\hline $\begin{array}{l}\text { Compartilhado. Os atores iam na reunião } \\
\text { com o governo }\end{array}$ & $\begin{array}{c}\text { Compartilhado. Os atores iam para as } \\
\text { reuniões }\end{array}$ & $\begin{array}{l}\text { Compartilhado; não tinham poder de } \\
\text { decisão; reunião nas sedes e governo. }\end{array}$ & $\begin{array}{l}\text { Recurso: } \mathrm{RH} \text { e estrutura } \\
\text { compartilhados }\end{array}$ & 1 \\
\hline Cada um arca com sua parte & Cada um arca com a sua parte & Cada um arca com a sua parte & $\begin{array}{l}\text { Recurso Financeiro } \\
\text { Compartilhado }\end{array}$ & 1 \\
\hline Não surgiu & Compartilha informação & Compartilha Informação & $\begin{array}{l}\text { Recurso Informação } \\
\text { Compartilhado }\end{array}$ & 6 \\
\hline Até esgotar o assunto & Até obter consenso & Esporádicas. Reuniões presenciais & Comunicação intensa & $1 ; 7$ \\
\hline Mútuo, Hherarquizado GF & Mútuo & Mútuo. Hierarquizado GF & Poder mútuo & $7 ; 9$ \\
\hline
\end{tabular}




\begin{tabular}{|c|c|c|c|c|}
\hline Não têm contratos & Não têm contratos & $\begin{array}{l}\text { Não tem mecanismos, nem confiança por } \\
\text { si só; não tem contrato }\end{array}$ & $\begin{array}{l}\text { Controle: poucos } \\
\text { mecanismos; informal }\end{array}$ & $1 ; 3$ \\
\hline Não foram relatados riscos & Não foram relatados riscos & Assimétrico; todos têm um risco & $\begin{array}{c}\text { Risco da ação e relação } \\
\text { próxima }\end{array}$ & $1 ; 2 ; 6$ \\
\hline \multicolumn{5}{|c|}{ Dimensão: Impactos da Colaboração } \\
\hline Efetivação da Lei & Efetivação da Lei & Não efetivou ainda o AS & Resultado Direto & \\
\hline $\begin{array}{l}\text { Lei consensual. Superação das divergências } \\
\text { sobre propostas inovadoras. Melhoria dos SIs } \\
\text { do governo para registro da LR de REEE. } \\
\text { Motivação para criar novas parcerias que } \\
\text { permitam o aprimoramento da LR de REEE, } \\
\text { devido ao histórico positivo da colaboração. }\end{array}$ & $\begin{array}{c}\text { Lei harmoniosa e consensual. } \\
\text { Referência mundial na LR de REEE e } \\
\text { critérios de qualidade para a UE, baseada na } \\
\text { norma EN 50625-1: 2014. Sinergia. } \\
\text { Aprendizado coletivo. }\end{array}$ & $\begin{array}{c}\text { Ajudou os atores a entenderem melhor a } \\
\text { necessidade de cada um. Novos } \\
\text { conhecimentos sobre o processo e o mercado } \\
\text { de REEE, aprendizagem coletiva acelerada. } \\
\text { Possibilitou identificar as competências dos } \\
\text { atores, para saber onde eles podem ajudar } \\
\text { mais. }\end{array}$ & Benefícios & \\
\hline $\begin{array}{l}\text { O governo exerce seu poder legítimo nas } \\
\text { negociações da lei e impõe sua vontade sem } \\
\text { considerar a opinião do outro, perdendo as } \\
\text { características de um processo colaborativo. }\end{array}$ & & \begin{tabular}{|c|} 
Falta de senso de urgência e de \\
obrigatoriedade para efetivar a LR \\
potencializa todos os outros. Não tem \\
consenso, não reconhecem os pleitos um dos \\
outros; falta de incentivos fiscais. \\
\end{tabular} & Desafios & \\
\hline & & & & \\
\hline
\end{tabular}

\section{Fonte: Autora, 2018}

Nota: Legenda das Referências no quadro: Hord (1981) $)^{1}$; Hord $(1986)^{2}$; Brna $(1998)^{3}$; Das e Teng $(1998)^{4}$; Balancieri $(2004)^{5}$; Polenske $(2004)^{6}$; Kemczinski et al. $(2008)^{7}$; Ansell e Gash (2008) ${ }^{8}$; Winckler e Molinari $(2011)^{9}$. 
APÊNDICE I - Resumen expandido en español 


\section{EI IMPACTO DE LA COLABORACIÓN Y COOPERACIÓN EN LA IMPLEMENTACIÓN DE LOS MODELOS DE LOGÍSTICA INVERSA DE RAEE: Los casos brasileño y europeo.}

\section{INTRODUCCIÓN GENERAL}

El acelerado crecimiento del mercado de Aparatos Eléctricos y Electrónicos (AEE), la obsolescencia programada y el aumento exponencial del descarte de sus residuos al final de su vida útil han generado impactos socioambientales en todas partes del mundo, cuando no son realizados de forma ambientalmente correcta. En el caso específico de los celulares, de acuerdo con Koga et al. (2014), el uso de la obsolescencia programada y perceptiva como estrategia de marketing de las empresas para incentivar el consumo de sus productos es responsable de aproximadamente el $90 \%$ de las adquisiciones de dichos aparatos. Según los autores, alrededor de $66 \%$ de los consumidores brasileños cambian sus teléfonos celulares porque están desactualizados tecnologicamente, porque se cree que ellos están viejos o para comprar un modelo más actual, todos ellos factores relacionados a la obsolescencia perceptiva; $24 \%$ lo hacen por motivo de destrozo, que puede estar relacionado a la obsolescencia programada; y solamente un $10 \%$ por otros motivos, como robo o perdida del aparato, siendo que en la, mayor parte de los casos ello ocurre en un periodo menor que 2 años de uso. Todo ese proceso contribuye a que haya un volumen creciente de residuos generados, que necesitan ser destinados de forma correcta, sea para su reutilizacion y reciclaje, sea para su descarte ambientalmente seguro.

En el 2010, se produjeron 33,8 millones de toneladas de Residuos de Aparatos Eléctricos y Electrónicos (RAEE) no mundo. En el 2014, la cantidad llegó a 41,8 Millones de Toneladas de RAEE, un aumento de un 24\%, mientras que la población creció un $14 \%$ en ese mismo período, presentando un aumento desproporcional (BALDÉ et al., 2015). Los autores alertan sobre el hecho de que, del total de RAEE generados en el 2014, solamente 6,5 millones fueron recolectados por sistemas de recogida oficiales, capaces de monitorear su volumen y flujo y garantizar el proceso ambientalmente correcto. Entre los factores que perjudican el cómputo de los datos sobre el restante del destino de los RAEE generados, están los sistemas de Logística Inversa (LI) de RAEE en países en desarrollo mal estructurados o sin control de datos sobre las 
etapas del proceso, el transbordo ilegal de dichos residuos con el objetivo de externalizar los costos del reciclaje de modo ambientalmente correcto, y los sistemas informales de LI de RAEE (Baldé et al., 2015).

En ese contexto, las situaciones potenciales de riesgos inherentes a los RAEE se elevan. Contribuye a ese escenario el hecho de que los AEE tienen en su composición tanto substancias tóxicas, como raras y con valor económico. Tales factores aumentan el riesgo de escasez de algunos elementos esenciales para el funcionamiento de los AEE, como oro y plata. Por otro lado, hay otros elementos que potencian los riesgos a la salud y al medioambiente, por contener elementos nocivos, como plomo, retardantes de llama, que liberan dioxinas y cadmio (SCHLUEP et al., 2009, MANOMAIVIBOOL; VASSANADUMRONGDEE, 2011; WANG et al., 2012; AUGUSTO, 2014).

Este fenómeno mundial, sin embargo, adquirió especial relevancia en los países en desarrollo en las últimas décadas (SCHLUEP et al., 2009, WANG et al., 2012). El aumento del PIB en los países pobres, asociado a la disminución del ciclo de vida del producto, estimula el debate sobre LI de RAEE, de acuerdo con Torretta et al. (2013). Según los autores, el desarrollo económico cambia los hábitos de la población, tanto en lo que respecta al uso doméstico de AEE, que se vuelve más intenso, cuanto en lo que respecta al tiempo de vida de dichos aparatos, ya que existe una tendencia de cambiar el equipo que está roto o desactualizado, en lugar de conservarlos. Aún de acuerdo a los autores, en países desarrollados, los AEE duran la mitad del tiempo que en países en desarrollo.

De esta manera, en los últimos años, la Li de RAEE obtuvo reconocimiento tanto académico cuanto profesional. Además de los riesgos a la salud y al medioambiente y del rápido crecimiento de los RAEE, drivers como la evolución de la legislación ambiental, el aumento de la presión de los consumidores para la responsabilidad social de las empresas y la colaboración entre los actores de la cadena inversa figuran entre los factores que potencian el resultado de la LI (LAU; WANG, 2009; JANSE; SCHUUR; BRITO, 2009). Este contexto ha generado diferentes modelos de LI en países desarrollados y en desarrollo.

Europa surge en el escenario mundial como ejemplo en la implementación de la LI de RAEE debido a los números logrados a lo largo de los años desde la aprobación de la Directiva de Residuos de Aparatos Eléctricos y Electrónicos (Waste Electrical and Electronic Equipment, WEEE) del 2002, que establece normas y metas para el descarte correcto de RAEE en todos los países miembros de la UE. Para esta investigación, es importante destacar que diversos países 
comenzaron sus actividades inversas en el área de AEE antes de la legislación de la Unión Europea, anticipándose incluso a la entrada en vigencia de leyes nacionales, como es el caso de Suecia y Noruega (AUGUSTO, 2014; YLÄ-MELLA et al., 2014).

Desde el 2002, la Directiva Europea determina las metas de recogida y reciclaje, asimismo el modelo basado en la Responsabilidad Ampliada del Productor (RAP), para implementar un sistema de tratamiento de RAEE, lo que define claramente el rol de dicho actor en la na cadena inversa de RAEE. Sin embargo, la definición del conjunto de actores que participarán del sistema de recogida de los RAEE es definida en legislación nacional, asimismo la forma de organización del sistema de LI y su financiamiento (ROTTER; CHANCEREL; SCHILL, 2011).

El resultado del compromiso de los países miembros en pro de la implementación de la Directiva de RAEE puede observarse en los informes del EUROSTAT, oficina de estadísticas de la Unión Europea que tiene el objetivo de entregar datos para direccionar las acciones de desarrollo de los países pertenecientes al bloque de la UE (EUROSTAT, 2016). Los países miembros muestran avances significativos en la implementación o perfeccionamiento de los sistemas de LI de RAEE, con el aumento exponencial de la recogida de los RAEE (EUROSTAT, 2016; YLÄ-MELLA et al., 2014). Suecia, Noruega, Dinamarca, Bélgica y Finlandia ocupan los 5 primeros puestos en el ranking de los países que siguen la Directiva de RAEE de la UE, en el item cantidad de RAEE en kilogramos, recogidos por habitantes al año (EUROSTAT, 2016). Un buen ejemplo de ello es Suecia, que tuvo un aumento de un $260 \%$ sobre la cantidad inicial de RAEE recogidos, siendo que el número per capita alcanzó 17,313 $\mathrm{kg}$ de RAEE/año, sobrepasando aproximadamente en más de 3 veces las metas establecidas por la Directiva WAEE de 4 kg de RAEE/hab./año (EUROSTAT, 2016).

El sistema de LI de RAEE en Europa está evolucionando para eficiencia en reciclaje, no restringiéndose solamente a la cantidad de RAEE recogidos, sino también al desarrollo de mejores prácticas, tanto en los procesos productivos cuanto en los procesos de reciclaje, para aumentar la reciclabilidad de los RAEE, sobrepasando las metas de recogida impuestas por la Directiva de RAEE (YLÄ-MELLA et al., 2014; EUROSTAT, 2016). Los excepcionales resultados presentados entre los países líderes de Europa deben ser seguidos por todos los países miembros, buscando la eficiencia de sus sistemas de LI de RAEE, visto que la Directiva reformulada, 2012/19 / UE, que entró en vigor el 13 de agosto del 2012, introduce metas de recogida graduales, más elevadas, exigiendo que los países miembros recolecten el $45 \%$ del 
peso médio de los AEE puestos en el mercado en los 3 últimos años, desde el 2016 hasta el 2018, pasando para el 65\% de este total, a partir del 2019 (EUROSTAT, 2013).

Un sistema eficaz de LI de RAEE exige acciones coordinadas de todas las etapas y actores involucrados, que se rigen por leyes claras (TORRETTA et al., 2013; AUGUSTO, 2014). Este se inicia en la recogida, exigiendo capilaridad y movilidad de los puntos de descarte, asimismo la actitud consciente de descarte del consumidor, coordinado con transporte, preprocesamiento, reciclaje y destinación ambientalmente correcta (JANG, 2010; MIGLIANO, 2012; TORRETTA et al., 2013; WANG et al., 2012; DEMAJOROVIC; MIGLIANO, 2013; AUGUSTO, 2014; DEMAJOROVIC; AUGUSTO; SOUZA, 2016). Los altos índices de recogida de los países miembros de la UE están relacionados a los esfuerzos de los gobiernos en la creación de leyes nacionales con el fin de atender a la Directiva WEEE, como en el caso de Finlandia, que creó legislación e infraestructura funcionales y eficientes de LI de RAEE en un corto tiempo, que están en vigor desde 2004, de acuerdo con Ylä-Mella et al. (2014). Además, varios países que ya tenían leyes nacionales sobre RAEE y sistemas de LI implementados, adaptaron la legislación nacional, para alinear sus resultados a las metas de la Directiva, como Suecia y Noruega (YLÄ-MELLA et al., 2014). Los esfuerzos gubernamentales no se limitan a legislar en favor del objetivo común de atender a la Directiva, sino en participar activamente del sistema de recogida, por intermedio de los municipios, que crean centrales de consolidación de RAEE, puntos fixos de recogida próximos a las áreas residenciales y recogida selectiva móvil, para atender a la demanda de los AEE al final de su vida, de modo de garantizar la capilaridad y alcanzar todas las oportunidades de descarte correcto, como Italia, que buscó la colaboración del consumidor, diversificando las formas de recogida. Suecia, Noruega y Finlandia crearon puntos de descarte de residuos especiales, próximos a las residencias, además de recogida selectiva móvil, ya que son países de baja densidad demográfica y gran espaciamiento de la población (YLÄ-MELLA et al., 2014). Otro ejemplo de esfuerzo del gobierno para volver la LI de RAEE más eficiente, atendiendo a las metas de la Directiva de RAEE de la EU, fue el caso de Rumania, que sintió la necesidad de crear políticas de incentivos financieros y educación ambiental para crear en la población la cultura de descarte correcto (TORRETTA et al., 2013).

Otra característica de estos modelos exitosos es la forma de organización del sistema de LI de RAEE, que normalmente son administrados por Organizaciones de Responsabilidad del Productor (ORP), creadas por los fabricantes con el objetivo de garantizar la eficiencia del 
sistema (SINHA-KHETRIWAL; KRAEUCHIB; SCHWANINGER，2005; HISCHIER; WÄGER; GAUGLHOFER, 2005; KHETRIWAL; KRAEUCHI; WIDMER, 2009, YLÄMELLA et al., 2014). Este tipo de sistema muchas veces se asocia con el gobierno local, que se responsabiliza por una parte de la operación, asimismo de los costos, y colabora con la fiscalización de la recogida (KHETRIWAL; KRAEUCHI; WIDMER, 2009). El sistema de financiamiento de la LI puede ser garantizado por Tarifa Anticipada de Reciclaje (TAR), pagadas por el consumidor en el momento de la compra y destacadas en la boleta (KHETRIWAL; KRAEUCHI; WIDMER, 2009) o por la industria de AEE (SINHAKHETRIWAL; KRAEUCHIB; SCHWANINGER， 2005; HISCHIER; WÄGER; GAUGLHOFER, 2005). Países como Suecia, Noruega, Finlandia, entre otros, tienen sus sistemas ejecutados por este tipo de institución, ORP, que garantiza el desempeño de la LI por sobre la media.

Los resultados de los países de la UE muestran un rol de países con modelos de alto desempeño implementados, que poseen factores comunes en la implementación y la mantención de LI de RAEE. Leyes claras, con roles bien definidos (MIGLIANO, 2012; AUGUSTO, 2014), esfuerzos coordinados de los actores de la cadena inversa para alcanzar los mismos objetivos, entre los sectores de AEE, minoristas y gobierno, además de las ORPs (SINHA-KHETRIWAL; KRAEUCHIB; SCHWANINGER, 2005; HISCHIER; WÄGER; GAUGLHOFER, 2005; KHETRIWAL; KRAEUCHI; WIDMER, 2009, TORRETTA et al., 2013; YLÄ-MELLA et al., 2014) que permiten una mayor capilaridad de los puntos de recogida (SINHA-KHETRIWAL; KRAEUCHIB; SCHWANINGER, 2005). Según Lau y Wang (2009), el trabajo conjunto es fundamental para disminuir la resistencia de los sectores empresariales en iniciar programas de LI, debido a los costos elevados que esta actividad involucra. Otros fatores importantes son el nivel de concientización de los ciudadanos (AUGUSTO, 2014; YLÄMELLA et al., 2014) y la comunicación y educación sobre el descarte correcto de los RAEE (DEMAJOROVIC et al., 2012; YLÄ-MELLA et al., 2014).

De este modo, se observa que diferentes autores utilizan palabras distintas para uno de los elementos centrales del éxito de los modelos de LI. Asociación, esfuerzos coordinados, compromiso de los consumidores e intercambio de información fortalecen la idea de que los actores de la cadena inversa necesitan estar dispuestos a colaborar en la construcción y operación de flujos reversos (SINHA-KHETRIWALA; KRAEUCHIB; SCHWANINGER, 2005; HISCHIER; WÄGER; GAUGLHOFER, 2005; KHETRIWAL; KRAEUCHI; 
WIDMER, 2009, TORRETTA et al., 2013; WANG et al., 2012; AUGUSTO, 2014; YLÄMELLA et al., 2014). Aun así, pocas investigaciones sobre esta temática se dedicaron a entender de forma profundizada el rol de la colaboración o cooperación de LI de RAEE. Esta investigación asume como supuesto que los programas de LI de RAEE, al ser sistemas complejos que involucran a múltiples actores, necesitan establecer relaciones sólidas y complementarias (VIEIRA, 2006), en la búsqueda de objetivos comunes, donde cada actor sabe cuál es su rol, el resultado deseado y las metas con las cuales él se compromete (GATTAZ, 2010).

Así, la efectividad de sistemas complejos depende de que diferentes actores estén dispuestos a colaborar o cooperar para un objetivo común. Sin embargo, estos conceptos no son sinónimos, según Polenske (2004). En el caso de la colaboración, los actores trabajan juntos, por ejemplo, en el desarrollo de una nueva tecnología, de forma vertical e interna, por un determinado tiempo. En dicho caso, los actores involucrados obtienen ventaja por el uso mutuo de recursos, tanto físicos, cuanto humanos (POLENSKE, 2004). En el caso de la cooperación, los actores trabajan de forma individualizada, horizontal y externa, compartiendo información, como es el caso de los clusters, que se benefician del ambiente cooperativo que propicia innovación y perfeccionamiento de técnicas y procesos, generando reducción de costos (POLENSKE, 2004). Según Polenske (2004), colaboración y cooperación son formas similares de comportamiento colectivo. Entre los aspectos de semejanza, podemos mencionar que ambas pueden ocurrir en empresas del sector público, privado, organizaciones locales, sindicatos, integrantes de la fuerza de trabajo u otros agentes, sea en el ámbito de la entidad o de la región, sea más allá de las fronteras regionales, nacionales e internacionales.

Aún de acuerdo con Polenske (2004), el gestor público capaz de entender la distinción entre cooperación, colaboración y competitividad podrá proyectar políticas industriales y regionais relevantes para ayudar a las empresas a competir en el mercado global y superar límites de actuación impuestos por la competencia. De esta manera, tales políticas permitirán que las empresas creen reglas de reciprocidad para el intercambio de informaciones de forma más fácil, con el objetivo de crear, mejorar y modificar procesos de producción a través del intercambio de información, adoptar nuevas tecnologias y/o desarrollar nuevas relaciones entre los actores de una determinada cadena. Sin embargo, pocos trabajos se han dedicado a hacer esta diferenciación, con investigaciones en profundidad para teorizar sobre los conceptos de forma distinta y produzir modelos que definan los factores que las componen, aportando 
beneficios o dificultando la implementación de sistemas basados en cooperación o colaboración. En lo que respecta la LI de RAEE, no se hallaron ni siquiera investigaciones que hayan sido balizadas por la esencia del tema. Por otro lado, no se trata de un tema exclusivo de la cadena inversa, ya que lo mismo ocurre en la cadena de suministro directa (OLIVEIRA et al., 2016)

Estos elementos del comportamiento de los actores involucrados en procesos de colaboración y cooperación pueden explicar en parte el éxito de los países europeos. Sin embargo, al mismo tiempo que la colaboración o cooperación potencian los resultados de las iniciativas en esos países, se verifica que la ausencia de éstas puede explicar igualmente menores niveles de efectividad de los modelos implementados. Italia, antes de adaptar la legislación nacional a la Directiva, no tenía un objetivo común a todos, ya que recolectava solamente residuos que le interesaban al reciclador, con un propósito financiero. Inicialmente, faltaba claridad de la legislación, estándarización del sistema de LI de RAEE y la recogida de tales residuos separada de los demás. Sin embargo, en la primera fase, incluso tras resolver las cuestiones iniciales, los resultados han sido limitados. En ese escenario, se buscó la cooperación de los ciudadanos. Se han creado cursos sobre la LI de RAEE en escuelas, con el objetivo de entender qué necesita hacerse para que la población trabaje de forma coordinada para disminuir el desperdicio y hacer el descarte correcto (TORRETTA et al., 2013). En el caso de Rumania, ha sido necesario aumentar el grado de concientización de la población, cuya ausencia, sumada al tiempo de vida útil de los AEE, que es aproximadamente el doble de la media europea, y la disminución de la población, debido a la baja tasa de natalidade, eran factores críticos para que Rumania consiguiese alcanzar la meta de $4 \mathrm{~kg}$ /por habitante de RAEE recolectados. Para ello, el gobierno rumano creó un proyecto piloto con campañas de descarte de RAEE, concentradas en fechas específicas, en nivel nacional, para aumentar la concientización de la población e incentivarla al descarte de RAEE. Estos hechos aumentaron considerablemente los índices de recogida de RAEE. Para el gobierno rumano, no bastaría solo con entregarles informaciones a los ciudadanos sobre la LI de RAEE, sería necessário mezclar esfuerzos con campañas e incentivos para que la población hiciera el descarte de los RAEE. En paralelo, el gobierno obligó a los consorcios de gestión de residuos a mejorar la comunicación, de modo de ejercer integralmente su rol en la cadena, para garantizar el alcance de las metas (TORRETTA et al., 2013). Aún los países líderes en recogida de RAEE, como Suecia, Noruega y Finlandia, tuvieron problemas con la crisis económica mundial y la consecuente disminución del consumo 
y descarte de AEE. Sin embargo, se cree que para continuar con el objetivo de eficiencia creciente de la LI, realizar plenamente el potencial de reciclaje de RAEE y establecer sistemas de recuperación eficaz de RAEE, aún es necesario más información y comunicación para lograr el compromisso del consumidor.

Al discutir estas cuestiones en países en desarrollo, los desafíos son aún mayores, ya que sus modelos todavía están en estagios preliminares y la realidad sociocultural y económica es muy distinta. Estas cuestiones son más evidenciadas debido al aumento del PIB, que altera el comportamiento del ciudadano, aumentando el consumismo y los cambios más frecuentes de los AEE por modelos más nuevos, de acuerdo con Torretta et al. (2013). Iniciativas en economias emergentes, como India, China, Corea del Sur y Brasil muestran que modelos específicos deben ser adaptados a la realidad local (SCHLUEP et al., 2009; MANOMAIVIBOOL; VASSANADUMRONDEE, 2011; WANG et al., 2012. AUGUSTO, 2014). El modelo emergente de LI en dichos países es forzado a lidear con la falta de legislación adecuada y de incentivos económicos, baja sensibilización del consumidor, productos sin marca $\mathrm{y}$ recolectores callejeros informales, que son responsables por el aumento de la recogida y procesamiento de RAEE con poca preocupación con los aspectos de salud, seguridade y protección del medioambiente (SCHLUEP et al., 2009; MANOMAIVIBOOL; VASSANADUMRONGDEE, 2011, WANG et al., 2012, AUGUSTO, 2014).

En el caso de Brasil, existe un paradojo, ya que a pesar de los problemas peculiares a los países en desarrollo enfrentados por la realidad brasileira, existe una legislación innovadora y muy avanzada, que trata de los Residuos Sólidos (RS), la Política Nacional de Residuos Sólidos (PNRS), del 2010. En el caso del sector de AEE, la PNRS obliga a los productores, importadores y minoristas a desarrollar e implementar un sistema de modelo de LI, independiente del sistema de gestión de residuos público (BRASIL, 2010a). La PNRS es también la primera legislación en nível mundial a reconocer la importancia de las organizaciones de recolectores en la cadena de reciclaje y exigir la integración, de forma colaborativa, de dichos trabajadores en el sistema LI (DEMAJOROVIC; MIGLIANO, 2013; AUGUSTO, 2014). La LI puede ser implementada a través de decreto, acuerdo de compromisso o Acuerdo Sectorial (AS). Sin embargo, existe um consenso de que la mejor forma sería por meio de acuerdo sectorial, ya que el gobierno no se siente capaz de diseñar el sistema, con todas las variables y la complejidad peculiar a los RAEE (AUGUSTO, 2014). 
Sin embargo, los actores que deberían presentar la propuesta de acuerdo sectorial han aplazado de todos los modos su elaboración e implementación, debido a los conflictos de interés, generando una increible morosidad. Han pasado más de 27 años, desde la primera Propuesta de Ley del Senado (PLS) presentada al Senado, hasta el momento (AUGUSTO, 2014), pero tal morosidad parece tener siempre el mismo motivo: transferir al máximo la responsabilidad y el costo para los otros actores de la cadena, quedando con la menor parte para si. De esta forma, por un lado el gobierno no resuelve las cuestiones de conflictos entre leyes, incentivos y financiamiento para el sistema de LI, bitributación de la cadena inversa, clasificación de los RAEE, y además declara que solo atenderá a tales cuestiones tras la firma de un acuerdo sectorial, pero no firma un decreto para ello. Por outro lado, fabricantes, distribuidores y minoristas intentan limitar su acción en el sistema de LI, alegando que la ley no especifica el rol exacto de cada actor en la responsabilidad compartida por el ciclo de vida del producto. El sector privado entra en consenso cuando atribuye la lentitud del proceso al gobierno, que no responde a las reinvindicaciones sobre los requisitos básicos legales y estructurales para implementación de la LI. El gobierno, por su turno, acusa a los actores de intentar postergar al máximo la definición del Acuerdo Sectorial y su implementación (AUGUSTO, 2014).

En ese contexto, es posible inferir sobre la falta de elementos que favorezcan la colaboración y cooperación en esos países, en especial en Brasil, que tiene la responsabilidad compartida como eje de la LI. La responsabilidad compartida exige acciones coordenadas, colaboración y cooperación entre todos los miembros de la cadena inversa y el gobierno, porque debería tener como objetivo común un sistema de LI de RAEE eficiente, con roles y resultados esperados, definidos de forma clara para cada actor, incluso el consumidor y el gobierno, transparencia en los procesos, comprometimiento por el todo e intercambio de informaciones, entrenamientos y recursos para la efectiva implementación del modelo brasileño, que ayude a establecer un ambiente de confianza y que haga posible esse intercambio (GATTAZ, 2010; MIGLIANO, 2012; AUGUSTO, 2014). Sin embargo, el escenario es opuesto a lo que se espera para tener condiciones mínimas de cooperación, con un ambiente en el que las partes actúan y reciben los beneficios de forma equilibrada (GATTAZ, 2010).

Con base en estos argumentos, se puede afirmar que el entendimiento sobre las diferencias entre colaboración y cooperación ayudan a los gestores a desarrollar políticas que favorezcan el comportamiento colaborativo y cooperativo de las empresas, garantizando la 
implantación exitosa de nuevos procesos, modelos de negocios y exigencias legislativas, en especial en Brasil, que exige la implementación del sistema de LI de RAEE, con base en la responsabilidad compartida de los actores por el ciclo de vida del producto de forma encadenada e individualizada, o sea, de forma cooperativa.

Pese a que los conflictos existentes entre los actores de la cadena inversa de AEE de Brasil están relacionados a los elementos esenciales a la colaboración y cooperación (DEMAJOROVIC; MIGLIANO, 2013; JANG, 2010; DEMAJOROVIC; AUGUSTO; SOUZA, 2016), objetivos comunes, definición clara del rol de cada actor, responsabilidad por los resultados deseados y compromisos asumidos (GATTAZ, 2010), se verifica que casi no existen investigaciones que hagan mención al rol de estos dos conceptos en la cadena inversa de AEE (JANG, 2010; WANG et al., 2012; AUGUSTO, 2014; DEMAJOROVIC; AUGUSTO; SOUZA, 2016). Se nota, así, que existe un vacío en la literatura respecto a la cooperación y colaboración en la cadena inversa de RAEE, lo que justifica la importancia del estudo propuesto.

De esta forma el proyecto de la tesis parte de la definición de los factores que involucran la implantación y la mantención de los sistemas de LI de RAEE en el mundo y en Brasil, retirados del proyecto de disertación de la autora y de la actualización de la literatura. Entre tales factores se destacan legislación, tecnología, compromiso de miembros de la cadena, concientización de consumidores, entre otros. Pese a que la literatura muestre como algunos de estos factores puedan ser más importantes en diferentes escenarios para explicar la efectividad de los diferentes modelos, se considera que la colaboración o la cooperación potencializam cada una de esas variables. En esse contexto, la pregunta de investigación es: ¿Cómo la colaboración y cooperación están influenciando la implementación del modelo de LI de RAEE en el escenario europeo y brasileño? Todos estes factores serán evaluados para entender cómo su presencia o ausencia impacta en la predisposición de los actores involucrados en la LI de RAEE a colaborar y cooperar en la formulación de política públicas y/o en su implantación y ejecución. Para atender a este propósito, el objetivo geral del proyecto de tesis es discutir el impacto de la colaboración y cooperación en la implementación del modelo de LI de RAEE en Brasil.

Para responder a la pregunta de investigación y alcanzar el objetivo central, los objetivos específicos serán:

a) Discutir los principales atributos de los conceptos de la colaboración y de la cooperación. 
b) Identificar los elementos de la colaboración y de la cooperación en los modelos internacionales de LI de RAEE.

c) Aplicar los factores determinantes e la colaboración y de la cooperación de la LI de RAEE en los modelos español, portugués, suizo y brasileño.

d) Comparar los modelos a partir de los resultados, de modo de entender el impacto de la colaboración y la cooperación en el modelo brasileño.

Para atender a estos objetivos, la investigación utilizo un enfoque cualitativo, exploratório y descriptivo, porque su objetivo es entender lo que motiva a los actores a implementar la LI de RAEE y como la colaboración y la cooperación impactan su resultado. La recolección de datos se hizo a través de estudios de caso múltiples, entrevistas en profundidades con entrevistas semiestructuradas, aplicadas a los principales drivers de la LI de RAEE en Brasil, España, Portugal y Suiza. El tratamiento de los datos utilizo la técnica de análisis de conteúdo.

\section{PRESENTACIÓN Y DISCUSIÓN DE LOS RESULTADOS}

Este capítulo tiene por objetivo presentar y discutir los resultados obtenidos en la investigación por inermedio de entrevistas, documentos e informes y observación de campo, en Suiza, Portugal, España y Brasil. Estos resultados y discusión atienden al $2^{\circ}, 3^{\circ}$ y $4^{\circ}$ objetivos de la tesis, que tenían el propósito de identificar los elementos de la colaboración y cooperación presentes en la implementación de la legislación y operacionalización de los sistemas de LI de RAEE en los países estudiados, aplicando los factores determinantes de la colaboración y cooperación en esos modelos de LI, para compararlos a partir de los resultados, de modo de entender el impacto de la colaboración y la cooperación en los modelos brasileño y europeo.

\subsection{IMPACTOS DE LA COLABORACIÓN Y COOPERACIÓN}

La colaboración facilita la elaboración de soluciones para cuestiones complexas, como leyes innovadoras (HARGROVE, 1998), promoviendo el compromiso de los stakeholders en la búsqueda de consenso y de mejor resultado para todos, reduciendo la inversión con la formulación de políticas contradictorias y normas innovadoras (ANSELL; GASH, 2008). Los resultados de las acciones colaborativas se potencian por el uso del conocimiento 
multidisciplinar de los integrantes del grupo, promoviendo el aprendizaje colectivo y acelerado (HARGROVE, 1998; ANSELL; GASH, 2008).

\subsubsection{Impactos, Beneficios y Desafíos de la Colaboración}

En ese escenario, los países europeos han obtenido diversos benefícios con la colaboración entre los actores. Suiza ha sido capaz de aprobar la ORDEE, crear mecanismos rigorosos de control y calidad y volverse referencia mundial en la LI de RAEE, atendiendo a las demandas de mercado de la población y de las empresas que ya realizaban LI, gracias al trabajo conjunto entre los actores de la industria de AEE y el gobierno, todo ello de un modo consensual. En ese caso, el gobierno suízo contó con el conocimiento de la industria de AEE para fundamentar los termos de la ley y aprimoramiento de los estándares de reciclaje de RAEE. Este comportamiento proactivo de los actores de la LI y la predisposición del gobierno para legislar en pro de la población han creado un marco legislativo y de conocimiento capaz de atender a las complexas demandas de la LI. Todos estos esfuerzos han transformado el país en referencia mundial en LI de RAEE y han servido de inspiración para las directivas de la UE. Un ejemplo de ello es la norma EN 50625-1: 2014, que define los criterios de calidad de reciclaje de los RAEE y que será usada para orientar los nuevos câmbios en la Directiva de RAEE. De acuerdo con Ansell y Gash (2008), la colaboración acelera el proceso de conocimiento colectivo, aportando benefícios para todos los involucrados y facilitando el proceso de creación e innovación.

En Portugal, el gobierno ha buscado la participación colaborativa de los actores en la elaboración de los Decretos con fuerza de Ley sobre RAEE, de las propuestas de licencias de las Entidades Gestoras (EG) y de los Operadores Gestores de Reciclaje (OGR) y de los sistemas de control de la LI. A través de este mecanismo participativo, el gobierno ha aprendido sobre las necesidades de cada actor y mostrado a ellos la importancia de los requisitos legales. De esta manera, ha sido posible aprovar las leyes y mecanismos de control de modo consensual, aún en las cuestiones más complejas. Un ejemplo de ello es el aprimoramento del Sistema de Información de registro de los RAEE, que automatizó diversos procesos y que, en un primer momento, fue muy combatida por los actores que la usarían. Hargrove (1998) explica que la colaboración permite aumentar las perspectivas de los actores respecto a un determinado problema y sensibilizarlos sobre la importancia de medidas frecuentemente controversiales, 
facilitando su entendimiento y aceptación. El histórico positivo de colaboración incentivó el gobierno a buscar más actores para trabajar conjuntamente en la discusión de sistemas de control y leyes que puedan mejorar los resultados de la LI de RAEE. De esta manera, el gobierno desea que el comercio minorista participe del sistema de control de LI de RAEE, haciendo que sean registrados los AEE vendidos en sus tiendas, para así poder direccionar las metas de LI en los AEE efectivamente vendidos. Actualmente, dichos valores se calculan por la cantidad de AEE fabricados, lo que puede generar discrepancias entre la projección de descarte y los AEE que fueron consumidos. Además, el gobierno ha contactado a las Entidades Gestoras, con el propósito de elaborar una ley que establezca una cámara de compensación de RAEE entre ellas, creando um marco legislativo que facilite la cooperación en la operación de la LI. Los resultados de ambos países refuerzan los planteamientos de Ansell y Gash (2008) sobre la importancia de la colaboración en la construcción de políticas públicas coerentes y en pro del interés de todos. Muestran, también, que tales gobiernos están preocupados con la creación de leyes que faciliten la cooperación entre las empresas que van a operar conjuntamente la LI de RAEE, ya que, según Verschoore y Balestrin (2008), la falta de estructura legislativa que respalde ese tipo de trabajo conjunto puede dificultar su implementación.

Sin embargo, en Brasil, apesar de que el gobierno haya elegido un mecanismo colaborativo para discutir el modelo de LI de RAEE, hasta ahora no ha sido posible concretar la colaboración. Ello porque, tras más de 5 años de discusión para implementar la LI de RAEE, no se ha llegado a un consenso sobre los términos del Acuerdo Sectorial (AS). Aun así, la actuación conjunta en el AS ha permitido que los actores reciban algunos beneficios de este proceso colaborativo. De esta manera, ha sido posible que los actores entiendan mejor la necesidad de cada uno, ampliando su perspectiva sobre el potencial del otro (HARGROVE, 1998), identifiquen las competencias de los actores, para saber donde podrían ayudar más (HORD, 1881; POLENSKE, 2004) y adquieran nuevos conocimientos sobre el proceso de LI y el mercado de RAEE, resultado del aprendizaje colectivo (ANSELL; GASH, 2008). Así, la industria se percató de que puede crear sus Entidades Gestoras, pues, además de atender a la Política Nacional de Residuos Sólidos (PNRS), la LI puede aportar lucros, un resultado característico de este proceso. Ello ocorre porque, de acuerdo con Hargrove (1998), la colaboración ayuda a la creación de nuevos productos y servicios como respuesta a cuestiones complexas, como la operación de LI de RAEE. Otro beneficio del aprendizaje colectivo fue el 
entendimento sobre las barreras para la efectivación de la LI. De esa forma, el gobierno comprendió la importancia de legislar sobre la peligrosidad de los RAEE para que la LI sea más facilmente ejecutable y, para ello, estableció una norma con el propósito de facilitar el descarte y transporte de los RAEE e inspirar el gobierno federal a hacer lo mismo en nivel nacional. Además, el gobierno federal estableció el decreto que determina que todos los actores del sector de AEE deberán incorporarse al sistema de LI definido por el Acuerdo Sectorial, aunque no hayan participado de las discusiones o subscrito el AS, lo que es uno de los pleitos importantes de la industria. Pese a que la mayoría de las barreras para la efectivación de la LI de RAEE no haya sido vencida, la participación en un proceso colaborativo hizo que los integrantes del grupo contribuyeran con sus conocimientos y habilidades distintas, para avanzar en diversos temas pendientes (HARGROVE. 1998).

Sin embargo, a pesar de los beneficios presentados en los casos de Suiza y Portugal y de los avances alcanzados en Brasil, quedan evidentes algunos desafíos para la efectivación de la colaboración y la comprobación de sus impactos positivos. En el caso de Portugal, el poder exercido por el gobierno en las negociaciones de las políticas puede generar conflictos de confianza en el grupo, que puede no sentirse escuchado en este proceso y perder la motivación para colaborar. Mientras, en Brasil, la cantidad de desafíos encontrados es mucho mayor. Al contrario de Portugal, el gobierno brasileño no ejerce nada del liderazgo que es inherente a su rol en el AS, siendo incapaz de estimular la búsqueda de resolución de los problemas y la sinergia entre los miembros (HORD, 1981). Este comportamiento se refleja en la inercia de los actores del gobierno federal para resolver los obstáculos legislativos para hacer posible la operación de la LI y la creación de incentivos fiscales. Además, algunos pleitos, como la revisión de la meta de un $17 \%$ de recogida de RAEE y la cantidad de puntos de recogida que deben ser implementados para operacionalizar la LI, parecen ser factores innegociables para el gobierno. La falta de actitud de parte del gobierno para atender a las demandas de los actores del AS y la falta de flexibilidad en la negociación perjudica el compromiso del grupo, ya que este no se siente atendido en ninguno de sus pleitos (ANSELL; GASH, 2008). En este contexto, los actores del sector privado no reconocen como siendo legal su obligación de implementar la LI de RAEE, por medio de la responsabilidad compartida. De esta manera, potencian el mayor desafío enfrentado para efectivar la colaboración en el escenario brasileño, que es la falta de sentido de urgencia para operacionalizar la LI de RAEE en el país. 
Brna (1998) plantea que la correta elección de la estructura que será adoptada en procesos de colaboración o cooperación es muy importante para su éxito. De esta forma, un análisis hecho a partir de los atributos de Motivación, Delimitación y Estructura en estos 3 países mostró que Brasil es el país que presenta más no conformidades con la literatura, conforme se muestra en el Cuadro 1. La recopilación de estos resultados fue extraída del Cuadro 2 , en el que se puede observar el detalle de las no conformidades de cada atributo.

Cuadro 1: Síntesis de las no conformidades en la colaboración

\begin{tabular}{|l|l|l|lr|}
\hline Portugal & Suiza & Brasil & \\
\hline Motivación $=0 / 3$ & Motivación $=0 / 3$ & Motivación $=3 / 3$ & Cantidad de & no \\
Delimitación $=1 / 4 *$ & Delimitación $=1 / 4 *$ & Delimitación $=2 / 4 *$ & conformidades & por \\
Estructura $=2 / 9 * *$ & Estructura $=1 / 9 * *$ & Estructura $=5 / 9 * *$ & dimensión \\
\hline $\begin{array}{l}\text { Implementación de la } \\
\text { Ley y superación de los } \\
\text { Resultados }\end{array}$ & $\begin{array}{l}\text { Implementación de la para atender } \\
\text { mercado y sociedad }\end{array}$ & $\begin{array}{l}\text { No efectivó el AS, ni } \\
\text { logró consenso }\end{array}$ & \\
\hline
\end{tabular}

Fuente: Elaborada por la autora (2018)

Nota 1: * indica que una de las no conformidades, “competidores actúan en colaboración”, es igual para los tres países.

Nota 2: ** indica que la no conformidad "cada uno responde por sus costos" es igual para los tres países.

Quizás este enfoque explique la cantidad de desafíos que Brasil enfrenta, con relación a Portugal y Suiza, dado que en Brasil, de los 16 atributos que componen las 3 dimensiones que describen las características del proceso de colaboración, 10 atributos presentan "no conformidad" con la literatura, o sea, sus valores no están de acuerdo con los autores del referencial teórico. Además, la mayoría de esos valores assumidos por los atributos son característicos del proceso de cooperación, como se puede observar en el Cuadro 2. En este caso, la categoria Motivación, que representa los motivos para iniciar un trabajo colaborativo, es la más afectada, y presenta en sus 3 atributos no conformidades relativas a la falta de voluntad y necesidad, percepción de oportunidades en actuar conjuntamente y disposición para superar los desafíos y actuar conjuntamente. Así, se percibe que la única razón por la que los actores siguen actuando conjuntamente es porque fue éste el mecanismo elegido por el gobierno. Aunque el sector privado encuentre importante estar en el grupo, su objetivo es defender sus pleitos, sobreponiéndolos a los objetivos comunes, como se puede notar en la segunda categoría, Delimitación. La otra categoría que presenta más divergencias con la literatura es la tercera, Estructura, responsable por la forma como las tarefas son divididas, como las relaciones 
son tratadas, como los recursos son disponibilizados y cuales son los mecanismos para construir la confianza entre el grupo.

A seguir viene Portugal, con 3 no conformidades y un desafío levantado. Pero en el caso de Portugal, el desafío levantado, a pesar de estar directamente relacionado a una de las no conformidades, aún no afecta las relaciones, pese a que los actores ya demuestren insatisfacción con la forma como el poder es ejercido por el gobierno en la elaboración de las leyes y normas y reclamen porque no siempre tienen sus pleitos aceptados. Sin embargo, declaran que el gobierno acata algunas de sus sugerencias, garantizando las pequenas vitorias, tan importantes para mantener el compromisso de los miembros en governanza colaborativa, de acuerdo con Ansell y Gash (2008).

Y por último, Suiza, con 2 no conformidades y ningun desafío relatado para obtener los resultados positivos de la colaboración. En este caso, se observa que los actores que actúan conjuntamente son motivados pelo desejo de ser sustentáveis e trabajar en pro de la comunidad y actúan de modo proactivo, creando voluntariamente los mecanismos necesarios para obtener los mejores resultados de la LI. Además, la LI de RAEE, desde um principio, fue vista como una oportunidad por los actores de la industria de AEE, por se tratar de un resíduo valioso, por la oportunidad de preservar el medioambiente y por el impacto positivo que ésta causaria en su imagen.

Es importante destacar que 2 de esas no conformidades identificadas en Suiza y Portugal son comunes a los 3 países y no parecen influenciar los resultados de la colaboración, anulando su efecto. Una de ellas trata de la actuación entre competidores y la otra se refiere al financiamiento de la acción. En la primera situación, surge uma nueva reflexión para el caso de la colaboración en el LI de RAEE y en la elaboración de políticas públicas. Diferentemente de aquello que la literatura apunta en otros campos del conocimiento, como investigación y educación (HORD, 1981; BRNA, 1998; POLENSKE, 2004), en los cuales no se aconseja la colaboración entre competidores, en la LI de RAEE esta se presenta posible entre competidores, ya que estos actúan como en un bloque de sector, para resolver una cuestión común, el impacto que su modelo de negocio causa al medioambiente. En la segunda situación, la no conformidad está atrelada al atributo recursos financieros, que de acuerdo a la literatura son compartidos, o se crea um fondo o se pide um préstamo conjunto para financiar las acciones en la colaboración (HORD, 1981; POLENSKE, 2004). Pero en el caso de la colaboración en la elaboración de leyes y normas de LI de RAEE, el discurso de todos los actores demuestra que es natural que 
cada uno de ellos se haga cargo de su parte de los gastos con la locomoción o la recepción de un grupo en sua organización, sin que ello necesite ser financiado colectivamente. Por lo tanto, se podría decir que Suiza no presenta ninguna no conformidad, Portugal 1 y Brasil 8, y que dichos valores, en estos dos atributos, no afectan los resultados finales de la colaboración. De esta manera, es necesario rever la matriz de factores determinantes de la colaboración para que ésta se adecue a la realidad de esta área del conocimiento, ya que fue elaborada a partir de la revisión de la literatura, la que no incluía ningun caso de colaboración en LI de RAEE. Para ello, se rehizo la matriz de atributos determinantes para la colaboración, considerando los resultados de esta investigación, alterando los valores que estos dos atributos pueden asumir e incluyendo el valor "predisposición para ser sustentable" en el atributo disposición. El Cuadro 2 muestra el resultado verificado en los 3 países y sus impactos en el proceso, incluyendo las referidas alteraciones.

Cuadro 2: Matriz del impacto de la colaboración en Portugal, Suiza y Brasil

\begin{tabular}{|c|c|c|c|c|}
\hline Portugal & Suiza & Brasil & $\begin{array}{l}\text { Valores de los } \\
\text { atributos }\end{array}$ & Ref. \\
\hline \multicolumn{5}{|c|}{ Dimensión Delimitación de la Colaboración } \\
\hline $\begin{array}{c}\text { Necesidad de atender a las } \\
\text { leyes }\end{array}$ & $\begin{array}{c}\text { Voluntad de atender a la } \\
\text { sociedad }\end{array}$ & No sienten obligación $*$ & Necesidad/Voluntad & 1,6 \\
\hline $\begin{array}{l}\text { Oportunidad de generar } \\
\text { divisas. Tener consenso }\end{array}$ & $\begin{array}{l}\text { Ter consenso. Padronizar } \mathrm{p} / \\
\text { todos. Recuperar materiales }\end{array}$ & $\begin{array}{l}\text { Lobby para disminuir la } \\
\text { responsabilidad. }\end{array}$ & Oportunidad & 1,6 \\
\hline $\begin{array}{l}\text { Histórico positivo de } \\
\text { colaboración. Sentido de } \\
\text { urgencia }\end{array}$ & $\begin{array}{l}\text { Iniciativa voluntaria. } \\
\text { Predisposición para ser } \\
\text { sustentable }\end{array}$ & $\begin{array}{l}\text { No tiene disposición, ni } \\
\text { sentido de urgencia. }\end{array}$ & Disposición & $1,6,8$ \\
\hline \multicolumn{5}{|c|}{ Dimensión Delimitación de la Colaboración } \\
\hline $\begin{array}{l}\text { Elaborar ley y sistemas de gestión y } \\
\text { control }\end{array}$ & Elaborar ley y criterios de calidad & Elaborar AS & $\begin{array}{c}\text { Naturaleza: } \\
\text { Elaboración de algo }\end{array}$ & 7 \\
\hline Objetivo del grupo. & Objetivo del grupo & Objetivo individual & Objetivo del Grupo &, $3 ; 6 ; 8$ \\
\hline Tangibles e intangibles & Tangibles e intangibles & Tangibles e intangibles & $\begin{array}{c}\text { Resultados Tangibles } \\
\text { y/o intangibles }\end{array}$ & $5 ; 8 ; 9$. \\
\hline $\begin{array}{c}\text { Competidores representados por } \\
\text { asociaciones }\end{array}$ & $\begin{array}{c}\text { Competidores representados por } \\
\text { asociaciones }\end{array}$ & $\begin{array}{c}\text { Competidores representados por } \\
\text { asociaciones. Restringen actores }\end{array}$ & $\begin{array}{c}\text { Competidores son } \\
\text { permitidos en grupo } \\
\text { asociación }\end{array}$ & $6 ; 9$ \\
\hline \multicolumn{5}{|c|}{ Dimensión Estructura de la colaboración } \\
\hline $\begin{array}{c}\text { Trabajan en pares. Intenta } \\
\text { mantener la dependencia. } \\
\text { Gobierno lidera las } \\
\text { discusiones }\end{array}$ & $\begin{array}{c}\text { En conjunto; } \\
\text { Interdependencia. }\end{array}$ & $\begin{array}{c}\text { Trabajan separados; } \\
\text { Reuniones paralelas; No } \\
\text { tiene interdependencia }\end{array}$ & $\begin{array}{l}\text { Trabajan juntos, } \\
\text { internamente; } \\
\text { Interdependencia }\end{array}$ & $\begin{array}{l}1 ; 5 ; \\
6 ; 7 \\
8 ; 9\end{array}$ \\
\hline Aporte & Aporte & Aporte & De apoyo, Aporte & $\begin{array}{l}1 ; 5 \\
9 ; 7\end{array}$ \\
\hline $\begin{array}{l}\text { Compartido. Los actores } \\
\text { participaban de las reuniones } \\
\text { con el gobierno. }\end{array}$ & $\begin{array}{l}\text { Compartido. Los actores } \\
\text { participaban de las } \\
\text { reuniones. }\end{array}$ & $\begin{array}{l}\text { Compartido; No tenían } \\
\text { poder de decisión; Reunión } \\
\text { en las sedes y Gobierno }\end{array}$ & $\begin{array}{l}\text { Recurso: RH y } \\
\text { Estructura } \\
\text { Compartidos }\end{array}$ & 1 \\
\hline
\end{tabular}




\begin{tabular}{|c|c|c|c|c|}
\hline Cada cual paga su parte & Cada cual paga su parte & Cada cual paga su parte & $\begin{array}{c}\text { Recurso Financ. } \\
\text { Se hace cargo } \\
\text { financiero de su } \\
\text { participación }\end{array}$ & 1 \\
\hline No surgió & Comparte Información & Comparte Información & $\begin{array}{l}\text { Recurso Inform.: } \\
\text { Compart }\end{array}$ & 6 \\
\hline Até agotar o assunto & Até obter consenso & Esporádicas & $\begin{array}{l}\text { Comunicação } \\
\text { Intensa }\end{array}$ & $1 ; 7$ \\
\hline Mutuo, Jerarquizado GF & Mutuo & Mutuo. Jerarquizado GF & Poder Mutuo & 7,9 \\
\hline No tienen contratos & No tienen contratos & $\begin{array}{l}\text { No tienen mecanismos, ni } \\
\text { confianza por si mismos; } \\
\text { No tienen contrato }\end{array}$ & $\begin{array}{l}\text { Control: pocos } \\
\text { mecanismos; } \\
\text { informal }\end{array}$ & $3 ; 1$ \\
\hline No se relataron riesgos & No se relataron riesgos & Todos tienen un riesgo & Riesgo compartido & $1 ; 2 ; 6$ \\
\hline \multicolumn{5}{|c|}{ Dimensión: Impactos de la Colaboración } \\
\hline Implementación de la Ley & Implementación da Ley & Aún no hizo efectivo el AS & Resultado Directo & \\
\hline $\begin{array}{c}\text { Ley consensual. Superación de } \\
\text { las divergencias. Mejora de los } \\
\text { SI del gobierno. Motivación } \\
\text { para establecer trabajos } \\
\text { conjuntos } \\
\end{array}$ & $\begin{array}{l}\text { Ley consensual. Referencia } \\
\text { mundial en la LI de RAEE y } \\
\text { criterios de calidad para la } \\
\text { UE. Aprendizaje colectivo. }\end{array}$ & $\begin{array}{l}\text { Entender las necesidades de } \\
\text { los demás. Aprendizaje } \\
\text { colectivo. Hizo posible } \\
\text { identificar las competencias }\end{array}$ & Beneficios & \\
\hline No exceder el uso del poder, & & $\begin{array}{l}\text { Falta sentido de } \\
\text { obligatoriedad que potencia } \\
\text { todos los demás. No hay } \\
\text { consenso, no reconocen los } \\
\text { pleitos; Falta de incentivos } \\
\text { fiscales. }\end{array}$ & Desafíos & \\
\hline
\end{tabular}

Elaborada por la Autora (2018)

Nota1: Subtítulo de las Referencias: Hord (1981) $)^{1}$; Hord (1986) ${ }^{2}$; Brna (1998) ${ }^{3}$; Das y Teng (1998) ${ }^{4}$; Balancieri $(2004)^{5}$; Polenske (2004) ${ }^{6}$; Kemczinski et al. $(2008)^{7}$; Ansell y Gash (2008) $)^{8}$; Winckler y Molinari (2011) ${ }^{9}$.

Subtítulo: Los colores más fuertes en los cuadros se utilizaron para marcar algún tipo de no conformidad. La $\mathrm{X}$ roja marca los atributos que tienen característica del proceso de cooperación. El marco rojo señala cuáles han sido los valores de atributos que asumieron otros valores, con base en los resultados de investigación

Además de la cantidad elevada de no conformidades y la ausencia de factores motivacionales, el Cuadro 2 muestra evidencia de los atributos que asumieron valores característicos de cooperación, en el caso brasileño. En ese contexto, Polenske (2004) alerta para el problema de la elección de una estructura inadecuada para actuar con uno de los dos conceptos, ya que ello puede dificultar la elaboración de políticas públicas o crear un clima de inseguridad entre los actores, ya que cada uno de ellos prevee un tipo de comportamiento, uso de recursos y resultados alcanzables. De esta forma, además de la dimensión Motivación, que está totalmente en desacuerdo con procesos colaborativos, en la dimensión Delimitación, los objetivos de los actores son individuales, no del grupo. En la dimensión estructura, el grupo no se aprovechó de la sinergia característica de reuniones frecuentes y presenciales, además de haberse dividido en dos bloques, que actuaban como adversários. Estos elementos fragilizaron más la confianza por si sola del grupo, exigiendo mecanismo de controles formales, como la garantía por decreto, que las empresas que no participaron del AS, tendrían que adherir obligatoriamente al modelo de LI de RAEE elegido por ellos. Eestos hechos corroboran Hord 
(1981) y Polenske (2004), sobre la importancia de construir un modelo adecuado a la naturaleza del proceso, respetando sus atributos.

\subsubsection{Impactos, Beneficios y Desafíos de la Cooperación}

La cooperación, cuando relacionada a la Delimitación y estructura necesarias para su implementación trae, entre sus beneficios, el aumento exponencial del conocimiento, complementariedad de las competencias y recursos, aumento de la capacidad de atender nuevos mercados y reducción de costos (POLENSKE, 2004; SILVA, 2007).

En ese escenario, la cooperación en la LI de RAEE en España y Portugal ha permitido que ambos países superen las metas de reciclaje. En el caso da Suiza, pese a la ausencia de meta, la cooperación entre los actores transformó al país en referencia mundial en la LI de RAEE y en criterios de calidad para reciclaje de RAEE. Con casi tres décadas de funcionamiento, Suiza recoge hoy día, cerca de 3 veces más RAEE que España y Portugal, con un promedio de $16 \mathrm{~kg}$ por persona en 2016. Portugal ha ultrapasado las metas de recogida de $4 \mathrm{~kg} /$ por persona/año de RAEE desde 2010, y en 2015 colectó 5,1 kg. España superó la meta en 2015, recogiendo 4,61 kg. Esos datos muestran que, a través de la cooperación, es posible alcanzar buenos resulados. La cooperación permite que los actores atiendan demandas más urgentes y mayores que la capacidad actual (KIRSCHNER; DICKINSON; BLOSSER, 1996; BALESTRIN; VARGAS, 2004; POLENSKE, 2004).

Observamos que es notoria la superioridad del sistema de LI de RAEE suizo. Ese desempeño está relacionado con la forma cooperativa con que los actores de la LI de RAEE actúan, impactando positivamente en los resultados del sistema. El primer punto a resaltar es la distribución de los puntos de recogida entre las ORP, pues no existe competencia entre ellas. Ese mecanismo duplica las posibilidades de recogida para ambas ORP. De esa forma, la red de recogida es formada por los canales de recogida selectiva de la municipalidad, mecanismo de acopio de las tiendas que venden AEE y por los puntos de recogida de los recicladores contratados, que actúan en sociedad con las ORP. Llama la atención el hecho de que en Suiza todas las tiendas, que vendan AEE, independientemente del tamaño del establecimiento, deben recoger el RAEE del mismo tipo que venden. Esas sociedades aumentan la presencia del sistema de recogida de RAEE, tan importante para la LI (LEITE; LAVEZ; SOUZA, 2009), garantizando más de 6000 puntos de descarte. Ese factor facilita la participación del consumidor 
en el descarte, pues no necesitará trasladarse demasiado para ello, aumentando el volumen de RAEE recogidos. Además, la distribución de puntos de recogidas también crea beneficios para los recicladores contratados por el sistema, que optimiza el transporte, atendiendo a tres asociaciones en un único viaje. De esa manera, todos los actores cooperan para potencializar los resultados de la LI, aumentando la recogida de RAEE, valorando y reciclando la mayor parte posible de substancias contenidas en esos dispositivos, aumentando la rentabilidad de los recicladores y disminuyendo los costos de reciclaje y valor de la TAR. Ese esfuerzo se convierte en otros beneficios, como el fomento a la economía verde, la reducción de residuos enviados para vertederos o sistemas de incineración, la preservación de los recursos naturales del planeta y mejora de la imagen de las instituciones, que participan de la LI.

España y Portugal también recibieron diversos beneficios por actuar de forma cooperativa en la LI de RAEE. En ambos países, los esfuerzos de las OG en búsqueda de alianzas con municipios, tiendas y entidades, como empresas y colegios, garantizaron la mayor presencia de la LI, menor costo del reciclaje, reducción del volumen de residuos enviado a los vertederos y disminución del impacto y riesgo ambientales debido al descarte correcto de los RAEE. Además, la LI de RAEE fomenta el mercado formal de las recicladoras de metales y chatarreros, que reciben compensaciones financieras de las OG por los informes del procesamiento y destino ambientalmente correctos de los RAEE. En España, esas empresas se unen a otras del mismo sector, pero que actúan con Códigos LER diferentes, para ampliar su mercado de actuación y ganar más competitividad. En ese escenario, según los actores de ambos países, los incentivos financieros para el descarte de RAEE, las campañas, que involucran la familia por intermedio de los hijos en edad escolar, y la publicidad en medios de comunicación, como anuncios en TV y radios, son elementos que potencializan el impacto de la cooperación del consumidor.

En Brasil, la cooperación de los actores involucrados en el AS ayudó a implementar el PP. Pero los resultados de recogida estuvieron por debajo de las expectativas, pues fueron recogidos solo cerca de $2 \%$ de la proyección de residuos generadas en el local, donde fue implementado el PP. Las particularidades del PP, por ser un proyecto que tuvo inicio, medio y fin, transforman resultados insatisfactorios en oportunidades de aprendizaje. Siendo así, el mayor impacto de la cooperación en el PP fue el aprendizaje colectivo acelerado (HARGROVE, 1998; ANSELL; GASH, 2008), pues posibilitó que los actores involucrados aprendieran mucho sobre el escenario brasileño y el comportamiento del consumidor en un corto periodo. Pese a 
que el PP duró cerca de 2 años, la ejecución de la LI duró sólo 8 meses. En ese escenario, parte de los bajos resultados de recogida del PP son atribuidos a la adhesión tardía de algunas tiendas de ventas al por menor, pues el material de comunicación del PP era conflictivo con las especificidades de las marcas. La resistencia inicial de las tiendas es explicada por Hord (1981) y Polenske (2004), quienes afirman que en procesos de cooperación es importante respetar la individualidad de los actores y su forma de operar. Además, el corto periodo del PP no permitió que las personas se acostumbraran al sistema de recogida y se habituaran a descartar. Aun así, el PP dejó como legado la reglamentación, a nivel estadual, sobre la peligrosidad de los RAEE, el reconocimiento de la capacidad operacional de Coopermiti y el potencial de mercado de la LI de RAEE.

Pese al aprendizaje que todos los países estudiados recibieron en las alianzas de la LI de RAEE, y de los beneficios, que afectaban positivamente a la competitividad de esos actores en los países europeos, es necesario superar diversos desafíos en los 4 países estudiados. En ese escenario, Suiza, el país que más presentó beneficios relacionados a la cooperación entre sus actores, aún necesita superar los problemas que pueden afectar el costo del reciclaje, por la falta de cooperación. En ese contexto, resaltamos 3 desafíos: la presencia de free riders, la importación de AEE por el consumidor sin el pago de la TAR y la falta de inversión en ecodesign. Los free riders, que representen por lo menos $2 \%$ del universo de empresas, que actúan en el mercado de AEE en Suiza, y los AEE importados afectan los costos del reciclaje, pues no contribuyen al sistema de LI, pero sus RAEE son encaminados a aquél. De esa forma, aumenta la cantidad de RAEE que necesita ser tratada, sin aumentar la recaudación, pues no hay restricción por marca al momento de la recogida. Por otro lado, la ausencia de inversión de los fabricantes en ecodesing podría ser superada por la inversión en $\mathrm{P} \& \mathrm{D}$, pero ello impactaría los precios de la TAR, aumentando el problema de importación, pues el costo de los AEE en Suiza es más alto, que en los países vecinos. Siendo así, pese a que quieran resolver la situación, no fue posible llegar a una solución. La única alternativa, creada hasta el momento, para mitigar ese problema fue el desarrollo de una App, que permite el pago voluntario de la TAR por el consumidor, cuando compra algún AEE en otro país. Sin embargo, como esa iniciativa es reciente no fue posible saber si el consumidor adhirió a la idea.

Portugal y España enfrentan desafíos similares respecto a la participación del consumidor en el descarte de RAEE: la falta de inclusión social del sector informal y la exportación ilegal de RAEE, debido a los altos costos del reciclaje. Ambos países necesitan 
más inversión en campañas de concientización para el consumidor sobre la importancia del descarte correcto de los RAEE. En ese punto, España tiene su problema más grave, pues la recogida selectiva es considerada reciente en el país y los municipios no lograron siquiera sensibilizar a los consumidores sobre el descarte de los reciclables comunes. De esa forma, pese a que el gobierno sea penalizado por la UE por no cumplir con las cuotas de recogida, el consumidor no se siente afectado por ello, pues no relaciona el aumento de las tasas con el hecho de no participar del sistema de recogida. En ese caso, para que el consumidor coopere es importante que sienta la necesidad o deseo de hacer el descarte correcto (HORD, 1981; POLENSKE, 2004), y para ello, necesita ser más sensibilizado. Además, en Portugal y España el sistema de recogida sufre con los robos de RAEE en los canales oficiales. El sector informal invade puntos de los municipios o pasa antes que los camiones de recogida para robar los RAEE, desarmarlos y vender solamente la parte que tiene valor. El problema se ve agravado, pues el sistema de recogida selectiva en España y Portugal contribuye con menos de lo que las OG necesitan para completar las cuotas de reciclaje de sus clientes. Por eso recurren a recicladores formales, que compran esos RAEE de personas que van hasta su empresa o de otros recicladores menores, quienes muchas veces aceptan esos equipos fragmentados. Este ciclo, asociado a la falta de fiscalización de esos puntos y a la ausencia de políticas públicas de inclusión social para ese actor, fomenta el mercado paralelo. Aunque esta solución ayude a que las OG alcancen sus metas generales, los dos países no atienden todas las metas por categorías. Además, el alto costo da reciclaje de RAEE ha motivado la exportación ilegal de RAEE para países en desarrollo. El problema del alto costo del reciclaje se agrava, pues Portugal y España no lograron motivar la industria de AEE para invertir en ecodesign. Por lo tanto, la falta de inversión en ecodesign es común a los 3 países europeos.

En el caso de Brasil, entre los desafíos que anteceden al PP, pero que fueron calificados como primordiales por los miembros del JICA, están la necesidad de que tanto el sector público cuanto el privado asuman su responsabilidad sobre la obligación de implementar la LI, para que ésta pueda ser efectuada. Sin esa Motivación inicial, la LI no será efectiva en Brasil (HORD, 1981; POLENSKE, 2004). Además, el PP mostró que la falta de definición clara de los roles de la legislación no permite que la cooperación sea efectuada en la LI de RAEE en el país (BALANCIERI, 2004; POLENSKE, 2004; KEMCZINSKI et al., 2008), pues los actores siguen intentando minimizar su obligación. Entre los desafíos que necesitan ser enfrentados cuando la LI de RAEE empiece en Brasil está la falta de costumbre, por parte del consumidor, 
de descartar sus RAEE, pues él intenta dar una segunda vida para sus AEE u otra finalidad, que cree más noble, que descartar. De esa forma, será necesario invertir en campañas de concientización y propaganda de masa para motivar el consumidor a participar de la LI, pues él necesita sentir que es importante y necesario cooperar en el proceso. Además, es clave facilitar el acceso para el descarte en locales con estacionamiento y con venta de productos de consumo diario, para que el consumidor se acuerde de descartar siempre que salga a comprar. En ese contexto, se percibe que la Motivación para participar de la LI tiene que existir para todos, pese a que la literatura no haya incluido al consumidor final en ninguno de los textos utilizados por el referencial teórico.

En este escenario, en que los objetivos, resultados esperados y roles necesitan ser bien definidos para avaliar los impactos positivos de la cooperación (BRNA. 1998), es necesario entender cómo esos elementos fueron construídos en los 4 países. De esa forma, se hizo un análisis de los atributos en las 3 dimensiones en los países estudiados y nuevamente se demostró que Brasil es el país que presenta más no conformidades con la literatura, conforme mostrado en el Cuadro 3. La compilación de esos resultados fue extraída del Cuadro 4, donde se puede observar el detalle de las no conformidades de cada atributo

Cuadro 3: Síntese de las no conformidades en la cooperación

\begin{tabular}{|l|l|l|l|l|}
\hline España & Portugal & Suiza & Brasil & \\
\hline Motivación $=1 / 3$ & Motivación $=0 / 3$ & Motivación =0/3 & Motivación = 2/3 & Cantidad de No \\
Delimitación $=0 / 4$ & Delimitación =0/4 & Delimitación =0/4 & Delimitación = 1/4 & conformidad \\
Estructura $=0 / 8$ & Estructura =0/8 & Estructura =0/8 & Estructura =3/8 & por dimensión \\
\hline
\end{tabular}

Fuente: Elaborada por la autora (2018)

En cooperación, solamente Brasil y España presentan no conformidad con la literatura. En el caso de España, ésta tiene relación con la falta de Motivación para alcanzar las metas antes del término del período de transición de la ley, ya que no hay sanciones de la UE. Pero tal factor no afecta a los otros atributos de la Motivación, tampoco está relacionado a un valor de colaboración. En cuanto al caso brasileño, los atributos que presentan no conformidad en laa dimensión Motivación están relacionados al comportamiento oportunista y a la procrastinación, ya que los actores de la industria, apesar de que reconozcan a las competencias de JICA para ejecutar el PP y se interesen por el aprendizaje que la acción proporcionaría, querían usar ese conocimiento para mostrar al gobierno que sus pleitos eran válidos y que sin ellos no sería posible realizar la LI de RAEE no país. Esta línea de razonamiento del sector privado afectó a 
la dimensión Delimitación, en el atributo objetivos individuales, porque, a pesar de ser importante, el objetivo del grupo no será capaz de satisfacer a todos los miembros, ya que son conflictuosos entre ellos. Ello porque, mientras el gobierno quiere probar con el PP que es posible realizar la LI, el sector privado quiere lo contrario. Sin embargo, tener sus necesidades atendidas, además de transparencia sobre los objetivos de cada uno, es condición sine qua non para obtener resultados positivos en la cooperación (POLENSKE, 2004; KEMCZINSKI et al., 2008; WINCKLER; MOLINARI, 2011). En la dimensión Estructura, aparecieron 2 atributos con valores divergentes de la literatura, con características más próximas de la definición de colaboración, pero con diferencias que no nos permiten afirmar con precisión que las estructuras hayan cambiado, como pasó con algunos atributos en el proceso de colaboración. Ocurre que las tarefas son hechas por separado, de acuerdo con la literatura de cooperación (HORD, 1981; POLENSKE. 2004), pero los actores no poseen la la libertad para actuar, y todo el poder queda centralizado en JICA. De esta manera, las empresas no conseguían mantener su soberanía sobre su rol y proceso, ya que debían realizar la actividad exatamente como el equipo definió que sería mejor, y muchas vecesbajo su supervisión. Como en algunos casos no estava prevista la obligación de que el integrante hiciera informes, el equipo de JICA iba diretamente a la empresa para inspeccionar cómo se estaba llevando a cabo aquella etapa del PP. Los procesos de control son importantes en la cooperación, pero cuando en exceso ellos quitan la libertad de la empresa y perjudican el clima de confianza, según Das y Teng (1998). La descripción de los atributos de las 4 dimensiones y las no conformidades pueden ser vistas en el Cuadro 4.

Cuadro 4: Matriz del impacto de la cooperación en España, Portugal, Suiza y Brasil.

\begin{tabular}{|c|c|c|c|c|c|}
\hline España & Portugal & Suiza & Brasil & Atributos & Ref. \\
\hline \multicolumn{6}{|c|}{ Dimensión Delimitación de la Cooperación } \\
\hline Atender Leyes & $\begin{array}{l}\text { Atender Leyes e } \\
\text { imagen sust. }\end{array}$ & $\begin{array}{c}\text { Atender al mercado e } \\
\text { imagen sust. }\end{array}$ & Aprobar AS & Necesidad/Deseo & 1,6 \\
\hline $\begin{array}{c}2^{\mathrm{a}} \text { vida del AEE, } \\
\text { aumento de } \\
\text { capilaridad y divisas }\end{array}$ & $\begin{array}{c}\text { Capilaridad y } \\
\text { volúmen, aumento de } \\
\text { divisas }\end{array}$ & $\begin{array}{l}\text { Recuperar materiales, } \\
\text { capilaridad, disminuir } \\
\text { costos e impactos, }\end{array}$ & $\begin{array}{c}\text { Sensibilizar a las } \\
\text { metas, aprender con } \\
\text { PP, sin costo. }\end{array}$ & Oportunidad & 1,6 \\
\hline $\begin{array}{l}\text { Proactividade, } \mathbf{s} / \\
\text { sentido de urgencia }\end{array}$ & Sentido de urgencia. & Iniciativa voluntaria & $\begin{array}{c}\text { S/ sentido de } \\
\text { urgencia }\end{array}$ & Disposición & $1,6,8$ \\
\hline \multicolumn{6}{|c|}{ Dimensión Delimitación de la Cooperación } \\
\hline Operacionalizar LI & Operacionalizar LI & Operacionalizar LI & Operacionalizou o PP & Naturaleza: Operación & $7 ; 9$ \\
\hline Objetivos individuales & Objetivos individuales & Objetivos individuales & $\begin{array}{l}\text { Objetivos individuales, } \\
\text { conflicto de interés }\end{array}$ & $\begin{array}{c}\text { Objetivos Individuales } \\
\text { garantizados por el grup }\end{array}$ & $1 ; 6 ; 7 ; 9$ \\
\hline Tangibles: Todos & Tangibles: Todos & Tangibles: Todos & Tangibles e intangibles & Resultados Tangibles & $1 ; 6 ; 7 ; 9$ \\
\hline $\begin{array}{l}\text { Competidores. S/ } \\
\text { sector informal }\end{array}$ & $\begin{array}{l}\text { Competidores. S/ sector } \\
\text { informal }\end{array}$ & $\begin{array}{l}\text { Actores Competidores. } \\
\text { ORP complementares }\end{array}$ & $\begin{array}{l}\text { Competidores. S/ } \\
\text { cooperativas. }\end{array}$ & Competidores & $1 ; 9$ \\
\hline
\end{tabular}


Conclusión

\begin{tabular}{|c|c|c|c|c|c|}
\hline \multicolumn{6}{|c|}{ Dimensión: Estructura de la Cooperación } \\
\hline $\begin{array}{l}\text { Separados, c/ SIG. } \\
\text { Independientes. }\end{array}$ & $\begin{array}{l}\text { Separados, c/ EG. } \\
\text { Independientes. }\end{array}$ & $\begin{array}{l}\text { Separados, c/ ORP. } \\
\text { Independientes. }\end{array}$ & $\begin{array}{l}\text { Separados; no tienen } \\
\text { autonomía para } \\
\text { alterar nada }\end{array}$ & $\begin{array}{c}\text { Trabajam } \\
\text { separados, o crean } \\
\text { OG; } \\
\text { Independientes. }\end{array}$ & $\begin{array}{c}1 ; 6 ; 7 ; \\
9\end{array}$ \\
\hline NO comparte & NO comparte & NO comparte & NO comparte & $\begin{array}{l}\text { Recursos físicos y } \\
\text { humanos: no } \\
\text { comparte }\end{array}$ & $1 ; 6$ \\
\hline $\begin{array}{l}\text { Crean fondo c/ TAR. } \\
\text { GM paga costos de } \\
\text { campañas. }\end{array}$ & $\begin{array}{l}\text { Crean fondo c/ TAR. } \\
\text { GM paga costos de } \\
\text { campañas. }\end{array}$ & Crean fondo $\mathrm{c} / \mathrm{TAR}$. & JICA financia el PP & $\begin{array}{l}\text { Recursos } \\
\text { financieros: Crean } \\
\text { fondos, no } \\
\text { comparten. }\end{array}$ & $6 ; 7 ; 10$ \\
\hline $\begin{array}{c}\text { Informa sobre el } \\
\text { processo }\end{array}$ & $\begin{array}{c}\text { Informa sobre el } \\
\text { processo }\end{array}$ & $\begin{array}{c}\text { Informa sobre el } \\
\text { processo }\end{array}$ & $\begin{array}{c}\text { Informa sobre el } \\
\text { processo }\end{array}$ & $\begin{array}{l}\text { Información: } \\
\text { Informa sobre el } \\
\text { processo }\end{array}$ & \\
\hline $\begin{array}{l}\text { Esporádicas y por } \\
\text { informes y SI }\end{array}$ & $\begin{array}{l}\text { Esporádicas y por } \\
\text { informes y SI }\end{array}$ & $\begin{array}{l}\text { Esporádicas y por } \\
\text { informes y SI }\end{array}$ & $\begin{array}{c}\text { Reuniones } \\
\text { presenciales } \\
\text { mensuales, informes }\end{array}$ & $\begin{array}{l}\text { Comunicación: } \\
\text { Esporádica c/ SI }\end{array}$ & $1 ; 6$ \\
\hline $\begin{array}{l}\text { Centrado en las } \\
\text { Organizaciones }\end{array}$ & $\begin{array}{l}\text { Centrado en las } \\
\text { Organizaciones }\end{array}$ & $\begin{array}{l}\text { Centrado en las } \\
\text { Organizaciones }\end{array}$ & $\begin{array}{c}\text { Centrado en JICA y } \\
\text { GF }\end{array}$ & $\begin{array}{l}\text { Poder: Centrado en } \\
\text { la organización }\end{array}$ & $1 ; 6$ \\
\hline $\begin{array}{c}\text { Contrato } \mathrm{c} / \text { todos y } \\
\text { TIC }\end{array}$ & $\begin{array}{c}\text { Contrato } \mathrm{c} / \text { todos } \mathrm{y} \\
\text { TIC } \\
\end{array}$ & $\begin{array}{c}\text { Contrato } \mathrm{c} / \text { todos } \mathrm{y} \\
\text { TIC } \\
\end{array}$ & Contrato con todos & $\begin{array}{l}\text { Mecanismos de } \\
\text { control formal }\end{array}$ & $7 ; 10$ \\
\hline $\begin{array}{l}\text { Dividido por etapa } \\
\text { está operando }\end{array}$ & $\begin{array}{c}\text { Queda para quien está } \\
\text { operando }\end{array}$ & $\begin{array}{l}\text { Queda para quien } \\
\text { está operando }\end{array}$ & $\begin{array}{l}\text { Queda para quien } \\
\text { está operando }\end{array}$ & $\begin{array}{l}\text { Riesgo dividido, } \\
\text { queda p/ quien está } \\
\text { operando. }\end{array}$ & $1,6,7$ \\
\hline \multicolumn{6}{|c|}{ Impactos da Cooperación } \\
\hline $4,61 \mathrm{~kg} /$ persona $/ 2015$ & $\begin{array}{c}5,1 \mathrm{~kg} / \text { por } \\
\text { persona } / 2015\end{array}$ & $16 \mathrm{~K} /$ persona $/ 2016$ & $2 \%$ de RAEE. & Resultado Directo & \\
\hline $\begin{array}{l}\text { Alcanzó metas, } \\
\text { capilaridad, } \\
\text { reducción costo, e } \\
\text { impacto y riesgo } \\
\text { ambiental }\end{array}$ & $\begin{array}{l}\text { Alcanzó metas, } \\
\text { capilaridad, reducción } \\
\text { costo, e impacto y } \\
\text { riesgo ambiental }\end{array}$ & $\begin{array}{l}\text { Capilaridad: }>6000 ; \\
\text { reducción costo, e } \\
\text { impacto y riesgo } \\
\text { ambiental, imagen. } \\
\text { Mayor rentabilidad } \\
\text { en reciclaje. }\end{array}$ & $\begin{array}{l}\text { Aprendizaje. } \\
\text { Reglamentación de } \\
\text { los RAEE; } \\
\text { Reconocimiento de } \\
\text { Coopermiti; } \\
\text { Potencial de } \\
\text { mercado. Nuevos PP } \\
\text { de la industria. } \\
\end{array}$ & Beneficio & \\
\hline $\begin{array}{c}\text { Incentivos } \\
\text { financieros para que } \\
\text { el consumidor haga } \\
\text { el descarte. }\end{array}$ & & $\begin{array}{l}\text { La colaboración en } \\
\text { las leyes. Presión de } \\
\text { otro actor. Sentido de } \\
\text { comunidad. } \\
\text { "Solidaridade" y } \\
\text { Confianza. } \\
\text { Propaganda p/ los } \\
\text { supermercados. } \\
\end{array}$ & & $\begin{array}{l}\text { Beneficios: } \\
\text { Factores que } \\
\text { facilitan }\end{array}$ & \\
\hline $\begin{array}{l}\text { Comportamiento del } \\
\text { consumidor. Sector } \\
\text { informal. } \\
\text { Robo y exportación } \\
\text { ilegal de RAEE }\end{array}$ & \begin{tabular}{|} 
Falta de investi// en \\
conscientização e \\
ecodesign. Sector \\
informal. \\
Fiscalización. Robo y \\
exportación ilegal de \\
RAEE \\
\end{tabular} & $\begin{array}{c}\text { Free Riders e } \\
\text { importación. AEE } \\
\text { sem TAR. TAR que } \\
\text { financie ecodesign. }\end{array}$ & $\begin{array}{l}\text { Asumir su } \\
\text { responsabilidad. } \\
\text { Leyes claras y } \\
\text { objetivas. } \\
\text { Comportamiento del } \\
\text { consumidor. }\end{array}$ & Desafío & \\
\hline
\end{tabular}

Elaborada por la Autora (2018)

Nota1: subtítulo de las Referencias: Hord (1981) ${ }^{1}$; Hord (1986) ${ }^{2}$; Brna (1998) ${ }^{3}$; Das y Teng (1998) ${ }^{4}$; Polenske $(2004)^{6}$; Kemczinski et al. $(2008)^{7}$; Ansell y Gash (2008) ${ }^{8}$; Winckler y Molinari (2011) ${ }^{9}$; Silva (2007) ${ }^{10}$

Nota2: Las celdas con tonos más oscuros fueron usadas para señalizar atributos con "no conformidades" con la literatura.

En ese escenario, el Cuadro 4 muestra que todos los casos optaron por la estructura adecuada para cooperar, conforme la literatura, aunque en Brasil el exceso de poder y control 
de uno de los actores haya comprometido algunas de las características importantes para hacer efectiva la cooperación. Sin embargo, se puede afirmar que los 4 países tuvieron éxito en el proceso de cooperación, ya que alcanzaron su objetivo principal. De esta forma, se nota la importancia de la definición de la estructura adecuada para cada tipo de proceso. Además de la importancia de respetar las características de sus atributos, para no dificultar su implementación ni generar desconfianza e insatisfacción entre los miembros del grupo. En el caso de Brasil, este resultado cobra relevancia, ya que el PP fue la primera iniciativa para operar la LI de RAEE de forma organizada. Además, contó con la participación voluntaria de todos los actores que discuten el AS.

Sin embargo, dos factores despiertan atención en el impacto de la cooperación: la diferencia de cantidad de RAEE recogidos por los países estudiados y los desafíos para obtener mejores resultados relacionados con el consumidor. Algunos factores pueden ser apuntados sobre la diferencia de RAEE recogidos. Primero, hay una diferencia entre el tiempo de los sistemas de LI de RAEE y dos características. En Suiza, estos llevan casi 3 décadas de funcionamiento, la Motivación para iniciar la LI fue la voluntad de un grupo de fabricantes y la necesidad de atender al consumidor. Además, sus ORP no compiten entre ellas y no tienen metas de recogida. De esa manera, además de la diferencia de tiempo de los sistemas, la Motivación para implementar la LI de RAEE en los otros países fue por fuerza de ley, los modelos de LI se basan en la competencia y el consumidor solo aparece en la matriz como un desafío a vencer. Ese último hecho lleva a la reflexión sobre el próximo factor que desentonó entre Suiza y los demás países: la presencia del deseo del consumidor en la dimensión Motivación. Pues, al contrario de Suiza, que ahorra con educación ambiental, debido al alto nivel de conciencia de sus ciudadanos, los otros países necesitan invertir algo alto en propaganda de masa si quieren sensibilizar ese actor para participar de la LI de RAEE de forma cooperativa.

\section{CONCLUSIONES}

El acelerado crecimiento del uso de los AEE y la obsolescencia programada y perceptiva han contribuido para el aumento exponencial del descarte de sus residuos al final de vida y al, mismo tiempo, aumentan riesgos socioambientales en el caso de la ausencia de destinación 
adecuada. Esta investigación muestra que la respuesta para este desafío ha sido ampliada en programas de LI.

En este escenario, Europa surge como ejemplo de implementación de la LI de RAEE debido a su entrada en vigor exitosa en diversos países. La mayor parte de los países europeos implementó la LI para atender la Directiva de RAEE del 2002, que establece normas y metas para el descarte correcto de RAEE, en todos los países miembros de UE.

Sin embargo, este estudio muestra que es preciso entender el fenómeno de los modelos de LI a partir de una perspectiva más amplia, que posibilite entender más allá del papel de la legislación, una vez que el nivel de efectividad de este proceso varía considerando los países estudiados. Para esta investigación, fue adoptada la presuposición de que los modelos de LI se pueden beneficiar y alcanzar mayor efectividad cuando la cooperación y colaboración están presentes. Es interesante notar que, incluso considerando que las características colaborativas y cooperativas son intrínsecas a los sistemas de LI de RAEE, pocos estudios han profundizado en esta temática al discutir tales modelos.

Este estudio mostró que, efectivamente, colaboración y cooperación son conceptos diferentes, pero muchas veces complementarios, ya que cuando actúan de modo alternado en los procesos para implementación de LI, potencian la realización de la cadena inversa de RAEE.

En algunos momentos, la colaboración permite la elaboración de leyes más efectivas y de sistemas de control y de calidad, además del desarrollo de nuevas tecnologías que faciliten la LI. En otros momentos, la cooperación asegura capilaridad, aumento del volumen de RAEE recogidos y reducción del costo de la LI. De esa forma, no es posible decir si la colaboración viene antes de la cooperación o viceversa, corroborando Kemczinski et al. (2007), que defienden una visión amplia de los conceptos, de forma que estos conceptos puedan ejecutarse separadamente o intercalados, sin orden correcto, pero respetando las características del proceso que se ejecutará en el momento. Por lo tanto, cuando se utilizan adecuadamente, ellos brindan resultados más efectivos al proceso de LI de RAEE.

Este trabajo mostró que el ejemplo más concreto de esto es el caso de Suiza, porque es el país que menos presenta no conformidades con la literatura y que presenta los mejores resultados en la LI de RAEE, siendo referencia mundial en el tema. Suiza presenta elementos de colaboración y cooperación muy claros. En el caso de la colaboración, estos actores participan conjuntamente en el desarrollo de las leyes, normas y sistemas para mejorar la LI, siempre buscando el consenso entre ellos y la mejor solución para el problema, en un proceso 
de mejora continua. El gobierno actúa como facilitador de este proceso, normando los sistemas creados y ampliando su delimitación, cuando entiende que ello puede mejorar los resultados, pero siempre de forma consensual. Más allá de eso, la mayoría de los participantes de la industria se mantienen cerca de las ORP, para ayudar en el proceso de búsqueda de soluciones, unidos por un sentido de comunidad. Este factor se debe a una particularidad del país, su tamaño. Esta proximidad geográfica entre actores facilita el proceso de colaboración, de acuerdo con Balancieri (2004), porque permite que haya mayor sinergia entre los miembros y que se compartan las competencias. Para esta investigación, se destaca que este vínculo entre los miembros de la industria y las ORP no fue encontrado en ninguno de los otros casos estudiados. En cuanto a los aspectos operacionales, relacionados con la cooperación, el sistema de LI de RAEE tiene roles claros para todos, con mecanismos que aseguran la transparencia de los procesos, enfocados en la búsqueda de los mejores resultados posibles. Para certificar la eficiencia del sistema y la motivación de los actores involucrados en la recogida, las ORP han desarrollado un sistema de contrapartida financiera muy bien delineado, para remunerarlos proporcionalmente a sus resultados, asegurando una mayor rentabilidad en el proceso. Para Brna (1998) es importante entender cuáles son los factores motivacionales de los actores, para que se pueda estimularlos y motivar su efectiva participación en la acción. Además, la investigación mostró un nuevo valor para los atributos de motivación, la predisposición suiza para ser sostenible, que surgió tanto en necesidad/deseo, cuanto en oportunidad y disposición para actuar de modo conjunto. Este factor estimula la búsqueda de más actores para trabajar conjuntamente, siempre que se perciba la oportunidad o necesidad de mejorar algo en el sistema. Es este escenario, las ORP crearon un sistema de recogida compartida, con alta capilaridad, construido por medio del trabajo conjunto con el sistema de recogida selectiva de la municipalidad, supermercados y de los OGR. Este sistema facilita la operación y reduce sus costos, lo que otorga una Tarifa Anticipada de Reciclaje (TAR) reducida al consumidor. De esta forma, Suiza reúne una serie de factores que facilitan la colaboración y cooperación en el país, garantizando la mejora constante de la LI de RAEE. Además, es el único caso que relató la motivación del consumidor para actuar en la LI de RAEE. Por lo tanto garantiza el elemento seminal para que todos los actores se motiven a participar de ella.

Se destaca que ninguno de los otros 3 países presentó un modelo de LI de RAEE con tantos elementos de colaboración y cooperación en armonía con la estructura descrita por la literatura cuanto Suiza, y con factores motivacionales basados en el deseo y oportunidad de 
todos los actores en ejecutarlas. Se resalta que, en el caso suizo, medidas voluntarias, aunque puntuales, se potencian con la legislación, que se traduce en un fuerte movimiento de cooperación y colaboración.

Ya en los casos de España y Portugal, los modelos de LI de RAEE se inician por fuerza obligatoria de la Directiva de la UE, que exige que los países que componen el bloque alcancen los resultados por ella determinados (EUR-LEX, 2015). Se nota que la Directiva impactó más fuertemente en la cooperación que en la colaboración, aunque en niveles diferentes para ambos. Específicamente en el caso de Portugal, se verifica que la legislación influyó de manera acentuada el proceso de cooperación, que se tradujo en atributos fuertes, como la estructura adecuada con papeles bien definidos y SI centralizados del gobierno, para garantizar el control y la transparencia del proceso y la sinergia entre los actores. En este escenario, Portugal es el país que está más próximo de Suiza en cuestiones de resultados y estructura para facilitar la colaboración y cooperación. Después del modelo suizo, es el caso que presenta menos no conformidades con la literatura, en los dos conceptos. De esta forma, gana el $2^{\circ}$ lugar en los resultados de la recogida entre países estudiados, pero lejos de los 16kg por habitante de Suiza. Desde 2010, Portugal consigue alcanzar las metas establecidas por la UE y viene aumentando gradualmente sus resultados de la recogida. Estos factores corroboran la literatura en lo que se refiere a la importancia de la delimitación y la estructura para hacer efectiva la cooperación en la puesta en marcha de sistemas complejos, como la LI de RAEE. En cuanto a los valores de RAEE recogidos, es importante resaltar que, para los actores que operan la LI en Portugal, la métrica de éxito del sistema está basada en las cuotas de recogida y en la atención de los requisitos de asociados. Por lo tanto, su motivación es la necesidad de cumplir las metas establecidas por la ley, dentro de lo que fue establecido por la Directiva de RAEE, no superarlas. De esta forma, se puede inferir que estos actores se limitan a hacer lo que la directiva determina, tanto que la mayor resistencia de las EG está relacionada con las metas más exigentes de Portugal, por encima de las que la UE estableció para la LI de RAEE. En este contexto, en lo que se refiere a la colaboración, dos factores se destacan por la diferencia con que Suiza y Portugal se ocupan de la motivación y el poder en estas relaciones. Primero, aunque el gobierno demuestre el deseo de ser sustentable, la ley de LI de RAEE fue elaborada para responder a la Directiva de RAEE, por lo que no fue motivada por la iniciativa de ninguno de los actores del sector de AEE, ni del gobierno. Segundo, a pesar de que el gobierno desea consenso entre los actores, busca las asociaciones colaborativas para validar sus propuestas, por medio de la 
concientización de los actores sobre la importancia de determinados puntos conflictivos y de la necesidad de esfuerzos que todos tienen que hacer para mejorar la gestión de los RAEE. De acuerdo con Ansell y Gash (2007) ninguno de estos comportamientos desentona de la colaboración, ya que ésta permite que el gobierno valide su propuesta de esta forma. Sin embargo, advierten para el riesgo de que el gobierno use su poder para persuadir a otros actores, generando conflictos de confianza en el grupo y desmotivando la participación colaborativa. Aun así, Portugal tiene un nivel muy bueno de efectividad de las leyes y sistemas de gestión de los RAEE, porque ha logrado implementar todo lo que fue necesario, en breve período. Aunque haya algunas quejas sobre la forma del gobierno en conducir las negociaciones en la elaboración de leyes y reglamentos, los autores continúan contribuyendo con los procesos de planificación de las leyes y sistemas de control, porque perciben que el gobierno demuestra interés en sus opiniones y a veces cede a sus reclamos. Sin embargo, este mecanismo enriquece el resultado del proceso y permite que todos tengan pequeñas victorias, tan importantes para validar las asociaciones colaborativas.

Sin embargo, en el caso español, aunque la fuerza externa haya sido la misma, los acuerdos sociales se limitaron a las actividades de cooperación, no siendo posible verificar elementos que permitiesen entender si la colaboración se efectuó de forma adecuada en el país. España es el país que tiene el menor resultado de recogida entre los tres países europeos y el que más ha tenido dificultades para alcanzar las metas hasta el momento. En este sentido, fue el caso que más tuvo no conformidades con la literatura sobre cooperación. Estos factores evidencian la importancia de elegir la estructura más adecuada para la naturaleza de la actividad que será realizada, así como entender cuáles son los elementos motivacionales que la anteceden. En este contexto, el modelo LI de RAEE no presenta, en la dimensión motivación en la cooperación, ninguna cita sobre los consumidores, los cuales presentan baja concientización ambiental en lo que se refiere a la recogida selectiva y gestión de RSU. Este hecho se agrava en la cuestión de los RAEE, porque para el consumidor estos tienen valor económico y, por lo tanto, no deben ser "botado en la basura". Sin embargo, es fundamental que este consumidor sea motivado a participar de la LI de RAEE. De esa forma, es necesario que se invierta en propaganda de masa, para que él sea convencido de la importancia de hacer el descarte, así como es motivado para comprar un producto nuevo. Además de eso, el sistema del municipio no cuenta con colectores específicos para RAEE, junto a los puntos de descarte, distribuidos por el municipio. Solo en Ecopuntos existen jaulas específicas para los RAEE, pero estos 
locales se sitúan más lejos de los centros comerciales, afectando la capilaridad de la LI. Ese factor no facilita el acceso al descarte, ni el recuerdo para descartar los RAEE. En este escenario, el sistema municipal recoge solo 1/3 de los residuos recogidos por los SIG. De esta forma, los SIG se han vuelto dependientes de recicladores proveedores, los cuales compran esos residuos de cualquier persona, incluyendo a aquellas que los roban en los puntos de recogida municipales, para vender y sobrevivir, debido a su vulnerabilidad social. Aún en relación con la dimensión de motivación, los actores parecen dar poca relevancia a las metas actuales, principalmente las específicas por categoría, porque la legislación está en período de transición hasta el 2019, durante el cual es aceptable que no se cumplan los objetivos anuales. En cambio, los recicladores proveedores percibieron en los SIG una forma de aumentar sus ingresos, porque además de vender los metales contenidos en los RAEE, actividad ya realizada por ellos, pueden emitir informes de gestión de dichos residuos. Para fortalecer y mejorar estos resultados, estos recicladores buscan alianzas con recicladores con Código LER diferentes, ampliando su alcance y ganando ventaja competitiva, además de invertir en marketing para atraer más clientes que vendan sus RAEE. Estos factores refuerzan Hord (1981) y Polenske (2004) sobre la importancia de la motivación en alianzas de cooperación.

En Brasil, los resultados de la lentitud pueden ser explicados por la fragilidad de la colaboración y cooperación en el país. Porque al mismo tiempo que ellas pueden potencializar los resultados de la LI, su ausencia puede explicar menores niveles de efectividades de estos sistemas. Tanto es así que en el caso brasileño se encuentra el mayor número de no conformidades con la literatura sobre colaboración y cooperación y también los menores resultados en la recogida de RAEE y avances incipientes en la legislación para implementarla, ya que tras 8 años de la aprobación de la PNRS, el AS no fue firmado. Si por un lado la colaboración es prácticamente inexistente debido a la falta de atributos de motivación, objetivos convergentes y estructura con valores divergentes a la naturaleza del proceso, la cooperación es limitada en función de las características del único caso de implementación de la LI de RAEE, que involucra a los actores del sector. En este sentido, algunos factores pueden ser enumerados para explicar mejor porque la colaboración no se efectúa en la elaboración del AS. Los elementos centrales para iniciar la búsqueda de alianzas para resolver problemas complejos, como la elaboración de un modelo de LI de RAEE, no aparecen en Brasil, porque los actores no tienen sentido de urgencia, ni prioridad, tampoco voluntad de implementar la LI de RAEE, porque la consideran sólo como un costo. Además, la única oportunidad que visualizan al 
participar del GT es intentar disminuir las responsabilidades de ellos por el proceso y reducir los costos de la LI. No lo buscan por complementariedad de competencia o aumento de sus capacidades, contrariando preceptos básicos para iniciar la colaboración. De esta forma, evitan que actores que tengan perspectivas diferentes de la suya, pero con conocimiento que pueda ayudar a viabilizar la LI, participen del AS, porque temen que estos actores levanten banderas que ellos han intentado evitar, como la inclusión de las cooperativas en la LI y la viabilidad económica de la operación sin la exención de impuestos sobre la TAR. Así, ninguno de los atributos de la motivación han sido atendidos, aunque los actores afirman que es importante poder participar del AS y el gobierno quiera disminuir los impactos ambientales de los RAEE y validar el modelo de LI de forma colaborativa. Sin deseo o necesidad, la alianza en favor de alguna cosa se vuelve mucho más compleja y difícil de realizar. En el caso de Brasil, los objetivos individuales se sobreponen a los del grupo y la expectativa de resultados tangibles es mayor que de los intangibles, más allá de ser incompatibles con los resultados esperados por los otros actores. Sin embargo, Brna (1998) y Polenske (2004) advierten sobre la importancia del objetivo del grupo, que tiene que ser mayor que los intereses personales para la efectividad de la colaboración. Con motivación y delimitación comprometidas, como se refleja en las no conformidades de la literatura, la estructura escogida para discutir el AS no favoreció aspectos como la sinergia y la facilitación de la innovación, porque las actividades fueron diseñadas para ser realizadas fuera del grupo, con reuniones esporádicas. Después de la reunión general con todos los miembros, éstos se dividían en dos subgrupos, sector privado y gobierno, e iban a discutir por separado, a lo largo del semestre, sobre los asuntos de su interés para prepararse para la próxima reunión, y muchas veces actuaban como adversarios. Este comportamiento deterioraba cualquier posibilidad de confianza entre los miembros. El intercambio de información con el grupo general, la GT, era hecho por mecanismos de comunicación asincrónicos y las personas enviadas para las reuniones tenían el rol de representar a su institución sólo como portavoz. Por tanto, se utilizó la estructura cooperativa en un proceso típicamente mental y colaborativo. En este caso, es posible inferir sobre la importancia del uso adecuado de la estructura, a partir de los factores determinantes para colaboración o cooperación. En cuanto al proceso cooperativo, el PP sólo tuvo 8 meses de puesta en ejecución, limitando sus resultados. Además fue ejecutado por un actor externo al contexto brasileño, la JICA, que centralizó todo el poder de decisión. Aunque el mismo PP haya logrado garantizar la motivación de los actores, porque estaban todos interesados en aprender sobre como la LI de 
RAEE funcionaría en Brasil y tener acceso al conocimiento del equipo de JICA, fueron actitudes oportunistas las que motivaron la adhesión al PP. En este caso, los actores, así como en el AS, veían la oportunidad de comprobar su punto de vista con los resultados del proyecto, para disminuir su parte de responsabilidad. En la cuestión de los objetivos, ellos eran individuales, lo que es característico de cooperación, y parte de ellos estaba declarada, como en el caso de obtener el conocimiento sobre el escenario brasileño, pero parte de lo que esperaban recibir de este aprendizaje era que él confirmara el punto de vista de estos actores. Pero ese tipo de resultado individual fue omitido del grupo. Sin embargo, en procesos cooperativos es importante que todos los resultados deseados sean declarados para garantizar la confianza entre los miembros. Por último, aunque las tareas y papeles hayan sido definidas claramente, el exceso de control del proponente del proyecto centralizó el poder y le quitó la autonomía a las empresas, generando desmotivación y descontento en la mayoría de los participantes. Este factor es corroborado por la actuación de los minoristas, que aumentaron los resultados de recogida, cuando consiguieron tener más control sobre la operación de recogida de RAEE en sus tiendas, creando campañas de descarte.

Así, para que la colaboración se haga efectiva en Brasil, en primer lugar el gobierno y el sector privado necesitan asumir su responsabilidad por la implementación de la LI de RAEE, atendiendo al atributo "necesidad". Además deben ser capaces de ver las ventajas que la LI puede generar para todos, cómo crear divisas, nuevos negocios y empleos con la implantación del reciclaje. De esta forma, sería posible obtener un valor positivo para el atributo “oportunidad”, lo que facilitaría la disposición para actuar conjuntamente, en la búsqueda del mejor modelo. Después de desarrollar los factores motivacionales, sería necesario que los actores tuvieran como objetivo común la definición de un modelo de LI de RAEE factible para todos. Por último, sería importante que se acerquen las relaciones de los actores involucrados en el AS por medio de reuniones presenciales, ofreciendo miembros capaces de articular los cambios legislativos necesarios para crear mecanismos que faciliten la cooperación en la operación de LI.

Naturalmente, la cantidad de países estudiados limita la investigación, en lo que se refiere a la generalización de los factores determinantes para la elección del concepto más adecuado para definir la estructura de trabajo conjunto a ser adoptada. Además, como se ve en la investigación, la realidad de los países hizo surgir nuevos valores para algunos atributos. Sin embargo, sin la investigación de un universo mayor, no fue posible agotar todas las 
posibilidades de valores que los atributos pueden asumir, para aplicar en sistemas de LI de RAEE. Para investigaciones futuras se recomienda la ampliación de la cantidad de países analizados, un enfoque que incluya al consumidor, para entender la diferencia de elementos que motivan su comportamiento y como éste puede ser afectado, para mejor construcción de un modelo conceptual y fomento de políticas públicas que incentiven su participación. Además, después de levantar los valores que los atributos puedan asumir en otros países, sería interesante hacer un estudio cuantitativo, que permita definir en qué grado los factores determinantes de colaboración y cooperación impactan en la implementación de LI de RAEE.

Incluso considerando los limites presentados, se cree que este estudio lanza una nueva mirada para entender los desafíos enfrentados para la implementación de la LI de RAEE en la realidad brasileña al interpretar el fenómeno a partir de las limitaciones de los procesos de colaboración y cooperación entre los actores involucrados. Además, fue posible crear una matriz conceptual con los factores determinantes para definir cuál es el tipo de trabajo conjunto más adecuado a ser adoptado. La investigación posibilitó levantar otros valores para atributos de la dimensión Motivación, como la "predisposición para ser sostenible", "histórico positivo en colaboración" y, en la dimensión Estructura, en el atributo recursos financieros, "cada uno se hace cargo de sus costos". De esta forma, la pesquisa puede contribuir para facilitar la implementación de LR de RAEE en empresas privadas y fomentar políticas públicas y sistemas de control para facilitar la cooperación y colaboración entre sus miembros. 